
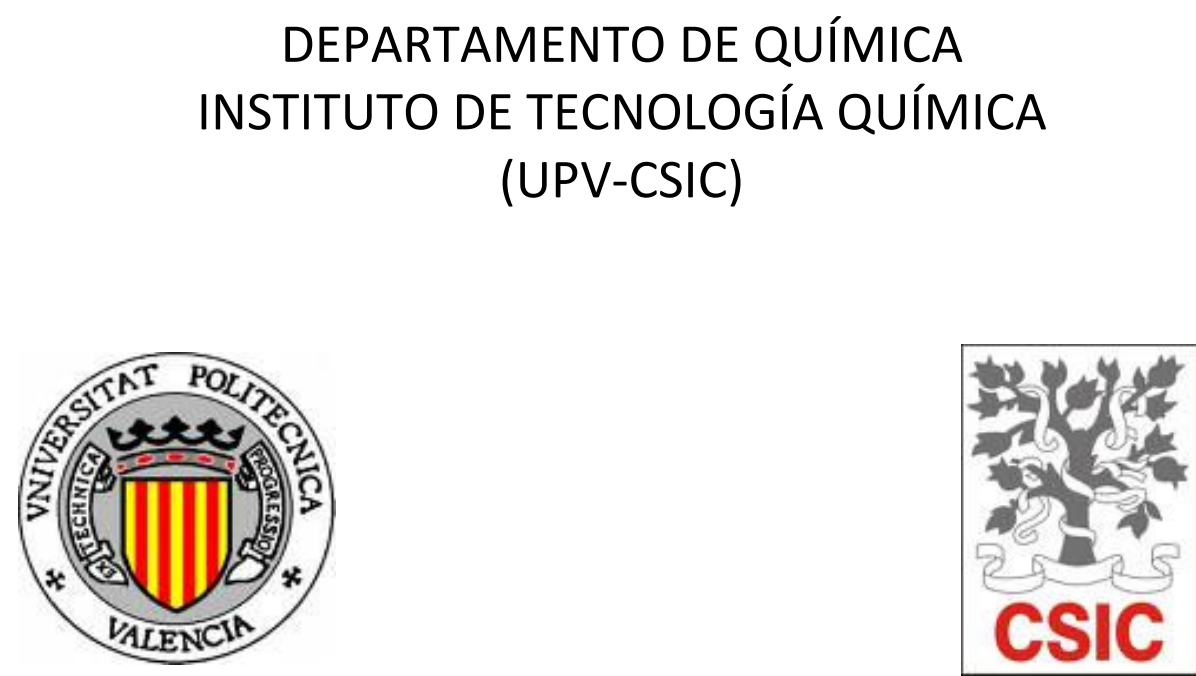

\title{
REQUERIMIENTOS FÍSICO-QUÍMICOS Y ESTRUCTURALES EN CATALIZADORES AVANZADOS PARA LA CONVERSIÓN DE GAS DE SÍNTESIS
}

TESIS DOCTORAL

\author{
Presentada por: \\ GONZALO PRIETO GONZÁLEZ \\ Dirigida por: \\ Prof. AGUSTÍN MARTÍNEZ FELIU
}

VALENCIA, 2010 



\title{
REQUERIMIENTOS FÍSICO-QUÍMICOS Y ESTRUCTURALES EN CATALIZADORES AVANZADOS PARA LA CONVERSIÓN DE GAS DE SÍNTESIS
}

\author{
MEMORIA \\ Presentada por: \\ Gonzalo Prieto González \\ Dirigida por: \\ Prof. Agustín Martínez Feliu \\ para optar al título de \\ DOCTOR EN CIENCIAS QUÍMICAS \\ UNIVERSIDAD POLITÉCNICA DE VALENCIA \\ DEPARTAMENTO DE QUÍMICA \\ INSTITUTO DE TECNOLOGÍA QUÍMICA \\ (UPV-CSIC)
}

Valencia, 2010 



\section{Agradecimientos}

Quiero expresar mi agradecimiento en estas líneas a todas aquellas personas que han hecho posible este trabajo de tesis doctoral de algún modo u otro:

En primer lugar, me gustaría agradecer al director del ITQ, el Prof. Avelino Corma, así como a la gerente del mismo, la Prof. Amparo Mifsud por considerar mi deseo de ingresar en un centro del prestigio del Instituto de Tecnología Química para realizar mi tesis doctoral, hace ya casi cinco años, y por la confianza y apoyo durante mi estancia aquí.

A su vez, quiero expresar mi agradecimiento al director de este trabajo de tesis doctoral, el Prof. Agustín Martínez, por la confianza depositada en mí desde el primer día, su accesibilidad, disposición y consejo durante estos años.

También quiero agradecer al personal investigador del ITQ por sus puertas abiertas y su contribución a mi formación, en especial a los Prof. Vicente Fornés, Fernando Rey, J.M. López y Jaime Primo (tutor de este trabajo desde el Departamento de Química), y los Drs. Cristina Martínez, Patricia Concepción, Alejandro Vidal, Urbano Díaz y J.M. Serra. A su vez, quiero dar las gracias a todas aquellas personas que han contribuido, con su colaboración, a la presente tesis doctoral, en especial a Dra. Patricia Concepción, Dra. Mariam Arribas, Dr. J.L. Jordá, el servicio de microscopía de la UPV, Raquel Pérez Cuquerella (per la ITQ-2 y les clases de valencià), Joan y Raúl, así como al personal encargado de las técnicas de caracterización (Maribel, Amparo, Rosa, Xusa, Fani, Alejandro, Adelina) por su disposición y su amabilidad infinitas. Por último, no quiero dejar de mencionar a Carlos López, predecesor en la línea de investigación en la que se enmarca esta tesis y gran colega, por compartir conmigo sus experiencias previas y sus herramientas para facilitar mi aterrizaje a la investigación.

También agradezco a Abengoa Bioenergía Nuevas Tecnologías S.A. por el permiso para publicar los datos incluidos en el capítulo 6 de esta memoria.

El párrafo que viene lo reservo para agradecer a toda la gente que recibió a aquel "guaje" asturiano con los brazos abiertos para brindarle su amistad y complicidad, tanto como para que los praos y les vaquines no se echasen tanto de menos. Ya sea con un balón, con mucha nieve o con sidras y pulpín de por medio son muchísimos los momentos que compartí con mucha gente pero si los nombro a todos no queda sitio para los resultados de la tesis. Mención especial para Zipi\&Zape-Pier\&Moliner y Coni y Ceci, por las aventuras por el mundo, desde el Sella hasta el GoldenGate pasando por Pipa y el huerto ta tío. A Ángel por contar siempre conmigo en todas las delanteras, y a todos los demás amos del balón, podemos!. A Tomi (el Osman de los creps), María, Laurent (manda algo a Gándia), Santi, y Sabel Minut (que chido!) por las miiil horas compartidas.

También a Ernest, Natali, Isi, Jonhy, Tere, Olallita, Mentxu, Imma, Franki, Yannick, Ana Primo (toda Ana tiene su Ramón García), Antoñito Leyva (el biri-biri), Laurita y Nono (er beti estaba en la UCl), Miriam y Dani (el megacuario en proyecto!), Sandrita y Michael (por introducir el arte de la paella en Asturies), Stefi, Pablo, Sabel ton amic, la comunidad de las chungas, y el gran etc de ilustres con los que compartí buenos momentos. $\mathrm{Y}$ a los galácticos llegados de lejos: Claudinha, Silvio, Carmela, Héctor, Abde, Jiang, Gerolamo, Sara, Froso, Younnes,....

A mis compañeros Noemi, Silvio y Belenix, porque el Palomar parece pequeñín pero es muy grande. 
A mis compañeros de piso varios (Charlie, Diana, Ale, Mo, Anita, Andrey, Pedrín) en estos años, por las series americanas de sofá máximo. A Pepo el del otru fondu d'Asturies, aunque sea tan culé.... y la comunidad correspondiente Sandrita, Bego, Igor Garbajosa, Pablo dale calor, Borja, porque mola no hablar de moleculinas ni danza-fama-triplete un ratín.

A Eva por su ayuda con el resum

A mis padres, mis abuelos, Paco, Jose y Manu por su cariño, confianza y apoyo en todos los sentidos, y por entender mis pocas y breves visitas por Eiros durante esta estancia en Valencia.

A Tania por su dulzura infinita, su apoyo incondicional y su cariño durante estos años. 
A mis padres, como todo lo que logre, por su trabajo sin domingos, por su cariño y su ilusión en que los tres "nenos" se formen y conozcan nuevos lugares, labores y futuros. 



\section{ÍNDICE GENERAL}

1. INTRODUCCIÓN GENERAL Y OBJETIVOS

1.1. Catálisis: retos en los sectores energético y petroquímico para 2 el siglo XXI.

1.1.1. El objetivo de la transformación química selectiva.

1.2. Rutas catalíticas de los $C_{1}$ : alternativas al petróleo. 5

1.2.1. Conversión catalítica de gas de síntesis.

1.3. Síntesis de Fischer-Tropsch. 12

1.3.1. Revisión histórica. 12

1.3.2. Evolución histórica en materia de reactores catalíticos. 14

1.3.3. Interés actual en los ámbitos económico y científico. 16

1.3.3.1. Marco de interés económico. 16

1.3.3.2. Marco de interés científico. 18

1.3.4. Fundamentos químicos de la SFT.

1.3.5. Catalizadores para la SFT. 24

1.3.6. Nivel de instalación industrial actual y perspectivas de los 29 procesos GTL basados en la SFT.

1.3.7. SFT catalizada por Co: aspectos científicos de interés actual. 33

1.3.7.1. Nivel 1: Partículas macroscópicas de catalizador, atricción y 35 propiedades mecánicas.

1.3.7.2. Nivel 2: Estructura porosa y transporte de materia. 37

1.3.7.3. Nivel 3: Nanopartículas metálicas, influencia del tamaño de 43 nanopartícula y fenómenos de desactivación por sinterizado.

1.3.7.4. Nivel 4: Reestructuración metálica superficial. 48

1.4. Síntesis selectiva de oxigenados por conversión de gas de 51 síntesis.

1.4.1. Los compuestos oxigenados superiores como combustibles y productos de química base.

1.4.2. Síntesis de alcoholes superiores $\left(C_{2+}\right)$.

1.4.2.1. Catalizadores de Rh: versatilidad y efecto promotor.

56

1.5. Estructura y objetivos de la tesis doctoral.

2. SECCIÓN EXPERIMENTAL

2.1. Síntesis de materiales.

2.1.1. Reactivos.

2.1.2. Síntesis de soportes catalíticos. 
2.1.2.3. Soportes catalíticos basados en $\mathrm{\gamma}-\mathrm{Al}_{2} \mathrm{O}_{3}$ de origen comercial.

2.1.2.5. Síntesis de sílices mesoestructuradas SBA-15.

2.1.2.6. Incorporación de recubrimiento de óxido metálico en la

2.1.3. Síntesis de catalizadores metálicos.

2.1.3.2. Catalizadores $\mathrm{Co} / \mathrm{SiO}_{2}(\mathrm{mf})$.

2.1.3.3. Catalizadores $\mathrm{Co} / \mathrm{SiO}_{2}$.

2.1.3.4. Catalizadores $\mathrm{RuCO} / \mathrm{Al}_{2} \mathrm{O}_{3}$.

2.2. Técnicas experimentales de caracterización físico-química. acoplado a Espectroscopio de Emisión (ICP-OES).

2.2.2. Análisis elemental (EA).

2.2.3. Difracción de rayos $X$ en polvo (XRD).

2.2.4. Adsorción de nitrógeno.

2.2.5. Porosimetría de intrusión de mercurio.

2.2.6. Espectroscopia de resonancia magnética nuclear de ${ }^{29} \mathrm{Si}\left({ }^{29} \mathrm{Si}\right.$ NMR).

2.2.7. Técnicas de temperatura programada.

2.2.7.1. Reducción a temperatura programada $\left(\mathrm{H}_{2}-T P R\right)$.

2.2.7.2. Oxidación a temperatura programada monitorizada por espectrometría de masas (TPO-MS).

2.2.8. Quimisorción de hidrógeno.

2.2.9. Análisis termogravimétrico (TG-DTA).

2.2.10. Técnicas de microscopía electrónica.

2.2.10.1. Microscopía electrónica de barrido (SEM).

2.2.10.2. Microscopía electrónica de transmisión (TEM y HRTEM).

2.2.11. Espectroscopia de reflectancia difusa ultravioleta-visible (DR UV-vis). 
2.2.14. Espectroscopia infra-rojo de transmisión con adsorción de CO (CO-FTIR).

2.3. Ensayos catalíticos.

2.3.1. Sistema de reacción.

2.3.2. Procedimiento experimental en los ensayos catalíticos.

2.3.2.1. Sintesis de Fischer-Tropsch.

2.3.2.2. Síntesis selectiva de compuestos oxigenados.

2.3.3. Resistencias difusionales.

2.3.3.2. Difusión intra-partícula.

2.3.4. Cálculos y parámetros descriptores de las propiedades catalíticas.

\section{ACTIVIDAD Y SELECTIVIDAD DE LA SÍNTESIS DE FISCHER-TROPSCH}

3.1. Introducción

3.1.1. Influencia del tamaño de nanopartícula de Co en la SFT: antecedentes.

3.1.2. Síntesis de coloides metálicos en medios micelares inversos.

3.1.3. Zeolitas deslaminadas como soportes catalíticos.

3.2. Planteamiento.

3.3. Catalizadores nanoparticulados altamente reducibles mediante síntesis micelar acoplada a un soporte deslaminado.

3.3.1. Caracterización del soporte catalítico SITQ-2(a).

3.3.2. Caracterización de los catalizadores 10\%Co/ITQ-2. 
3.4.2.3. Reducibilidad y naturaleza química de las especies de Co.

3.4.4. Estudio de los catalizadores mediante CO-FTIR.

3.4.4.1. Topología metálica superficial de los catalizadores reducidos.

3.5. Conclusiones.

4. INFLUENCIA DE LA HISTORIA TÉRMICA EN LOS CATALIZADORES $\mathrm{CO} / \mathrm{SiO}_{2}$ PARA LA SFT

4.1. Introducción.

4.2. Planteamiento.

4.3. Resultados y discusión.

4.3.1. Contenido metálico y dispersión de los catalizadores.

4.3.2. Propiedades estructurales de $\mathrm{Co}_{3} \mathrm{O}_{4}$ en los catalizadores calcinados en aire.

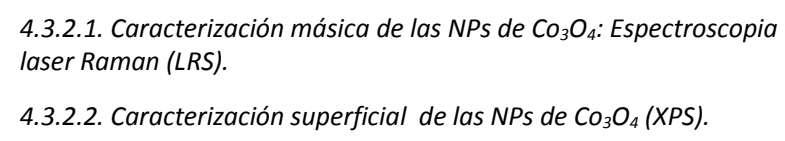

4.3.3. Reducibilidad y propiedades estructurales de los catalizadores reducidos.

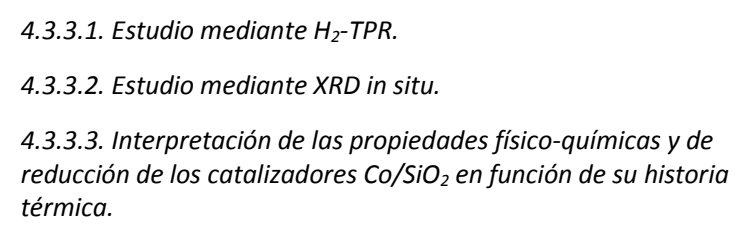

\subsubsection{Actividad catalítica.} metálica y diámetro de poro. 
5.1. Introducción. 264

5.1.1. Dispersión y porosidad en la SFT. 264

5.1.2. Soportes porosos convencionales: acoplamiento porosidad- 265 dispersión.

5.1.3. Nuevos materiales de morfología nanofibrosa y estructura porosa bimodal jerarquizada.

5.2. Planteamiento.

5.3. Resultados y discusión. 268

5.3.1. Caracterización de los soportes. 268

5.3.1.1. Propiedades texturales. 268

5.3.1.2. Propiedades estructurales. 272

5.3.1.3. Propiedades morfológicas. 273

5.3.2. Caracterización de los catalizadores $\mathrm{RuCO} / \mathrm{Al}_{2} \mathrm{O}_{3}$. 275

5.3.2.1. Composición química. 275

5.3.2.2. Propiedades texturales. 277

5.3.2.3. Dispersión metálica. 278

5.3.2.4. Reducibilidad. 284

5.3.3. Resultados catalíticos. 287

5.3.3.1. Estado transitorio. 289

5.3.3.2. Estado pseudo-estacionario. 292

5.3.4. Conclusiones. 304

5-B: Catalizadores mesoestructurados RuCo/SBA-15: Influencia de 307 la longitud de poro.

5.4. Introducción. 308

5.5. Planteamiento. 311

5.6. Resultados y discusión. 313

5.6.1. Caracterización de los soportes SBA-15. 313

5.6.1.1. Propiedades texturales. 313

5.6.1.2. Morfología y direccionalidad de los poros.

5.6.2. Caracterización de los catalizadores RuCo/SBA-15. 322

5.6.2.1. Composición química. 322

5.6.2.2. Propiedades texturales. 323

5.6.2.3. Dispersión metálica. $\quad 326$

5.6.2.4. Tratamiento de calcinación en aire. 331

5.6.2.5. Tratamiento de reducción en hidrógeno. 334 
5.6.4. Conclusiones. 340

Referencias. $\quad 342$

6. APROXIMACIÓN AL EFECTO PROMOTOR EN CATALIZADORES DE 347 Rh PARA LA SÍNTESIS SELECTIVA DE COMPUESTOS OXIGENADOS

6.1. Introducción. 348

6.2. Planteamiento. 350

6.3. Resultados y discusión. 355

6.3.1. Caracterización de los soportes catalíticos. 355

6.3.1.1. Composición química y propiedades texturales. 355

6.3.1.2. Difracción de rayos $X$. 357

6.3.1.3. Propiedades electrónicas: poder electro donante-aceptor de $\quad 359$ los óxidos bidimensionales $\mathrm{MO}_{\mathrm{X}}$.

6.3.2. Caracterización de los catalizadores modelo $\mathrm{Rh} / \mathrm{M} @ \mathrm{Al}_{2} \mathrm{O}_{3}$.

6.3.2.1. Contenido metálico. 366

6.3.2.2. Dispersión metálica. $\quad 366$

6.3.2.3. Reducibilidad de las fases $M O_{x}$ y Rh. 368

6.3.3. Comportamiento catalítico. 372

6.3.4. Propiedades electrónicas de las NPs de Rh en los catalizadores 386 activados.

6.3.4.1. Estado de oxidación y propiedades electrónicas de los 386 componentes: XPS.

6.3.4.2. Interacción de las NPs de Rh con CO: CO-FTIR. 390

6.3.5. Estudio mediante CO-FTIR en condiciones de reacción. 396

Referencias.

7. CONCLUSIONES GENERALES $\quad 419$

ANEXOS

ANEXO I: Índice de Figuras.

ANEXO II: Índice de Tablas.

ANEXO III: Lista de acrónimos y abreviaturas.

RESUMEN-ABSTRACT-RESUM 




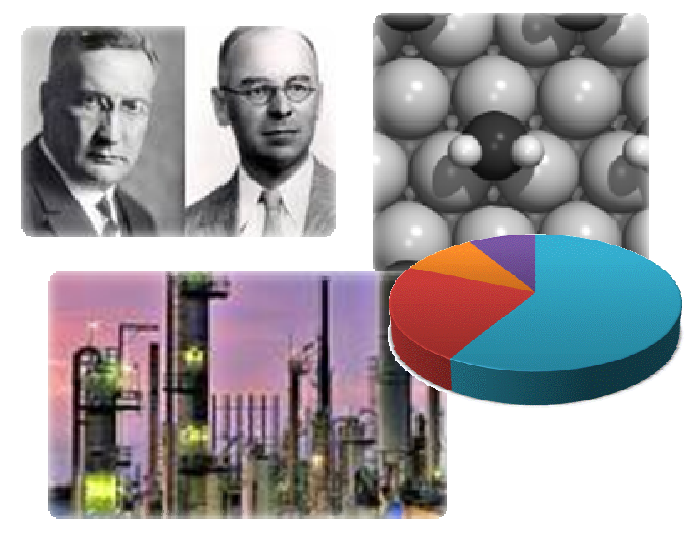

\section{INTRODUCCIÓN} GENERAL 


\subsection{Catálisis: retos en los sectores energético y petroquímico para el siglo XXI.}

En 1835, a partir de la recopilación de varios resultados publicados por diferentes científicos, J.J. Berzelius definió por primera vez un catalizador como "una sustancia cuya mera presencia induce reacciones químicas que de otro modo no tendrían lugar" [1].

Desde entonces, el empleo generalizado de catalizadores para acelerar las transformaciones químicas e incrementar su selectividad ha derivado en cambios sin precedentes en multitud de procesos a gran escala como la obtención y utilización de combustibles de transporte, o la síntesis de productos químicos de base y especializados (polímeros, química fina), reduciendo los requerimientos energéticos y el impacto medioambiental de los mismos. Hoy en día, el mercado mundial de catalizadores produce unas ventas anuales de alrededor de 11 billones de dólares.

Como disciplina científica que persigue el desarrollo de materiales y procesos en los que las transformaciones químicas tienen lugar de manera más eficaz, la catálisis representa uno de los principales pilares en la búsqueda de la sostenibilidad. A comienzos de esta década, un informe elaborado por la Sociedad Norteamericana de la Industria Química concluyó que un tercio de los productos de producción masiva en los Estados Unidos involucra un proceso catalítico en alguna de las etapas de la cadena de producción [2].

La catálisis ha supuesto una fuerza impulsora para multitud de procesos de refino de petróleo [3], en base a la cual se han producido desarrollos sociales en el último siglo. Hoy en día, cuando las previsiones indican que las reservas del crudo no pueden garantizar el suministro para las generaciones futuras, la catálisis constituirá un vector principal en la 
transición desde la economía del petróleo hacia una nueva era post-petróleo en la que los combustibles y los productos químicos de base se obtendrán exclusivamente desde fuentes materiales alternativas.

\subsubsection{El objetivo de la transformación química selectiva.}

La producción selectiva de un producto de reacción, de entre varios compuestos cuya formación es termodinámicamente posible, es uno de los conceptos clave en el desarrollo de procesos químicos más sostenibles.

Si bien la necesidad de desarrollar transformaciones químicas selectivas (incluso estereoselectivas) se comprende fácilmente en campos específicos como la química fina, la gran escala de producción de los procesos catalíticos relacionados con los combustibles o los productos químicos de base penaliza en gran medida su no selectividad, en términos de consumo energético y producción de subproductos indeseados. En este sentido, en 2008, un informe del Subcomité Científico para la Energía de los Estados Unidos [4] destacaba la necesidad de incrementar la selectividad de las transformaciones químicas en los procesos de producción de combustibles como una de las claves en el acercamiento a un futuro energético sostenible.

Décadas de investigación y desarrollo han dado lugar a un gran número de catalizadores heterogéneos, principalmente sólidos, empleados a escala industrial pero cuyas características más determinantes requieren de estudios a un nivel de observación nanométrico [5]. Por lo tanto, la denominada nanociencia, definida como la aplicación de herramientas de física, química y ciencia de materiales en la preparación y caracterización de materiales a escala nanométrica, se ha revelado como indispensable en el estudio de las propiedades de los catalizadores heterogéneos, así como en la síntesis de nuevos materiales catalíticos con propiedades controladas. 
Los avances recientes en este campo han constituido un impacto en la catálisis heterogénea, facilitando el estudio de los catalizadores y los procesos catalíticos a escalas de observación que permiten establecer correlaciones entre la selectividad de las transformaciones catalíticas y varias características químicas y estructurales de los catalizadores [5].

Gran parte de los procesos catalíticos heterogéneos emplean un catalizador constituido por un sólido poroso, de elevada área superficial, sobre el cual se dispersa una fase (multi)metálica en forma de nanopartículas cuyo tamaño normalmente es inferior a los $100 \mathrm{~nm}$. De entre los factores determinantes de la selectividad catalítica en los procesos catalizados por nanopartículas metálicas se pueden destacar [6]:

- la estructura superficial de las fases metálicas, que viene determinada por el tamaño y forma de las nanopartículas metálicas.

- $\quad$ las propiedades electrónicas de las nanopartículas metálicas y el soporte catalítico, así como la disposición relativa entre ambas fases, que determina la naturaleza y la densidad de los centros activos presentes en la región de interfase metal/soporte o la capacidad para establecer flujos electrónicos entre ambas entidades.

- las propiedades químicas de los metales, especialmente su composición superficial y el estado de oxidación de los átomos metálicos expuestos.

- los fenómenos de reestructuración superficial inducidos por los adsorbatos, que modifican las propiedades superficiales de los metales durante su interacción con los reactivos, intermedios y/o productos de reacción. 
- las propiedades texturales del soporte catalítico que determinan la cinética de los procesos de transporte de materia en las proximidades de los centros catalíticos metálicos.

La comprensión de los factores determinantes para la actividad y selectividad de una determinada transformación catalítica, así como la síntesis dirigida de nuevos materiales catalíticos a partir del conocimiento adquirido, permitirá desarrollar procesos catalíticos más selectivos.

\subsection{Rutas catalíticas de los $C_{1}$ : alternativas al petróleo.}

La Agencia Internacional para la Energía (International Energy Agency) estima que el consumo mundial de energía prácticamente se duplicará entre 2004 y 2030, principalmente debido al desarrollo de países como India y China, y que la mayor parte de esta demanda energética provendrá de recursos fósiles como carbón y petróleo [7,8,9]. Por lo tanto, el consumo mundial de petróleo se incrementaría de 80 millones de barriles por día en 2003 hasta unos 118 millones de barriles diarios en 2030.

Alguno de los principales focos de demanda energética son de naturaleza móvil, destacando principalmente el transporte, por lo que gran parte de los combustibles que harán frente a este incremento de la demanda energética durante el presente siglo son líquidos, a la espera de un desarrollo tecnológico suficiente de alternativas como el $\mathrm{H}_{2}$.

Como se recoge en la previsión representada en la Fig. 1.1, el progresivo agotamiento de los yacimientos petrolíferos requerirá de un papel cada vez más preponderante por parte de combustibles líquidos alternativos al crudo. De acuerdo a estas predicciones, los combustibles líquidos derivados de fuentes materiales abundantes, como el gas natural, y 
renovables, como la biomasa, incrementarán su contribución a satisfacer la demanda energética mundial en un $5000 \%$ hasta finales de este siglo.

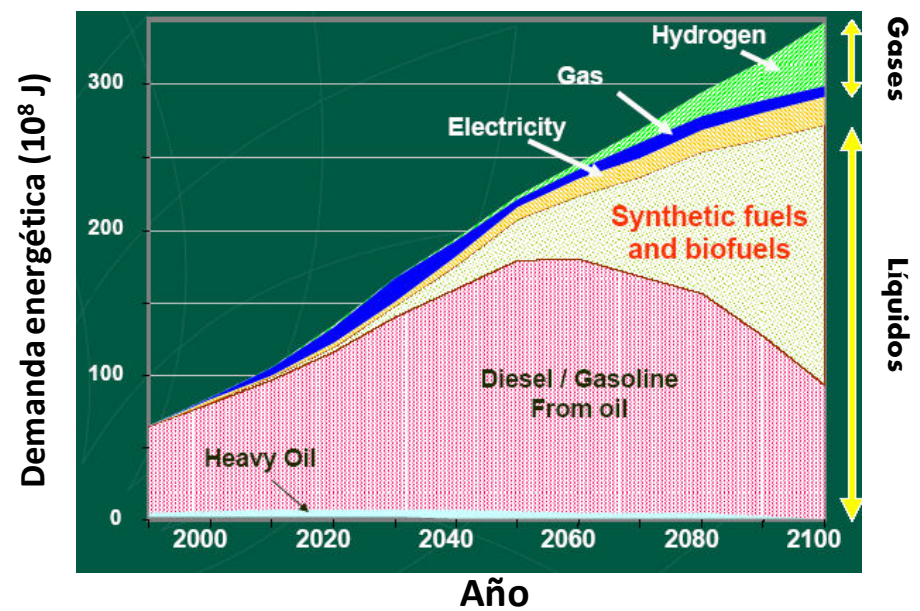

Figura 1.1: Evolución de la demanda mundial estimada de combustibles gaseosos y líquidos, por tipo, durante el presente siglo. Fuente: International Energy Agency (wWw.IEA.org).

Históricamente, el desarrollo de la sociedad ha ido ligado al empleo de materias de base carbono, como fuentes de productos químicos y energía. Originalmente la madera, posteriormente el carbón (que supuso una revolución industrial y social), en la actualidad el petróleo y en el futuro el gas natural, estas fuentes de carbono han sido progresivamente menos condensadas, con una menor relación $\mathrm{C} / \mathrm{H}$ en su composición, lo que también resulta en un menor contenido en heteroátomos $(\mathrm{O}, \mathrm{N}, \mathrm{S})$, y por lo tanto, en una reducción de las emisiones de gases altamente contaminantes en la combustión de los combustibles obtenidos. En el límite de esta tendencia se encuentra el $\mathrm{CH}_{4}$, principal componente del gas natural (70$90 \%)$, cuyo empleo como "unidad estructural" para obtener productos de interés industrial, con un mayor contenido en carbono, constituye el principal ejemplo de las denominadas "rutas catalíticas de los $C_{1}$ ". A través 
de estas rutas catalíticas, el $\mathrm{CH}_{4}$ puede convertirse en productos químicos de base o combustibles.

Las rutas catalíticas directas de conversión de metano (oxidación parcial, acoplamiento oxidativo, dehidroaromatización, etc) se encuentran en la actualidad a un nivel de desarrollo que no permite su implantación en procesos a gran escala $[10,11]$. Estos procesos presentan limitaciones de tipo termodinámico, derivados de la estabilidad de la molécula de $\mathrm{CH}_{4}\left(\Delta \mathrm{H}_{\mathrm{f}}{ }^{0}=-75\right.$ $\mathrm{kJ} / \mathrm{mol} \mathrm{C}$ ), que requiere de condiciones muy drásticas para su activación, y cinéticas, puesto que la conversión de metano en productos primarios más reactivos favorece la formación de subproductos de oxidación completa en aquellos procesos que involucran el uso de $\mathrm{O}_{2}$ como reactivo. Ambos tipos de restricciones limitan los rendimientos por paso y penaliza la selectividad catalítica al trabajar a elevados niveles de conversión [11].

Una versión más versátil y eficiente de las rutas catalíticas de los $C_{1}$ se tiene empleando gas de síntesis como intermedio en el proceso. El gas de síntesis (comúnmente abreviado syngas en inglés) es una mezcla gaseosa que comprende principalmente $\mathrm{CO}$ e $\mathrm{H}_{2}$ en una relación molar $\mathrm{H}_{2} / \mathrm{CO}=0.5-3$, y que puede contener, a su vez, $\mathrm{CO}_{2}$ (típicamente <10\%). El "almacenamiento del carbono" en una unidad estructural más reactiva como el monóxido de carbono da lugar a una gran variedad de rutas catalíticas que permiten convertir el gas de síntesis en productos químicos de base de gran facturación mundial como alcoholes, ácidos carboxílicos u olefinas de cadena corta, así como en combustibles en el rango de la gasolina, el queroseno y el diesel. A su vez, el gas de síntesis presenta ventajas en términos de descontaminación con respecto a otras fuentes de carbono como el petróleo, lo que resulta en productos más "limpios". En este sentido, el gas de síntesis puede contener originalmente entre menos de 100 y $3.10^{4} \mathrm{ppm}$ de azufre, en función de la materia prima y la tecnología empleadas para su 
obtención [12]. No obstante, este azufre se encuentra en formas directamente separables mediante absorción $\left(\mathrm{H}_{2} \mathrm{~S}\right.$ y COS, fundamentalmente) lo que facilita los procesos de purificación (hidrodesulfuración).

\subsubsection{Conversión catalítica de gas de síntesis.}

La obtención de gas de síntesis por gasificación de carbón es un proceso que data originalmente de los años 1850, durante los cuales se comenzaron a emplear los gases derivados del carbón para calentar e iluminar varias ciudades británicas y estadounidenses. Posteriormente, con el descubrimiento de las rutas catalíticas de conversión de gas de síntesis en hidrocarburos líquidos, en los años 1920, el carbón se convirtió en la primera materia prima empleada en la obtención de combustibles sintéticos a gran escala [13]. Los procesos de síntesis de compuestos líquidos que emplean carbón como fuente de carbono para gas de síntesis se conocen como procesos Coal-to-Liquids o CTL.

El gas de síntesis puede obtenerse también mediante gasificación de biomasa. Los procesos de síntesis de compuestos líquidos que emplean biomasa como fuente de carbono reciben la denominación general de Biomass-to-Liquids o BTL. El gas de síntesis obtenido por gasificación de biomasa contiene típicamente hasta un $12 \%$ de $\mathrm{CH}_{4}$, lo que requiere una etapa de reformado posterior [14]. En este caso, el coste de instalación de los gasificadores, las unidades de limpieza y acondicionamiento del gas de síntesis constituye hasta un $75 \%$ del coste de instalación total de la planta, lo que requiere de elevadas eficiencias en la posterior conversión del gas de síntesis para justificar económicamente los procesos BTL $[15,16,17]$.

La gasificación de carbón resulta en un gas de síntesis con una relación $\mathrm{H}_{2} / \mathrm{CO}$ de alrededor de 0.8 , mientras que el gas de síntesis obtenido 
por gasificación de biomasa, con reformado posterior del $\mathrm{CH}_{4}$ producido, presenta una relación $\mathrm{H}_{2} / \mathrm{CO}$ entorno a 1-1.5 si se emplea aire y entorno a 1.5-2 si se emplea oxígeno en la gasificación. Por su parte, el reformado de materias primas más hidrogenadas como asfaltos o naftas resulta en relaciones molares $\mathrm{H}_{2} / \mathrm{CO}$ de aprox. 0.9-1 [18]. Si la aplicación posterior del gas de síntesis lo requiere, esta relación $\mathrm{H}_{2} / \mathrm{CO}$ puede incrementarse en una etapa catalítica posterior a través de la reacción de desplazamiento de gas de agua (water gas shift reaction o WGSR), de acuerdo a la ecuación 1.1 [19].

$$
\mathrm{H}_{2} \mathrm{O}+\mathrm{CO} \rightarrow \mathrm{H}_{2}+\mathrm{CO}_{2} \quad \text { (Ec. 1.1) }
$$

Finalmente, los procesos de conversión de metano, de manera indirecta a través de gas de síntesis (procesos Gas-to-Liquids o GTL), son los que más atención reciben en la actualidad y aquellos que presentan un mayor nivel de implantación a gran escala. La principal motivación para este liderazgo del metano como fuente de carbono para las rutas catalíticas del gas de síntesis es el gran potencial de las reservas de gas natural existentes a nivel mundial. De acuerdo a un informe publicado por Chew en 2003 [20], las reservas probadas de gas natural en forma de depósitos convencionales ascienden a $176 \mathrm{Tm}^{3}$, mientras que las potenciales se estiman en unos 368 $\mathrm{Tm}^{3}$. Pero, adicionalmente, las reservas mundiales de gas natural se incrementan considerablemente cuando se consideran otro tipo de yacimientos no convencionales como los asociados al carbón (hasta 260 $\mathrm{Tm}^{3}$ ) y, principalmente, aquellos en forma de hidratos (clathratos) sólidos [21] existentes en algunos sedimentos submarinos, que se estiman en hasta unos $20000 \mathrm{Tm}^{3}$, aunque en este último caso se requiere del desarrollo de tecnologías de extracción viables. La situación geográfica de estos yacimientos de gas natural, muy alejados de las regiones del planeta de 
mayor demanda energética, hace que su explotación rentable pase por su conversión in situ en productos líquidos transportables [22,23].

El metano puede convertirse en gas de síntesis mediante reformado con vapor de agua, reformado seco (empleando $\mathrm{CO}_{2}$ ) u oxidación parcial con aire [24]. El reformado con vapor es el proceso más extendido y se ha empleado a escala industrial desde los años 30. Este proceso $\left(\mathrm{CH}_{4}+\mathrm{H}_{2} \mathrm{O} \rightarrow\right.$ $\mathrm{CO}+3 \mathrm{H}_{2}$ ) es altamente endotérmico, y constituye el principal sumidero energético de los procesos GTL. Sin embargo, la combinación del reformado con vapor con la oxidación parcial $\left(\mathrm{CH}_{4}+1 / 2 \mathrm{O}_{2} \rightarrow \mathrm{CO}+2 \mathrm{H}_{2}\right)$, que es exotérmica, ha dado lugar a un proceso híbrido denominado comúnmente reformado autotérmico, que reduce sensiblemente los requerimientos energéticos de la generación de gas de síntesis. De manera general, en los procesos de oxidación parcial y reformado autotérmico se emplea $\mathrm{O}_{2}$ en lugar de aire, con el objetivo de evitar la dilución del gas de síntesis en $\mathrm{N}_{2}$. El nitrógeno es inerte en el proceso catalítico, lo que obliga a trabajar a una presión más elevada en el reactor y resulta en su acumulación en el caso de operar con reciclos. Por el contrario, el empleo de $\mathrm{O}_{2}$ requiere de una planta auxiliar de fraccionamiento de aire que eleva considerablemente los costes de instalación y operación de la planta.

El reformado de gas natural con vapor resulta en un gas de síntesis de relación $\mathrm{H}_{2} / \mathrm{CO}$ típicamente superior a 2.5 , mientras que el reformado autotérmico da lugar a una relación $\mathrm{H}_{2} / \mathrm{CO}$ de alrededor de 2 [25].

En la actualidad, existen dos procesos basados en la conversión catalítica de gas de síntesis cuyo nivel de desarrollo tecnológico ha derivado en su instalación a escala industrial: la síntesis de metanol [26] y la síntesis de hidrocarburos o sintesis de Fischer-Tropsch (SFT) [27]. 
El proceso catalítico más importante en las tecnologías GTL es la SFT debido a su versatilidad, su elevado grado de implantación industrial y el amplio mercado para los productos obtenidos. Además, los productos de la SFT suponen un menor coste específico de transporte, por unidad energética equivalente, frente a otras formas de transportar el "metano" presente en los yacimientos remotos de gas natural hasta las regiones de consumo. La Fig. 1.2 representa la variación del coste de transporte, tanto por bombeo en conducciones como por mar en tanques, con la distancia para gas natural licuado (GNL) y algunos productos líquidos derivados de la conversión in situ a través de gas de síntesis como metanol $(\mathrm{MeOH})$, etanol (EtOH) y productos de la SFT.

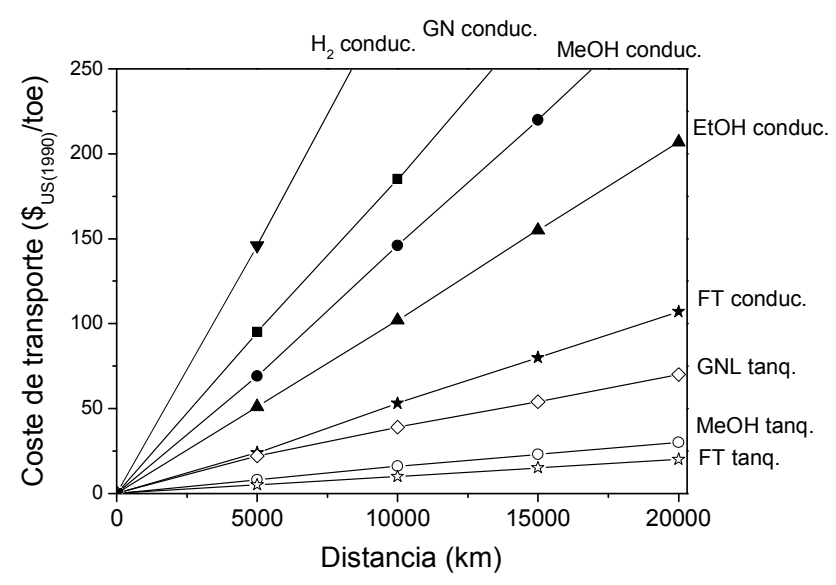

Figura 1.2: Variación del coste de transporte con la distancia de transporte para $\mathrm{H}_{2}$ gas natural (GN), gas natural licuado (GNL) y varios productos de conversión de gas de síntesis (metanol, etanol e hidrocarburos derivados de la síntesis de FischerTropsch) para su transporte desde las regiones de producción mediante conducciones (conduc.) y mediante tanques en buques petroleros (tanq.). Adaptada de [28].

Como se observa, empleando cualquiera de los dos tipos de transporte, el mínimo coste específico se tiene para los productos de la SFT. La figura sirve también para percibir la necesidad de "licuar el carbono", 
presente en forma de $\mathrm{CH}_{4}$ en estos yacimientos, in situ antes de su transporte a regiones de demanda, a la vista del elevado coste de transportar gas natural $\mathrm{O}_{2} \mathrm{H}_{2}$ (como vector energético derivado del reformado) empleando gasoductos.

\subsection{Síntesis de Fischer-Tropsch.}

\subsubsection{Revisión histórica.}

La síntesis de hidrocarburos, principalmente metano, por hidrogenación catalítica de CO sobre catalizadores metálicos basados en $\mathrm{Ni}$ y Co fue descubierta por primera vez por Sabatier y Senderers [29] en 1902. Posteriormente, en 1913, una patente asignada a BASF describía la producción de hidrocarburos líquidos por conversión catalítica de gas de síntesis [30]. Durante ese periodo, tenía lugar en Alemania un intenso esfuerzo de investigación para desarrollar procesos de conversión de las abundantes reservas de carbón del país en combustibles y productos químicos. A comienzos de los años 20, este esfuerzo científico dio como resultado el descubrimiento de la síntesis de hidrocarburos líquidos por conversión catalítica de gas de síntesis sobre catalizadores de Fe alcalinizados, en condiciones de elevada presión (10-15 $\mathrm{MPa}$ ) y temperatura (350-450ㄷ), por parte de Franz Fischer y Hans Tropsch en el Instituto KaiserWilhelm para el Carbón, en Mülheim [31]. Más tarde, estos mismos científicos lograron llevar a cabo la síntesis de hidrocarburos de cadena larga sobre catalizadores basados en Fe y Co en condiciones de operación más suaves (0.1 MPa y 250-300으) [32].

En 1934, los derechos de la patente desarrollada por Fischer y Tropsch fueron adquiridos por Ruhrchemie AG, que implantó el proceso de la síntesis de Fischer-Tropsch a escala industrial en Alemania, construyéndose 9 plantas en 4 años que operaban con un catalizador basado en Co y una 
capacidad combinada de alrededor de 13000 barriles/día. Los embargos económicos a los que el país se vio sometido tras la Primera Guerra Mundial (1914-1918) fueron uno los principales factores que impulsaron al país a apostar por la tecnología de la SFT para el autoabastecimiento de combustibles líquidos derivados de las reservas nacionales de carbón. Posteriormente, Alemania empleó la SFT para proveerse de combustibles durante la Segunda Guerra Mundial (1939-1945), pero las plantas dejaron de estar operativas al finalizar el conflicto bélico y la SFT pasó a un segundo plano en Europa. No obstante, el conocimiento de la tecnología por parte del resto del mundo propició que varios países llevaran a cabo estudios para investigar las posibilidades de esta nueva vía de obtención de hidrocarburos. Estados Unidos construyó una planta en Bronsville (Texas) en los años 50, empleando gas natural como fuente de gas de síntesis, con una capacidad productiva 6000 barriles/día. Sin embargo, la planta se cerró pocos años después de su puesta en funcionamiento debido a la no competitividad del proceso con respecto al refino de petróleo, tras un incremento acusado del precio del gas natural [33].

Sudáfrica también poseía extensas reservas de carbón cuya extracción resultaba poco costosa. En 1955, estimulada por las previsiones de incremento en el precio del crudo, Sasol abrió en Sasolburg la primera planta de SFT en este país, que empleaba un catalizador basado en Fe [34]. Sin embargo, el descubrimiento de nuevas y extensas reservas de crudo en Medio Oriente truncó las previsiones en el incremento del precio del petróleo, lo que provocó, a nivel mundial, un descenso en el interés de la SFT como tecnología alternativa. En el caso de Sudáfrica, no obstante, el embargo por parte de la Organización de los Países Exportadores de Petróleo (OPEP) en los años 70, a consecuencia de la implantación del Apartheid, sirvió para reincentivar la SFT como tecnología de independencia 
energética, construyéndose dos nuevas plantas para la conversión de carbón en combustibles líquidos que comenzaron a operar entre 1980 y 1982.

Con posterioridad, el interés se centró en desarrollar procesos a partir de las extensas reservas de gas natural (GTL) y en la optimización de catalizadores basados en Co. En 1993, Mossgas (actual PetroSA) construyó en Mossel Bay (Sudáfrica) una planta de GTL con una producción aproximada de 22000 barriles/día. Poco después, Shell comenzó la operación de una planta de 12000 barriles/día en Bintulu (Malasia). Más recientemente, la planta Oryx-GTL (Qatar) co-operada por Sasol y Qatar Petroleum (QP) entró en operación en 2007 con una producción de aproximadamente 34000 barriles/día [35].

\subsubsection{Evolución histórica en materia de reactores catalíticos.}

No cabe duda que uno de los impulsos principales para el desarrollo de la tecnología de la SFT hasta el nivel de implantación industrial actual ha sido el desarrollo de nuevas tecnologías de reactores. El carácter fuertemente exotérmico de la síntesis, que impone estrictos requerimientos en términos de intercambio de calor, la operación en continuo a elevadas capacidades, y el manejo de reactivos en fase gaseosa y productos pesados en fase líquida y pseudo-sólida, son los principales factores que acentúan el papel del reactor catalítico como parámetro crítico en la economía de un proceso basado en la SFT. De manera adicional, el diseño del reactor catalítico, en concreto su hidrodinámica, determina en gran medida la naturaleza del catalizador, estableciéndose un sinergismo entre catalizador y reactor como se comentará en secciones posteriores.

Durante el comienzo de la implantación del proceso en Alemania en tiempos de la Segunda Guerra Mundial, la configuración más empleada fue la de lecho fijo multi-tubular, optimizado para una retirada eficiente del 
calor de reacción. Más tarde, comenzó el desarrollo de tecnologías que permiten una producción a mayor escala, basándose en conceptos previos como lecho fluidizado, slurry, etc [36]. Los reactores de lecho fluidizado circulante (Circulating Fluidized-Bed Reactor o CFBR) permitieron un incremento en la capacidad del proceso cuando esta tecnología se instaló por primera vez en el complejo de Sasolburg (Sudáfrica) en 1955.

A partir de los años 90, el creciente interés de la ruta sintética de baja temperatura, empleando catalizadores basados en Co, para maximizar la producción de hidrocarburos de elevado peso molecular (ceras) hizo necesario concebir reactores que permiten el manejo de grandes volúmenes de productos líquidos. En este sentido, se han propuesto los reactores multitubulares de lecho fijo operando en un medio trifásico (Trickel-bed Multitubular Fixed-Bed Reactor o TB-FBR) como los instalados en la primera planta del proceso Shell Middle Distillates (SMDS), que opera un catalizador de Co en Bintulu (Malasia) desde 1993.

Sin embargo, uno de los principales hitos en el desarrollo histórico de las tecnologías de reactores para la SFT ha tenido lugar más recientemente, con el desarrollo de los reactores de Slurry mezclados por burbujeo (Slurry Bubble Column Reactor o SBCR) [36]. Este diseño permite una mejor evacuación del calor de reacción, una retirada y reposición de catalizador sencilla, y bajas pérdidas de carga hidrodinámica. En concreto, esta tecnología ha permitido alcanzar un máximo histórico en la capacidad por reactor en la planta Oryx-GTL, funcional en Ras-Laffan (Qatar) desde hace aproximadamente dos años, empleando un catalizador de Co [37]. 


\subsubsection{Interés actual en los ámbitos económico y científico.}

\subsubsection{Marco de interés económico.}

En las últimas dos décadas se está viviendo un renovado interés en la síntesis de Fischer-Tropsch desde un punto de vista económico, que ha tenido como resultado la puesta en marcha de varias plantas de elevada capacidad, así como numerosos proyectos de desarrollo de nuevos procesos GTL, CTL y BTL para su implantación o su licenciación. Entre los factores que han impulsado este renovado interés en la SFT desde el punto de vista industrial cabe destacar:

- En primer lugar, el incremento del precio del petróleo. A pesar de su carácter fluctuante, determinado por cuestiones políticas y bélicas, se espera un aumento del precio del petróleo derivado del agotamiento de los yacimientos.

- En segundo lugar, la creciente conciencia ecológica que se traduce en una legislación en materia de combustibles cada día más restrictiva. Los combustibles sintéticos (gasolina, queroseno y diesel) obtenidos mediante la SFT presentan contenidos en azufre, nitrógeno y aromáticos nulos o prácticamente nulos, en función de la naturaleza de la fuente material empleada para producir el gas de síntesis. Además, poseen excelentes propiedades comburentes, especialmente en el caso del diesel sintético.

La elevada selectividad de la SFT hacia hidrocarburos lineales, especialmente cuando se emplean catalizadores basados en Co, reduce el coste de los tratamientos de "adecuación" del producto, consistentes principalmente en un hidrocraqueo catalítico para mejorar las propiedades en frío, $y$, a su vez, confiere al diesel sintético final valores del índice de cetano (IC) de hasta $>70$, muy superiores al 
IC típicamente inferior a 50 propio del diesel de refinería $[38,39,40]$. De hecho, desde hace años el combustible sintético obtenido mediante procesos de SFT, se ha empleado como componente de mezcla para incrementar la calidad de algunos combustibles de refinería. Por otra parte, las buenas propiedades comburentes del diesel sintético se reflejan en emisiones de gases de combustión menos contaminantes, con contenidos en hidrocarburos inquemados, CO y de materia sólida particulada inferiores a $0.1,1$ y $0.06 \mathrm{~g} / \mathrm{hp} \cdot \mathrm{h}$, respectivamente [41].

- En tercer lugar, razones geopolíticas como la concentración de las reservas de gas natural en regiones muy alejadas de los puntos de mayor consumo y la necesidad de su conversión en productos líquidos para su transporte, o los deseos de varios países de reducir su dependencia del suministro de crudo por parte de los países productores.

- Por último, los incentivos gubernamentales para las fuentes materiales renovables, como la biomasa, en la búsqueda de una economía con producción neta de $\mathrm{CO}_{2}$ nula, puede considerarse otro importante factor que ha contribuido al interés renovado en la síntesis de Fischer-Tropsch como transformación catalítica central de los procesos de BTL. En este sentido, la Unión Europa planea incrementar la fracción de combustibles líquidos de origen biomásico desde un 2\% en 2005 hasta un 8\% en 2020 [42,43]. En 2007, la compañía Choren construyó una planta BTL que emplea tecnología de SFT licenciada por Shell para producir diesel desde biomasa. 


\subsubsection{Marco de interés científico.}

Desde el punto de vista científico, en los últimos 20 años, la síntesis de Fischer-Tropsch ha acaparado un número ingente de publicaciones científicas, como respuesta al renovado interés que el proceso está recibiendo en el ámbito económico e industrial. Como norma general, los estudios llevados a cabo en este campo están relacionados con cuestiones cada día más fundamentales y emplean técnicas de preparación y caracterización de catalizadores de creciente sofisticación, con el objetivo de elucidar algunas cuestiones que permanecen sin resolver. De entre estas materias de debate científico actual, cabe destacar el efecto de la estructura porosa del soporte, la dispersión metálica, la historia térmica o el papel de los metales promotores a la hora de determinar la actividad y selectividad de los catalizadores, así como los procesos de reestructuración superficial, aglomeración metálica, deposición de carbono, re-oxidación, etc, alguno de los cuales parecen estar relacionados con la desactivación de los catalizadores en las condiciones de operación empleadas en la industria.

Adicionalmente, en paralelo a su desarrollo como tecnología química, la SFT parece haber alcanzado una nueva dimensión científica ante las sospechas de que esta reacción catalítica ocurre de manera espontánea en la naturaleza. Recientemente, se han publicado resultados que apuntan a que la síntesis catalítica de hidrocarburos superiores $\left(C_{2+}\right)$ tiene lugar en la naturaleza a partir de fuentes de carbono inorgánicas en determinadas regiones hidrotermales [44]. Un trabajo del grupo del profesor Proskurowski en 2008 [45] postula que la distribución de pesos moleculares de los hidrocarburos que se generan de manera natural en la región hidrotermal sub-oceánica de Lost City es compatible con el mecanismo de la síntesis de Fischer-Tropsch, que en este caso estaría catalizada por ciertas rocas ultramáficas que contienen metales como Fe y Ni. La ocurrencia de este 
mecanismo catalítico en la naturaleza seguramente constituye un factor adicional para el atractivo científico de la síntesis de Fischer-Tropsch.

\subsubsection{Fundamentos químicos de la SFT.}

De manera global, la SFT se puede describir a través de dos reacciones principales, descritas por las ecuaciones 1.2 y 1.3, para la formación de parafinas y $\alpha$-olefinas de carácter lineal, respectivamente.

$$
\begin{gathered}
(2 n+1) \mathrm{H}_{2}+n \mathrm{CO} \rightarrow \mathrm{C}_{n} \mathrm{H}_{2 n+2}+n \mathrm{H}_{2} \mathrm{O} \\
2 n \mathrm{H}_{2}+n \mathrm{CO} \rightarrow \mathrm{C}_{n} \mathrm{H}_{2 n}+n \mathrm{H}_{2} \mathrm{O}
\end{gathered}
$$

La reacción de desplazamiento de gas de agua (water gas shift reaction o WGSR) es una reacción secundaria que tiene lugar en las condiciones de la síntesis, de acuerdo a la ecuación 1.1.

Por último, la reacción de Boudouard puede depositar carbono en la superficie del catalizador, de acuerdo a la ecuación 1.4.

$$
2 \mathrm{CO} \rightarrow \mathrm{C}+\mathrm{CO}_{2} \quad \text { (Ec. 1.4) }
$$

La SFT es una reacción controlada por la cinética, esto es, tanto la velocidad de conversión de $\mathrm{CO}$ como el patrón de productos obtenidos obedecen a consideraciones de tipo cinético. Se han propuesto varios mecanismos de reacción, cada uno de los cuales considera una etapa en la superficie metálica del catalizador como la controlante de la cinética global. Los modelos mecanísticos más ampliamente considerados son: el mecanismo "carburo", propuesto ya inicialmente por Fischer y Tropsch [32], que considera la hidrogenación de carburo metálico para dar lugar a intermedios $\mathrm{CH}_{\mathrm{x}}$ adsorbidos, en el paso cinético controlante; el mecanismo "oxigenado" o "enol", propuesto por Storch y col. [46] y modificado 
posteriormente por Kummer y col. [47], que considera como paso cinéticamente limitante la hidrogenación de $\mathrm{CO}$ hasta especies "enol" $\mathrm{CHOH}$ cuya condensación con pérdida de agua resulta en el crecimiento de cadena; y el mecanismo "inserción de carbonilo", derivado de estudios con catalizadores en fase líquida, en el que se considera el crecimiento de cadena por inserción de una molécula de CO activada no-disociativamente [48].

En la actualidad no existe un mecanismo de reacción capaz de explicar completamente todas las evidencias experimentales, siendo aún hoy objeto de controversia en la literatura científica la naturaleza de la etapa limitante de la velocidad global, así como la naturaleza de los intermedios de reacción $[49,50,51]$. Es probable que los mecanismos operativos sean diferentes en función del catalizador (Fe o Co) empleado [52]. A su vez, algunos estudios revisitan el mecanismo original de tipo "carburo", encontrando nuevas evidencias experimentales que apoyan este modelo mecanístico, pero limitado a la superficie más externa del metal activo [53], es decir, excluyendo una contribución de la hidrogenación de carburos metálicos de tipo másico (bulk).

En cualquier caso, está generalmente aceptado que el proceso de formación de hidrocarburos transcurre a través de 3 etapas catalíticas que tienen lugar en la superficie metálica del catalizador:

1) Una etapa de iniciación en la que el $\mathrm{H}_{2}$ y el $\mathrm{CO}$ se adsorben, se disocian y se combinan sobre los centros activos para dar lugar a especies mono-carbonadas parcialmente hidrogenadas.

2) Una etapa de propagación durante la cual las especies monocarbonadas se ensamblan de forma secuencial siguiendo un mecanismo de polimerización por adición en cadena, dando lugar a especies $\mathrm{C}_{\mathrm{x}} \mathrm{H}_{\mathrm{y}}$ lineales. 
3) Una etapa de terminación en la que las cadenas en crecimiento se desorben del centro activo. Dependiendo del evento catalítico que preceda a la desorción se forman parafinas, $\alpha$-olefinas o productos oxigenados. Si la etapa de terminación involucra la hidrogenación por inserción de $\mathrm{H}$ o de una unidad $\mathrm{CH}_{3}$, el producto se desorbe como una parafina; si por el contrario se produce la abstracción de hidrógeno en el carbono $\beta$ se obtiene una $\alpha$ olefina; finalmente, si precede la inserción de una molécula de CO activada no-disociativamente se obtiene un producto oxigenado. La selectividad de la síntesis de Fischer-Tropsch a productos oxigenados es, generalmente, muy limitada.

La selectividad de la SFT es función del balance entre la cinética de las etapas de propagación y de terminación, aunque, como se comentará más adelante, en condiciones reales de operación algunas reacciones secundarias para las $\alpha$-olefinas como la re-adsorción o isomerización pueden contribuir a determinar el patrón de selectividades, especialmente en el rango de los hidrocarburos más pesados. Idealmente, en ausencia de reacciones secundarias, de acuerdo con la naturaleza de polimerización de la etapa de propagación, y considerando la cinética de cada evento de inserción como independiente de la longitud de la cadena en crecimiento, la distribución de productos obtenida puede describirse mediante la ecuación potencial 1.5:

$$
W_{n} / n=\alpha^{n-1} \cdot(1-\alpha)^{2}
$$

siendo $\mathrm{W}_{\mathrm{n}}$ la fracción másica de los productos cuya longitud de cadena es de $n$ átomos de carbono y $\alpha$ el parámetro denominado probabilidad de crecimiento de cadena. El valor de $\alpha$ constituye un balance entre las constantes cinéticas para los eventos de propagación y terminación 
de una cadena hidrocarbonada en crecimiento, de acuerdo a la ecuación 1.6, y es una función del catalizador y las condiciones de reacción.

$$
\alpha=r_{\text {propag. }} / r_{\text {propag. }}+r_{\text {termin }}
$$

Este modelo predice una distribución de productos denominada distribución de Anderson-Schulz-Flory o ASF $[54,55,56]$ de modo que, tras linealización de la ecuación 1.6, una representación de $\operatorname{Ln}\left(\mathrm{W}_{\mathrm{n}} / n\right)$ frente a $n$ generaría una línea recta de pendiente $\alpha$. No obstante, los fenómenos de readsorción de $\alpha$-olefinas en los centros metálicos dan lugar a dos distorsiones con respecto a la distribución predicha. Estas desviaciones, representadas en la Fig. 1.3, consisten en una menor producción de etano (probablemente debida que el proceso de readsorción para el etileno es mucho más favorable energéticamente que para el resto de $\alpha$-olefinas [57]) y una mayor selectividad hacia productos de cadena larga derivada de la participación de las $\alpha$-olefinas re-adsorbidas en los procesos de crecimiento de cadena [58]. 


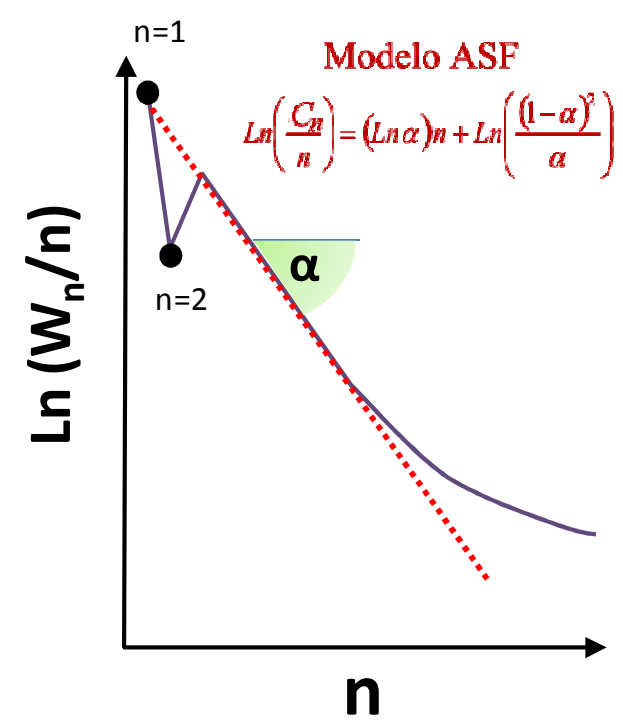

Figura 1.3: Distribuciones de productos de la sintesis de Fischer-Tropsch real (línea continua) y predicha por el modelo de ASF (línea punteada).

De acuerdo a esta distribución de productos, existe una selectividad máxima teórica para todas las fracciones de productos, excepto el metano, tal y como se muestra en la Fig. 1.4, en función de la probabilidad de crecimiento de cadena. Puesto que el valor de $\alpha$ es función del tipo de catalizador, del reactor y de las condiciones experimentales, estas variables se pueden seleccionar durante el diseño de la operación, en función de la fracción de productos que se desee maximizar.

Este aspecto de la reacción confiere, por otro lado, cierto grado de versatilidad a los procesos basados en la SFT, que permiten maximizar los productos en el rango de la gasolina o los destilados medios y ceras, adaptándose a las demandas vigentes. 


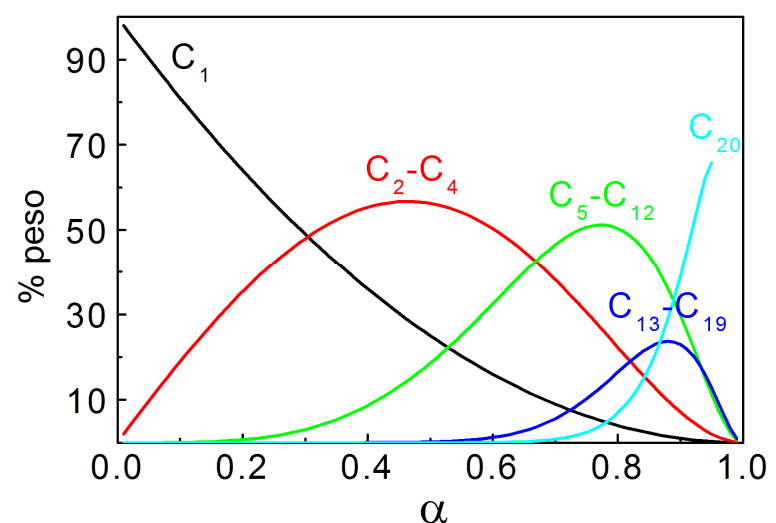

Figura 1.4: Composición de la mezcla de hidrocarburos obtenidos en la SFT en función del parámetro $\alpha$.

\subsubsection{Catalizadores para la SFT.}

Los metales de transición de los grupos 3, 4, 5 y 6 del sistema periódico presentan actividad para la disociación de CO, sin embargo no son adecuados para la SFT puesto que presentan una baja o nula capacidad para disociar $\mathrm{H}_{2}$ y forman fases de óxidos muy estables, que requieren condiciones demasiado severas para su reducción. Por otro lado, ciertos metales de carácter noble pertenecientes a los grupos 10 y 11 como Ir, Pd, $\mathrm{Pt}, \mathrm{Ag}, \mathrm{Au}$, así como los metales del grupo 12 presentan una barrera energética demasiado elevada para la disociación de $\mathrm{CO}$ en las condiciones de reacción [59]. Los metales que combinan actividad en la disociación de $\mathrm{CO}$ e $\mathrm{H}_{2}$, y que son activos en la conversión de gas de síntesis, se encuentran situados entre estos dos grupos en el sistema periódico, como se muestra en la Fig. 1.5.

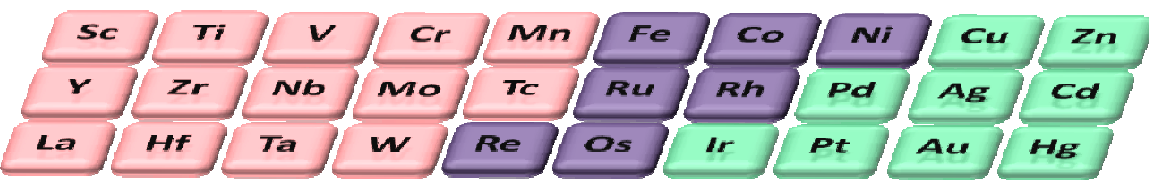

Figura 1.5: Grupos de metales de transición agrupados según su capacidad de disociar $\mathrm{CO}, \mathrm{H}_{2}$ ó $\mathrm{CO}$ e $\mathrm{H}_{2}$. 
El Ru es el metal más activo [60], sin embargo, es demasiado caro y poco accesible como para emplearse en procesos de conversión de gas de síntesis a gran escala. Por su parte el $\mathrm{Ni}$ posee una gran capacidad de hidrogenación, lo que resulta en una indeseada elevada selectividad hacia la metanación y además, posee una gran tendencia a formar (sub)carbonilos volátiles en las condiciones de reacción que resultan en aglomeración metálica y la contaminación de los productos. El Rh, por otra parte, presenta una actividad catalítica intrínseca tres veces inferior al $\mathrm{Ni}$ [60] y produce metano junto con productos oxigenados $C_{2}$ principalmente. Generalmente, Co y Fe son los dos metales de elección para los procesos basados en la SFT.

El hierro es unas 200 veces más económico que el Co pero presenta una menor actividad y selectividad intrínseca hacia hidrocarburos de cadena larga. Las condiciones de trabajo óptimas, típicamente, requieren de elevadas temperaturas $\left(>350^{\circ} \mathrm{C}\right.$ ) y en estas condiciones los catalizadores de Fe son más sensibles a la desactivación por deposición de formas refractarias de carbón en la superficie del mismo. Por otro lado, este metal es más activo hacia la WGSR, algo que, si bien a priori puede verse como una pérdida de eficacia, permite operar con gas de síntesis de relación $\mathrm{H}_{2} / \mathrm{CO}$ inferiores a 1.5, lo que resulta de interés en procesos de CTL y BTL [61].

Por su parte el cobalto, a pesar de ser más caro, es más activo y más selectivo a hidrocarburos de cadena larga, mientras que trabaja de manera óptima a temperaturas más suaves, típicamente en el rango $180-230$ ㄷ C y es más resistente a la desactivación, lo que prolonga el tiempo de vida útil de los catalizadores. Además, este metal es muy poco activo hacia la WGSR, lo que requiere de una relación $\mathrm{H}_{2} / \mathrm{CO}$ en la alimentación entorno a 2 , limitando su aplicación a los procesos de GTL. 
La mayoría de los procesos basados en la SFT de reciente implantación a escala industrial, así como gran parte de aquellos previstos para ser instalados a corto y medio plazo, emplean gas natural como fuente de gas de síntesis (GTL) y catalizadores basados en Co, que permiten elevadas conversiones por paso en la etapa reactiva, maximizando la producción de hidrocarburos de cadena larga (valores de $\alpha>0.9$ ), como precursores del diesel sintético.

El primer catalizador de Co empleado por Fischer y Tropsch en el Instituto Kaiser Wilheim presentaba una composición másica 46\%Co: $8 \% \mathrm{ThO}_{2}: 46 \%$ kieselguhr (tierra de diatomeas) y se preparó mediante coprecipitación empleando una disolución acuosa de los nitratos de Co y Th en presencia de la tierra de diatomeas $\left(\mathrm{SiO}_{2}\right)$ suspendida en el medio [62].

De acuerdo con lo descrito en la literatura de patentes y científica, en la actualidad, los catalizadores de Co empleados para la SFT consisten en la fase metálica (10-30\%-p Co) soportada sobre un óxido inorgánico poroso, de carácter refractario, que típicamente es $\mathrm{SiO}_{2}, \mathrm{Al}_{2} \mathrm{O}_{3} \mathrm{y}$, en menor grado $\mathrm{TiO}_{2}$. Generalmente, en la composición del catalizador se incluyen, a su vez, un metal promotor de reducción como $\mathrm{Ru}, \mathrm{Re}, \mathrm{Pt}$ ó $\mathrm{Pd}$ en contenidos normalmente inferiores al 1.5\%-p, que se reduce a bajas temperaturas $\left(<150\right.$ 으) y presenta una elevada actividad en la disociación de $\mathrm{H}_{2}$, lo que promueve, a través de fenómenos de migración superficial o spill over, la reducción de las fases de Co vecinas, permitiendo obtener elevados grados de reducción. De manera opcional, los catalizadores contienen un segundo promotor "estructural", normalmente de carácter alcalino como K, Ba, La,Ce, Zr ó $\mathrm{Mn}$.

La técnica más extensamente empleada para sintetizar los catalizadores basados en Co es la impregnación, de manera común, a 
humedad incipiente (incipent wetness impregnation) [63], es decir, hasta saturación del volumen de poro del soporte, empleando disoluciones acuosas de sales solubles (comúnmente nitratos) de los componentes metálicos a soportar. La disolución de los precursores metálicos penetra en la estructura porosa del soporte mediante fuerzas capilares, de modo que el volumen de disolución empleada no supera el volumen de saturación de los poros del soporte, minimizándose la deposición de los precursores metálicos en la superficie externa de las partículas de catalizador. Un tratamiento de secado posterior retira el disolvente y deposita los precursores metálicos en el interior de los poros del soporte. Seguidamente, los precursores metálicos se descomponen en los correspondientes óxidos, típicamente mediante un tratamiento térmico denominado calcinación. Finalmente, el catalizador calcinado se reduce, de manera común empleando $\mathrm{H}_{2}$, para generar las fases de $\mathrm{Co}^{\circ}$ catalíticamente activas. Esta reducción suele realizarse in situ en el reactor de síntesis antes del comienzo de la operación del catalizador, puesto que una ulterior exposición al ambiente tiene como consecuencia la pasivación del catalizador, volviéndolo inactivo.

A lo largo de las últimas décadas, numerosas empresas y laboratorios han optimizado la composición y las metodologías de síntesis de los catalizadores basados en Co. Los esfuerzos de investigación han resultado en abundante documentación de know how y la publicación de numerosas patentes en las que se protege la tecnología propia para su instalación industrial o su licenciación. En este sentido, Exxon ha investigado principalmente catalizadores $\mathrm{Co} / \mathrm{TiO}_{2}$. La mayor parte de las patentes asignadas a Exxon describen catalizadores soportados en $\mathrm{TiO}_{2}$ con un contenido en Co entre el $11 \%$ y $12 \%$ en peso combinado con distintos aditivos que actúan como promotores estructurales o mejoran la actividad catalítica. Para cargas metálicas superiores, el $\mathrm{TiO}_{2}$ no resulta tan interesante 
como soporte debido a que su baja área superficial (11-15 $\mathrm{m}^{2} / \mathrm{gr}$ ) y volumen de poro $\left(0.1-0.2 \mathrm{~cm}^{3} / \mathrm{gr}\right)$ no permite alcanzar elevadas dispersiones metálicas. No obstante, el uso de este tipo de catalizadores solamente es adecuado para reactores de lecho fijo debido a su limitada resistencia mecánica y, además, la formación de titanatos de cobalto $\left(\mathrm{CoTiO}_{3}\right)$ durante los tratamientos de calcinación y regeneración de los catalizadores $\mathrm{Co} / \mathrm{TiO}_{2}$ reduce el rendimiento de utilización del metal puesto que estas especies son muy estables e inactivas en la SFT [64] .

Por su parte, Gulf/Chevron, Sasol y Statoil han centrado sus esfuerzos en el desarrollo de catalizadores soportados en $\mathrm{Al}_{2} \mathrm{O}_{3}$. Las patentes de Gulf/Chevron describen métodos de impregnación a partir de disoluciones orgánicas de los metales precursores. Los catalizadores desarrollados combinan Co con Re y algún óxido de lantánido, especialmente La [65]. También se han descrito métodos de activación cíclicos (oxidaciónreducción) que mejoran notablemente la actividad de los catalizadores [66]. Los catalizadores desarrollados por Statoil combinan Co y Re (como promotor de reducción) con óxidos de lantánidos y K [67]. Por su parte, las patentes asignadas a Sasol describen el empleo de $\mathrm{Pt}$ o $\mathrm{Pd}$ como promotores de reducción para las fases de Co [68]. Esta empresa también ha estudiado y patentado nuevos métodos de preparación que emplean técnicas a vacío [69] y tratamientos post-síntesis, como un recubrimiento parcial del soporte con carbón [70], que modifica la interacción $\mathrm{Co}^{-} \mathrm{Al}_{2} \mathrm{O}_{3}$ y, de acuerdo con los autores, mejora la actividad y selectividad del catalizador.

Shell, por su parte, ha patentado una gran variedad de catalizadores de $\mathrm{Co} / \mathrm{SiO}_{2}$ sintetizados mediante impregnación. La mayoría de estos catalizadores se han diseñado para su uso en reactores de lecho fijo, como el reactor multitubular TB-FBR empleado en el proceso SMDS para la 
producción de destilados medios. La mayoría de estos catalizadores contienen óxidos de $\mathrm{Zr}$, Ti o $\mathrm{Cr}$ como promotores.

\subsubsection{Nivel de instalación industrial actual y perspectivas de los procesos GTL basados en la SFT.}

En la actualidad, los procesos GTL basados en la SFT producen más de $10^{5}$ barriles/día en unas 5 plantas principales, operativas en diferentes regiones del planeta, fundamentalmente el sur de África y Asia. La Tabla 1.1 recoge la localización, la tecnología y la capacidad de producción de las plantas de GTL que operan actualmente o estarán operativas a corto plazo en todo el mundo.

La tradición de Sudáfrica en la síntesis de Fischer-Tropsch, derivada de la apuesta por la tecnología CTL para autoabastecerse de combustibles durante el embargo económico de la OPEP en los años 70, ha derivado en una de las principales capacidades instaladas en procesos GTL, con dos plantas en Sasolburg y Mossel Bay operadas por Sasol y PetroSA, respectivamente.

No obstante, la planta de mayor capacidad operativa en la actualidad se inauguró en 2007 bautizada como Oryx-GTL, y se encuentra situada en Ras Laffan (Qatar). Esta planta, fruto de una colaboración entre QatarPetroleum (QP) y Sasol, emplea el proceso Sasol Phase Distillate (SPD $\left.{ }^{\circledR}\right)$. La Fig. 1.6-a muestra un diagrama de flujo esquematizado para el proceso SPD, que es conceptualmente representativo para la mayoría de los procesos GTL.

En el proceso SPD el gas de síntesis se obtiene por reformado autotérmico de metano con vapor de agua y $\mathrm{O}_{2}$ y la síntesis de FischerTropsch tiene lugar en un reactor de tipo Slurry (SBCR) desarrollado por Sasol, empleando un catalizador basado en $\mathrm{Co} / \mathrm{Al}_{2} \mathrm{O}_{3}$. Los productos de la síntesis de Fischer-Tropsch se procesan, posteriormente, antes de poder 
comercializarse. Los procesos más destacados a los que se someten los hidrocarburos derivados de la SFT de baja temperatura (catalizada por Co) comprenden la oligomerización e isomerización de olefinas de cadena corta para producir gasolina, así como la hidroisomerización e hidrocraqueo de ceras para producir combustibles diesel y queroseno, así como lubricantes [71]. La Fig. 1.6-b complementa al diagrama de flujo con una vista panorámica nocturna de la planta Oryx-GTL en la que se identifican las unidades principales del proceso. 
Tabla 1.1: Operador, localización, tecnología, producción y antigüedad de las plantas comerciales de síntesis de Fischer-Tropsch operativas e instaladas.

\begin{tabular}{|c|c|c|c|c|}
\hline Compañía & Localización & $\begin{array}{l}\text { Tecnología } \\
\text { instalada }\end{array}$ & $\begin{array}{l}\text { Producción } \\
\text { (barriles/día) }\end{array}$ & $\begin{array}{c}\text { Fecha de } \\
\text { inauguración } \\
\text { (propuesta) }\end{array}$ \\
\hline Sasol & $\begin{array}{l}\text { Sasolburg } \\
\text { (Sudáfrica) }\end{array}$ & $\begin{array}{c}\text { Sasol Slurry } \\
\text { (Catalizador Fe) }\end{array}$ & 5000 & 2004 \\
\hline PetroSA & $\begin{array}{l}\text { Mossel Bay } \\
\text { (Sudáfrica) }\end{array}$ & $\begin{array}{c}\text { Sasol CFN } \\
\text { (Catalizador Fe) }\end{array}$ & 36000 & 1992 \\
\hline Shell & $\begin{array}{l}\text { Bintulu } \\
\text { (Malasia) }\end{array}$ & $\begin{array}{c}\text { SMDS } \\
\text { (Catalizador de } \\
\text { Co en reactor de } \\
\text { lecho fijo) }\end{array}$ & 14700 & 1993 \\
\hline $\begin{array}{l}\text { Sasol-Qatar } \\
\text { Petroleum }\end{array}$ & $\begin{array}{l}\text { Ras Laffan } \\
\text { (Qatar) }\end{array}$ & $\begin{array}{c}\text { Sasol SPD } \\
\text { (Catalizador de } \\
\text { Co en reactor de } \\
\text { slurry) }\end{array}$ & 34000 & 2007 \\
\hline $\begin{array}{l}\text { Chevron- } \\
\text { NNPC }\end{array}$ & $\begin{array}{l}\text { Escarvaros } \\
\text { (Nigeria) }\end{array}$ & $\begin{array}{c}\text { Sasol SPD } \\
\text { (Catalizador de } \\
\text { Co en reactor de } \\
\text { slurry) }\end{array}$ & 34000 & (2010) \\
\hline $\begin{array}{l}\text { Shell-Qatar } \\
\text { Petroleum }\end{array}$ & $\begin{array}{l}\text { Ras Laffan } \\
\text { (Qatar) }\end{array}$ & $\begin{array}{c}\text { SMDS } \\
\text { (Catalizador de } \\
\text { Co en reactor de } \\
\text { lecho fijo) }\end{array}$ & 70000 & (2009) \\
\hline $\begin{array}{l}\text { World GTL- } \\
\text { Petrotrin }\end{array}$ & $\begin{array}{l}\text { Point-à- } \\
\text { Pierre } \\
\text { (Trinidad) }\end{array}$ & $\begin{array}{l}\text { Antigua planta de } \\
\text { síntesis de } \\
\text { metanol } \\
\text { (Catalizador de } \\
\text { Co) }\end{array}$ & 2250 & (2009) \\
\hline
\end{tabular}




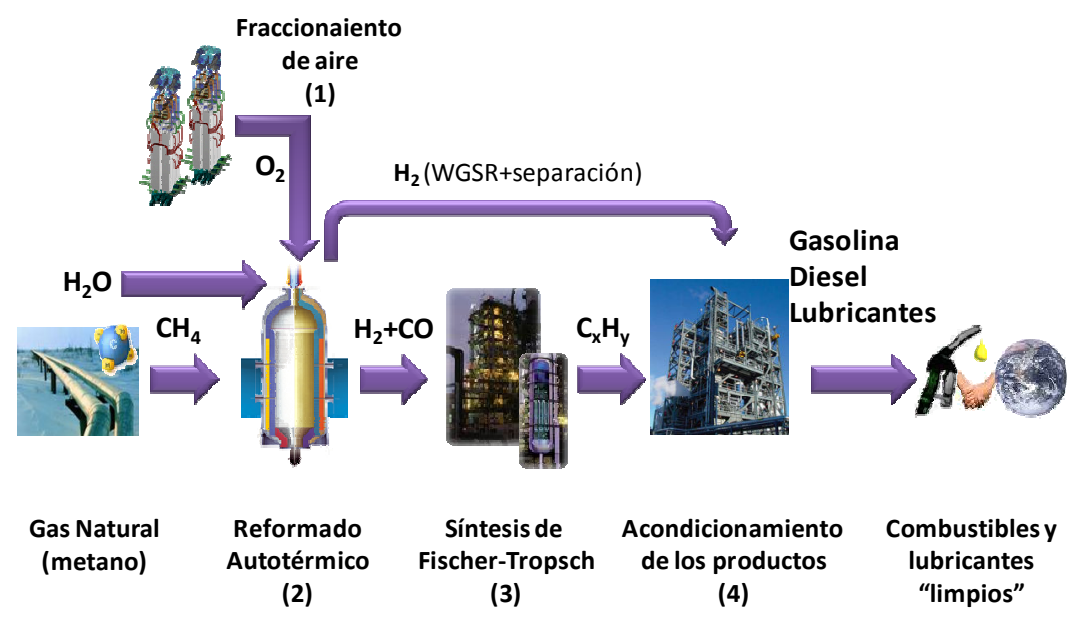

(a)

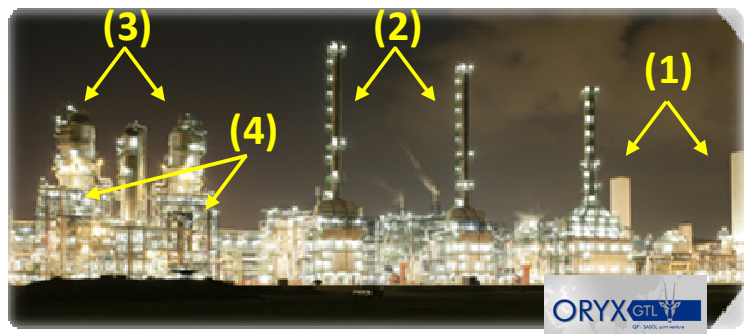

(b)

Figura 1.6: (a) Representación esquemática del diagrama de flujo para el proceso $S P D^{\circledR}$ (Sasol Phase Distillate); (b) vista nocturna de la planta Oryx-GTL ${ }^{\circledR}$ operada por Sasol-QP en Ras Laffan (Qatar) en la que se identifican las operaciones básicas esquematizadas en (a).

En la actualidad, son numerosas las compañías que proyectan la construcción de plantas GTL a escala industrial y aún más numerosos los proyectos que se encuentran en un nivel de instalación piloto. Así, empresas multinacionales líderes en el sector como Sasol, Chevron, Shell, ExxonMobil, Statoil y ConocoPhillips mantienen en la actualidad proyectos de plantas de producción, en muchos casos en colaboración con empresas de carácter nacional como QP (Qatar), PDVSA (Venezuela), o EGPC (Egipto), algunos de los cuales se encuentran ya en las etapas finales de estudio de viabilidad y su 
inauguración está prevista para antes de 2012. Estos proyectos contemplan localizaciones en Ocenía (Australia), América (Venezuela, Perú, Bolivia), África (Nigeria, Egipto) y Europa (Rusia), lo que resultará en una importante globalización de los procesos GTL, pero sobre todo estarán localizados en países asiáticos como Irán y, principalmente, Qatar, que harán de este pequeño país de Medio Oriente la capital mundial de los procesos GTL. Además de las mencionadas, otras empresas como Eni (en colaboración con el IFP), Rentech, BP o Axens operan plantas a escala piloto, en alguna de las cuales ya han comenzado estudios de escalado a nivel comercial.

\subsubsection{SFT catalizada por Co: aspectos científicos de interés actual.}

Los catalizadores de SFT basados en Co han sido objeto de un intenso estudio, especialmente durante las últimas dos décadas. Este interés en los catalizadores basados en Co es consecuencia de las ventajas que ofrecen respecto de los catalizadores basados en $\mathrm{Fe}$, especialmente en términos de tiempo de vida útil, así como la tendencia a emplear gas de síntesis derivado del gas natural $\left(\mathrm{H}_{2} / \mathrm{CO}>1\right)$ y a maximizar la fracción de productos de cadena larga (destilados medios y ceras) en las plantas comerciales. Esto último viene regido por una tendencia global, pero acentuada especialmente en Europa, hacia el desplazamiento de la gasolina por los combustibles diesel [72] y, adicionalmente, por el hecho de que uno de los productos que más incrementan los beneficios de una planta GTL es la fracción de lubricantes [73].

Inicialmente se identificó la especie reducida $\mathrm{Co}^{0}$ como fase activa en la SFT. La atribución de actividad catalítica a las fases metálicas reducidas se basó en una serie de observaciones experimentales tales como que monocristales de $\mathrm{Co}^{0}$ son activos [74] o el hecho de que las fases de $\mathrm{Co}^{0}$ se detectan siempre en los catalizadores activos antes, durante y después de la 
reacción de SFT, mientras que materiales que contienen Co en forma de óxidos o especies que no se reducen durante los tratamientos de activación, como silicatos o aluminatos, no muestran actividad catalítica.

En estudios posteriores, se ha incrementado el conocimiento acerca de la actividad catalítica de los catalizadores para la SFT basados en Co. Khodakov y col. [75] han publicado recientemente una extensa revisión, que contiene cerca de 600 referencias bibliográficas, en la que se sintetiza gran parte de los resultados más relevantes obtenidos en las últimas décadas.

No obstante, en la actualidad varios aspectos de gran importancia científica y tecnológica permanecen aún sin clarificar completamente, de modo que el objetivo principal de la presente tesis doctoral es llevar a cabo estudios encaminados a elucidar alguno de estos aspectos de debate científico actual. A lo largo de los siguientes apartados se resumirán los conocimientos más importantes adquiridos en el campo de la SFT catalizada por Co así como los conceptos que requieren de estudios adicionales.

Esta discusión se estratificará analizando un catalizador de Co para la SFT a diferentes escalas de observación, como se esquematiza en la Fig. 1.7. En una escala de observación del orden de metros, el catalizador se encuentra en el interior del reactor catalítico constituyendo el lecho de reacción (en las configuraciones de reactor de lecho fijo) o bien disperso en una fase gaseosa o líquida (en las configuraciones de lecho fluidizado y de tipo Slurry, respectivamente). Las partículas macroscópicas de catalizador presentan dimensiones del orden de cm-mm. A un nivel de observación más detallado, la estructura porosa del soporte catalítico presenta típicamente macroporos, de dimensiones desde $50 \mathrm{~nm}$ hasta centenas de micras, y/o mesoporos, en el rango de 2-50 nm. Las nanopartículas metálicas soportadas presentan dimensiones típicamente $<50 \mathrm{~nm}$. Finalmente, a escala de 
observación atómica (dimensiones del orden de $\AA$ ) se describen los fenómenos de adsorción y reconstrucción superficial de las nanopartículas metálicas.

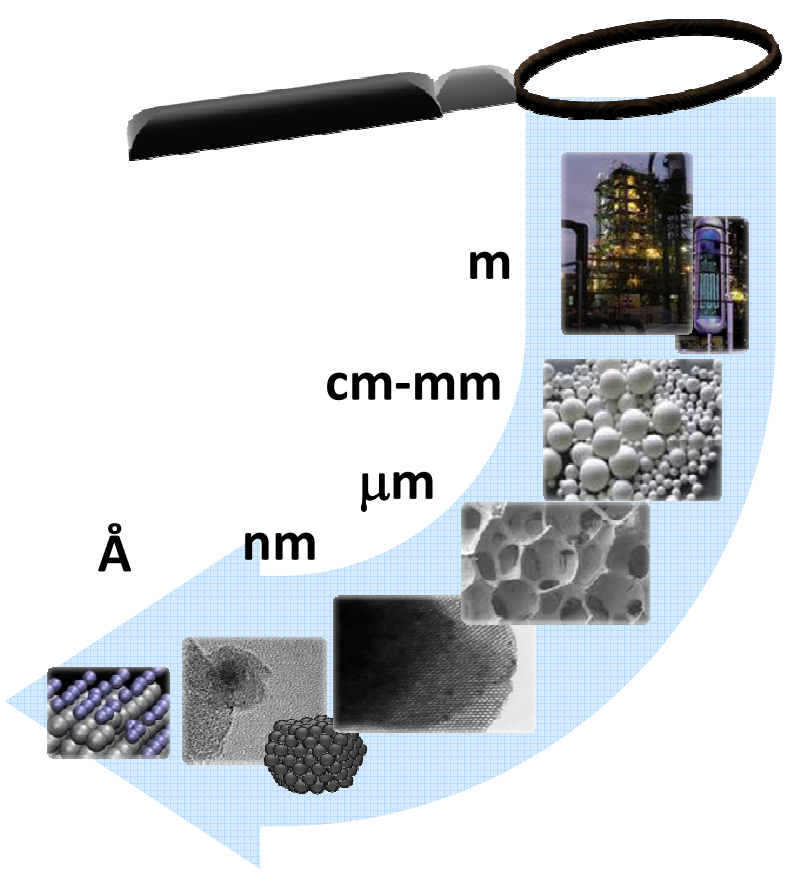

Figura 1.7: Representación esquemática de los diferentes niveles de observación para el estudio de un catalizador de Fischer-Tropsch.

1.3.7.1. Nivel 1: Partículas macroscópicas de catalizador, atricción y propiedades mecánicas.

El tamaño de partícula macroscópica (pellet) de los catalizadores de la SFT es función del tipo de hidrodinámica del reactor empleado. Así, en configuraciones de lecho fijo se requieren pellets cuyos diámetros típicamente exceden $1 \mathrm{~mm}$, con el objetivo de mantener pérdidas de carga aceptables a lo largo del lecho catalítico. Por el contrario, los reactores de lecho fluidizado o de tipo slurry emplean pellets de catalizador cuyo tamaño suele ser inferior a $80 \mu \mathrm{m}$, típicamente en el rango 20-70 $\mu \mathrm{m}$. 
A este nivel de estudio se manifiestan los fenómenos de atricción. La atricción es muy común en configuraciones de reactor en las que las partículas de catalizador están sometidas a tensiones debido a su desplazamiento relativo respecto a la fase empleada para fluidizar el sólido catalítico y las colisiones entre las partículas de catalizador o con las paredes internas del reactor. El término atricción comprende todos los fenómenos que producen la degradación de las partículas macroscópicas del catalizador. Suele manifestarse principalmente durante la operación del catalizador aunque también puede tener lugar durante diferentes etapas de su preparación y conformado, y típicamente desencadena la formación de finos. La formación de finos de catalizador puede tener consecuencias drásticas durante la operación del reactor catalítico, como modificar las propiedades hidrodinámicas del lecho fluidizado, contaminar los productos líquidos de reacción, o producir atascos en los sistemas de filtración y conducción aguas abajo del reactor. Generalmente, se contemplan dos modos principales de atricción: abrasión, consistente en la generación de finos de pequeño tamaño por erosión superficial de los pellet catalíticos, y fragmentación, que consiste en la fragmentación de los pellet del catalizador en fragmentos ligeramente menores que las partículas originales. Además de las condiciones de operación, el fenómeno de atricción depende de la estructura porosa del soporte catalítico y de su composición química, por lo que la resistencia mecánica es un parámetro importante a considerar durante el diseño del catalizador. Wei y col. [76] encontraron que la resistencia mecánica de varios catalizadores de Co es una función del soporte catalítico y decrece en el orden $\mathrm{Co} / \mathrm{Al}_{2} \mathrm{O}_{3}>\mathrm{Co} / \mathrm{SiO}_{2}>\mathrm{Co} / \mathrm{TiO}_{2}$ (rutilo) $>\mathrm{Co} / \mathrm{TiO}_{2}$ (anatasa).

A pesar de la importancia de la hidrodinámica del lecho catalítico y las propiedades mecánicas de las partículas macroscópicas de catalizador, la 
presente tesis doctoral no contemplará cuestiones relativas a este nivel de estudio macroscópico, centrándose en el diseño de catalizadores a niveles de observación correspondientes a dimensiones de menor magnitud.

\subsubsection{Nivel 2: Estructura porosa y transporte de materia.}

Numerosos trabajos han estudiado el papel de los fenómenos de transporte de materia intra-pellet en la actividad y la selectividad de la síntesis de Fischer-Tropsch. Ya originalmente, Fischer y Tropsch mostraron que se obtenían mayores velocidades de reacción y selectividades a productos líquidos $\left(\mathrm{C}_{5+}\right)$ empleando catalizadores de Fe en forma de pellet de menor tamaño $[32,77]$. Anderson y col. [78] atribuyeron resultados similares a restricciones difusionales para los reactivos $\mathrm{H}_{2}$ y $\mathrm{CO}$, que disminuyen su presión parcial en las cercanías de los centros activos, y con ello la cinética de la síntesis. Estudios posteriores describieron los procesos de difusión intra-pellet en lechos fijos y reactores de slurry, incluyendo solamente gradientes de concentración para el $\mathrm{H}_{2}$, desarrollando modelos que analizan la influencia del transporte difusivo de $\mathrm{H}_{2}$ sobre la actividad catalítica $[79,80]$. Sin embargo, estos estudios no describen la influencia del transporte de materia intra-pellet sobre el patrón de selectividades de la síntesis.

A comienzos de los años 90, el grupo dirigido por el profesor Iglesia, en Exxon, desarrolló el modelo de "re-adsorción de $\alpha$-olefinas incrementada por difusión" a partir de numerosos experimentos catalíticos empleando catalizadores de Co y Ru soportados sobre óxidos de diferentes composiciones $\left(\mathrm{Al}_{2} \mathrm{O}_{3}, \mathrm{SiO}_{2}, \mathrm{TiO}_{2}, \mathrm{Al}_{2} \mathrm{O}_{3}-\mathrm{TiO}_{2}\right)$ y porosidades, conformados en forma de pellets de diferentes tamaños, desde los típicos de operaciones en reactores fluidizados $(<80 \mu \mathrm{m})$ hasta los empleados en reactores de lecho fijo (0.8-2 mm). Este modelo es el más ampliamente aceptado en la 
actualidad y describe la influencia de los procesos difusionales intra-pellet tanto para reactivos (CO) como para productos ( $\alpha$-olefinas) en la actividad catalítica y la selectividad de la SFT.

La Fig. 1.8 muestra un esquema de un pellet de un catalizador que en las condiciones de la SFT presenta su estructura porosa llena de hidrocarburos líquidos (productos de reacción). Como se muestra, el modelo considera los perfiles de fugacidad para CO (como reactivo limitado por el transporte difusional) y $\alpha$-olefinas debidos al control cinético ejercido por los fenómenos de difusión desde la fase gaseosa externa hacia los centros metálicos activos en el interior de los poros y viceversa. El incremento en el tiempo de residencia para las $\alpha$-olefinas (productos primarios de la SFT), debido a su difusión retardada en los poros rellenos de ceras líquidas, aumenta la probabilidad de re-adsorción sobre centros metálicos donde estas $\alpha$-olefinas pueden experimentar inserción en las cadenas de hidrocarburos en crecimiento y/o hidrogenación, lo que incrementa el peso molecular de los productos de reacción y la relación parafinas/olefinas en los mismos. Por otro lado, el perfil de concentración que se establece para el $\mathrm{CO}$, incrementa la relación $\mathrm{H}_{2} / \mathrm{CO}$ en la cercanía de los centros activos con respecto a la fase gas externa, resultando en un descenso en la velocidad de las etapas cinéticas de propagación (crecimiento de cadena) que presentan un orden de reacción positivo con la fugacidad de $\mathrm{CO}$, e incrementa la probabilidad de terminación por hidrogenación, lo que se traduce en productos de reacción más ligeros [81]. A su vez, la limitación difusional para la llegada de CO a los centros activos puede producir un descenso en la velocidad de reacción, incluso teniendo en cuenta que la hidrogenación de CO presenta un orden de reacción negativo con respecto a la fugacidad de CO $[82,83]$. 


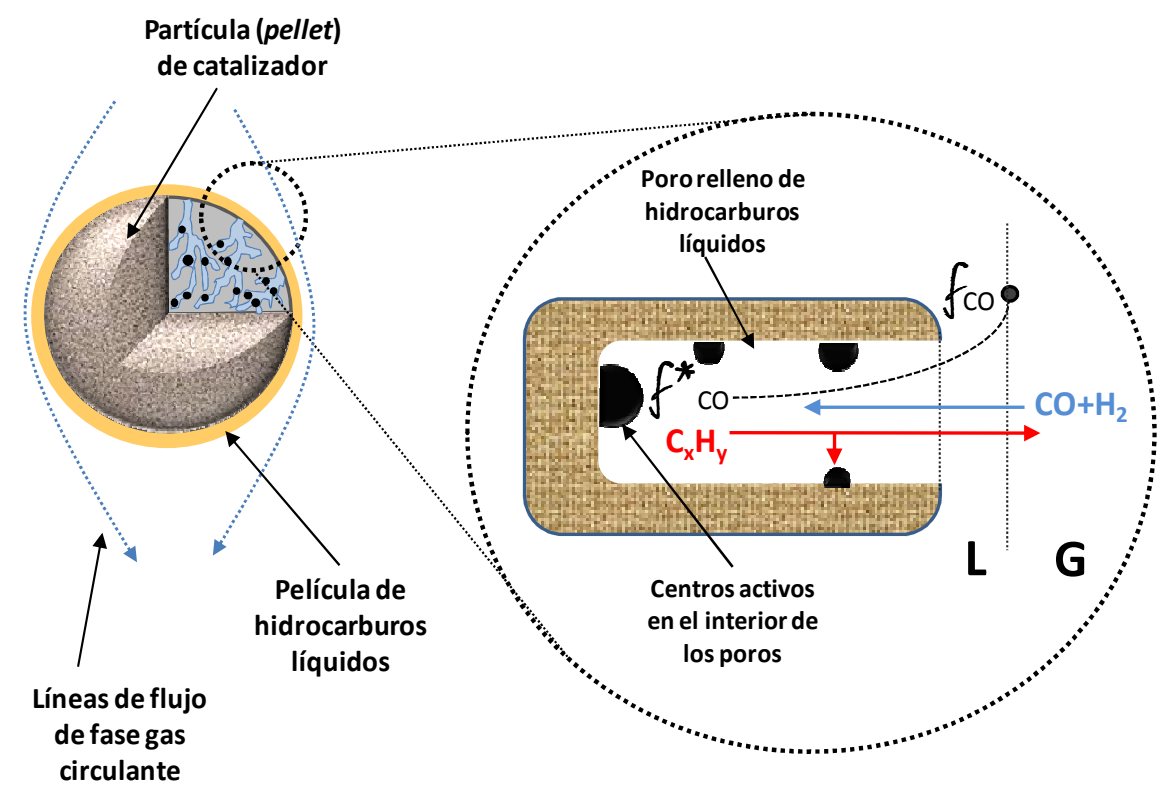

Figura 1.8: Representación esquemática de los fenómenos de difusión intra-partícula que se establecen en un catalizador de Fischer-Tropsch en condiciones de operación. Adaptada de [84].

Un análisis dimensional de las ecuaciones diferenciales que rigen el transporte difusional intra-pellet, el consumo de reactivos y la re-adsorción de $\alpha$-olefinas llevó a identificar un parámetro estructural del catalizador $(\chi)$ que controla la magnitud relativa de las cinéticas de las etapas superficiales (consumo de $\mathrm{CO}$ y re-adsorción de $\alpha$-olefinas) y de las etapas de transporte de materia intra-pellet (difusión de $\mathrm{CO}$ y $\alpha$-olefinas). Este parámetro estructural se define de acuerdo a la ecuación $1.7[83,84]$ :

$$
\chi=\frac{R^{2} \cdot \varepsilon \cdot \theta_{C o^{0}}}{D P}
$$

donde $\mathrm{R}$ representa el radio de partícula macroscópica (pellet) del catalizador, $\varepsilon$ denota la porosidad del catalizador (expresada como tanto por uno del volumen total de pellet que corresponde a los poros), $\theta_{\text {co }}$ representa 
la densidad volumétrica de centros metálicos catalíticos sobre los que tiene lugar la conversión de CO y la re-adsorción de $\alpha$-olefinas y DP corresponde al diámetro de poro del catalizador.

El efecto contrapuesto de los fenómenos difusionales para CO y $\alpha$ olefinas sobre la selectividad de la síntesis resulta en una selectividad máxima hacia hidrocarburos pesados para valores intermedios del parámetro estructural $\chi$. La Fig. 1.9 representa la variación de la selectividad a hidrocarburos líquidos $\mathrm{C}_{5_{+}}$con el valor de $\chi$ para varios catalizadores de $\mathrm{Ru}$ y Co, de acuerdo a los resultados recopilados en el grupo de investigación de Exxon durante los años 90.

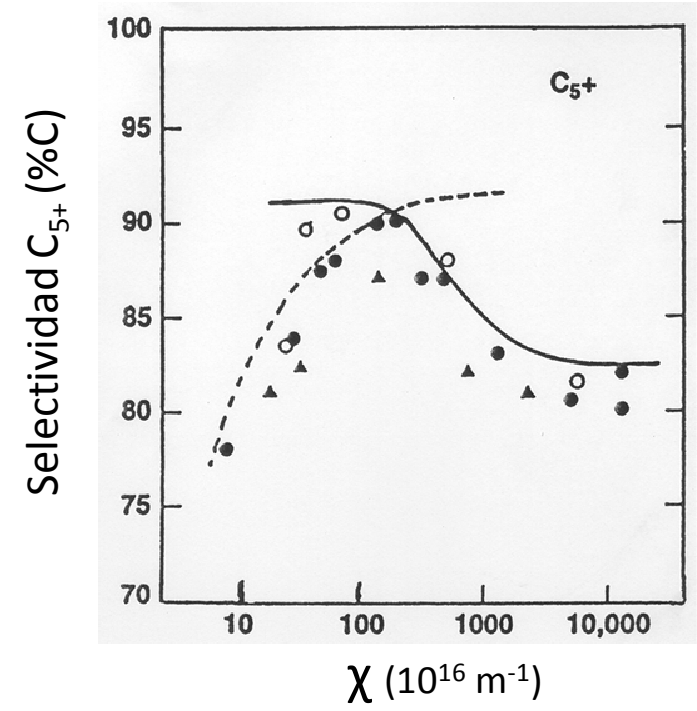

Figura 1.9: Selectividad a la fracción de hidrocarburos $C_{5+}$ en función del parámetro estructural $\chi$. Adaptada de [85].

La máxima selectividad a hidrocarburos $C_{5+}$ se obtiene para catalizadores con un valor de $\chi$ de $100-200 \cdot 10^{16} \mathrm{~m}^{-1}$. Para menores valores de $\chi$, la re-adsorción de $\alpha$-olefinas controla la selectividad de la síntesis de modo que un incremento en la dispersión del catalizador $\left(\theta_{c_{0}}\right)$, una disminución del DP o, principalmente, un incremento de $\mathrm{R}$ (del que $\chi$ 
presenta una dependencia cuadrática) resulta en una mayor selectividad a productos pesados. Por el contrario, para valores de $\chi$ superiores a $200 \cdot 10^{16}$ $\mathrm{m}^{-1}$, la restricción difusional para el acceso de CO hacia los centros activos es la etapa que controla la selectividad de la síntesis de modo que incrementos en la dispersión, el tamaño de pellet o disminuciones del DP resultan en un indeseado descenso en la selectividad hacia productos de reacción de cadena larga. Para estos valores elevados de $\chi$, los perfiles de concentración intra-pellet para el CO resultan, a su vez, en menores velocidades de reacción, como se comentó con anterioridad.

Los catalizadores empleados en reactores de lecho fijo, como los instalados en el proceso SMDS de Shell, requieren de diámetros de pellet típicamente superiores a 0.8-1 $\mathrm{mm}$. Este tipo de catalizadores presentan típicamente valores de $\chi>200 \cdot 10^{16} \mathrm{~m}^{-1}$, por lo que la selectividad de la síntesis está controlada por el acceso difusional de CO a través de la estructura porosa hasta los centros metálicos [85]. Maximizar la selectividad a productos líquidos en estos casos requiere disminuir, dentro de lo posible, el valor de $\chi$ para lo cual, varias estrategias son posibles.

Por un lado, se ha propuesto el empleo de catalizadores con distribuciones no uniformes de las fase metálicas como los de tipo eggshell, en los que la fase activa está concentrada en una fina capa localizada en la periferia del pellet de catalizador (Fig. 1.10-a), de modo que se acorta la longitud de difusión para el CO [86]. No obstante, las metodologías de preparación empleadas para lograr las distribuciones eggshell, como la impregnación con sales metálicas fundidas, de elevada viscosidad [86], resultan en dispersiones metálicas pobres, lo que da lugar a actividades catalíticas inferiores con respecto a catalizadores preparados por técnicas de impregnación convencionales. Por otro lado, gran parte del volumen de 
pellet está libre de fase activa, lo que incrementa sensiblemente el volumen del lecho catalítico para alcanzar una determinada productividad.

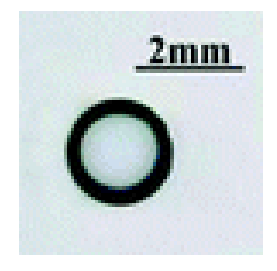

(a)

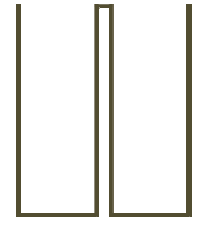

Soporte $\mathrm{SiO}_{2}$ macroporoso

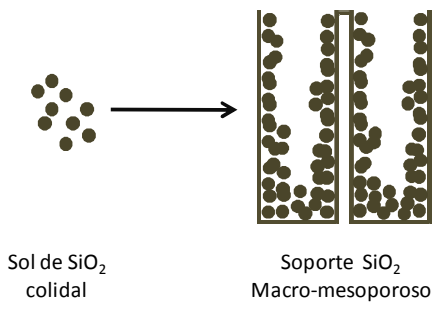

(b)

Figura 1.10: (a) Imagen de microscopía óptica de la sección de un catalizador $\mathrm{Co} / \mathrm{SiO}_{2}$ con distribución de fase soportada tipo "eggshell"; (b) Esquema representativo de la sintesis de un soporte de $\mathrm{SiO}_{2}$ macro-mesoporoso por introducción de un sol nanoparticulado en los macroporos de un sustrato macroporoso, adaptado de [87].

Por otro lado, una estrategia alternativa consiste en incrementar la dispersión metálica manteniendo una porosidad muy abierta que facilite el acceso difusional de $\mathrm{CO}$ en catalizadores con porosidad bimodal. En este sentido, Tsubaki y col. $[88,89]$ han propuesto la generación de una red mesoporosa secundaria en el interior de los canales de un soporte macroporoso, mediante la introducción de nanopartículas del óxido empleado como soporte en el interior de los macroporos del sustrato original. Esta metodología se ha estudiado para soportes basados en $\mathrm{SiO}_{2}$, $\mathrm{Al}_{2} \mathrm{O}_{3}$ y $\mathrm{TiO}_{2}[88,89,90]$. No obstante, los soportes de porosidad bimodal presentan superficies específicas tan sólo ligeramente superiores a las del sustrato macroporoso, de modo que las mejoras en dispersión metálica y actividad catalítica, respecto de los catalizadores macroporosos, son tan sólo modestas.

El capítulo 5 de la presente memoria de tesis estudia la influencia de la estructura porosa (diámetro de poro y longitud de poro) de catalizadores RuCo/Al $\mathrm{O}_{3}$ y RuCo/SBA-15 sobre la actividad y selectividad catalíticas, empleando soportes de porosidad controlada. Ese estudio aborda, a su vez, 
la síntesis de nuevas estructuras porosas que resultan en catalizadores más activos y selectivos a destilados medios.

\subsubsection{Nivel 3: Nanopartículas metálicas, influencia del tamaño de nanopartícula y fenómenos de desactivación por sinterizado.}

Las nanopartículas de Co de los catalizadores comerciales empleados en las plantas GTL presentan distribuciones de tamaño poco uniformes, típicamente en el rango 5-50 $\mathrm{nm}$. La cuestión de si todos los centros metálicos presentan la misma actividad catalítica intrínseca, independientemente del tamaño de la nanopartícula a la que pertenecen, ha atraído un gran interés científico durante las últimas dos décadas.

Para las reacciones catalizadas por metales, una revisión de los trabajos científicos que han estudiado el efecto del tamaño de nanopartícula metálica en la actividad catalítica por centro superficial, expresada comúnmente como frecuencia de renovación del sitio activo o turnover frequency (TOF), permite distinguir tres tendencias generales que se esquematizan en la Fig. 1.11. Generalmente, el valor de TOF permanece prácticamente constante al variarse el tamaño de nanopartícula metálica (comportamiento de tipo I), o bien el valor de TOF se incrementa drásticamente para las nanopartículas de menor tamaño, especialmente para tamaños inferiores a 3-4 $\mathrm{nm}$ (comportamiento de tipo II). Un tercer comportamiento, infrecuente y comúnmente denominado "no clásico" es aquel en que el valor de TOF se incrementa al aumentar el tamaño de nanopartícula hasta un valor límite (comportamiento de tipo III-a) o bien pasa por un máximo para un determinado tamaño de nanopartícula (tipo IIIb). 


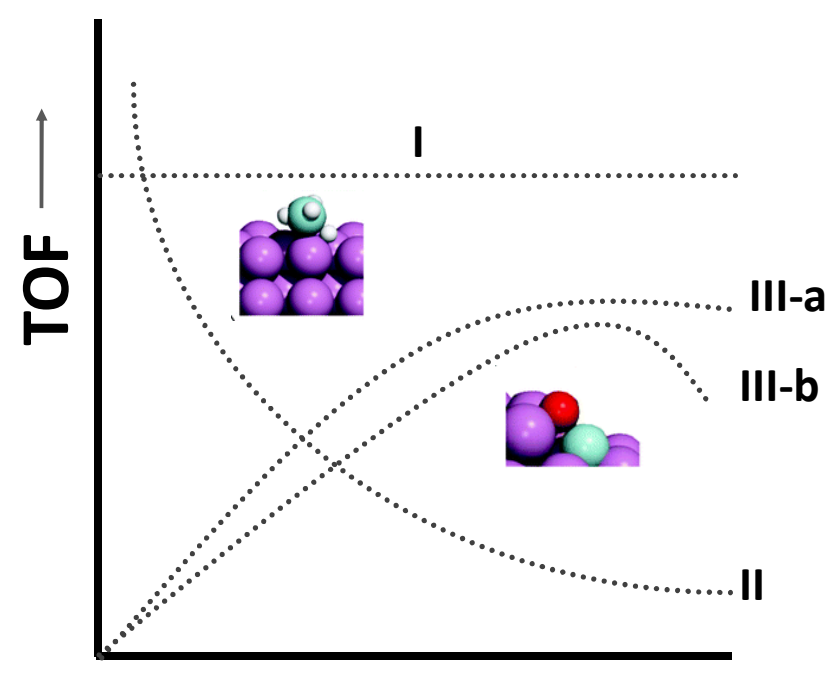

Tamaño de nanopartícula

Figura 1.11: Dependencia de la actividad intrínseca (TOF) con el tamaño de nanopartícula para diferentes tipos de sensibilidad a la estructura. Adaptada de [91].

Las reacciones cuyo valor de TOF es una función del tamaño de nanopartícula metálica se conocen desde hace aprox. medio siglo. En 1969, el profesor M. Boudart acuñó el término de reacciones "insensibles y sensibles a la estructura" para denominar a aquellas reacciones catalíticas cuyo valor de TOF era constante o cambiaba sensiblemente al variar el tamaño de nanopartícula metálica, respectivamente [92]. Desde entonces, numerosas reacciones se han manifestado como sensibles a la estructura.

La sensibilidad a la estructura surge como resultado de que la barrera energética para la activación de un enlace, en una etapa cinéticamente relevante del proceso catalítico, depende sensiblemente del átomo o agrupación de átomos metálicos sobre los que tiene lugar. La topología superficial de los metales no es ideal, y de manera común presenta varias irregularidades. La Fig. 1.12-a muestra una imagen de microscopía de barrido de efecto túnel (STM) de una superficie metálica real en la que se observan terrazas planas, pero también gran variedad de irregularidades 
como escalones, vértices y vacantes atómicas [93]. Gran parte de este tipo de defectos superficiales, en los que los átomos metálicos presentan índices de coordinación anormalmente bajos, se esquematizan en el modelo rígido de una superficie metálica que se muestra en la Fig. 1.12-b.

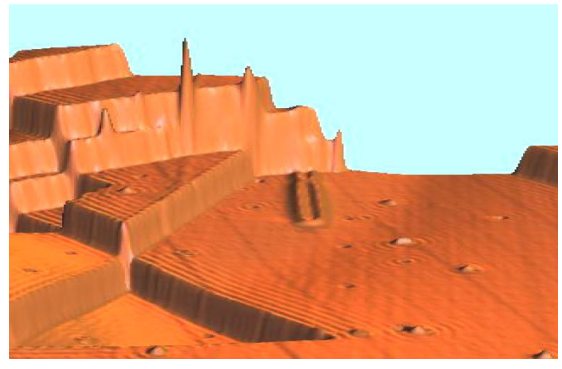

(a)

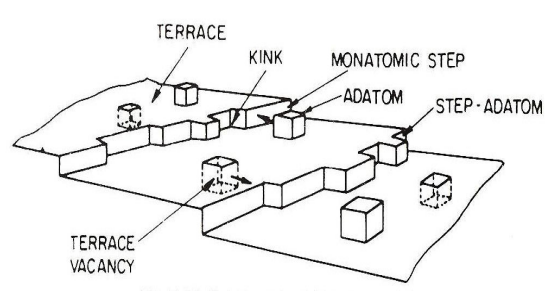

(b)

Figura 1.12: (a) Representación tridimensional de una superficie metálica real obtenida mediante STM [93]; y (b) esquema de una superficie metálica conteniendo varios tipos de centros metálicos derivados de su no-idealidad, [94].

La topología superficial de las nanopartículas metálicas, y por tanto la densidad superficial de átomos metálicos que ocupan posiciones con defecto de coordinación (posiciones de defectos), así como los índices de Miller de los planos expuestos en forma de terrazas (posiciones de terraza) cambian con el tamaño de nanopartícula, especialmente en el rango de tamaños inferior a $4 \mathrm{~nm}$. En su versión más clásica, la sensibilidad a la estructura se manifiesta para tamaños de nanopartícula inferiores a 3-4 nm y está relacionada con la mayor actividad intrínseca de los átomos superficiales que presentan índices de coordinación metálica anormalmente bajos, en posiciones de arista, vértice, escalón, etc y, por lo tanto, densidades electrónicas superiores a los átomos cuya esfera de coordinación está más satisfecha [95].

El tamaño de nanopartícula determina en gran medida la estructura y reactividad de las fases metálicas. La Fig. 1.13 muestra los rangos de estabilidad de diferentes estructuras cristalinas en función del rango de 
tamaños. Para diámetros inferiores a $1 \mathrm{~nm}$ no se puede distinguir entre átomos de superficie y átomos internos (bulk) y estos agregados, que contienen típicamente menos de 50 átomos [96], se denominan clusters y su reactividad suele recordar a la de una molécula, modificándose sensiblemente su estructura por la adsorción de reactivos y/o intermedios de reacción [97]. Entre 1 y $4 \mathrm{~nm}$, el número de átomos metálicos superficiales es superior al del resto de átomos internos y las nanopartículas adquieren típicamente morfologías poliédricas ideales (como las formas platónicas o arquimídeas: cuboctahedros, icosaedros o decahedros). En esta región, la topología superficial cambia sensiblemente con el diámetro de partícula por lo que es el rango de tamaños en los que se manifiesta típicamente la sensibilidad a la estructura en su versión más clásica. Entre 4 y $10 \mathrm{~nm}$ la densidad superficial de átomos en posiciones de defecto no varía sensiblemente con el tamaño. En este rango de tamaños, no obstante, la relación superficie/volumen aún es elevada y el exceso de energía superficial puede estabilizar estructuras que no son estables para tamaños superiores. Por ejemplo, la fase $f c c$ para el $\mathrm{Co}^{0}$ puede ser estable a temperatura ambiente cuando el metal está disperso en forma de nanopartículas, mientras que la termodinámica predice la mayor estabilidad de la fase $h c p$ a temperatura ambiente [98]. Finalmente, para tamaños superiores a $10 \mathrm{~nm}$, la superficie de las partículas presenta mayoría de átomos en posiciones de terraza y el comportamiento catalítico normalmente recuerda al de monocristales que expongan el plano cristalográfico más estable. 


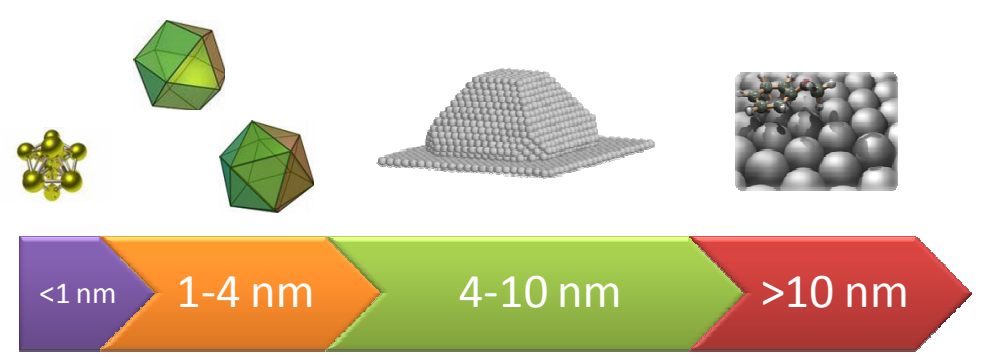

Tamaño de nanopartícula

Figura 1.13: Regímenes de estabilidad para diferentes estructuras metálicas en función del tamaño de partícula.

La insensibilidad a la estructura se ha relacionado con reacciones en las que el paso cinéticamente limitante comprende la adición de un grupo funcional a un reactivo cuando ambas especies se encuentran co-adsorbidas, siendo un ejemplo la adición de un grupo $\mathrm{H}$ en la hidrogenación de una olefina [91]. Por el contrario, la sensibilidad a la estructura clásica (comportamiento de tipo II en la Fig. 1.11) es típico de las reacciones en las que el paso cinético limitante de la velocidad de reacción involucra la ruptura o formación de un enlace de tipo $\sigma$, como en la activación de $\mathrm{CH}_{4}$ [99], la apertura de anillo pirrólico [100] o la hidrogenolisis de alcanos [92]. Por último, el comportamiento de tipo III, o sensibilidad a la estructura no clásica, se ha relacionado con la ruptura o formación de un enlace de tipo $\pi$ en el paso limitante de la velocidad de reacción. Un ejemplo de este tipo de reacción es la síntesis de $\mathrm{NH}_{3}$, que involucra la disociación de $\mathrm{N}_{2}$ en la etapa limitante de la cinética global, lo que ocurre de manera preferente en centros metálicos de tipo doble-escalón o centros " $\mathrm{B}_{5}$ " cuando se cataliza por Ru [101] y centros " $C_{7}$ ", de estructura similar, cuando se cataliza por Fe [102]. Estos centros activos no son posibles por debajo de un determinado tamaño de nanopartícula mientras que su proporción relativa es máxima para un determinado tamaño de cristal [103]. 
En cuanto a la síntesis de Fischer-Tropsch catalizada por Co, durante los últimos años ha existido controversia en torno a su carácter sensible o insensible a la estructura. En este sentido, algunos grupos de investigación han concluido que el valor de TOF no es función del tamaño de nanopartícula [104], mientras que más recientemente otros autores encontraron comportamientos de tipo III-a, de acuerdo a la Fig. 1.11, empleando catalizadores de Co soportados sobre nanofibras de carbono (CNF) [105] y comportamientos de tipo III-b llevando a cabo la reacción con nanopartículas de Ru suspendidas en un medio acuoso [106].

Otro aspecto de los catalizadores de Co para la SFT, de gran importancia tecnológica, es la desactivación. Estudios recientes [107] han sugerido que el principal mecanismo de desactivación es la aglomeración metálica a través de un mecanismo de coalescencia, que resulta en un incremento progresivo del tamaño medio de nanopartícula metálica, con la consecuente pérdida de centros metálicos superficiales. Los fenómenos de aglomeración metálica corresponden también a este nivel de observación nanométrico.

El capítulo 3 de la presente tesis doctoral estudia la sensibilidad a la estructura de la SFT catalizada por catalizadores modelo basados en Co, empleando técnicas de caracterización in situ, como aproximación para entender las causas de la misma.

\subsubsection{Nivel 4: Reestructuración metálica superficial.}

En muchos casos, la topología superficial de los metales antes o después del proceso catalítico puede no coincidir con la estructura de la misma durante la catálisis. Se conoce que la adsorción de moléculas desde la fase gaseosa puede modificar significativamente la estructura de determinadas superficies metálicas. Estos fenómenos se denominan 
reestructuración o reconstrucción superficial inducida por adsorbato [108]. Las modificaciones de la superficie metálica pueden tener consecuencias muy importantes en la estructura de los centros activos o la desactivación de los catalizadores.

El monóxido de carbono es una molécula que muestra un marcado carácter invasivo sobre las superficies metálicas y, por lo tanto, está comúnmente relacionada con fenómenos de reestructuración superficial [109]. Generalmente, la formación de especies de (sub)carbonilos metálicos superficiales incrementa la movilidad superficial de los átomos metálicos promoviendo la reestructuración superficial $[110,111]$.

En el caso de la hidrogenación de CO sobre catalizadores de Co, Wilson y de Groot estudiaron la evolución de la superficie (0001) de $\mathrm{Co}^{0}$ cuando se expone a condiciones de hidrogenación de $\mathrm{CO}$ a presiones de 0.4 MPa [110]. Tal y como se muestra en la Fig. 1.14, estos autores encontraron modificaciones drásticas de la disposición atómica respecto de la superficie original, que resulta en la formación de multitud de islas de un átomo de altura en la superficie metálica. En su trabajo, estos autores relacionan la formación de estas islas en la superficie metálica con la creación de centros activos de estructura $C_{7}$ que, de acuerdo con un paralelismo con la activación de $\mathrm{N}_{2}$ en la síntesis de $\mathrm{NH}_{3}$, serían los más activos para la activación disociativa de CO. 


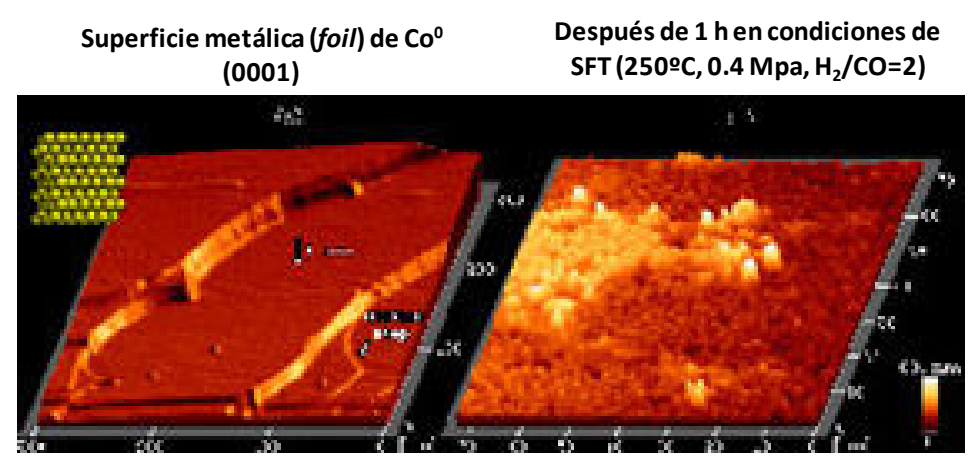

Figura 1.14: Imagen de STM (Scanneling Tunneling Microscopy) de la superficie metálica de un foil de $\mathrm{Co}^{\circ}$ (0001) antes (a) y después de su exposición a condiciones de hidrogenación de $\mathrm{CO}\left(\mathrm{H}_{2} / \mathrm{CO}=2, \mathrm{~T}=250^{\circ} \mathrm{C}, \mathrm{P}=0.4 \mathrm{MPa}\right)$ durante 1 hora [110].

Por otro lado, Beitel y col. [111,112], empleando PM-RAIRS, encontraron la formación de defectos en la superficie de un monocristal de $\mathrm{Co}^{0}$, que originalmente sólo presentaba centros superficiales en terrazas, tras su exposición a 300 mbar de CO o gas de síntesis.

Los fenómenos de reestructuración superficial son de tremenda importancia en el estudio de la sensibilidad a la estructura de la SFT, puesto que, durante la reacción, la topología superficial de las nanopartículas metálicas puede diferir significativamente de la de las nanopartículas tras el tratamiento de reducción del catalizador. La reconstrucción superficial también podría tener implicaciones en la desactivación del catalizador.

El capítulo 3 de la presente tesis doctoral, estudia la sensibilidad a la estructura de la SFT contemplando la reestructuración superficial de las nanopartículas metálicas en condiciones de reacción.

Por su parte, el capítulo 4 estudia la influencia de la historia térmica de los catalizadores en la topología superficial de las nanopartículas metálicas y su relación con la actividad catalítica intrínseca. 


\subsection{Síntesis selectiva de oxigenados por conversión de gas de síntesis.}

\subsubsection{Los compuestos oxigenados superiores como combustibles y productos de química base.}

Si bien el papel de los procesos de conversión catalítica en el campo de los combustibles se presume principal, de acuerdo a todo lo comentado a lo largo de esta introducción hasta este punto, es posible que una futura economía del $\mathrm{H}_{2}$, cuando se solventen las dificultades tecnológicas que a día de hoy son aún retos, desplace, al menos parcialmente, a los combustibles sintéticos derivados del gas de síntesis, incluso en campos tan demandantes como el transporte. No obstante, aparte de combustibles, la sociedad actual demanda grandes cantidades de productos químicos de base como disolventes y reactivos para industrias tan intensivas como las de los polímeros. En este campo, se requiere de fuentes carbonosas alternativas que aseguren la producción de estos compuestos químicos de base frente al agotamiento del crudo, que hoy en día es la única materia prima empleada.

El carbono del gas de síntesis constituye una unidad estructural adecuada para la síntesis de productos químicos de interés. Estos productos químicos requieren de una cierta reactividad química para poder sufrir transformaciones posteriores, y esta reactividad está habitualmente relacionada con la presencia de heteroátomos en su fórmula.

La producción de compuestos oxigenados por conversión catalítica de gas de síntesis se conoce desde los trabajos originales de Fischer y Tropsch empleando catalizadores de Fe. Hoy en día, se conoce la formación de alcoholes, ácidos carboxílicos, ésteres, éteres y cetonas por hidrogenación catalítica de CO sobre determinados catalizadores. De hecho, la síntesis selectiva de metanol por conversión de gas de síntesis es un proceso bien 
establecido a escala industrial, cuya producción mundial ronda las $35 \cdot 10^{6}$ t/año. Sin embargo, la síntesis de oxigenados superiores $\left(C_{2+}\right)$ por conversión de gas de síntesis no ha llegado a este nivel de desarrollo, principalmente, por la ausencia de catalizadores que den lugar a los rendimientos requeridos.

Varios compuestos oxigenados superiores presentan un mercado mundial muy extenso.

El ácido acético constituye un mercado mundial de alrededor de $5 \cdot 10^{9}$ t/año. La mayor parte del ácido acético producido a nivel mundial se obtiene mediante carbonilación de metanol empleando un reactivo yodado y un catalizador homogéneo basado en Rh ó Ir [113], siendo BP la principal productora mundial. También es posible su obtención por rutas fermentativas oxidativas catalizadas por bacterias del género acetobacter [114].

Por su parte el etanol se emplea como aditivo para gasolinas, como combustible puro y como origen de varias rutas sintéticas de gran importancia tecnológica [115]. La producción mundial de etanol superó las $36 \cdot 10^{5}$ t/año en 2005 , siendo Brasil y EEUU los principales productores. De acuerdo a un informe emitido por la Agencia Estadounidense de la Energía, se requerirá una producción anual de $22 \cdot 10^{5}$ t/año de etanol en 2012 , sólo en EEUU. Etanol se produce en la actualidad a través de dos rutas catalíticas principales: la fermentación de azúcares derivados del maíz o la caña [116] y la hidratación de etileno de refinería [117]. A pesar de que la ruta fermentativa se practica a escala comercial, presenta algunas limitaciones como los elevados requerimientos energéticos para operaciones de separación por destilación, y la incapacidad para trabajar con azúcares derivados de biomasa lignocelulósica, que contiene una proporción 
importante de azúcares de tipo pentosa, además de los azúcares de tipo hexosa que pueden procesarse por esta ruta. En oposición a esta ruta biocatalítica, la obtención de etanol y alcoholes superiores a través de una ruta termoquímica, esto es, la conversión catalítica de gas de síntesis obtenido por gasificación de biomasa (incluyendo hemicelulosa y lignina) permitiría velocidades de producción significativamente superiores y una menor especificidad para la materia prima $[115,118]$. Esta alternativa ha recibido un importante interés científico en las últimas décadas, que se espera se incentive a medida que se agoten las reservas de crudo.

\subsubsection{Síntesis de alcoholes superiores $\left(C_{2+}\right)$.}

Durante el embargo de los países de la OPEP en los años 70, tuvo lugar un intenso interés en el desarrollo de procesos catalíticos para la síntesis de alcoholes superiores (principalmente etanol) por conversión catalítica de gas de síntesis, que posteriormente se desactivó cuando se normalizó el suministro de crudo. No obstante, a lo largo de las décadas de los 80 y los 90 se desarrollaron cinco grupos principales de catalizadores heterogéneos, sin que desde entonces se haya sumado ninguna alternativa reseñable [115]:

- La modificación de catalizadores de síntesis de metanol de tipo $\mathrm{Cu}-\mathrm{ZnO}-\mathrm{Al}_{2} \mathrm{O}_{3}$ mediante la adición de promotores de carácter alcalino ( $\mathrm{K}, \mathrm{Na}, \mathrm{Cs}$, etc) da lugar a catalizadores selectivos a alcoholes superiores, principalmente isobutanol, mediante un mecanismo que involucra condensaciones aldólicas consecutivas del metanol producido [119].

- Dow y Union Carbide desarrollaron en los años 80 catalizadores basados en sulfuros de $\mathrm{Mo}\left(\mathrm{MoS}_{\mathrm{x}}\right)$ promovidos por metales de transición y alcalinos, que producen alcoholes superiores 
de naturaleza lineal, requiriendo la presencia de azufre (ppm) en el gas de síntesis alimentado.

- $\quad$ El IFP desarrolló a finales de los 80 catalizadores basados en Cu-Co sintetizados por coprecipitación y promovidos con varios metales de transición.

- Numerosas empresas, entre las que destacan Union Carbide, BP y The Dalian Institute han patentado catalizadores basados en nanopartículas soportadas de Rh promovidas con óxidos de metales de transición y, opcionalmente, metales alcalinos.

Al contrario que la síntesis de metanol, la conversión catalítica de gas de síntesis a alcoholes $\mathrm{C}_{2+}$ no ha llegado a emplearse a nivel comercial aunque, como se recoge en la Tabla 1.2, varios procesos basados en tecnologías patentadas se han desarrollado, algunos a escala piloto.

Tabla 1.2: Procesos, catalizadores y nivel de escala de desarrollo para la síntesis de alcoholes superiores por vía termoquímica [115].

\begin{tabular}{ccc}
\hline Proceso & Catalizador & Escala \\
\hline Dow & $\begin{array}{c}\text { (M)MoS } \\
\text { alcalinizado }\end{array}$ & n.d. \\
$\begin{array}{c}\text { Dow } \\
\text { Ecalene }\end{array}$ & $\begin{array}{c}\text { MoS }_{x} \\
\text { nanoparticulado }\end{array}$ & $\begin{array}{c}\text { Laboratorio (con planes de } \\
\text { escalado a } 2 \mathrm{~m}^{3} / \text { día) }\end{array}$ \\
$\begin{array}{c}\text { Octamix } \\
\text { IFP- }\end{array}$ & $\begin{array}{c}\text { Cu-Zn } \\
\text { alcalinizado }\end{array}$ & Planta piloto (2 t/día) \\
Idemitsu & Cu-Co & Planta piloto (20 barriles/día) \\
SEHT & $\begin{array}{c}\text { Cu-Zn } \\
\text { alcalinizado }\end{array}$ & Planta piloto (40 t/día) \\
\hline
\end{tabular}

n.d.: no disponible.

Los catalizadores basados en nanopartículas de Rh presentan una serie de ventajas respecto a los demás sistemas catalíticos como las temperaturas de trabajo relativamente suaves (250-320C), su elevada 
selectividad hacia alcoholes $\mathrm{C}_{2+}$, principalmente etanol, resultando en elevadas relaciones $\mathrm{C}_{2+} /$ metanol, así como una menor actividad para la reacción competitiva WGSR. Además, al contrario que los catalizadores basados en $\mathrm{MoS}_{\mathrm{x}}$, los catalizadores de Rh no requieren de la presencia de compuestos azufrados en el gas de síntesis alimentado, algo que no es común, especialmente para gas de síntesis de orígenes de bajo contenido en azufre, como la biomasa. Por el contrario, los principales inconvenientes de este sistema catalítico son la baja actividad intrínseca y el elevado precio y escasa disponibilidad del Rh. Estos inconvenientes han hecho que los catalizadores basados en Rh no se hayan considerado como una alternativa para los procesos de síntesis de alcoholes superiores a escala comercial.

No obstante, las limitaciones derivadas del precio del metal activo podrían resultar menos importantes si tenemos en cuenta la tendencia más actual en el precio de este metal a nivel mundial. En este sentido, desde hace aprox. un año, el precio del Rh ha caído aprox. un $80 \%$ respecto a la media de los últimos 3 años, como se muestra en la tendencia representada en la Fig. 1.15.

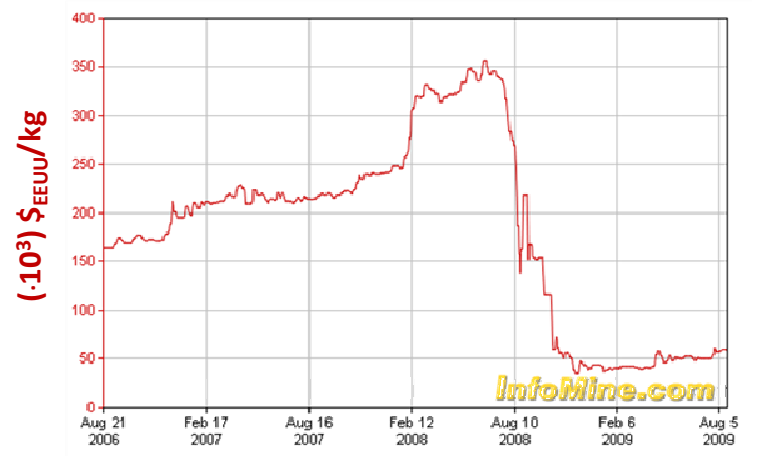

Figura 1.15: Evolución del precio del Rh durante los últimos 3 años. Fuente: www.infomine.com (Agosto 2009). 
De acuerdo a un informe publicado por Johnson Matthey [120], este drástico descenso en el precio del $\mathrm{Rh}$ es debido, principalmente, a las mejoras en los procesos de reciclaje de catalizadores de tres vías, que han reducido notablemente la demanda de Rh extra en el sector automovilístico. Las mejoras en los procesos de reciclaje se aplican también sobre catalizadores industriales, lo que resulta en un abaratamiento de los catalizadores basados en este metal para aplicaciones comerciales. De hecho, la demanda de Rh para aplicaciones industriales ha crecido un $8 \%$ en el último año, principalmente debido a la instalación de nuevas plantas de oxo-síntesis (hidroformilación de olefinas con CO para producir aldehídos y alcoholes, empleando como catalizadores complejos de Rh), especialmente en China. Este descenso en el precio del Rh puede ser una fuerza impulsora que re-incentive la investigación en la conversión catalítica de gas de síntesis en compuestos oxigenados superiores como una alternativa con potenciales aplicaciones industriales, siempre que esta investigación derive en nuevos catalizadores que mejoren el estado de la técnica actual.

\subsubsection{Catalizadores de Rh: versatilidad y efecto promotor.}

Aparte de consideraciones comerciales, los catalizadores basados en $\mathrm{Rh}$ presentan una faceta que les hace especialmente interesantes desde el punto de vista científico y que consiste en un singular y drástico efecto de los promotores.

En catálisis, se denominan promotores aquellos componentes de un catalizador que por sí solos no son responsables de la actividad catalítica pero, tales que su incorporación a un catalizador que contiene otras fases activas, generalmente en pequeñas cantidades, mejora la actividad catalítica, la selectividad y/o la resistencia a la desactivación. A pesar de que la naturaleza real de los mecanismos de promoción puede resultar bastante 
compleja y aún se requieren modelos más detallados y, preferiblemente, individuales para cada sistema catalítico [121], generalmente los promotores se dividen en "estructurales", aquellos que simplemente incrementan la dispersión de las fases activas y "electrónicos", cuya presencia en las cercanías de las fases activas modifica sus propiedades adsorptivas o genera nuevos centros activos [122]. En muchos casos, la influencia de la naturaleza del soporte sobre las propiedades catalíticas de un sistema está relacionada con el papel promotor del propio soporte.

En el caso de los catalizadores de Rh se conoce que, en ausencia de otros metales promotores, las nanopartículas de $\mathrm{Rh}^{0}$ soportadas sobre $\mathrm{SiO}_{2} \mathrm{O}$ $\mathrm{Al}_{2} \mathrm{O}_{3}$ presentan actividades catalíticas muy bajas y producen acetaldehído como producto oxigenado mayoritario, mientras que prácticamente no se forman alcoholes [123]. Sin embargo, la presencia de promotores como Fe, tanto de manera intencionada como en forma de impurezas en el soporte catalítico [124], cambia drásticamente el comportamiento catalítico incrementando la actividad y dando lugar a etanol como principal producto.

La búsqueda del promotor o combinación de promotores óptimos para maximizar la selectividad a alcoholes superiores ha generado numerosos trabajos científicos en las últimas dos décadas. En 1978 Ichikawa y col. [125] estudiaron el efecto promotor de varios óxidos de metales de transición, concluyendo que los metales de carácter ligeramente alcalino como La, Cr, Ti y Th incrementan el rendimiento a etanol. Más tarde, Yu-Hua y col. [126] estudiaron el efecto promotor de varios óxidos de lantánidos (La, $\mathrm{Ce}, \mathrm{Pr}, \mathrm{Nd}$ y Sm) en catalizadores $2 \% \mathrm{Rh} / \mathrm{SiO}_{2}$ encontrando que Ce y $\mathrm{Pr}$ dan lugar a la mayor selectividad a etanol. En determinados casos, se han reportado resultados contradictorios para un mismo promotor. Así, mientras que algunos estudios $[127,128]$ concluyen que $\mathrm{Mn}$ es un promotor adecuado para la síntesis de alcoholes, Ponec [129] encontró que la presencia de Mn 
resulta en pobres actividades y selectividades a alcoholes en catalizadores $\mathrm{Rh} / \mathrm{SiO}_{2}$.

Además, este sistema catalítico presenta una extremada sensibilidad del patrón de selectividades con respecto al/los promotor/es presentes en la composición, de modo que catalizadores de composición muy similar dan lugar a productos oxigenados diferentes. En este sentido, mientras que catalizadores $\mathrm{Rh}-\mathrm{Ir}-\mathrm{Mn}-\mathrm{Li} / \mathrm{SiO}_{2}$ presentan elevadas selectividades hacia ácido acético [130], los catalizadores $\mathrm{Rh}-\mathrm{Fe}-\mathrm{Mn}-\mathrm{Li} / \mathrm{SiO}_{2}$ producen principalmente etanol [131]. De manera similar, Sachtler y col. mostraron que catalizadores $\mathrm{Rh} / \mathrm{NaY}$ son selectivos a ácido acético [132], mientras que la incorporación de pequeñas cantidades de Fe resulta en catalizadores Rh-Fe/NaY selectivos a etanol, de acuerdo a otros resultados publicados por el mismo grupo de investigación [133].

La cantidad de promotor óptima también ha sido objeto de estudio. En general, la actividad y selectividad catalíticas pasan por un máximo cuando se incrementa la relación promotor/Rh, lo que se ha interpretado en términos de decoración y, en el límite, oclusión de las nanopartículas de Rh por las fases de promotor [134]. Sin embargo, la relación óptima promotor/Rh depende en gran medida del sistema en estudio, habiéndose encontrado valores óptimos de $\mathrm{Fe} / \mathrm{Rh}$ tan diferentes como 2.3 para catalizadores $\mathrm{Rh}-\mathrm{Fe} / \mathrm{SiO}_{2}$ [123], 4.6 para $\mathrm{Rh}-\mathrm{Fe} / \mathrm{TiO}_{2}$ [135] y 9.2 para catalizadores $\mathrm{Rh}-\mathrm{Fe} / \mathrm{Al}_{2} \mathrm{O}_{3}[136]$.

Estos resultados sugieren la necesidad de estudios sistemáticos que permitan relacionar la naturaleza de los promotores con la actividad catalítica y, especialmente la selectividad de la conversión catalítica de gas de síntesis empleando catalizadores de Rh. En este sentido, Somorjai y col. $[137,138]$ acometieron un estudio exhaustivo del papel de varios óxidos 
promotores $\left(\mathrm{AlO}_{\mathrm{x}}, \mathrm{TiO}_{\mathrm{x}}, \mathrm{VO}_{\mathrm{x}}, \mathrm{FeO}_{\mathrm{x}}, \mathrm{ZrO}_{\mathrm{x}}, \mathrm{NbO}_{\mathrm{x}}, \mathrm{TaO}_{\mathrm{x}}\right.$ y $\left.\mathrm{WO}_{\mathrm{x}}\right)$ empleando "catalizadores modelo inversos", consistentes en monocristales de $\mathrm{Rh}^{0}$ recubiertos parcialmente por "parches" del óxido promotor, de modo que el fenómeno de promoción química se localiza en la interfase $M \mathrm{M}_{\mathrm{x}} / \mathrm{Rh}^{0}$. Estos autores concluyen que la acidez Lewis es la propiedad más importante de los óxidos promotores, la cual controla los modos de activación de CO en la interfase $\mathrm{Rh} /$ promotor $\mathrm{y}$, por tanto, la velocidad de reacción. $\mathrm{TiO}_{\mathrm{x}}, \mathrm{NbO}_{x} \mathrm{y}$ $\mathrm{TaO}_{x}$ son los promotores más efectivos desde el punto de vista de la actividad catalítica en la hidrogenación de CO. No obstante en estos estudios los experimentos catalíticos se llevan a cabo en condiciones de metanación y no se discuten tendencias en términos de selectividad catalítica.

Al contrario que en los sistemas modelo empleados por estos autores, en los catalizadores reales, la fase dispersa es el Rh. A priori, parece plausible que el comportamiento catalítico de un monocristal de Rh, incluso promovido por sobrecapas de óxidos metálicos, diste significativamente de las características del metal en forma de nanopartículas soportadas. Así pues, resultaría más relevante estudiar el "efecto promotor" en los catalizadores de Rh de forma sistemática pero empleando catalizadores modelo cuya naturaleza fuese más parecida a los sistemas de interés industrial. De acuerdo con la literatura previa en este campo, los centros activos selectivos a la formación de productos oxigenados se encuentran en la frontera entre las fases de $\mathrm{Rh}^{0}$ y el óxido promotor, de modo que una estrategia para maximizar el número de dichos centros activos en los catalizadores modelo es maximizar la superficie de contacto Rh-promotor.

El capítulo 6 de esta memoria recoge los resultados más relevantes de un estudio en el que se examinan las propiedades físico-químicas y catalíticas de catalizadores de $\mathrm{Rh}$ soportado sobre $\mathrm{\gamma}-\mathrm{Al}_{2} \mathrm{O}_{3}$ porosa de elevada área superficial, cuya superficie se encuentra recubierta por el óxido 
promotor $\mathrm{MO}_{\mathrm{x}}$. El recubrimiento de $\mathrm{MO}_{\mathrm{x}}$ corresponde aprox. con una monocapa, de modo que el soporte común $\left(\mathrm{Al}_{2} \mathrm{O}_{3}\right)$ homogeniza las propiedades texturales de todos los catalizadores, mientras que la presencia de una "monocapa" de óxido promotor maximiza la superficie de contacto promotor-Rh. El estudio pretende relacionar las propiedades electrónicas de los promotores con las características catalíticas, especialmente el patrón de selectividades, de los catalizadores de Rh.

\subsection{Estructura y objetivos de la tesis doctoral.}

A lo largo de la presente tesis doctoral se sintetizarán varias series de catalizadores metálicos soportados. La preparación de estos catalizadores involucrará diferentes estrategias de síntesis basadas en el empleo de coloides metálicos para el control de la dispersión metálica, estructuras organizadas formadas por surfactantes como plantillas para controlar la estructura porosa de los soportes catalíticos, así como técnicas de deposición controlada de capas de óxidos metálicos con el objeto de gobernar las propiedades químicas y los fenómenos de promoción catalítica. Estas series de catalizadores se diseñarán a priori de forma que supongan sistemas catalíticos modelo adecuados para estudiar determinados aspectos fundamentales de especial relevancia en las reacciones de conversión catalítica de gas de síntesis a productos de interés como hidrocarburos precursores de diesel sintético (síntesis de Fischer-Tropsch) o productos oxigenados (síntesis selectiva de oxigenados).

La presente tesis doctoral consta de 4 capítulos dedicados a la descripción y discusión de los resultados obtenidos.

Tres de estos capítulos se dedican a un estudio de los catalizadores de Co para la síntesis de Fischer-Tropsch. A lo largo de estos tres capítulos, el objetivo fundamental es la comprensión de la influencia de determinadas 
características del catalizador en la actividad y selectividad catalíticas. Un análisis del estado del arte permitió identificar aquellos aspectos considerados de especial relevancia para el diseño de nuevas generaciones de catalizadores de Fischer-Tropsch, los cuales comprenden la influencia del tamaño de nanopartícula metálica (Capítulo 3), de la historia térmica de los catalizadores y su papel a la hora de determinar la microestructura de las fases metálicas (Capítulo 4), así como de la estructura porosa (diámetro y longitud de los poros) del soporte catalítico que alberga dichas fases metálicas (Capítulo 5).

Por su parte, el Capítulo 6 de la presente tesis doctoral consiste en una aproximación al efecto promotor en los catalizadores basados en $\mathrm{Rh}$ para la conversión selectiva de gas de síntesis en compuestos oxigenados. Este capítulo emplea catalizadores modelo cuyas propiedades electrónicas se controlan dentro de un amplio rango con el fin de encontrar patrones generales en el fenómeno de promoción catalítica.

Los catalizadores modelo se ensayarán en condiciones realistas de operación y se caracterizarán exhaustivamente mediante una amplia batería de técnicas con el objetivo de comprender lo más detalladamente posible la relación entre sus propiedades físico-químicas y su comportamiento catalítico.

De manera general, más allá de las particularidades de cada capítulo, la presente tesis doctoral persigue sentar las bases para el diseño y preparación de nuevas generaciones de catalizadores nanoparticulados avanzados con propiedades físico-químicas y estructurales optimizadas a diferentes escalas de observación, desde el nivel atómico (microestructura y topología metálica superficial) hasta el nivel meso-macroscópico (estructura porosa) para los procesos de conversión de gas de síntesis. 


\section{Referencias}

\footnotetext{
1 J.J. Berzelius, Jahresberichte 15 (1835) 237.

2 Chem. Ind. 121 (2002) 22.

3 C. Marcilly, J. Catal. 216 (2003) 47.

4 "New Science for a Secure and Sustainable Energy Future", Basic Energy Science Advisory
} Committee, J. Hemminger (chairman) (U.S. Department of Energy) (2008).

5 A.T. Bell, Science 299 (2003) 1688.

${ }^{6}$ G.A. Somorjai, J.Y. Park, Angew. Chem. Int. Ed. 47 (2008) 9212.

7 Energy Information Administration, International Energy Outlook; US Department of Energy: Washington DC (2007).

8 International Energy Agency, Global Energy Outlook: Issues and challenges, 10th International Energy Forum (2006).

9 C. Song, Catal. Today 115 (2006) 2.

10 J.H. Lunsford, Catal. Today 63 (2000) 165.

11 A. Holmen, Catal. Today 142 (2009) 2.

12 R.P. Gupta, B.S. Turk, J.W. Portzer, D.C. Cicero, Environm. Prog. 20 (2001) 187.

13 D. Vallentin, Energy Policy 36 (2008) 2030.

14 C. N. Hamelinck, A. P. C. Faaij, H. den Uil, H. Boerrigter, Energy 9 (2004) 1743.

15 M. J. A. Tijmensen, A. P. C. Faaij, C. N. Hamelinck, M. R. M. van Hardeveld, Biomass Bioenergy 23 (2002) 129

${ }^{16}$ M. J. Prins, K. J. Ptasinski, F. J. J. G. Janssen, Fuel Process. Technol. 86 (2004) 375.

17 E. van Steen, M. Claeys, Chem. Eng. Technol. 31 (2008) 655.

18 D.L. Yakobson, Annual Energy Conference, New Orleans (2001) 25.

19 D. S. Newsome, Catal. Rev. Sci. Eng. 21 (1980) 275.

${ }^{20}$ K. Chew, "Quantifying the world's gas resources", Fundamentals of gas to liquids (2003) p. 11, Petroleum economics (London).

${ }^{21}$ R. Hoffmann, "Old Gas, New Gas". American Scientist 94 (2006) 16.

22 S.Mokhatab, W.A. Poe, J.G. Speight, Handbook of Natural Gas Transmission and Processing (2006) 1.

23 L. Dong, S. Wei, S. Tan, H. Zhang, Petrol. Sci. 5 (2008) 388.

24 T.V. Choudhary, V.R. Choudhary, Angew. Chem. Int. Ed. 47 (2008) 1828.

25 P.K. Bakkerud, J.N. Gol, K. Aaberg-Petersen, I. Dybkjaer, Stud. Surf. Sci. Catal. 147 (2004) 13.

${ }^{26}$ K. Klier, Adv. Catal. 31 (1982) 243.

27 A.A. Adesina, Appl. Catal. A 138 (1996) 345.

28 T. Takeshita, K. Yamaji, Energy Policy 36 (2008) 2773. 
${ }^{29}$ P. Sabatier, J.B. Sanderers, J. Soc. Chem. Ind. 21 (1902) 504.

${ }^{30}$ A. Mittasch, C. Schneider, J. patente alemana 293787 (1902)

${ }^{31}$ F. Fischer, H. Tropsch, Brennstoff-Chem. 4 (1923) 276

${ }^{32}$ F. Fischer, H. Tropsch, Brennstoff-Chem. 7 (1926) 97.

33 M.E. Dry, J.C. Hoogendoorn, Catal. Rev.-Sci. Eng., 23 (1981) 265.

${ }^{34}$ M.E. Dry, Endeavour 8 (1984) 2.

${ }^{35}$ Petroleum Review 60 (2006) 7.

${ }^{36}$ B.H. Davis, Prepr. Pap.-Am. Chem. Soc., Div. Fuel Chem. 48 (2003) 787.

37 http://www.sasol.com (consultada en agosto 2009)

38 J.H. Gregor, Catal. Lett. 7 (1990) 317

${ }^{39}$ M.A. Vannice, J. Catal. 50 (1977) 228.

${ }^{40}$ M.E. Dry, J. Chem. Technol. Biotechnol. 77 (2001) 77.

${ }^{41}$ B. McCormick, T. Alleman, DOE EPAct Rulemaking Worksho, Washington, DC (2002).

${ }^{42}$ Chemische Rundschau 11 (2006) 21.

${ }^{43}$ H. Leibold, A. Hornung, H. Seifert, Powder Tech. 18 (2008) 265.

44 T.M. McCollom, J.S. Seewald, Chem. Rev. 107 (2007) 382.

45 G. Proskurowski, M.D. Lilley, J.S. Seewald, G.L. Früh-Green, E.J. Olson, J.E. Lupton, S.P. Sylva, D.S. Kelley, Science 319 (2008) 604.

${ }^{46}$ D. Storch, N. Golumbic, R.B. Anderson, "The Fischer-Tropsch and related syntheses", John Wiley and Sons Ed., New York (1951)

${ }^{47}$ J.T. Kummer, P.H. Emmet, J. Am. Chem. Soc. 75 (1953) 5177.

${ }^{48}$ H. Pichler, H. Schultz, Chem. Ing. Tech. 12 ( 1970) 1160.

49 H. Shulz, E. van Steen, M. Claeys, Topics in Catal. 2 (1995) 223.

${ }^{50}$ P.M. Maitlis, R. Quyoum, H.C. Long, M.L. Turner, Appl. Catal. A 186 (1999) 363.

${ }^{51}$ J.P. Hindermann, G.J. Hutchings, A. Kiennemann, Catal.Rev.-Sci. Eng. 35 (1993) 1.

52 B.H. Davis, Fuel Proc. Tech. 71 (2001) 157.

${ }^{53}$ M.E. Dry, Catal. Process., Proceedings of the South African Catal. Soc. Meeting (1993).

${ }^{54}$ G.V. Schulz, Z. Phys. Chem. 32 (1936) 27.

55 P.J. Flory, J. Am. Chem. Soc. 58 (1936) 1877.

${ }^{56}$ R.B. Anderson, The Fischer-Tropsch Synthesis, Academic Press Ed. (1984) Chapter 5.

57 J. Cheng, T. Song, P. Hu, C.M. Lok, P. Ellis, S. French, J. Catal. 255 (2008) 20.

${ }^{58}$ R.J. Madon, E. Iglesia, J. Catal. 139 (1993) 576.

59 Z.P. Liu, P. Hu, J. Chem.Phys. 114 (2001) 8244.

${ }^{60}$ M.A. Vannice, J. Catal. 37 (1975) 449.

${ }^{61}$ E. van Steen, M. Claeys, Chem. Eng. Technol. 31 (2008) 655.

62 A.N. Stranges, "Germany's Synthetic Fuel Industry 1927-45", AIChE Meeting (2003) New Orleans (http://www.fischertropsch.org). 
${ }^{63}$ S.-Y. Lee, R. Aris, Catal. Rev. Sci. Eng. 27 (1985) 207.

${ }^{64}$ S.L. Soled, E. Iglesia, R.A. Fiato, G.B. Ansell, patente US 5.397.806 (1995).

${ }^{65}$ H. Beuther, C.L. Kivi, T.P. Kobylinski, R.B. Pannell, patente US 4.493 .905 (1985).

${ }^{66}$ T.P. Kobylinski, C.L. Kivi, R.B. Pannell, E.L. Hedí, patente US 4.605.680 (1986).

${ }^{67}$ S. Eri, J.G. Goodwinm G. Marcelin, T. Riis, patente US4.801.573 (1989).

${ }^{68}$ P.J. Van Berge, J. Van De Loosdrecht, J.L. Visiage, patente WO 0139882 (2001).

${ }^{69}$ R.L. Espinoza, J.L. Visagle, P.J. van Berge, F.H. Bolder, patente E 0736326 A1.

${ }^{70}$ P.J. Van Berge, J. Van De Loosdrecht, J.L. Visiage, patente WO 0196015 (2001).

${ }^{71}$ A. de Klerk, Green Chem. 10 (2008) 1249.

${ }^{72}$ J. Shore, J. Kackworth, US National Petrochemical and Refiners Association annual meeting, San Antonio (2007).

${ }^{73}$ A. de Klerk, Proceedings of the EuropaCat Conference, Salamanca, Spain (2009).

${ }^{74}$ J.J.C. Geerlings, M.C. Zonnevylle, C.P.M. de Groot, Surf. Sci. 241 (1991) 315.

75 A.Y. Khodakov, W. Chu, P. Fongarland, Chem. Rev. 107 (2007) 1692.

${ }^{76}$ D. Wei, J.G. Goodwin Jr. R. Oukaci, A.H. Singleton, Appl. Catal. A 210 (2001) 137.

${ }^{77}$ F. Fischer, H. Koch, Brennstoff-Chem. 13 (1932) 61

${ }^{78}$ R.B. Anderson, B. Seligman, J.F. Schultz, R. Kelly, M.A. Elliot, Ind. Eng. Chem. 16 (1935) 6.

${ }^{79}$ D. Stern, A.T. Bell, H. Kienemann, Chem. Eng. Sci. 40 (1985) 1655.

${ }^{80}$ M.F.M. Post, A.C. van't Hoog, J.K. Minderhoud, S.T. Sie, AIChe J. 35 (1989) 1107.

${ }^{81}$ C.S. Kellner, A.T. Bell, J. Catal. 70 (1981) 418.

82 E. Iglesia, S.C. Reyes, R.J. Madon, S.L. Soled, Adv. Catal. Relat. Subj. 39 (1993) 221

${ }^{83}$ R.J. Madon, E. Iglesia, J. Catal. 149 (1994) 428.

${ }^{84}$ E. Iglesia, S.C. Reyes, R.J. Madon, J. Catal. 129 (1991) 238.

${ }^{85}$ E. Iglesia, Appl. Catal. A 161 (1997) 59.

${ }^{86}$ E. Iglesia, S.L. Soled, J.E. Baumgartner, S.C. Reyes, J. Catal. 153 (1995) 108.

${ }^{87}$ Y. Zhang, Y. Yoneyama, K. Fujimoto, . Tsubaki, Top. Catal. 26 (2004) 129.

${ }^{88}$ R. Takahashi, S. Sato, T. Sodesawa, M. Yabuki, J. Catal. 200 (2001) 197.

${ }^{89}$ Y. Zhang, Y. Yoneyama, N. Tsubaki, Chem. Commun. 11 (2002) 1216.

${ }^{90}$ S. Sun, K. Fujimoto, Y. Zhang, N. Tsubaki, Catal. Commun. 4 (2003) 361.

${ }^{91}$ R.A. van Santen, Acc. Chem. Res. 42 (2009) 57.

${ }^{92}$ M. Boudard, Adv. Catal. Relat. Subj. 20 (1969) 153.

${ }^{93}$ M.F. Crommie, C.P. Lutz, D.M. Eigler, Nature 363 (1993) 524.

${ }^{94}$ G.A. Somorjai, Catal. Lett. 7 (1990) 169.

95 G.A. Somorjai, "Surface science view of catalysis: the past, present and future", Proceedings of the $8^{\text {th }}$ International Congress on Catalysis, Berlin (1984) 113.

${ }^{96}$ B.C. Gates, Chem. Rev. 95 (1995) 511. 
97 A. Uzun, B.C. Gates, Angew. Chem. Int. Ed. 47 (2008) 9245.

98 O. Kitakami, H. Sato, Y. Shimada, F. Sato, M. Tanaka, Phys. Rev. B 56 (1997) 13849.

99 J. Wei, E. Iglesia, Angew. Chem. Int. Ed. 43 (2004) 3685.

100 J.N. Kuhn, W.Huang, C.-K. Tsung, Y.Zhang, G.A. Somorjai, J. Am. Chem. Soc. 130 (2008) 14026.

101 K. Honkala, A. Hellman, I. N. Remediakis, A. Logadottir, A. Carlsson, S. Dahl, C. H. Christensen, J. K. Nørskov, Science 307 (2005) 555.

102 N.O. Spencer,R.C. Schoonmaker, G.A. Somorjai, J. Catal.74 (1982) 129.

103 H.N. Topsoe, N. Topsoe, H. Bohlbro, J. Dumesic, Studies in Surface Science and Catalysis: Proceeding of the 7th International Congress on Catalysis; Seiyama, T., Tanabe, K., Eds. Amsterdam (1981) 247.

104 E. Iglesia, S.L. Soled, R.A. Fiato, J. Catal. 137 (1992) 212.

105 G.L. Bezemer, J.H. Bitter, H.P.C.E. Kuipers, H. Oosterbeek, J.E. Holewijn, X. Xu, F. Kapteijn, A.J. van Dillen, K.P. de Jong, J. Am. Chem. Soc. 128 (2006) 3956.

${ }^{106}$ C.-X. Xiao, Z.-P. Cai, T. Wang, Y. Kou, N. Yan, Angew. Chem. Int. Ed. 47 (2008) 746.

107 S.Soled, C. Kliewer, G. Kiss, J. Baumgartner, "Reversible and Irreversible Changes in Co Fischer-Tropsch Catalysts During Synthesis", Proceedings of the $21^{\text {st }}$ North American Catalysis Society Meeting, San Francisco (2009).

${ }^{108}$ M.A. Van Hove, G.A. Somorjai, Prog. Surf. Sci. 30 (1989) 201.

109 G.A. Somorjai, Introduction to surface chemistry and catalysis, Ed. John Wiley \& Sons (1994).

110 J. Wilson, C. de Groot, J. Phys. Chem. 99 (1995) 7860.

111 G.A. Beitel, A. Laskov, H. Oosterbeek, E.W. Kuipers, J. Phys. Chem. 100 (1996) 12494.

112 G.A. Beitel, C.P.M. de Groot, H. Oosterbeek, J.H. Wilson, J. Phys. Chem. B 101 (1997) 4035 .

113 G.J. Sunley, D.J. Watson, Catal. Today 58 (2000) 293.

114 C. Ghommidh, J.M. Navarro, G. Durand, Biotech. Bioeng. 24 (2004) 605. y referencias incluidas.

115 V. Subramani, S.K. Gangwal, Energy \& Fuels 22 (2008) 814.

116 J.R. Rostrup-Nielsen, Science 308 (2005) 1421.

117 C.M. Fougret, W.F. Holderich, Appl. Catal. A 207 (2001) 295.

118 J. Spivey, A. Egbebi, Chem. Soc. Rev. 36 (2007) 1.

${ }^{119}$ M. Xu, M.J. L. Gines, A.-M. Hilmen, B.L. Stephens, E. Iglesia, J. Catal. 171 (1997) 130.

120 M. Maatouk, Dow Jones Newswires (44-207-842-9447) en www.tradingmarkets.com/ .site/news/Stock\%20News/2333250, consultada en agosto de 2009.

121 L.E.Y. Nonneman, V. Ponec, Catal. Lett. 7 (1990) 197.

122 S. Brosda, C.G. Vayenas, J. Wei, Appl. Catal. A 68 (2006) 109. 
123 R Burch, M.I. Petch, Appl. Catal. A 88 (1992) 39.

124 L.E.Y. Nonneman, A.G.T.M. Bastein, V. Ponec, R. Burch, Appl. Catal. 62 (1990) L23.

125 M. Ichikawa, K. Shikakura, M. Kawai, "Heterogeneous catalysis related to energy problems", Proceedings of China- Japan-USA Heterogeneous Catalysis Symposium (Dalian, China) (1982).

${ }^{126}$ D. Yu-Hua, C. De-An, T. Khi-Rui, Appl. Catal. 35 (1987) 77.

127 T. Matsuzaki, K. Takeuchi, T. Hanaoka, H. Arawaka, Y. Sugi, Appl. Catal. A 105 (1993) 159

128 J. Hu, Y. Wang, C. Cao, D.C. Elliot, D.J. Stevens, J.F. White, Catal. Today 120 (2007) 90.

129 V. Ponec, Stud. Surf. Sci. Catal. 64 (1991) 117.

${ }^{130}$ T. Nakajo, H. Arakawa, K. Sano, H. Noguchi, S. Matsuhira, Chem. Lett. (1987) 593.

${ }^{131}$ H.Y. Luo, P.Z. Lin, S.B. Xie, H.W. Zhou, C.H. Xu, S.Y. Huang, L.W. Lin, D.B. Liang, P.L. Yin, Q. Xin, J. Mol. Catal. A 122 (1997) 115.

${ }^{132}$ B.-Q. Xu, W.M.H. Sachtler, J. Catal. 180 (1998) 194.

133 V. Schünemann, H. Treviño, G.D. Lei, D.C. Tomczak, W.M.H. Sachtler, K. Fogash, J.A. Dumesic, J. Catal. 153 (1995) 144.

134 M. Ojeda, M- López-Granados, S. Rojas, P. Terreros, F. J. García-García, J.L.G. Fierro, Appl. Catal. A 261 (2004) 47.

135 M.A. Haider, M.R. Gogate, R.J. Davis, J. Catal. 261 (2009) 9.

${ }^{136}$ R. Burch, M.J. Hayes, J. Catal. 165 (1997) 249.

137 A. Boffa, C. Lin, A.T. Bell, G.A. Somorjai, J. Catal. 149 (1994) 149.

138 A.B. Boffa, C. Lin, A.T. Bell, G.A. Somorjai, Catal. Lett. 27 (1994) 243. 


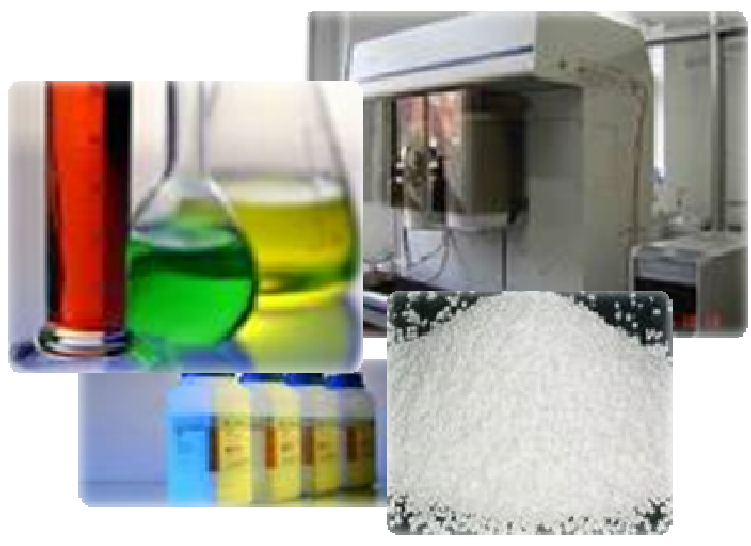

2.

SECCIÓN EXPERIMENTAL 


\subsection{Síntesis de materiales.}

\subsubsection{Reactivos.}

Los reactivos comerciales empleados en el trabajo experimental de la presente tesis se utilizaron, generalmente, en la forma en que se adquieren, sin tratamientos posteriores, salvo que se indique lo contrario explícitamente en la sección correspondiente.

\subsubsection{Síntesis de soportes catalíticos.}

\subsubsection{Síntesis de zeolita deslaminada ITQ-2.}

La zeolita deslaminada ITQ-2 se sintetizó, en su forma puramente silícea, siguiendo el procedimiento patentado por el Instituto de Tecnología Química y publicado por Corma y colaboradores [1].

En primer lugar, se sintetizó un precursor laminar de estructura MWW, en un medio hidrotermal siguiendo el procedimiento recogido en [2].

Seguidamente, el espacio interlaminar de este precursor se hinchó dispersando el sólido en una disolución acuosa del surfactante iónico bromuro de cetiltrimetilamonio (CTABr, Aldrich, $29 \%(\mathrm{p}))$ e hidróxido de tetrapropilamonio (TPAOH, Fluka, $40 \%(\mathrm{p})$ ) y tratando la suspensión a reflujo durante 16 horas. Posteriormente, las láminas zeolíticas, separadas por el surfactante intercalado en el espacio interlaminar, se desordenaron mediante un tratamiento en ultrasonidos $(50 \mathrm{~W}, 40 \mathrm{kHz}$ ) durante 1 hora. El sólido se recuperó por ultra-centrifugación tras ajustar el pH de la suspensión a 2 empleando $\mathrm{HCl}(\mathrm{aq})(37 \%(\mathrm{p})$, Aldrich), se secó a 100 드 durante 12 horas y se calcinó en flujo de aire a 550ํ durante 5 horas para retirar la materia orgánica. 
A lo largo del trabajo de la presente tesis doctoral se sintetizaron dos lotes de zeolita deslaminada ITQ-2 pura sílice que se denominan ITQ-2(a) e ITQ-2(b), respectivamente, en esta memoria.

\subsubsection{Sililación superficial de ITQ-2.}

Se aplicó un procedimiento de sililación superficial a la zeolita deslaminada ITQ-2. Experimentalmente, el sólido silíceo se evacuó a 300C durante 2 horas en un matraz Schlenck de dos bocas. Posteriormente, se añadió sobre el sólido una disolución conteniendo el agente sililante 1,1,1,3,3,3-hexametildisilazano (HMDS) en tolueno, bajo atmósfera protectora de $\mathrm{N}_{2}$. Las proporciones molares empleadas fueron 1 (ITQ-2) : 0.15 HMDS : 10 tolueno. La suspensión se trató a reflujo bajo agitación vigorosa y atmósfera de $\mathrm{N}_{2}$ durante 12 horas. Posteriormente, el sólido se filtró, se lavó con tolueno y se secó a temperatura ambiente durante 12 horas. Con el objeto de retirar cualquier exceso de materia orgánica adsorbida sobre la superficie del sólido sililado, éste se trató a reflujo en etanol durante 12 horas, y posteriormente se filtró, se lavó abundantemente con etanol y se secó a 100 으 durante 12 horas.

Los soportes catalíticos basados en ITQ-2 sililada se emplean en el capítulo 3 de esta memoria para preparar catalizadores modelo Co/ITQ-2. Los soportes catalíticos sililados se denominan SITQ-2(a) y SITQ-2(b), respectivamente, de acuerdo con la nomenclatura empleada para los dos lotes de zeolita ITQ-2 preparados (sección 2.1.2.1.).

\subsubsection{Soportes catalíticos basados en $\mathrm{y}-\mathrm{Al}_{2} \mathrm{O}_{3}$ de origen comercial.}

En el capítulo 5 se recogen los resultados obtenidos con catalizadores basados en soportes catalíticos comerciales de tipo $\mathrm{\gamma}-\mathrm{Al}_{2} \mathrm{O}_{3}$ (Sasol). Dos de las muestras comerciales (Puralox Th100/150 y Catalox HTa101) se adquirieron en forma de $\mathrm{\gamma}-\mathrm{Al}_{2} \mathrm{O}_{3}$ y se utilizaron sin modificaciones. 
En cambio, las otras dos muestras comerciales (Catapal-B y Pural-SB) se comercializan en forma de boehmita y pseudo-boehmita, respectivamente. Para cristalizar estos sólidos en forma de $\mathrm{\gamma}-\mathrm{Al}_{2} \mathrm{O}_{3}$, se calcinaron en horno de mufla a 500ㄷ durante 10 horas (rampa térmica de 5 horas desde temperatura ambiente). En todos los casos, los sólidos, en forma de polvo, se tamizaron para separar la fracción con tamaño de partícula en el rango de 45-65 $\mu \mathrm{m}$.

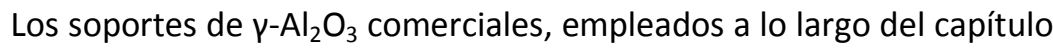
5 , se denominan de acuerdo a lo indicado en la tabla 2.1:

Tabla 2.1: Denominación de los soportes basados en $\mathrm{\gamma}-\mathrm{Al}_{2} \mathrm{O}_{3}$ de origen comercial.

\begin{tabular}{cc}
\hline Denominación & $\begin{array}{c}\text { Procedencia } \\
\text { comercial }\end{array}$ \\
\hline $\mathrm{Al}_{2} \mathrm{O}_{3} 1$ & Derivado de Catapal-B \\
$\mathrm{Al}_{2} \mathrm{O}_{3} 2$ & Derivado de Pural-SB \\
$\mathrm{Al}_{2} \mathrm{O}_{3} 3$ & Puralox Th100/150 \\
$\mathrm{Al}_{2} \mathrm{O}_{3}{ }_{3}$ & Catalox HTa101 \\
\hline
\end{tabular}

2.1.2.4. Síntesis de $\mathrm{\gamma}-\mathrm{Al}_{2} \mathrm{O}_{3}$ de morfología nanofibrosa.

La muestra de $\mathrm{V}^{-} \mathrm{Al}_{2} \mathrm{O}_{3}$ de morfología nanofibrosa se sintetizó siguiendo el procedimiento publicado en [3], con modificaciones. Experimentalmente, se añadió lentamente $(1 \mathrm{~mL} / \mathrm{min})$ una disolución acuosa $0.2 \mathrm{M}$ de $\mathrm{Al}\left(\mathrm{NO}_{3}\right)_{3}$ (Aldrich) sobre una disolución reguladora de $\mathrm{NH}_{4} \mathrm{Cl}$ $(2 \mathrm{M}) / \mathrm{NH}_{4} \mathrm{OH}(2 \mathrm{M})(\mathrm{pH}=10.5)$. En el procedimiento de síntesis se emplea $\mathrm{Al}\left(\mathrm{NO}_{3}\right)_{3}$ como fuente de aluminio en lugar de $\mathrm{NaAlO}_{2}$ como en la referencia [3], con el fin de evitar la presencia de $\mathrm{Na}$ en los catalizadores de $\mathrm{Co}$ soportados que, incluso a nivel de ppm, puede producir un descenso drástico de la actividad catalítica [4]. El sólido precipitado se filtró y se lavó con agua desionizada hasta ausencia de iones $\mathrm{Cl}^{-}$en las aguas de lavado (test de $\left.\mathrm{Ag}\left(\mathrm{NO}_{3}\right)\right)$. Posteriormente, la torta húmeda de sólido se mezcló con el 
surfactante no iónico $\mathrm{C}_{11-15} \mathrm{H}_{23-31} \mathrm{O}\left(\mathrm{CH}_{2} \mathrm{CH}_{2} \mathrm{O}\right)_{7} \mathrm{H}$ (Tergitol 15-TS-7, Aldrich) en una proporción molar $\mathrm{Al}(\mathrm{OH})_{3}:$ surfactante: $\mathrm{H}_{2} \mathrm{O}$ de 1:0.4:160. La mezcla ( $\mathrm{pH}=7-7.3)$ se cargó en un autoclave teflonado $(250 \mathrm{~mL})$ y se sometió a un tratamiento hidrotermal a $100^{\circ} \mathrm{C}$ durante 48 horas en estático. El producto ( $\mathrm{pH}=3.5-4)$ se diluyó con agua desionizada, se alcalinizó hasta $\mathrm{pH}=9$ con una disolución de $\mathrm{NH}_{3}(\mathrm{aq})(25 \%(\mathrm{p})$, Aldrich) y el sólido se recuperó por ultracentrifugación (14000 rpm, 1 hora). El sólido recuperado se secó a temperatura ambiente durante 12 horas y posteriormente se calcinó en mufla a $500 \circ \mathrm{C}$ durante 20 horas (rampa de calentamiento de $2 \circ \mathrm{C} / \mathrm{min}$ ) para eliminar el surfactante orgánico y cristalizar las nanofibras de boehmita en $y$ $\mathrm{Al}_{2} \mathrm{O}_{3}$. El soporte catalítico basado en $\gamma-\mathrm{Al}_{2} \mathrm{O}_{3}$ de morfología nanofibrosa se denomina $\mathrm{Al}_{2} \mathrm{O}_{3} \_$nf a lo largo de esta memoria.

\subsubsection{Síntesis de sílices mesoestructuradas SBA-15.}

La síntesis de soportes mesoestructurados tipo SBA-15 con diferentes morfologías de partícula primaria, cuya aplicación en catálisis se estudia en las secciones 5.4 a 5.6, se llevó a cabo utilizando tetraetil-orto-silicato (TEOS, Merck) como fuente de Si y el polímero tri-bloque no iónico Pluronic 123 (P123, Aldrich, $\mathrm{PM}=5800 \mathrm{~g} / \mathrm{mol}$ ) como agente micelante. Se sintetizaron varias mesoestructuras caracterizadas por poseer distintas longitudes $y$ diámetros de poro, siguiendo los procedimientos que se detallan a continuación.

a) SBA-15 de poro ancho y largo (11_SBA_L).

La síntesis de SBA-15 de poro ancho $(11 \mathrm{~nm})$ y morfología de partícula convencional (poros largos) se llevó a cabo ajustando la temperatura de la etapa hidrotermal como describen Fulvio y colaboradores [5]. En primer lugar, se disolvió la cantidad adecuada de P123 en una disolución acuosa 1.7M de $\mathrm{HCl}$ y, posteriormente, se añadió TEOS lentamente. La composición 
molar final del gel de síntesis corresponde a las proporciones 1 P123: 55 $\mathrm{SiO}_{2}$ : $350 \mathrm{HCl}: 11100 \mathrm{H}_{2} \mathrm{O}$. La suspensión resultante se agitó a 40ㄷ durante 20 minutos, se cargó en un autoclave teflonado $(250 \mathrm{~mL})$ y se sometió a tratamiento hidrotermal en estático, a $120^{\circ} \mathrm{C}$ durante 72 horas. Tras el tratamiento, el sólido se recuperó por filtración, se secó a 100ㄷ durante 12 horas y finalmente se calcinó en flujo de aire a $550 \circ \mathrm{C}$ durante 5 horas (rampa térmica de $2^{\circ} \mathrm{C} / \mathrm{min}$ en flujo de $\mathrm{N}_{2}$ ).

b) SBA-15 de poro ancho y corto (11SBA_M y 11SBA_C).

Las mesoestructuras SBA-15 de poro ancho (11 nm) y corto se prepararon de acuerdo al procedimiento de emulsión agua-alcano propuesto recientemente por Bao y colaboradores [6]. Se emplearon dos versiones del método sintético para obtener sílices con dos longitudes de poro diferentes (poros cortos en 11SBA_C y de longitud media en 11SBA_M). Experimentalmente, se disolvieron $\mathrm{P} 123$ y $\mathrm{NH}_{4} \mathrm{~F}$ en una disolución acuosa 1.2 $\mathrm{M}$ de $\mathrm{HCl}$ a una temperatura de $32-37^{\circ} \mathrm{C}$. Por otro lado, se mezcló TEOS con un alcano, decano (>99\%, Aldrich) y dodecano (>99\%, Aldrich), respectivamente, para preparar 11SBA_C y 11SBA_M. La composición molar final del gel de síntesis correspondió a las siguientes proporciones 1 P123: 77 $\mathrm{SiO}_{2}$ : $260 \mathrm{HCl}: 1.8 \mathrm{NH}_{4} \mathrm{~F}: 235\left(\mathrm{C}_{12} \mathrm{H}_{26}\right.$ ó $\left.\mathrm{C}_{10} \mathrm{H}_{22}\right): 11700 \mathrm{H}_{2} \mathrm{O}$. La suspensión resultante se cargó en un autoclave teflonado $(250 \mathrm{~mL})$ y se sometió a tratamiento hidrotermal en estático a $1000^{\circ} \mathrm{C}$ durante 48 horas. Tras el tratamiento, el sólido se recuperó por filtración, se secó a 100C durante 12 horas y, finalmente, se calcinó en flujo de aire a 550 ㄷ C durante 5 horas (rampa térmica de $2^{\circ} \mathrm{C} / \mathrm{min}$ en flujo de $\mathrm{N}_{2}$ ).

c) SBA-15 de poro estrecho y largo (7SBA_L).

Una mesoestructura SBA-15 de morfología convencional (poro largo) y diámetro de poro más estrecho $(7 \mathrm{~nm})$ se preparó siguiendo el 
procedimiento original presentado por Zhao y col. [7]. Se disolvió P123 en una disolución acuosa $2.0 \mathrm{M}$ de $\mathrm{HCl}$ a 35으. Seguidamente, se añadió TEOS lentamente para completar un gel de síntesis cuya composición molar corresponde con las siguientes proporciones 1 P123: $60 \mathrm{SiO}_{2}$ : $345 \mathrm{HCl}: 9240$ $\mathrm{H}_{2} \mathrm{O}$. La suspensión resultante se cargó en un autoclave teflonado $(250 \mathrm{~mL})$ y se sometió a tratamiento hidrotermal en estático a $80^{\circ} \mathrm{C}$ durante 72 horas. El sólido se recuperó por filtración, se secó a 100 ㄷ durante 12 horas y finalmente se calcinó en flujo de aire a $550 \circ \mathrm{C}$ durante 5 horas (rampa térmica de $2{ }^{\circ} \mathrm{C} / \mathrm{min}$ en flujo de $\mathrm{N}_{2}$ ).

\subsubsection{Incorporación de recubrimiento de óxido metálico en la superficie} de $\mathrm{\gamma}-\mathrm{Al}_{2} \mathrm{O}_{3}$ : sintesis de soportes $\mathrm{M} @ \mathrm{Al}_{2} \mathrm{O}_{3}$.

En el capítulo 6 se estudian las propiedades físico-químicas y catalíticas de catalizadores de Rh soportados sobre alúmina recubierta por una capa de óxido bidimensional, con un recubrimiento nominal coincidente con el valor descrito para la monocapa. La metodología empleada para la preparación de los soportes promovido por óxidos en monocapa se adecuó en cada caso para obtener un recubrimiento elevado del óxido de promotor (M) sobre la superficie de la alúmina, evitándose la formación de especies cristalinas tridimensionales.

De manera general, la alúmina se obtuvo por calcinación de pseudoboehmita comercial de elevada área (Pural SB, Sasol Materials) en un horno de mufla a $500^{\circ} \mathrm{C}$ durante 10 horas (rampa térmica de 5 horas desde temperatura ambiente).

Posteriormente, la alúmina se seca en estufa a 150 드 durante 3 horas antes de ser pesada, con el objetivo de que el agua adsorbida no disturbe la pesada y, por lo tanto, los recubrimientos en el sólido final coincidan lo más fielmente posible con los valores nominales que se incluyen en la Tabla 2.2 . 
Posteriormente, se pesaron $15 \mathrm{~g}$ de alúmina seca y se deshidrataron a vacío (aprox. $1-2$ mbar) y $350 \mathrm{C}$ durante 20 horas.

La tabla 2.2. incluye la naturaleza de los precursores metálicos empleados para promover la alúmina con cada uno de los promotores (M).

En los casos en los que se empleó un precursor metálico de naturaleza orgánica (alcóxido o acetilacetonato) se preparó una disolución del precursor del metal en $75 \mathrm{~mL}$ del disolvente indicado en la Tabla 2.2. La preparación de la disolución se lleva a cabo bajo atmósfera anhidra de $\mathrm{N}_{2}$ con el fin de evitar la hidrólisis fortuita del alcóxido metálico, en su caso. La cantidad de precursor de $\mathrm{M}$ empleada es la necesaria para conseguir las cargas metálicas requeridas para el recubrimiento en monocapa en cada caso (ver Tabla 2.2). El soporte $\left(\gamma-\mathrm{Al}_{2} \mathrm{O}_{3}\right)$ deshidratado se pone en contacto con la disolución del precursor metálico a $40^{\circ} \mathrm{C}$ en un baño de silicona, durante 20 horas. Posteriormente, el disolvente se retira por evaporación a vacío en un evaporador rotatorio.

En los casos en los que se emplea un nitrato como precursor de $\mathrm{M}$, el soporte de $\mathrm{y}-\mathrm{Al}_{2} \mathrm{O}_{3}$ se impregnó a humedad incipiente con una disolución acuosa del precursor de $\mathrm{M}$, de modo que la cantidad de éste disuelta es la requerida para el recubrimiento en monocapa en cada caso.

Los sólidos impregnados se secan finalmente a 60ㄷ $\mathrm{C}$ durante 10 horas y a $100 \circ \mathrm{C}$ durante una noche y se calcinan en flujo de aire a 500 드 durante 3 horas ( $3 \circ \mathrm{C} / \mathrm{min})$. 
Tabla 2.2: Denominación, naturaleza del promotor, recubrimiento superficial, precursor y disolvente empleados en la síntesis de los soportes catalíticos basados en $\mathrm{Al}_{2} \mathrm{O}_{3}$ recubiertos por óxidos bidimensionales en "monocapa".

\begin{tabular}{|c|c|c|c|c|}
\hline Soporte & $\begin{array}{l}\text { Promotor } \\
\text { (M) }\end{array}$ & $\begin{array}{c}\delta^{\mathrm{a}} \\
\left(\mathrm{at} / \mathrm{nm}^{2}\right)\end{array}$ & $\begin{array}{c}\text { Precursor } \\
\text { de } M\end{array}$ & Disolvente \\
\hline $\mathrm{Fe} @ \mathrm{Al}_{2} \mathrm{O}_{3}$ & $\mathrm{Fe}$ & 4.5 & $\begin{array}{c}\mathrm{Fe}\left(\mathrm{C}_{5} \mathrm{H}_{7} \mathrm{O}_{2}\right)_{3} \\
99.9 \%+(\text { Aldrich })\end{array}$ & Metanol \\
\hline $\mathrm{V} @ \mathrm{Al}_{2} \mathrm{O}_{3}$ & V & 7.0 & $\begin{array}{c}\mathrm{VO}\left(\mathrm{OC}_{3} \mathrm{H}_{7}\right)_{3} \\
(\text { Aldrich })\end{array}$ & Etanol \\
\hline $\mathrm{Nb} @ \mathrm{Al}_{2} \mathrm{O}_{3}$ & $\mathrm{Nb}$ & 5.0 & $\begin{array}{c}\mathrm{Nb}\left(\mathrm{OC}_{2} \mathrm{H}_{5}\right)_{5} \\
\text { 99.95\% (Aldrich) }\end{array}$ & Etanol \\
\hline $\mathrm{Ta} @ \mathrm{Al}_{2} \mathrm{O}_{3}$ & Ta & 5.0 & $\begin{array}{c}\mathrm{Ta}\left(\mathrm{OC}_{2} \mathrm{H}_{5}\right)_{5} \\
99.98 \%(\text { Aldrich })\end{array}$ & Etanol \\
\hline $\mathrm{Ti} @ \mathrm{Al}_{2} \mathrm{O}_{3}$ & $\mathrm{Ti}$ & 4.5 & $\begin{array}{c}\mathrm{Ti}\left(\mathrm{OC}_{2} \mathrm{H}_{5}\right)_{4} \\
>95 \%(\text { Alfa-Aesar })\end{array}$ & Etanol \\
\hline $\mathrm{Y} @ \mathrm{Al}_{2} \mathrm{O}_{3}$ & Y & 4.5 & $\mathrm{Y}\left(\mathrm{C}_{5} \mathrm{H}_{7} \mathrm{O}_{2}\right)_{3}$ (Alfa-Aesar) & $\begin{array}{c}2 \%(v) \text { ácido } \\
\text { acético/metanol }\end{array}$ \\
\hline $\operatorname{Pr} @ \mathrm{Al}_{2} \mathrm{O}_{3}$ & $\operatorname{Pr}$ & 4.5 & $\operatorname{Pr}\left(\mathrm{NO}_{3}\right)_{3} .5 \mathrm{H}_{2} \mathrm{O}$ (Aldrich) & $\mathrm{H}_{2} \mathrm{O}$ \\
\hline $\mathrm{Nd} @ \mathrm{Al}_{2} \mathrm{O}_{3}$ & $\mathrm{Nd}$ & 4.5 & $\mathrm{Nd}\left(\mathrm{NO}_{3}\right)_{3} .6 \mathrm{H}_{2} \mathrm{O}$ (Aldrich) & $\mathrm{H}_{2} \mathrm{O}$ \\
\hline $\mathrm{Sm} @ \mathrm{Al}_{2} \mathrm{O}_{3}$ & Sm & 4.5 & $\mathrm{Sm}\left(\mathrm{NO}_{3}\right)_{3} .6 \mathrm{H}_{2} \mathrm{O}($ Aldrich $)$ & $\mathrm{H}_{2} \mathrm{O}$ \\
\hline
\end{tabular}

\subsubsection{Síntesis de catalizadores metálicos.}

\subsubsection{Catalizadores Co/ITQ-2.}

En un primer estudio (sección 3.3) se investiga la influencia de la ruta de síntesis y las propiedades superficiales del soporte ITQ-2 en las características físico-químicas de catalizadores Co/ITQ-2. Las dos rutas sintéticas que se comparan consisten, por un lado, en la dispersión de la fase metálica en un medio micelar y su deposición sobre el soporte y, por otro lado, la impregnación, como referencia de las metodologías convencionales de síntesis de catalizadores. En este estudio se empleó como soporte catalítico el primer lote de zeolita deslaminada ITQ-2, tanto en su forma 
calcinada (ITQ-2(a)) como en su forma sililada (SITQ-2(a)), para preparar cuatro catalizadores con un contenido nominal del $10 \%(p)$ Co.

Los catalizadores de referencia se prepararon mediante impregnación del soporte con una disolución etanólica de $\mathrm{Co}\left(\mathrm{NO}_{3}\right)_{2} \cdot 6 \mathrm{H}_{2} \mathrm{O}$ (Aldrich) en una proporción de $10 \mathrm{~mL} / \mathrm{g}$ soporte. Se empleó etanol como disolvente, en lugar de agua, debido a la hidrofobicidad que presenta el soporte sililado, el cual no recibe un "mojado" adecuado por parte del agua. La suspensión del soporte en la disolución metálica se agitó durante 1 hora y, posteriormente, el disolvente se retiró en un evaporador rotatorio a temperatura ambiente. El sólido se secó a $60^{\circ} \mathrm{C}$ durante 12 horas y se calcinó en flujo de aire a 500 C. Los catalizadores preparados por impregnación sobre ITQ-2(a) y SITQ2(a) se denominan (im)10Co/ITQ y (im)10Co/SITQ, respectivamente.

Para sintetizar los catalizadores siguiendo la ruta coloidal, se preparó en primer lugar, una microemulsión inversa estabilizada por el surfactante no iónico 1,1,3,3-(tetrametilbutil)fenil-polietilenglicol (Triton X114, Aldrich). Para ello, se mezcló una disolución de Triton X114 en n-hexanol e isopropanol con una disolución acuosa de $\mathrm{Co}\left(\mathrm{NO}_{3}\right)_{2} \cdot 6 \mathrm{H}_{2} \mathrm{O}$ (Aldrich), lo que dio lugar a una microemulsión inversa estable, transparente y de tonalidad rosa. La concentración de $\mathrm{Co}\left(\mathrm{NO}_{3}\right)_{2}$ en la fase acuosa fue de $0.3 \mathrm{M}$, mientras que la relación molar $\mathrm{H}_{2} \mathrm{O}$ /surfactante se fijó en 6 . Tras someter a la microemulsión a burbujeo de $\mathrm{Ar}$, para desplazar el aire del medio, se añadió hidracina $\left(\mathrm{N}_{2} \mathrm{H}_{4} \cdot \mathrm{H}_{2} \mathrm{O}, 98 \%\right.$, Aldrich) en una cantidad correspondiente a 8 veces la cantidad estequiométrica para la reducción (ideal) de los iones $\mathrm{Co}^{2+}$ de acuerdo a la ecuación 2.1.

$$
2 \mathrm{Co}^{2+}+\mathrm{N}_{2} \mathrm{H}_{4}+4 \mathrm{OH}^{-} \longrightarrow 2 \mathrm{Co}+\mathrm{N}_{2}+4 \mathrm{H}_{2} \mathrm{O}
$$

La suspensión marronácea resultante se agitó vigorosamente bajo burbujeo de Ar durante 3 minutos. Posteriormente, se añadió la cantidad 
requerida del soporte (ITQ-2(a) ó SITQ-2(a)) para alcanzar una carga metálica nominal del 10\%(p)Co. La suspensión se sometió a ultrasonidos (100W, 42 $\mathrm{kHz}$ ) durante 1 minuto $\mathrm{y}$, seguidamente, se añadió a la misma tetrahidrofurano (200 mL/g $\left.\mathrm{g}_{\mathrm{TQ} \mathrm{-}-2}\right)(\mathrm{THF}$, reagent grade, Aldrich), gota a gota, para desestabilizar la microemulsión y permitir la deposisición cuantitativa de las nanopartículas del complejo Co-hidrazina formado, sobre la superficie del soporte. Finalmente, el sólido se filtró, se lavó abundantemente con nheptano y etanol, se secó a temperatura ambiente durante 12 horas y se calcinó a 500 C C durante 3 horas en flujo de aire. Con el objeto de permitir una descomposición lenta de los complejos Co-hidrazina, se empleó una velocidad de calentamiento lenta $(19 \mathrm{C} / \mathrm{min})$ y flujo de aire diluido en $\mathrm{N}_{2}$ (aire $/ \mathrm{N}_{2}: 1 / 1$, vol) durante la rampa térmica del programa de calcinación. Los catalizadores preparados empleando una microemulsión inversa y soportados sobre ITQ-2(a) y SITQ-2(a) se denominan (me)10Co/ITQ y (me)10Co/SITQ, respectivamente.

En un segundo estudio (sección 3.4), se prepararon catalizadores modelo 10\%Co/ITQ-2 con distinta dispersión metálica, empleando la metodología de la microemulsión inversa y el segundo lote de zeolita deslaminada ITQ-2 en su forma sililada (SITQ-2). En este caso, con el objeto de extender el rango de tamaños de nanopartícula para preparar catalizadores con diferentes niveles de dispersión metálica, la preparación de los catalizadores comprende el empleo de dos microemulsiones inversas y la deposición de las nanopartículas del complejo Co-hidrazina sobre la superficie sililada de SITQ-2. Experimentalmente, se preparó una primera microemulsión inversa disolviendo el surfactante no-iónico 1,1,3,3(tetrametilbutil)fenil-polietilenglicol (Triton X114, Aldrich) en ciclohexano (Scharlab). La concentración del surfactante en el disolvente orgánico se fijó en el rango 0.06-1.3 M. Posteriormente, se añadió 2-propanol (95\%, Aldrich) 
como co-surfactante en una proporción molar 2-propanol/ciclohexano de 1.7. Esta disolución orgánica se agitó a temperatura ambiente mientras se burbujeó Ar para desplazar el aire de la misma. Seguidamente, se añadió una disolución acuosa de $\mathrm{Co}\left(\mathrm{NO}_{3}\right)_{2} \cdot 6 \mathrm{H}_{2} \mathrm{O}$ (Aldrich) sobre la disolución de surfactante y co-surfactante para preparar una microemulsión inversa transparente. La concentración de Co en la fase acuosa se varió en el rango 0.05-3.0 M. Por otro lado, se preparó una microemulsión inversa idéntica, pero conteniendo hidracina $\left(\mathrm{N}_{2} \mathrm{H}_{4} \cdot \mathrm{H}_{2} \mathrm{O}, 98 \%\right.$ Aldrich) en la fase acuosa en lugar del precursor de Co. La cantidad de hidracina varió entre 8, 10 o 16 veces la cantidad estequiométrica necesaria para reducir, idealmente, el cobalto de acuerdo con la ecuación 2.1.

La microemulsión conteniendo hidrazina se añadió sobre la correspondiente conteniendo Co, bajo flujo de Ar. Instantáneamente, se formó una suspensión de color marrón claro cuya tonalidad depende de los parámetros empleados en las micromulsiones (ver tabla 3.8). Esta suspensión se agitó durante 3 minutos y posteriormente se añadió a la misma la cantidad adecuada del soporte (SITQ-2(b)) para obtener una carga metálica de $10 \%$ Co en peso y se sometió a ultrasonidos durante 1 minuto para dispersar adecuadamente las nanoláminas del soporte. Seguidamente, se añadió gota a gota THF (200 mL/g ITQ-2 (Aldrich) bajo flujo de Ar para desestabilizar completamente el medio micelar y completar la deposición del complejo Co-hidrazina sobre la superficie sililada del soporte. Finalmente, el sólido se filtró, se lavó abundantemente con n-heptano y etanol, se secó a temperatura ambiente durante 12 horas y se calcinó a $500{ }^{\circ} \mathrm{C}$ durante 3 horas en flujo de aire. Con el objeto de permitir una descomposición lenta de los complejos Co-hidrazina, se empleó una velocidad de calentamiento lenta $\left(1{ }^{\circ} \mathrm{C} / \mathrm{min}\right)$ y flujo de aire diluido en $\mathrm{N}_{2}$ (aire $/ \mathrm{N}_{2}: 1 / 1$, vol) durante la rampa térmica del programa de calcinación. 
Los catalizadores preparados de esta forma se denominaron 10Co/ITQ $(x)$, donde $x=1$ a 7 en función de los parámetros de la microemulsión inversa empleada en la preparación (tabla 3.8).

\subsubsection{Catalizadores $\mathrm{Co} / \mathrm{SiO}_{2}(\mathrm{mf})$.}

El catalizador referencia de baja dispersión metálica estudiado en la sección 3.4 se preparó utilizando nanopartículas comerciales de $\mathrm{Co}_{3} \mathrm{O}_{4}$ (nanopowder, Aldrich). Como soporte se empleó una sílice amorfa porosa (Silica gel 100, Fluka) en polvo. Experimentalmente, se suspendieron conjuntamente en etanol la $\mathrm{SiO}_{2}$ y la cantidad requerida de $\mathrm{Co}_{3} \mathrm{O}_{4}$ para obtener una carga metálica de $30 \%$ Co, en peso. La suspensión se trató en ultrasonidos durante 30 minutos y, posteriormente, el disolvente se retiró por evaporación en un evaporador rotatorio a temperatura ambiente. Finalmente, el sólido se secó a 100 C C durante 12 horas y se calcinó a 500ㄷ C en flujo de aire durante 3 horas. El catalizador se denomina $30 \mathrm{Co} / \mathrm{SiO}_{2}(m f)$, donde $m f$ denota la "mezcla física" de las nanopartículas de $\mathrm{SiO}_{2}$ y $\mathrm{Co}_{3} \mathrm{O}_{4}$.

Por su parte, en el estudio de CO-FTIR recogido en la sección 3.4.4, el catalizador $30 \mathrm{Co} / \mathrm{SiO}_{2}(\mathrm{mf})$ se diluyó por mezcla física con $\mathrm{SiO}_{2}$ hasta obtener un material con una carga metálica de 10\%(p)Co, que se empleó exclusivamente en los experimentos de espectroscopia de infra-rojo. Este material se denomina $10 \mathrm{Co} / \mathrm{SiO}_{2}(m f)$.

\subsubsection{Catalizadores $\mathrm{Co} / \mathrm{SiO}_{2}$.}

En el capítulo 4 se estudia la influencia de la historia térmica sobre las propiedades físico-químicas y catalíticas de los catalizadores de Co para la SFT. Los catalizadores $20 \% \mathrm{Co} / \mathrm{SiO}_{2}$ empleados en este capítulo se prepararon por impregnación sobre $\mathrm{SiO}_{2}$ comercial (Silica gel spherical, DP=17-23 nm, Fluka). El soporte se secó a 150 ㅇ C durante 12 horas antes de la incorporación del metal. Posteriormente, se incorporó el precursor de Co 
por impregnación a volumen de poro empleando una disolución que contiene la cantidad adecuada de $\mathrm{Co}\left(\mathrm{NO}_{3}\right)_{2} \cdot 6 \mathrm{H}_{2} \mathrm{O}$ (Aldrich) para obtener un contenido nominal del $20 \%(p)$ Co en el catalizador final. La impregnación se llevó a cabo en dos etapas hasta el punto de humedad incipiente (incipient wetness), mediando una etapa de secado a $600^{\circ} \mathrm{C}$ durante 1 hora entre ambas impregnaciones. Posteriormente, el sólido se secó a 60 ㄷ C durante 12 horas. Finalmente, el sólido se separó en cuatro partes iguales. Tres de estas alícuotas se calcinaron en flujo de aire a diferentes temperaturas en el rango de $300-550 \circ \mathrm{C}$, durante 3 horas (rampa de calentamiento de 1 으 $/ \mathrm{min}$ ). Durante la calcinación de estos catalizadores, se empleó una etapa de 3 horas a 300 C común a todos ellos, incrementándose posteriormente la temperatura para aquellos sólidos calcinados a una temperatura final superior a $300^{\circ} \mathrm{C}$, durante 3 horas adicionales, de acuerdo a los programas de calcinación esquematizados en la Tabla 2.3. Una cuarta parte del catalizador seco no se calcinó y se empleó en catálisis tras una "reducción directa" ( $r d$ ) en flujo de $\mathrm{H}_{2}$. Por último, también se preparó un catalizador mediante calcinación del soporte $\left(\mathrm{SiO}_{2}\right)$ en aire a alta temperatura $\left(550^{\circ} \mathrm{C}\right)$, antes de la impregnación con el precursor metálico, y posterior calcinación de las especies de Co incorporadas, en aire a una temperatura más baja $\left(300^{\circ} \mathrm{C}\right)$, lo que se denominó "doble calcinación" (dc). Los catalizadores se denominan $20 \mathrm{Co} / \mathrm{SiO}_{2} x$ donde $x=300,425,550$ en función de la temperatura final de calcinación, " $r$ " para la reducción directa (no calcinado) y " $d c$ " para el catalizador de "doble calcinación", como se indica en la Tabla 2.3. 
Tabla 2.3: Denominación y programa térmico de calcinación para los catalizadores $20 \% \mathrm{Co} / \mathrm{SiO}_{2}$ estudiados en el capítulo 4.

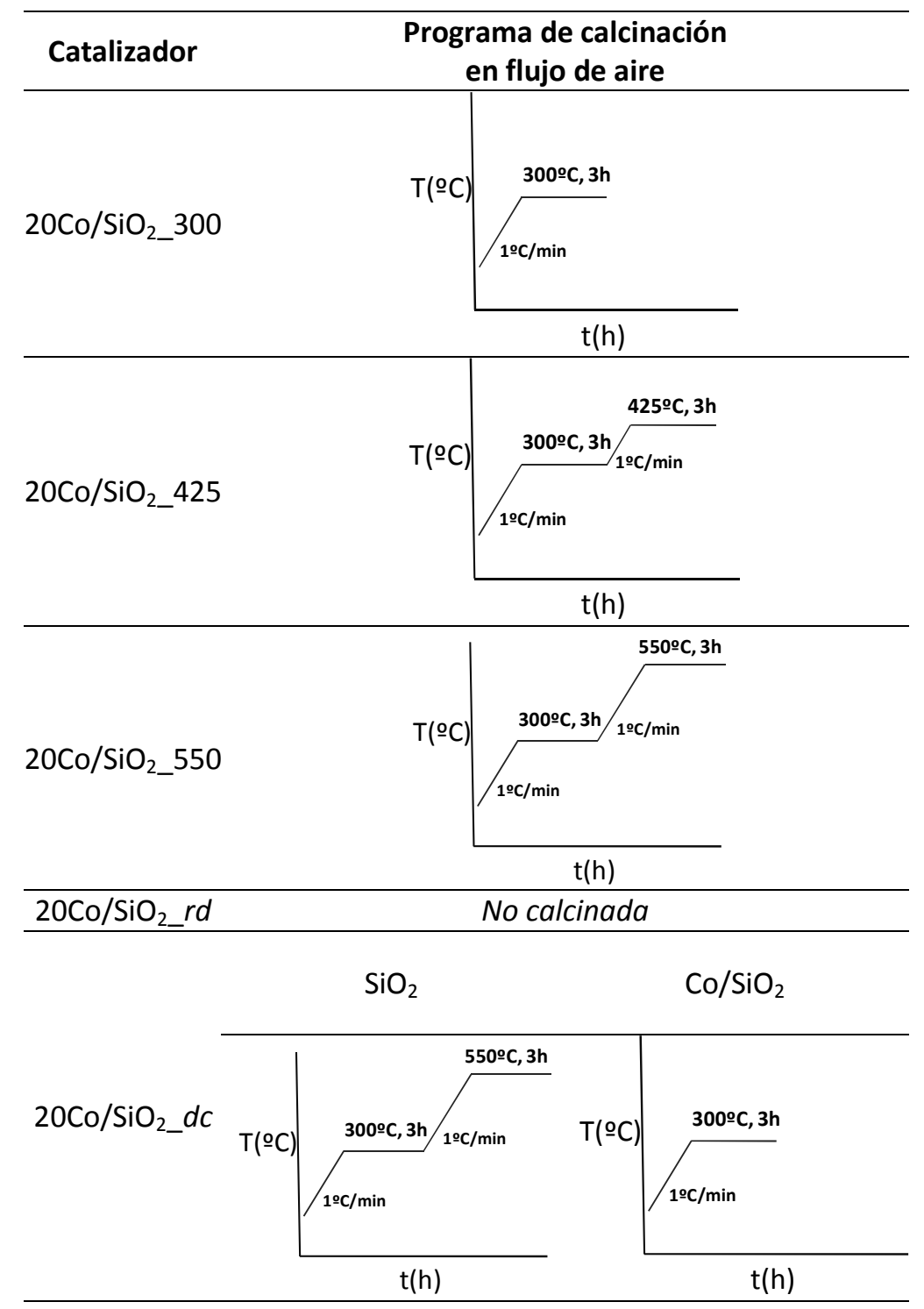

\subsubsection{Catalizadores $\mathrm{RuCo} / \mathrm{Al}_{2} \mathrm{O}_{3}$.}

Los catalizadores $0.5 \% \mathrm{Ru}-20 \% \mathrm{Co} / \mathrm{Al}_{2} \mathrm{O}_{3}$ y $1 \% \mathrm{Ru}-30 \% \mathrm{Co} / \mathrm{Al}_{2} \mathrm{O}_{3}$ estudiados en el capítulo 5-a se prepararon por impregnación con un exceso 
de disolución acuosa respecto del volumen de poro. Los soportes, previamente tamizados en el rango de tamaño de partícula de 45-65 $\mu \mathrm{m}$, se secaron a 150 ㄷ C durante 12 horas antes de la incorporación de los metales. La incorporación de los metales se llevó a cabo por impregnación con una disolución conteniendo las cantidades adecuadas de $\mathrm{Co}\left(\mathrm{NO}_{3}\right)_{2} \cdot 6 \mathrm{H}_{2} \mathrm{O}($ Aldrich) y disolución acuosa de $\mathrm{Ru}(\mathrm{NO})\left(\mathrm{NO}_{3}\right)_{3}\left(1.5 \% \mathrm{Ru}\right.$ en $\mathrm{HNO}_{3}$ diluido, Aldrich) para obtener los correspondientes contenidos nominales de cada metal en el catalizador final. El soporte y la disolución metálica $(10 \mathrm{~mL} / \mathrm{g})$ se pusieron en contacto, bajo agitación magnética, a temperatura ambiente durante 1 hora. Posteriormente, el disolvente se eliminó en un evaporador rotatorio a 50 ㄷ $\mathrm{C}$ y el sólido se secó a 100 C C durante 12 horas. Finalmente, el sólido se calcinó en flujo de aire a $300^{\circ} \mathrm{C}$ durante 3 horas (rampa de calentamiento de 1 으 $\mathrm{C} / \mathrm{min})$. Los catalizadores se denominan $x \mathrm{Co} / \mathrm{Al}_{2} \mathrm{O}_{3} \_y$, donde $x=20$ ó 30 en función de la carga metálica de Co e y=1-4 ó nf de acuerdo a la nomenclatura empleada para los soportes catalíticos (secciones 2.1.2.3 y 2.1.2.4).

\subsubsection{Catalizadores RuCo/SBA-15.}

Los catalizadores $1 \%$ Ru-20\%Co/SBA-15 empleados en el capítulo 5-b se prepararon por impregnación a volumen de poro. Los soportes se secaron a 100 C durante 12 horas antes de la impregnación. Seguidamente, se disolvieron en agua desionizada ( $3 \mathrm{~mL} / \mathrm{g}$ soporte) las cantidades requeridas de $\mathrm{Co}\left(\mathrm{NO}_{3}\right)_{2} \cdot 6 \mathrm{H}_{2} \mathrm{O}$ (Aldrich) y disolución acuosa de $\mathrm{Ru}(\mathrm{NO})\left(\mathrm{NO}_{3}\right)_{3}(1.5 \% \mathrm{Ru}$ en $\mathrm{HNO}_{3}$ diluido, Aldrich) para obtener las cargas metálicas nominales arriba mencionadas. Los soportes se impregnaron hasta el punto de humedad incipiente en dos etapas, mediando una etapa de secado a $60^{\circ} \mathrm{C}$ durante 1 hora entre ambas impregnaciones. Finalmente, los sólidos se secaron a 60 C durante 12 horas y se calcinaron en flujo de aire a $300^{\circ} \mathrm{C}$ durante 3 horas, empleando una velocidad espacial para el gas de $3000 \mathrm{~h}^{-1}$, de modo que son despreciables los efectos del tiempo de residencia en el lecho de sólido de 
los gases derivados de la descomposición de los nitratos precursores sobre la dispersión metálica final, según los resultados publicados recientemente por de Jong y col. [8]. Los catalizadores se denominan 20Co/xSBA_ $y$, donde $x=7$ ó 11 e $y=L, M$ ó $C$, de acuerdo con la nomenclatura empleada para los soportes catalíticos (sección 2.1.2.5).

\subsubsection{Catalizadores $\mathrm{Rh} / \mathrm{M} @ \mathrm{Al}_{2} \mathrm{O}_{3}$.}

Los catalizadores Rh/M@ $\mathrm{Al}_{2} \mathrm{O}_{3}$ se prepararon por impregnación.

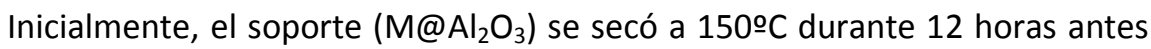
de la impregnación. Seguidamente, se preparó una disolución de $\mathrm{RhCl}_{3} \cdot \mathrm{xH}_{2} \mathrm{O}$ (34.7\%(p) de Rh determinado por ICP-OES, pureza metálica $>97 \%$, Aldrich) conteniendo la cantidad adecuada de Rh para alcanzar una carga metálica nominal de $2.5 \%(\mathrm{p}) \mathrm{Rh}$. La relación volumétrica entre la disolución impregnante y el soporte a impregnar se mantuvo fija en $1 \mathrm{~mL} / \mathrm{g}$. La impregnación se llevó a cabo en dos etapas hasta el punto de humedad incipiente con una etapa intermedia de secado a $600^{\circ} \mathrm{C}$ durante 30 minutos. Finalmente, el sólido se secó a 100 드 durante 12 horas y se calcinó en horno de mufla a $400 \circ \mathrm{C}$ durante 4 horas (rampa térmica de $2 \circ \mathrm{C} / \mathrm{min}$ ).

Por otro lado, se ha preparado un catalizador que contiene Li con el objetivo de neutralizar la acidez superficial del soporte $\mathrm{Ta}_{\mathrm{A}} \mathrm{Al}_{2} \mathrm{O}_{3}$. En este caso, el contenido en Li se fijó en el equivalente a un recubrimiento superficial de 1 átomo Li/nm², que corresponde a un contenido de $0.2 \%(\mathrm{p})$ Li. La preparación de este catalizador ( $\mathrm{Rh} / \mathrm{Li}-\mathrm{Ta}_{\mathrm{A}} \mathrm{Al}_{2} \mathrm{O}_{3}$ ) se llevó a cabo de modo idéntico al descrito para el resto de muestras $\mathrm{Rh} / \mathrm{M} @ \mathrm{Al}_{2} \mathrm{O}_{3}$ con la única diferencia de que el soporte se impregnó con una disolución que contiene tanto $\mathrm{RhCl}_{3} \cdot \mathrm{xH}_{2} \mathrm{O}$ como la cantidad requerida de $\mathrm{LiNO}_{3}$ (ultrapuro, Aldrich). 


\subsection{Técnicas experimentales de caracterización físico-química.}

\subsubsection{Análisis químico por Plasma de Acoplamiento Inductivo acoplado a Espectroscopio de Emisión (ICP-OES).}

La composición metálica de los catalizadores se determinó por ICPOES en un equipo Varian 715-ES. Las muestras sólidas en polvo (aprox. 20-30 mg) se disgregaron en una mezcla de $\mathrm{HNO}_{3} / \mathrm{HF} / \mathrm{HCl}$ de proporciones volumétricas $1 / 1 / 3$. En todos los casos, la recta de calibrado se adecuó a la concentración aproximada prevista de analito y se determinó utilizando disoluciones estándar (Aldrich).

\subsubsection{Análisis elemental (EA).}

El contenido en carbono y nitrógeno de determinadas muestras sólidas se determinó en un analizador elemental Fisons EA1108 empleando sulfanilamida como referencia.

\subsubsection{Difracción de rayos $X$ en polvo (XRD).}

La técnica de difracción de rayos $\mathrm{X}$ se basa en el análisis de la radiación difractada por un sólido sobre el cual se incide con un haz monocromático de rayos $\mathrm{X}$ con un ángulo variable. La longitud de onda de los rayos X ( $1 \AA$ ) es del orden de magnitud del espaciado interplanar de la mayoría de las estructuras cristalinas, lo que provoca fenómenos de dispersión. La difracción se produce como consecuencia de las interferencias constructivas debidas a la periodicidad cristalina en la muestra. Para cada línea de difracción, el ángulo de incidencia de la radiación se relaciona con el espaciado interplanar de la periodicidad cristalina de acuerdo a la ecuación de Bragg [9] (ecuación 2.2):

$$
n \lambda=2 d_{h k l} \cdot \operatorname{sen}(\theta) \quad(\text { Ec. 2.2) }
$$


donde $n$ es un número entero $(n=1,2,3, \ldots), d_{h k l}$ es el espaciado interplanar de los planos cristalinos con índices de Miller (h $\mathrm{k}$ l) y $\lambda$ y $\theta$ son la longitud de onda $y$ el ángulo de incidencia del haz de rayos $X$, respectivamente.

Esta técnica se ha empleado en el presente trabajo para identificar fases cristalinas en los soportes catalíticos y los catalizadores metálicos, para estudiar la dispersión metálica de promotores metálicos dispuestos en forma de óxidos bi-dimensionales sobre la superficie de $\mathrm{\gamma}-\mathrm{Al}_{2} \mathrm{O}_{3}$, así como para estimar cuantitativamente el tamaño de cristal medio de las fases cristalinas de los soportes catalíticos o las fases metálicas. En este sentido, la anchura que adquieren las señales de difracción de rayos $X$ es debida a imperfecciones en la estructura cristalina de la fase estudiada. El nivel de imperfección de la estructura está relacionado, principalmente, con el tamaño de cristal, de modo que los cristales de menor tamaño dan lugar a señales de difracción más anchas. La aplicación de este concepto para el estudio del tamaño de cristal se llevó a cabo a través de la ecuación de Scherrer [10] que relaciona la anchura del pico de difracción a la mitad de su intensidad máxima (FWHM, acrónimo del término en inglés Full Width at Half Maximum) con el tamaño medio de cristal, según la ecuación 2.3:

$$
d_{\text {cristal }}=\frac{k \cdot \lambda}{F W H M \cdot \cos (\theta)}
$$

donde $\mathrm{k}$ es un factor geométrico interpretable como la esfericidad supuesta a los cristales, $\lambda$ es la longitud de onda de la radiación incidente

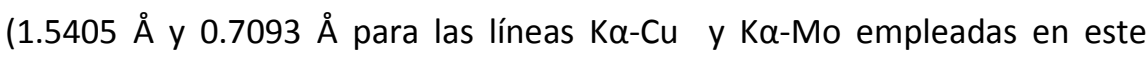
trabajo, respectivamente) y FWHM y $\theta$ son la anchura a la mitad de la intensidad máxima (corregida por la anchura de pico instrumental) y la posición de la señal de difracción analizada, respectivamente. 
Los difractogramas de rayos $\mathrm{X}$ de las muestras en polvo se adquirieron, de forma general, a temperatura ambiente, en un difractómetro Phillips $X^{\prime}$ Pert empleando radiación monocromática correspondiente a la línea $\mathrm{K} \alpha-\mathrm{Cu}$. De manera común, el difractograma se obtuvo en el rango de ángulos $2 \theta=20-80$ o empleando un incremento de 0.04 ㅇ por paso durante el barrido. En determinados casos se registraron difractogramas con un barrido más lento (incremento de 0.01으 por paso)

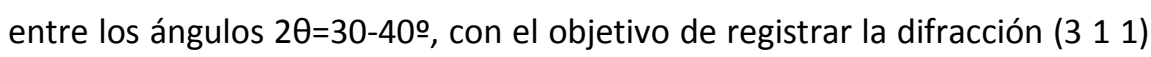
de la fase $\mathrm{CO}_{3} \mathrm{O}_{4}\left(2 \theta=36.8^{\circ}\right)$, minimizando el ruido experimental, para estimar el tamaño de cristal aplicando la ecuación de Scherrer.

De esta forma se determinó el tamaño medio de partícula de $\mathrm{Co}_{3} \mathrm{O}_{4}$ $\left(d\left(\mathrm{Co}_{3} \mathrm{O}_{4}\right) \mathrm{x}\right)$, suponiendo monocristalinidad, en los catalizadores de cobalto en su forma calcinada. A partir del valor de $d\left(\mathrm{CO}_{3} \mathrm{O}_{4}\right)_{x}$ se estimó el diámetro medio de cristal correspondiente a las partículas reducidas de $\mathrm{Co}^{0}$ haciendo uso de la corrección para la contracción de volumen propuesta en la literatura [11], $d\left(\mathrm{Co}^{0}\right)_{\mathrm{X}}=0.75 \cdot d\left(\mathrm{CO}_{3} \mathrm{O}_{4}\right)_{\mathrm{X}}$. Para los soportes catalíticos basados en $\mathrm{\gamma}-\mathrm{Al}_{2} \mathrm{O}_{3}$, el tamaño de cristal de $\mathrm{Al}_{2} \mathrm{O}_{3}$ se determinó aplicando la ecuación de Scherrer a la difracción (4 0 0). En ambos casos, la anchura de pico instrumental se determinó previamente utilizando $\alpha-\mathrm{Al}_{2} \mathrm{O}_{3}$ policristalina (Merck), se asumió un factor de forma k=0.9 y los picos experimentales se ajustaron a una curva gaussiana empleando el software especializado APDW de Philips.

En determinados experimentos se combinó la técnica de difracción de rayos $X$ en polvo con tratamientos térmicos in situ en atmósfera controlada. En estos casos, los difractogramas se adquirieron en un equipo Panalytical $X^{\prime}$ Pert PRO. La muestra se cargó en un reactor XRK-900 de Anton Parr, acoplado al difractómetro, y se trató en un flujo de $\mathrm{N}_{2}(50 \mathrm{~mL} / \mathrm{min})$ y $\mathrm{H}_{2}(5$ $\mathrm{mL} / \mathrm{min}$ ) a temperaturas crecientes desde temperatura ambiente hasta 
$400 \circ \mathrm{C}$ registrando los difractogramas cada $25^{\circ} \mathrm{C}$, una vez que la muestra ha permanecido 15,30 y 45 minutos a cada una de las temperaturas. Los difractogramas se registraron en el rango $2 \theta=12-30$ (paso de barrido de $0.08^{\circ}$ ), empleando radiación monocromática correspondiente a la línea $\mathrm{K} \alpha$ Mo y operando el equipo a un voltaje e intensidad de tubo de $45 \mathrm{kV}$ y 40 $\mathrm{mA}$, respectivamente.

\subsubsection{Adsorción de nitrógeno.}

La técnica de adsorción de gases se fundamenta en el estudio de los fenómenos de adsorción y desorción gas-sólido para obtener información sobre las propiedades texturales del adsorbente. La interpretación de las isotermas de adsorción-desorción empleando las propiedades geométricas del adsorbato y la modelización matemática de los fenómenos superficiales que determinan la termodinámica de los procesos de adsorción y desorción permiten obtener información acerca de la superficie específica, el diámetro de los poros y el volumen de poro del sólido estudiado. El adsorbato más comúnmente empleado es el nitrógeno a la temperatura de -196ㄷ․

Las isotermas de adsorción-desorción de $\mathrm{N}_{2}$ se registraron a -196C C en un equipo Micromeritics ASAP 2000. Las muestras, aprox. $200 \mathrm{mg}$ en un tamaño de pellet de $0.25-0.8 \mathrm{~mm}$, se trataron a vacío durante 12 horas antes de las medidas de adsorción. La temperatura empleada en este pretratamiento fue, de forma general $400^{\circ} \mathrm{C}$, aunque en determinadas muestras que presentan material orgánico sensible a los tratamientos térmicos en vacío (como los soportes silíceos sililados SITQ-2(a) y SITQ-2(b)), la temperatura del tratamiento fue de $200 \circ \mathrm{C}$.

La superficie específica se calculó utilizando el modelo BrunauerEmmet-Teller (B.E.T.) [12]. El volumen de microporo se obtuvo a partir del gráfico t-plot empleando el espesor estadístico de adsorbato de Harkins-Jura 
[13]. La distribución de diámetro de poro, así como el diámetro medio de poro se obtuvieron mediante el modelo Barret-Joyner-Halenda (B.J.H.) [14] aplicado sobre la rama de adsorción de la isoterma, salvo que se indique lo contrario.

\subsubsection{Porosimetría de intrusión de mercurio.}

La técnica de porosimetría de intrusión de $\mathrm{Hg}$ se fundamenta en el análisis de los cambios de volumen derivados de la intrusión de $\mathrm{Hg}$ en los poros de un material sólido poroso en función de la presión del sistema, a temperatura ambiente. La interpretación matemática de los datos experimentales se basa en la dependencia de la presión requerida para introducir $\mathrm{Hg}$ en el interior de los poros con el diámetro de los mismos, de acuerdo a la ecuación de Washburn que describe la intrusión de líquidos en cavidades sólidas en ausencia de capilaridad [15]. La interpretación de los resultados requiere asumir un modelo geométrico para los poros y describir la interacción físico-química en la interfase $\mathrm{Hg}$-sólido a través de la tensión superficial o el ángulo de contacto. Esta técnica se empleó en el presente trabajo para determinar el volumen de macroporo (poros de DP>50 nm) en los soportes catalíticos basados en $\mathrm{Y}^{-} \mathrm{Al}_{2} \mathrm{O}_{3}$, complementando la caracterización por adsorción de $\mathrm{N}_{2}$ que no es adecuada para detectar macroporos [16].

Las isotermas de intrusión de $\mathrm{Hg}$ se registraron en un porosímetro Fisons Pascal 240. Las muestras, aprox. $100 \mathrm{mg}$, en un tamaño de partícula de $45-65 \mu \mathrm{m}$, se secaron a $80^{\circ} \mathrm{C}$ durante 12 horas y se deshidrataron a temperatura ambiente y 0.2 mbar de presión antes de realizar la medidas. En la estimación del diámetro de poro se asumió un ángulo de contacto de 141 y un modelo de poro cilíndrico. El volumen de macroporo se determinó por integración de la distribución de volumen de poro en el rango de $50 \mathrm{~nm}$ 
hasta $10^{4} \mathrm{~nm}$, donde comienza la intrusión en los huecos inter-partícula para el polvo micrométrico.

\subsubsection{Espectroscopia de resonancia magnética nuclear de ${ }^{29} \mathrm{Si}\left({ }^{29} \mathrm{Si}\right.$} NMR).

La espectroscopia de resonancia magnética nuclear es un técnica fundamentada en el análisis de la interacción de los momentos magnéticos nucleares de determinados átomos, cuyo momento magnético nuclear es distinto de cero, con un campo magnético externo. La técnica es extremadamente sensible al entorno químico de los núcleos analizados. Sobre muestras sólidas en las que las interacciones bipolares y cuadrupolares, así como la anisotropía del desplazamiento químico, introducen un ensanchamiento excesivo de las líneas espectrales, la técnica puede aplicarse con giro de la muestra al ángulo mágico (MAS, acrónimo del término en inglés Magic Angle Spinning) de 54074' $\left(\cos ^{2}(\theta)=1 / 3\right)$ que anula la contribución de las interacciones bipolares y cuadrupolares de primer orden que dependen de un término $\left(3 \cos ^{2}(\theta)-1\right)$.

La técnica de ${ }^{29}$ Si-MAS NMR se empleó para estudiar los entornos de coordinación de los átomos de Si en los soportes catalíticos ITQ-2 en su forma calcinada y sililada, de modo que se pudo cuantificar el grado de sililación superficial.

Los espectros de resonancia magnética nuclear de ${ }^{29} \mathrm{Si} \quad\left({ }^{29} \mathrm{Si}-\mathrm{MAS}\right.$ NMR) se registraron en un equipo Bruker AV400 empleando una cápsula de $7 \mathrm{~mm}$ y una frecuencia de giro de $5 \mathrm{kHz}$.

\subsubsection{Técnicas de temperatura programada.}

El comportamiento de reducción, oxidación, descomposición, desorción o reacción superficial de una especia adsorbida se puede estudiar 
mediante técnicas de temperatura programada, en las que las muestras se someten a una rampa térmica bajo una atmósfera controlada, mientras se detectan las especies emitidas o consumidas por los procesos que tienen lugar sobre la muestra. En el presente trabajo, se han utilizado la reducción (TPR), oxidación (TPO), desorción (TPD) y reacción superficial de adsorbato (TPSR) a temperatura programada para obtener distintos tipos de información acerca de los catalizadores o los precursores de los mismos. En todos los casos, los experimentos se llevaron a cabo en un equipo Micromeritics Autochem 2910.

\subsubsection{Reducción a temperatura programada $\left(H_{2}-T P R\right)$.}

El comportamiento de reducción de determinadas muestras de soportes catalíticos y catalizadores metálicos se determinó por $\mathrm{H}_{2}$-TPR. Entre 30 y $100 \mathrm{mg}$ de muestra, en la granulometría $0.25-0.40 \mathrm{~mm}$ se cargaron en forma de lecho fijo, entre lana de cuarzo, en un tubo en $U$ de cuarzo. Las muestras se trataron en flujo de $\mathrm{Ar}$ a temperatura ambiente durante 30 minutos y, posteriormente, el gas circulante se sustituyó por $10 \% \mathrm{H}_{2}(\mathrm{vol}) / \mathrm{Ar}$ (50 mL/min) y la temperatura se incrementó desde temperatura ambiente hasta $900-1100^{\circ} \mathrm{C}$ a una velocidad de $10^{\circ} \mathrm{C} / \mathrm{min}$. Aguas abajo del reactor se colocó una trampa de 2-propanol/ $/ \mathrm{N}_{2}(\mathrm{l})$ para retener el agua formada en las reducciones, y se registró el consumo de $\mathrm{H}_{2}$ en un detector de conductividad térmica ( $T C D)$, previamente calibrado utilizando la reducción de CuO como referencia. En determinados casos, el experimento de $\mathrm{H}_{2}$-TPR se llevó a cabo en ausencia de trampa de 2-propanol/ $\mathrm{N}_{2}(\mathrm{l})$ aguas abajo del reactor y se empleó un espectrómetro de masas para registrar las señales de ciertos fragmentos derivados de las especies gaseosas emitidas por la muestra durante los procesos de reducción (TPR-MS). 
En el mismo dispositivo experimental, se llevaron a cabo una serie de experimentos diferentes encaminados a estimar el grado de reducción (GR) de los catalizadores de cobalto después de tratamientos de reducción como los empleados in situ en el reactor de Fischer-Tropsch antes de los experimentos catalíticos. En estos casos, la muestra (100 mg, 0.25-0.40 mm) se redujo en flujo de $\mathrm{H}_{2}$ en el tubo de cuarzo a 400 으 ó 450 으 (en función de los catalizadores) durante 10 horas, empleando una rampa de calentamiento de $1 \stackrel{\circ}{ } \mathrm{C} / \mathrm{min}$, tal y como se procede antes de los experimentos catalíticos. Tras la reducción, la superficie de la muestra se limpió haciendo uso de un flujo de $\operatorname{Ar}$ a la temperatura de reducción durante 30 minutos. Posteriormente, el gas circulante se sustituyó por $10 \% \mathrm{H}_{2}(\mathrm{vol}) / \mathrm{Ar}$ y la temperatura de la muestra se incrementó hasta 900 ㄷ $\mathrm{C}$ a una velocidad de $10^{\circ} \mathrm{C} / \mathrm{min}$, mientras el agua se retenía aguas abajo en una trampa de 2propanol $/ \mathrm{N}_{2}(I)$ y el consumo de $\mathrm{H}_{2}$ se registraba en el detector TCD. En el cálculo del grado de reducción (\%), se asumió la reducción completa de los óxidos de $\mathrm{Ru}$ (que tiene lugar a $\mathrm{T}<150$ 으) y la reducción de $\mathrm{Co}_{3} \mathrm{O}_{4}$ a $\mathrm{CoO}$ que se produce de forma cuantitativa para $\mathrm{T}<350^{\circ} \mathrm{C}$. El consumo de $\mathrm{H}_{2}$ registrado durante el $\mathrm{H}_{2}$-TPR de la muestra previamente reducida (400 ó 450 으, $10 \mathrm{~h}$ ) se asoció con la reducción de $\mathrm{CoO}$ resistente al tratamiento previo en $\mathrm{H}_{2}$. Así, el grado de reducción se calculó de acuerdo a la siguiente ecuación 2.4:

$$
G R(\%)=[1-F / T] \cdot 100
$$

donde $\mathrm{F}$ es la cantidad de Co que se reduce durante el experimento de $\mathrm{H}_{2}$-TPR empleando la muestra pre-reducida $\left(400^{\circ} \mathrm{C}, 10 \mathrm{~h}\right)$ y $\mathrm{T}$ es la cantidad de Co que se reduce durante un experimento de $\mathrm{H}_{2}$-TPR desde temperatura ambiente hasta $900^{\circ} \mathrm{C}$ para la muestra calcinada. El valor de $\mathrm{T}$ está de acuerdo, en todos los casos, con la cantidad de Co determinada por ICP-OES (desviación relativa $<5 \%$ ). 


\subsubsection{Oxidación a temperatura programada monitorizada por espectrometría de masas (TPO-MS).}

La calcinación de ciertos precursores de catalizadores se monitorizó por TPO-MS en el mismo dispositivo experimental empleado para los ensayos de $\mathrm{H}_{2}$-TPR. Experimentalmente, $100 \mathrm{mg}$ de muestra, en la granulometría 0.10-0.25 mm, se expusieron a un flujo de aire sintético (50 $\mathrm{mL} / \mathrm{min}$ ) y la temperatura de la muestra se incrementó desde temperatura ambiente hasta $900^{\circ} \mathrm{C}$ a una velocidad de calentamiento de $10^{\circ} \mathrm{C} / \mathrm{min}$. En ausencia de trampas frías aguas abajo del reactor, los gases emitidos durante el tratamiento se analizaron en línea mediante un espectrómetro de masas.

\subsubsection{Quimisorción de hidrógeno o CO.}

La técnica de quimisorción de gases emplea moléculas sencillas (comúnmente $\mathrm{H}_{2}, \mathrm{CO}, \mathrm{CO}_{2}$ ) para cuantificar la superficie de un sólido que participa de manera específica en el fenómeno de quimisorción. La quimisorción de $\mathrm{H}_{2}$ es una técnica muy empleada para la cuantificación de superficies metálicas en catalizadores metálicos en su forma reducida, y está fundamentada en la capacidad que tienen las nanopartículas metálicas para quimisorber moléculas de $\mathrm{H}_{2}$, así como en ciertas aproximaciones estequiométricas de la quimisorción $\left(\mathrm{H}_{2} /\right.$ Metal) y geométricas (grado de empaquetamiento superficial de los átomos metálicos expuestos). La quimisorción de $\mathrm{H}_{2}$ se ha empleado en el presente trabajo para conocer la dispersión metálica de los catalizadores de Co en su forma reducida. De acuerdo a los trabajos previos publicados por el grupo del Prof. Bartholomew [17,18], el fenómeno de quimisorción en Co presenta naturaleza activada, por lo que son necesarias temperaturas típicamente en el rango $100-150^{\circ} \mathrm{C}$, en función del soporte catalítico y de la dispersión metálica, para maximizar el recubrimiento. El mismo grupo de investigación, 
que posee una amplia experiencia en el empleo de técnicas analíticas basadas en la quimisorción de gases, demostró que la quimisorción de $\mathrm{H}_{2}$ sobre Co es reversible, es decir, no es estable ante tratamientos de evacuación isotérmica. De este modo, con el objetivo de contabilizar el $\mathrm{H}_{2}$ débilmente adsorbido, la metodología que ha de emplearse en el estudio de los catalizadores de Co está basada en una isoterma simple, en lugar de la doble isoterma (mediando evacuación entre las dos isotermas registradas), más comúnmente empleada para metales de carácter noble.

Los experimentos de quimisorción de $\mathrm{H}_{2}$ se llevaron a cabo en un equipo Micromeritics ASAP 2010C. La muestra de catalizador, 0.3-1.0 g en un tamaño de partícula 0.40-1.0 mm, se cargó en un tubo de cuarzo en forma de $\mathrm{U}$, se secó en flujo de $\mathrm{He}$ a $120^{\circ} \mathrm{C}$ durante una hora y se redujo durante 10 horas a la temperatura de reducción aplicada, en su caso, antes de los experimentos de reacción $(400-450$ ㅇ) empleando una rampa de calentamiento de 1으/min. Tras la reducción, la muestra se evacuó a 1.3 Pa y se enfrió en vacío hasta la temperatura a la que se registra la isoterma de quimisorción. La isoterma de quimisorción se registró a 150 ㄷ C para los catalizadores soportados sobre $\mathrm{Al}_{2} \mathrm{O}_{3}$ y a 100 ㅇ $\mathrm{C}$ para los catalizadores soportados sobre $\mathrm{SiO}_{2}$ o ITQ-2 puesto que se encontró experimentalmente que estas temperaturas maximizan la cantidad de $\mathrm{H}_{2}$ quimisorbido en cada caso. Como se comentó, debido a la naturaleza reversible del proceso de quimisorción sobre Co, se utilizó la cantidad total de $\mathrm{H}_{2}$ quimisorbido (reversible+irreversible), por extrapolación de la isoterma a presión cero, para estimar la superficie metálica total. La dispersión metálica $(D(\%))$ y el tamaño medio de nanopartícula $\left(d\left(\mathrm{CO}^{0}\right)_{\mathrm{H}}\right)$ se estimaron a partir del contenido metálico de los catalizadores (ICP-OES), corregido por el grado de reducción (GR) estimado según se explicó en la sección 2.2.7.1, y asumiendo una estequiometría de quimisorción de $\mathrm{H}_{2}: \mathrm{Co}_{0}=1: 2$, una geometría de 
nanopartícula esférica, una densidad volumétrica para el $\mathrm{Co}^{0}$ de $8.9 \mathrm{~g} / \mathrm{cm}^{3}$, y una densidad atómica superficial de 14.6 átomos $/ \mathrm{nm}^{2}$ [17], de acuerdo a las ecuaciones 2.5 a 2.8 .

$$
\begin{aligned}
& D(\%)=\frac{\text { Átomos metálicos superficiales }}{\text { Átomos metálicos totales reducidos }} \cdot 100 \quad \text { (Ec. 2.5) } \\
& D(\%)=\frac{\left[H_{2, a d s} \cdot \frac{N_{A}}{10^{-6}}\right] \cdot 2}{\frac{x_{C o}(\%)}{100} \cdot \frac{1}{P A_{C o}} \cdot N_{A} \cdot \frac{G R}{100}} \cdot 100 \quad \text { (Ec. 2.6) } \\
& d\left(C o^{0}\right)_{H}=6 \cdot\left(\frac{V}{S}\right)_{\text {esfera }} \text { equivalente } \\
& d\left(C o^{0}\right)_{H}=6 \cdot \frac{\rho_{C o}^{S}}{\frac{\rho_{C o} \cdot N_{A}}{10^{14} \cdot P A_{C o}}} \cdot \frac{100}{D(\%)} \\
& \text { (Ec. 2.7) }
\end{aligned}
$$

donde $\mathrm{H}_{2, \text { ads }}$ es la cantidad total de $\mathrm{H}_{2}$ quimisorbido $(\mu \mathrm{mol} / \mathrm{g}), \mathrm{N}_{\mathrm{A}}$ es el número de Avogadro, $\mathrm{PA}_{\mathrm{co}}$ es el peso atómico del $\mathrm{Co}(\mathrm{g} / \mathrm{mol})$, $\mathrm{D}$ es la dispersión metálica (\%), $x_{c_{0}}$ es la carga metálica del catalizador (\%(p)), GR es el grado de reducción del catalizador, $\rho_{C o}$ es la densidad del Co $\left(\mathrm{g} / \mathrm{cm}^{3}\right), \rho_{C o}^{S}$ denota la densidad atómica superficial para las nanopartículas de Co (átomos $/ \mathrm{nm}^{2}$ ), y $\vee$ y $\mathrm{S}$ son el volumen y la superficie de la esfera equivalente de diámetro igual al tamaño de nanopartícula metálica. 
Por su parte, se ha empleado la quimisorción de CO para cuantificar la superficie metálica en los catalizadores Rh/M@ $@ \mathrm{Al}_{2} \mathrm{O}_{3}$ estudiados en el capítulo 6 de esta memoria. En este caso, se emplea CO como adsorbato, en lugar de $\mathrm{H}_{2}$, con el objetivo de minimizar la contribución de las fases promotoras $\mathrm{MO}_{x}$ a la adsorción total. En este sentido, los experimentos de CO-FTIR realizados sobre estos catalizadores no muestran señales de IR debidas a la adsorción de $\mathrm{CO}$ sobre las fases $\mathrm{MO}_{\mathrm{x}}$ a temperatura ambiente, lo que sugiere la especificidad de las fases de $\mathrm{Rh}^{0}$ para el fenómeno de quimisorción de CO. En este caso, el experimento de quimisorción se llevó a una temperatura de $35^{\circ} \mathrm{C}$ tras la reducción de la muestra $(150 \mathrm{mg})$ in situ, en flujo de $\mathrm{H}_{2}$, a $300^{\circ} \mathrm{C}$ durante 6 horas (rampa térmica $19 \mathrm{C} / \mathrm{min}$ ). El procedimiento empleado consiste en la doble isoterma, con evacuación a 35 ㄷ $\mathrm{C}$ entre ambas isotermas, con el objetico de cuantificar solamente el CO adsorbido de manera irreversible $\left(\mathrm{CO}_{\text {ads,irrev }}\right)$. La estimación de la dispersión metálica y el tamaño de nanopartícula metálica se llevó a cabo de manera idéntica a la mostrada por las ecuaciones 2.5-2.8 para el caso de Co, asumiendo reducción completa a $\mathrm{Rh}^{0}$, modelo geométrico de nanopartícula esférica, una densidad atómica superficial de 16.3 átomos $/ \mathrm{nm}^{2}$ y una relación estequiométrica $\mathrm{CO} / \mathrm{Rh}_{(\mathrm{s})}$ superficial de 2 , es decir, formación mayoritaria de especies di-carbonilo, en concordancia con los resultados de CO-FTIR para las mismas muestras (ver sección 6.3.5).

\subsubsection{Análisis termogravimétrico y térmico diferencial (TG-DTA).}

La técnica de TG-DTA permite monitorizar tanto las variaciones de masa como los flujos de calor experimentados por una muestra durante su calentamiento a temperatura programada. Los experimentos de TG-DTA se llevaron a cabo en un equipo Mettler-Toledo TGA/SDTA 851, empleando aprox. $10 \mathrm{mg}$ de muestra en polvo que se cargó en un crisol de $\mathrm{Al}_{2} \mathrm{O}_{3}$ acoplado a una balanza de precisión y un termopar de medida tipo $\mathrm{S}$ (Rh-Pt). 
La muestra (aprox. $10 \mathrm{mg}$ ) se calentó desde $30 \circ \mathrm{C}$ hasta 800 으 a una velocidad de calentamiento de $10^{\circ} \mathrm{C} / \mathrm{min}$ en flujo de aire sintético (50 $\mathrm{mL} / \mathrm{min})$.

\subsubsection{Técnicas de microscopía electrónica.}

2.2.10.1. Microscopía electrónica de barrido (SEM).

La técnica de SEM (Scanning Electron Microscopy) emplea la transducción de los electrones secundarios emitidos por una muestra, al ser sometida a un haz de electrones acelerados en un campo eléctrico, para construir una imagen de la morfología superficial de la muestra analizada. En el presente trabajo, se ha utilizado SEM para conocer la morfología de partícula primaria de los soportes mesoestructurados SBA-15 (sección 5.6.1.2) así como para estudiar la textura macroporosa de la muestra de $\psi$ $\mathrm{Al}_{2} \mathrm{O}_{3}$ nanofibrosa (sección 5.3.1.3).

Las micrografías electrónicas de barrido se registraron en un microscopio Hitachi S-4100 de emisión de campo equipado con un detector BSE-AUTRATA, empleando muestras en polvo previamente sombreadas por un recubrimiento de oro.

\subsubsection{Microscopía electrónica de transmisión (TEM y HRTEM).}

La técnica de TEM (Transmission Electron Microscopy) genera una imagen de contraste, de resolución a escala nanométrica, a partir de los electrones transmitidos a través de una muestra ultrafina situada en el camino de un haz de electrones acelerados. A lo largo del presente trabajo, la microscopía TEM se ha empleado en el modo de campo brillante (bright field) para conocer la morfología y el tamaño de partícula primaria de soportes catalíticos de dimensiones nanométricas como ITQ-2, $\gamma-\mathrm{Al}_{2} \mathrm{O}_{3}$, la direccionalidad y longitud de los poros en las mesoestructuras SBA-15, así como para estudiar el tamaño, morfología y localización de nanopartículas 
metálicas en los catalizadores metálicos. En determinados casos, la técnica microscópica se combinó con la espectroscopia de dispersión de rayos $X$ (EDX) para realizar mapas composicionales de algunas regiones de la muestra previamente registradas en modo imagen. Finalmente, la variedad de alta resolución (HT, High Resolution) se empleó para estudiar los planos cristalinos en determinadas nanopartículas metálicas y apreciar, por ejemplo, fenómenos de pasivación superficial o re-oxidación en nanopartículas de Co o estudiar la posición relativa de los promotores respecto de las nanopartículas de $\mathrm{Rh}$ en los catalizadores $\mathrm{Rh} / \mathrm{M} @ \mathrm{Al}_{2} \mathrm{O}_{3}$.

Las micrografías electrónicas de transmisión de media-baja magnificación $(1 \mathrm{kX}-50 \mathrm{kX})$ se obtuvieron en un microscopio Philips CM10 operado a 100 kV. Por su parte, las micrografías electrónicas de transmisión de media-alta magnificación (50kX-120kX) y de alta resolución (HRTEM) se obtuvieron en un microscopio Tecnai $G^{2}$ de emisión de campo, equipado con microanálisis por espectroscopia de dispersión de rayos X (EDX), operado a $200 \mathrm{kV}$.

Las muestras se prepararon por suspensión del sólido en etanol y tratamiento en ultrasonidos durante un minuto. Posteriormente, la suspensión se dejó decantar durante otro minuto y se extrajo una gota de la parte superior de la misma que se depositó sobre una rejilla de cobre (300 mesh) recubierta por una capa agujereada de carbono (holey carbon film).

Cuando los catalizadores de cobalto se estudiaron en su forma reducida, se sometieron, en primer lugar, al tratamiento de reducción en flujo de $\mathrm{H}_{2}$ a $400-450^{\circ} \mathrm{C}$ durante 10 horas en un reactor de lecho fijo de cuarzo y posteriormente, se pasivaron en una atmósfera de $<1 \% \mathrm{O}_{2} / \mathrm{N}_{2}$ y se almacenaron bajo esa atmósfera pasivante hasta la preparación de la muestra para microscopía. El tratamiento de pasivación genera una capa de 
óxido de dimensiones nanométricas en la superficie externa de las nanopartículas de Co, que disminuye la cinética de difusión del oxígeno, preservando el resto de la nanopartícula en el estado reducido, y permitiendo la exposición del catalizador pasivado al ambiente sin que sufra re-oxidación espontánea. El proceso de re-oxidación de las fases de $\mathrm{Co}^{0}$ es muy exotérmico y puede dar lugar a la formación de regiones calientes sobre la superficie del catalizador, promoviendo re-distribución y aglomeración de las fases metálicas [19].

Por el contrario, en el caso de los soportes catalíticos y los catalizadores en su forma calcinada, las muestras no se sometieron a ningún tratamiento térmico antes de la observación microscópica.

Las distribuciones de tamaño de nanopartícula metálica de Co se obtuvieron a partir de la medida directa de 100-200 nanopartículas sobre diferentes micrografías tomadas en distintas posiciones de la gradilla portamuestra. En las muestras reducidas y pasivadas se corrigió el diámetro de nanopartícula de Co por la correspondiente contracción volumétrica para la "corteza" de 3-4 nm de CoO generada por el tratamiento de pasivación. En determinadas muestras con tamaño de partícula pequeño (típicamente $<7$ $\mathrm{nm}$ ) en las que se detectó por HRTEM la re-oxidación completa de las nanopartículas a $\mathrm{CoO}$, la corrección por contracción de volumen para la correspondiente nanopartícula de $\mathrm{Co}^{0}$ se llevó a cabo considerando todo el diámetro medido de nanopartícula re-oxidada. Salvo que se indique lo contrario, el tamaño medio de nanopartícula se calculó como media ponderada por superfice según la ecuación 2.9, y la desviación típica se obtuvo como indica la ecuación 2.10 : 


$$
\begin{gathered}
d\left(\mathrm{Co}^{0}\right)_{T}=\frac{\sum_{i} n_{i} \cdot\left(d_{i}\right)^{3}}{\sum n_{i} \cdot\left(d_{i}\right)^{2}} \quad \text { (EC. 2.9) } \\
\sigma_{T}=\sqrt{\frac{\sum_{i} n_{i} \cdot\left(d_{i}-d\left(C o^{0}\right)_{T}\right)^{2}}{\sum n_{i}}} \quad \text { (Ec. 2.10) } \\
\text { donde } \mathrm{n}_{\mathrm{i}} \text { es la frecuencia de ocurrencia del tamaño } \mathrm{d}_{\mathrm{i}} \text {, una vez }
\end{gathered}
$$
nanopartículas.

\subsubsection{Espectroscopia de reflectancia difusa ultravioleta-visible (DR UV-} vis).

En la región UV-visible del espectro electromagnético se producen absorciones de fotones por parte de las especies metálicas, relacionadas con transiciones electrónicas inter-atómicas (ligando-metal) ó intra-atómicas (típicamente transiciones $d-d$ en átomos metálicos). La espectroscopia UVvis, aplicada a sólidos catalíticos, permite obtener información acerca del estado de oxidación y la coordinación para centros metálicos.

La técnica se ha empleado en el modo de reflectancia difusa (DR, Diffuse Reflectance) para conocer la naturaleza de las especies de Co en los catalizadores modelo Co/ITQ-2 calcinados, en función de la dispersión metálica de los mismos (sección 3.4.2.3).

Por otro lado, en el caso de los óxidos metálicos semiconductores, la mínima energía de fotón necesaria para inducir la promoción de un electrón desde el orbital HOMO (banda de valencia en el caso de los óxidos) hasta el orbital LUMO (o banda de conducción), denominada energía en el borde de absorción UV-vis (EBA(UV-vis)), es una función de la naturaleza del óxido 
(polaridad del enlace $\mathrm{M}-\mathrm{O}$ ), del estado de coordinación para los átomos metálicos, así como del tamaño de cluster y cristalinidad de las especies de óxido metálico. Esta técnica es capaz, por tanto, de detectar la presencia de especies cristalinas (identificadas por su valor de EBA(UV-vis)) incluso cuando estas especies presentan un tamaño de cristal tan pequeño que no es detectable por técnicas de difracción de rayos X. En el presente trabajo, esta técnica se ha empleado para estudiar la naturaleza (bi-dimensional amorfa vs. cristalina) y las propiedades electrónicas (acidez-basicidad óptica $[20,21,22])$ de los óxidos metálicos depositados sobre $\mathrm{Al}_{2} \mathrm{O}_{3}$ en los soportes

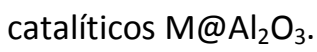

Los espectros UV-vis de reflectancia de difusa se obtuvieron en un equipo Cary 5, empleando $\mathrm{BaSO}_{4}$ como referencia de reflectancia. Los espectros se representan utilizando la función de Kubelka-Munk $(F(R)=((1-$ $\left.\left.\mathrm{R}^{2}\right) / 2 \mathrm{R}\right)$ ). Para la estimación de la $\mathrm{EBA}(\mathrm{UV}$-vis) se asumieron transiciones electrónicas directas-permitidas, obteniéndose el valor de EBA(UV-vis) por extrapolación lineal a ordenada en el origen cero en la región de absorción incipiente de la representación $(F(R) \cdot h u)^{(1 / 2)} v s$. hu, donde hu es la energía del fotón incidente [23].

Adicionalmente, la técnica de DR UV-vis se combinó con la adsorción de alizarina (denominación IUPAC: 1,2-dihidroxi-9,10-antracenodiona), como molécula sonda, para estudiar las características electrónicas superficiales (carácter electro donante-aceptor o acidez-basicidad Lewis) de los soportes

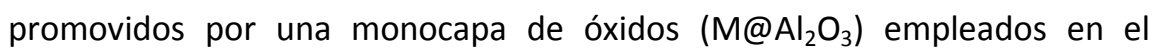
capítulo 6 de esta memoria. Experimentalmente, de manera general, $150 \mathrm{mg}$ del soporte $\mathrm{M} @ \mathrm{Al}_{2} \mathrm{O}_{3}$ calcinado (en el caso de los soportes promovidos por óxidos de lantánidos e itrio, la calcinación se realizó en aire a 600 ㄷ C con el objetivo de descarbonatar la superficie del óxido) se suspendieron en $20 \mathrm{~mL}$ de etanol y sobre esta suspensión se añadieron $20 \mathrm{~mL}$ de una disolución 


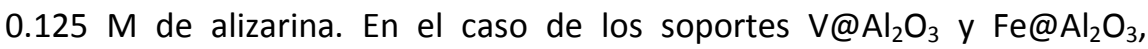
también se llevaron a cabo los experimentos con los sólidos en estado reducido, para lo cual los soportes se sometieron a un tratamiento de reducción ex situ a $500^{\circ} \mathrm{C}$ y $650^{\circ} \mathrm{C}$, respectivamente, durante 3 horas en flujo de $\mathrm{H}_{2}$ y se mantuvieron en vacío hasta su adición sobre la disolución etanólica de alizarina. En todos los casos, la suspensión resultante se agitó durante $10 \mathrm{~min}$, y el sólido se filtró, se lavó con etanol hasta ausencia de colorante en los líquidos de lavado y finalmente se secó a temperatura ambiente y vacio en un desecador durante 12 horas antes de registrar su espectro de DR UV-vis.

\subsubsection{Espectroscopia fotoelectrónica de rayos $X(X P S)$.}

La espectroscopia fotoelectrónica de rayos X (XPS, acrónimo del término anglosajón $X$-ray Photoelectron Spectroscopy) es una técnica de caracterización superficial de carácter no destructivo que permite obtener información, tanto cualitativa como cuantitativa, de las especies químicas en superficie con una capacidad de penetración de hasta unos $6 \mathrm{~nm}$. La técnica se fundamenta en el análisis de las energías cinéticas de los electrones emitidos por la muestra cuando la superficie de ésta se bombardea con radiación de rayos $X$. La energía cinética $\left(E_{K}\right)$ de los electrones desprendidos de un átomo se relaciona con la energía de enlace $\left(\mathrm{E}_{\mathrm{E}}\right)$ y con la energía de los fotones de rayos- $\mathrm{X}$ incidentes $(\mathrm{h} v$ ) mediante el balance energético recogido en la ecuación 2.11.

$$
\mathrm{E}_{\mathrm{K}}=(\mathrm{h} \cdot \mathrm{v})-\mathrm{E}_{\mathrm{E}}-\phi
$$

donde $\phi$ es la función de trabajo del espectroscopio, la cual es función, entre otras variables, del nivel de vacío en la cámara de análisis. 
En los espectros de XPS se registra la señal recogida en un analizador en función de la energía de enlace $\left(\mathrm{E}_{\mathrm{E}}\right)$ para los electrones despedidos. Por un lado, los espectros de XPS permiten obtener información cuantitativa de la composición superficial de la muestra. Por otro lado, la energía de enlace es una función del estado de oxidación del átomo del que son emitidos los electrones. En el presente trabajo, la técnica de XPS se ha empleado para estudiar la composición superficial de las nanopartículas de $\mathrm{Co}_{3} \mathrm{O}_{4}$ en los catalizadores $\mathrm{Co} / \mathrm{SiO}_{2}$ calcinados, en función de la temperatura de calcinación aplicada durante su preparación (capítulo 4), así como para conocer la composición superficial, el estado de oxidación y la carga electrónica parcial de las NPs de Rh en los catalizadores Rh/M@ $@ \mathrm{Al}_{2} \mathrm{O}_{3}$ tras el tratamiento de reducción (capítulo 6).

Los espectros de XPS se obtuvieron en un equipo SPECS equipado con un detector Phoibos 150 9MCD, empleando radiación monocromática de la línea $\mathrm{K} \alpha-\mathrm{Mg}(1253.6 \mathrm{eV})$ y manteniendo una energía de paso constante en el analizador de $50 \mathrm{eV}$.

Las muestras se molieron y se conformaron en pastillas autosoportadas y se evacuaron en la pre-cámara del equipo a $1.3 \times 10^{-7} \mathrm{~Pa}$.

En el caso de los catalizadores Rh/M@ $@ \mathrm{Al}_{2} \mathrm{O}_{3}$, recogidos en el capítulo 6 de esta memoria, que se analizaron en su estado reducido, las muestras se sometieron a un tratamiento de reducción en la pre-cámara del equipo de XPS idéntico al realizado en el reactor catalítico antes de los experimentos de SSO, es decir, $300^{\circ} \mathrm{C}$ durante 6 horas (rampa de calentamiento de 1 o $\mathrm{C} / \mathrm{min}$ ) en flujo de $\mathrm{H}_{2}$. Posteriormente, las muestras se evacuaron antes de introducirse en la cámara de análisis. 
Para los catalizadores $\mathrm{Co} / \mathrm{SiO}_{2}$, las energías de enlace se refirieron a la línea Si2p para corregir por los efectos de carga en la muestra, mientras que en el caso de los catalizadores Rh/M@ $@ \mathrm{Al}_{2} \mathrm{O}_{3}$ se empleó la línea $\mathrm{Al} 2 \mathrm{p}$, ambas correspondientes al soporte catalítico. El área de las señales se determinó mediante ajuste por combinación lineal de curvas gaussianas tras sustraer un fondo de espectro no lineal de tipo Shirley.

\subsubsection{Espectroscopia laser-Raman (LRS).}

La espectroscopia Raman se fundamenta en la dispersión inelástica que sufren los fotones de una fuente de radiación monocromática, normalmente LASER, al interaccionar con una muestra. Esta técnica permite obtener información acerca de estados vibracionales y rotacionales de los sólidos analizados, así como acerca de modos de vibración cuantizados de redes cristalinas como los fonones.

En la presente tesis se ha empleado la espectroscopia Raman para estudiar las propiedades de las nanopartículas de $\mathrm{Co}_{3} \mathrm{O}_{4}$ en función de la temperatura de calcinación de los catalizadores $\mathrm{Co} / \mathrm{SiO}_{2}$.

Los espectros se adquirieron en un equipo Renishaw Raman In Via equipado con un microscopio Leika DM LM y un diodo laser $(\lambda=514 \mathrm{~nm})$ como fuente de radiación. El laser se enfocó sobre regiones de la muestra de 3-5 $\mu \mathrm{m}$ de diámetro, empleando un objetivo 50X y una longitud óptica de 8 $\mathrm{mm}$. Se registraron los espectros en la región de desplazamiento raman de 100-3000 cm $\mathrm{cm}^{-1}$, con una resolución $<4 \mathrm{~cm}^{-1}$, acumulando 10 barridos en un tiempo total de acumulación de $100 \mathrm{~s}$. 


\subsubsection{Espectroscopia infra-rojo de transmisión con adsorción de CO (CO-FTIR).}

La técnica de espectroscopia de infra-rojo de transformada de Fourier (FTIR) permite obtener información estructural de las muestras analizadas, a través de la absorción de radiación IR $\left(\lambda=750-10^{5} \mathrm{~nm}\right)$ debida a transiciones energéticas en ciertos niveles vibracionales de los enlaces químicos. La técnica de FTIR se ha empleado en el presente trabajo para estudiar las modificaciones que tienen lugar en los grupos hidroxilo superficiales de la zeolita ITQ-2 cuando se silila su superficie (sección 3.3.1.2). Los espectros de FTIR se registraron en un equipo Nicolet 710 empleando pastillas de sólido auto-soportadas $\left(10 \mathrm{mg} / \mathrm{cm}^{2}\right)$ previamente evacuadas en una celda a $200 \circ \mathrm{C}$ y $10^{-2} \mathrm{~Pa}$.

Por su parte, en combinación con la adsorción de moléculas sonda como el monóxido de carbono (CO), la espectroscopia CO-FTIR se convierte en una técnica sensible exclusivamente a la superficie de los materiales, que permite estudiar las modificaciones electrónicas que tienen lugar en los enlaces de la molécula sonda adsorbida y que son sensibles a la naturaleza química, el estado de oxidación, la coordinación y la densidad electrónica del sitio de adsorción.

La teoría desarrollada por Blyholder en los años 60 [24] es la más aceptada para la interpretación de los espectros de IR de CO adsorbido sobre centros metálicos. De acuerdo a este modelo, la molécula de CO se interpreta en base a la teoría de orbitales moleculares aplicada a especies de tipo carbonilo $[25,26]$. El enlace C-O de una molécula de CO resulta, por un lado, de la combinación de un orbital híbrido $\mathrm{sp}_{\mathrm{z}}$ del átomo de carbono con un orbital $p_{z}$ del átomo de oxígeno para dar lugar a un enlace tipo $\sigma$, mientras que por otro lado, los orbitales $p_{x} y p_{y}$ de los átomos de carbono y oxígeno se combinan en dos enlaces tipo $\pi$. Esta situación deja un par 
electrónico libre en el orbital molecular $5 \sigma$ (HOMO), el cual puede coordinarse con un aceptor, como los orbitales d vacíos de los átomos metálicos sobre los que se adsorbe la molécula de $\mathrm{CO}$, formándose un enlace de simetría $\sigma$ entre la molécula de CO y el átomo metálico sobre el que se adsorbe. Puesto que la formación de un único enlace $\sigma$ daría lugar a un exceso de carga formal negativa sobre el átomo metálico, se considera la retro-donación electrónica desde los orbitales d ocupados del átomo metálico hacia el orbital anti-enlazante $\pi^{*}$ (LUMO) del adsorbato, como se muestra esquemáticamente en la Fig. 2.1, lo que debilita el enlace C-O y determina su frecuencia de adsorción en el IR, dotando a la molécula de CO de características de "sonda". A pesar de que se ha cuestionado este modelo simple en algunos casos $[27,28]$, es el más ampliamente aceptado a la hora de interpretar los espectros de FTIR-CO.

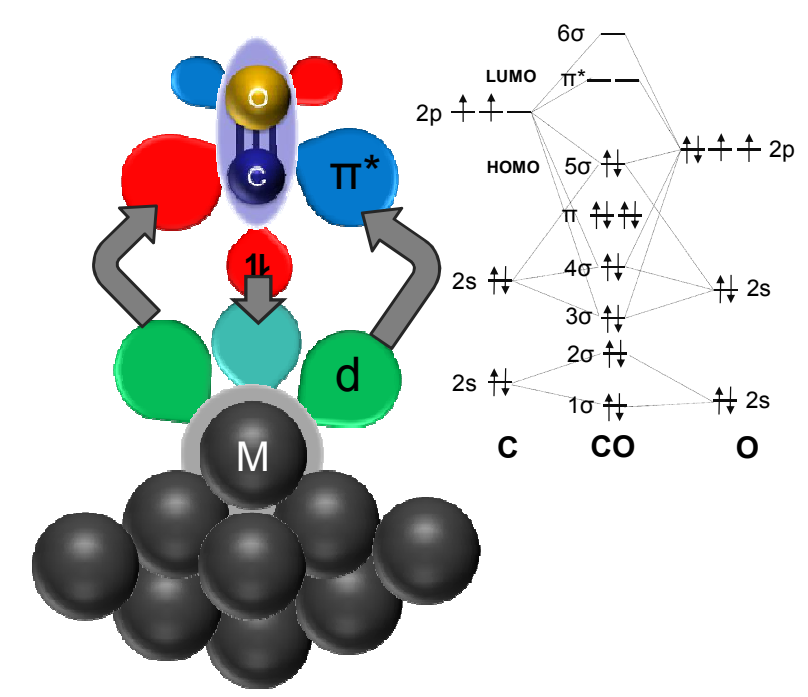

Figura 2.1: Representación esquemática de los fenómenos de donación electrónica CO-metal y retro-donación metal-CO para una molécula de CO adsorbida sobre un sitio metálico. La figura incluye, a su vez, el diagrama de orbitales moleculares para la molécula de CO.

La magnitud de la retro-donación metal-a-CO es función del modo geométrico de adsorción del CO (adsorción lineal, adsorción tipo puente, di- 
carbonilo, tilted, etc), así como de la densidad de carga electrónica de los orbitales d externos del átomo metálico sobre el que se adsorbe la molécula [24]. Esta densidad electrónica de los orbitales d del átomo metálico depende de su estado de oxidación, su índice de coordinación metal-metal (es decir, de su posición específica en la superficie metálica), la presencia cercana de átomos más electronegativos o electrodonantes, etc. El análisis de las frecuencias de adsorción en el IR para el enlace C-O de moléculas de CO adsorbidas se emplea, muy ampliamente, para estudiar el estado de oxidación, la naturaleza de los planos cristalinos expuestos (que presentan diferentes modos de empaquetamiento para los átomos), los fenómenos de promoción química, o la topología superficial (densidad de defectos de baja coordinación metal-metal como esquinas, vértices, huecos, etc) de nanopartículas metálicas. Algunos de los casos de adsorción posibles, que dan lugar a diferentes frecuencias para las señales de IR asociadas con el CO adsorbido, se esquematizan en la Fig.2.2. Además de la naturaleza del sitio metálico y el modo de adsorción, la frecuencia de IR para la molécula de CO adsorbida depende de interacciones dipolo-dipolo con otras moléculas adsorbidas sobre sitios vecinos, y por lo tanto, el nivel de "recubrimiento" de la superficie metálica es otra variable a considerar a la hora de emplear esta técnica. 


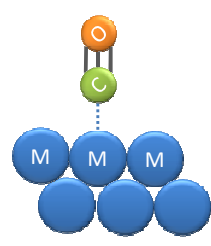

a)

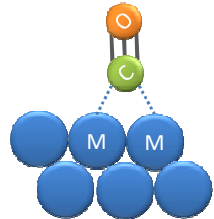

c)

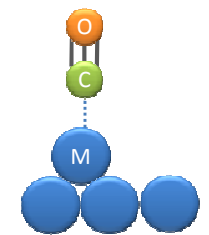

b)

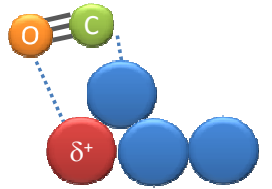

d)

Figura 2.2: Representación esquemática de diferentes modos de adsorción de CO sobre centros metálicos que dan lugar a señales de FTIR a diferentes frecuencias: (a) adsorción lineal sobre un centro metálico en terraza, (b) adsorción lineal sobre un centro metálico de baja coordinación (defecto superficial), (c) adsorción de CO en geometría puenteada (bridged) sobre centros metálicos en terraza, (d) adsorción tipo "inclinado" (tilted) sobre un centro metálico en la vecindad de un átomo electronegativo que coordina al extremo oxígeno de la molécula de CO.

En el caso de la conversión catalítica de gas de síntesis, el monóxido de carbono empleado como sonda es, a su vez, el reactivo principal. Esto permite emplear esta técnica analítica para estudiar la superficie metálica del catalizador mientras la reacción tiene lugar (los términos "at work" y "operando" son los más comúnmente empleados para referirse a la caracterización durante la catálisis). En este caso, la técnica de CO-FTIR adquiere una mayor relevancia, puesto que permite obtener información acerca de las interacciones catalizador-reactivo durante los eventos catalíticos, así como acerca de las modificaciones que pueda sufrir la superficie del catalizador en el transcurso de la reacción catalítica.

La naturaleza de los centros metálicos superficiales en los catalizadores reducidos se estudió por CO-FTIR en un espectrómetro Bio-Rad FTS-40A empleando una celda de cuarzo con ventanas de KRS-5 que permite trabajar en condiciones de flujo y que puede acoplarse a un horno eléctrico para trabajar a temperaturas de hasta $500^{\circ} \mathrm{C}$. 
Las muestras de los catalizadores en polvo se conformaron en forma de pastillas auto-soportadas $\left(5-10 \mathrm{mg} / \mathrm{cm}^{2}\right)$. En algunos casos los catalizadores se redujeron en flujo de $\mathrm{H}_{2}$ y se pasivaron en atmósfera de $<1 \% \mathrm{O}_{2} / \mathrm{N}_{2}$ ex situ $\mathrm{y}$, posteriormente se sometieron a un tratamiento de reducción adicional en flujo de $\mathrm{H}_{2}$ en la celda. En otros casos, se llevó a cabo un único tratamiento de reducción en flujo de $\mathrm{H}_{2}$ in situ en la celda, empleando las muestras en su forma calcinada o seca original. Tras el tratamiento de reducción en la celda, las muestras se evacuaron $\left(10^{-5} \mathrm{mbar}\right)$ a una temperatura 50 ㅇ C superior a la empleada durante la reducción con el objetivo de retirar completamente las especies de $\mathrm{H}_{2}$ adsorbidas sobre la superficie metálica del catalizador reducido. El enfriamiento de la muestra hasta temperatura ambiente se realizó en vacío.

En un conjunto de experimentos destinados a evaluar la naturaleza de los centros metálicos en los catalizadores reducidos, se introdujeron en la celda pulsos consecutivos de CO $(99.97 \%$, Linde) a temperatura ambiente $\left(P_{\mathrm{CO}}=5-250\right.$ mbar) en el caso de los catalizadores de $\mathrm{Co}, \mathrm{O}-175{ }^{\circ} \mathrm{C}\left(\mathrm{P}_{\mathrm{CO}}=3-25\right.$ mbar) en el caso de los catalizadores de Rh, registrando el espectro de IR tras cada uno de los pulsos. En determinados casos, para los catalizadores de Co, la muestra se evacuó a temperatura ambiente y se repitieron las dosis crecientes de CO registrando, de nuevo, el espectro tras cada una de las dosis, para estudiar los efectos reestructurantes del CO sobre la superficie metálica.

En un segundo tipo de experimentos, las muestras reducidas y evacuadas se estudiaron mediante CO-FTIR en condiciones de reacción a presión atmosférica. En este caso la pastilla de catalizador, tras la reducción y la evacuación, se expuso a un flujo de gas de síntesis (Ar:CO: $\mathrm{H}_{2}$ de 10:30:60 en el caso de la SFT y 10:45:45 en el caso de la SSO) en la celda. Este flujo se mantuvo durante $1 \mathrm{~h}$ a temperatura ambiente para asegurar homogeneidad 
en todo el volumen de la celda. Posteriormente, la temperatura de la muestra se incrementó progresivamente desde temperatura ambiente hasta la temperatura de reacción $\left(220^{\circ} \mathrm{C}\right.$ en el caso de la SFT y $280^{\circ} \mathrm{C}$ en el caso de la SSO), registrando el espectro de FTIR a cada temperatura y tras diferentes tiempos de reacción (TOS) a la temperatura final del experimento. Tras $3 \mathrm{~h}$ en condiciones de reacción, la muestra se sometió a una evacuación progresiva registrando los correspondientes espectros FTIR de evacuación, para conocer la estabilidad relativa de las diferentes especies adsorbidas sobre el catalizador.

\subsection{Ensayos catalíticos.}

\subsubsection{Sistema de reacción.}

Los ensayos catalíticos se llevaron a cabo en un reactor continuo de lecho fijo, diseñado y construido en el Instituto de Tecnología Química [29]. En la Figura 2.3 se muestra un esquema simplificado del reactor y del resto de elementos del sistema reacción. La característica más destacable del reactor es su sistema de control de temperaturas de dos puntos, que permite llevar a cabo la reacción de conversión de gas de síntesis en ausencia de gradientes longitudinales de temperatura, a pesar de la fuerte exotermicidad de la reacción. 


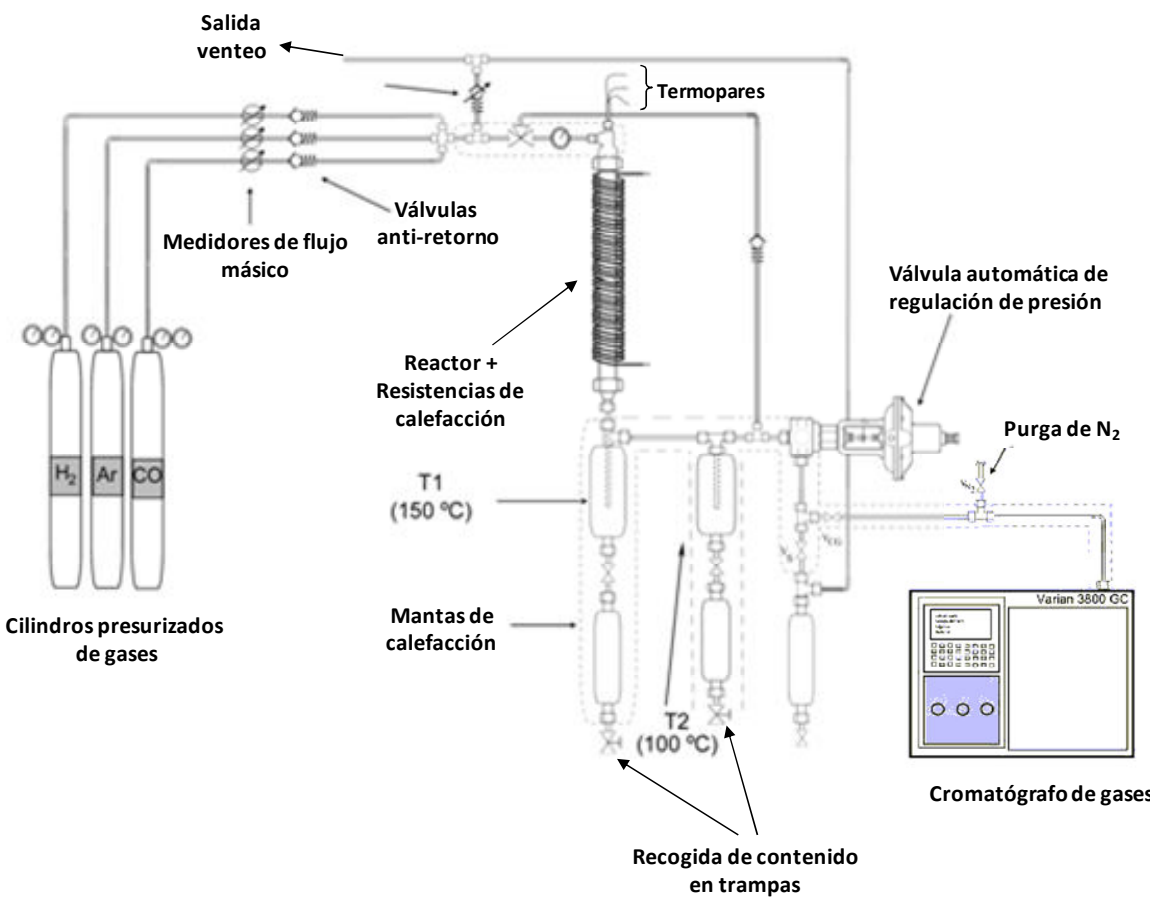

Figura 2.3: Esquema simplificado del sistema de reacción empleado para los experimentos catalíticos, [29].

El sistema de reacción puede dividirse en tres partes: alimentación, reacción y análisis de productos, que a continuación se describen de manera más detallada.

La zona de alimentación consta de tres caudalímetros másicos para gases $\left(\mathrm{H}_{2}, \mathrm{CO}\right.$ y $\left.\mathrm{Ar}\right)$, con tres válvulas anti-retorno aguas-abajo de los mismos, un manómetro hidráulico, una llave de tres vías y una válvula de seguridad conectada con una salida de venteo. Los gases se suministran mediante cilindros de alta presión (Abelló-Linde) conectados directamente con los caudalímetros. El calibrado de los caudalímetros se llevó a cabo a presión atmosférica (aguas-abajo de los mismos) y a temperatura ambiente, empleando un burbujeador calibrado que permite obtener una medida de la velocidad de desplazamiento lineal de burbujas generadas por el paso del 
gas a través de una columna de agua conteniendo un surfactante. Durante el calibrado, la presión aguas-arriba de los caudalímetros se mantuvo en 1.0 $M P a$, de modo que esta diferencia de presión $(\Delta P)$ entre los dos extremos de los caudalímetros se mantuvo, posteriormente, en las condiciones de trabajo de los mismos, es decir, cuando el reactor se encuentra presurizado. La respuesta de los caudalímetros es lineal en todo el rango de caudales empleado para llevar a cabo su calibrado.

Durante los experimentos de síntesis selectiva de compuestos oxigenados, en esta zona de alimentación se instaló un filtro comercial para carbonilos metálicos (Nanochem Purifilter MTX de Matheson Trigas) que permite trabajar a elevada presión (hasta 7.0 MPa). El filtro se instaló justo aguas-arriba del reactor catalítico. La retención de los carbonilos metálicos (Fe y $\mathrm{Ni}$ ), que pueden formarse por reacción de CO con el acero de los cilindros presurizados en los que se almacenan los gases, es crucial a la hora de obtener resultados reproducibles en la reacción y asegurar la estabilidad catalítica de los catalizadores de Rh [30].

La zona de reacción consta, por un lado, del reactor de lecho fijo tubular de $10.3 \mathrm{~mm}$ de diámetro interno, fabricado en acero $310 \mathrm{y}$, por otro lado, de una línea de by-pass que permite desviar los gases alimentados evitando que circulen por el reactor. El reactor se calienta mediante dos resistencias de $400 \mathrm{~W}$ de potencia, controladas de forma independiente mediante sendos dispositivos electrónicos (Philips KS4O) con ajuste PID. La línea de by-pass está conectada directamente con la válvula de regulación de presión (Badger-Meter). En el interior del reactor se encuentra una vaina para termopares, fabricada en acero 316, de $3 \mathrm{~mm}$ de diámetro externo, que recorre el reactor longitudinalmente a lo largo de su eje central. En su interior se colocan tres termopares tipo K (aleación Inconel ${ }^{\circledR} 600$, diámetro $0.05 \mathrm{~mm}$ ) de forma que el extremo de medida de los mismos se encuentra 
equidistante a lo largo de toda la longitud del lecho catalítico. Los termopares superior e inferior corresponden con el punto de medida de los sistemas de control PID asociados con las resistencias calefactoras superior e inferior, respectivamente. Por el contrario, el termopar central no se encuentra incorporado en ningún bucle de control y se utiliza como sonda móvil para registrar el perfil longitudinal de temperatura a lo largo del lecho catalítico en cualquier momento de la operación.

Por último, la zona de análisis de los productos de reacción comprende, en primer lugar, dos trampas para productos pesados y un filtro de partículas sólidas (Swagelok SS-4F-7, $7 \mu \mathrm{m}$ ) que se encuentran aguasabajo del reactor, en la región del equipo que se mantiene presurizada durante los experimentos. Las trampas, denominadas "trampa 1" y "trampa 2 " (ver Fig. 2.3), se mantienen a una temperatura de $150 \circ \mathrm{C}$ y $100 \circ \mathrm{C}$, respectivamente. Seguidamente, en el sentido de la línea de flujo, se encuentra la válvula neumática de regulación de presión, una línea que conecta el sistema reactivo con el equipo de cromatografía de gases, el cromatógrafo de gases y, por último, una línea a venteo. Con el fin de evitar la condensación de cualquier producto, la línea que conecta el reactor con el cromatógrafo se mantiene calefactada a $200^{\circ} \mathrm{C}$. A su vez, se dispone de una línea auxiliar de $\mathrm{N}_{2}$ de baja presión que se emplea para purgar la línea que conecta la válvula de regulación de presión del sistema reactivo con el cromatógrafo de gases, entre dos análisis consecutivos, con el fin de asegurar la retirada de cualquier depósito que haya podido generarse a partir de los productos de menor volatilidad que se analizan en línea.

En términos de seguridad, el sistema de reacción completo se encuentra en el interior de un armario que cuenta con un potente sistema de extracción. Por otro lado, el laboratorio cuenta con un detector de CO fijo 
(Drager Regard-1) de una sensibilidad de $1 \mathrm{ppm}$ y un sensor de CO personal (Drager Micropac St-Ds) con una sensibilidad de 5 ppm.

\subsubsection{Procedimiento experimental en los ensayos catalíticos.}

\subsubsection{Síntesis de Fischer-Tropsch.}

a) Carga del reactor.

Los experimentos de la síntesis de Fischer-Tropsch se llevaron a cabo utilizando 1.0-1.5 g de catalizador en el tamaño granulométrico de 0.25-0.40 $\mathrm{mm}$, diluido con gránulos de SiC (Carlo Erba) en la granulometría 0.60-0.80 $\mathrm{mm}$ hasta un volumen total de lecho de $6.4 \mathrm{~cm}^{3}$. El lecho catalítico descansa sobre un fondo de lecho formado por lana de cuarzo compactada de $1 \mathrm{~cm}$ de espesor. Con el fin de asegurar la homogeneidad del lecho catalítico y evitar diferencias en la concentración volumétrica local de catalizador a lo largo del mismo, que pueden ser fuente de puntos calientes en las regiones con mayor relación local catalizador/SiC debido a la exotermicidad de la reacción de hidrogenación de $\mathrm{CO}$, la carga del lecho se llevó a cabo en tres etapas alícuotas conteniendo idénticas masas de catalizador y SiC.

Una vez sellado el reactor, se somete a un test de estanqueidad durante 1 hora, alimentando Ar hasta una presión total 1.5 MPa superior a la presión de trabajo durante el experimento catalítico.

b) Tratamientos de activación y arranque del experimento catalítico.

El catalizador se redujo in situ en flujo de $\mathrm{H}_{2}\left(200 \mathrm{~cm}^{3} / \mathrm{min} \cdot \mathrm{g}_{\text {cat }}\right)$ a una temperatura de $400-450^{\circ} \mathrm{C}$ (rampa térmica de 1 으 $\mathrm{C} / \mathrm{min}$ ) durante 10 horas, a presión atmosférica. Posteriormente, el reactor se dejó enfriar hasta 100 드 en flujo de $\mathrm{H}_{2}$, se introdujo en el reactor un flujo de la mezcla de gases de reacción (CO: $\mathrm{H}_{2}: \mathrm{Ar}$ con una relación volumétrica de 3:6:1) y la presión se incrementó lentamente hasta $2.0 \mathrm{MPa}$. Finalmente, la temperatura del

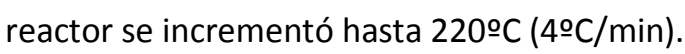




\section{c) Ensayo catalítico.}

Se tomó como tiempo inicial de reacción el momento en que se alcanzó la temperatura final del experimento. Durante los primeros minutos en las condiciones de reacción se registró el perfil de temperatura en el lecho catalítico. En aquellos experimentos en los que se detectó la presencia de regiones cuya temperatura se desviaba más de dos grados de la temperatura de reacción, se modificó ligeramente la posición longitudinal de las resistencias calefactoras hasta conseguir un perfil térmico para la totalidad de la longitud del lecho catalítico donde $T=220 \pm 2{ }^{\circ} \mathrm{C}$, que en los casos más complicados se logró siempre durante los primeros 15 minutos de experimento catalítico, esto es, mucho antes de realizar el primer análisis cromatográfico.

En las condiciones de reacción empleadas, se produce un descenso de la actividad catalítica (acompañado por cambios sensibles en el patrón de selectividades) durante unas 5-6 horas, típicamente. Tras este periodo transitorio inicial, se alcanza un estado pseudo-estacionario durante el cual las variaciones de actividad y selectividad son mucho menos acusadas (sección 5.3.3.1). De manera general, en todos los experimentos catalíticos de síntesis de Fischer-Tropsch se aplica una velocidad espacial (GHSV, Gas Hourly Space Velocity) constante durante las primeras 8 horas de reacción. Tras este tiempo, el reactor permanece presurizado, a 100 ㅇ $\mathrm{C}$ y en flujo de $10 \% \mathrm{H}_{2} /$ Ar hasta la siguiente jornada. Durante el segundo día de experimento catalítico, la velocidad espacial se ajusta para alcanzar una determinada conversión de CO y poder así establecer comparaciones entre los comportamientos catalíticos de diferentes catalizadores a niveles de isoconversión, puesto que se conoce que el nivel de conversión es un parámetro muy influyente en el patrón de selectividad de la síntesis. 
En determinados experimentos en los que se persigue mantener unas condiciones de conversión diferencial, la velocidad espacial se fijó en valores que mantienen la conversión de $\mathrm{CO}<10 \%$ en el estado pseudo-estacionario.

Aproximadamente cada hora durante el experimento de reacción, la corriente de gases que sale del sistema catalítico se desvía hacia el CG para realizar los análisis en línea. En el caso de los productos recogidos en las dos trampas de alta presión, su extracción se hizo, de forma general, dos veces a lo largo de toda la jornada, es decir, cada 4 horas de reacción aproximadamente. Los productos recogidos en las trampas son, de manera general, sólidos en el caso de la trampa 1 y líquidos para la trampa 2, y se almacenaron en viales cerrados y bajo refrigeración.

d) Análisis e identificación de productos.

Para el análisis de los productos de reacción se empleó un cromatógrafo de gases Varian 3800, que cuenta con un sistema de 3 columnas empaquetadas, una columna capilar y dos detectores: detector de conductividad térmica (TCD, Thermal Conductivity Detector) y detector de ionización en llama (FID, Flame lonization Detector).

El sistema de columnas empaquetadas (tamiz molecular 13X y dos columnas Porapak HysepQ), conectadas con el detector TCD, permite separar y cuantificar los gases permanentes, es decir, $\mathrm{CO}, \mathrm{CO}_{2}, \mathrm{Ar}, \mathrm{CH}_{4}, \mathrm{C}_{2} \mathrm{H}_{6}$, $\mathrm{C}_{2} \mathrm{H}_{4}, \mathrm{C}_{3} \mathrm{H}_{8}, \mathrm{C}_{3} \mathrm{H}_{6}$, así como $\mathrm{H}_{2} \mathrm{O}$.

La columna capilar (WCOT Fused silica, $25 \mathrm{~m}$ ) conectada al detector FID permite analizar hidrocarburos desde $C_{1}$ hasta $C_{20}$, discriminando entre n-parafinas, $\alpha$-olefinas, olefinas lineales internas, alcoholes $y$ otros compuestos oxigenados, isoparafinas e isoolefinas (éstas últimas tan sólo en 
el rango $\mathrm{C}_{4}-\mathrm{C}_{6}$ ). Todos estos productos han sido previamente identificados mediante el análisis de patrones comerciales (Supelco Park, Aldrich).

Los productos analizados en línea con el sistema de reacción se inyectaron directamente en forma de gas mediante sendos loops de inyección en los canales de los detectores TCD y FID. Los parámetros principales del programa empleado para la separación se resumen en la Tabla 2.4:

Tabla 2.4: Características del programa empleado en el CG para la separación de los productos de reacción

\begin{tabular}{cc}
\hline \multicolumn{2}{c}{ Canal FID } \\
\hline Caudal gas portador (He) & $30 \mathrm{~mL} / \mathrm{min}$ \\
\hline Relación de Split en injector & 30 (2 minutos iniciales), \\
& 2 (resto de análisis) \\
\hline \multicolumn{2}{c}{ Canal TCD } \\
\hline Caudal de gas portador (He) & $40 \mathrm{~mL} / \mathrm{min}$ \\
\hline \multicolumn{2}{c}{ Horno de columnas } \\
\hline \multicolumn{3}{c}{$\mathrm{T}=35 \circ \mathrm{O}, \mathrm{t}=17 \mathrm{~min}$} \\
Programa térmico & Rampa $\left(\mathrm{T} 35^{\circ} \mathrm{C} \rightarrow 250^{\circ} \mathrm{C}\right), 10^{\circ} \mathrm{C} / \mathrm{min}$ \\
& $\mathrm{T}=200^{\circ} \mathrm{C}, \mathrm{t}=12.5 \mathrm{~min}$ \\
\hline
\end{tabular}

Por su parte, antes de su análisis cromatográfico, las muestras de los productos líquidos y sólidos recogidos en las trampas durante los experimentos se trataron como sigue:

Las muestras recogidas en la trampa 1 consisten principalmente en ceras sólidas, las cuales se disolvieron en $\mathrm{CS}_{2}$ (aprox. $40 \mathrm{mg} / \mathrm{mL}$ ) antes de inyectarse manualmente $1 \mu \mathrm{L}$ de la disolución resultante en el inyector del canal FID del cromatógrafo.

Las muestras recogidas en la trampa 2 consisten en dos fases líquidas, una acuosa y otra orgánica que contiene hidrocarburos líquidos con alcoholes de cadena corta disueltos (responsables de una cierta turbidez 
para esta fase). Las fases se separaron por decantación en una pipeta Pasteur, de modo que tan sólo la masa de la fase orgánica se empleó en la contabilización de productos para el balance de materia de carbono. Una alícuota de la fase orgánica se diluyó en $\mathrm{CS}_{2}$ y se inyectó en el $\mathrm{CG}$ como se indicó anteriormente.

Las Figuras 2.4 y 2.5 muestran cromatogramas representativos para un análisis en línea en los canales del TCD y del FID, respectivamente. Por su parte, las Figuras 2.6 y 2.7 muestran cromatogramas representativos para un análisis de los productos recogidos en la trampa 1 y la trampa 2, respectivamente.

Como se observa en estas figuras, el análisis en línea detecta hidrocarburos en el rango $C_{1}-C_{20}$, mientras que los análisis de las trampas 1 y 2 contienen típicamente hidrocarburos en los rangos $C_{6}-C_{30}$ y $C_{8}-C_{50}$, respectivamente. 


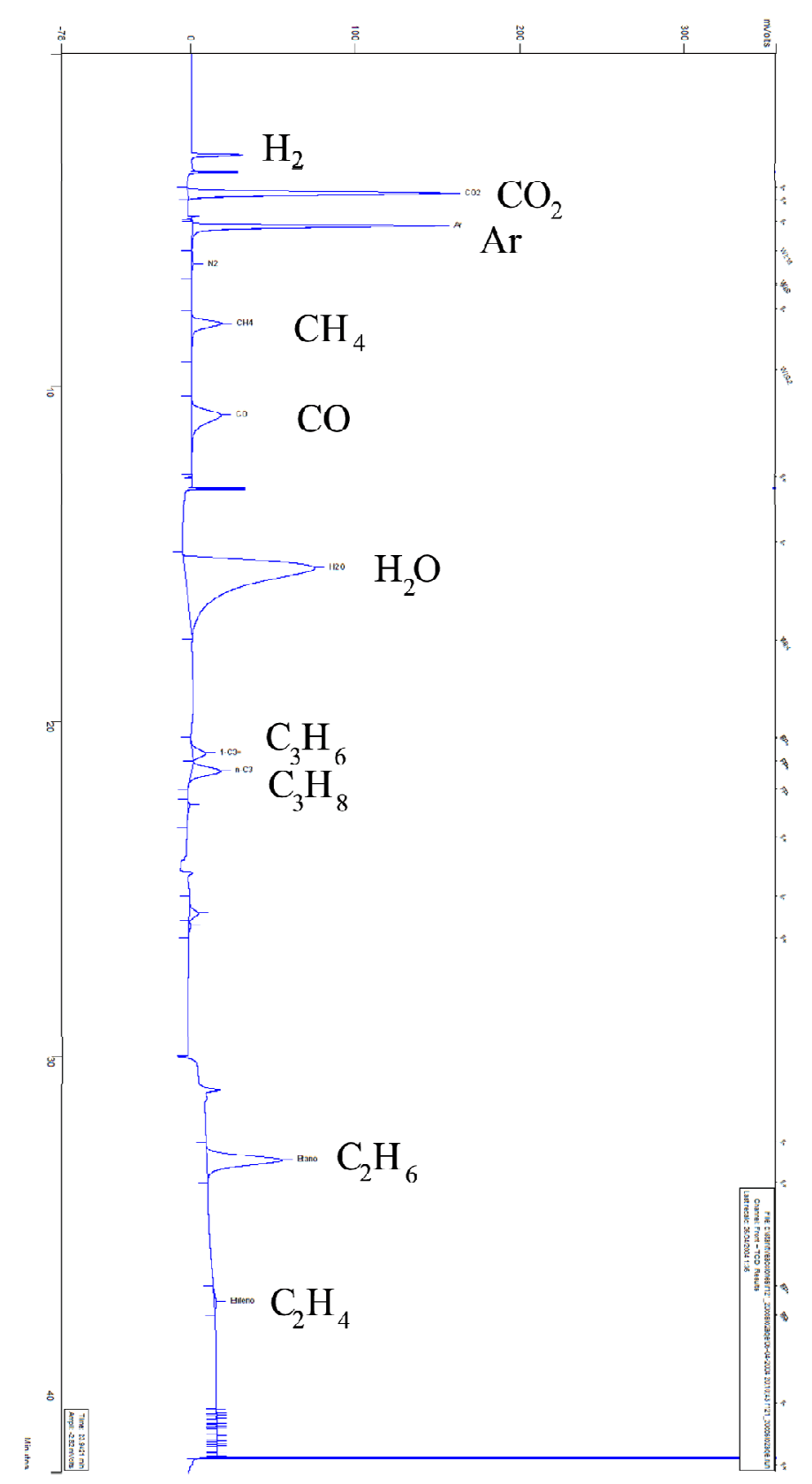

Figura 2.4: Cromatograma representativo de un análisis de los productos en línea en el canal del detector TCD. 


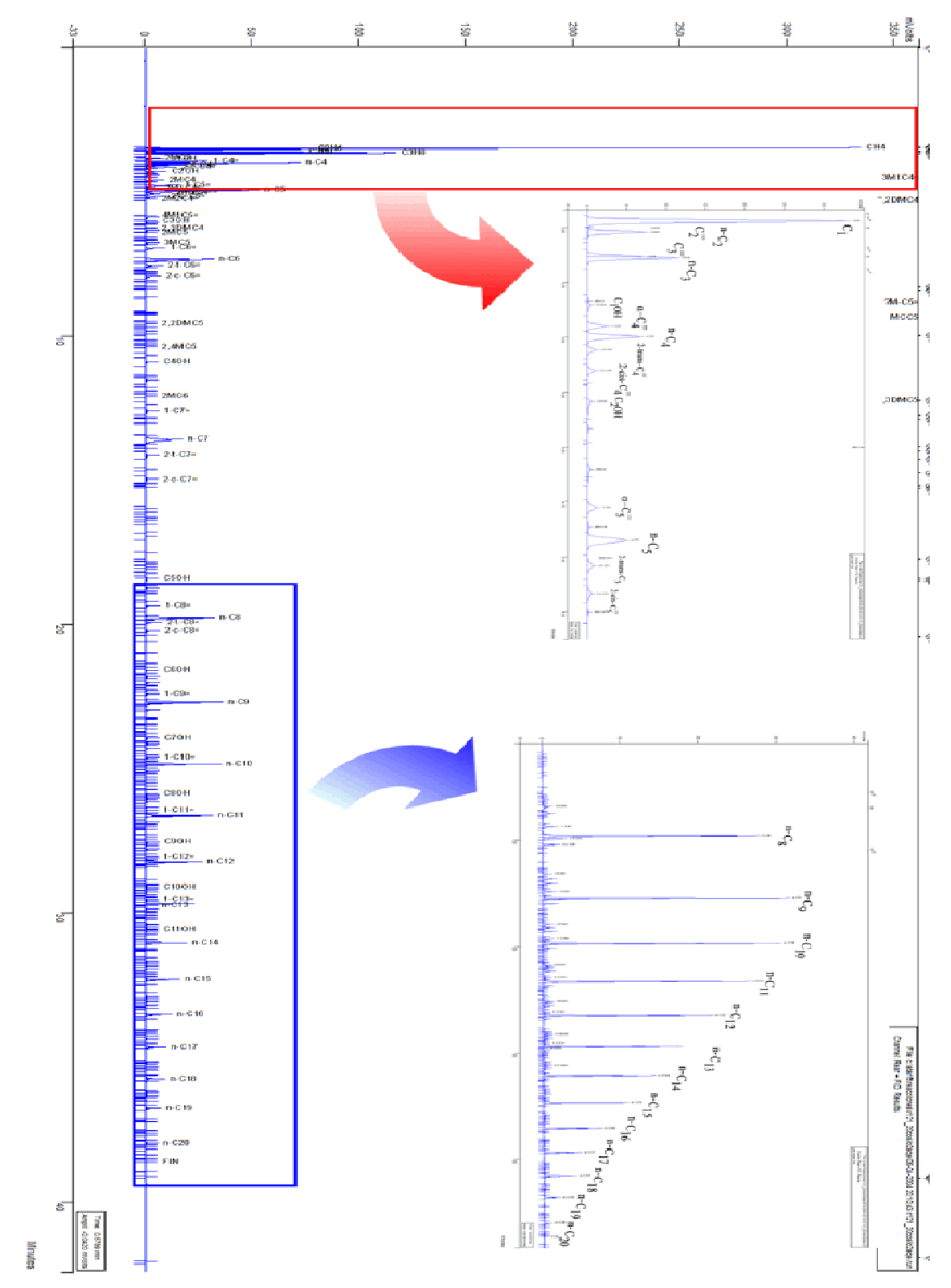

Figura 2.5: Cromatograma representativo de un análisis de los productos en línea en el canal del detector FID. 


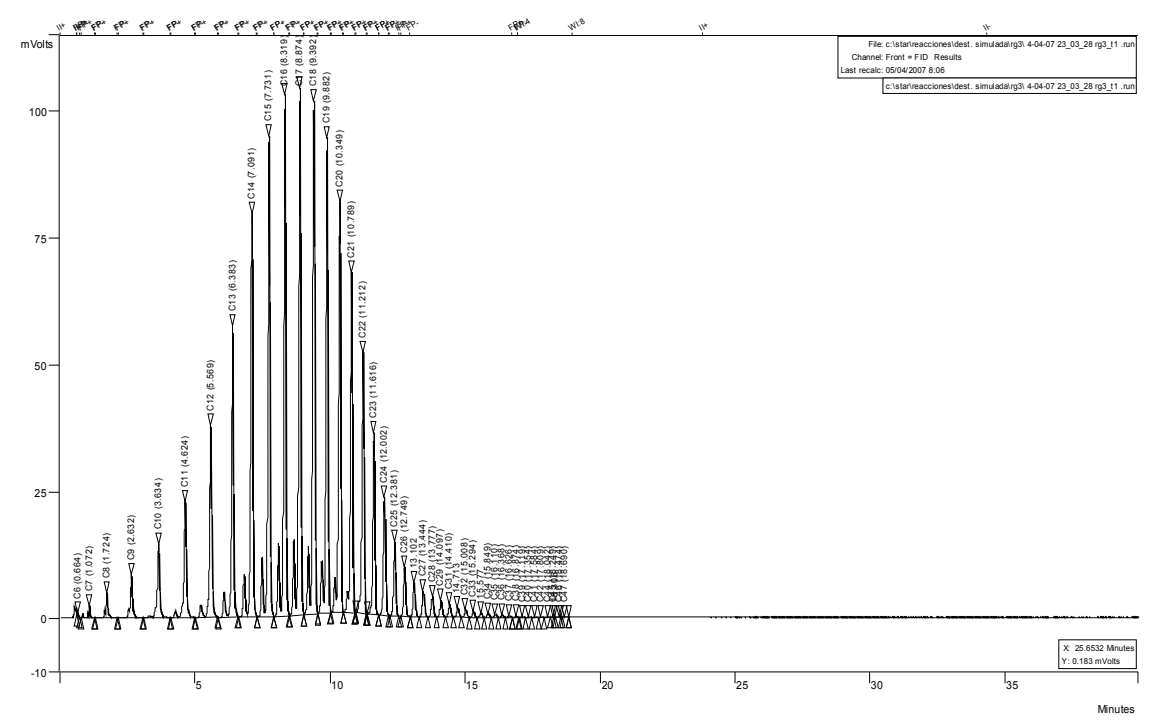

Figura 2.6: Cromatograma representativo de un análisis de los productos recogidos en trampa 1.

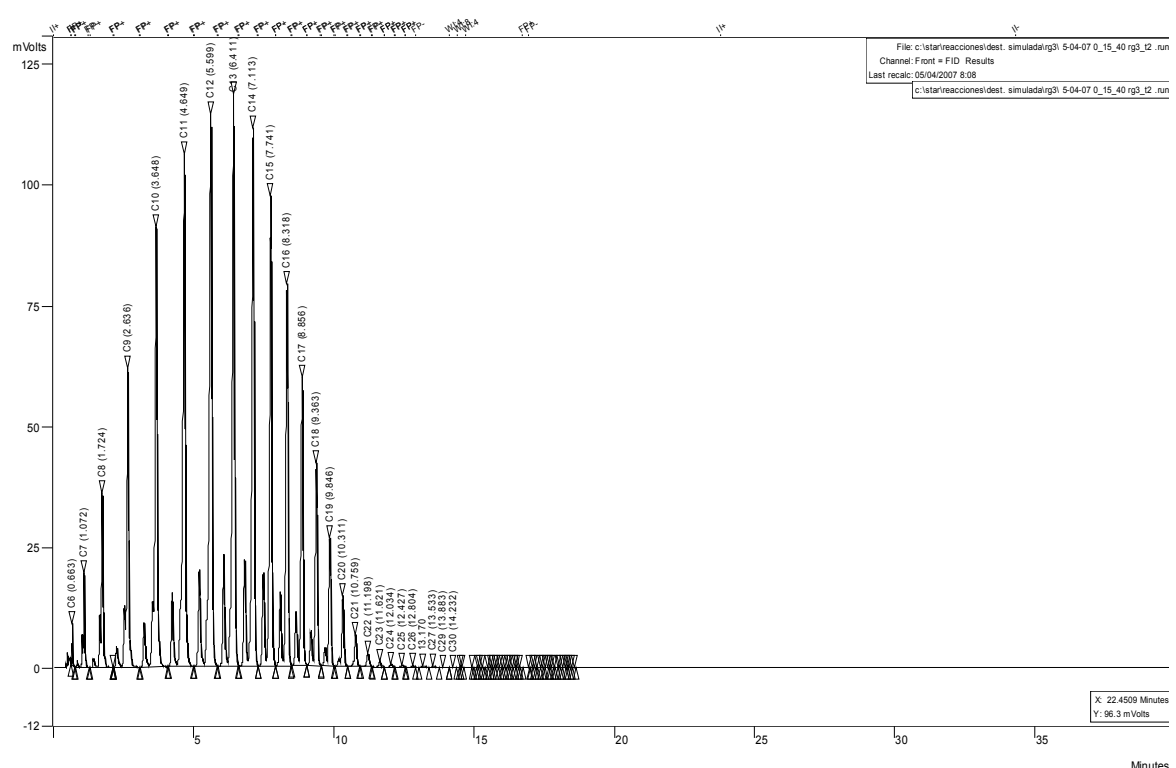

Figura 2.7: Cromatograma representativo de un análisis de los productos en recogidos en trampa 2. 


\subsubsection{Sintesis selectiva de compuestos oxigenados.}

\section{a) Carga del reactor}

Los experimentos de la síntesis de oxigenados se llevaron a cabo empleando 1.0-1.5 g de catalizador en el tamaño granulométrico de 0.25$0.40 \mathrm{~mm}$, diluido con gránulos de SiC (Carlo Erba) en la granulometría 0.60$0.80 \mathrm{~mm}$ hasta un volumen total de lecho de $6.4 \mathrm{~cm}^{3}$. La carga del reactor se llevó a cabo siguiendo el mismo procedimiento experimental que para los experimentos de la SFT (sección 2.3.2.1.).

b) Tratamientos de activación y arranque del experimento catalítico.

El catalizador se redujo in situ en flujo de $\mathrm{H}_{2}\left(130 \mathrm{~cm}^{3} / \mathrm{min} \cdot \mathrm{g}_{\text {cat }}\right)$ a una temperatura de $300^{\circ} \mathrm{C}$ (rampa térmica de $1 \stackrel{\circ}{ } \mathrm{C} / \mathrm{min}$ ) durante 10 horas, a presión atmosférica. Posteriormente, el reactor se dejó enfriar hasta 100 드 en flujo de $\mathrm{H}_{2}$, se introdujo en el reactor un flujo de la mezcla de gases de reacción (CO: $\mathrm{H}_{2}: \mathrm{Ar}$ con una relación volumétrica de 4.5:4.5:1) y la presión se incrementó lentamente hasta $5.0 \mathrm{MPa}$. Finalmente, la temperatura del reactor se incrementó hasta $280^{\circ} \mathrm{C}\left(4^{\circ} \mathrm{C} / \mathrm{min}\right)$.

\section{c) Ensayo catalítico.}

Se tomó como tiempo inicial de reacción el momento en que se alcanzó la temperatura final del experimento $\left(280^{\circ} \mathrm{C}\right)$.

De manera general, en todos los experimentos catalíticos de síntesis de oxigenados se aplica una velocidad espacial (GHSV, Gas Hourly Space Velocity) de $2.8 \mathrm{~L}\left(\mathrm{CO}+\mathrm{H}_{2}\right) / \mathrm{g}_{\text {cat }} \cdot \mathrm{h}$ durante las primeras 8 horas de reacción. Tras este tiempo, el reactor permanece presurizado, a 100 으 y en flujo de $\mathrm{N}_{2}$ hasta la siguiente jornada. Durante el segundo día de experimento catalítico, la velocidad espacial se ajusta para alcanzar una conversión de CO de $<15 \%$ y así establecer comparaciones entre las selectividades catalíticas a niveles de conversión quasi-diferencial. 
Aproximadamente cada 1-2 horas durante el experimento de reacción, la corriente de gases que sale del sistema catalítico se desvía hacia el CG para realizar los análisis en línea. En estos experimentos no se retiene ningún producto de reacción en las trampas de alta presión del equipo, las cuales se mantienen a $150^{\circ} \mathrm{C}$, al igual que el resto de líneas de flujo aguasabajo del reactor catalítico.

d) Análisis e identificación de productos.

Para el análisis de los productos de reacción se emplearon el mismo cromatógrafo de gases y el programa térmico descritos en la sección 2.3.2.1. para los experimentos de SFT.

Los productos analizados en línea con el sistema de reacción se inyectaron directamente en forma de gas, mediante sendos loops de inyección, en los canales de los detectores TCD y FID.

\subsubsection{Resistencias difusionales.}

En un proceso catalítico heterogéneo gas-solido se establecen una serie de etapas conectadas en serie que dan lugar, de forma global a la conversión de reactivos y la aparición de productos en la fase gaseosa. Estas etapas comprenden:

- la transferencia de materia desde la fase gas hasta la superficie externa de las partículas porosas de catalizador (difusión extra-partícula),

- la transferencia de materia desde la superficie externa de las partículas de catalizador hasta los centros activos presentes en el interior de la estructura porosa (difusión intra-partícula),

- los procesos de adsorción, activación, disociación, recombinación de átomos y desorción que tienen lugar sobre los 
centros activos, cuya secuencia y velocidad relativa depende en gran medida del mecanismo de reacción, y suelen englobarse en el concepto de "etapa de reacción superficial",

- la transferencia de masa intra-partícula para los productos de reacción desde los centros activos hasta la superficie externa de las partículas de catalizador. Durante esta etapa se pueden acoplar fenómenos de re-adsorción de productos sobre centros activos y su participación en nuevas etapas de reacción superficial,

- y, finalmente, la transferencia de materia desde la superficie de las partículas de catalizador hasta la fase gas externa.

Como en todo proceso constituido por la combinación de varias etapas en serie, la velocidad global será una combinación de las cinéticas de las etapas elementales. Si la cinética de una de estas etapas es mucho más lenta que las demás, ésta puede convertirse en "etapa cinética controlante", de modo que la velocidad del proceso global sea igual a la velocidad de esa etapa controlante.

La investigación en catálisis intenta establecer patrones de comportamiento catalítico de los materiales atendiendo a sus propiedades químicas superficiales, esto es, requiere que la velocidad global del proceso catalítico esté relacionada con etapas de reacción en superficie, y no esté controlada por fenómenos de transferencia de masa. En el caso de trabajar en condiciones de cinética controlada por fenómenos de transferencia difusional de materia, las variables medidas experimentalmente (velocidad de reacción, rendimiento, TOF, etc) no serán función de las propiedades específicas de los centros activos, dando lugar a una indeseada homogeneización aparente para las propiedades catalíticas de los materiales estudiados. 


\subsubsection{Difusión extra-partícula}

La etapa de difusión extra-partícula establece un perfil de concentración para los reactivos en una película alrededor de la superficie externa de las partículas de catalizador (Fig. 2.8).

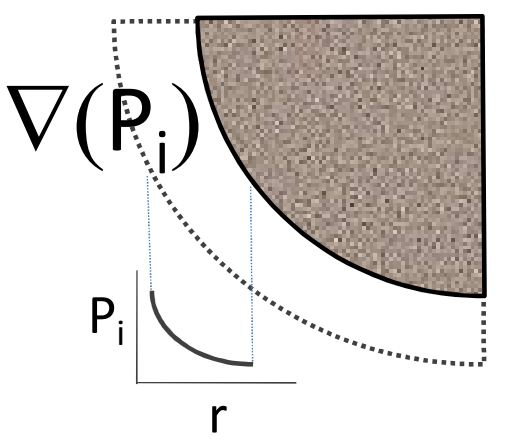

Figura 2.8: Representación esquemática de la formación de un perfil de concentración alrededor de las partículas de catalizador cuando la etapa de transferencia de materia extra-partícula presenta relevancia cinética.

El procedimiento experimental comúnmente empleado para poner de manifiesto el posible control de la etapa de difusión extra-partícula consiste en modificar el coeficiente de transferencia de materia entre la fase gas y la superficie de las partículas variando la hidrodinámica del sistema. Así, se llevan a cabo varios experimentos en los que se varía sistemáticamente la velocidad lineal de la fase gas en torno a las partículas de catalizador sin modificar el tiempo de contacto, es decir, manteniendo constante el cociente entre caudal de gas y masa de catalizador. En ausencia de control cinético por etapas de difusión extra-partícula, la modificación del coeficiente de transferencia de materia no conllevará modificación alguna de la cinética global del proceso catalítico y los experimentos han de mostrar la misma actividad catalítica.

En lo que respecta a la SFT, este tipo de experimentos se llevaron a cabo en un trabajo de tesis doctoral anterior [29] con el sistema catalítico 
empleado en el presente trabajo. Allí se evidenció que para el rango de caudales de reactivos que se emplea en los experimentos catalíticos, no existe relevancia cinética para la etapa de difusión extra-partícula.

Otra metodología aceptada para estudiar la influencia de la etapa de difusión extra-partícula en la cinética global de un proceso catalítico es la estimación de la energía de activación aparente para la reacción [31]. En caso de un control cinético por parte de la etapa de transferencia de materia por difusión extra-partícula, la energía de activación aparente suele ser $<10$ $15 \mathrm{~kJ} / \mathrm{mol}$. Al comienzo del presente trabajo se llevaron a cabo experimentos catalíticos de $\mathrm{SFT}$, con el catalizador $30 \mathrm{Co} / \mathrm{SiO}_{2}(\mathrm{mf})$ en los que se varió la temperatura de reacción en el rango $220-260$ ㅇ C a una presión total de 2.0 MPa. A su vez, se modificó el tiempo de contacto para mantener la conversión de CO en valores $\leq 15 \%$. La Fig. 2.9 muestra el gráfico de Arrhenius obtenido a partir de los valores de la frecuencia de turnover (TOF) a las distintas temperaturas de reacción.

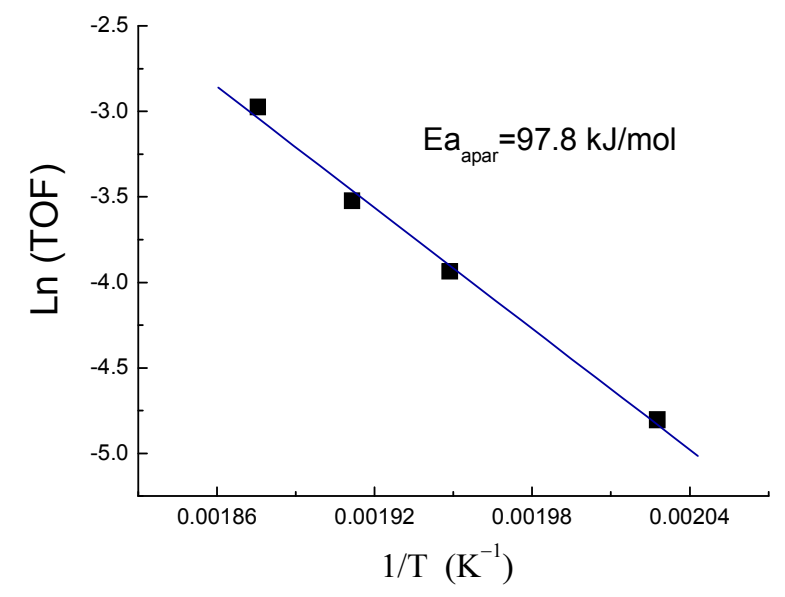

Figura 2.9: Diagrama de Arrhenius para el TOF obtenido en los experimentos catalíticos realizados con el catalizador $30 \mathrm{Co} / \mathrm{SiO}_{2}(\mathrm{mf})$ en el rango de temperaturas de $220-260^{\circ} \mathrm{C}$. 
La energía de activación aparente calculada es de $97.8 \mathrm{~kJ} / \mathrm{mol}$, lo que está de acuerdo con los valores en el rango de $94-105 \mathrm{~kJ} / \mathrm{mol}$, que se pueden encontrar en la bibliografía para la SFT catalizada por Co [32,33,34,35], y descarta un control cinético por parte de la etapa de difusión extra-partícula.

En el caso de la reacción de síntesis de oxigenados por conversión de gas de síntesis, la Fig. 2.10 muestra el diagrama de Arrhenius obtenido a partir de los valores de velocidad de formación de $\mathrm{CH}_{4}$ y etanol (principal producto oxigenado) en el rango de temperaturas de 280-320으, empleando el catalizador 2.5Rh/Sm@ $@ \mathrm{Al}_{2} \mathrm{O}_{3}$. La velocidad espacial se ajustó en cada experimento para obtener conversiones de $\mathrm{CO}$ en el rango de $15 \pm 3 \%$. Se observa que las energías de activación aparentes toman valores de 124.5 y $93.2 \mathrm{~kJ} / \mathrm{mol}$ para la formación de $\mathrm{CH}_{4}$ y etanol, respectivamente, lo que descarta que exista un control cinético por etapas de transferencia de materia extra-partícula en las condiciones de los ensayos catalíticos.

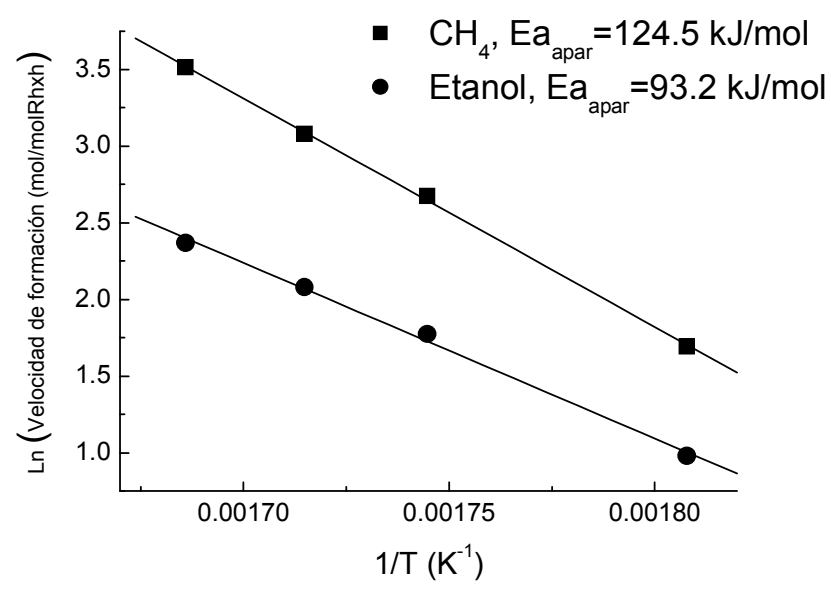

Figura 2.10: Diagrama de Arrhenius para las velocidades de formación de $\mathrm{CH}_{4}$ y etanol para los experimentos catalíticos realizados con el catalizador 2.5Rh/Sm@Al $\mathrm{O}_{3}$ en el rango de temperaturas de 280-320C. 


\subsubsection{Difusión intra-partícula.}

De manera común, los experimentos dirigidos a verificar la influencia de las etapas de transferencia de materia intra-partícula involucran modificar el tamaño de partícula macroscópica del catalizador (pellet) mientras se mantienen constantes el resto de parámetros de los ensayos catalíticos (tiempo de contacto, temperatura, etc).

Para la reacción de síntesis de oxigenados, la influencia de la transferencia de materia intra-partícula se estudió en dos experimentos catalíticos preliminares, empleando un catalizador $\mathrm{Rh}-\mathrm{Li}-\mathrm{Mn}-\mathrm{Fe} / \mathrm{SiO}_{2}$ suministrado por ABNT (Abengoa Bioenergía Nuevas Tecnologías S.A.) en la granulometría 0.40-0.60 mm. El primero de los experimentos se llevó a cabo con el catalizador en la forma en la que se recibió, mientras que para el segundo experimento el catalizador se molturó y se conformó en el tamaño de pellets empleado para todos los experimentos catalíticos incluidos en esta memoria (0.25-0.40 mm). Las velocidades de reacción en estado estacionario (12 horas de reacción) determinadas para ambos experimentos ( $\mathrm{T}=340$ 으, $\mathrm{P}=5.0 \mathrm{MPa}$ ) difieren tan sólo en un $7 \%$, lo que descarta un control cinético por etapas de difusión intra-partícula en los rangos de tamaño de pellet empleados en este trabajo.

Por su parte, en el caso de la síntesis de Fischer-Tropsch, se conoce, con especial detalle y rigor a partir de los trabajos del grupo dirigido por el Prof. Iglesia en Exxon Mobil (actual Exxon) [36,37,38], que cuando se emplea un tamaño de partícula de catalizador en el rango de los comúnmente empleados en reactores de lecho fijo, para mantener la pérdida de carga hidrodinámica en valores aceptables, es decir, $>0.2 \mathrm{~mm}$ a escala de laboratorio y $>1 \mathrm{~mm}$ a escala industrial, los procesos de difusión intrapartícula para reactivos (CO) y productos presentan necesariamente 
relevancia cinética en la síntesis de Fischer-Tropsch. En estos casos, tanto la velocidad de reacción global, como el patrón de selectividades de la síntesis, dependen de la cinética de estas etapas de transferencia de materia intrapartícula.

El hecho de que, en condiciones de reacción, un catalizador de síntesis de Fischer-Tropsch presenta sus poros llenos de hidrocarburos líquidos, es el aspecto distintivo que ralentiza los fenómenos difusionales en los poros y les confiere una relevancia cinética en el proceso catalítico global. Sie y colaboradores [39] simularon un gráfico de Thiele-Wheeler (factor de eficacia. vs. módulo de Thiele [40]) a partir de datos reales de la SFT catalizada por cobalto, encontrando que los fenómenos difusionales intrapartícula interfieren en la cinética global para tamaños de pellet $>0.5 \mathrm{~mm}$. El tamaño de pellet a partir del cual adquiere relevancia cinética la etapa de difusión intra-partícula para el CO es de tan sólo $0.15 \mathrm{~mm}$ según Wang y col. [41] y de 0.09-0.14 mm de acuerdo a los datos publicados por Iglesia y col. $[36,37]$ para catalizadores de Co y/o Ru.

El tamaño de pellet empleado en el reactor de lecho fijo con el que se realizaron los experimentos del presente trabajo $(0.25-0.40 \mathrm{~mm})$ hace esperar que las etapas de transferencia de materia intra-partícula muestren relevancia cinética en la SFT. Estos aspectos serán tratados exhaustivamente en el capítulo 5 en el que se diseñan las estructuras porosas de los soportes catalíticos con el fin de influir sobre la cinética de estas etapas difusionales intra-partícula.

\subsubsection{Cálculos y parámetros descriptores de las propiedades catalíticas.}

La interpretación cuantitativa de los resultados cromatográficos se hizo en base a la detección de Ar, como gas de referencia interna, en el detector TCD. Así, la conversión de CO para un análisis cromatográfico se 
calculó a partir de las áreas cromatográficas para CO y $\operatorname{Ar}$ (detector TCD) y las áreas cromatográficas para un análisis de los gases de alimentación en ausencia de catalizador:

$$
X_{C O}(\%)=\frac{\widetilde{W}_{C O}^{i n}-\widetilde{W}_{C O}^{\text {out }}}{\widetilde{W}_{C O}^{i n}} \cdot 100=\frac{\left[\frac{A_{C O}}{A_{A r}}\right]_{\text {Alim. }}-\left[\frac{A_{C O}}{A_{A r}}\right]_{\text {Análisis }}}{\left[\frac{A_{C O}}{A_{A r}}\right]_{\text {Alim. }}} \cdot 100
$$

donde $\mathrm{X}_{\mathrm{CO}}$ denota la conversión de $\mathrm{CO}, \widetilde{W}_{\mathrm{CO}}$ representa el caudal molar de CO a la entrada (in) y a la salida (out) del reactor, A corresponde al área bajo el pico cromatográfico de CO ó Ar y los subíndices "Alim." y "Análisis" corresponden a la corriente de alimentación (en ausencia de conversión catalítica) y a la corriente del análisis durante el experimento catalítico, respectivamente.

Para el cálculo del flujo molar de cada uno de los gases detectados en el canal del TCD, a la salida del reactor, se tomó como referencia el caudal molar de Ar introducido en la alimentación, de acuerdo a la ecuación 2.13 para un gas $i$, donde $i=\mathrm{CO}_{2}, \mathrm{CO}, \mathrm{CH}_{4}, \mathrm{C}_{2} \mathrm{H}_{4}, \mathrm{C}_{2} \mathrm{H}_{6}, \mathrm{C}_{3} \mathrm{H}_{6}, \mathrm{C}_{3} \mathrm{H}_{8}$ :

$$
\widetilde{W}_{i}^{\text {out }}=\left[\frac{A_{i} / A_{A r}}{f_{i(A r)}}\right]_{T C D} \cdot \widetilde{W}_{A r}^{i n}
$$

donde $f_{i(A r)}$ es el factor de respuesta cromatográfico molar, para el canal del TCD, del compuesto $i$ respecto del Ar.

El caudal molar de cada uno de los productos de reacción detectados en el canal del detector FID se calculó utilizando como base el caudal molar 
de $\mathrm{CH}_{4}$ determinado en el canal del detector TCD según la ecuación 2.13. En este caso, se empleó el cociente de áreas cromatográficas en el canal del FID, así como el factor de respuesta cromatográfico másico, para el canal del FID, del compuesto $i$ respecto del $\mathrm{CH}_{4}\left(\mathrm{f}_{\mathrm{i}(\mathrm{CH} 4)}\right)$ y los correspondientes pesos moleculares (PM) según la ecuación 2.14:

$$
\widetilde{W}_{i}^{\text {out }}=\left[\frac{A_{i} / A_{\mathrm{CH}_{4}}}{f_{i(\mathrm{CH})}}\right]_{T C D} \cdot \frac{P M_{\mathrm{CH}_{4}}}{P M_{i}} \cdot \widetilde{W}_{C H_{4}}^{\text {out }}
$$

Los factores de respuesta para los compuestos detectados en el TCD, relativos al $\mathrm{Ar}$, se obtuvieron experimentalmente inyectando muestras gaseosas desde cilindros presurizados conteniendo mezclas certificadas de los gases (Abelló-Linde). Todos los factores de respuesta empleados en el detector TCD se calcularon en base molar.

Por su parte, los factores de respuesta para los compuestos oxigenados detectados en el FID se obtuvieron experimentalmente inyectando muestras patrón líquidas que contienen los compuestos oxigenados (agrupados por similitud química) y n-heptano, preparadas por pesada empleando compuestos comerciales de pureza conocida (>97\%). La pesada se llevó a cabo bajo refrigerio con hielo y por orden de volatilidad, para minimizar el error debido a las pérdidas por evaporación durante la misma. La preparación de las mezclas patrón se realizó por triplicado, en tres proporciones relativas diferentes, de modo que los factores de respuesta respecto del $\mathrm{n}$-heptano se obtuvieron promediando los tres resultados experimentales $(\sigma<10 \%)$. Los factores de respuesta obtenidos respecto del $n$ heptano se convirtieron en factores de respuesta relativos al $\mathrm{CH}_{4}$ empleando el valor $f_{n \text {-heptano(CH4) }}$ recogido en la literatura para detectores FID [42]. En el 
caso de los hidrocarburos no oxigenados, se emplearon los factores de respuesta, relativos a $\mathrm{CH}_{4}$, recogidos en la literatura [42], siendo su valor $1 \pm 0.04$, en todos los casos. Todos los factores de respuesta empleados para el detector FID se calcularon en base másica.

La selectividad al producto $i$, en base molar de carbono, se calculó a partir de los caudales molares para cada uno de los productos $i$ a la salida del reactor y el número de átomos de carbono en la molécula del producto $i$ $\left(N(C)_{i}\right)$, de acuerdo con la ecuación 2.15:

$$
S_{i}(\%)=\left[\frac{\widetilde{W}_{i}^{\text {out }} \cdot N(C)_{i}}{\sum_{i}\left(\widetilde{W}_{i}^{\text {out }} \cdot N(C)_{i}\right)}\right] \cdot 100 \quad \text { (Ec. 2.15) }
$$

Para cada análisis el balance molar de carbono (B.C.) se calculó contabilizando los átomos de carbono que abandonan el reactor en forma de productos o CO no convertido, de acuerdo con los cálculos cromatográficos, y comparando este resultado con el flujo molar de carbono alimentado como CO en la mezcla de reactivos, de acuerdo con la ecuación 2.16:

$$
\text { B.C. }(\%)=\left[\frac{\sum_{i}\left(\widetilde{W}_{i}^{\text {out }} \cdot N(C)_{i}\right)}{\widetilde{W}_{C O}^{\text {in }}}\right] \cdot 100
$$

En los experimentos de la síntesis de Fischer-Tropsch en los que se recogió una parte de los productos en las trampas y se analizó por separado, los resultados del análisis se convirtieron en moles de cada producto $i$ simplemente promediando la masa total recogida por la fracción de área cromatográfica correspondiente al producto en cuestión (factor de respuesta en el canal del FID unitario para todos los hidrocarburos). Estos 
moles de cada producto $i$, recogidos en las trampas, se prorratearon entre los análisis en línea correspondientes al periodo del experimento reactivo empleado para acumular productos en las trampas, y finalmente se incorporaron a los balances de carbono para cada análisis, de modo que los balances de carbono para los diferentes análisis de un experimento de SFT en condiciones pseudo-estacionarias (segundo día de experimento) son de $100 \pm 2 \%$.

En el caso de la reacción de síntesis de compuestos oxigenados, todos los productos se analizan en línea y los balances de carbono alcanzan valores directamente del $100 \pm 2 \%$ en todos los casos.

En determinados casos la actividad catalítica se expresó como rendimiento temporal por masa de cobalto (CTY, Cobalt-time-yield) o por masa de rodio (RTY, Rhodium-time-yield). En estos casos, la actividad se relativiza a la masa de metal de la forma que se muestra en las ecuaciones 2.17 y 2.18 , respectivamente:

$$
C T Y\left(\mathrm{~mol} \mathrm{CO} / \mathrm{h} \cdot \mathrm{g}_{\mathrm{Co}}\right)=\frac{\widetilde{W}_{C O}^{\text {in }}(\mathrm{mol} / \mathrm{h}) \cdot X_{C O}(\%)}{M_{c a t}(\mathrm{~g}) \cdot x_{C o}(\%)}
$$

$$
R T Y\left(\mathrm{~mol} \mathrm{CO} / \mathrm{h} \cdot \mathrm{g}_{R h}\right)=\frac{\widetilde{W}_{C O}^{\text {in }}(\mathrm{mol} / \mathrm{h}) \cdot X_{C O}(\%)}{M_{c a t}(\mathrm{~g}) \cdot x_{R h}(\%)}
$$

donde $M_{\text {cat }}$ denota la masa de catalizador empleada en el experimento y $x_{\mathrm{Co}}$ y $x_{\mathrm{Rh}}$ representan la carga metálica de Co y $\mathrm{Rh}$, respectivamente, en el catalizador.

La actividad catalítica intrínseca expresada como frecuencia de renovación del sitio activo o "frecuencia de turnover" (Turnover frequency, 
TOF), en base al número total de átomos metálicos superficiales, se calculó como se muestra en las ecuaciones 2.19 y 2.20 para el caso particular de catalizadores de Co para la SFT:

$$
\begin{gathered}
\operatorname{TOF}\left(s^{-1}\right)=\frac{\text { Moléculas CO convert }}{\text { Átomos metálicos superficiales }} \\
\operatorname{TOF}\left(\mathrm{s}^{-1}\right)=\frac{C T Y\left(\mathrm{~mol} \mathrm{CO} / \mathrm{h} \cdot \mathrm{g}_{C o}\right)}{3600 \cdot \frac{\mathrm{D}(\%)}{100 \cdot P A_{C o}}}
\end{gathered}
$$

donde $D(\%)$ es la dispersión metálica, es decir, el porcentaje de átomos metálicos reducidos que ocupan posiciones superficiales.

De manera general, para el cálculo del TOF se emplea el valor de dispersión metálica (D) obtenido por quimisorción de $\mathrm{H}_{2}$. En determinados casos, con fines comparativos o por no disponer de datos de quimisorción de $\mathrm{H}_{2}$, se emplea la dispersión estimada a partir del tamaño de nanopartícula de $\mathrm{Co}^{0}$ obtenido mediante el análisis de XRD como se explicó en la sección 2.2.3. La ecuación 2.21 permite calcular la dispersión metálica desde $d\left(\mathrm{Co}^{\circ}\right) \times$ bajo la asunción de un modelo esférico para las nanopartículas.

$$
D(\%)=\frac{d\left(C o^{0}\right)}{6} \cdot \frac{\rho_{S, C o}}{\rho_{C o} \cdot N_{A} / P A_{C o}} \cdot 100
$$

La evaluación de parámetros descriptores de actividad como CTY (ó RTY) y TOF se llevó a cabo, de forma general, para dos momentos del ensayo catalítico: 
Tiempo inicial: se calculan las magnitudes al tiempo inicial con el fin de que no estén influidas por la cinética de las etapas de transferencia de materia intra-partícula (cuya cinética pasa a ser relevante cuando los poros del catalizador se llenan de hidrocarburos durante el transcurso de la SFT) ni por la desactivación del catalizador. Para el cálculo de los rendimientos o el TOF inicial se empleó la conversión de CO extrapolada a tiempo de reacción cero. Para la extrapolación se emplearon los datos de conversión para los primeros análisis ( $\mathrm{t}=0.3-3$ horas) ajustados mediante un polinomio $s p$-line.

Estado pseudo-estacionario: los rendimientos y el TOF se calculan a partir del valor de conversión de CO promediado para todos los análisis obtenidos durante el estado pseudo-estacionario del experimento, esto es, el segundo día de reacción. 


\section{Referencias}

\footnotetext{
${ }^{1}$ A. Corma, V. Fornés, S.B. Pergher, Th.L.M. Maesen, J.G. Buglass, Nature 396 (1998) 353.

${ }^{2}$ A. Corma, V. Fornés, S.B. Pergher, patentes EP 9605004 (1996) y WO 9717290, (1997)

${ }^{3}$ H.Y. Zhu, J.D. Riches, J.C. Barry, Chem. Mater. 14 (2002) 2086.
}

${ }^{4}$ ø. Borg, S. Eri, E.A. Blekkan, S. Storsæter, H. Wigum, E. Rytter, A. Holmen, J. Catal. 248 (2007) 89.

${ }^{5}$ P.F. Fulvio, S. Pikus, M. Jaroniec, J. Mater. Chem. 15 (2005) 5049.

${ }^{6}$ H. Zhang, J. Sun, D. Ma, G. Weinberg, D.S. Su, X. Bao, J. Phys. Chem. B 110 (2006) 25908.

${ }^{7}$ D. Zhao, Q. Huo, J. Feng, B.F. Chmelka, G.D. Stucky, J. Am. Chem. Soc. 120 (1998) 6024.

${ }^{8}$ J.R.A. Sietsma, H. Friedrich, A. Broersma, M. Versluijs-Helder, A.J. van Dillen, P.E. de Jongh, K.P. de Jong, J. Catal. 260 (2008) 227.

${ }^{9}$ B. D. Cullity Elements of X-Ray Diffraction. Ed. Addison-Wesley Inc. (1967).

${ }^{10}$ P. Scherrer, Göttinger Nachrichten Gesell., vol. 2 (1918) 98.

${ }^{11}$ D. Schanke, S. Vada, E.A. Blekkan, A.M. Hilmen, A. Hoff, A. Holmen, J. Catal. 156 (1995) 85.

${ }^{12}$ S. Brunauer, P.H. Emmett, E. Teller, J. Am. Chem. Soc. 60 (1938) 309.

${ }^{13}$ W.D. Harkins, G. Jura, J. Am. Chem. Soc. 66 (1944) 1366.

${ }^{14}$ E.P. Barrett, L.G. Joyner, P.P. Halenda, J. Am. Chem. Soc. 73 (1951) 373.

${ }^{15}$ E.W. Washburn. Phys. Rev. 17-3 (1921) 273.

${ }^{16}$ K.S.W. Sing, D.H. Everett, R.A.W. Haul, L. Moscou, R.A. Pierotti, J. Rouquérol, T. Siemieniewska, Pure. Appl. Chem. 57 (1985) 603.

${ }^{17}$ R.C. Reuel, C.H. Bartholomew, J. Catal. 85 (1984) 63.

${ }^{18}$ R.D. Jones, C.H. Bartholomew, Appl. Catal. 39 (1988) 77.

${ }^{19}$ F. Huber, Z. Yu, S. Lögdberg, M. Rønning, D. Chen, H. Venvik, A. Holmen, Catal. Lett. 110 (2006) 211.

${ }^{20}$ A. Lebouteiller, P. Courtine, J. Sol. Chem. 137 (1998) 94.

${ }^{21}$ E. Bordes-Richard, P. Courtine, "Optical basicity: a scale of acidity/basicity of solids and its application to oxidation catalysts” en Metal oxides: chemistry and applications, J.L.G. Fierro Ed., Marcel Dekker (2005).

${ }^{22}$ X. Zhao, X. Wang, H. Lin, Z. Wang, Physica B 392 (2007) 132.

23 J. Tauc, Amorphous and liquid semiconductors, Plenum Ed., Cambridge (1978).

${ }^{24}$ G. Blyholder, J. Phys. Chem. 68 (1964) 2772.

${ }^{25}$ L.E. Orgel, Inorg. Chem. 1 (1962) 25.

${ }^{26}$ C.J. Ballhausen, Organometallic Chemistry, H. Zeiss Ed., Reinhold Publ. Corp., New York (1960).

${ }^{27}$ F. Greuter, D. Heskett, E.W. Plummer, H.-J. Freund, Phys. Rev. B 27 (1983) 7117. 
${ }^{28}$ P.S. Bagus, K. Hermann, Phys. Rev. B 33 (1986) 2987.

${ }^{29}$ C. López, Sílices mesoporosas ordenadas y zeolitas deslaminadas como soportes para catalizadores de Co para la sintesis de Fischer-Tropsch, Tesis doctoral, Universidad Politécnica de Valencia- Instituto de Tecnología Química (UPV-CSIC) (2004).

${ }^{30}$ R. Burch, M.J. Hayes, J. Catal. 165 (1997) 249.

${ }^{31}$ I. Chorkendorff, J.W. Niemantsverdriet, Concepts of modern catalysis and kinetics, Ed. Wiley VCH. (2003).

${ }^{32}$ G. D. Weatherbee, C. H. Bartholomew, J. Catal. 87 ( 1984) 352.

${ }^{33}$ I.C. Yates, C.N. Satterfield, Energy Fuels 5 (1991) 168.

${ }^{34}$ E. Iglesia, S.L. Soled, J.E. Baumgartner, S.C. Reyes, Top. Catal. 2 (1995) 17.

35 G.C. Cooper, T.-H. Nguyen, Y.-J. Lee, K.M. Hardiman, T. Safinski, F.P. Lucien, A.A.

Adesina, Catal. Today 131 (2008) 255.

${ }^{36}$ E. Iglesia, S.C. Reyes, R.J. Madon, J. Catal. 129 (1991) 238.

${ }^{37}$ E. Iglesia, S.C. Reyes, R.J. Madon, S.L. Soled, Adv. Catal. 39 (1993) 221.

${ }^{38}$ R.J. Madon, E. Iglesia, J. Catal. 149 (1994) 428.

${ }^{39}$ S.T. Sie, R. Krishna, Appl. Catal. A 186 (1999) 55.

${ }^{40}$ R.B. Bird, W.E. Stewart, E.N.Lightfoot, Transport Phenomena, $2^{\mathrm{a}}$ edición, Ed. John Wiley \& Sons. (2001)

${ }^{41}$ Y.-N. Wang, Y.-Y. Xu, H.-W. Xiang,Y.-W. Li, B.-J. Zhang, Ind. Eng. Chem. Res. 40 (2001) 4324.

${ }^{42}$ W.A. Dietz, J. Gas Chromat. (1967) 68. 


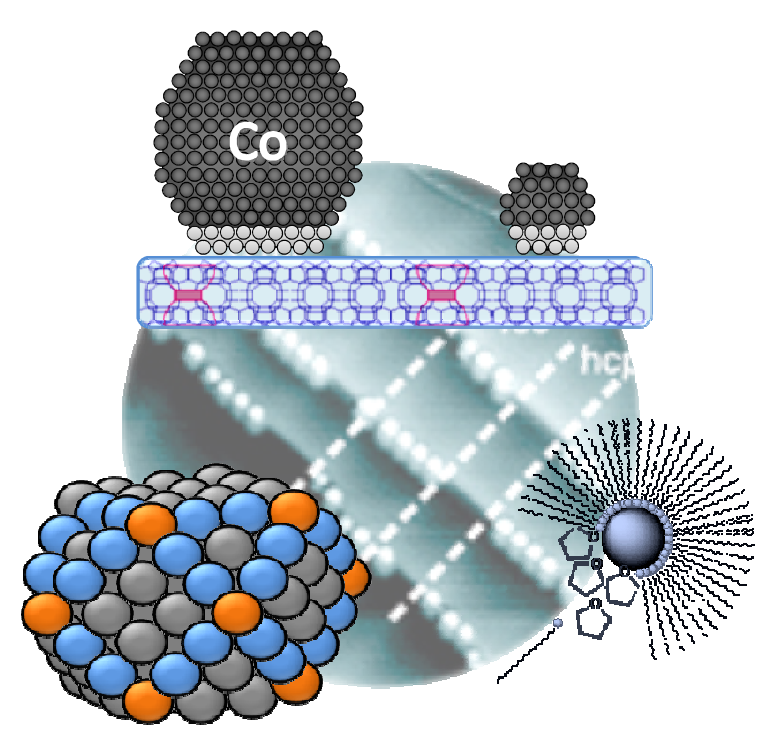

\section{INFLUENCIA DEL TAMAÑO DE NANOPARTÍCULA EN LA ACTIVIDAD Y SELECTIVIDAD DE LA SÍNTESIS DE FISCHER-TROPSCH}




\subsection{Introducción}

\subsubsection{Influencia del tamaño de nanopartícula de Co en la SFT: antecedentes.}

Considerando que el centro activo para la SFT es el cobalto en estado metálico, la actividad catalítica sería, en principio, proporcional al número de átomos de $\mathrm{Co}^{0}$ superficiales. Desde el punto de vista del diseño del catalizador, una elevada densidad superficial de $\mathrm{Co}^{0}$ requiere de la obtención de partículas de cobalto altamente dispersas y fácilmente reducibles. La mayor parte de los catalizadores comerciales presentan dispersiones metálicas modestas, con tamaños de nanopartícula medios entorno a $20 \mathrm{~nm}$ [1], lo que significa que tan sólo aprox. el 5\% de los átomos metálicos son superficiales. Iglesia y col. [2] estudiaron el comportamiento catalítico de una serie de catalizadores de Co, sintetizados mediante impregnación, presentando diámetros medios de nanopartícula en el rango de 9-200 nm y encontraron que la actividad catalítica por centro metálico superficial (TOF) no varía con el tamaño de nanopartícula en este rango de tamaños, representativo de los catalizadores comerciales.

Por lo tanto, una reducción del tamaño medio de nanopartícula hasta, por ejemplo, aprox. $5 \mathrm{~nm}$, manteniendo la actividad intrínseca por centro metálico, resultaría en un incremento de cuatro veces en el rendimiento del metal. En este sentido, se han empleado soportes de elevada área superficial como sílices mesoporosas ordenadas $[3,4,5]$ o carbones activados [6] y rutas de síntesis alternativas a la impregnación como la deposiciónprecipitación [7], adsorción de complejos metálicos [8] o procedimientos solgel [9] para preparar catalizadores de Co con tamaños de nanopartícula de Co inferiores a $10 \mathrm{~nm}$. No obstante, en la mayoría de los casos, en contra de lo esperado a priori, se obtuvieron actividades catalíticas inesperadamente bajas y pobres selectividades a productos de cadena larga $[5,9,10,11]$. 
Esta menor actividad catalítica de los catalizadores más dispersos se relacionó tradicionalmente con la presencia de especies metálicas no reducidas, inactivas en catálisis, como consecuencia de la menor reducibilidad propia de las NPs de pequeño tamaño $[5,12,13]$. Estas nanopartículas de menor tamaño presentan una elevada relación superficie/volumen e interaccionan fuertemente con los grupos hidroxilo superficiales de los soportes catalíticos $\left(\mathrm{SiO}_{2}\right.$, y especialmente, $\left.\mathrm{Al}_{2} \mathrm{O}_{3} \circ \mathrm{TiO}_{2}\right)$, resultando en la formación de óxidos mixtos como silicatos, aluminatos o titanatos durante los tratamientos térmicos de activación del catalizador. Estos óxidos mixtos no se reducen a las temperaturas empleadas en los tratamientos de reducción, lo que reduce el número de centros activos $\left(\mathrm{Co}^{\circ}\right)$ en el catalizador final.

Otros autores, en cambio, atribuyeron esta baja actividad catalítica a un efecto del tamaño de partícula de $\mathrm{Co}^{\circ}$, que resulta en un descenso del valor de TOF para las NPs de menor tamaño $[14,15,16,17]$, aunque en la mayoría de los casos, una posible interferencia por parte de especies de Co no reducidas no puede descartarse completamente $[14,15]$.

En oposición a estos trabajos, otros estudios no encuentran ninguna correlación aparente entre el valor de TOF y el tamaño de nanopartícula $[18,19]$. Una vez más, los catalizadores más dispersos empleados en estos estudios muestran grados de reducción limitados [19], lo que añade incertidumbre a los resultados, incluso cuando la actividad se expresa por centro metálico $\left(\mathrm{Co}^{\circ}\right)$, puesto que la presencia de fases oxidadas en la vecindad de éstos podría modificar sus propiedades catalíticas.

Por lo tanto, resulta evidente el interés de estudiar el efecto del tamaño de nanopartícula en la SFT catalizada por Co empleando catalizadores modelo, altamente reducibles. Bezemer y col. [20] reportaron 
recientemente una sensibilidad a la estructura no clásica empleando catalizadores Co/CNF preparados mediante impregnación y deposiciónprecipitación controlada. No obstante, empleando esta metodología, partículas de Co menores de $5 \mathrm{~nm}$ sólo se consiguen para cargas metálicas muy bajas $(<5 \%(p))$. Además, el empleo de un soporte "inerte" como las nanofibras de carbono, si bien permite elevados grados de reducción para los catalizadores más dispersos, no es muy representativo de un catalizador real de SFT, por lo que las conclusiones extraídas empleando este sistema modelo podrían no ser extrapolables a los catalizadores más relevantes desde el punto de vista industrial, que contienen cargas metálicas típicamente $>10 \%$ Co y emplean óxidos inorgánicos como soporte catalítico.

Desacoplar los parámetros de dispersión metálica y reducibilidad, que están directamente interrelacionados para las metodologías convencionales de síntesis de catalizadores, y preparar catalizadores modelo altamente reducibles y con un tamaño de nanopartícula de Co uniforme, a niveles de carga metálica industrialmente relevantes, supone un reto sintético que permitiría obtener materiales catalíticos idóneos para acometer el estudio del efecto de tamaño de nanopartícula en la SFT.

\subsubsection{Síntesis de coloides metálicos en medios micelares inversos.}

La síntesis de nanopartículas metálicas empleando microemulsiones inversas es una herramienta ampliamente empleada en la preparación de catalizadores soportados con una distribución de tamaño de NP estrecha y controlable [21,22]. Esta metodología de síntesis ex-soporte permite dispersar las fases metálicas, de manera uniforme, y de forma independiente de la carga metálica y las propiedades químicas o texturales del soporte catalítico, al contrario de lo que rige para métodos de preparación más convencionales como la impregnación. 
Las microemulsiones inversas son medios bifásicos, termodinámicamente estables, isotrópicos y transparentes que consisten en una fase orgánica continua en la cual se encuentra dispersa una fase acuosa en el interior de micelas inversas de dimensiones nanométricas, estabilizadas por un surfactante $y$, opcionalmente, un co-surfactante. El empleo de esta técnica para la preparación de nanopartículas metálicas, óxidos nanométricos e incluso tamices moleculares con un tamaño de partícula homogéneo ha dado lugar a una vasta literatura y numerosas revisiones a lo largo de los últimos 10 años [22,23,24]. Como se esquematiza en la Fig. 3.1, la síntesis de nanopartículas metálicas comprende, de manera común, la disolución de precursores metálicos en la fase acuosa de la microemulsión, seguida por la nucleación y crecimiento de una fase metálica sólida en el interior de las micelas, provocada típicamente por un cambio de $\mathrm{pH}$ o la adición de un agente reductor como $\mathrm{H}_{2}, \mathrm{NaBH}_{4} \circ$ hidrazina. Aprovechando el dinamismo interno de las microemulsiones, cuyas micelas intercambian con rapidez su contenido, el agente responsable de la formación de la fase metálica insoluble puede añadirse en otra microemulsión que se mezcla con la anterior.

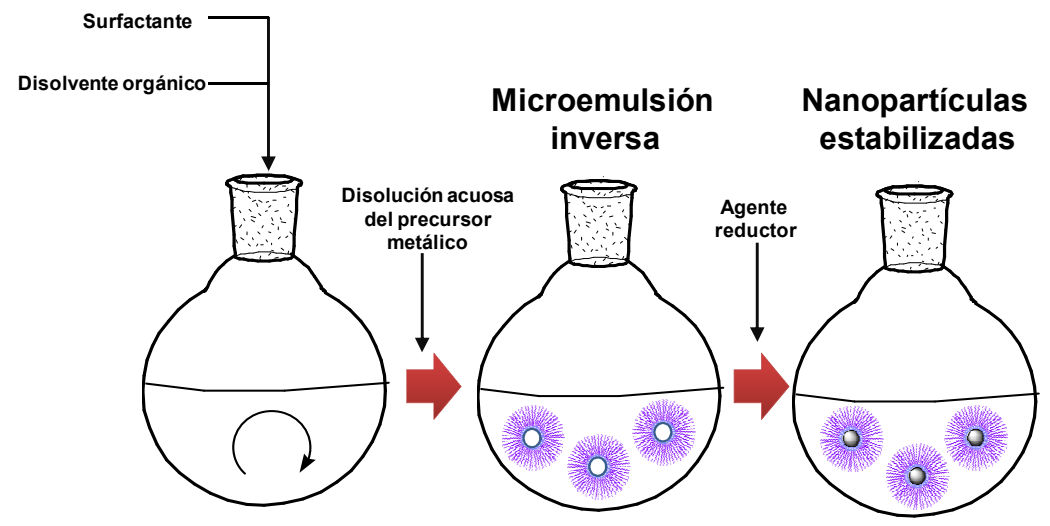

Figura 3.1: Representación esquemática de la preparación de nanopartículas metálicas empleando una microemulsión inversa. 
Cuando el objetivo es soportar las nanopartículas sintetizadas, en la literatura se han empleado dos estrategias principales:

En la primera de éstas, el soporte se sintetiza in situ en el medio micelar que contiene los coloides metálicos, por ejemplo por hidrólisis y condensación de un precursor de tipo alcóxido. Esta metodología se ha empleado para preparar catalizadores soportados sobre $\mathrm{SiO}_{2}$ y $\mathrm{TiO}_{2}$ pero presenta como principal inconveniente la frecuente encapsulación parcial o total de las nanopartículas metálicas en la fase del soporte, lo que no es deseable para aplicaciones catalíticas [25].

Una segunda estrategia comprende la deposición controlada de las nanopartículas sintetizadas sobre un soporte suspendido. Normalmente, la microemulsión se desestabiliza empleando un agente adecuado, lo que permite depositar las nanopartículas obtenidas sobre el soporte. Stucky y col. describieron la introducción de nanopartículas metálicas en el interior de los mesoporos de la mesoestructura SBA-15 [26] y de espumas mesocelulares de sílice (MCF) [27] empleando ultrasonidos como fuerza impulsora. No obstante, la inclusión de varias nanopartículas en el mismo mesoporo puede resultar en bloqueos y pérdidas en superficie metálica accesible, especialmente en el caso de los soportes mesoestructurados formados por canales unidimensionales poco interconectados. Para elevadas cargas metálicas es preferible el empleo de un soporte con una elevada área superficial externa, accesible a las micelas para la deposición de su contenido de manera lo más dispersa posible. En este sentido los soportes nanométricos de porosidad inter-partícula pueden dispersarse de manera eficaz en el medio micelar y captar las nanopartículas sintetizadas en la microemulsión. 


\subsubsection{Zeolitas deslaminadas como soportes catalíticos.}

Las zeolitas deslaminadas constituyen una familia de zeolitas, sin análogo natural, sintetizadas por primera vez en el Instituto de Tecnología Química. A esta familia pertenecen los materiales ITQ-2, ITQ-6 e ITQ-18, obtenidos mediante exfoliación de (alumino)silicatos laminares precursores de zeolitas microporosas como MCM-22, ferrierita y NU-6, respectivamente. Este tipo de zeolitas presenta una estructura laminar desordenada, con una superficie externa muy elevada, típicamente superior a $500 \mathrm{~m}^{2} / \mathrm{g}$, y fácilmente accesible para reactivos e incluso agregados de mayor tamaño como las micelas inversas, cuyo diámetro típicamente está comprendido en el rango de 10-70 $\mathrm{nm}$ [28]. Esta característica les hace especialmente adecuadas como soportes catalíticos para ser combinados con la síntesis de nanopartículas metálicas en medios micelares.

Otra propiedad destacada de las zeolitas deslaminadas es su elevada estabilidad hidrotermal, heredada de la naturaleza cristalina del (alumino)silicato laminar precursor. Esta característica les confiere interés como soportes catalíticos para la SFT, cuyas condiciones de reacción y la generación de agua como subproducto generan un medio hidrotermal en el reactor. En este sentido, las zeolitas deslaminadas ITQ-2 e ITQ-6 han mostrado buenas propiedades como soporte para catalizadores de Co empleados en la SFT [10].

En concreto, la zeolita deslaminada ITQ-2 se sintetizó por primera vez en el Instituto de Tecnología Química por Corma y col. [29]. En la estructura del material, esquematizada en la Fig. 3.2, cada lámina individual presenta una elevada superficie externa formada por semicavidades delimitadas por anillos de 12 miembros de $0.71 \mathrm{~nm}$ de diámetro. El espacio intra-laminar 
posee canales sinusoidales formados por anillos de 10 miembros ( 0.40 a 0.55 $\mathrm{nm})$.
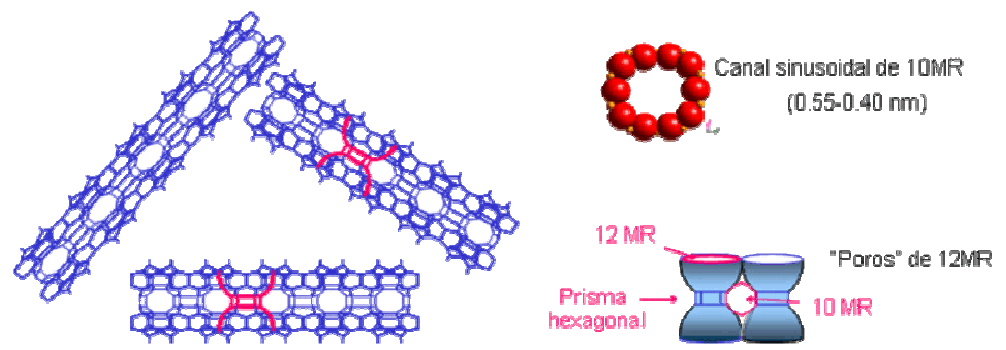

Figura 3.2: Esquema de la estructura de la zeolita deslaminada ITQ-2, [29].

\subsection{Planteamiento.}

En este capítulo de la memoria se explorará una nueva ruta sintética para preparar catalizadores modelo Co/ITQ-2 de elevada reducibilidad y dispersión metálica uniforme, presentando tamaños de nanopartícula en el rango de 5-10 nm, en el que se han encontrado efectos del tamaño de nanopartícula en la SFT. Esta metodología combina la síntesis ex-soporte de una fase de Co nanoparticulada, empleando un medio micelar inverso, y su posterior deposición sobre la superficie externa de la zeolita deslaminada ITQ-2, previamente sililada. Los tratamientos de sililación consisten en la reacción de los grupos silanoles superficiales $(\mathrm{Si}-\mathrm{OH})$ de los sólidos silíceos, con agentes organosilícicos $\left(\mathrm{Si}^{*}-\mathrm{R}_{\mathrm{x}}\right)$, que poseen grupos hidrolizables, de modo que éstos se anclan mediante enlaces covalentes (Si-O-Si ${ }^{*}$ ) convirtiendo la superficie de la sílice en hidrófoba [30]. Estos tratamientos se emplean comúnmente para modificar las propiedades superficiales de materiales silíceos para aplicaciones médicas y catalíticas [30]. Recientemente, la sililación superficial del soporte silíceo se evidenció como un método eficaz para mejorar las propiedades de reducibilidad de catalizadores de Co/SBA-15 de elevada dispersión, como consecuencia de la disminución de la reactividad de los grupos silanol superficiales del soporte 
frente a las fases metálicas soportadas, durante los tratamientos térmicos de activación [31].

En la primera parte de este capítulo (sección 3.3), se compararán las características físico-químicas de catalizadores sintetizados de acuerdo a la nueva ruta sintética propuesta con catalizadores preparados mediante impregnación. En esta parte de la investigación se estudiarán las consecuencias del empleo de una microemulsión para dispersar la fase metálica, así como del empleo del soporte deslaminado en su forma silícea original o tras un tratamiento de sililación superficial.

En la segunda parte del capítulo (sección 3.4), se estudiará la influencia del tamaño de nanopartícula sobre las propiedades físico-químicas y catalíticas de estos catalizadores modelo en la SFT, empleando ensayos reactivos y técnicas de caracterización in situ y operando.

\subsection{Catalizadores nanoparticulados altamente reducibles} mediante síntesis micelar acoplada a un soporte deslaminado.

\subsubsection{Caracterización del soporte catalítico SITQ-2(a).}

Para la preparación de los cuatro catalizadores que se estudian en esta sección 3.3 se empleó como soporte catalítico el primero de los lotes de zeolita deslaminada ITQ-2, tanto en su forma original (calcinada) (ITQ-2(a)) como en su forma sililada (SITQ-2(a)).

\subsubsection{Propiedades texturales y morfológicas.}

La Tabla 3.1 resume las propiedades texturales determinadas mediante adsorción de $\mathrm{N}_{2}$ para la zeolita deslaminada en sus formas calcinada (ITQ-2(a)) y sililada (SITQ-2(a)). 
Tabla 3.1: Propiedades texturales de los soportes catalíticos basados en zeolita deslaminada ITQ-2 calcinada y sililada.

\begin{tabular}{lcccc}
\hline & \multicolumn{4}{c}{ Adsorción $\mathrm{N}_{2}$} \\
\cline { 2 - 5 } Muestra & $\begin{array}{c}\text { Área } \\
\text { B.E.T. } \\
\left(\mathrm{m}^{2} / \mathrm{g}\right)\end{array}$ & $\begin{array}{c}\mathrm{VP}^{\mathrm{a}} \\
\left(\mathrm{cm}^{3} / \mathrm{g}\right)\end{array}$ & $\begin{array}{c}\mathrm{VP}_{\text {micro }}{ }^{\mathrm{b}} \\
\left(\mathrm{cm}^{3} / \mathrm{g}\right)\end{array}$ & $\begin{array}{c}\text { Parámetro } \\
\text { C (B.E.T. })^{\mathrm{c}}\end{array}$ \\
\hline ITQ-2(a) & 964 & 0.64 & 0.01 & 84 \\
SITQ-2(a) & 877 & 0.58 & 0.01 & 28 \\
\hline${ }^{a}$ Volumen de poro. \\
${ }^{b}$ Volumen de microporo. \\
${ }^{c}$ Parámetro C de interacción adsorbato-adsorbente del modelo B.E.T.
\end{tabular}

Al contrario que para las zeolitas tridimensionales de estructura ITQ1 , que se obtendrían por calcinación directa del precursor laminar MWW y que, típicamente presentan valores de volumen de microporo $\left(\mathrm{VP}_{\text {micro }}\right)$ de aprox. 0.1-0.2 $\mathrm{cm}^{3} / \mathrm{g}$ [32], el proceso de deslaminación da lugar a un material cuyo $\mathrm{VP}_{\text {micro }}\left(0.01 \mathrm{~cm}^{3} / \mathrm{g}\right)$ es despreciable frente al volumen de poro total (VP), de modo que prácticamente la totalidad del área superficial $\left(964 \mathrm{~m}^{2} / \mathrm{g}\right)$ corresponde a superficie externa. La sililación posterior reduce tanto el área específica como el VP del material en aprox. un 9\%, mientras que no modifica el $\mathrm{VP}_{\text {micro. }}$ Por otro lado, el parámetro $\mathrm{C}$ del modelo B.E.T. está directamente relacionado con el cambio de entalpía en el proceso de "condensación" de las moléculas de $\mathrm{N}_{2}$ adsorbidas en la primera monocapa, con respecto a la condensación en una fase líquida másica o bulk [33]. Se ha descrito que el valor de $\mathrm{C}$ es menor para las superficies más hidrófobas, para las que la interacción entre el sólido y el $\mathrm{N}_{2}$ adsorbido es menos energética. Por tanto, el descenso en el valor de C desde 84 para ITQ-2(a) hasta 28 para la correspondiente muestra sililada SITQ-2(a) tiene lugar como resultado del recubrimiento de la superficie del sólido accesible para el $\mathrm{N}_{2}$ con los grupos orgánicos trimetilsililo [34,35]. 
La textura del soporte deslaminado se ha estudiado también mediante SEM. La Figura 3.3 muestra micrografías de SEM representativas para el precursor laminar de estructura MWW así como para el sólido obtenido por deslaminación del mismo.

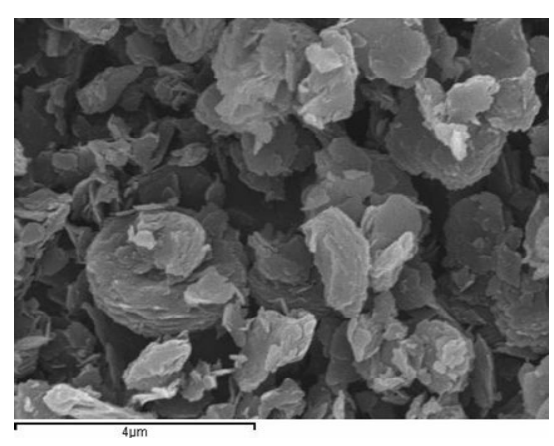

(a)

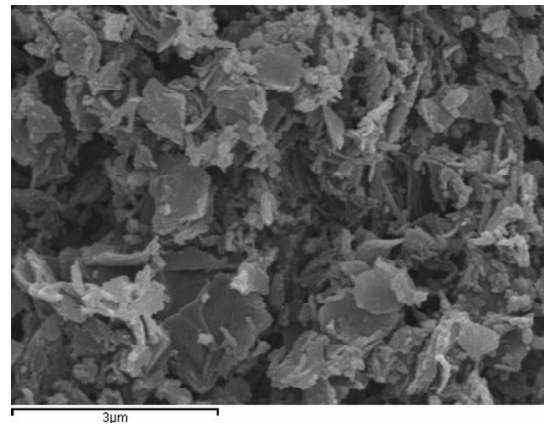

(b)

Figura 3.3: Micrografías SEM del precursor laminar con estructura MWW (a) y la zeolita deslaminada ITQ-2(a) obtenida por deslaminación del mismo (b).

Se observa que las partículas del precursor laminar presentan aspecto de placas hexagonales apiladas, de acuerdo con su naturaleza laminar. Tras el proceso de deslaminación, la morfología planar se mantiene para una parte del sólido mientras que aparecen otras regiones en las que la morfología de las partículas primarias presenta un carácter más acicular.

Adicionalmente, se empleó TEM para explorar la morfología del soporte catalítico laminar sililado SITQ-2(a) a un nivel de observación más detallado. La Figura 3.4 muestra dos micrografías representativas a media magnificación. 


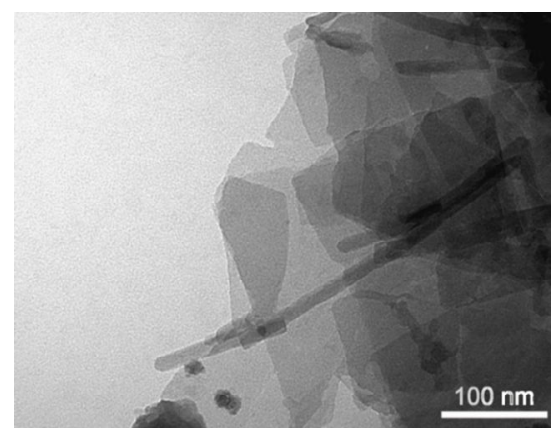

(a)

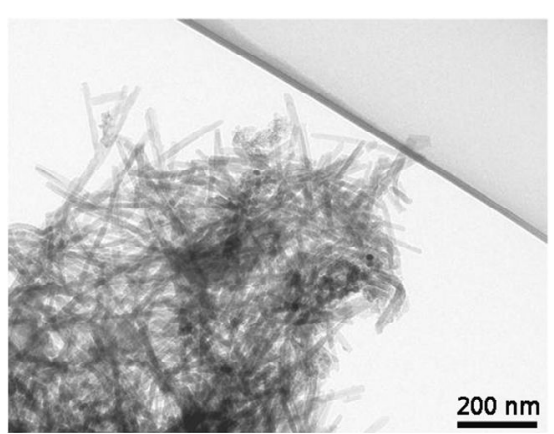

(b)

Figura 3.4: Micrografías TEM representativas de dos regiones de estudio para la muestra SITQ-2(a).

En la Figura 3.4-a se observa la presencia de láminas nanométricas, cuyo contraste en TEM es limitado, debido a su fino espesor. Estas láminas son el resultado de la deslaminación del precursor MWW. Adicionalmente, en esta Fig. 3.4-a se observa la presencia de alguna partícula del soporte con morfología acicular. De hecho, a pesar de que la morfología laminar es la predominante, de acuerdo a la observación por TEM de varias regiones de la muestra, es posible encontrar, a su vez, regiones en las que predomina la forma acicular para las nanopartículas primarias de SITQ-2(a), como se muestra en la Figura 3.4-b. Este hecho podría estar relacionado con la existencia de una población de cristales del precursor laminar con una mayor relación de aspecto (Longitud/Sección). Sin embargo, este tipo de cristales no se perciben en la Fig. 3.3-a, lo que sugiere que podrían ser el resultado de fracturas longitudinales de las láminas del precursor MWW durante su exfoliación. De todos modos, en este punto no se puede dar una explicación definitiva para la aparición de formas aciculares en el material ITQ-2.

\subsubsection{Composición química y grado de sililación superficial.}

Como se recoge en la Tabla 3.2, la muestra ITQ-2(a) presenta un contenido en carbono de $0.4 \%(p)$, evidenciando que el tratamiento de calcinación al que se somete el soporte durante su síntesis no retira de 
forma cuantitativa la materia orgánica, de modo que permanecen restos carbonosos derivados del agente director de estructura y/o los surfactantes empleados durante la síntesis hidrotermal y la deslaminación. Tras el tratamiento de sililación, el contenido en carbono se incrementa hasta el $8.4 \%(p)$ como consecuencia del anclaje superficial de los grupos trimetilsililo.

Tabla 3.2: Contenido en carbono determinado por análisis elemental para la zeolita deslaminada ITQ-2 calcinada y sililada.

\begin{tabular}{cc}
\hline Muestra & $\begin{array}{c}\text { Contenido en } \\
\text { Carbono (\%(p)) }\end{array}$ \\
\hline ITQ-2(a) & 0.4 \\
SITQ-2(a) & 8.4 \\
\hline
\end{tabular}

El proceso de sililación superficial de la zeolita ITQ-2 se estudió, de manera cuantitativa, mediante espectroscopia ${ }^{29} \mathrm{Si}-\mathrm{NMR}$. Esta técnica permite discriminar entre diferentes entornos para los átomos de Si en el sólido, de forma que es posible cuantificar qué porcentaje de los grupos silanol ( $\mathrm{Si}-\mathrm{OH})$ superficiales reaccionan con el reactivo sililante durante el tratamiento de sililación. La Fig. 3.5 muestra los espectros de ${ }^{29} \mathrm{Si}-\mathrm{NMR}$ para la zeolita deslaminada en sus formas calcinada (ITQ-2(a)) y sililada (SITQ2(a)). En ambas muestras se observan varias señales en el rango -90 a -120 ppm que corresponden a diferentes entornos de los átomos de Si en la red de la zeolita. Además, en la muestra sililada se distingue una señal adicional a $13.9 \mathrm{ppm}$ debida a los átomos de Si de los grupos trimetilsililo [Si-O-Si$\left.\left(\mathrm{CH}_{3}\right)_{3}\right]$ anclados superficialmente durante el tratamiento de sililación.

La contribución de cada señal individual se determinó mediante una deconvolución del espectro empleando funciones de tipo gaussiano y manteniendo constantes los parámetros espectroscópicos de posición $(\delta)$ y anchura de banda a media altura (FWHM). En el espectro incluido como 
detalle en la Fig. 3.5 se muestra, a modo de ejemplo, la deconvolución de los picos en la región de desplazamiento químico de -90 a -120 para la muestra ITQ-2(a). Las señales a aprox. -105, -110 y -119 ppm corresponden a átomos de Si $Q^{4}\left[\mathbf{S i}-(\mathrm{O}-\mathrm{Si})_{4}\right]$ en diferentes posiciones cristalográficas de la estructura MWW, mientras que las señales a -101 y -92 ppm se deben a especies de $\mathrm{Si}$ $\mathrm{Q}^{3}\left[\mathrm{OH}-\mathrm{Si}-(\mathrm{O}-\mathrm{Si})_{3}\right]$ y $\mathrm{Q}^{2}\left[(\mathrm{OH})_{2}-\mathrm{Si}-(\mathrm{O}-\mathrm{Si})_{2}\right]$, respectivamente [36].

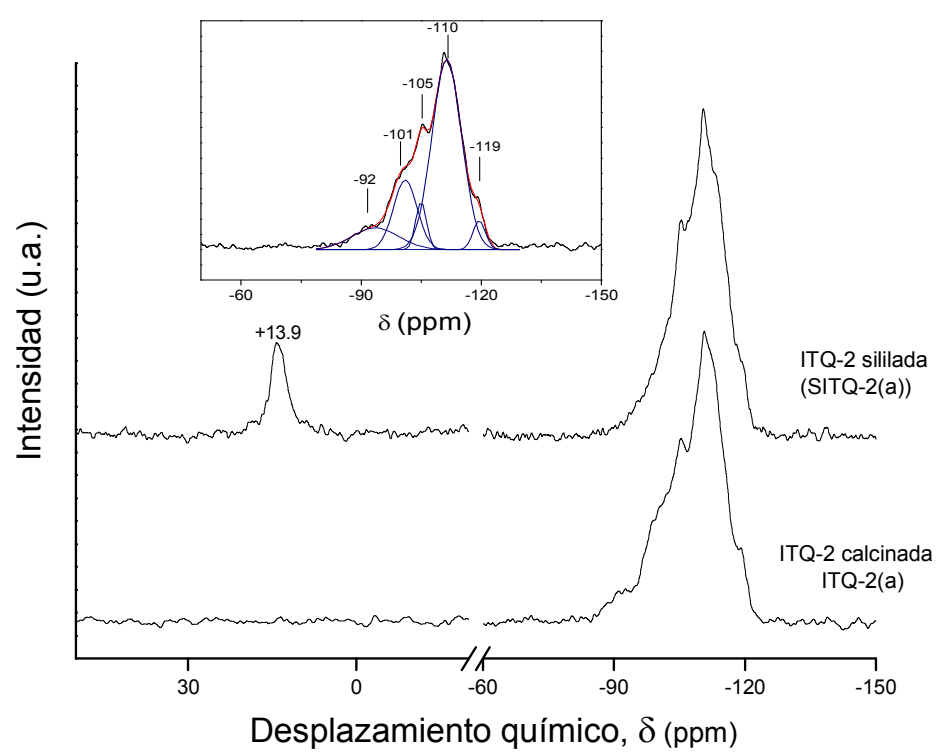

Figura 3.5: Espectros de ${ }^{29}$ Si-NMR para la zeolita deslaminada ITQ-2 en sus formas calcinada y sililada. El detalle muestra un ejemplo de la deconvolución de picos en la región -90 a -120 ppm del espectro para el material calcinado.

El área relativa correspondiente a los átomos $Q^{4} \mathrm{Si}$ es mayor en la muestra sililada ( $82.6 \%$ frente a $71.4 \%$ en la no-sililada), debido al anclaje superficial de los grupos trimetilsililo sobre los grupos $\mathrm{OH}$ superficiales asociados con especies originalmente de tipo $Q^{3} \mathrm{Si}$ y $\mathrm{Q}^{2} \mathrm{Si}$. Considerando la proporcionalidad de todas las señales de ${ }^{29} \mathrm{Si}-\mathrm{NMR}$ con respecto al número de átomos de ${ }^{29} \mathrm{Si}$, el grado de sililación (GS) se ha determinado a partir de las áreas relativas de las especies $\left(\mathrm{Q}^{2} \mathrm{Si}+\mathrm{Q}^{3} \mathrm{Si}\right)$ en la muestra calcinada y en la sililada, de acuerdo a la ecuación 3.1. 


$$
G S(\%)=\frac{\left[A_{Q^{2}}+A_{Q^{3}}\right]_{I T Q-2(a)}-\left[A_{Q^{2}}+A_{Q^{3}}\right]_{S / T Q-2(a)}}{\left[A_{Q^{2}}+A_{Q^{3}}\right]_{I T Q-2(a)}} \cdot 100
$$

La aplicación de la ecuación 3.1 a los espectros incluidos en la Fig. 3.5 da como resultado un valor de GS del $40 \%$.

Por su parte, el recubrimiento de la superficie con los grupos orgánicos trimetilsililo en SITQ-2(a) se estimó de acuerdo a la ecuación 3.2:

$$
\alpha\left(\text { grupos } / \mathrm{nm}^{2}\right)=\frac{(\Delta C / 100) \cdot \frac{N_{A}}{12} \cdot \frac{1}{3}}{A \cdot 10^{18}}
$$

donde $A\left(\mathrm{~m}^{2} / \mathrm{g}\right)$ es la superficie específica (B.E.T.) de la zeolita deslaminada en su forma calcinada (ITQ-2(a)), $\Delta C$ es la ganancia en carbono $(\%(p))$ experimentada por el material cuando éste se silila superficialmente $y$ $\mathrm{N}_{\mathrm{A}}$ es el número de Avogadro. De acuerdo con el incremento en el contenido en carbono experimentado tras la sililación (Tabla 3.2) y el área superficial del soporte (Tabla 3.1), el recubrimiento superficial se estimó en 1.22 grupos orgánicos por $\mathrm{nm}^{2}$. Este valor está dentro del rango típico de los recubrimientos alcanzados por sililación de materiales silíceos en condiciones experimentales similares a las empleadas en este trabajo $[36,37]$.

Finalmente, se ha empleado la espectroscopia FTIR para estudiar la naturaleza de los grupos silanol, presentes en la superficie del soporte silíceo, que reaccionan durante el tratamiento de sililación. La Figura 3.6 muestra los espectros FTIR del soporte deslaminado en sus formas calcinada y sililada. 


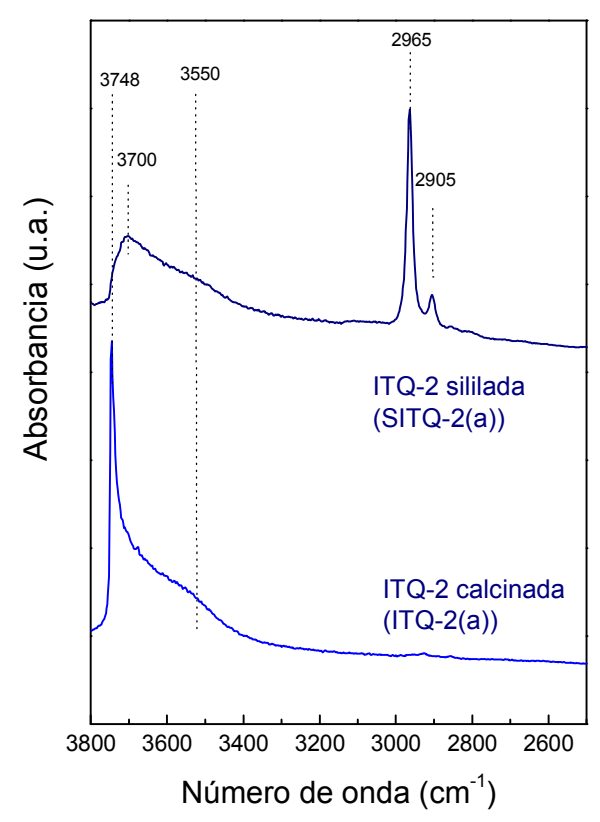

Figura 3.6: Espectros de FTIR para la zeolita deslaminada ITQ-2 en sus formas calcinada y sililada.

Antes de la sililación, la zeolita ITQ-2 calcinada muestra una banda intensa y estrecha a $3748 \mathrm{~cm}^{-1}$ asociada a grupos silanol (Si-OH) libres, y una banda ancha y menos intensa centrada aprox. a $3550 \mathrm{~cm}^{-1}$ debida a grupos Si-OH enlazados por puentes de hidrógeno [38]. La banda correspondiente a grupos silanoles libres $\left(3748 \mathrm{~cm}^{-1}\right)$ desaparece prácticamente de manera completa en la muestra sililada. Por el contrario, no se observan cambios significativos en la intensidad de la banda a $3550 \mathrm{~cm}^{-1}$ tras la sililación, lo que indica que los grupos silanoles unidos por puentes de hidrógeno no han reaccionado con el agente sililante, al menos en un grado apreciable, en las condiciones experimentales empleadas. Adicionalmente, el espectro FTIR de la muestra sililada presenta una banda ancha a aprox. $3700 \mathrm{~cm}^{-1}$, que se ha atribuido a nuevos grupos silanoles formados tras la sililación de uno de los grupos hidroxilo en especies $(\mathrm{OH})_{2}-\mathrm{Si}-(\mathrm{OSi})_{2}$ [37]. Además de ésta, también se observa la aparición de dos nuevas bandas a 2905 y $2965 \mathrm{~cm}^{-1}$ en el 
espectro de SITQ-2(a), atribuidas a las vibraciones de tensión simétrica y asimétrica, respectivamente, de enlaces $\mathrm{C}-\mathrm{H}$ en los grupos orgánicos anclados por sililación [39].

Así pues, los resultados de espectroscopia ${ }^{29}$ Si-NMR y FTIR evidencian que aprox. el $40 \%$ de los grupos silanoles superficiales presentes en la zeolita deslaminada ITQ-2, especialmente aquellos que no se encuentran asociados mediante puentes de hidrógeno, se "protegen" por anclaje de grupos orgánicos durante la sililación, haciendo la superficie del soporte hidrófoba. Por otro lado, el análisis termogravimétrico indica que estos grupos orgánicos, anclados en la superficie silícea, son estables en atmósfera de aire hasta una temperatura de $440-500$ ㄷ.

\subsubsection{Caracterización de los catalizadores $10 \%$ Co/ITQ-2.}

3.3.2.1. Preparación y activación por calcinación.

Como se describe en el apartado 2.1.3.1 (Sección experimental), se prepararon para este estudio cuatro catalizadores, empleando las metodologías de síntesis y los soportes que se indican en la Tabla 3.3.

Tabla 3.3: Nomenclatura, método de síntesis y soporte catalítico empleado para los catalizadores $10 \%$ Co/ITQ-2.

\begin{tabular}{ccc}
\hline Catalizador & $\begin{array}{c}\text { Método de } \\
\text { síntesis }\end{array}$ & $\begin{array}{c}\text { Soporte } \\
\text { catalítico }\end{array}$ \\
\hline im_10Co/ITQ & Impregnación & ITQ-2(a) \\
\hline im_10Co/SITQ & Impregnación & SITQ-2(a) \\
\hline me_10Co/ITQ & $\begin{array}{c}\text { Microemulsión } \\
\text { inversa }\end{array}$ & ITQ-2(a) \\
me_10Co/SITQ & $\begin{array}{c}\text { Microemulsión } \\
\text { inversa }\end{array}$ & SITQ-2(a) \\
\hline
\end{tabular}


En primer lugar, se estudiará la naturaleza y el tamaño de las nanopartículas sintetizadas en el medio coloidal empleado para preparar los catalizadores me_10Co/ITQ y me_10Co/SITQ. La Fig. 3.7 muestra una micrografía de TEM, junto con el correspondiente histograma de tamaños, para las nanopartículas metálicas obtenidas por adición de hidrazina sobre la microemulsión inversa que contiene el precursor de Co (sección 2.1.3.1).
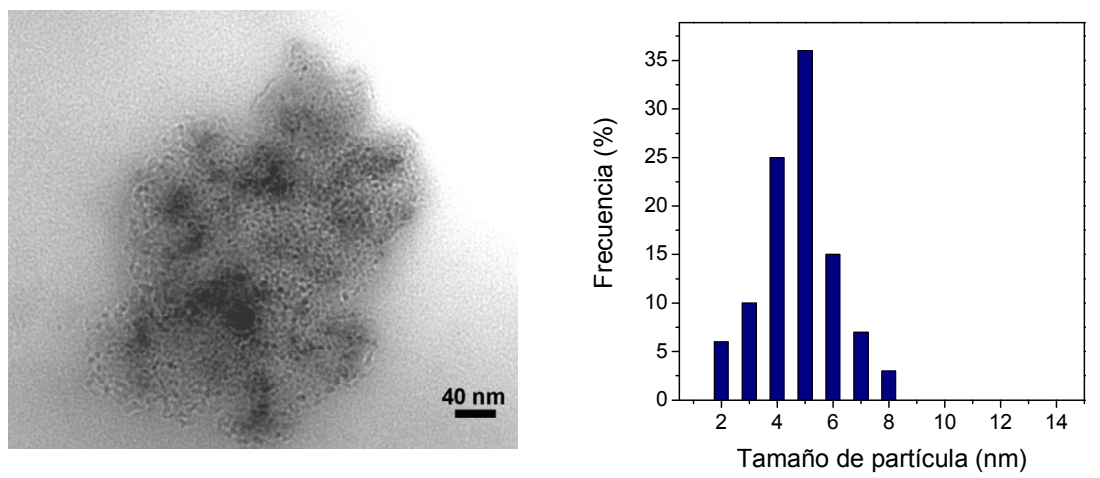

Figura 3.7: Micrografía de TEM y distribución de tamaño de las nanopartículas sintetizadas en la microemulsión inversa y empleadas para preparar los catalizadores me_10Co/ITQ y me_10Co/SITQ.

Como se observa, las nanopartículas sintetizadas en las micelas inversas presentan una distribución de tamaño de tipo gaussiano y relativamente estrecha, cuyo valor medio es de $4.9 \mathrm{~nm}$.

Se conoce que a temperatura ambiente, la hidrazina no es capaz de reducir los iones $\mathrm{Co}^{2+}$ a $\mathrm{Co}^{0}$ en disolución acuosa. Puesto que la hidrazina da lugar a disoluciones acuosas básicas, la especie activa en medio acuoso se suele representar como el ácido conjugado $\left(\mathrm{N}_{2} \mathrm{H}_{5}{ }^{+}\right)$. El potencial de reducción estándar para el ión hidrazinio $\left(\mathrm{N}_{2} \mathrm{H}_{5}^{+}\right)$es $-0.23 \mathrm{~V}\left(\mathrm{~N}_{2}+5 \mathrm{H}^{+}+4 \mathrm{e}^{-} \rightarrow \mathrm{N}_{2} \mathrm{H}_{5}^{+}\right)$, mientras que el potencial de reducción estándar para el ión $\mathrm{Co}^{2+}$ es $-0.28 \mathrm{~V}$, lo que indica que, al menos en condiciones estándar, la reducción de los 
iones metálicos no es termodinámicamente posible. Para lograr la reducción de los iones $\mathrm{Co}^{2+}$ a $\mathrm{Co}^{0}$ con la hidrazina se precisa de calentamiento o la aplicación de ultrasonidos, como mostraron algunos trabajos recientes $[40,41]$. Por el contrario, cuando se añade hidrazina sobre disoluciones acuosas de $\mathrm{Co}^{2+}$, se forma un complejo metálico insoluble de tipo hidróxidohidrazina, como se ha descrito para el caso de $\mathrm{Ni}^{2+}$ [42]. La formación de este complejo en el interior de la fase acuosa nanométrica, estabilizada en las micelas de la microemulsión, imparte un control sobre el tamaño de nanopartícula. A pesar de no obtenerse nanopartículas de $\mathrm{Co}^{0}$, la posibilidad de controlar el tamaño de nanopartícula del compuesto de $\mathrm{Co}^{2+}$ permite obtener catalizadores conteniendo nanopartículas de $\mathrm{Co}^{0}$ de diferentes tamaños tras los tratamientos de calcinación y reducción.

La evolución del catalizador me_10Co/SITQ durante el tratamiento térmico de calcinación se estudió mediante TG-DTA y TPO-MS. La Fig. 3.8 muestra los correspondientes perfiles de TG y DTA acoplados a los espectros de detección de varias especies $\left(\mathrm{H}_{2} \mathrm{O}, \mathrm{CO}_{2}, \mathrm{NO}_{\mathrm{x}}\right)$ en los gases emitidos durante el experimento de TPO-MS. En el perfil de TG se distinguen cuatro pérdidas de masa principales. La pérdida de masa denominada etapa (a), en el rango de temperaturas de 100-120드. presenta un carácter endotérmico y corresponde con la desorción del agua adsorbida sobre la superficie del soporte. La magnitud de esta pérdida (3.7\%) es sensiblemente inferior a la experimentada por un catalizador soportado sobre ITQ-2 no sililada (12\%) (espectro no mostrado), debido al carácter hidrófobo de SITQ-2(a), que reduce sensiblemente la cantidad de agua adsorbida desde el ambiente. Posteriormente, alrededor de $1600^{\circ} \mathrm{C}$ tiene lugar la etapa (b), de carácter exotérmico y que se corresponde con procesos de deshidratación (se detecta $\mathrm{H}_{2} \mathrm{O}$ ) y descomposición (se registran $\mathrm{NO}_{x}$ ) asociados con las especies Co-hidrazina soportadas. Seguidamente, entre 200 y 250 으 tiene lugar la 
etapa (c), exotérmica, durante la que se detectan tanto $\mathrm{H}_{2} \mathrm{O}$ y $\mathrm{CO}_{2}$ en los gases de escape, relacionados con la combustión de las moléculas de surfactante residuales, como una señal importante de $\mathrm{NO}_{x}$, que no vuelven a detectarse a temperaturas superiores, lo que sugiere que durante esta etapa (c) también tiene lugar la descomposición completa de las especies Cohidrazina y la cristalización de $\mathrm{CO}_{3} \mathrm{O}_{4}$. Por último, entre $430-460$ 으, tiene lugar una pérdida de masa (3.4\%) denominada etapa (d), también exotérmica, relacionada con la descomposición de los grupos orgánicos trimetilsililo en la superficie del soporte sililado, lo que resulta en la emisión de $\mathrm{H}_{2} \mathrm{O}$ y $\mathrm{CO}_{2}$, como se observa en los perfiles de TPO-MS.

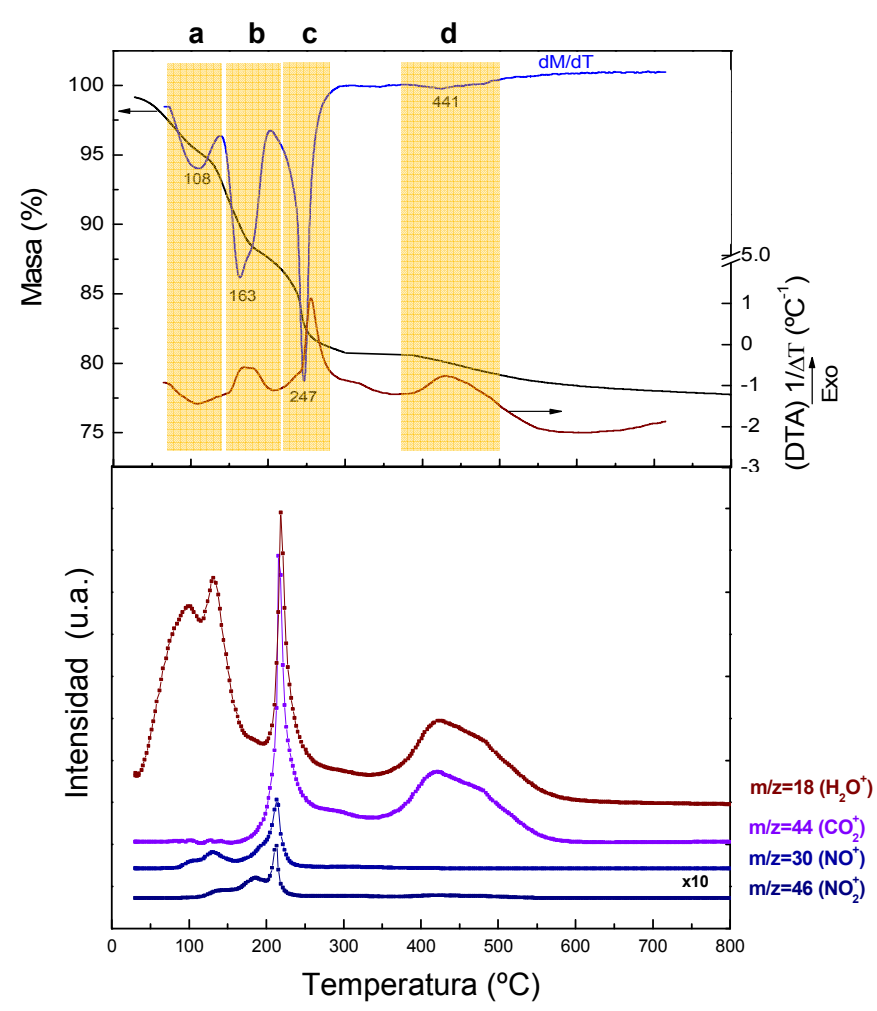

Figura 3.8: Perfiles de TG (incluyendo derivada $d M / d T$ ) y DTA (parte superior), así como los correspondientes perfiles de TPO-MS para fragmentos con $m / z=18,30,44$ y 46 (parte inferior) durante la calcinación en aire del catalizador me_10Co/SITQ. 
Así pues, estos resultados indican que durante la calcinación del catalizador preparado por microemulsión y soportado sobre la zeolita deslaminada sililada, la descomposición de las especies nanométricas Cohidrazina, que resulta en la cristalización de óxidos de Co, tiene lugar mientras los grupos orgánicos anclados por sililación "protegen" las fases metálicas de sufrir reacción frente a los grupos silanol superficiales del soporte. Los grupos sililantes se retiran completamente por calcinación, dejando libres los grupos silanol del soporte, durante la última de las etapas que tienen lugar en el proceso de calcinación. Los catalizadores calcinados presentan un contenido en carbono del $0.5-0.6 \%(p)$, similar, o tan sólo ligeramente superior al del soporte deslaminado en su forma original (ITQ2(a)) (Tabla 3.2), indicando que la retirada de los grupos trimetilsililo superficiales tiene lugar de forma prácticamente cuantitativa en las condiciones empleadas para la calcinación.

De este modo, todos los catalizadores finales, tanto los soportados sobre ITQ-2(a) como sobre el sólido inicialmente sililado SITQ-2(a), tras la etapa de calcinación, están constituidos por una fase de óxido de Co soportada sobre el soporte en su forma silícea. Los materiales así preparados constituyen un sistema catalítico modelo representativo de los catalizadores empleados en el proceso de Fischer-Tropsch, que emplean como soporte catalítico un óxido inorgánico ( $\mathrm{SiO}_{2}$ ó $\mathrm{Al}_{2} \mathrm{O}_{3}$ generalmente), a diferencia de los basados en soportes carbonosos, como nanofibras de carbono (CNF).

\subsubsection{Composición química.}

La Tabla 3.4 recoge los contenidos metálicos determinados mediante ICP-OES para los catalizadores 10\%Co/ITQ-2 calcinados. Los contenidos en Co experimentales se encuentran dentro del rango $8.6-11.3 \%$, esto es, presentan desviaciones máximas del $14 \%$ respecto del contenido nominal 
del $10 \%$, lo que indica que la deposición de Co sobre el soporte es prácticamente cuantitativa, también cuando se emplea la ruta sintética basada en el empleo de una microemulsión inversa.

Tabla 3.4: Contenido en cobalto de los catalizadores 10\%Co/ITQ-2.

\begin{tabular}{cc}
\hline Muestra & $\begin{array}{c}\text { Contenido Co } \\
(\%(p))\end{array}$ \\
\hline im_10Co/ITQ & 10.7 \\
im_10Co/SITQ & 11.3 \\
me_10Co/ITQ & 8.6 \\
me_10Co/SITQ & 9.3 \\
\hline
\end{tabular}

\subsubsection{Dispersión metálica.}

La dispersión metálica de los catalizadores 10\%Co/ITQ-2 se estudió mediante XRD (para las muestras en su forma calcinada), TEM (para las muestras reducidas y pasivadas ex situ) y quimisorción de $\mathrm{H}_{2}$ (para los catalizadores reducidos in situ).

La Fig. 3.9 muestra los difractogramas de rayos $X$ para los cuatro catalizadores calcinados. Se observa que la espinela mixta de $\mathrm{Co}^{2+}$ y $\mathrm{Co}^{3+}$, $\mathrm{CO}_{3} \mathrm{O}_{4}$ (JCPDS: 42-1467) es la única fase metálica cristalina detectada. Por otro lado, como se recoge en la Tabla 3.5, los catalizadores sintetizados mediante impregnación, presentan tamaños de cristal de $\mathrm{CO}_{3} \mathrm{O}_{4}$ de 7.6-11.8 $\mathrm{nm}$, superiores a los tamaños de cristal para los correspondientes catalizadores preparados en la microemulsión inversa (5.6-5.8 nm) cuyas señales de difracción son más anchas. 
$\square \mathrm{Co}_{3} \mathrm{O}_{4}$

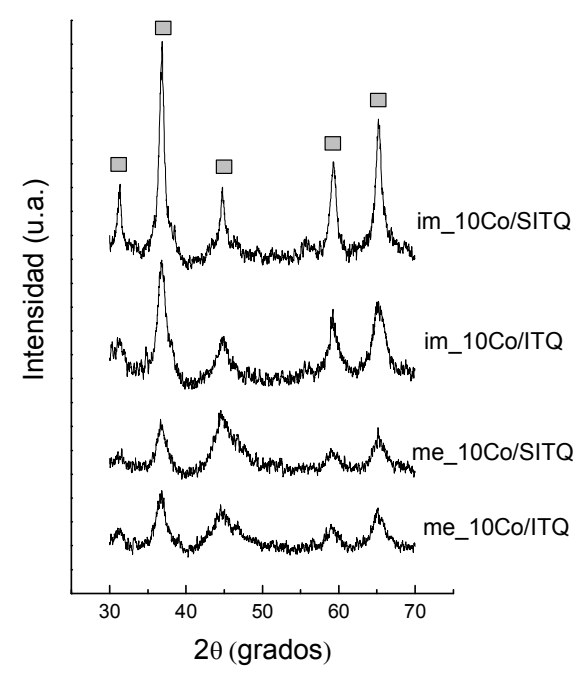

Figura 3.9: Difractogramas de XRD para los catalizadores $10 \%$ Co/ITQ-2 calcinados.

A su vez, el valor de $d\left(\mathrm{CO}_{3} \mathrm{O}_{4}\right)_{x}$ es menos dependiente de la naturaleza de la superficie del soporte (silícea o sililada) cuando se emplea un medio micelar en la síntesis que cuando la síntesis se lleva a cabo mediante impregnación. En este último caso, durante la impregnación, probablemente se consigue un mojado menos eficiente de la superficie hidrófoba de SITQ2(a), lo que resulta, tras la activación térmica, en un tamaño de cristal de $\mathrm{CO}_{3} \mathrm{O}_{4}$ un $55 \%$ superior para im_10Co/SITQ que para im_10Co/ITQ.

Tabla 3.5: Dispersión metálica de los catalizadores 10\%Co/ITQ-2.

\begin{tabular}{|c|c|c|c|c|c|c|}
\hline \multirow[b]{2}{*}{ Catalizador } & \multirow{2}{*}{$\begin{array}{c}\mathrm{XRD} \\
d\left(\mathrm{Co}_{3} \mathrm{O}_{4}\right) \mathrm{x} \\
(\mathrm{nm})\end{array}$} & \multicolumn{2}{|c|}{ TEM } & \multicolumn{3}{|c|}{ Quimisorción $\mathrm{H}_{2}$} \\
\hline & & $\begin{array}{c}d\left(\mathrm{Co}^{0}\right)_{\mathrm{T}} \\
(\mathrm{nm})\end{array}$ & $\begin{array}{c}\sigma_{\mathrm{T}} \\
(\mathrm{nm})\end{array}$ & $\begin{array}{c}\mathrm{H}_{2, \text { ads }} \\
(\mu \mathrm{mol} / \mathrm{g})\end{array}$ & $\begin{array}{c}d\left(\mathrm{Co}^{0}\right)_{\mathrm{H}} \\
(\mathrm{nm})\end{array}$ & $\begin{array}{c}D \\
(\%)\end{array}$ \\
\hline im_10Co/ITQ & 7.6 & n.d. & n.d. & n.d. & n.d. & n.d. \\
\hline im_10Co/SITQ & 11.8 & 11.9 & 4.4 & 75 & 10.9 & 9.2 \\
\hline me_10Co/ITQ & 5.6 & n.d. & n.d. & n.d. & n.d. & n.d. \\
\hline me_10Co/SITQ & 5.8 & 6.2 & 0.9 & 199 & 4.1 & 24.3 \\
\hline
\end{tabular}


Por su parte, las Figs. 3.10-a y b muestran micrografías de TEM representativas para el catalizador me_10Co/ITQ. En ellas se aprecia la presencia de NPs metálicas (con mayor contraste en las micrografías) de tamaño uniforme soportadas sobre el material deslaminado. La Fig. 3.10-a muestra una región en la que la morfología del soporte es de tipo laminar mientras que la región estudiada en la Fig. 3.10-b corresponde con una región del soporte catalítico que presenta morfología acicular, de acuerdo a lo comentado en la sección 3.3.1.1. Por otro lado, la Fig. 3.10-c muestra una micrografía representativa para im_Co/SITQ en la que se aprecian tanto nanopartículas de pequeño tamaño $<10 \mathrm{~nm}$ como otros agregados metálicos de mayor tamaño $>20 \mathrm{~nm}$ (flechas en Fig. 3.10-c).

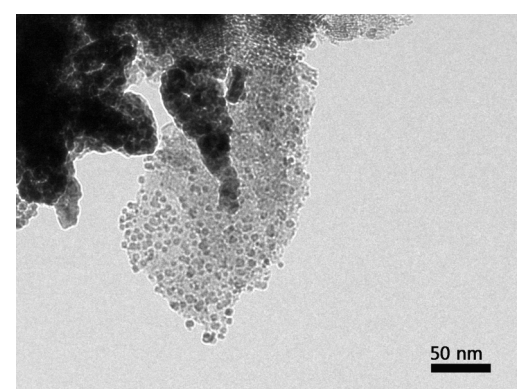

(a)

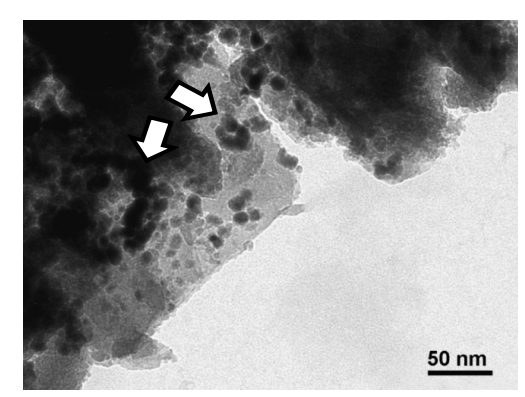

(c)

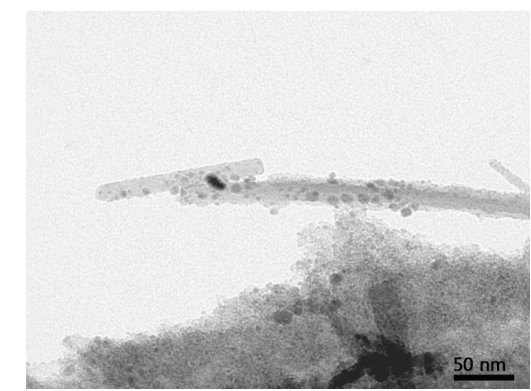

(b)

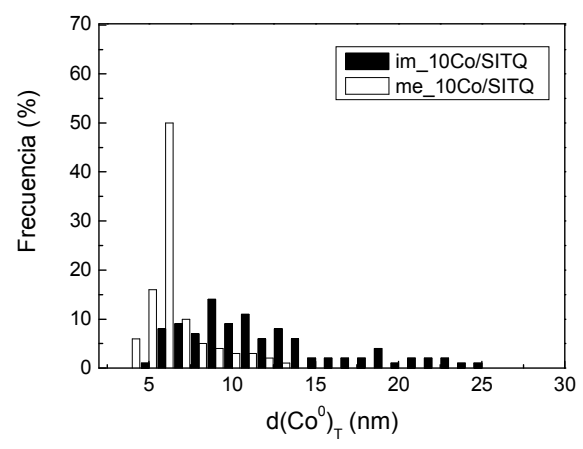

(d)

Figura 3.10: Micrografías de TEM representativas para los catalizadores me_10Co/SITQ (a y b) e im_10Co/SITQ (c) reducidos y pasivados, así como los correspondientes histogramas de tamaño de nanopartícula (d). 
Las distribuciones de tamaño de nanopartícula de Co, determinadas desde el análisis de las micrografías de TEM para los catalizadores im_10Co/SITQ y me_10Co/SITQ, se comparan en la Fig. 3.10-d. El histograma correspondiente al catalizador sintetizado mediante microemulsión inversa presenta un tamaño de nanopartícula más homogéneo, centrado alrededor de 5-6 nm, mientras que, por el contrario, el catalizador sintetizado mediante impregnación presenta una distribución de tamaños más heterogénea, observándose nanopartículas en el rango 3-23 nm.

Los valores del tamaño medio de nanopartícula así como la desviación típica de la distribución de tamaños, determinados por TEM para estos dos catalizadores, se recogen en la Tabla 3.5. En concordancia con los resultados de XRD para los catalizadores calcinados, la muestra obtenida empleando un medio coloidal presenta un $d\left(\mathrm{CO}^{0}\right)_{\mathrm{T}}$ de $6.2 \mathrm{~nm}$, inferior al valor de $d\left(\mathrm{CO}^{0}\right)_{\mathrm{T}}=11.9 \mathrm{~nm}$ obtenido para el catalizador preparado por impregnación. A su vez, la desviación típica $\left(\sigma_{T}\right)$ es significativamente inferior para el primero (aprox. $17 \%$ de $d\left(\mathrm{Co}^{0}\right)_{\mathrm{T}}$ ) evidenciando la mayor homogeneidad de tamaño de nanopartícula obtenida empleando la metodología de síntesis que combina la microemulsión inversa con el soporte deslaminado y sililado superficialmente.

Finalmente, los tamaños de nanopartícula metálica determinados por quimisorción de $\mathrm{H}_{2}$ para los catalizadores im_10Co/SITQ y me_10Co/SITQ reducidos también indican que se obtiene una mayor dispersión metálica empleando la microemulsión inversa durante la síntesis del catalizador (Tabla 3.5). En este caso, $d\left(\mathrm{Co}^{\circ}\right)_{H}$, toma sistemáticamente valores inferiores al tamaño de nanopartícula determinado por TEM, con desviaciones $<30 \%$ entre ambos resultados. 


\subsubsection{Reducibilidad.}

La reducibilidad de los catalizadores $10 \% \mathrm{Co} / \mathrm{ITQ}-2$ se ha estudiado mediante $\mathrm{H}_{2}$-TPR. Los correspondientes perfiles de reducción, incluidos en la Fig. 3.11 muestran diferencias muy significativas en la reducibilidad de las partículas de $\mathrm{CO}_{3} \mathrm{O}_{4}$ en los distintos catalizadores. En todos los casos se observan picos de reducción en el rango de temperaturas de 300 ㄷ $\mathrm{C}-450$ 으 $\mathrm{C}$ que se atribuyen a la reducción de $\mathrm{CO}_{3} \mathrm{O}_{4}$ a $\mathrm{Co}^{0}$ en dos etapas, de acuerdo a las ecuaciones 3.3 y 3.4 [43]:

$$
\begin{gathered}
\mathrm{Co}_{3} \mathrm{O}_{4}+\mathrm{H}_{2} \rightarrow 3 \mathrm{CoO}+\mathrm{H}_{2} \mathrm{O} \\
\mathrm{CoO}+\mathrm{H}_{2} \rightarrow \mathrm{Co}^{0}+\mathrm{H}_{2} \mathrm{O}
\end{gathered}
$$

Estas dos etapas de reducción se aprecian claramente en forma de dos máximos de reducción para las muestras preparadas por microemulsión, mientras que, por el contrario, aparecen como picos solapados en las obtenidas por impregnación. A temperaturas superiores a $500^{\circ} \mathrm{C}$ se observa la reducción de especies de cobalto interaccionando más fuertemente con el soporte, e incluso de especies silicato de cobalto cuya reducción tiene lugar a temperaturas superiores a $700^{\circ} \mathrm{C}$ [44]. La proporción de especies de cobalto difícilmente reducibles ( $T>500^{\circ} \mathrm{C}$ ) es netamente superior en los catalizadores soportados sobre ITQ-2 no sililada (im_Co/ITQ-2(a) y me_Co/ITQ-2(a)). Por tanto, la sililación de la superficie de ITQ-2 resulta en un aumento significativo de la reducibilidad de las partículas de Co, debido a una menor interacción de las mismas con el soporte. 


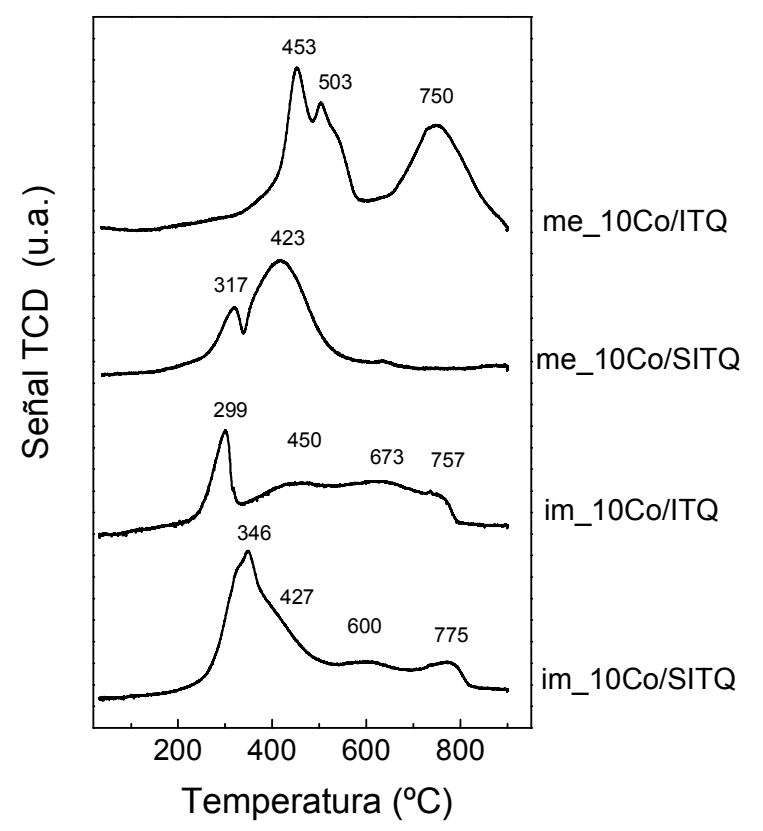

Figura 3.11: Perfiles de $\mathrm{H}_{2}$-TPR para los catalizadores $10 \% \mathrm{CO} / \mathrm{ITQ}-2$.

En cuanto al efecto del método de preparación, los catalizadores obtenidos por impregnación presentan perfiles de reducción menos localizados en temperatura que los de microemulsión, observándose, en los primeros, consumos de $\mathrm{H}_{2}$ en toda la zona de reducción, desde aprox. 300ㄷ $\mathrm{C}$ a $800^{\circ} \mathrm{C}$. Esto se debe a una distribución más heterogénea de tamaños de nanopartícula metálica, y por tanto del nivel de interacción con el soporte, cuando el Co se deposita por impregnación, como se discutió anteriormente a partir de los resultados de TEM.

A modo de conclusión, los resultados de esta parte de la investigación evidencian que la combinación de la síntesis de NPs en medios micelares inversos, y su posterior deposición sobre la superficie sililada de la zeolita deslaminada ITQ-2, permite obtener un catalizador de Co soportado sobre un soporte de naturaleza silícea (tras la calcinación) que presenta, de manera simultánea, una alta dispersión, con tamaños de nanopartícula 
metálica de aprox. $5 \mathrm{~nm}$, y una distribución de tamaño de nanopartícula estrecha. A su vez, el nuevo procedimiento de síntesis propuesto resulta en catalizadores que presentan una elevada reducibilidad, minimizando la presencia de fases metálicas de difícil reducción, algo que tiene lugar para catalizadores preparados por impregnación, incluso para menores niveles de dispersión metálica.

\subsection{Catalizadores modelo $\mathrm{Co} / \mathrm{ITQ}-2$ y $\mathrm{Co} / \mathrm{SiO}_{2}$ : influencia del tamaño de nanopartícula en la síntesis de Fischer-Tropsch.}

La nueva metodología de síntesis que combina la dispersión del metal mediante química coloidal ex-soporte, con el soporte deslaminado y sililado superficialmente, y que permite obtener catalizadores de dispersión controlada y elevada reducibilidad, se ha extendido en este punto de la investigación para preparar una serie de catalizadores modelo 10\%Co/ITQ-2 que permitan realizar estudios de reactividad y caracterización físico-química dirigidos a elucidar la influencia del tamaño de nanopartícula metálica en la SFT.

Como se recoge en el apartado 2.1.3.1 de la Sección Experimental, en este segundo estudio se ha empleado como soporte catalítico el segundo de los lotes de zeolita deslaminada ITQ-2 sintetizados (ITQ-2(b)). A su vez, con el objeto de extender el rango de tamaños de nanopartícula metálica con respecto al estudio anterior (sección 3.3), se ha modificado ligeramente el procedimiento experimental, empleando en este caso, un procedimiento que comprende dos microemulsiones idénticas conteniendo $\mathrm{Co}^{2+} \mathrm{e}$ hidrazina, respectivamente, en lugar de la adición de hidrazina sobre una única microemulsión.

Con el objetivo de obtener una batería de muestras con diferente dispersión metálica, se variaron sistemáticamente las características de la 
microemulsión empleada en la síntesis. Como se recoge en la Tabla 3.6, para esto se incrementa progresivamente la concentración de surfactante en la fase orgánica ([Surf] org) mientras que se disminuyen gradualmente la relación molar $\mathrm{H}_{2} \mathrm{O}$ /surfactante $(\mathrm{R})$ y la concentración molar del precursor metálico en la fase acuosa $\left([\mathrm{Co}]_{\mathrm{aq}}\right)$ para incrementar la dispersión metálica en el orden $10 \mathrm{Co} / \mathrm{ITQ}(1)<\ldots<10 \mathrm{Co} / \mathrm{ITQ}(5)$. Con el objetivo de incrementar aún más la dispersión metálica para los catalizadores 10Co/ITQ(6 y 7), de forma complementaria, se incrementó el exceso estequiométrico de hidrazina (ver ecuación 2.1) desde un valor de 8 hasta 10 y 16 veces, respectivamente. Una mayor concentración de hidrazina incrementa la velocidad de los procesos de nucleación frente a la correspondiente velocidad de crecimiento del cluster [45]. Este efecto, combinado con la creciente compartimentación ejercida por las concentraciones del metal y el surfactante en las fases acuosa y orgánica, respectivamente, debería permitir un incremento adicional en la dispersión metálica para estas dos muestras.

Adicionalmente, se preparó el catalizador de referencia $\left(30 \% \mathrm{Co} / \mathrm{SiO}_{2}(\mathrm{mf})\right)$ de baja dispersión metálica, empleando una mezcla física (en suspensión) de $\mathrm{Co}_{3} \mathrm{O}_{4}$ nanoparticulado comercial y $\mathrm{SiO}_{2}$ porosa, siguiendo el procedimiento descrito en la sección 2.1.3.2. 
Tabla 3.6: Detalle de los parámetros de las microemulsiones inversas empleadas para sintetizar los catalizadores modelo 10\%Co/ITQ-2.

\begin{tabular}{|c|c|c|c|c|}
\hline Muestra & $\begin{array}{c}\mathrm{R}^{\mathrm{a}} \\
(\mathrm{mol} / \mathrm{mol})\end{array}$ & $\begin{array}{l}{[\mathrm{Co}]_{\mathrm{aq}}^{\mathrm{b}}} \\
(\mathrm{mol} / \mathrm{L})\end{array}$ & $\begin{array}{c}{ }_{\text {[Surf] }}{ }^{\mathrm{c}}{ }^{\mathrm{c}} \\
\text { (mol/L) }\end{array}$ & $E R^{d}$ \\
\hline 10\%Co/ITQ(1) & 50 & 3.0 & 0.06 & 8 \\
\hline $10 \% \mathrm{Co} / \mathrm{ITQ}(2)$ & 25 & 1.65 & 0.13 & 8 \\
\hline 10\%Co/ITQ(3) & 10 & 0.56 & 0.65 & 8 \\
\hline 10\%Co/ITQ(4) & 7 & 0.30 & 0.65 & 8 \\
\hline 10\%Co/ITQ(5) & 5 & 0.24 & 0.65 & 8 \\
\hline 10\%Co/ITQ(6) & 5 & 0.10 & 0.80 & 10 \\
\hline 10\%Co/ITQ(7) & 5 & 0.05 & 1.30 & 16 \\
\hline
\end{tabular}

\subsubsection{Caracterización de los soportes catalíticos.}

La Tabla 3.7 recoge las propiedades texturales de la zeolita deslaminada original (ITQ-2(b)) y su correspondiente forma sililada (SITQ2(b)), determinadas por adsorción de $\mathrm{N}_{2}$. La zeolita ITQ-2 calcinada muestra un área superficial de $761 \mathrm{~m}^{2} / \mathrm{g}$, y un VP de $0.92 \mathrm{~cm}^{3} / \mathrm{g}$, mientras que el $V P_{\text {micro }}$ es de tan sólo $0.02 \mathrm{~cm}^{3} / g$, de acuerdo con su naturaleza deslaminada. La superficie específica y el VP decrecen ligeramente con el tratamiento de sililación ( $28 \%$ y $20 \%$, respectivamente), sin modificación del VP $P_{\text {micro. }}$.

Tabla 3.7: Propiedades texturales y contenido en carbono para los soportes catalíticos basados en zeolita deslaminada ITQ-2(b) en sus formas calcinada y sililada, y $\mathrm{SiO}_{2}$ porosa comercial.

\begin{tabular}{|c|c|c|c|c|}
\hline \multirow[b]{2}{*}{ Muestra } & \multicolumn{3}{|c|}{ Adsorción de $\mathrm{N}_{2}$} & \multirow[b]{2}{*}{$\begin{array}{c}\text { Contenido en C } \\
(\%(p))\end{array}$} \\
\hline & $\begin{array}{c}\text { Área B.E.T. } \\
\left(\mathrm{m}^{2} / \mathrm{g}\right)\end{array}$ & $\begin{array}{c}\mathrm{VP} \\
\left(\mathrm{cm}^{3} / \mathrm{g}\right)\end{array}$ & $\begin{array}{l}\mathrm{VP}_{\text {micro }} \\
\left(\mathrm{cm}^{3} / \mathrm{g}\right)\end{array}$ & \\
\hline ITQ-2(b) & 761 & 0.92 & 0.02 & 0.54 \\
\hline SITQ-2(b) & 546 & 0.74 & 0.02 & 7.00 \\
\hline $\mathrm{SiO}_{2}$ & 387 & 0.80 & n.d. & n.d. \\
\hline
\end{tabular}


El contenido en $\mathrm{C}$ de la zeolita calcinada es de $0.54 \%(\mathrm{p})$, como consecuencia de la permanencia, tras el tratamiento de calcinación, de restos carbonosos derivados del agente director de estructura o los surfactantes empleados durante la síntesis hidrotermal y la deslaminación. El contenido en carbono se incrementa hasta un 7.0\%(p) para SITQ-2(b), lo que corresponde con un recubrimiento ( $\alpha$, ecuación 3.2) de 1.5 grupos trimetilsililo por $\mathrm{nm}^{2}$.

Por otro lado, la $\mathrm{SiO}_{2}$ amorfa comercial empleada para preparar el catalizador referencia posee una superficie específica de $387 \mathrm{~m}^{2} / \mathrm{g}$ y un volumen de poro de $0.8 \mathrm{~cm}^{3} / g$, como también se recoge en la Tabla 3.7 .

\subsubsection{Caracterización de los catalizadores.}

\subsubsection{Composición química.}

Varios catalizadores Co/ITQ-2 se estudiaron mediante AE e ICP-OES antes de su calcinación, es decir, tras el tratamiento de secado, con el objetivo de obtener información acerca de su contenido en carbono y la naturaleza de la especie Co-hidrazina que se deposita desde la microemulsión inversa. Como se muestra en la Tabla 3.8, el contenido en carbono de los catalizadores analizados se incrementa desde 1.48 hasta $4.14 \%(p)$ en el orden $10 \% \mathrm{Co} / \mathrm{ITQ}(1)<\ldots<10 \% \mathrm{Co} / \mathrm{ITQ}(4)$, es decir, la cantidad de carbono retenido en el material es tanto mayor cuanto menor es la relación $\mathrm{H}_{2} \mathrm{O}$ /surfactante, es decir, mayor es el contenido en surfactante de la microemulsión empleada en la síntesis del catalizador (Tabla 3.6), lo que evidencia que el $\mathrm{C}$ determinado proviene de restos del surfactante empleado en el medio micelar.

Por otro lado, la relación atómica N/Co en los catalizadores no calcinados estudiados es prácticamente constante entorno a $3 / 2$, indicando que la naturaleza de las especies Co-hidrazina es la misma en todos los 
catalizadores, independientemente de los parámetros empleados en la microemulsión (Tabla 3.6). De acuerdo a la relación $\mathrm{N} / \mathrm{Co}=3 / 2$, se puede proponer la fórmula molecular $\left[\mathrm{CO}_{2}\left(\mathrm{~N}_{2} \mathrm{H}_{4}\right) \mathrm{NO}_{3}\right](\mathrm{OH})_{3}$ para estas especies depositadas en forma de nanopartículas sobre la superficie de SITQ-2(b). La formación de especies de naturaleza similar se ha observado al añadir hidracina a disoluciones acuosas de $\mathrm{Pd}^{2+}$ en condiciones en las que no tiene lugar la reducción del metal a su estado elemental [46]. De hecho, la presencia de especies $\mathrm{N}_{2} \mathrm{H}_{4}\left(\mathrm{~N}-\mathrm{N}\right.$ a $\left.978 \mathrm{~cm}^{-1}\right)$ y $\mathrm{NO}_{3}^{-}\left(1360 \mathrm{~cm}^{-1}\right)$ se confirmó mediante espectroscopia IR para muestras seleccionadas, antes de la calcinación (espectros no mostrados). No obstante, un estudio exhaustivo de la composición y estructura del precipitado Co-hidrazina carece de relevancia para el presente trabajo, puesto que esta especie se descompone durante los primeros momentos del tratamiento de calcinación de los catalizadores, como se evidenció por TG-DTA y TPO-MS en la sección 3.3.2.1.

Por otra parte, como se recoge también en la Tabla 3.8, los contenidos metálicos determinados mediante ICP-OES para los catalizadores calcinados coinciden satisfactoriamente con los valores nominales (desviaciones relativas $<10 \%$ ).

Tabla 3.8: Análisis químico de los catalizadores 10\% Co/ITQ-2 y 30\% $\mathrm{Co} / \mathrm{SiO}_{2}$ antes y después de la calcinación.

\begin{tabular}{|c|c|c|c|c|}
\hline \multirow[b]{2}{*}{ Muestra } & \multicolumn{2}{|c|}{ Muestras sin calcinar } & \multicolumn{2}{|c|}{ Muestras calcinadas } \\
\hline & $\begin{array}{c}\text { Contenido C } \\
(\%(p))\end{array}$ & $\mathrm{N} / \mathrm{Co}$ & $\begin{array}{c}\text { Contenido Co } \\
(\%(p))\end{array}$ & $\begin{array}{c}\text { Contenido C } \\
(\%(p))\end{array}$ \\
\hline 10\%Co/ITQ(1) & 1.48 & 1.5 & 9.3 & 0.64 \\
\hline 10\%Co/ITQ(2) & --- & --- & 9.0 & 0.52 \\
\hline 10\%Co/ITQ(3) & 3.16 & 1.5 & 9.6 & 0.74 \\
\hline 10\%Co/ITQ(4) & 4.14 & 1.6 & 10.1 & 0.83 \\
\hline 10\%Co/ITQ(5) & --- & --- & 10.5 & 0.54 \\
\hline 10\%Co/ITQ(6) & --- & --- & 9.4 & 0.61 \\
\hline 10\%Co/ITQ(7) & --- & --- & 9.6 & 0.58 \\
\hline $30 \% \mathrm{Co} / \mathrm{SiO}_{2}$ & --- & --- & 28.7 & 0.01 \\
\hline
\end{tabular}


Finalmente, los contenidos en $C$ en los materiales calcinados se encuentran en el rango $0.52-0.83 \%$, de modo que, esencialmente, corresponden a los residuos carbonosos presentes en la zeolita ITQ-2 calcinada original (Tabla 3.7). No obstante, para algunos catalizadores se produce un ligero incremento en el contenido de carbono de hasta un $0.29 \%(p)$, indicando que la retirada de las especies orgánicas (grupos trimetilsililo anclados superficialmente o surfactante proveniente de la microemulsión) no tiene lugar de manera completa durante el tratamiento de calcinación. Este incremento en el contenido de carbono no parece seguir ninguna pauta clara y no existe correlación evidente entre el mismo y la cantidad de surfactante empleada en la preparación del catalizador (Tabla 3.6). Finalmente, el catalizador $30 \mathrm{Co} / \mathrm{SiO}_{2}(\mathrm{mf})$ calcinado no contiene carbono puesto que no se emplean sustancias carbonosas en su preparación.

\subsubsection{Dispersión metálica.}

En primer lugar, la dispersión metálica en los catalizadores calcinados se estudió por medio de XRD. La única fase metálica cristalina detectada en los catalizadores $30 \mathrm{Co} / \mathrm{SiO}_{2}(\mathrm{mf})$ y $10 \mathrm{Co} / \mathrm{ITQ}(1$ a 5$)$ calcinados es la espinela $\mathrm{Co}_{3} \mathrm{O}_{4}$. En la Figura 3.12, que muestra de forma detallada la difracción más intensa correspondiente al plano cristalino $\left(\begin{array}{lll}3 & 1 & 1\end{array}\right)$, para catalizadores seleccionados, donde se perciben diferencias evidentes en la anchura de las señales de difracción relacionadas con distintos tamaños medios de cristal $\left(d\left(\mathrm{CO}_{3} \mathrm{O}_{4}\right) \times\right)$. 


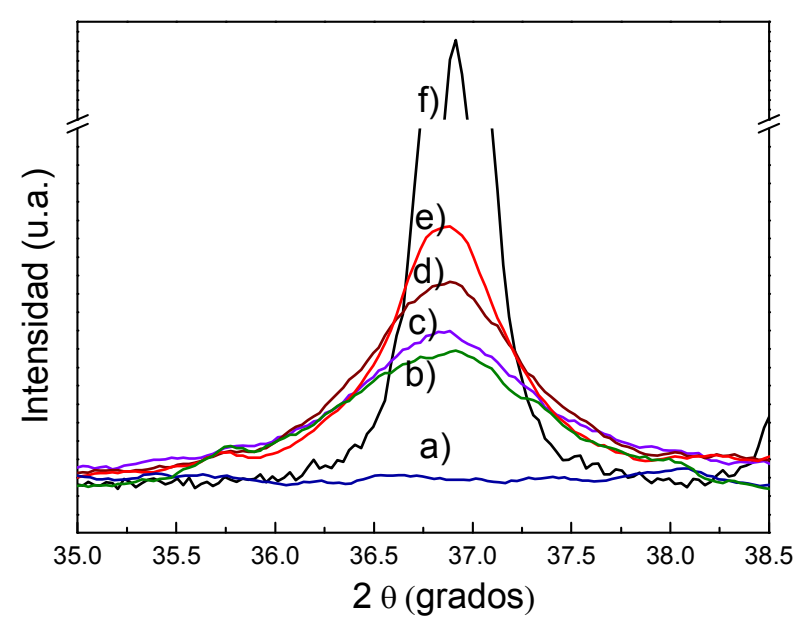

Figura 3.12: Detalle del difractograma de rayos $X$ mostrando la difracción del plano (3 1 1) para $\mathrm{CO}_{3} \mathrm{O}_{4}$ en los catalizadores 10Co/ITQ(5) (b), 10Co/ITQ(4) (c), 10Co/ITQ(2) (d), 10Co/ITQ(1) (e) y $30 \mathrm{Co} / \mathrm{SiO}_{2}(\mathrm{mf})$ (f) calcinados. El difractograma para el soporte ITQ-2(a) se muestra también como referencia (a).

La estimación del tamaño de cristal mediante la ecuación de Scherrer muestra un valor de $d\left(\mathrm{CO}_{3} \mathrm{O}_{4}\right)_{x}$ de $125 \mathrm{~nm}$ para $30 \mathrm{Co} / \mathrm{SiO}_{2}(\mathrm{mf})$ (Tabla 3.9). Por lo tanto, el empleo de $\mathrm{Co}_{3} \mathrm{O}_{4}$ nanocristalino comercial en la preparación de este catalizador resulta en una baja dispersión metálica. Por otro lado, para las muestras $10 \mathrm{Co} / \mathrm{ITQ}(1$ a 5$), d\left(\mathrm{CO}_{3} \mathrm{O}_{4}\right)_{\mathrm{x}}$ decrece desde 12.5 hasta 5.9 $\mathrm{nm}$, correspondiendo con $d\left(\mathrm{Co}^{\circ}\right)_{x}=9.4-4.4 \mathrm{~nm}$ en los catalizadores reducidos, como resultado del control que ejerce el medio micelar sobre el tamaño de nanopartícula metálica.

Por el contrario, no se detectan fases de óxido de Co por XRD en los catalizadores $10 \mathrm{Co} / \mathrm{ITQ}(6)$ y $10 \mathrm{Co} / \mathrm{ITQ}(7)$, lo que puede deberse a la ausencia de $\mathrm{Co}_{3} \mathrm{O}_{4}$ o a su presencia en forma de cristales muy pequeños, no detectables por XRD (<2-3 nm), de acuerdo con la mayor dispersión metálica esperada para estas muestras a la vista de los parámetros empleados para el medio micelar durante su preparación (Tabla 3.6). 
Tabla 3.9: Dispersión metálica de los catalizadores 10\%Co/ITQ-2 y 30\% Co/SiO 2 .

\begin{tabular}{|c|c|c|c|c|c|c|c|}
\hline \multirow[b]{2}{*}{ Catalizador } & \multicolumn{2}{|c|}{ XRD } & \multicolumn{3}{|c|}{ Quimisorción $\mathrm{H}_{2}$} & \multicolumn{2}{|c|}{ TEM } \\
\hline & $\begin{array}{c}d\left(\mathrm{Co}_{3} \mathrm{O}_{4}\right)_{x} \\
(\mathrm{~nm})\end{array}$ & $\begin{array}{c}d\left(\mathrm{Co}^{0}\right)_{x} \\
(\mathrm{~nm})\end{array}$ & $\begin{array}{c}\mathrm{H}_{2, \mathrm{ads}} \\
(\mu \mathrm{mol} / \mathrm{g})\end{array}$ & $\begin{array}{c}D \\
(\%)\end{array}$ & $\begin{array}{c}d\left(\mathrm{Co}^{0}\right)_{\mathrm{H}} \\
(\mathrm{nm})\end{array}$ & $\begin{array}{c}d\left(\mathrm{Co}^{0}\right)_{T} \\
(\mathrm{~nm})\end{array}$ & $\begin{array}{c}\sigma_{\mathrm{T}} \\
(\mathrm{nm})\end{array}$ \\
\hline $30 \% \mathrm{Co} / \mathrm{SiO}_{2}$ & 125 & 94 & 16.6 & 0.7 & 141 & 183 & 56 \\
\hline $10 \% \mathrm{Co} / \mathrm{ITQ}(1)$ & 12.5 & 9.4 & 73 & 9.6 & 10.4 & 12.8 & 3.4 \\
\hline $10 \% \mathrm{Co} / \mathrm{ITQ}(2)$ & 9.9 & 7.4 & 82 & 11.2 & 8.9 & 8.2 & 2.0 \\
\hline 10\%Co/ITQ(3) & 9.1 & 6.8 & 122 & 13.6 & 7.3 & n.d. ${ }^{a}$ & n.d. \\
\hline $10 \% \mathrm{Co} / \mathrm{ITQ}(4)$ & 6.8 & 5.1 & 161 & 17.8 & 5.6 & 6.3 & 1.5 \\
\hline 10\%Co/ITQ(5) & 5.9 & 4.4 & n.d. & n.d. & n.d. & n.d. & n.d. \\
\hline
\end{tabular}

La dispersión metálica en los catalizadores reducidos se estudió, a su vez, mediante quimisorción de $\mathrm{H}_{2}$. Los resultados correspondientes de dispersión metálica (D) y tamaño medio de nanopartícula metálica $\left(d\left(\mathrm{Co}^{0}\right)_{\mathrm{H}}\right)$ se recogen también en la Tabla 3.9. Se observa que el catalizador $30 \mathrm{Co} / \mathrm{SiO}_{2}(\mathrm{mf})$ presenta una dispersión metálica muy baja $(0.7 \%)$ que corresponde con un valor de $d\left(\mathrm{Co}^{0}\right)_{\mathrm{H}}=141 \mathrm{~nm}$. Si bien esta baja dispersión metálica está en línea con la caracterización por XRD, el valor de $d\left(\mathrm{CO}^{\circ}\right)_{\mathrm{H}}$ es sensiblemente mayor que el calculado desde los resultados de XRD sobre la muestra calcinada $\left(d\left(\mathrm{Co}^{0}\right)_{x}=94 \mathrm{~nm}\right)$, lo que sugiere que durante el tratamiento de reducción tiene lugar aglomeración metálica (sintering), debido probablemente, a una interacción limitada entre la fase de $\mathrm{Co}_{3} \mathrm{O}_{4}$ y el soporte de $\mathrm{SiO}_{2}$. Por otro lado, los catalizadores modelo $10 \mathrm{Co} / \mathrm{ITQ}(1$ a 4$)$ presentan dispersiones metálicas en el rango de 9.6-17.8\%, correspondientes con $d\left(\mathrm{CO}^{0}\right)_{\mathrm{H}}$ en el rango de 10.4-5.6 nm. En este caso, los valores de $d\left(\mathrm{CO}^{0}\right)_{H}$ estimados por quimisorción de $\mathrm{H}_{2}$ concuerdan de modo satisfactorio con los correspondientes valores obtenidos por XRD, aunque $d\left(\mathrm{CO}^{0}\right)_{H}$ es sistemáticamente superior (7-20\%) al correspondiente $d\left(\mathrm{CO}^{0}\right)_{X}$, sugiriendo que cierto nivel de aglomeración metálica, aunque limitado, tiene lugar durante el tratamiento de reducción. 
Adicionalmente, se llevó a cabo una caracterización por TEM de los catalizadores reducidos y pasivados. La Figura 3.13 muestra micrografías TEM, a media magnificación, representativas para los catalizadores 10Co/ITQ(4), 10Co/ITQ(2), 10/ColTQ(1) y 30Co/SiO 2 (mf). 
a)
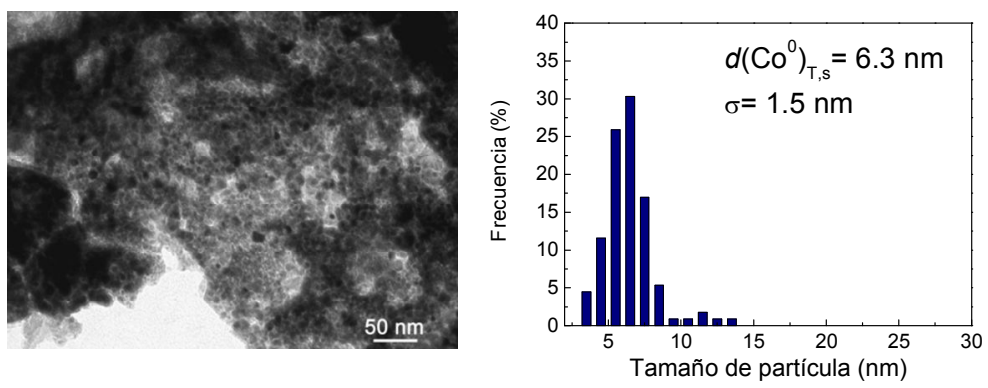

b)
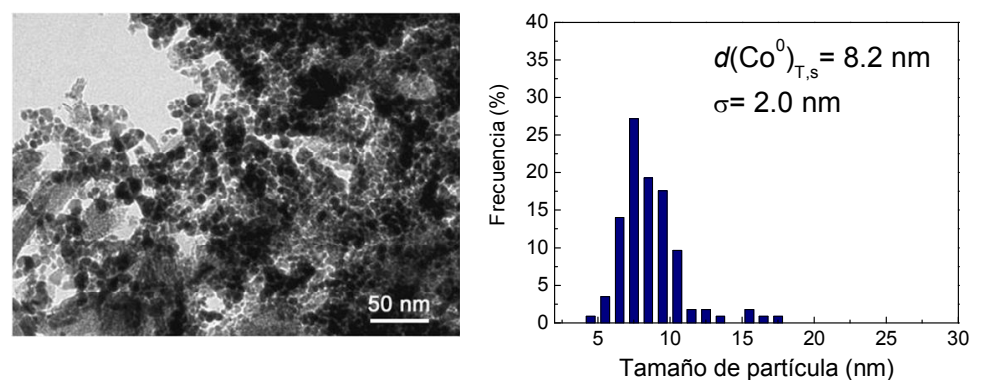

c)
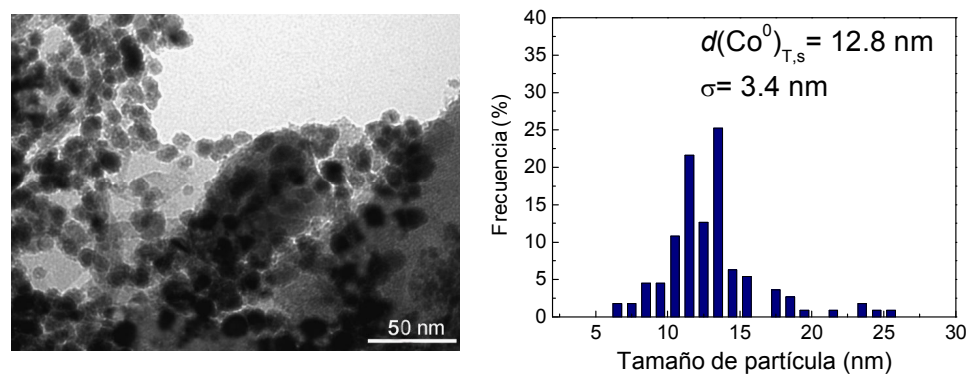

d)
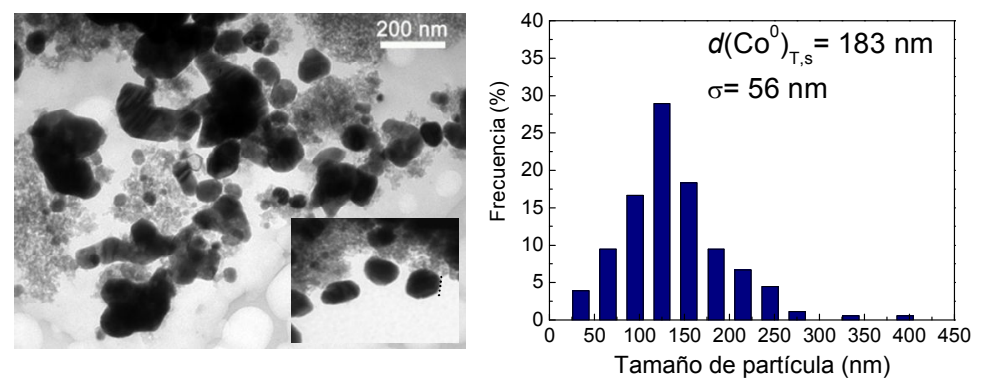

Figura 3.13: Micrografías de TEM representativas y las correspondientes distribuciones de tamaño de nanopartícula para los catalizadores 10Co/ITQ(4) (a), Co/ITQ(2) (b), 10Co/ITQ(1) (c) y 30CoSiO $(\mathrm{mf})(\mathrm{d})$ reducidos y pasivados. 
Como se observa en las micrografías, los catalizadores $10 \% \mathrm{Co} / \mathrm{ITQ}-2$ consisten en nanopartículas de Co de forma pseudo-esférica (identificadas por su mayor contraste) dispersas sobre las láminas del soporte (de menor contraste). Las distribuciones de tamaño de nanopartícula, incluidas en la Fig. 3.13, muestran un carácter aproximadamente unimodal, estrecho y gaussiano con valores de $d\left(\mathrm{Co}^{0}\right)_{\mathrm{T}}$ de $12.8,8.2$ y $6.3 \mathrm{~nm}$ para $10 \mathrm{Co} / \mathrm{ITQ}(1)$, $10 \mathrm{Co} / \mathrm{ITQ}(2)$ y $10 \mathrm{Co} / \mathrm{ITQ}(4)$, respectivamente.

Tal y como se recoge en la Tabla 3.9, para los catalizadores 10\%Co/ITQ-2, la desviación estándar en la distribución de tamaños de nanopartícula toma valores en el rango de 1.5-3.4 nm, correspondiente con un $22-24 \%$ del valor medio en todos los casos, y ésta se incrementa con valores de $d\left(\mathrm{Co}^{0}\right)_{T}$ crecientes, quizás como resultado de una menor homogeneidad en el tamaño de nanopartícula cuando se emplean micelas de mayor tamaño en la síntesis (mayor valor de $\mathrm{R}$, ver Tabla 3.6). Los valores de $d\left(\mathrm{Co}^{\circ}\right)_{T}$ se han estimado corrigiendo por una capa de pasivado ( $\left.\mathrm{CoO}\right)$ de 3 $\mathrm{nm}$ de grosor, como se detalló en la sección 2.2.10.2, para 10Co/ITQ(1) y $10 \mathrm{Co} / \mathrm{ITQ}(2)$, mientras que para $10 \mathrm{Co} / \mathrm{ITQ}(4)$ se consideró la reoxidación completa de las nanopartículas en las condiciones empleadas para el pasivado y la preparación de la muestra para microscopía. De hecho, la Fig. 3.14 muestra una micrografía de HRTEM para Co/ITQ(4) en la que se aprecia la presencia de nanocristales de 6-8 $\mathrm{nm}$ de diámetro que muestran el espaciado interplanar de 2.1 Å propio del plano cristalográfico $\left(\begin{array}{lll}2 & 0 & 0\end{array}\right)$ de la fase $\mathrm{CoO}$, y que, por lo tanto, corresponden con nanopartículas de $\mathrm{Co}^{0}$ de 4.5-6 nm de diámetro que se han re-oxidado completamente. De hecho, el menor contraste relativo que se observa para las nanopartículas metálicas en la Figura 3.13-a para $10 \mathrm{Co} / \mathrm{ITQ}(4)$ puede ser una consecuencia de la presencia de $\mathrm{CoO}$ en lugar de $\mathrm{Co}^{\circ}$. 


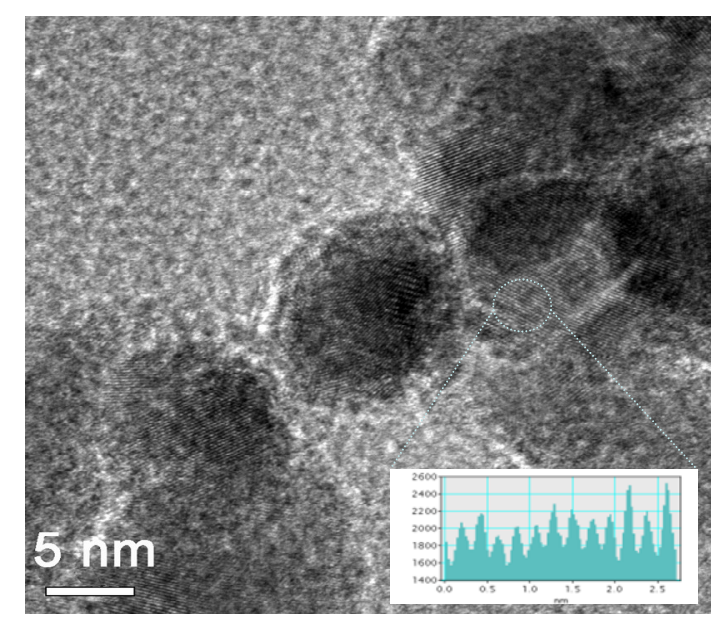

Figura 3.14: Micrografía de alta resolución (HR-TEM) para el catalizador 10Co/ITQ(4) reducido y pasivado y perfil de espaciado cristalino, que evidencia la re-oxidación completa a $\mathrm{CoO}$.

Por último, la muestra $30 \mathrm{Co} / \mathrm{SiO}_{2}(\mathrm{mf})$ presenta un valor de $d\left(\mathrm{Co}^{0}\right)_{\mathrm{T}}$ de $183 \mathrm{~nm}$, el cual está más de acuerdo con el valor estimado por quimisorción de $\mathrm{H}_{2}\left(d\left(\mathrm{CO}^{0}\right)_{H}=141 \mathrm{~nm}\right)$ que con el derivado del análisis por XRD, confirmando la existencia de aglomeración metálica durante el tratamiento de reducción. Para este catalizador el diámetro de nanopartícula medido directamente sobre las micrografías no se corrigió por ninguna capa de pasivado, que posee un espesor despreciable frente al diámetro de la partícula. Por su parte, la distribución de tamaños de nanopartícula es, en este caso, sensiblemente más ancha que en el caso de los catalizadores modelo $10 \% \mathrm{Co} / \mathrm{ITQ}-2$ sintetizados en un medio coloidal. Finalmente, como se observa en la Figura 3.13-d, los cristales metálicos se encuentran exclusivamente sobre la superficie externa de las partículas de $\mathrm{SiO}_{2}$ en el catalizador de referencia.

\subsubsection{Reducibilidad y naturaleza química de las especies de Co.}

El comportamiento en reducción de los catalizadores modelo $10 \% \mathrm{Co} / \mathrm{ITQ}-2$ y $30 \% \mathrm{Co} / \mathrm{SiO}_{2}(\mathrm{mf})$ se estudió por medio de $\mathrm{H}_{2}$-TPR. Los perfiles 
de $\mathrm{H}_{2}$-TPR se muestran en la Fig. 3.15 organizados verticalmente de acuerdo al diámetro de nanopartícula de óxido de $\mathrm{Co}\left(d\left(\mathrm{Co}_{3} \mathrm{O}_{4}\right)_{\mathrm{x}}\right)$. Aquellos catalizadores que no presentan nanopartículas de $\mathrm{Co}_{3} \mathrm{O}_{4}$ detectables por XRD se han incluido también en la figura y se han situado considerando el orden de dispersión metálica esperado en base a los parámetros de las microemulsiones inversas empleados durante la síntesis (ver Tabla 3.6). Como se puede observar, para los catalizadores modelo $30 \mathrm{Co} / \mathrm{SiO}_{2}(\mathrm{mf})$ y $10 \mathrm{Co} / \mathrm{ITQ}(1 \mathrm{a} 5)$ tienen lugar dos consumos de $\mathrm{H}_{2}$ principales en el rango de temperaturas de 230-750 ํ que corresponden con la reducción de $\mathrm{Co}_{3} \mathrm{O}_{4}$ en dos etapas: $\mathrm{Co}_{3} \mathrm{O}_{4} \rightarrow \mathrm{CoO}$ (señal I a temperaturas de $257-322^{\circ} \mathrm{C}$ ) y $\mathrm{CoO} \rightarrow \mathrm{Co}^{0}$ (señal II a temperaturas de 306-444ํㅡ), de acuerdo con la literatura $[43,47]$. Esta asignación viene respaldada, también, por el hecho de que el cociente de consumos de $\mathrm{H}_{2}$ señal II/ señal I toma valores en el rango 3-3.7 para todas las muestras, aproximadamente de acuerdo con el valor estequiométrico esperado de 3. 


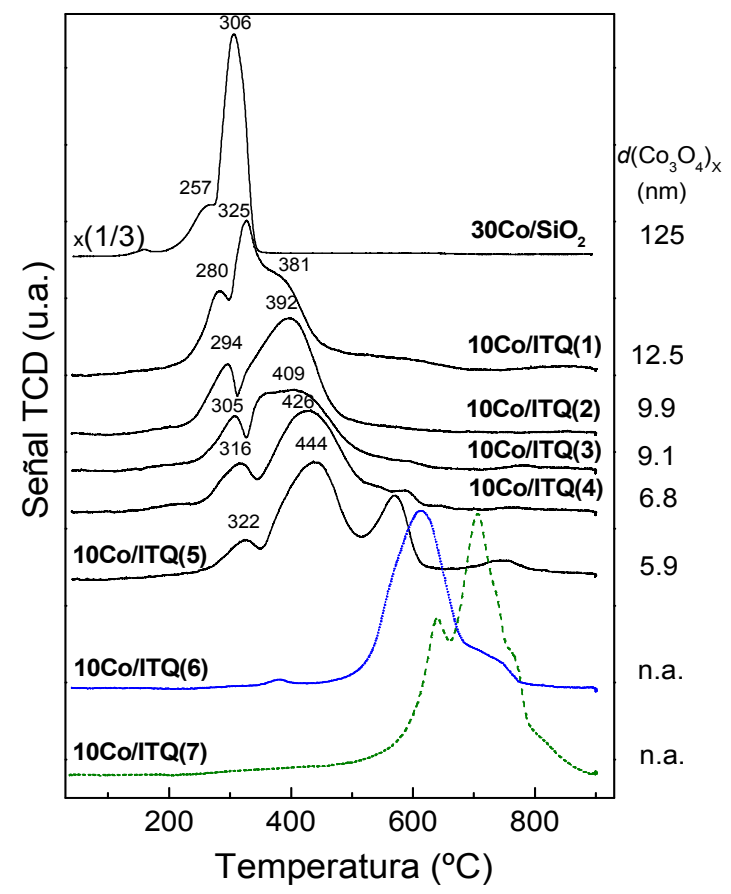

Figura 3.15: Perfiles de $\mathrm{H}_{2}$-TPR para los catalizadores 10Co/ITQ(1-7) y 30Co/SiO $(\mathrm{mf})$.

Como se observa en la Fig. 3.15, tiene lugar un continuo desplazamiento de las temperaturas para el máximo de las señales I y II cuando disminuye $d\left(\mathrm{CO}_{3} \mathrm{O}_{4}\right) x$. La Fig. 3.16 muestra la variación de la temperatura de las señales de $\mathrm{H}_{2}$-TPR con el tamaño de nanopartícula de $\mathrm{CO}_{3} \mathrm{O}_{4}$ para todos los catalizadores $\mathrm{Co} / \mathrm{ITQ}-2$. 


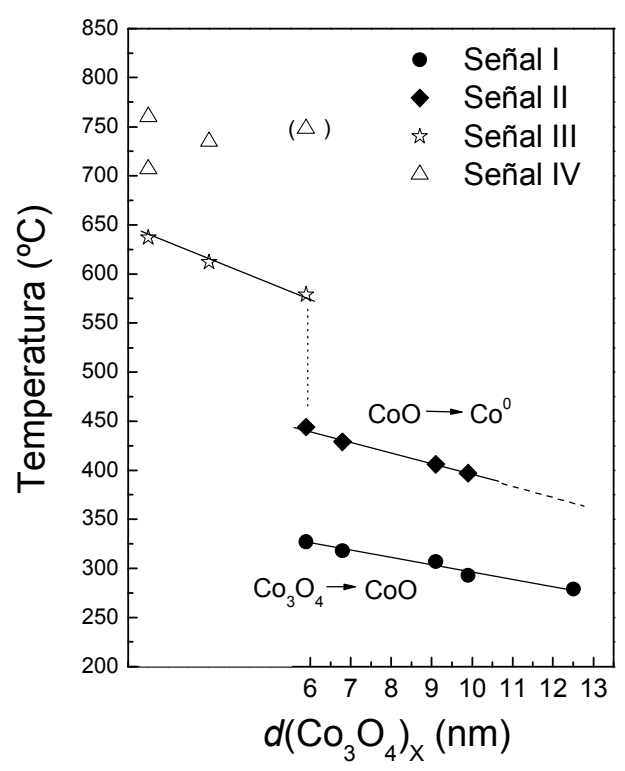

Figura 3.16: Evolución de la temperatura para los procesos de reducción de los catalizadores 10Co/ITQ(1 a 7) en función del tamaño de nanopartícula.

Se observa que las temperaturas para las dos etapas de reducción de $\mathrm{Co}_{3} \mathrm{O}_{4}$ (señales I y II) se incrementan continuamente cuando decrece $d\left(\mathrm{CO}_{3} \mathrm{O}_{4}\right)_{x}$ en el rango $12.5-5.9 \mathrm{~nm}$.

No se observan, por su parte, procesos de reducción en el régimen de altas temperaturas $\left(>530^{\circ} \mathrm{C}\right)$ para los catalizadores que presentan $d\left(\mathrm{CO}_{3} \mathrm{O}_{4}\right) \mathrm{x}$ en el rango de 125 a $6.8 \mathrm{~nm}$. Por el contrario, cuando el tamaño de nanopartícula de $\mathrm{CO}_{3} \mathrm{O}_{4}$ se disminuye hasta $5.9 \mathrm{~nm}$ en $10 \mathrm{Co} / \mathrm{ITQ}(5)$, se desarrollan dos señales adicionales: una intensa a 567ำ (señal III), junto con otra débil a temperaturas muy elevadas de $747^{\circ} \mathrm{C}$ (señal IV). Incrementando aún más la dispersión metálica (disminuyendo el tamaño de nanopartícula metálica) para $10 \mathrm{Co} / \mathrm{ITQ}(6)$, prácticamente se eliminan las contribuciones de las señales de reducción propias de $\mathrm{Co}_{3} \mathrm{O}_{4}(\mathrm{~T}<530$ 으), de acuerdo con la ausencia de difracciones de rayos $X$ para esta fase (sección 3.4.2.2.), mientras que el pico III se desarrolla a $611^{\circ} \mathrm{C}$, con un hombro adicional, 
menos intenso, a $738^{\circ} \mathrm{C}$ (señal IV). Finalmente, forzando las condiciones de síntesis hacia aún una mayor dispersión metálica en 10Co/ITQ(7), se desplaza la denominada señal III hacia mayores temperaturas (632으) y se reduce de manera acusada su intensidad relativa frente a la señal predominante de muy alta temperatura (señal IV a $T>680^{\circ} \mathrm{C}$ ) que, en este caso, aparece como una contribución intensa a $707^{\circ} \mathrm{C}$ con un hombro a $763^{\circ} \mathrm{C}$.

Se percibe en la Fig. 3.16 que $10 \mathrm{Co} / \mathrm{ITQ}(5)$, con un $d\left(\mathrm{Co}_{3} \mathrm{O}_{4}\right)_{x}=5.9 \mathrm{~nm}$, es una muestra de transición entre los catalizadores menos dispersos que muestran exclusivamente las señales propias de la reducción de $\mathrm{Co}_{3} \mathrm{O}_{4}$ (señales I y II) y las muestras de mayor dispersión metálica que muestran principalmente señales de reducción a temperaturas por encima de 530ㄷ (señales III y IV). Al igual que para las señales I y II, se observa que la denominada señal III muestra una temperatura que es función de $d\left(\mathrm{CO}_{3} \mathrm{O}_{4}\right)_{x}$. Por el contrario, la señal de más alta temperatura (señal IV entre $680{ }^{\circ} \mathrm{C}$ y 770 ㄷ) no muestra una dependencia evidente con la dispersión.

Por lo tanto, los perfiles de $\mathrm{H}_{2}$-TPR sugieren una evolución coherente de la naturaleza de las especies de Co (identificadas por los diferentes procesos de reducción) con la dispersión metálica para el conjunto de catalizadores modelo $10 \% \mathrm{Co} / \mathrm{ITQ}-2$, gracias a que la metodología de síntesis empleada permite un control sobre la dispersión metálica. Además, esta tendencia permite "aislar" algunas señales de reducción predominantes en ciertas muestras, lo que se espera que corresponda con catalizadores conteniendo prácticamente un solo tipo de especies metálicas.

Para elucidar la evolución de la naturaleza de las especies metálicas con la dispersión en los catalizadores modelo 10\%/Co/ITQ-2 calcinados se empleó la espectroscopia DR UV-vis. Esta información es de especial interés 
para las especies de Co que se reducen a temperaturas superiores a las empleadas generalmente en los tratamientos de reducción aplicados antes de la catálisis $\left(300^{\circ} \mathrm{C}-500^{\circ} \mathrm{C}\right.$ ) y que son catalíticamente inactivas para la SFT [12]. La Fig. 3.17 recoge los espectros UV-vis para el grupo de catalizadores 10\%Co/ITQ-2 seleccionado.

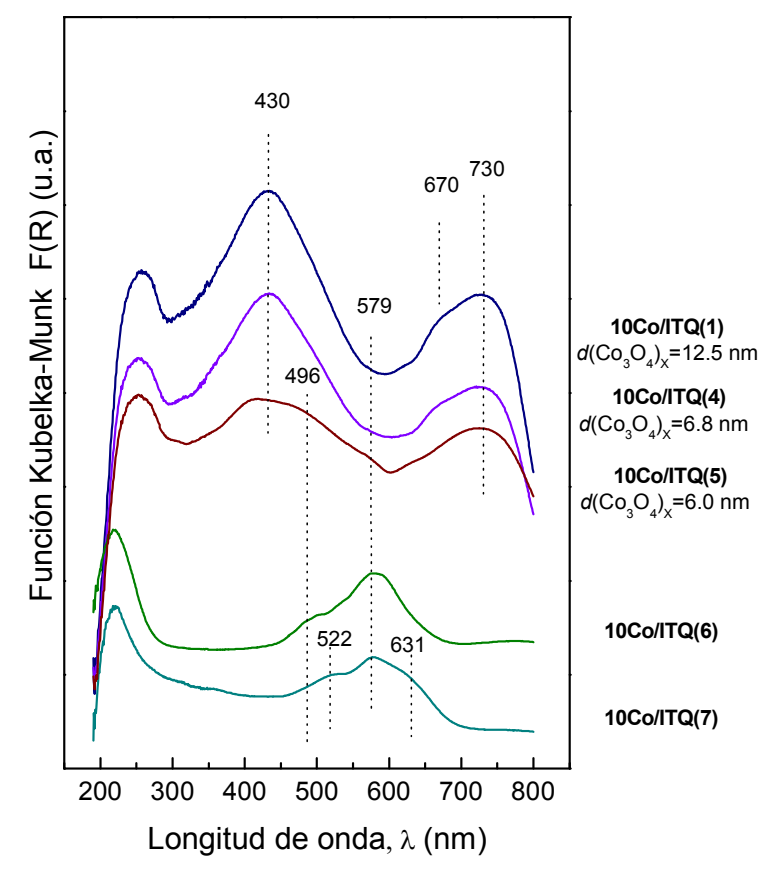

Figura 3.17: Espectros de DR UV-vis para catalizadores 10\%Co/ITQ-2 calcinados seleccionados.

Todos los espectros muestran varias bandas anchas en el rango de 300-800 nm debidas a transiciones electrónicas ligando-metal y transiciones electrónicas intra-atómicas $d$-d asociadas con los iones de Co. Los catalizadores 10Co/ITQ(1 y 4) muestran bandas a 430 y $730 \mathrm{~nm}$ (con un hombro a $670 \mathrm{~nm}$ ) que se atribuyen a transiciones electrónicas oxígenometal para los iones $\mathrm{Co}^{2+}$ y $\mathrm{Co}^{3+}$, respectivamente, en la red de la espinela $\mathrm{Co}_{3} \mathrm{O}_{4}$ [48]. No se observan bandas adicionales en la región 450-650 nm, de 
acuerdo con la presencia de $\mathrm{Co}_{3} \mathrm{O}_{4}$ como única fase metálica en estas muestras, como se discutió en base a los perfiles de $\mathrm{H}_{2}$-TPR. En el otro extremo, la muestra de mayor dispersión metálica $10 \mathrm{Co} / \mathrm{ITQ}(7)$ muestra un triplete con máximos de absorción situados a 522, 579 y $631 \mathrm{~nm}$ que son típicos, respectivamente, para las transiciones electrónicas $d-d 4 \mathrm{~A}^{2} \rightarrow 2 \mathrm{~T}^{1}, 4 \mathrm{~T}^{1}$ у $2 \mathrm{~T}^{2}$ en iones $\mathrm{Co}^{2+}$ en coordinación tetraédrica pura en la red de silicatos de tipo $\mathrm{Co}_{2} \mathrm{SiO}_{4}$ [49]. Así pues, en esta muestra, el Co reacciona, incorporándose en el interior de la estructura del soporte silíceo, durante la calcinación. De acuerdo con este resultado, la denominada señal IV de los perfiles de $\mathrm{H}_{2}$-TPR puede asignarse a $\mathrm{Co}_{2} \mathrm{SiO}_{4}$ de tipo bulk y el hecho de que el Co no esté presente en forma de especies superficiales explica la ausencia de una dependencia de la temperatura para esta señal IV con la dispersión metálica (Fig. 3.16). De manera distinta 10Co/ITQ(6) apenas absorbe a $631 \mathrm{~nm}$ mientras que la señal más energética se desplaza a menores longitudes de onda $(496 \mathrm{~nm})$ con respecto al espectro de 10Co/ITQ(7). Este tipo de modificación en el espectro puede estar relacionado con la presencia de silicatos de $\mathrm{Co}^{2+}$ conteniendo Co tanto en coordinación tetraédrica como octaédrica, o bien a una distorsión parcial de la coordinación tetraédrica en el silicato de Co debida a la presencia de algún ligando adicional para los iones $\mathrm{Co}^{2+}$, como grupos $\mathrm{OH}$ de los silanoles existentes en la superficie del soporte $[48,50]$. Esta última explicación indicaría que las especies de silicato de Co presentes en 10Co/ITQ(6) son pequeños clusters localizados en la superficie del soporte, al contrario que las especies de tipo bulk que se infieren de los resultados de UV-vis para la muestra 10Co/ITQ(7). Esta interpretación está apoyada, a su vez, por el hecho de que la temperatura a la que se registra la señal III de $\mathrm{H}_{2}$-TPR, que es predominante para la muestra 10Co/ITQ(6), es una función de la dispersión metálica (Fig. 3.16). La ausencia de bandas debidas a $\mathrm{Co}_{3} \mathrm{O}_{4}$ en $10 \mathrm{Co} / \mathrm{ITQ}(6)$ descarta la asignación del pico III de reducción $\left(580^{\circ} \mathrm{C}-640^{\circ} \mathrm{C}\right)$ a especies $\mathrm{Co}_{3} \mathrm{O}_{4}$ de muy pequeño tamaño, que 
interaccionan fuertemente con el soporte silíceo, como propusieron algunos autores con anterioridad [44]. Finalmente, 10Co/ITQ(5), como muestra de transición, presenta las bandas relacionadas con la espinela $\mathrm{Co}_{3} \mathrm{O}_{4}$, junto con hombros menos intensos a 496 y $579 \mathrm{~nm}$ asociados con la presencia de los mencionados hidroxi-silicatos de Co superficiales presentes, probablemente, en la interfase de contacto entre las nanopartículas de $\mathrm{Co}_{3} \mathrm{O}_{4}$ y la zeolita deslaminada ITQ-2.

Regresando a la discusión de reducibilidad, para los catalizadores 10Co/ITQ(1 a 4) el valor de GR se incrementa de $87 \%$ a $96 \%$ cuando $d\left(\mathrm{CO}_{3} \mathrm{O}_{4}\right) \times$ se incrementa desde 6.8 hasta $12.5 \mathrm{~nm}$, mientras que para el catalizador de baja dispersión $30 \mathrm{Co} / \mathrm{SiO}_{2}(\mathrm{mf})$ la reducción es completa (GR $\approx 100 \%)$ en las condiciones aplicadas durante el tratamiento de reducción, antes de la catálisis. Estos elevados valores de GR ( $\geq 87 \%)$ aseguran que, para este grupo de catalizadores que no presentan especies de tipo silicato metálico en su forma calcinada, no existirá una contribución apreciable de especies metálicas oxidadas durante los ensayos catalíticos.

Así pues, en síntesis, la dispersión metálica homogénea que se obtiene en los catalizadores modelo $10 \% \mathrm{Co} / \mathrm{ITQ}-2$, junto con los resultados de $\mathrm{H}_{2}$-TPR y DR UV-vis, permite estudiar cómo evolucionan de forma progresiva la naturaleza química y la reducibilidad de las especies de Co soportadas con la dispersión metálica, hasta niveles de dispersión elevados. A su vez, este sistema modelo permite concluir que la energía de activación para las etapas de reducción del óxido $\mathrm{Co}_{3} \mathrm{O}_{4}$ depende del tamaño de nanopartícula metálica. Esta conclusión puede parecer obvia a la vista de los trabajos previos en los que se describe que las nanopartículas de $\mathrm{Co}_{3} \mathrm{O}_{4}$ de menor tamaño son menos reducibles que las de mayor tamaño $[5,12]$. Sin embargo, la conclusión alcanzada en el presente trabajo no está distorsionada por señales de reducción de alta temperatura (catalizadores 
$30 \mathrm{Co} / \mathrm{SiO}_{2}(\mathrm{mf})$ y $10 \mathrm{Co} / \mathrm{ITQ}(1$ a 4$\left.)\right)$ relacionadas con compuestos mixtos $\mathrm{Co}-\mathrm{Si}$, que típicamente coexisten con las fases de óxido de Co en los catalizadores de elevada dispersión metálica preparados por métodos de síntesis más convencionales, como impregnación, debido a su distribución de tamaños de nanopartícula inherentemente más ancha (ver secciones 3.3.2.3. y 3.3.2.4. para im_Co/ITQ-2).

La mejora en reducibilidad, gracias a la protección (con grupos orgánicos sililantes) de los grupos silanoles del soporte durante la descomposición de los precursores metálicos y la cristalización de $\mathrm{Co}_{3} \mathrm{O}_{4}$, encuentra su límite para $d\left(\mathrm{Co}_{3} \mathrm{O}_{4}\right)$ x alrededor de $5.9 \mathrm{~nm}$ (muestra $10 \mathrm{Co} / \mathrm{ITQ}(5))$. Para nanopartículas de $\mathrm{CO}_{3} \mathrm{O}_{4}$ de tamaño inferior a este límite, la interacción entre las fases metálicas soportadas y el soporte ITQ-2 promueve su reacción durante las fases finales del tratamiento de calcinación, una vez que los grupos orgánicos protectores se han descompuesto, dando lugar a hidroxi-silicatos de Co superficiales primero, probablemente en la interfase $\mathrm{Co}_{3} \mathrm{O}_{4}$-soporte, y a silicatos $\mathrm{Co}_{2} \mathrm{SiO}_{4}$ de tipo bulk cuando la dispersión metálica se incrementa aún más (para la muestra 10Co/ITQ(7)).

\subsubsection{Actividad catalítica.}

A la vista de sus propiedades físico-químicas, la serie de catalizadores $10 \% \mathrm{Co} / \mathrm{ITQ}-2$ y el catalizador de referencia de baja dispersión $30 \mathrm{Co} / \mathrm{SiO}_{2}(\mathrm{mf})$ constituyen un conjunto de candidatos idóneos para estudiar los efectos del tamaño de nanopartícula en la SFT.

La actividad catalítica de los catalizadores se ha evaluado a 2.0MPa y $\mathrm{T}=220^{\circ} \mathrm{C}$. Solamente se han ensayado catalizadores cuyo $\mathrm{GR} \geq 87 \%$, con el fin de asegurar que los resultados catalíticos no se encuentran distorsionados por la presencia de especies de Co oxidadas, las cuales se conoce que 
presentan baja actividad y una selectividad elevada hacia la metanación $[3,13]$. En todos los experimentos, la velocidad espacial (GHSV) se ajustó para lograr una conversión en estado pseudo-estacionario de $10 \pm 2 \%$. Este nivel de conversión relativamente bajo persigue limitar los cambios de composición de la fase gaseosa a lo largo del lecho catalítico y evitar la presencia de una elevada presión parcial de $\mathrm{H}_{2} \mathrm{O}\left(\mathrm{P}_{\mathrm{H}_{2} \mathrm{O}}\right)$ puesto que este subproducto presenta un efecto auto-catalítico, que incrementa la actividad en la SFT catalizada por $\mathrm{Co} / \mathrm{SiO}_{2}$, cuando está presente en cantidades importantes en el lecho reactivo, al trabajar a elevados niveles de conversión [51]. Limitar la presión parcial de $\mathrm{H}_{2} \mathrm{O}$ es también beneficioso desde el punto de vista de evitar la re-oxidación de las nanopartículas de Co de menor tamaño durante la reacción catalítica. El fenómeno de re-oxidación puede ser responsable de la desactivación de los catalizadores de Co más dispersos en condiciones realistas de operación en la SFT [52], aunque estudios recientes han descartado la re-oxidación de nanopartículas de Co de tamaño $\geq 6 \mathrm{~nm}$ bajo condiciones de SFT relevantes desde el punto de vista industrial [53].

La Tabla 3.10 recoge los resultados catalíticos para los catalizadores ensayados en la SFT.

Como se puede observar, el catalizador $30 \mathrm{Co} / \mathrm{SiO}_{2}(m f)\left(d\left(\mathrm{Co}^{0}\right)_{\mathrm{H}}=141\right.$ $\mathrm{nm}$ ) muestra un $\mathrm{CTY}_{\mathrm{e}}$ de $3.3 \cdot 10^{-3} \mathrm{~mol} \mathrm{CO} /\left(\mathrm{g}_{\mathrm{Co}} \cdot \mathrm{h}\right)$, muy inferior al de los catalizadores $10 \% \mathrm{Co} / \mathrm{ITQ}-2\left(14 \cdot 10^{-3}-53 \cdot 10^{-3} \mathrm{~mol} \mathrm{CO} /\left(\mathrm{g}_{\mathrm{co}} \cdot \mathrm{h}\right)\right)$, como cabe esperar del hecho de que el primero presenta una dispersión metálica sensiblemente inferior. No obstante, el incremento esperado en CTY cuando se incrementa la dispersión metálica no se mantiene para la serie de catalizadores $10 \% \mathrm{Co} / \mathrm{ITQ}-2$. De hecho, el valor de $\mathrm{CTY}_{\mathrm{e}}$ disminuye continuamente de $10 \mathrm{Co} / \mathrm{ITQ}(1)$ a $10 \mathrm{Co} / \mathrm{ITQ}(4)$, es decir, cuando $d\left(\mathrm{Co}^{0}\right)_{\mathrm{H}}$ 
disminuye de $10.4 \mathrm{~nm}$ a $5.6 \mathrm{~nm}$, o de forma equivalente, el número de centros metálicos expuestos se dobla (ver valores de $\mathrm{H}_{2, a d s}$ en Tabla 3.9). Así, este descenso en el $\mathrm{CTY}_{\mathrm{e}}$ está relacionado con una disminución en la actividad intrínseca de los centros metálicos cuando disminuye $d\left(\mathrm{CO}^{0}\right)_{H}$.

Adicionalmente, cabe comentar que puede descartarse un efecto derivado de una desactivación diferencial para los catalizadores en función de su nivel de dispersión, puesto que las tendencias comentadas se mantienen íntegramente cuando se consideran los valores de TOF iniciales (extrapolados para tiempo de reacción cero), y que, por ende, no pueden estar influidos por los fenómenos de desactivación. Por lo tanto, estas tendencias están inequívocamente relacionadas con fenómenos intrínsecos relacionados con el tamaño de nanopartícula de $\mathrm{Co}^{0}$.

Tabla 3.10: Resultados catalíticos para catalizadores modelo 10\%Co/ITQ-2 seleccionados y $30 \% \mathrm{Co} / \mathrm{SiO}_{2}(\mathrm{mf})$. Condiciones de reacción: $T=220^{\circ} \mathrm{C}, P=2.0 \mathrm{MPa}$, $\mathrm{H}_{2} / \mathrm{CO}=2, \mathrm{X}_{\mathrm{CO}}=10 \pm 2 \%$.

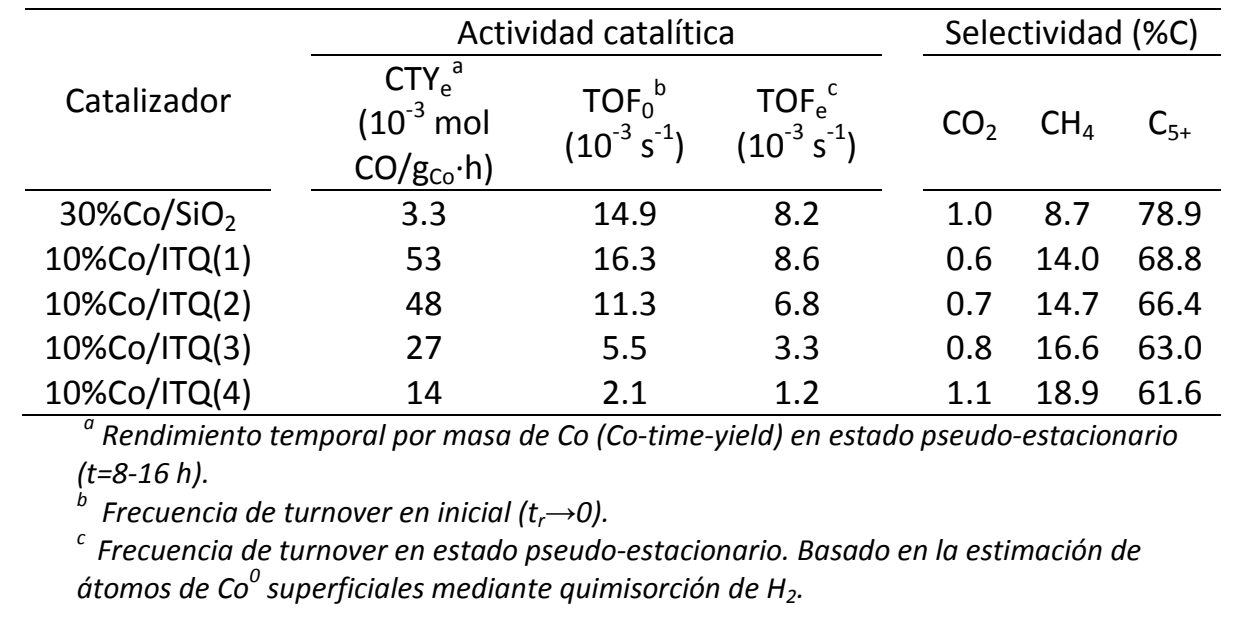

La Figura 3.18-a muestra la variación del valor de TOF, basado en los datos de quimisorción de $\mathrm{H}_{2}$, frente a $d\left(\mathrm{Co}^{0}\right)_{H}$. Como se observa, el valor de TOF se incrementa al crecer $d\left(\mathrm{CO}^{\circ}\right)_{H}$ en el rango de 5.6 a $10.4 \mathrm{~nm}$ y después 
permanece prácticamente constante para mayores diámetros de partícula metálica hasta $d\left(\mathrm{Co}^{0}\right)_{\mathrm{H}}=141 \mathrm{~nm}$.

Recientemente, Bezemer y col. [17] encontraron un descenso de TOF al disminuir $d\left(\mathrm{CO}^{\circ}\right)$ en el rango 2.6 a $8 \mathrm{~nm}$ y un valor de TOF constante para mayores $d\left(\mathrm{Co}^{\circ}\right)$ en la SFT catalizada por Co/CNF a $3.5 \mathrm{MPa}$ y $210^{\circ} \mathrm{C}$. Los resultados obtenidos en el presente trabajo empleando catalizadores soportados sobre ITQ-2 y $\mathrm{SiO}_{2}$ están en concordancia cualitativa con los publicados por estos autores, aunque en este caso la dependencia del valor de TOF con la dispersión metálica se mantiene hasta valores de $d\left(\mathrm{Co}^{\circ}\right)$ de 10 $\mathrm{nm}$.

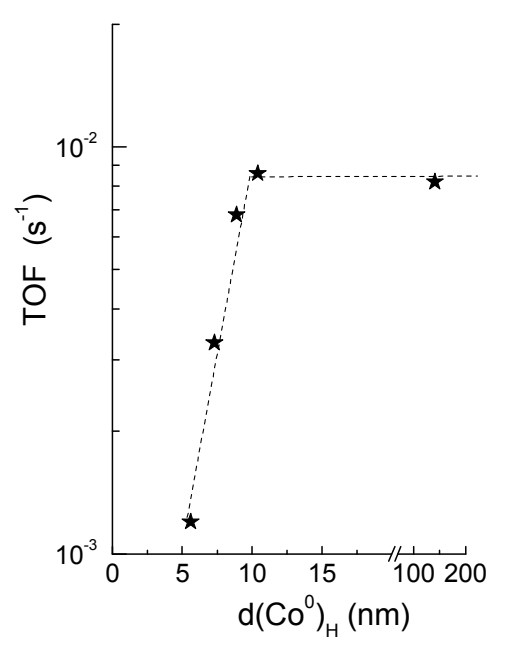

(a)

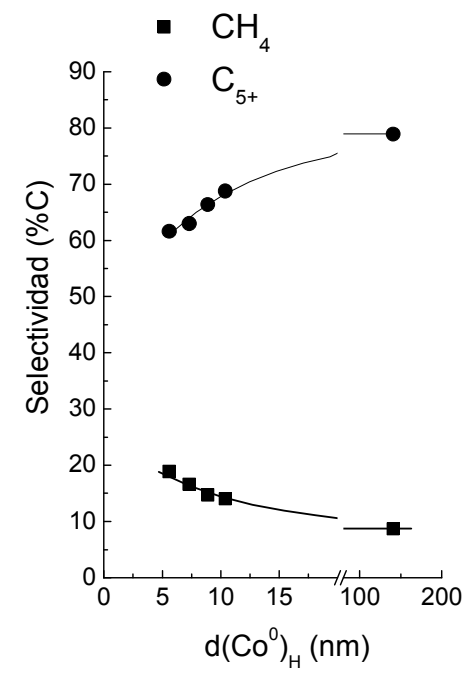

(b)

Figura 3.18: Dependencia de la actividad (TOF) (a) y la selectividad catalítica (b) con el diámetro de nanopartícula de $\mathrm{Co}^{\circ}$. Condiciones de reacción: $T=220^{\circ} \mathrm{C}, P=2.0 \mathrm{MPa}$, $\mathrm{H}_{2} / \mathrm{CO}=2, \mathrm{X}_{\mathrm{CO}}=10 \pm 2 \%$.

En lo que respecta a la selectividad de la síntesis (a $X_{C O}=10 \%$ ), los resultados recogidos en la Tabla 3.10 indican que la selectividad a $\mathrm{CH}_{4}$ decrece desde 18.9 hasta $14.0 \%$ mientras que la selectividad a los productos 
de cadena larga $\left(C_{5+}\right)$ se incrementa de 61.6 a $68.8 \%$ para los catalizadores 10\%Co/ITQ-2 en el orden 10Co/ITQ(1) a 10Co/ITQ(4). Así, tal y como muestra la Figura 3.18-b, la selectividad a $\mathrm{CH}_{4}$ disminuye mientras que la de los productos $\mathrm{C}_{5+}$ se incrementa al incrementarse $d\left(\mathrm{CO}^{0}\right)_{H}$ en el rango de 5.6 a $10.4 \mathrm{~nm}$. Además, al contrario de lo observado para el valor de TOF, un incremento ulterior de $d\left(\mathrm{Co}^{\circ}\right)_{\mathrm{H}}$ hasta $141 \mathrm{~nm}$ (catalizador $30 \mathrm{Co} / \mathrm{SiO}_{2}(m f)$ ) supone aún un incremento importante en la selectividad a la fracción $\mathrm{C}_{5+}$ (hasta $78.9 \%$ ) a expensas de los hidrocarburos más ligeros $\left(\mathrm{S}_{\mathrm{CH} 4}=8.0 \%\right)$. Otros autores también encontraron un incremento en la selectividad a hidrocarburos $\mathrm{C}_{5+}$ con $d\left(\mathrm{Co}^{\circ}\right)$ en el rango de tamaños de nanopartícula para los que el valor de TOF permanece constante [17], sin que de momento se haya propuesto una explicación para este hecho experimental.

En este punto debe mencionarse que esta evolución de la selectividad a las diferentes fracciones de productos no puede explicarse por la variación en la densidad volumétrica de centros metálicos $\left(\mathrm{Co}^{0}\right)$ en los diferentes catalizadores, la cual influye en la probabilidad de re-adsorción de $\alpha$-olefinas (sección 1.3.7.2) [54]. De hecho, se esperaría una tendencia opuesta ya que los catalizadores menos dispersos muestran una menor densidad volumétrica de centros metálicos y, por tanto, una menor probabilidad para la re-adsorción de $\alpha$-olefinas, lo que resultaría en una menor selectividad a productos de cadena larga. Así pues, las diferencias en selectividad observadas para los catalizadores modelo estudiados en este capítulo son el resultado de diferentes propiedades intrínsecas relacionadas con el diámetro de NP metálica.

Finalmente, conviene resaltar que no existen diferencias significativas en la selectividad a $\mathrm{CO}_{2}$ para los catalizadores (0.6-1.1\%) ni una correlación evidente entre la misma y $d\left(\mathrm{Co}^{0}\right)_{\mathrm{H}}$ (Tabla 3.10). Se ha demostrado que las especies de Co no reducidas muestran una mayor actividad hacia la WGSR 
que incrementa la producción de $\mathrm{CO}_{2}$ y la metanación [55]. Así pues, el hecho de que se obtengan bajas selectividades a $\mathrm{CO}_{2}$ con los catalizadores modelo $10 \% \mathrm{Co} / \mathrm{ITQ}-2$ y $30 \mathrm{Co} / \mathrm{SiO}_{2}(\mathrm{mf})$ es una prueba indirecta adicional de la elevada reducibilidad de los mismos.

Durante el trabajo de la presente tesis doctoral, otros autores $[17,56]$ han publicado trabajos adicionales en los que se pone de manifiesto esta sensibilidad a la estructura de tipo III-a (ver Fig. 1.11) empleando catalizadores monodispersos y altamente reducibles. La siguiente sección pretende generar una explicación para este efecto del tamaño de NP no clásico empleando técnicas espectroscópicas in situ y operando y microscopía electrónica.

\subsubsection{Estudio de los catalizadores mediante CO-FTIR.}

3.4.4.1. Topología metálica superficial de los catalizadores reducidos.

La naturaleza de los centros metálicos superficiales en catalizadores seleccionados, tras el tratamiento de reducción en $\mathrm{H}_{2}$, se ha estudiado mediante espectroscopia de $\mathrm{CO}$ adsorbido a temperatura ambiente (COFTIR). Considerando los resultados experimentales mostrados en la Fig. 3.18a, se han seleccionado para este estudio tres muestras que abarcan tanto el rango de $d\left(\mathrm{CO}^{0}\right)_{H}$ estudiado (5.6-141 nm) como el rango de valores de TOF encontrados en los experimentos catalíticos: $30 \mathrm{Co} / \mathrm{SiO}_{2}(\mathrm{mf})$ con $d\left(\mathrm{Co}^{0}\right)_{\mathrm{H}}=141$ $\mathrm{nm}, 10 \mathrm{Co} / \mathrm{ITQ}(1) \operatorname{con} d\left(\mathrm{Co}^{0}\right)_{\mathrm{H}}=10.4 \mathrm{~nm}$, ambos con un valor de TOF similar, $\mathrm{y}$ $10 \mathrm{Co} / \mathrm{ITQ}(4)$ con $d\left(\mathrm{Co}^{0}\right)_{\mathrm{H}}=5.6 \mathrm{~nm}$ que presenta el menor de los valores de TOF de todos los catalizadores ensayados en la SFT. Debido a cuestiones de opacidad, el catalizador $30 \mathrm{Co} / \mathrm{SiO}_{2}(\mathrm{mf})$ se diluyó por mezcla física con la cantidad adecuada de $\mathrm{SiO}_{2}$ para alcanzar una carga metálica del 10\%(p)Co que permite obtener una pastilla lo suficientemente transparente. El 
catalizador obtenido por dilución se denomina $10 \mathrm{Co} / \mathrm{SiO}_{2}(\mathrm{mf})$ a lo largo de la discusión de los resultados de CO-FTIR.

La Fig. 3.19 muestra los espectros de FTIR en la región de carbonilos metálicos (1800-2100 $\left.\mathrm{cm}^{-1}\right)$, tras la exposición de los catalizadores reducidos a 5 mbar de $\mathrm{CO}$, a temperatura ambiente.

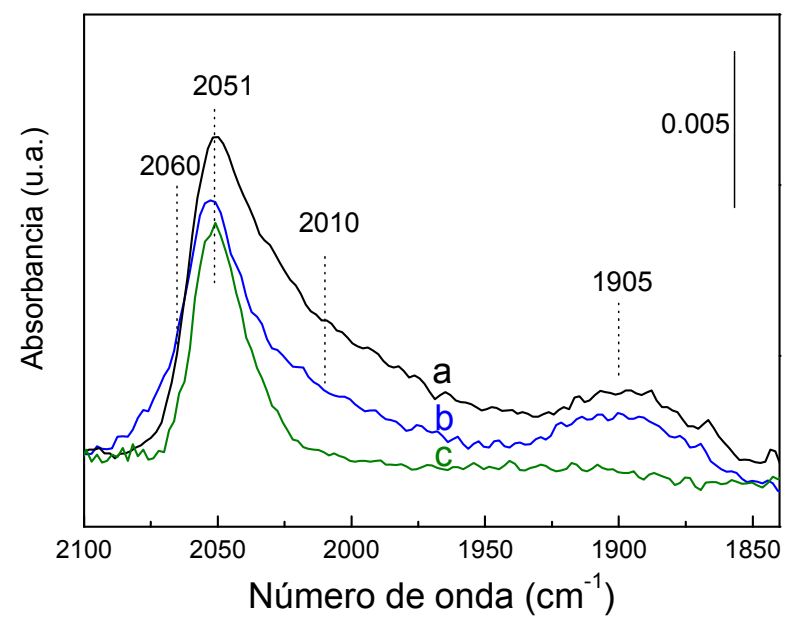

Figura 3.19: Espectros de FTIR tras la exposición de los catalizadores 10Co/ITQ(1) (a), 10Co/ITQ(4) (b) y $10 \mathrm{Co} / \mathrm{SiO}_{2}(\mathrm{mf})$ (c), previamente reducidos, a 5 mbar de CO a temperatura ambiente.

Se observan dos señales principales a aproximadamente 2051 y 1905 $\mathrm{cm}^{-1}$, las cuales se asignan a $\mathrm{CO}$ adsorbido sobre centros metálicos de $\mathrm{Co}^{0}$ en los modos lineal y puenteado (bridged), respectivamente $[57,58]$. La banda a aprox. $2050 \mathrm{~cm}^{-1}$ se ha asociado en trabajos previos con CO adsorbido en modo lineal sobre nanopartículas de $\mathrm{Co}^{0} / \mathrm{SiO}_{2}$ de estructura cristalina $f c c$ [59], lo cual está de acuerdo con la preponderancia de esta fase cristalina en los catalizadores modelo empleados en este estudio, cuyo tratamiento de reducción se realiza a una temperatura $\left(450^{\circ} \mathrm{C}\right)$ superior a la de la transición $h c p \rightarrow f c c\left(415^{\circ} \mathrm{C}\right)$. La preponderancia de la mencionada banda de IR sugiere su asignación a CO adsorbido sobre centros metálicos situados en un plano 
metálico de exposición superficial preferente para las nanopartículas de cristalografía cúbica, como el plano (1 111 ).

Por otro lado, la banda a $2051 \mathrm{~cm}^{-1}$ aparece mostrando una clara asimetría, con un hombro a menores frecuencias (aprox. $2010 \mathrm{~cm}^{-1}$ ), para los catalizadores $10 \mathrm{Co} / \mathrm{ITQ}(1)$ y $10 \mathrm{Co} / \mathrm{ITQ}(4)$, mientras que este hombro apenas es perceptible para la muestra de baja dispersión metálica $10 \mathrm{Co} / \mathrm{SiO}_{2}(\mathrm{mf})$.

Las bandas de carbonilos de cobalto de baja frecuencia (2000-2030 $\mathrm{cm}^{-1}$ ) se han asociado en la literatura a centros metálicos superficiales de baja coordinación, situados en planos cristalográficos de baja densidad de empaquetamiento, o bien aristas o vértices, que presentan una mayor capacidad de retro-donación electrónica desde los orbitales metálicos d hacia el orbital $\pi^{*}$ anti-enlazante de la molécula de CO [60,61] (Sección 2.2.14). La presencia de una mayor densidad superficial en este tipo de centros de $\mathrm{Co}^{0}$ de baja coordinación en los catalizadores 10\%Co/ITQ-2, sintetizados mediante química coloidal, está de acuerdo con su menor tamaño de nanopartícula metálica, en oposición a las nanopartículas de gran tamaño existentes en $10 \mathrm{Co} / \mathrm{SiO}_{2}(m f)$, que exponen, de manera preferente, planos cristalinos superficiales bien definidos ( $\mathrm{Co}^{0}$ en terrazas). A la vista de las intensidades relativas de las bandas a 2051 y $2010 \mathrm{~cm}^{-1}$, no se infieren diferencias significativas en la proporción de centros metálicos de baja coordinación entre los catalizadores 10Co/ITQ(1) y 10Co/ITQ(4). Este hecho puede parecer sorprendente a primera vista, puesto que cabe esperar una mayor proporción de centros metálicos en defectos para NPs de menor tamaño (Sección 1.3.7.3). No obstante, en el rango de tamaños de nanopartícula de 5.6-10.4 nm estas variaciones en la proporción de centros superficiales en defectos serán sólo modestas, como se muestra de manera esquemática en la Fig. 3.20 para un modelo de nanopartícula de $\mathrm{Co}^{\circ}$ cuboctaédrico. Por el contrario, en el rango de tamaño de nanopartícula 
donde típicamente se manifiesta el fenómeno de sensibilidad a la estructura clásica $(<4 \mathrm{~nm})$, tienen lugar variaciones importantes en la proporción superficial de este tipo de centros metálicos con el diámetro de nanopartícula.
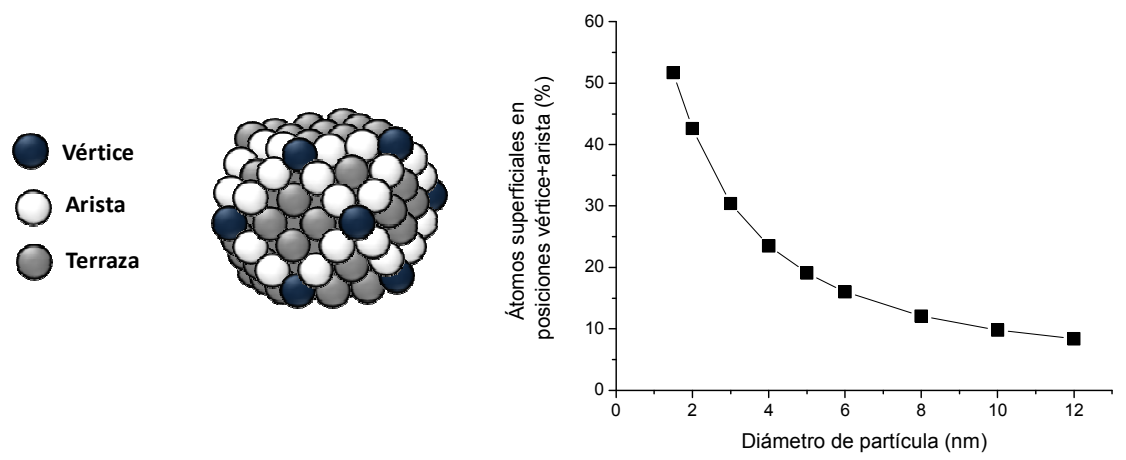

Figura 3.20: Evolución de la proporción de átomos superficiales en posiciones de baja coordinación (vérticestaristas) con el tamaño de nanopartícula para nanopartículas de $\mathrm{Co}^{0}$ de geometría cuboctaédrica ideal [62].

Adicionalmente, en la Figura 3.19 se observa la contribución de un hombro a elevadas frecuencias $\left(2060 \mathrm{~cm}^{-1}\right.$ ) para la muestra 10Co/ITQ(4). La asignación de esta banda a $2060 \mathrm{~cm}^{-1}$ es un poco controvertida de acuerdo con la literatura científica disponible, puesto que se han propuesto tanto especies di-carbonilo sobre centros metálicos en posiciones de defectos [63], como una estructura parcialmente hidrogenada $\mathrm{Co}(\mathrm{H}) \mathrm{CO}$ [64] o $\mathrm{CO}$ adsorbido sobre centros parcialmente oxidados $\mathrm{Co}^{\delta+}[65,66,67]$.

La asignación a especies di-carbonilo no es consistente con los datos experimentales mostrados en la Figura 3.19, puesto que requeriría de la existencia de bandas de IR para los modos de vibración simétrico y antisimétrico del dicarbonilo, las cuales no se detectan en el espectro. Por otro lado, la posibilidad de una especie parcialmente hidrogenada de tipo $\mathrm{Co}(\mathrm{H}) \mathrm{CO}$ tampoco es consistente puesto que el tratamiento de evacuación a 
elevada temperatura al que se someten las muestras tras el tratamiento de reducción (Sección 2.2.14) asegura una retirada eficiente de las especies de $\mathrm{H}_{2}$ adsorbido [68]. Así pues, la banda a $2060 \mathrm{~cm}^{-1}$ que aparece en el espectro de $10 \mathrm{Co} / \mathrm{ITQ}(4)$ se asigna de modo tentativo a CO adsorbido linealmente sobre centros $\mathrm{Co}^{\delta+}$ presentes en la interfase entre las nanopartículas metálicas y el soporte. La presencia de grupos oxigenados ( $\mathrm{Si}-\mathrm{OH})$ en la superficie del soporte (ITQ-2) induce un carácter electropositivo en los centros metálicos adyacentes. Esta asignación es coherente con una mayor contribución de la superficie de contacto con el soporte para las nanopartículas de menor tamaño presentes en 10Co/ITQ(4). De hecho, una inspección detallada de resultados previos de caracterización de catalizadores de Co mediante CO-FTIR revela que otros autores encontraron una mayor contribución de bandas en la región $2060-2070 \mathrm{~cm}^{-1}$ cuando se disminuye el tamaño de nanopartícula metálica en catalizadores $\mathrm{Co} / \mathrm{Al}_{2} \mathrm{O}_{3}$ $[64,69]$ y $(f c c)$ RuCo/SBA-15 [70].

Por último, no se detectan bandas adicionales en la región de aprox. $2175 \mathrm{~cm}^{-1}$, asociadas con CO adsorbido sobre centros $\mathrm{Co}^{2+}$ (en óxidos ó silicatos de cobalto), para las tres muestras estudiadas. Esto es una consecuencia de su elevada reducibilidad. Por el contrario, cuando se estudia en idénticas condiciones una muestra que no se reduce de manera completa durante el pretratamiento en $\mathrm{H}_{2}$, como $10 \mathrm{Co} / \mathrm{ITQ}(5)$, se percibe claramente una banda en esta posición (espectro no mostrado).

Seguidamente, se ha estudiado la evolución del espectro de CO-FTIR con el incremento en la dosis de $\mathrm{CO}$, a temperatura ambiente. Las Figs. 3.21 y 3.22 muestran la evolución de los espectros de CO-FTIR con la dosis de CO en el rango de 5-250 mbar para los catalizadores 10Co/ITQ(1) y 10Co/ITQ(4), respectivamente. 


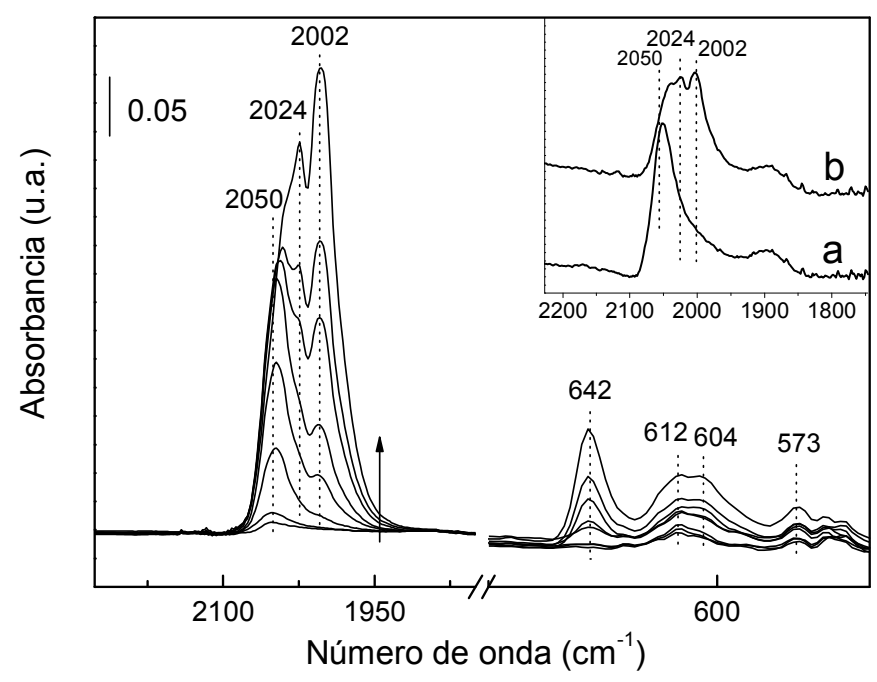

Figura 3.21: Evolución del espectro de FTIR con la dosis de CO ( $P_{C O}=5-250$ mbar) a temperatura ambiente para el catalizador 10Co/ITQ(1) previamente reducido. EI detalle de la figura muestra el espectro en la región de carbonilos metálicos a baja dosis de CO (5 mbar) para la muestra recién reducida (a) y la muestra re-evacuada tras alcanzar una primera dosis de 250 mbar de CO (b).

Como se observa, se desarrollan nuevas bandas relativamente intensas a aprox. 2024 y $2002 \mathrm{~cm}^{-1}$ cuando se incrementa progresivamente la dosis de CO. La menor frecuencia y mayor estabilidad (frente a la evacuación de la celda) de estas bandas con respecto a la banda original a aprox. $2050 \mathrm{~cm}^{-1}$, sugieren la adsorción lineal de CO sobre centros metálicos de baja coordinación. De manera interesante, tras una primera exposición a 250 mbar de CO y la evacuación de la muestra, la re-adsorción de CO sobre los catalizadores $10 \% \mathrm{Co} / \mathrm{ITQ}-2$ no reproduce los espectros originales, como se muestra en los detalles incluidos en las Figs. 3.21 y 3.22 para una dosis de 5 mbar. La imposibilidad de recuperar los espectros originales sugiere la existencia de reestructuración superficial para las nanopartículas metálicas, responsable del desarrollo de las nuevas bandas a 2002 y $2024 \mathrm{~cm}^{-1}$ cuando se incrementa la presión de CO en la celda. Dicha reestructuración es irreversible ante una evacuación de la celda a temperatura ambiente. 


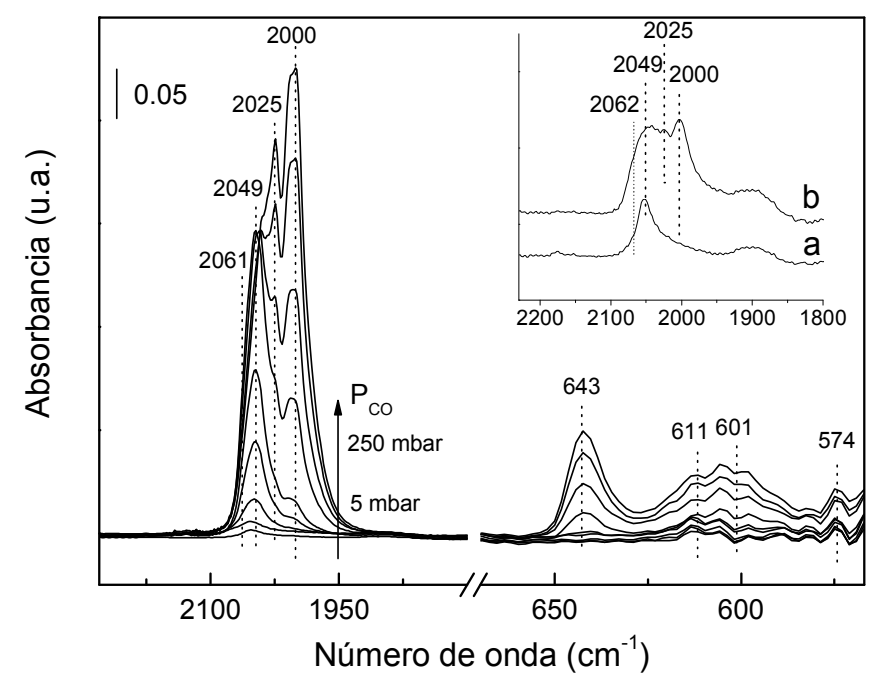

Figura 3.22: Evolución del espectro de FTIR con la dosis de CO $\left(P_{C O}=5-250 \mathrm{mbar}\right)$ a temperatura ambiente para el catalizador 10Co/ITQ(4) previamente reducido. EI detalle de la figura muestra el espectro en la región de carbonilos metálicos a baja dosis de CO (5 mbar) para la muestra recién reducida (a) y la muestra re-evacuada tras alcanzar una primera dosis de 250 mbar de CO (b).

Por el contrario, se observa un comportamiento radicalmente distinto para la muestra de baja dispersión metálica $10 \mathrm{Co} / \mathrm{SiO}_{2}(\mathrm{mf})$, en la Fig. 3.23, para la cual no aparecen nuevas bandas al incrementarse la presión de CO en la celda. Además, la re-adsorción de CO tras una dosis de 250 mbar y la subsecuente evacuación de la celda (detalle en la Fig. 3.23), recupera completamente el espectro original. Así pues, no se puede inferir reestructuración metálica superficial en este caso. 


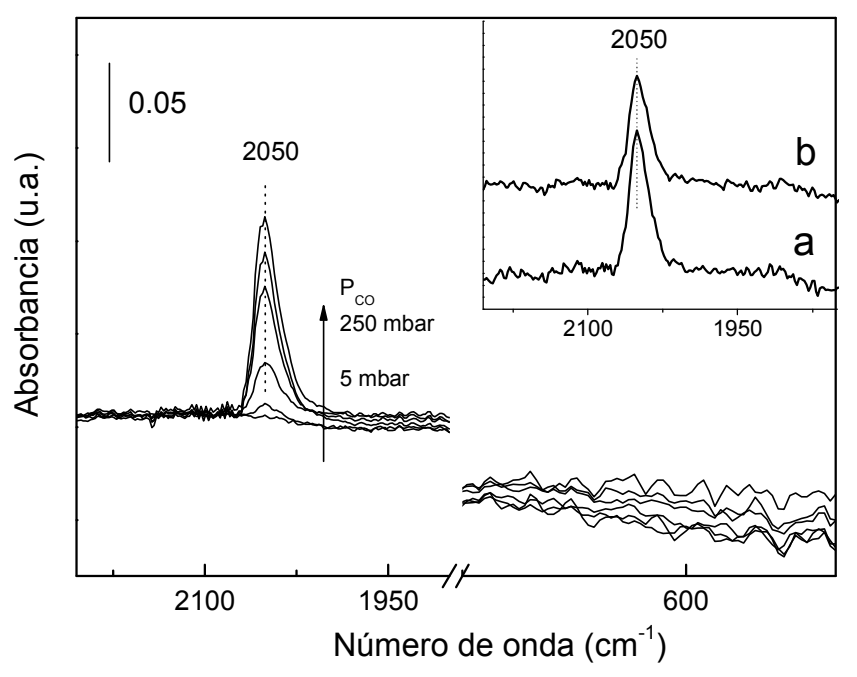

Figura 3.23: Evolución del espectro de FTIR con la dosis de CO ( $P_{C O}=5-250$ mbar), a temperatura ambiente, para el catalizador $10 \mathrm{Co} / \mathrm{SiO}_{2}(\mathrm{mf})$ previamente reducido. El detalle de la figura muestra el espectro en la región de carbonilos metálicos a baja dosis de CO (5 mbar) para la muestra recién reducida (a) y la muestra re-evacuada tras alcanzar una primera dosis de 250 mbar de CO (b).

Como se mencionó en la sección 1.3.7.4 de la Introducción General, la reestructuración superficial de Co inducida por $\mathrm{CO}$ es un fenómeno que se ha propuesto previamente para catalizadores de Co en base a resultados de STEM [71] y PM-RAIRS [63] empleando monocristales de $\mathrm{Co}^{0}$ expuestos a atmósferas de $\mathrm{CO}$ o gas de síntesis a elevada temperatura. Los resultados que se muestran en esta sección sugieren que la reestructuración superficial puede tener lugar a temperatura ambiente y en ausencia de $\mathrm{H}_{2}$ para nanopartículas de Co de diámetro inferior a unos $11 \mathrm{~nm}$, como las existentes en los catalizadores 10\%Co/ITQ-2 estudiados. La reestructuración superficial parece, por tanto, dependiente del tamaño de nanopartícula, siendo más favorable para pequeñas nanopartículas que para las nanopartículas de mayor tamaño presentes en $10 \mathrm{Co} / \mathrm{SiO}_{2}(m f)$. 
Adicionalmente, una inspección detallada de los espectros de CO-FTIR incluidos en las Figs. 3.21 y 3.22 en el rango de bajas frecuencias, evidencia que se desarrollan nuevas bandas a 642,612 y $573 \mathrm{~cm}^{-1}$ cuando se incrementa la presión de $\mathrm{CO}$ en la celda de 5 a 250 mbar, para los catalizadores $10 \mathrm{Co} / \mathrm{ITQ}(1)$ y $10 \mathrm{Co} / \mathrm{ITQ}(4)$. Por el contrario, estas bandas en el rango de bajas frecuencias no surgen en el caso de $10 \mathrm{Co} / \mathrm{SiO}_{2}(\mathrm{mf})$ (Fig. 3.23). En cuanto a la asignación de estas bandas de $I R$, se conoce que las vibraciones de tensión de los enlaces metal-carbono y metal-oxígeno aparecen en la región de 700-300 $\mathrm{cm}^{-1}$. De hecho, la vibración de tensión Co$\mathrm{O}$ se ha descrito a $612 \mathrm{~cm}^{-1}$ [72]. Además, la vibración de tensión del enlace Co- $\mathrm{C}$ en grupos $\mathrm{Co}-\mathrm{CH}_{3}$ se ha detectado a $522 \mathrm{~cm}^{-1}$ [73], mientras que Lavrentiev y col. [74] asignaron las bandas de IR a 560 y $643 \mathrm{~cm}^{-1}$ a carburo de Co. Así pues, del desarrollo de las bandas de IR a $612 \mathrm{~cm}^{-1}$ (Co-O) y 573 y $642 \mathrm{~cm}^{-1}$ (que asociamos a Co-C) se puede inferir la disociación de CO, dando lugar a la adsorción de adátomos de O y C sobre los átomos metálicos.

Es interesante que, de acuerdo a los resultados de CO-FTIR obtenidos en este trabajo, el desarrollo de las bandas en el rango $700-500 \mathrm{~cm}^{-1}$ está directamente relacionado con la parición de las bandas de carbonilos de $\mathrm{Co}^{0}$ a 2024 y $2002 \mathrm{~cm}^{-1}$, asignadas a planos cristalográficos de baja densidad de empaquetamiento o centros metálicos de baja coordinación como resultado de la reestructuración de la superficie de las nanopartículas de $\mathrm{Co}^{0}$. De este modo, se puede inferir que la reestructuración de la superficie metálica es debida a adátomos de $\mathrm{O}$ o $\mathrm{C}$ derivados de la disociación de CO. De hecho, mientras que la mayoría de los autores asumen que la formación de (sub)carbonilos de $\mathrm{CO}$ móviles $\left(\mathrm{Co}(\mathrm{CO})_{\mathrm{x}}\right)$ es responsable de la reestructuración superficial del $\mathrm{Co}^{0}[63,75,76]$, estudios teóricos por DFT muy recientes sugieren que los adátomos de $\mathrm{C}$ adsorbidos tiene un papel determinante en la reestructuración superficial de tipo "clock" en 
determinadas caras cristalinas de $\mathrm{Co}^{0}-f c c$ [77]. El hecho de que tan sólo las nanopartículas de diámetro inferior a aprox. $11 \mathrm{~nm}$ sufren la reestructuración superficial a temperatura ambiente, en ausencia de $\mathrm{H}_{2}$, apunta hacia el papel decisivo de los centros metálicos en posiciones de defecto que están presentes, aunque en baja proporción relativa, en las nanopartículas de menor tamaño de los catalizadores 10Co/ITQ(1) y 10Co/ITQ(4) (banda a aprox. $2010 \mathrm{~cm}^{-1}$ en la Figura 3.19). A pesar de la baja proporción relativa de este tipo de centros para las nanopartículas de $d\left(\mathrm{CO}^{0}\right)>5 \mathrm{~nm}$ (Fig. 3.20), estos átomos de $\mathrm{Co}^{0}$ de baja coordinación presentan una menor barrera energética para la disociación de CO debido a una mayor retro-donación electrónica metal- $\mathrm{CO}$, como muestran estudios teóricos recientes $[78,79]$. Este tipo de centros podrían actuar como una fuente de especies ( $\mathrm{C}$ y O), derivadas de la disociación de $\mathrm{CO}$, que se envían por mecanismos de migración superficial (spill-over) sobre los centros metálicos presentes en terrazas (banda a aprox. $2050 \mathrm{~cm}^{-1}$ en Fig. 3.19), promoviendo la reestructuración superficial. De hecho, más recientemente, otros autores [80] han propuesto los centros metálicos de baja coordinación como "puerta" para adátomos de C que se introducen en las capas metálicas más externas de nanopartículas de $\mathrm{Pd}^{0}$.

\subsubsection{Catálisis monitorizada por CO-FTIR.}

La evolución de la superficie de los catalizadores durante la reacción de SFT se ha estudiado mediante CO-FTIR, empleando catalizadores recién reducidos en la celda. Se registraron los espectros de IR a diferentes temperaturas $\left(25-220^{\circ} \mathrm{C}\right)$ mientras los catalizadores se exponían a un flujo de gas de síntesis, como se detalla en la sección 2.2.14. La Fig. 3.24 muestra estos espectros para el catalizador 10Co/ITQ(1), como catalizador representativo de todos los estudiados, que presentan evoluciones muy similares. 


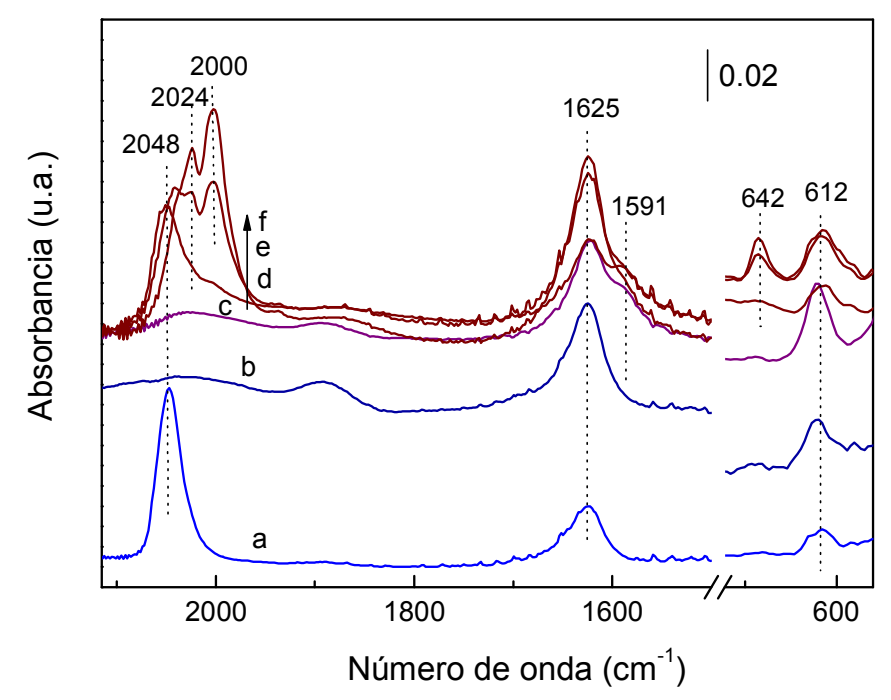

Figura 3.24: Evolución del espectro de FTIR con la temperatura para el catalizador 10Co/ITQ(1) reducido y expuesto a una corriente de gas de síntesis $\left(\mathrm{H}_{2} / \mathrm{CO}=2\right)$ a $25 \circ \mathrm{C}$ (a), $160^{\circ} \mathrm{C}$ (b), $200^{\circ} \mathrm{C}$ (c); y evolución del espectro de FTIR con el tiempo de reacción después de 120 (d), 210 (e) y 240 (f) minutos en condiciones de síntesis de FischerTropsch.

A $25 \circ \mathrm{C}$, el espectro muestra dos bandas principales a $2048 \mathrm{~cm}^{-1}$ (asociada a CO adsorbido en modo lineal sobre $\mathrm{Co}^{0}-f c c$ ) y a $1625 \mathrm{~cm}^{-1}$ debida a los modos de deformación de la molécula de $\mathrm{H}_{2} \mathrm{O}$, probablemente presente en concentración de trazas en la corriente gaseosa alimentada y que se adsorbe sobre la superficie del soporte. La presencia de $\mathrm{H}_{2}$ coadsorbido o el menor tiempo de contacto en el modo de flujo parecen inhibir la reestructuración superficial a temperatura ambiente en este caso, puesto que no se desarrollan claramente las bandas a 2024 y $2002 \mathrm{~cm}^{-1}$. Al incrementarse la temperatura hasta 160 y $200 \stackrel{\circ}{\circ}$, la banda a $1625 \mathrm{~cm}^{-1}$ debida al $\mathrm{H}_{2} \mathrm{O}$ es la única que se observa en el rango $1500-2100 \mathrm{~cm}^{-1}$. La ausencia de bandas para carbonilos de Co en la región $2000-2060 \mathrm{~cm}^{-1}$ puede deberse a un bloqueo completo de los centros metálicos superficiales debido a especies $\mathrm{H}, \mathrm{CH}_{\mathrm{x}} \mathrm{u} \mathrm{O}$ adsorbidas. De hecho, la presencia de especies de oxígeno adsorbidas puede inferirse de la banda a $612 \mathrm{~cm}^{-1}$, que es la 
única detectada en la región de $300-700 \mathrm{~cm}^{-1}$ para este rango de temperaturas.

Tras incrementarse la temperatura hasta $220^{\circ} \mathrm{C}$ (aplicada también en los experimentos catalíticos en el reactor de lecho fijo, a 2.0MPa) se registraron los espectros de IR a diferentes tiempos. A esta temperatura se recuperan rápidamente las bandas de carbonilos de $\mathrm{Co}^{0}$, probablemente debido a la desorción de los intermedios de reacción adsorbidos, dejando centros metálicos libres, disponibles para la adsorción de CO. De manera interesante, la evolución del espectro de IR en la región de carbonilos lineales de CO (2000-2060 $\left.\mathrm{cm}^{-1}\right)$ en condiciones de la SFT para todos los catalizadores estudiados, incluyendo la muestra de baja dispersión metálica $10 \mathrm{Co} / \mathrm{SiO}_{2}(\mathrm{mf})$, es similar a la observada a temperatura ambiente y elevadas dosis de CO (Figs. 3.21 y 3.22), en aquel caso restringida para los catalizadores $10 \% \mathrm{Co} / \mathrm{ITQ}-2$ con $d\left(\mathrm{Co}^{0}\right)_{\mathrm{H}}<11 \mathrm{~nm}$. Este hecho revela que durante la SFT tiene lugar una reestructuración en la superficie del metal de naturaleza similar a la encontrada a temperatura ambiente en presencia de $\mathrm{CO}$ puro. Simultáneamente, la banda asociada con $\mathrm{H}_{2} \mathrm{O}$ crece en intensidad, debido a su formación como producto de la síntesis, mientras que se desarrolla una nueva banda a $1591 \mathrm{~cm}^{-1}$ asociada con modos de vibración de tensión para el enlace $\mathrm{C}-\mathrm{C}$, como evidencia de procesos de crecimiento de cadena típicos de la síntesis de hidrocarburos.

La banda a $1591 \mathrm{~cm}^{-1}$ muestra una intensidad relativa sensiblemente mayor para la muestra 10Co/ITQ(1) que para los catalizadores $10 \mathrm{Co} / \mathrm{ITQ}(4)$ y $10 \mathrm{Co} / \mathrm{SiO}_{2}(m f)$, de acuerdo con el mayor valor de $\mathrm{CTY}_{\mathrm{e}}$ observado para la primera en los experimentos catalíticos de SFT a elevada presión (Tabla 3.10). Así pues, teniendo en cuenta la diferencia de presión y otras diferencias hidrodinámicas entre los experimentos catalíticos llevados a cabo en el reactor de lecho fijo y los ensayos realizados en la celda de FTIR, los 
resultados experimentales de CO-FTIR en condiciones de reacción son representativos, cualitativamente, del comportamiento catalítico de los catalizadores en los ensayos reactivos de alta presión, confirmando el menor valor de TOF para las nanopartículas de $d\left(\mathrm{CO}^{0}\right)_{\mathrm{H}}=5.6 \mathrm{~nm}$ que para las correspondientes de $d\left(\mathrm{Co}^{0}\right)>10 \mathrm{~nm}$.

Adicionalmente, es interesante observar cómo en la Figura 3.24, la banda de IR a $642 \mathrm{~cm}^{-1}$, relacionada con especies de carburo superficiales (adátomos de $\mathrm{C}$ adsorbidos) se desarrolla, una vez más, de manera estrictamente simultánea a la aparición de las bandas de carbonilos a 2024 y $2002 \mathrm{~cm}^{-1}$. Así pues, en concordancia con resultados teóricos recientes [77], estos experimentos suponen la primera evidencia experimental del papel del carbono, de tipo carburo superficial, como agente reestructurante de la superficie de $\mathrm{CO}^{\circ}-f c c$.

En línea con estos resultados, recientemente se han encontrado evidencias similares acerca de la formación de los "verdaderos" centros activos por reestructuración de la superficie metálica debida a la incorporación de adátomos de $\mathrm{C}$, derivados de la disociación de las primeras moléculas de reactivo adsorbidas, dentro de las capas metálicas más externas de las nanopartículas de Pd durante la reacción de hidrogenación de alquinos $[81,82]$. El hecho de que, al contrario que con CO puro a temperatura ambiente, el catalizador $10 \mathrm{Co} / \mathrm{SiO}_{2}(\mathrm{mf})$ también sufre reestructuración metálica superficial, sugiere un papel importante para el $\mathrm{H}_{2}$ (y/o la temperatura) promoviendo la reestructuración de superficies metálicas en las que predominan originalmente la terrazas. De hecho, cálculos teóricos basados en DFT sobre superficies de $\mathrm{Ni}^{0}$ y $\mathrm{Co}^{0}$ han sugerido un mecanismo de disociación de $\mathrm{CO}$ inducida por $\mathrm{H}_{2}$, a través de especies parcialmente hidrogenadas $(\mathrm{H})_{\times} \mathrm{CO}$ como intermedios $[83,84]$. La presencia 
de hidrógeno co-activado, y la asunción de especies $(\mathrm{H})_{x} \mathrm{CO}$ parcialmente hidrogenadas, reduce la energía de activación para la disociación de CO en superficies metálicas planas, aproximándola a la de los procesos que tienen lugar sobre centros metálicos de baja coordinación [84].

A modo de resumen, los resultados de CO-FTIR sugieren que la naturaleza y la extensión de la reestructuración metálica superficial durante la SFT es similar para todos los catalizadores, independientemente del diámetro de nanopartícula.

No obstante, a pesar de esta similar reestructuración superficial, se encuentran diferencias en los espectros de CO-FTIR durante la SFT, en especial, para el catalizador que presenta un menor tamaño de nanopartícula y un menor valor de TOF. La Fig. 3.25 muestra los espectros de CO-FTIR para los tres catalizadores estudiados tras 4 horas en condiciones de SFT (espectros a,b y c).

Como se observa, además de las bandas asociadas a carbonilos de Co (1900-2050 cm $\left.\mathrm{cm}^{-1}\right), \mathrm{H}_{2} \mathrm{O}\left(1625 \mathrm{~cm}^{-1}\right)$ y especies $\mathrm{C}_{2+}$ adsorbidas $\left(1591 \mathrm{~cm}^{-1}\right)$, como un hombro débil en el caso de los catalizadores que presentan un menor CTY, se puede percibir una contribución no despreciable a $2060 \mathrm{~cm}^{-1}$ (asociada a átomos de $\mathrm{Co}^{\delta+}$ ) en el espectro del catalizador menos activo (10Co/ITQ(4)). Esta banda, que ya estaba presente como un débil hombro en este catalizador recién reducido (Fig. 3.19), se ve incrementada en condiciones de reacción. De hecho, la importancia relativa de esta contribución a $2060 \mathrm{~cm}^{-1}$ para el catalizador 10Co/ITQ(4) se percibe en el espectro de detalle incluido en la Fig. 3.25, en el que se muestra la deconvolución lorentziana del mismo y la correspondiente al espectro para el catalizador 10Co/ITQ(1), para el que esa componente no se discierne de manera inequívoca. 


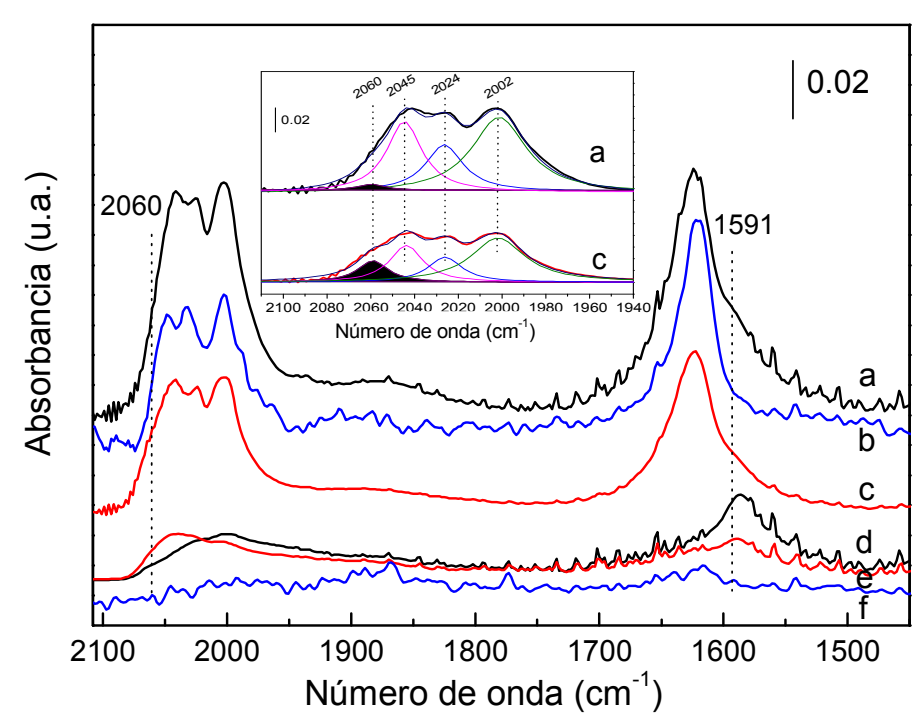

Figura 3.25: Espectros de FTIR después de 4 horas en condiciones de síntesis de Fischer-Tropsch ( $\left.T=220^{\circ} \mathrm{C}, P_{\text {atm }}\right)$ para los catalizadores 10Co/ITQ(1) (a), 10Co/SiO $2(\mathrm{mf})(b)$, y 10Co/ITQ(4) (c); y espectros de FTIR tras 4 horas de reacción y posterior evacuación de la celda a 25C para 10Co/ITQ(1) (d), 10Co/ITQ(4) (e) y $10 \mathrm{Co} / \mathrm{SiO}_{2}(\mathrm{mf})(f)$.

Además, en los correspondientes espectros de evacuación (espectros d, e y f) se percibe con claridad que la componente a $2060 \mathrm{~cm}^{-1}$ es la más estable para el catalizador 10Co/ITQ(4) mientras que las bandas a 2000-2050 $\mathrm{cm}^{-1}$ predominan para los otros dos catalizadores. En este punto, es preciso mencionar que un tratamiento de evacuación más severo $\left(10^{-5}\right.$ bar, 450 으), que se requiere para retirar las especies $\mathrm{C}_{2+}$ adsorbidas en el catalizador (banda a $1591 \mathrm{~cm}^{-1}$ ), hace desaparecer las bandas de IR en la región 300-700 $\mathrm{cm}^{-1}$ para las especies C-Co), recupera la banda original a $2050 \mathrm{~cm}^{-1}$ como señal de carbonilos predominante y reduce la contribución a $2060 \mathrm{~cm}^{-1}$ para el catalizador 10Co/ITQ(4), lo que apunta a la inestabilidad de las especies de tipo carburo, que promueven la reestructuración superficial de las nanopartículas de $\mathrm{Co}^{\circ}$. Este resultado indica que para obtener información acerca de las especies involucradas en estos cambios estructurales para las 
nanopartículas metálicas son necesarios estudios en condiciones de reacción ("operando"), como el llevado a cabo en este trabajo.

Por lo tanto, los resultados muestran que, en las condiciones de reacción, la proporción de los centros $\mathrm{Co}^{\delta+}$, en la interfase entre las nanopartículas de $\mathrm{Co}^{0}$ y el soporte silíceo, se incrementa para las nanopartículas de menor tamaño $(5.6 \mathrm{~nm})$. Por el contrario, este tipo de centros no presentan una contribución importante para catalizadores cuyo $d\left(\mathrm{CO}^{\circ}\right)$ excede los $10 \mathrm{~nm}$. Es igualmente destacable el hecho de que no existen diferencias importantes en los espectros CO-FTIR en condiciones de reacción para los catalizadores $10 \mathrm{Co} / \mathrm{ITQ}(1)$ y $10 \mathrm{Co} / \mathrm{SiO}_{2}(\mathrm{mf})$, cuyo tamaño de partícula difiere en más de un orden de magnitud, así como que la contribución de la señal a $2060 \mathrm{~cm}^{-1}$ es la única diferencia encontrada entre éstos, que presentan un valor de TOF similar, y el catalizador 10Co/ITQ(4), cuya actividad intrínseca es unas 7 veces menor, a 2.0MPa (Fig. 3.18-a). De acuerdo a la teoría desarrollada por Blyholder (sección 2.2.14), se predice un menor coeficiente de absorción para el $\mathrm{CO}$ adsorbido sobre los centros $\mathrm{Co}^{\delta+}$, de modo que su proporción real en el catalizador puede infraestimarse considerando tan sólo su contribución al espectro CO-FTIR (detalle en Fig. 3.25). De manera adicional, puesto que su formación está relacionada con cambios estructurales durante la SFT, la proporción de este tipo de centros $\left(\mathrm{Co}^{\delta+}\right)$ puede verse favorecida a presiones elevadas $y$, por lo tanto, ser mayor durante los experimentos llevados a cabo a 2.0MPa, explicando un descenso del TOF de hasta 7 veces respecto al de los catalizadores $10 \mathrm{Co} / \mathrm{ITQ}(1)$ y $10 \mathrm{Co} / \mathrm{SiO}_{2}(\mathrm{mf})$. De hecho, Bezemer y col. [17] encontraron que los efectos del tamaño de nanopartícula sobre el TOF son dependientes de la presión a la que se lleva a cabo la reacción, manifestándose para tamaños inferiores a $6 \mathrm{~nm}$ a presión atmosférica, pero extendiéndose hasta 8-9 $\mathrm{nm}$ a 3.5 MPa. 
Por otro lado, no se detectan bandas de CO-FTIR a $2175 \mathrm{~cm}^{-1}$ (CO$\mathrm{Co}^{2+}$ ) después de 4 horas en las condiciones de SFT, lo que descarta, al menos al límite de detección de la técnica, la re-oxidación de los catalizadores durante la reacción en las condiciones empleadas en la celda de FTIR. Así pues, a la vista de los resultados de esta sección, se está en condiciones de asignar el menor valor de TOF observado para las nanopartículas de $\mathrm{Co}^{\circ}$ de menor tamaño a la presencia de una mayor proporción de centros electropositivos $\left(\mathrm{Co}^{\delta+}\right)$ en la frontera con el soporte, para los cuales se ha predicho una menor actividad catalítica para la disociación de CO [60].

\subsubsection{Análisis microscópico de los catalizadores tras la SFT.}

Los resultados obtenidos en el estudio por CO-FTIR pueden racionalizarse en términos de un incremento en la superficie de contacto entre las nanopartículas metálicas y el soporte durante la SFT, probablemente debido a cambios morfológicos en las nanopartículas (aplanamiento), los cuales pueden estar relacionados con la reestructuración superficial evidenciada mediante CO-FTIR. Esta hipótesis concurre con resultados de EXAFS publicados por otros autores [7], que muestran que tiene lugar un descenso en el número de coordinación medio Co-Co durante la SFT a presión atmosférica, y que son coherentes tanto con un aplanamiento como con una re-dispersión de las nanopartículas.

Con el objetivo de estudiar estos cambios morfológicos en las nanopartículas de $\mathrm{Co}$, se analizaron catalizadores seleccionados después de los experimentos catalíticos en el reactor de lecho fijo $\left(\mathrm{T}=220^{\circ} \mathrm{C}, \mathrm{P}=2.0 \mathrm{MPa}\right.$, $\left.X_{C O}=10 \%\right)$ empleando TEM.

La Fig. 3.26 muestra micrografías representativas para el catalizador 10Co/ITQ(2) después de 12 horas de reacción. Se observan las 
nanopartículas metálicas dispersas sobre las láminas del soporte deslaminado, no encontrándose grandes aglomerados metálicos aunque sí la presencia de regiones mostrando nanopartículas individuales asociadas en grupos, con espaciados limitados entre las mismas. En este caso, la corteza de óxido, asociada con la pasivación del catalizador, presenta un espesor más reducido de lo común (típicamente unos $1.5 \mathrm{~nm}$ ), probablemente debido a que la presencia de hidrocarburos adsorbidos reduce la cinética de oxidación superficial.

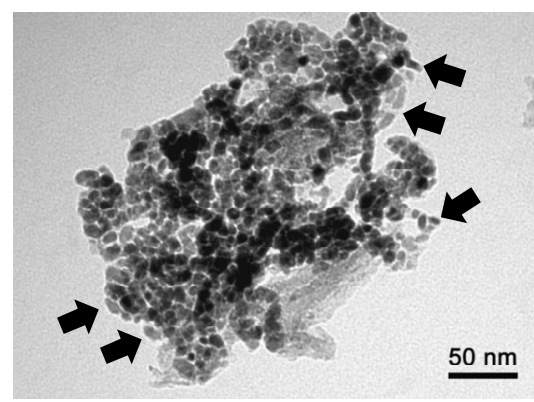

(a)

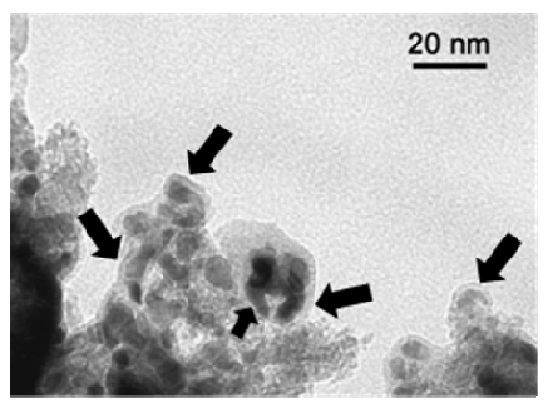

(b)

Figura 3.26: Micrografías de TEM para el catalizador 10Co/ITQ(2) después de 12 horas en condiciones de reacción en la síntesis de Fischer-Tropsch a elevada presión $\left(T=220^{\circ} \mathrm{C}, P=2.0 \mathrm{MPa}, X_{C O}=10 \%\right)$. Las flechas en las figuras indican la presencia de nanopartículas de Co aplanadas, observadas en perfil en los bordes de las láminas del soporte.

En las micrografías no se aprecia una morfología especial para las nanopartículas enfocadas "en planta" mientras que aquellas enfocadas "en perfil", situadas en los bordes de las partículas de soporte (flechas en las Fig. 3.26-a y 3.25-b) presentan una morfología aplanada apareciendo como nanobarras (nanorods) en la imagen de transmisión. Este aplanamiento de las nanopartículas tiene como resultado un incremento en la superficie de contacto entre la fase metálica y el soporte.

En cuanto al tamaño de nanopartícula para el catalizador 10Co/ITQ(2) tras reacción, se obtiene un valor de $d\left(\mathrm{Co}^{0}\right)_{\mathrm{T}}=10.3 \mathrm{~nm}$, en contraste con el 
valor de $8.2 \mathrm{~nm}$ obtenido para el catalizador reducido (Tabla 3.9), lo que puede ser debido a una combinación de cierto nivel (limitado) de aglomeración metálica y a la observación en planta de nanopartículas aplanadas, cuya proyección presenta un tamaño incrementado.

Cuando se analiza por TEM un catalizador más disperso, como 10Co/ITQ(4), después de los experimentos reactivos, la re-oxidación completa que sufren las nanopartículas de menor tamaño durante la preparación de la muestra para microscopía hace que no se perciban estos cambios de morfología de las nanopartículas, puesto que la re-oxidación parece restituir las formas pseudo-esféricas originales.

En línea con los resultados analizados en esta sección, recientemente se han descrito cambios morfológicos, normalmente rápidos, reversibles e inducidos por ciertos reactivos gaseosos, en otros sistemas metálicos nanoparticulados expuestos a determinadas atmósferas que modelizan condiciones de pretratamiento o catálisis. Estos cambios morfológicos se han identificado empleando técnicas microscópicas (Environmental Transmission Electron Microscopy o ETEM) [85] o absorción de rayos $X$ (EXAFS) [86] operadas mientras los catalizadores se exponen a atmósferas controladas. De hecho, se ha descrito que atmósferas gaseosas como las encontradas en la conversión de gas de síntesis, conteniendo $\mathrm{H}_{2} \mathrm{O}, \mathrm{CO}$ e $\mathrm{H}_{2}$, producen un marcado aplanamiento reversible de nanopartículas de $\mathrm{Cu}$ soportadas sobre $\mathrm{ZnO}$, incrementando en gran medida la superficie de contacto Cu-soporte, incluso para presiones de $<5$ mbar $[85,87]$. Nuestros resultados indican que un cambio morfológico similar tiene lugar para las nanopartículas de $\mathrm{Co}^{0} / \mathrm{ITQ}-2$, lo que incrementa la proporción de centros $\mathrm{Co}^{\delta+}$ en la interfase metal-soporte. A su vez, los resultados apuntan a que este tipo de centros son los responsables del descenso de TOF para tamaños 
de nanopartícula inferiores a $10 \mathrm{~nm}$, tal y como se resume esquemáticamente en la Fig. 3.27.

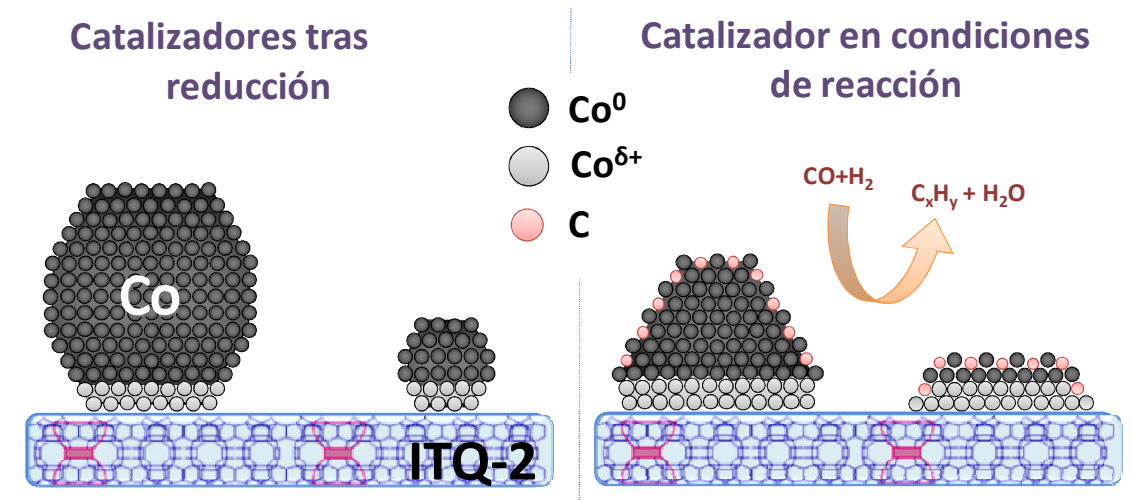

Figura 3.27: Resumen esquemático de los cambios estructurales superficiales y morfológicos que sufren las nanopartículas de $\mathrm{Co}^{0}$ en condiciones de reacción de acuerdo a los resultados de CO-FTIR y TEM para las nanopartículas cuyo tamaño es $>10 \mathrm{~nm}$ (TOF máximo) ó <10 nm (TOF disminuido).

\subsection{Conclusiones.}

Las principales conclusiones del presente capítulo se enumeran a continuación:

1. La combinación de la síntesis de nanopartículas metálicas en una microemulsión inversa y su incorporación posterior sobre la superficie de la zeolita deslaminada ITQ-2, sililada superficialmente, permite obtener catalizadores que presentan una distribución de tamaño de nanopartícula más estrecha que para catalizadores preparados por impregnación.

2. A su vez, la "protección" de los grupos silanol reactivos del material deslaminado ITQ-2, mediante su sililación, previene la reacción de las fases metálicas con el soporte silíceo durante la activación del catalizador y la cristalización de $\mathrm{Co}_{3} \mathrm{O}_{4}$. Esto da lugar a catalizadores 
más reducibles, incluso para tamaños de nanopartícula de $\mathrm{Co}^{0}$ de aprox. $5 \mathrm{~nm}$.

3. Las energías de activación para las dos etapas de la reducción de $\mathrm{CO}_{3} \mathrm{O}_{4} \quad\left(\mathrm{CO}_{3} \mathrm{O}_{4} \rightarrow \mathrm{CoO} \rightarrow \mathrm{CO}^{\circ}\right)$ presentan una dependencia similar con respecto al tamaño de nanopartícula de $\mathrm{Co}_{3} \mathrm{O}_{4}$ en el rango de elevadas dispersiones metálicas (5.9-12.5 nm).

4. La naturaleza de las especies metálicas en los catalizadores Co/ITQ-2 calcinados evoluciona progresivamente con la dispersión metálica, de modo que la espinela $\mathrm{Co}_{3} \mathrm{O}_{4}$ es la única fase para $d\left(\mathrm{CO}_{3} \mathrm{O}_{4}\right) \geq 6.8 \mathrm{~nm}$, mientras que incrementar progresivamente la dispersión metálica da lugar a la formación de especies hidroxi-silicato de $\mathrm{Co}^{2+}$, probablemente por reacción de la interfase de las nanopartículas metálicas con el soporte, y de manera ulterior, a la formación de silicatos de $\mathrm{Co}^{2+}$ por reacción completa con la fase silícea del soporte.

5. La actividad catalítica por centro metálico superficial, expresada como frecuencia de turnover (TOF) en la síntesis de Fischer-Tropsch ( $\mathrm{T}=220 \circ \mathrm{C}, \mathrm{P}=2.0 \mathrm{MPa}, \mathrm{H}_{2} / \mathrm{CO}=1, \mathrm{X}_{\mathrm{CO}}=10 \%$ ) se incrementa con el tamaño de nanopartícula de $\mathrm{Co}^{0}$ en el rango de 5.6-10.4 nm y permanece prácticamente constante para mayores tamaños de nanopartícula, hasta $141 \mathrm{~nm}$.

6. Los estudios de CO-FTIR sobre los catalizadores modelo sintetizados evidencian que adátomos de C, derivados de la disociación de CO, promueven una reestructuración superficial en las nanopartículas de $\mathrm{Co}^{\circ}$ durante la síntesis de Fischer-Tropsch, favoreciendo centros superficiales de menor coordinación (defectos o planos cristalinos de menor índice de empaquetamiento), independientemente del tamaño de nanopartícula (5.6-141 nm). 
7. La única diferencia espectroscópica entre los catalizadores que presentan un valor de TOF máximo $\left(d\left(\mathrm{Co}^{0}\right)>10 \mathrm{~nm}\right)$ y un catalizador que presenta un valor de TOF inferior $\left(d\left(\mathrm{CO}^{0}\right)=5.6 \mathrm{~nm}\right)$ es la contribución de centros parcialmente oxidados $\mathrm{Co}^{\delta+}$, en la interfase metal-soporte, que se incrementa en el catalizador más disperso en condiciones de reacción. Este incremento en la superficie de contacto entre las nanopartículas y el soporte está relacionado con un cambio de morfología en las nanopartículas (aplanamiento), como sugieren los estudios por TEM de los catalizadores tras la reacción. Este tipo de centros interfaciales $\mathrm{Co}^{\delta+}$ se proponen como responsables de la sensibilidad a la estructura "no clásica" para la SFT catalizada por Co. 


\section{Referencias.}

\footnotetext{
${ }^{1}$ R. Oukaci, A.H. Singleton, J.G. Goodwin, Appl. Catal. A 186 (1999) 129.

${ }^{2}$ E. Iglesia, S.L. Soled, R.A. Fiato, J. Catal. 137 (1992) 212.

3 J. Panpranot, J.G. Goodwin Jr., A Sayari, Catal. Today 77 (2002) 269.

4 A. Griboval-Constant, A.Y. Khodakov, R. Bechara, V.L. Zholobenko, J. Catal. 144 (2002)
} 609.

5 A. Martínez, C. López, F. Márquez, I. Díaz, J. Catal. 220 (2003) 486.

${ }^{6}$ L. D'Souza, L. Jiao, J.R. Regalbuto, J.T. Miller, A.J. Kropf, J. Catal. 248 (2007) 165.

7 G.L. Bezemer, P.B. Radstake, V. Koot, A.J. van Dillen, J.W. Geus, K.P. de Jong, J. Catal. 237 (2006) 291.

${ }^{8}$ L. D’Souza, J.R. Regalbuto, J.T. Miller, J. Catal. 254 (2008) 157.

${ }^{9}$ K. Okabe, X. Li, M. Wei, H. Arakawa, Catal. Today 89, (2004) 431.

${ }^{10}$ P. Concepción, C. López, A. Martínez, V.F. Puntes, J. Catal. 228 (2004) 321.

11 J. Panpranot, J.G. Goodwin Jr., A Sayari, Catal. Today 77 (2002) 269.

${ }^{12}$ A.Y. Khodakov, J. Lynch, D. Bazin, B. Rebours, N. Zanier, B. Moison, P. Chaumette, J. Catal. 168 (1997) 16.

13 A. Y. Khodakov, A. Griboval-Constant, R. Bechara, V.L. Zholobenko, J. Catal. 206 (2002) 230.

14 R.C. Reuel, C.H. Bartholomew, J. Catal. 85 (1984) 78.

15 A.S. Lisitsyn, A.V. Golovin, V.L. Kuznetsov, Y.I. Yermakov, J. Catal. 95 (1985) 527.

16 A. Barbier, A. Tuel, I. Arcon, A. Kodre, G.A. Martin, J. Catal. 200 (2001) 106.

17 G.L. Bezemer, J.H. Bitter, H.P.C.E. Kuipers, H. Oosterbeek, J.E. Holewijn, X. Xu, F. Kapteijn, A.J. van Dillen, K.P. de Jong, J. Am. Chem. Soc. 128 (2006) 3956.

18 I. Fernández-Morales, A. Guerrero-Ruiz, F.J. López-Garzón, I. Rodríguez-Ramos, C. Moreno-Castilla, Appl. Catal. 14 (1985) 159.

19 Ø. Borg, P.D.C. Dietzel, A.I. Spjelkavik, E.Z. Tveten, J.C. Walmsley, S. Diplas, S. Eri, A. Holmen, E. Rytter, J. Catal. 259 (2008) 161.

20 G.L. Bezemer, J.H. Bitter, H.P.C.E. Kuipers, H. Oosterbeek, J.E. Holewijn, X. Xu, F. Kapteijn, A.J. van Dillen, K.P. de Jong, J. Am. Chem. Soc. 128 (2006) 3956.

${ }^{21}$ B.L. Cushing, V.L. Kolesnichenko, C.J. O'Connor, Chem. Rev. 104 (2004) 3893.

${ }^{22}$ I. Capek, Adv. Colloid Interf. Sci. 110 (2004) 49.

${ }^{23}$ V. Uskokovic, M. Drofenik, Surf. Rev. Lett. 12 (2002) 239.

${ }^{24}$ S. Eriksson, V. Nylén, S. Rojas, M. Boutonnet, Appl. Catal. A 265 (2004) 207.

${ }^{25}$ M. Kishida, K.-I. Ichiki, T. Hanaoka, H. Nagata, K. Wakabayahi, Catal. Today 45 (1998) 203. 
${ }^{26}$ D.Y. Zhao, J.L. Feng, Q.S. Huo, N. Melosh, G.H. Fredrickson, B.F. Chmelka, G.D. Stucky, Science 279 (1998) 548.

27 P. Schmidt-Winkel, W.W. Lukens, D.Y. Zhao, P.D. Yang, B.F. Chmelka, G.D. Stucky, J. Am. Chem. Soc. 121 (1999) 254.

${ }^{28}$ P. Somasundaran (Ed.), "Surface science and colloid science", Tailor \& Francis, New York (2006).

${ }^{29}$ A. Corma, V. Fornés, S.B. Pergher, Th.L.M. Maesen, J.G. Buglass, Nature 396 (1998) 353.

${ }^{30}$ A.P. Wight, M.E. Davis, Chem. Rev.102 (2002) 3589.

31 D.J. Kim, B.C. Dunn, P. Cole, G. Turpin, R.D. Ernst, R.J. Pugmire, M. Kang, J.M. Kim, E.M. Eyring, Chem. Commun. (2005) 1562.

32 M.J. Díaz-Cabañas, M.A. Camblor, C. Corell, A. Corma, patente ES2105982 (1998).

${ }^{33}$ S. Brunauer, P.H. Emmett, E. Teller, J. Am. Chem. Soc. 60 (1938) 309.

${ }^{34}$ L. Jelinek, E. S. Kováts, Langmuir 10 (1994) 4225.

35 D. Brunel, A. Cauvel, F. Di Renzo, F. Fajula, B. Fubini, B. Onida, E. Garrone, New J. Chem. 10 (2000) 807.

${ }^{36}$ X.S. Zhao, G.Q. Lu, J. Phys. Chem. B 102 (1998) 1556.

37 X.S. Zhao, G.Q. Lu, A.K. Whitaker, G.J. Millar, H.Y. Zhu, J. Phys. Chem. B 101 (1997) 6525.

${ }^{38}$ V.Y. Davidov, Adsorption on silica surfaces, E. Papier Ed., Marcel Dekker (2000) 63.

39 A. Schmohl, A.K. Hess, Superlatt. Micostruct. 36 (2004) 113.

${ }^{40}$ C.P. Gibson, K.J. Putzer, Science 267 (1995) 1338.

${ }^{41}$ Z. Gui, R. Fan, W. Mo, X. Chen, L. Yang, Y. Hu, Mater. Res. Bull. 38 (2003) 169.

${ }^{42}$ J. W. Park, E.H. Chae, S.H. Kim, J.H. Lee, J.W. Kim, S.M. Yoon, J.-Y. Choi, Mater. Chem. Phys. 97 (2006) 371.

${ }^{43}$ P. Arnoldy, J.A. Moulijn, J. Catal. 93 (1985) 38.

${ }^{44}$ E. van Steen, G.S. Sewell, R.A. Makhothe, C. Micklethwaite, H. Manstein, M. de Lange,

C.T. O'Connor, J. Catal. 162 (1996) 220.

45 D-H. Chen, S-H. Wu, Chem. Mater. 12 (2000) 1354.

${ }^{46}$ D.-Y Chung, B.-H. Kim, Y.-J Shin, J.-H. Yoo, J.-D. Kim, J. Radioanal. Nuclear Chem. 204 (1996) 265.

${ }^{47}$ B. Viswanathan, R. Gopalakrishnan, J. Catal. 99 (1986) 342.

${ }^{48}$ T. He, D. Chen, X. Jiao, Y. Wang, Y. Duan, Chem. Mater. 17 (2005) 4023.

49 Y. Okamoto, K. Nagata, T. Adachi, T. Imanaka, K. Inamura, T. Takyu, J. Phys. Chem. 95 (1991) 310 .

50 A.A. Verberckmoes, B.M. Weckhuysen, R.A. Schoonheydt, Micropor. Mesopor. Mater. 22 (1998) 165 .

${ }^{51}$ S. Krishnamoorthy, M. Tu, M.P. Ojeda, D. Pinna, E. Iglesia, J. Catal. 211 (2002) 422. 
52 A.M. Hilmen, D. Schanke, K.F. Hanssen, A. Holmen, Appl. Catal. A 186 (1999) 169.

53 A.M. Saib, A. Borgna, J. van de Loosdrecht, P.J. van Berge, J.W. Niemantsverdriet, Appl. Catal. A 312 (2006) 12.

${ }^{54}$ E. Iglesia, S.C. Reyes, R.J. Madon, J. Catal. 129 (1991) 238.

${ }^{55}$ D. Schanke, S. Vada, E.A. Blekkan, A.M. Hilmen, A. Hoff, A. Holmen, J. Catal. 156 (1995) 85 .

${ }^{56}$ T. Herranz, X. Deng, A. Cabot, J. Guo, M. Salmeron, J. Phys. Chem. B 113 (2009) 10721.

${ }^{57}$ S. Sun, N. Tsubaki, K. Fujimoto, Appl. Catal. A 202 (2000) 121.

58 J.L. Zhang, J.G. Chen, J. Ren, Y.H. Sun, Appl. Catal. A 243 (2001) 59.

${ }^{59}$ D. Song, J. Li, Q. Cai, J. Phys. Chem. C 111 (2007) 18970.

${ }^{60}$ G. Blyholder, L.D. Neff, J. Phys. Chem. 73 (1969) 3494.

${ }^{61}$ L.E.S Rygh, C.J. Nielsen, J. Catal. 194 (2000) 401.

${ }^{62}$ R.E. Benfield, J. Chem. Soc. Faraday Trans. 88 (1992) 1107.

63 G.A. Beitel, C.P.M. de Groot, H. Oosterbeek, J.H. Wilson, J. Phys. Chem. B 101 (1997) 4035 .

${ }^{64}$ M.J. Heal, E.C. Leisegang, R.G. Torington, J. Catal. 51 (1978) 314.

65 J.G. Choi, H.K. Rhee, S.H. Moon, Appl. Catal. 13 (1985) 269.

${ }^{66}$ G. Kadinov, Ch. Bonev, S. Todorova, A. Palazov, J. Chem. Soc. Faraday Trans. 94 (1998) 3027.

67 L.E.S. Rygh, O.H. Ellestad, P. Klæboe, C.J. Nielsen, Phys. Chem. Chem. Phys. 2 (2000) 1835.

${ }^{68}$ R.D. Jones, C.H. Bartholomew, Appl. Catal. 39 (1988) 77.

${ }^{69}$ V.B. Kazanskii, A.V. Zaitsev, V.Y. Borokov, A.L. Lapidus, Appl. Catal. 40 (1988) 17.

${ }^{70}$ H. Xiong, Y. Zhang, K. Liew, J. Li, J. Mol. Catal. A 295 (2008) 68.

71 J. Wilson, C. de Groot, J. Phys. Chem. B 99 (1995) 7860.

${ }^{72}$ Z. Hu, L. Mo, X. Feng, J. Shi, Y. Wang, Y. Xie, Mater. Chem. Phys. 114 (2009) 53.

73 S. Nie, L.G. Marzilli, N.T. Yu, J. Am. Chem. Soc. 111 (1989) 9256.

${ }^{74}$ V. Lavrentiev, H. Abe, S. Yamamoto, H. Naramoto, K. Narumi, Surf. Interf. Anal. 35 (2003) 36.

75 G.A. Beitel, A. Laskov, H. Oosterbeek, E.W. Kuipers, J. Phys. Chem. B 100 (1996) 12494.

76 N. Kruse, J. Schweicher, A. Bundhoo, A. Frennet, T. Visart de Bocarmé, Top. Catal. 48 (2008) 145 .

${ }^{77}$ I.M. Ciobîcă, R.A. van Santen, P.J. van Berge, J. van de Loosdrecht, Surf. Sci. 602 (2008) 17.

${ }^{78}$ Q. Ge, M. Neurock, J. Phys. Chem. B 110 (2006) 15368.

79 J. Cheng, X-Q. Gong, P. Hu, C.M. Lok, P. Ellis, S. French, J. Catal. 254 (2008) 285.

${ }^{80}$ F. Viñes, C. Loschen, F. Illas, K.M. Neyman, J. Catal. 266 (2009) 59. 
81 D. Teschner, J. Borsodi, A. Wootsch, Z. Révay, M. Hävecker, A. Knop-Gericke, S.D. Jackson, R. Schlögl, Science 320 (2008) 86.

82 D. Teschner, Z. Révay, J. Borsodi, M. Hävecker, A. Knop-Gericke, R. Schlögl, D. Miltroy, S.D. Jackson, D. Torres, P. Sauet, Angew. Chem. Int. Ed. 47 (2008) 1.

${ }^{83}$ O.R. Inderwildi, S.J. Jenkins, D.A. King, J. Phys. Chem. C 112 (2008) 1305.

${ }^{84}$ M.P. Andersson, F. Abild-Pedersen, I.N. Remediakis, T. Bligaard, G. Jones, J. Engbæk, O. Lytken, S. Horch, J.H. Nielsen, J. Sehested, J.R. Rostrup-Nielsen, J.K. Nørskov, I. Chorkendorff, J. Catal. 255 (2008) 6.

85 P.L. Hansen, J.B. Wagner, S. Helveg, J.R. Rostrup-Nielsen, B.S. Clausen, H. Topsøe, Science 295 (2002) 2053

${ }^{86}$ M.A. Newton, C. Belver-Coldeira, A. Martínez-Arias, M. Fernández-García, Nature 6 (2007) 528 .

${ }^{87}$ P.C.K. Vesborg, I. Chorkendorff, I. Knudsen, O. Balmes, J. Nerlov, A.M. Molenbroek, B.S. Clausen, S. Helveg, J. Catal. 262 (2009) 65. 


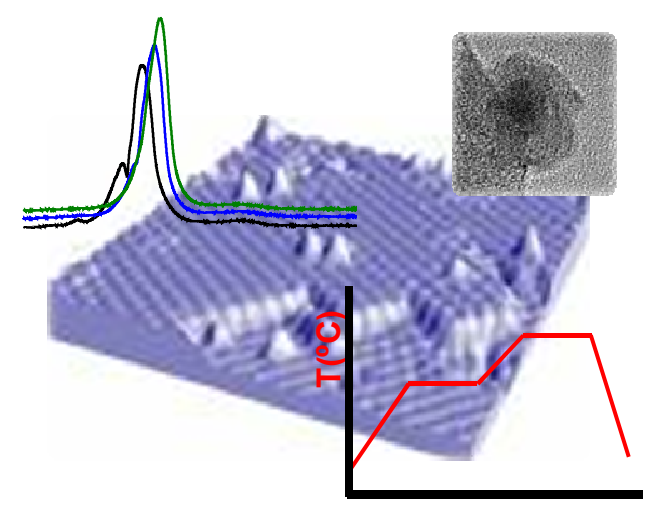

$\mathbf{t}(\mathbf{h})$

\section{INFLUENCIA DE LA HISTORIA TÉRMICA EN LOS CATALIZADORES $\mathrm{CO} / \mathrm{SiO}_{2}$ PARA LA SFT}




\subsection{Introducción.}

Como se comentó en la introducción general de esta memoria, los catalizadores de Co para la SFT se preparan, de manera general, mediante impregnación de un soporte poroso con una disolución acuosa del precursor metálico. Tras la impregnación, el sólido se seca (50-150드) para retirar el disolvente. Seguidamente, el material se somete a una serie de tratamientos térmicos que se agrupan bajo el término de "historia térmica" del catalizador. Estos tratamientos térmicos comprenden, de manera general, una calcinación, típicamente en atmósfera de aire, para descomponer el precursor de $\mathrm{Co}$ y cristalizar una fase de óxido (generalmente $\mathrm{Co}_{3} \mathrm{O}_{4}$ ) y, finalmente, un tratamiento de reducción in situ que genera las especies de $\mathrm{Co}^{\circ}$ catalíticamente activas.

Varios investigadores han centrado su interés en comprender la influencia de esta historia térmica en las propiedades del catalizador obtenido.

Por un lado, en el caso del tratamiento de reducción, se ha prestado especial atención a la influencia de la composición de la fase gaseosa reductora $[1,2]$, la velocidad de calentamiento [3] y la temperatura final del tratamiento [4] a la hora de determinar la microestructura cristalina de las fases de $\mathrm{Co}^{0}$ resultantes. El Co metálico presenta dos estructuras cristalográficas principales (cúbica centrada en las caras $(f c c)$ y hexagonal compacta $(h c p)$ ), existiendo una transición de fase $h c p \rightarrow f c c$ para una temperatura de alrededor de $415-430{ }^{\circ} \mathrm{C}$ en el caso del metal en su forma másica [5]. Puesto que esta temperatura de transición de fase cae en el rango de las temperaturas típicamente requeridas para reducir los catalizadores soportados de SFT (300-500ㄷ), la temperatura de reducción $\left(T_{r}\right)$ se ha considerado como un parámetro determinante de la 
microestructura de las fases de $\mathrm{Co}^{0}$ en los catalizadores de SFT. A su vez, algunos autores han relacionado la microestructura de las NPs de $\mathrm{Co}^{\circ}$ con el comportamiento catalítico, concluyendo que la fase $h c p$ presenta una actividad intrínseca superior a la fase $f c c[1,7]$.

Por otro lado, en lo que respecta al tratamiento de calcinación, se ha estudiado la influencia de varios parámetros como la composición de la atmósfera [6,7], la hidrodinámica gas-sólido [8], la velocidad de calentamiento y la temperatura final de calcinación $\left(T_{c}\right)[6,7]$ e incluso la supresión del tratamiento (protocolo de activación por reducción directa) [9] sobre las propiedades catalíticas finales de los catalizadores basados en Co. Sin embargo, generalmente, estos efectos se han interpretado exclusivamente en términos de dispersión metálica y reducibilidad de modo que se considera que las condiciones de calcinación determinan la dispersión y reducibilidad de los óxidos de Co resultantes, lo que a su vez determina la densidad de centros $\mathrm{Co}^{0}$ superficiales después del subsiguiente tratamiento de reducción. Al contrario que en el caso del tratamiento de reducción, no se han considerado generalmente diferencias en la naturaleza y actividad intrínseca de los centros $\mathrm{Co}^{0}$ relacionadas con las condiciones de calcinación previas. La principal razón para esto estriba en que los catalizadores calcinados se someten siempre al tratamiento de reducción antes de convertirlos en su estado catalíticamente activo. De hecho, considerando la literatura científica y de patentes para los catalizadores de Co empleados en la SFT, la temperatura de calcinación $\left(T_{c}\right)$ parece escogerse de un modo más o menos arbitrario en el rango de $300-550^{\circ} \mathrm{C}$. En otros casos, la naturaleza del precursor metálico o bien la ruta de síntesis empleada dictan un valor mínimo para $T_{c}$ con el objetivo de completar la descomposición del precursor o la retirada de fases orgánicas empleadas en la síntesis, respectivamente $[10,11,12]$. 
Enache y col. [7] encontraron valores de TOF superiores para catalizadores de Co, derivados de precursores de tipo nitrato, activados por reducción directa y adscribieron esta superior actividad catalítica por centro metálico a una mayor contribución de fases de $\mathrm{Co}^{0} h c p$ y de baja cristalinidad, en comparación con los catalizadores previamente calcinados. Por su parte Chu y col. [13] encontraron un descenso del $56 \%$ en el valor de CTY cuando se incrementa $T_{c}$ desde 340 hasta $550 \circ \mathrm{C}$ para catalizadores $\mathrm{Co} / \mathrm{Al}_{2} \mathrm{O}_{3}$. Aunque no se reportan datos de TOF en este caso, las diferencias en dispersión metálica y reducibilidad, aparentemente, no explican completamente este descenso en actividad, lo que sugiere un efecto adicional de $T_{c}$ sobre el valor de TOF. En este sentido, los catalizadores Co/ITQ-2 estudiados en el capítulo 3 de esta memoria, sometidos a una $T_{c}$ de 500 ㅇ $\mathrm{C}$, presentan valores de TOF entre 2 y 3 veces inferiores a los recogidos en la literatura para otros catalizadores $\left(\mathrm{Co} / \mathrm{SiO}_{2}, \mathrm{Co} / \mathrm{Al}_{2} \mathrm{O}_{3}\right.$ y $\left.\mathrm{Co} / \mathrm{CNF}\right)$ con tamaños de NP similar, cuya activación no involucra calcinación en aire o bien ésta se lleva a cabo a menores temperaturas ( $\leq 350 \circ \mathrm{C}$ ).

De hecho, un escrutinio detallado de los datos publicados en la literatura para catalizadores de Co activados siguiendo diferentes protocolos sugiere un efecto no despreciable de la temperatura de calcinación sobre el valor de TOF. La Fig. 4.1 muestra la evolución de la actividad catalítica por centro metálico superficial (TOF) en función del tamaño de nanopartícula metálica $\left(d\left(\mathrm{Co}^{0}\right)\right)$ para un conjunto de datos obtenidos por diferentes grupos de investigación a lo largo de los últimos 10 años. En los casos en los que la actividad no se expresa como TOF en la referencia bibliográfica, la actividad por centro superficial se ha calculado a partir de los datos de tamaño de nanopartícula metálica y grado de reducción de los catalizadores, así como la velocidad espacial y la conversión en los experimentos catalíticos. A su vez, debido a la inhomogeneidad en la temperatura de reacción empleada en los 
diferentes estudios, se han estimado los valores de TOF a una temperatura de reacción de $220^{\circ} \mathrm{C}$ a partir de los valores de TOF publicados a otras temperaturas de reacción, considerando una dependencia con la temperatura de tipo Arrhenius y una energía de activación aparente $\left(E_{a}\right)$ de $97 \mathrm{~kJ} / \mathrm{mol}$. Este valor de $E_{a}$ se determinó a partir de los experimentos preliminares de esta tesis doctoral (ver sección 2.3.3.1) y es representativo de los valores de $E_{a}$ publicados $(90-115 \mathrm{~kJ} / \mathrm{mol}$ ) en numerosos trabajos científicos $[14,15,16]$. De todos modos, variaciones de $E_{a}$ en el rango de 90$115 \mathrm{~kJ} / \mathrm{mol}$ resultan en modificaciones del valor de TOF a $220^{\circ} \mathrm{C}$, representado en la Fig. 4.1, inferiores al $18 \%$, lo que no modifica sustancialmente las tendencias que se comentan a continuación.

La Tabla 4.1 recoge con más detalle la naturaleza de los catalizadores y las condiciones de reacción empleadas en cada estudio. 
Tabla 4.1: Simbología, tipo de catalizadores y condiciones de reacción empleadas en los trabajos científicos recogidos en la recopilación de datos catalíticos representada en la Fig. 4.1.

\begin{tabular}{|c|c|c|c|c|c|c|}
\hline \multirow{2}{*}{ Referencia } & \multirow{2}{*}{ Símbolo } & \multirow{2}{*}{ Catalizadores } & \multicolumn{4}{|c|}{ Condiciones reacción } \\
\hline & & & $\mathrm{T}(\mathrm{o} \mathrm{C})$ & $\mathrm{P}(\mathrm{MPa})$ & $\mathrm{H}_{2} / \mathrm{CO}$ & $\mathrm{X}_{\mathrm{CO}}(\%)$ \\
\hline [17] & (1) & $\mathrm{ReCo} / \mathrm{Al}_{2} \mathrm{O}_{3}$ & 210 & 2.0 & 2.1 & 50 \\
\hline [18] & $\Delta$ & $\mathrm{RuCo} / \mathrm{Al}_{2} \mathrm{O}_{3}$ & 220 & " 2.0 & 2.0 & 40 \\
\hline [19] & $\Delta$ & $\begin{array}{l}\mathrm{RuCo} / \mathrm{TiO}_{2} \\
\mathrm{RuCo} / \mathrm{SiO}_{2}\end{array}$ & 200 & 2.0 & 2.05 & $50-60$ \\
\hline [20] & $\triangleleft$ & RuCo/SBA-15 & 220 & 2.0 & 2.0 & 55 \\
\hline$[21]$ & O & $\mathrm{Co} / \mathrm{CNF}$ & 210 & 3.5 & 2.0 & $4-65$ \\
\hline$[22]$ & 8 & $\mathrm{Co} / \mathrm{SiO}_{2}$ & 180 & 0.1 & 2.0 & $<5$ \\
\hline [23] & $\mathbf{\square}$ & $\begin{array}{l}\mathrm{Co} / \mathrm{SiO}_{2} \\
\mathrm{Co} / \mathrm{Al}_{2} \mathrm{O}_{3}\end{array}$ & 210 & 2.0 & 2.05 & $55-65$ \\
\hline $\begin{array}{c}\text { Este } \\
\text { capítulo }\end{array}$ & $\nabla$ & $\mathrm{Co} / \mathrm{SiO}_{2}$ & 220 & 2.0 & 2.0 & 5 \\
\hline [24] & $\bigcirc$ & $\begin{array}{c}\mathrm{Co} / \mathrm{MCM}-41 \\
\mathrm{Co} / \mathrm{SBA}-15 \\
\mathrm{Co} / \mathrm{SiO}_{2}\end{array}$ & 190 & 0.1 & 2.0 & $<5$ \\
\hline$[25]$ & $\square$ & Co/SBA15 & 265 & 0.7 & 2.0 & $5-10$ \\
\hline [26] & 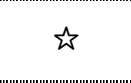 & $\begin{array}{c}\mathrm{Co} / \mathrm{ITQ}-2 \\
\mathrm{Co} / \mathrm{SiO}_{2}\end{array}$ & 220 & 2.0 & 2.0 & 10 \\
\hline$[27]$ & $\triangleleft$ & $\mathrm{Co} / \mathrm{SiO}_{2}$ & 220 & 2.0 & 2.0 & 10 \\
\hline $\begin{array}{c}\text { Este } \\
\text { capítulo }\end{array}$ & $\nabla$ & $\mathrm{Co} / \mathrm{SiO}_{2}$ & 220 & 2.0 & 2.0 & 5 \\
\hline
\end{tabular}

Los catalizadores recogidos en la Fig. 4.1 se han agrupado en tres series:

- Catalizadores activados por calcinación en aire a temperaturas $\angle 350^{\circ} \mathrm{C}$ o bien activados por reducción directa, eliminando la etapa de calcinación en aire (símbolos llenos y línea continua en Fig. 4.1).

- Catalizadores activados por calcinación a temperaturas $>450^{\circ} \mathrm{C}$ (símbolos abiertos y línea quebrada). 
- Catalizadores promovidos con $\mathrm{Re}$ o $\mathrm{Ru}$ activados en condiciones comparables a los catalizadores de la primera serie, (símbolos semi-Ilenos y línea punteada).

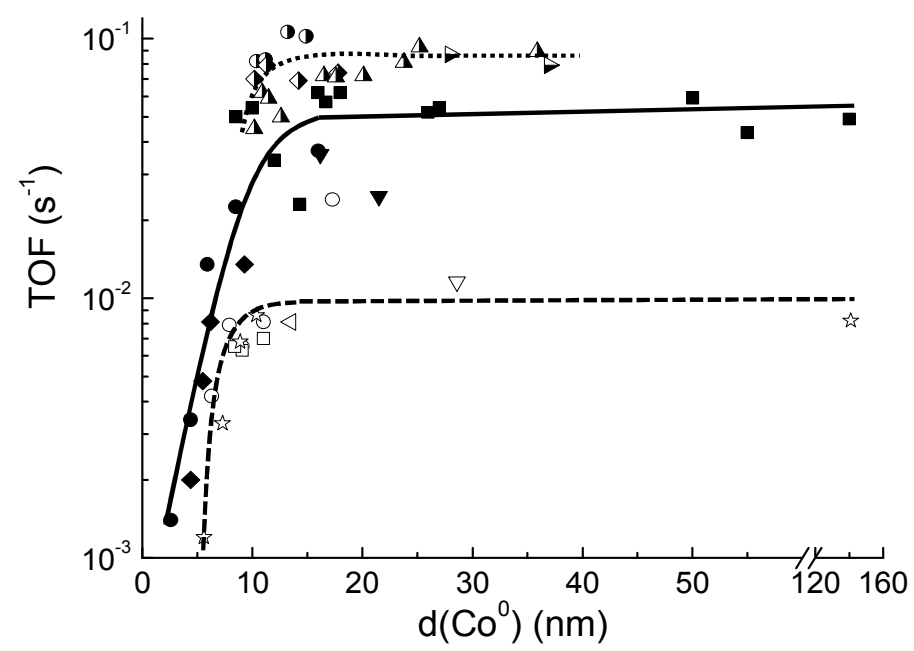

Figura 4.1: Evolución de la actividad catalítica por centro superficial (TOF(220ㄷ)) con el tamaño de nanopartícula de $\mathrm{Co}^{0}$ para catalizadores activados por reducción directa o calcinación a baja temperatura $\left(<350^{\circ} \mathrm{C}\right)$ (símbolos llenos y línea continua), activados por calcinación a temperaturas elevadas (>450C) (símbolos abiertos y línea quebrada) y bimetálicos promovidos por Ru o Re (símbolos semi-llenos y línea punteada) extraídos de la literatura (ver Tabla 4.1 para más detalles).

A pesar de que existe una cierta dispersión de los puntos en cada serie, y alguna singularidad en forma de datos fuera de las tendencias generales (líneas de guía visual), probablemente asociadas a las diferencias en las condiciones de ensayo catalítico $\left(\mathrm{P}, \mathrm{X}_{\mathrm{CO}}\right)$ y las metodologías empleadas para estimar $d\left(\mathrm{Co}^{0}\right)\left(\mathrm{XRD}\right.$, quimisorción $\left.\mathrm{H}_{2}, \mathrm{XPS}\right)$, se percibe con claridad que la sensibilidad a la estructura no clásica, evidenciada en el capítulo 3 de esta memoria, se manifiesta a tres niveles de TOF diferentes para cada una de las tres series de catalizadores. 
Así pues, esta compilación de resultados bibliográficos sugiere que una temperatura de calcinación elevada $\left(T_{c}>450 \circ \mathrm{C}\right)$ supone un descenso en el TOF de unas 2-5 veces, para un mismo valor de $d\left(\mathrm{Co}^{\circ}\right)$, respecto de los catalizadores cuya activación comprende una reducción directa o bien una calcinación en aire a temperaturas más suaves $\left(T_{c}<350\right.$ 으 $)$ seguidas, en todo caso, de la reducción. Estas diferencias en TOF causadas por la elección de las condiciones de activación de los catalizadores son de un valor comparable o superior a las debidas a la introducción de promotores metálicos de elevado coste $(\mathrm{Ru}, \mathrm{Re})$ en la composición del catalizador, como se observa en la Fig. 4.1.

De todo lo comentado se desprende la necesidad de un estudio sistemático de la influencia de la temperatura de calcinación en las propiedades estructurales y catalíticas de las nanopartículas de $\mathrm{Co}^{0}$ en la SFT.

\subsection{Planteamiento.}

En este capítulo se estudia la influencia de la historia térmica sobre la actividad catalítica intrínseca de los catalizadores de $\mathrm{Co}^{0}$ para la SFT. Con el objeto de estudiar estos efectos sin interferencias por parte de la sensibilidad a la estructura evidenciada en el capítulo 3 de esta memoria, se prepararon una serie de catalizadores soportados sobre $\mathrm{SiO}_{2}$ comercial porosa con un área superficial relativamente baja $\left(146 \mathrm{~m}^{2} / \mathrm{g}\right)$ y diámetro de poro ancho (19 nm), para obtener tamaños medios de NP metálica en el rango en el que el valor de TOF no depende de la dispersión metálica, es decir, $d\left(\mathrm{Co}^{\circ}\right)>10 \mathrm{~nm}$. Los catalizadores se activaron bien por reducción directa o bien mediante calcinación en aire a diferentes temperaturas en el rango de $300-550^{\circ} \mathrm{C}$, seguidas, en todo caso, por un idéntico tratamiento de 
reducción in situ a $400^{\circ} \mathrm{C}$, tal y como se describe en la sección 2.1.3.3 de la parte experimental de esta memoria.

\subsection{Resultados y discusión.}

\subsubsection{Contenido metálico y dispersión de los catalizadores.}

Los contenidos metálicos determinados mediante ICP-OES en los catalizadores calcinados, incluidos en la Tabla 4.2, concuerdan razonablemente con el valor nominal del $20 \%(p)$ (desviaciones $<13 \%$ ). En el caso de la muestra $\mathrm{Co} / \mathrm{SiO}_{2}$ rd, que no se calcina, se analizó tras la impregnación y el secado y, por tanto, el contenido metálico es sensiblemente inferior al valor nominal debido a la contribución de la masa de las especies nitrato provenientes del precursor metálico.

Tabla 4.2: Contenido metálico, dispersión metálica y grado de reducción (400ㄷ, 10h) para los catalizadores $\mathrm{Co} / \mathrm{SiO}_{2}$.

\begin{tabular}{|c|c|c|c|c|c|c|c|}
\hline \multirow{3}{*}{ Muestra } & \multirow{3}{*}{$\begin{array}{c}\text { Co } \\
(\%(p))\end{array}$} & \multicolumn{5}{|c|}{ Dispersión metálica } & \multirow{3}{*}{$\begin{array}{l}G^{C} \\
(\%)\end{array}$} \\
\hline & & \multirow{2}{*}{$\begin{array}{c}\text { XRD } \\
d\left(\mathrm{Co}_{3} \mathrm{O}_{4}\right)_{X} \\
(\mathrm{~nm})\end{array}$} & \multirow{2}{*}{$\begin{array}{c}\text { TEM } \\
\mathrm{d}\left(\mathrm{Co}^{0}\right)_{\mathrm{T}} \\
(\mathrm{nm})\end{array}$} & \multicolumn{3}{|c|}{ Quimisorción $\mathrm{H}_{2}$} & \\
\hline & & & & $\begin{array}{c}\mathrm{H}_{2} \text {, ads } \\
(\mu \mathrm{mol} / \mathrm{g})\end{array}$ & $\begin{array}{l}D^{b} \\
(\%)\end{array}$ & $\begin{array}{c}d\left(\mathrm{Co}^{0}\right)_{\mathrm{H}} \\
(\mathrm{nm})\end{array}$ & \\
\hline $\mathrm{Co} / \mathrm{SiO}_{2} \_r d$ & $14.7^{\mathrm{a}}$ & --- & 16.4 & 113.2 & 5.9 & 16.2 & 82 \\
\hline $\mathrm{Co} / \mathrm{SiO}_{2} \_300$ & 22.5 & 18.5 & 26.2 & 85.4 & 4.5 & 21.5 & 92 \\
\hline $\mathrm{Co} / \mathrm{SiO}_{2}{ }_{4} 425$ & 22.5 & 23.1 & n.d. ${ }^{d}$ & 74.9 & 3.9 & 24.5 & 93 \\
\hline $\mathrm{Co} / \mathrm{SiO}_{2} \_550$ & 22.5 & 26.3 & 31.2 & 64.2 & 3.4 & 28.6 & 93 \\
\hline $\mathrm{Co} / \mathrm{SiO}_{2} \_d c$ & 24.3 & 20.9 & n.d. & 81 & 4.0 & 24.3 & 90 \\
\hline
\end{tabular}

${ }^{a}$ Análisis para la muestra tras la impregnación y el secado.

${ }^{b}$ Dispersión metálica.

${ }^{c}$ Grado de reducción. Estimado mediante $\mathrm{H}_{2}$-TPR de la muestra reducida previamente en flujo de $\mathrm{H}_{2}$ (400ㄷ, 10h), ver sección 2.2.7.1.

${ }^{d}$ n.d.: No determinado.

Por su parte, la dispersión metálica en los catalizadores $\mathrm{Co} / \mathrm{SiO}_{2}$ se estudió mediante XRD en las muestras calcinadas y mediante quimisorción de $\mathrm{H}_{2}$ en su forma reducida. Además, también se analizaron mediante TEM muestras seleccionadas reducidas y pasivadas.

La espinela $\mathrm{CO}_{3} \mathrm{O}_{4}$ es la única fase cristalina detectada por XRD en los catalizadores calcinados. La Tabla 4.2 incluye los valores de diámetro medio 
de cristal $\left(d\left(\mathrm{CO}_{3} \mathrm{O}_{4}\right)_{\mathrm{X}}\right)$ determinados mediante XRD en los catalizadores calcinados. Se observa que un incremento en la temperatura de calcinación en el orden $\mathrm{Co} / \mathrm{SiO}_{2} 300>\mathrm{Co} / \mathrm{SiO}_{2} 425>\mathrm{Co} / \mathrm{SiO}_{2}$ 550 resulta en un incremento progresivo en el tamaño de cristal de $\mathrm{Co}_{3} \mathrm{O}_{4}$ desde $18.5 \mathrm{~nm}$ hasta $26.3 \mathrm{~nm}$, como resultado de un mayor grado de sinterizado de las fases metálicas. A su vez, $\mathrm{Co} / \mathrm{SiO}_{2} d c$ muestra un $d\left(\mathrm{CO}_{3} \mathrm{O}_{4}\right)_{x}$ similar al de $\mathrm{Co} / \mathrm{SiO}_{2}{ }_{3} 300$, sugiriendo que la pre-calcinación del soporte a elevada temperatura no provoca cambios significativos en sus propiedades texturales que se traduzcan en diferencias en el nivel de interacción metalsoporte para las fases metálicas soportadas posteriormente.

Por su parte, los resultados de quimisorción de $\mathrm{H}_{2}$ indican que la descomposición del precursor metálico por reducción directa da lugar a mayores dispersiones metálicas que cuando se emplea un tratamiento de calcinación en aire previo a la reducción. A su vez, para los catalizadores que se someten a calcinación, los resultados de quimisorción de $\mathrm{H}_{2}$ están de acuerdo con los resultados de XRD, mostrando una disminución de la dispersión metálica en el orden $\mathrm{Co} / \mathrm{SiO}_{2} 300>\mathrm{Co} / \mathrm{SiO}_{2} 425>\mathrm{Co} / \mathrm{SiO}_{2} 550$. 
a)
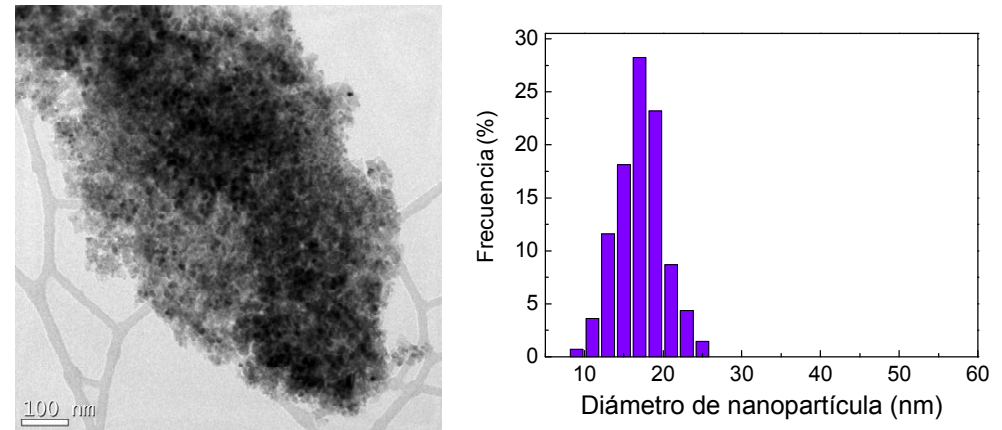

b)
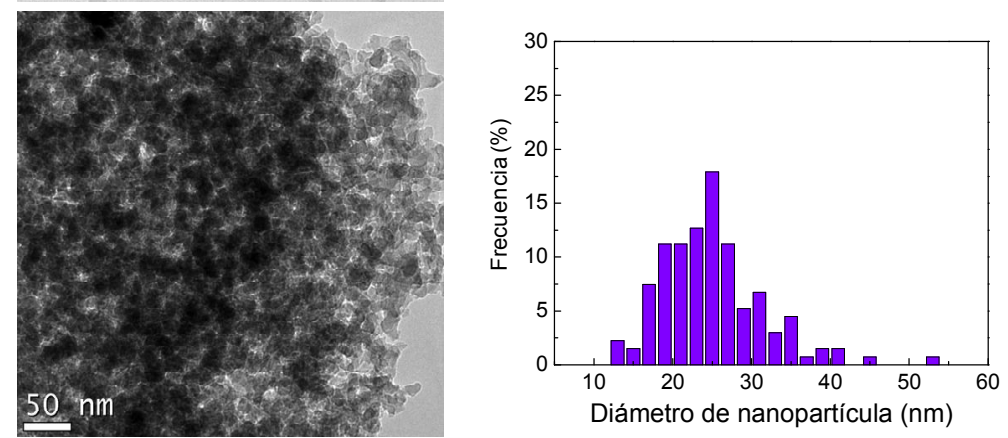

c)
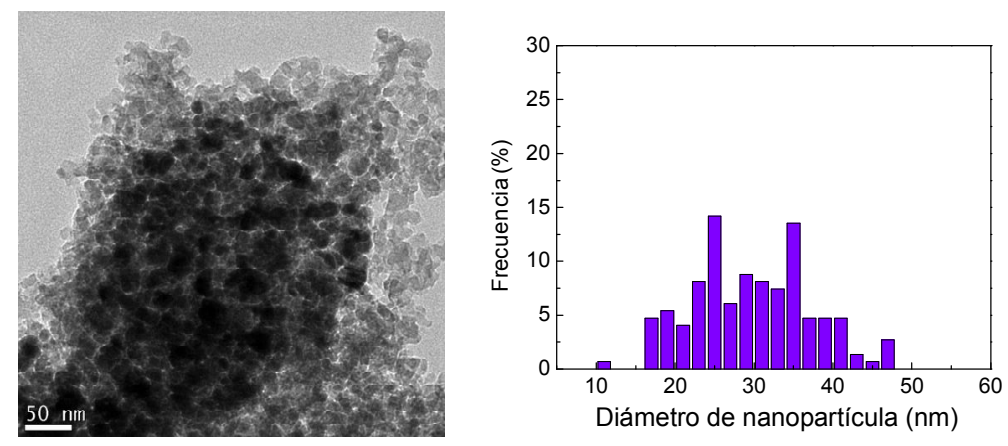

Figura 4.2: Micrografías de TEM representativas y los correspondientes histogramas de tamaño de nanopartícula metálica para los catalizadores a) $\mathrm{Co} / \mathrm{SiO}_{2}$ rd, b) $\mathrm{Co} / \mathrm{SiO}_{2} \_425$ y c) $\mathrm{Co} / \mathrm{SiO}_{2} \_550$ reducidos y pasivados.

Finalmente, la Fig. 4.2 muestra micrografías de TEM a media magnificación representativas para los catalizadores $\mathrm{Co} / \mathrm{SiO}_{2} r d$, $\mathrm{Co} / \mathrm{SiO}_{2} \_300$ y Co/SiO 2 550, así como los correspondientes histogramas para el tamaño de nanopartícula metálica. Por su parte, la Fig. 4.3 muestra una imagen de HRTEM para $\mathrm{Co} / \mathrm{SiO}_{2}$ rd en la que se distingue claramente una NP 
de Co que presenta un "núcleo" de $\mathrm{Co}^{0}-f c c$ (espaciado interplanar $d=2.0 \AA$ ) y una corteza de $\mathrm{CoO}(d=2.1 \AA$ ) de $3 \mathrm{~nm}$ de espesor.

Los valores de $d\left(\mathrm{Co}^{0}\right)_{T}$ recogidos en la Tabla 4.2 se han corregido teniendo en cuenta la contracción volumétrica debida a la reducción de esta corteza de óxido. Como se observa, los valores de $d\left(\mathrm{CO}^{0}\right)_{T}$ concuerdan satisfactoriamente con los correspondientes $d\left(\mathrm{Co}^{0}\right)_{\mathrm{H}}$ determinados por quimisorción de hidrógeno, mostrando desviaciones relativas inferiores al $22 \%$.

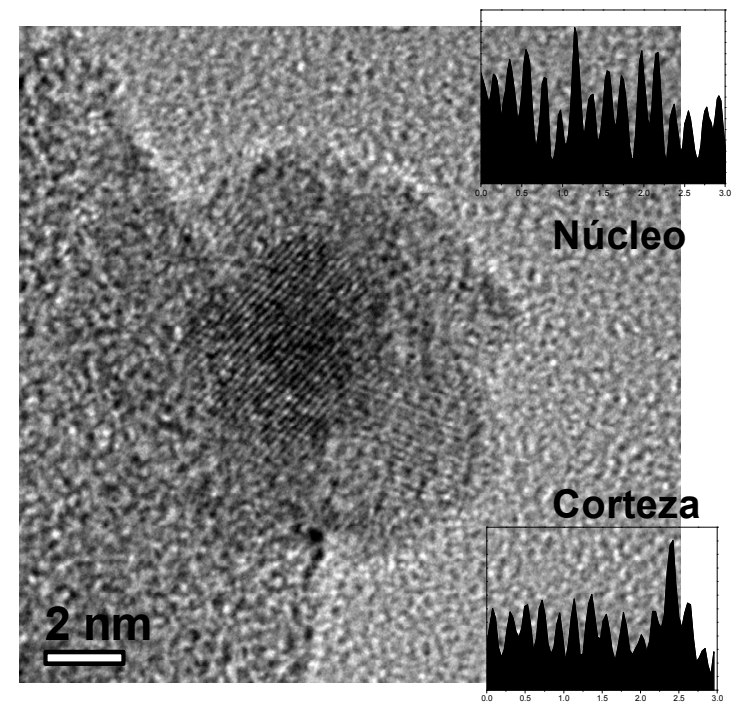

Figura 4.3: Micrografía de HRTEM para el catalizador $\mathrm{Co}_{\mathrm{SiO}}{ }_{2}{ }_{2}$ rd reducido y pasivado.

Cabe destacar dos hechos adicionales que se perciben mediante el análisis por TEM:

- Por un lado, considerando los valores de desviación típica $\left(\sigma_{T}\right.$ en Tabla 4.2) derivados de los histogramas representados en la Fig. 4.2, se observa que la distribución de tamaño de NPs se ensancha progresivamente en el orden $\mathrm{Co} / \mathrm{SiO}_{2} r d<\mathrm{Co} / \mathrm{SiO}_{2}$ 300 $<$ 
$\mathrm{Co} / \mathrm{SiO}_{2} 550$, indicando que el proceso de aglomeración metálica que tiene lugar durante el tratamiento de calcinación en aire, especialmente para $T_{c}$ elevadas, da lugar a una menor homogeneidad en el tamaño de NP que el tratamiento de reducción directa.

- En segundo lugar, simultáneamente a este ensanchamiento de la distribución de tamaños de NP, la aplicación del tratamiento de calcinación da lugar a un mayor grado de agrupamiento de las NPs metálicas individuales (metal clustering), lo que reduce la homogeneidad de ocupación de la superficie del soporte por parte de las fases metálicas. Este fenómeno retira Co de la parte más externa de las partículas porosas de $\mathrm{SiO}_{2}$, mientras que reduce la distancia media entre nanopartículas, especialmente para $\mathrm{Co} / \mathrm{SiO}_{2}{ }_{5} 550$, que se calcina a una $T_{c}$ más elevada (Fig. 4.2-c).

Finalmente, como conclusión importante de esta sección, cabe remarcar que el tamaño medio de NP metálica determinado para toda la serie de catalizadores $\mathrm{Co} / \mathrm{SiO}_{2}$ se encuentra en el rango 16-30 nm, esto es, al menos un $60 \%$ superior al valor crítico de $10 \mathrm{~nm}$ por debajo del cual se manifiesta el efecto del tamaño de NP sobre el TOF (capítulo 3). Incluso para el catalizador con mayor dispersión metálica $\left(\mathrm{Co} / \mathrm{SiO}_{2} r\right.$ rd), la contribución de NPs de tamaño $<10 \mathrm{~nm}$ es despreciable a la vista del correspondiente histograma derivado del análisis microscópico (Fig. 4.2-a).

\subsubsection{Propiedades estructurales de $\mathrm{CO}_{3} \mathrm{O}_{4}$ en los catalizadores calcinados en aire.}

4.3.2.1. Caracterización másica de las $\mathrm{NPs}_{\text {de }} \mathrm{CO}_{3} \mathrm{O}_{4}$ : Espectroscopia láser Raman (LRS).

Todos los catalizadores calcinados en aire presentan $\mathrm{CO}_{3} \mathrm{O}_{4}$ como única fase metálica cristalina, de acuerdo a los resultados de XRD (sección 4.3.1). Idealmente, esta fase presenta una estructura tipo espinela, que se 
muestra esquemáticamente en la Fig. 4.4, con cationes $\mathrm{Co}^{2+}$ y $\mathrm{Co}^{3+}$ ocupando $1 / 8$ y $1 / 2$ de los sitios catiónicos de red $8 a$ (coordinación tetrahédrica (Th)) y $16 d$ (coordinación octahédrica $(O h)$ ), respectivamente. No obstante, se conoce de trabajos que emplean $\mathrm{Co}_{3} \mathrm{O}_{4}$ en su forma másica en aplicaciones relacionadas con sus propiedades eléctricas que la proporción y la localización de ambos cationes puede variar significativamente en función de los tratamientos térmicos a los que se someta este óxido mixto. En este sentido, estudios de EPR [28] y, más recientemente, XRD con refinamiento de Rietveld [29] han demostrado que la temperatura de calcinación en atmósfera de aire, en el rango $250-600^{\circ} \mathrm{C}$, influye marcadamente en la proporción de los iones $\mathrm{Co}^{2+}$ y $\mathrm{Co}^{3+}$ y su distribución entre las dos posiciones de red y también las 3 posiciones intersticiales existentes en la estructura $(16 c(O h), 48 f(T h)$ y $8 b(T h))$. Es probable que estos fenómenos sean trasladables a las NPs de $\mathrm{Co}_{3} \mathrm{O}_{4}$ soportadas y que, por lo tanto, la estructura cristalina y la proporción $\mathrm{Co}^{2+} / \mathrm{Co}^{3+}$ varíe para los catalizadores $\mathrm{Co} / \mathrm{SiO}_{2}$ activados a diferentes temperaturas en el rango 300-500ㄷ.
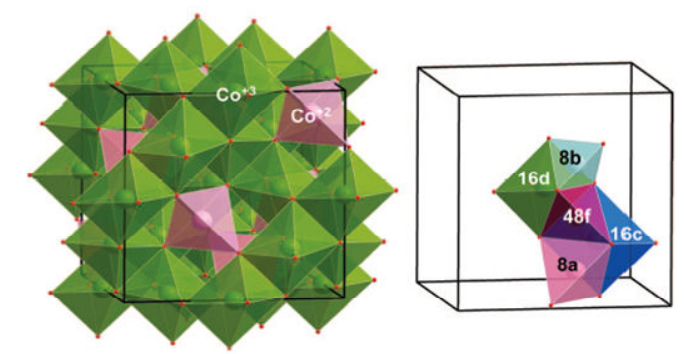

\section{Sitios de red: $16 \mathrm{~d}(\mathrm{Oh})$ $8 \mathrm{a}(\mathrm{Th})$ Sitios intersticiales: $16 \mathrm{c}(\mathrm{Oh})$ $48 f(T h)$ $8 \mathrm{~b}(\mathrm{Th})$}

Figura 4.4: Estructura cristalina de la espinela de $\mathrm{Co}^{2+}$ y $\mathrm{Co}^{3+}$, adaptada de [29].

La elucidación de las ocupaciones relativas de los diferentes sitios en estructura de $\mathrm{CO}_{3} \mathrm{O}_{4}$ mediante XRD no es viable para materiales soportados con tamaños de cristal nanométrico, por lo que se requiere de otras técnicas para estudiar el ordenamiento estructural de las diferentes muestras $\mathrm{Co} / \mathrm{SiO}_{2}$ calcinadas. En este sentido, la espectroscopia Raman es una técnica 
que permite estudiar los modos de vibración fónicos de las redes cristalinas, los cuáles son sensibles a cambios en la ordenación de los iones a nivel atómico [30].

La estructura cristalina de la espinela $\mathrm{Co}_{3} \mathrm{O}_{4}$ corresponde al grupo espacial de simetría $\mathrm{O}_{\mathrm{h}}{ }^{7}(\mathrm{Fd} 3 \mathrm{~m})$, con una celda de Bravais reducida constituída por 14 átomos ( $Z=2)$. Existen 5 modos activos en Raman para esta estructura $\left(\mathrm{A}_{1 \mathrm{~g}}+\mathrm{E}_{\mathrm{g}}+3 \mathrm{~F}_{2 \mathrm{~g}}\right)$ [31]. El espectro Raman de los catalizadores $\mathrm{Co} / \mathrm{SiO}_{2}$ calcinados muestra las señales correspondientes a los 5 modos activos [31]: $689 \mathrm{~cm}^{-1}\left(A_{1 \mathrm{~g}}\right), 616 \mathrm{~cm}^{-1}\left(F_{2 g(1)}\right), 519 \mathrm{~cm}^{-1}\left(F_{2 g(2)}\right), 479 \mathrm{~cm}^{-1}\left(E_{g}\right)$ y $193 \mathrm{~cm}^{-1}\left(F_{2 g(3)}\right)$. La comparación de los espectros para los diferentes catalizadores evidencia diferencias en posición, simetría e intensidad relativa en la señales de algunos de los fonones de la estructura $\mathrm{Co}_{3} \mathrm{O}_{4}$, los cuales están relacionados con diferencias en el ordenamiento atómico en la estructura cristalina.

La Fig. 4.5-a muestra en detalle la señal Raman correspondiente al modo $A_{1 g}$ para los catalizadores calcinados. Se observa que cuando la temperatura de calcinación de los catalizadores se incrementa desde 300 드 (para $\mathrm{Co} / \mathrm{SiO}_{2} 300$ y Co/SiO${ }_{2} d c$ ) hasta 550 oC (para $\mathrm{Co} / \mathrm{SiO}_{2} 550$ ), progresivamente, la señal se desplaza a menores desplazamientos Raman y se ensancha, con una ligera asimetría hacia menores frecuencias.

En la Fig. 4.5-b se representa la evolución tanto de la posición como de la anchura (FWHM) de la señal con la temperatura de calcinación. Por un lado, los catalizadores $\mathrm{Co} / \mathrm{SiO}_{2} 300$ y $\mathrm{Co} / \mathrm{SiO}_{2} \_d c$, muestran características espectrales similares, lo que indica que las tendencias están exclusivamente relacionadas con la temperatura final a la que se calcinan las especies de Co $\left(T_{c}\right)$. Por otro lado, las propiedades de las señales Raman difieren de aquellas para $\mathrm{Co}_{3} \mathrm{O}_{4}$ másico (elevada cristalinidad, Aldrich) tanto más cuanto más 
elevada es la temperatura de calcinación. Estos resultados se relacionan con un incremento en el desorden catiónico en las muestras, separándose de la estructura de espinela ideal, al incrementarse $T_{c}$. En concreto, el fonón $A_{1 g}$ se ha relacionado con la red de oxígenos correspondientes a los sitios de red $16 d(\mathrm{Oh})[32,33]$, lo que sugiere que la temperatura de calcinación modifica la ocupación de los mismos por parte de los cationes $\mathrm{Co}^{3+}$. Finalmente, cabe comentar que la evolución de la posición y la anchura de esta señal Raman con el tamaño de cristal de la fase $\mathrm{Co}_{3} \mathrm{O}_{4}$ es contraria a la esperada de acuerdo al "efecto de confinamiento del fonón", que produce desplazamientos y ensanchamientos de las señales cuando se reduce el tamaño de cristal [30]. Por lo tanto, los efectos observados están relacionados exclusivamente con diferentes grados de desorden catiónico en las NPs de $\mathrm{CO}_{3} \mathrm{O}_{4}$.

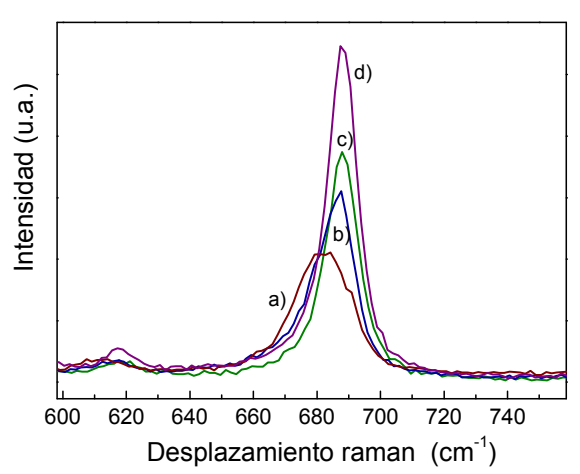

(a)

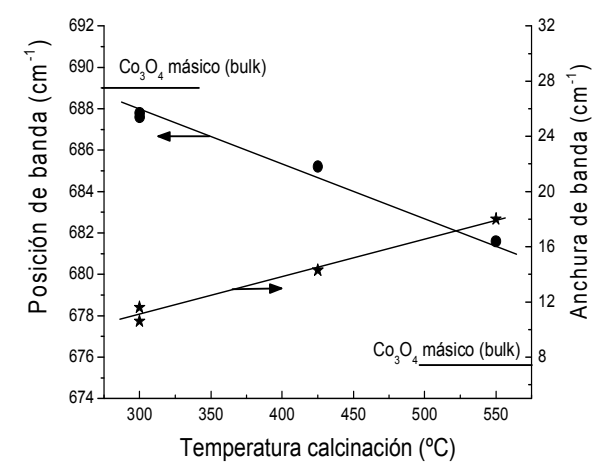

(b)

Figura 4.5: (a) Espectro Raman para los catalziadores calcinados a) $\mathrm{Co} / \mathrm{SiO}_{2} \_550$, b) $\mathrm{Co} / \mathrm{SiO}_{2}{ }_{2} 425$, c) $\mathrm{Co} / \mathrm{SiO}_{2} \_300$ y d) $\mathrm{Co} / \mathrm{SiO}_{2}$ dc en el rango de desplazamiento Raman $600-750 \mathrm{~cm}^{-1}$ (modo de vibración fundamental $A_{1 g}$ ); y (b) evolución de la posición y la anchura de banda de la señal $A_{1 g}$ con la temperatura de calcinación de los catalizadores.

Por otro lado, la Fig. 4.6 muestra una inversión en la intensidad (también si se considera el área integrada) de las señales asignadas a los modos Raman $E_{g}$ y $F_{2 g}$ al incrementarse $T_{c}$ desde 300 a 550ㄷ․ Esta inversión 
de la intensidad viene acompañada por un desplazamiento a menores frecuencias y un ensanchamiento, como en el caso de la señal $A_{1 g}$ discutida con anterioridad. En este sentido, se ha encontrado recientemente que las señales asociadas a los modos de vibración fundamentales $E_{g}$ y $F_{2 g}$ presentan diferentes sensibilidades al desorden catiónico en óxidos con estructura de tipo perovskita [34], de acuerdo a lo cual las bandas $E_{g}$ experimentan un descenso en su intensidad integrada más acusado que las señales $F_{2 g}$ cuando se incrementa el desorden catiónico (definido como un escalar $\eta$ de acuerdo a [35]) mediante tratamientos térmicos. Este resultado concurre con la discusión realizada en base a la señal del fonón $A_{1 g}$, apuntando hacia un incremento en el desorden catiónico en la estructura cristalina $\left(\mathrm{Co}^{2+}\right)\left(\mathrm{Co}^{3+}\right)_{2} \mathrm{O}_{4}$, es decir una mayor desviación respecto de las ocupaciones de sitios de red ideales, cuando se incrementa la temperatura de calcinación aplicada a las $\mathrm{NPs}$ de $\mathrm{Co}_{3} \mathrm{O}_{4}$ presentes en los catalizadores $\mathrm{Co} / \mathrm{SiO}_{2}$ calcinados en aire.

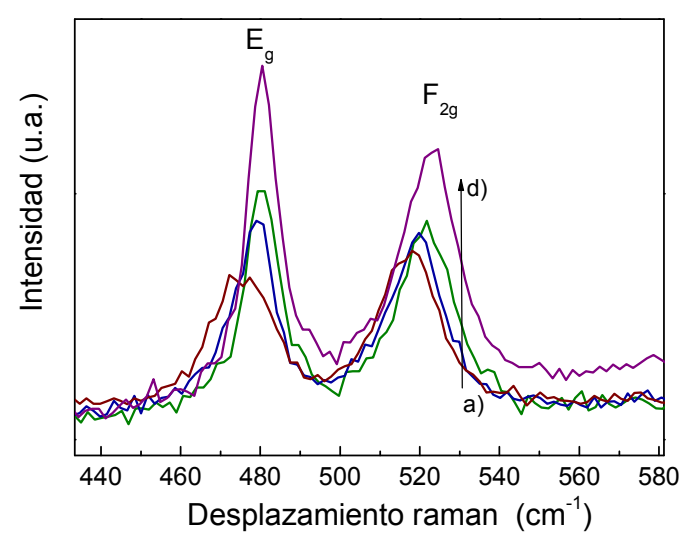

Figura 4.6: Espectro Raman para los catalizadores calcinados a) $\mathrm{Co} / \mathrm{SiO}_{2} \_550$, b) $\mathrm{Co} / \mathrm{SiO}_{2} \_425$, c) $\mathrm{Co} / \mathrm{SiO}_{2}$ _ 300 y d) $\mathrm{Co} / \mathrm{SiO}_{2}$ _dc en el rango de desplazamiento Raman 450-580 cm (modos de vibración fundamentales $E_{g y} F_{2 g}(1)$ ).

Desafortunadamente, los estudios acerca de la interpretación cuantitativa de los espectros Raman en términos de orden catiónico en los 
óxidos metálicos son aún escasos e inconclusivos, por lo que, de momento, no se puede dar una interpretación más detallada de la proporción de cationes y la situación de los mismos en la red cristalina de las NPs de $\mathrm{Co}_{3} \mathrm{O}_{4}$ soportadas. En este sentido, se han propuesto varios modelos que postulan tanto la migración de cationes $\mathrm{Co}^{2+}$ y $\mathrm{Co}^{3+}$ desde posiciones intersticiales hacia posiciones de red, preferiblemente de coordinación tetraédrica $(8 a)$

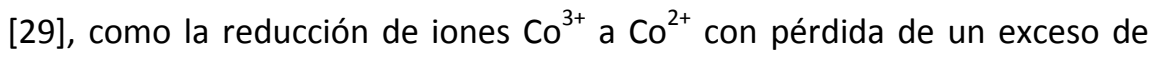
oxígeno que ocupa originalmente posiciones intersticiales [28,36], cuando se incrementa la temperatura de calcinación. Independientemente de cuál sea el mecanismo real, estas diferencias en la ordenación catiónica (bulk) son función de la historia térmica (concretamente $T_{c}$ ) y pueden tener consecuencias en las propiedades superficiales de las $\mathrm{NPs}$ de $\mathrm{Co}_{3} \mathrm{O}_{4}$, como se estudia en la sección siguiente.

4.3.2.2. Caracterización superficial de las $\mathrm{NPs}_{\text {de }} \mathrm{CO}_{3} \mathrm{O}_{4}$ (XPS).

La evolución de las propiedades estructurales de las nanopartículas de $\mathrm{CO}_{3} \mathrm{O}_{4}$ con la temperatura de calcinación evidenciada en la sección anterior podría traducirse, a su vez, en cambios composicionales en la superficie de las mismas. Para comprobar esta hipótesis, se ha realizado un estudio mediante XPS de las propiedades superficiales de las NPs de $\mathrm{Co}_{3} \mathrm{O}_{4}$ presentes en un catalizador calcinado a $300 \circ \mathrm{C}\left(\mathrm{Co} / \mathrm{SiO}_{2} 300\right)$ y otro catalizador calcinado a $550 \circ \mathrm{C}\left(\mathrm{Co} / \mathrm{SiO}_{2} 550^{\circ} \mathrm{C}\right)$.

La Fig. 4.7 muestra los espectros de XPS en la región de fotoemisión Co2p, así como la región para los electrones Auger Co(LMM), en los dos catalizadores mencionados en su estado calcinado. A su vez, se incluyen en la figura los espectros correspondientes a dos sustancias empleadas como referencia: un compuesto de $\mathrm{Co}^{2+}$ (acetato de $\mathrm{Co}(\mathrm{II})$ tetrahidratado, Aldrich) y un compuesto de $\mathrm{Co}^{3+}$ (acetilacetonato de $\mathrm{Co}(\mathrm{III}), 98 \%$ Aldrich). 


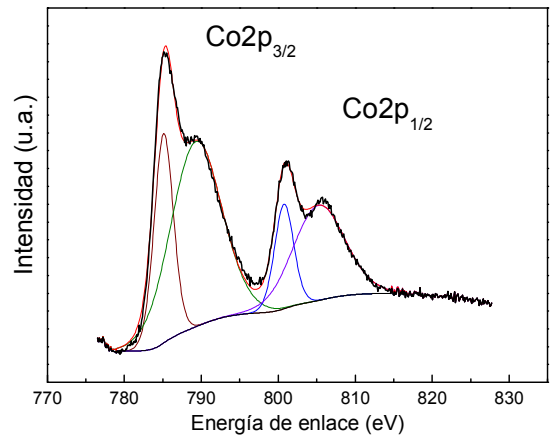

(a)

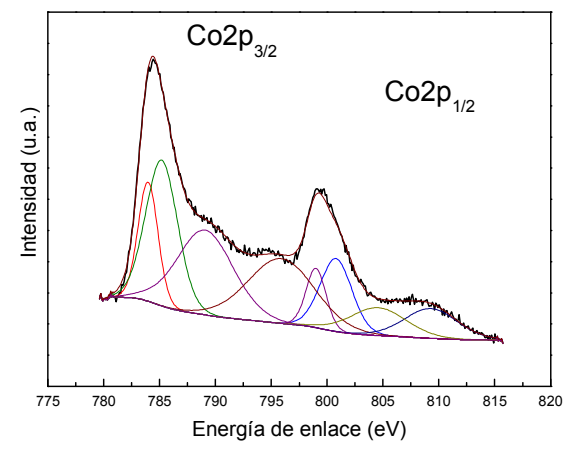

(c)

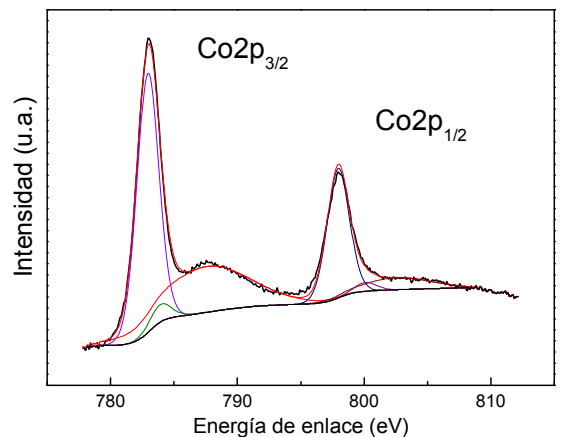

(b)

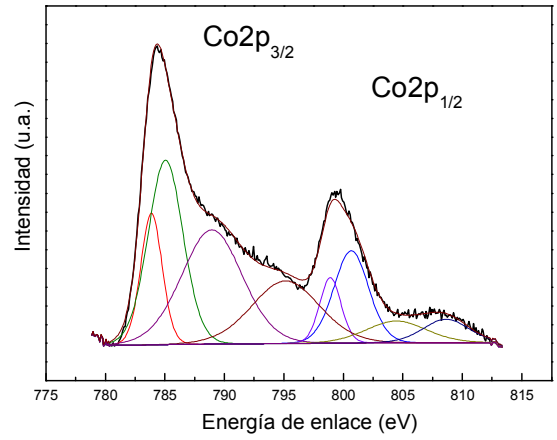

(d)

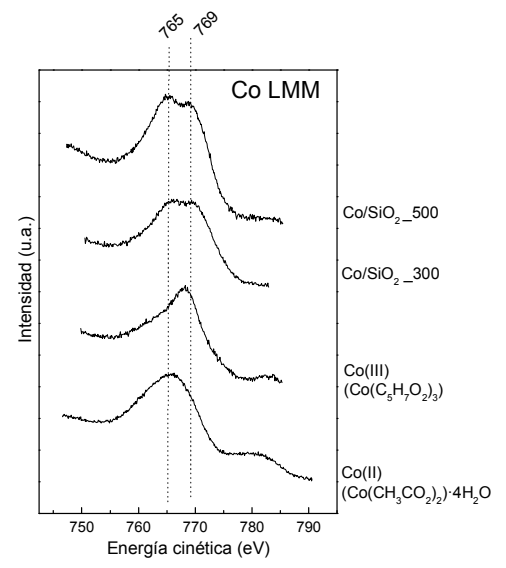

(e)

Figura 4.7: Espectros de XPS (Co2p) para los compuestos patrón (a) $\mathrm{Co}\left(\mathrm{CH}_{3} \mathrm{CO}_{2}\right)_{2} \cdot 4 \mathrm{H}_{2} \mathrm{O}$, (b) $\mathrm{Co}\left(\mathrm{C}_{5} \mathrm{H}_{7} \mathrm{O}_{2}\right)_{3}$ y los catalizadores calcinados (c) $\mathrm{Co} / \mathrm{SiO}_{2}{ }_{2} 300 \mathrm{y}$ (d) $\mathrm{Co} / \mathrm{SiO}_{2}$ _550. El espectro incluido en (e) muestra una comparativa de la línea XAES Co(LMM) para los cuatro sólidos. 
Por su parte, la Tabla 4.3 incluye los resultados de la interpretación cuantitativa de los espectros de XPS. La deconvolución de la señal Co2 $\mathrm{p}_{3 / 2}$ para los catalizadores $\mathrm{Co} / \mathrm{SiO}_{2}$, en dos componentes asociadas con la presencia de iones $\mathrm{Co}^{2+}$ y $\mathrm{Co}^{3+}$ en la estructura de la espinela $\mathrm{Co}_{3} \mathrm{O}_{4}$, se llevó a cabo manteniendo las anchuras espectroscópicas (FWHM) de cada componente, obtenidas por deconvolución de los correspondientes espectros para los sólidos patrones de $\mathrm{Co}^{2+}$ y $\mathrm{Co}^{3+}$. Como se recoge en la Tabla 4.3, la componente correspondiente a $\mathrm{Co}^{2+}$ presenta una energía de enlace $\mathrm{Co} 2 \mathrm{p}_{3 / 2}$ aprox. 1-2 eV superior a la correspondiente energía de enlace para $\mathrm{Co}^{3+}$. La integración de las componentes asociadas con cada estado de oxidación del Co en los espectros de los catalizadores $\mathrm{Co} / \mathrm{SiO}_{2}$ evidencia que la relación $\mathrm{Co}^{2+} / \mathrm{Co}^{3+}$ superficial es superior (2.27) para el catalizador calcinado a $550^{\circ} \mathrm{C}$ que para el correspondiente catalizador calcinado a $300^{\circ} \mathrm{C}$ (1.96). No obstante, en ambos casos esta relación atómica $\mathrm{Co}^{2+} / \mathrm{Co}^{3+}$ superficial presenta valores significativamente superiores al valor de $1 / 2$ esperado para la estructura másica ideal de la espinela, en concordancia con resultados previos [37]. Esto sugiere un enriquecimiento de la superficie de las $\mathrm{NPs}$ de $\mathrm{Co}_{3} \mathrm{O}_{4}$ en $\mathrm{Co}^{2+}$, que se ve magnificado al emplear una elevada $\mathrm{T}_{\mathrm{c}}$.

Tabla 4.3: Interpretación cuantitativa de los resultados de XPS para catalizadores $\mathrm{Co} / \mathrm{SiO}_{2}$ seleccionados en su estado calcinado.

\begin{tabular}{|c|c|c|c|}
\hline Muestra & $\begin{array}{c}\text { E.E Co } 2 p_{3 / 2}{ }^{a} \\
\left(\mathrm{Co}^{2+}\right) \\
(\mathrm{eV})\end{array}$ & 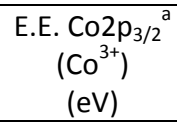 & $\mathrm{Co}^{2+} / \mathrm{Co}^{3+\mathrm{b}}$ \\
\hline $\mathrm{Co} / \mathrm{SiO}_{2}{ }_{2} 300$ & 785.1 & 783.9 & 1.96 \\
\hline $\mathrm{Co} / \mathrm{SiO}_{2}=550$ & 785.1 & 783.8 & 2.27 \\
\hline $\mathrm{Co}\left(\mathrm{CH}_{3} \mathrm{CO}_{2}\right)_{2} \cdot 4 \mathrm{H}_{2} \mathrm{O}$ & 785.2 & --- & --- \\
\hline $\mathrm{Co}\left(\mathrm{C}_{5} \mathrm{H}_{7} \mathrm{O}_{2}\right)_{3}$ & --- & 783.0 & --- \\
\hline
\end{tabular}

Asimismo, la mayor proporción superficial de $\mathrm{Co}^{2+}$ para el catalizador $\mathrm{Co} / \mathrm{SiO}_{2} 550$ calcinado se percibe en la región Auger del espectro (Fig. 4-e), 
puesto que este catalizador presenta una mayor intensidad para valores de energía cinética de $765 \mathrm{eV}$, asociados con $\mathrm{Co}^{2+}$, que la muestra $\mathrm{Co} / \mathrm{SiO}_{2} 300$.

Así pues, de los resultados de XPS se puede concluir que los tratamientos de calcinación a elevada temperatura dan lugar a NPs de $\mathrm{CO}_{3} \mathrm{O}_{4}$ cuya superficie se encuentra enriquecida en $\mathrm{Co}^{2+}$ con respecto a la estequiometria másica ideal. Queda claro, por tanto, que las diferencias de ordenamiento catiónico en la estructura cristalina de las $\mathrm{NPs}$ de $\mathrm{CO}_{3} \mathrm{O}_{4}$ en función de $T_{c}$, reveladas mediante LRS en la sección anterior, se traducen en cambios composicionales en la superficie de estos cristales de óxido de Co. En definitiva, los diferentes protocolos de calcinación empleados, en concreto $T_{c}$, dan lugar a fases metálicas en las muestras calcinadas $\left(\mathrm{CO}_{3} \mathrm{O}_{4} / \mathrm{SiO}_{2}\right)$ no equivalentes ni másica ni superficialmente.

Las secciones siguientes estudiarán las posibles implicaciones que estas diferencias estructurales y composicionales puedan tener en los fenómenos de reducción de los catalizadores $\mathrm{Co} / \mathrm{SiO}_{2}$ previamente calcinados.

\subsubsection{Reducibilidad y propiedades estructurales de los catalizadores reducidos.}

\subsubsection{Estudio mediante $\mathrm{H}_{2}$-TPR.}

La reducibilidad de los catalizadores $\mathrm{Co} / \mathrm{SiO}_{2}$ calcinados se estudió mediante $\mathrm{H}_{2}$-TPR. Los correspondientes perfiles de $\mathrm{H}_{2}$-TPR se muestran en la Fig. 4.8. Para la muestra $\mathrm{Co} / \mathrm{SiO}_{2} 300$, se observa una primera señal de reducción a $163^{\circ} \mathrm{C}$, muy débil, que puede estar relacionada con la descomposición de una pequeña cantidad del precursor nitrato que no se descompone durante el tratamiento de calcinación a 300 C. Esta asignación está reforzada por la ausencia de esta señal para los catalizadores cuya temperatura final de calcinación es de $425^{\circ} \mathrm{C}$ o superior. Adicionalmente, 
$\mathrm{Co} / \mathrm{SiO}_{2} 300$ presenta dos señales principales de reducción (señal I a $T_{1, \text { máx }}=264$ 으 y señal II a $T_{2, \text { máx }}=310^{\circ} \mathrm{C}$ ) cuyo cociente de áreas (señal I/señal II) es de 3.3, lo que sugiere su asignación a la reducción de $\mathrm{Co}_{3} \mathrm{O}_{4}$ en dos etapas de acuerdo a las ecuaciones 3.3 y 3.4. De manera interesante, al incrementarse $T_{c}$ en el orden $\mathrm{Co} / \mathrm{SiO}_{2} 300<\mathrm{Co} / \mathrm{SiO}_{2} 450<\mathrm{Co} / \mathrm{SiO}_{2} 550$, tiene lugar un cambio progresivo en los perfiles de $\mathrm{H}_{2}$-TPR desde el doblete (señal I- señal II) para $\mathrm{Co} / \mathrm{SiO}_{2}$ 300 hasta una señal simple, prácticamente simétrica, para $\mathrm{Co} / \mathrm{SiO}_{2}$ 550. Este cambio en el comportamiento de reducción comprende a su vez un ligero desplazamiento de los eventos de reducción hacia temperaturas más elevadas. El análisis de las áreas de los perfiles de reducción en el rango de temperaturas de $200-450$ ㅇ C indica que prácticamente tiene lugar el mismo consumo de $\mathrm{H}_{2}$ en la reducción de estas tres muestras $(\sigma=4 \%)$, sugiriendo que progresivamente, las reducciones relacionadas con la señal I y la señal II pasan de tener lugar de manera consecutiva a ocurrir de forma prácticamente simultánea cuando se incrementa $T_{c}$ para el catalizador. Esta tendencia no parece estar relacionada con ninguna modificación de las propiedades del soporte catalítico durante los tratamientos de calcinación a elevada temperatura (deshidroxilación parcial, por ejemplo) que podría afectar a los fenómenos de reducción de las fases metálicas, puesto que la muestra $\mathrm{Co} / \mathrm{SiO}_{2} d c$ (anexo A-I en la Fig. 4.8) muestra una reducción en dos etapas similar al comportamiento de $\mathrm{Co} / \mathrm{SiO}_{2}$ 300. Esto sugiere que es la temperatura a la que se calcinan las fases metálicas, y no el soporte catalítico, lo que provoca los cambios en el comportamiento de reducción. 


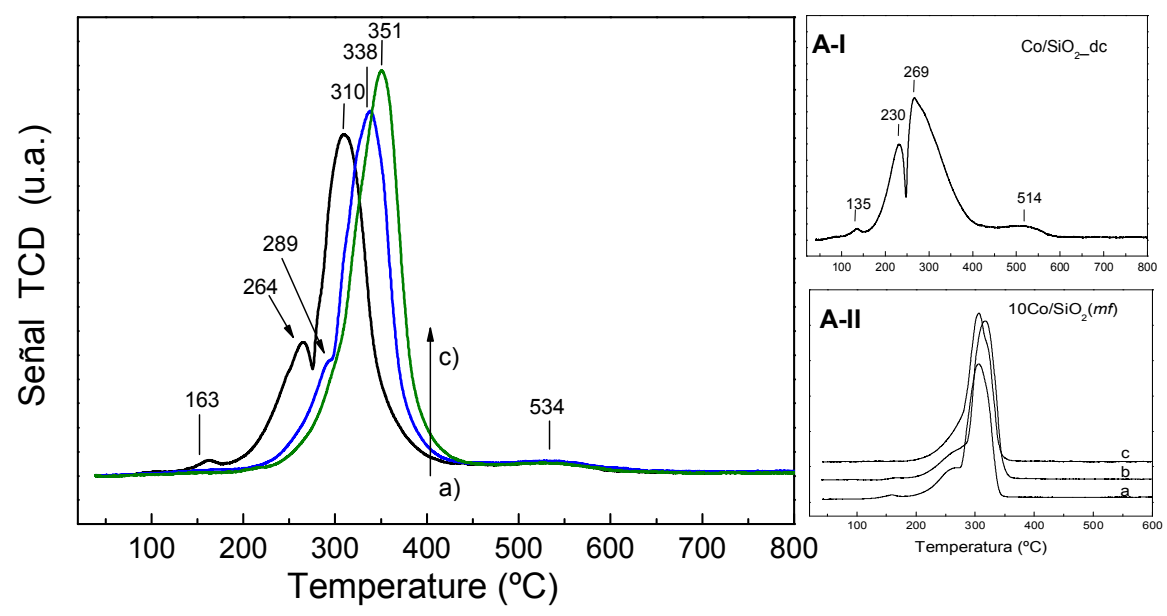

Figura 4.8: Perfiles de $\mathrm{H}_{2}$-TPR para los catalizadores a) $\mathrm{Co} / \mathrm{SiO}_{2} \_300$, b) $\mathrm{Co} / \mathrm{SiO}_{2} 425$ y c) $\mathrm{Co} / \mathrm{SiO}_{2}$ _550. La figura incluye dos anexos, A-l: perfil de $\mathrm{H}_{2}$-TPR para el catalizador $\mathrm{Co} / \mathrm{SiO}_{2} \_d c$, y A-II: perfiles de reducción para las muestras de baja dispersión $10 \mathrm{Co} / \mathrm{SiO}_{2}(\mathrm{mf})$ calcinadas a a) 300C, b) 425C y c) 550C.

Algunos investigadores han encontrado previamente que la fase másica de $\mathrm{CO}_{3} \mathrm{O}_{4}$ puede presentar perfiles de reducción que involucran dos señales o una señal simple $[38,39,40]$, y propusieron que estas diferencias podrían estar relacionadas con diferencias en el tamaño de cristal de $\mathrm{Co}_{3} \mathrm{O}_{4}$. Las variaciones de $d\left(\mathrm{Co}_{3} \mathrm{O}_{4}\right) \times$ para los catalizadores estudiados en este capítulo no son muy importantes ( $\sigma=15 \%$ ), no obstante, con el objetivo de comprobar esta hipótesis se analizaron por $\mathrm{H}_{2}$-TPR tres muestras de baja dispersión sintetizadas mediante mezcla física de $\mathrm{SiO}_{2}$ y nanopartículas de $\mathrm{Co}_{3} \mathrm{O}_{4}$ comerciales (ver apartado 2.1.3.2 en la Sección Experimental) y activadas por calcinación a diferentes $T_{c}$ de acuerdo a los mismos programas térmicos empleados para los catalizadores $\mathrm{Co} / \mathrm{SiO}_{2}$ que se estudian en este capítulo (Tabla 2.3). Estas muestras presentan tamaños de cristal de $d\left(\mathrm{Co}_{3} \mathrm{O}_{4}\right)_{x}=41-73 \mathrm{~nm}$, es decir, significativamente superiores a los de las muestras $\mathrm{Co} / \mathrm{SiO}_{2} 300$ a 550. Los perfiles de $\mathrm{H}_{2}$-TPR para estas muestras de baja dispersión muestran un comportamiento cualitativamente de acuerdo 
con el encontrado para los catalizadores $\mathrm{Co} / \mathrm{SiO}_{2}$, es decir, la evolución desde dos señales de reducción hacia una única señal cuando se incrementa la temperatura de calcinación de la muestra (anexo A-II en Fig. 4.8). Esto descarta que las tendencias discutidas se deban a diferencias en el tamaño de cristal de $\mathrm{Co}_{3} \mathrm{O}_{4}$, y por lo tanto deben estar relacionadas con la temperatura máxima a la que se calcinan las fases de Co en los catalizadores soportados.

\subsubsection{Estudio mediante XRD in situ.}

El comportamiento de los catalizadores durante el tratamiento de reducción se ha estudiado adicionalmente monitorizando la evolución de las fases cristalinas mediante XRD in situ ( $\left.\mathrm{H}_{2}-\mathrm{XRD}\right)$. La Fig. 4.9 muestra los difractogramas obtenidos durante la reducción de los catalizadores $\mathrm{Co} / \mathrm{SiO}_{2} \_r d, \mathrm{Co} / \mathrm{SiO}_{2} 300$ y $\mathrm{Co} / \mathrm{SiO}_{2}$ 550 en el rango de temperaturas de 30400 C, así como la correspondiente evolución de las fases cristalinas representada cualitativamente por el área normalizada para las difracciones más intensas de cada fase: $\mathrm{CO}_{3} \mathrm{O}_{4}\left(\begin{array}{lll}3 & 1 & 1\end{array}\right), \mathrm{CoO}\left(\begin{array}{llll}2 & 0 & 0\end{array}\right), \mathrm{Co}^{0}-f c c\left(\begin{array}{lll}1 & 1 & 1\end{array}\right), \mathrm{Co}^{0}-h c p$ $\left(\begin{array}{lll}1 & 0 & 1\end{array}\right), \mathrm{Co}\left(\mathrm{NO}_{3}\right)_{2} \cdot 4 \mathrm{H}_{2} \mathrm{O}$ (JCPDS:18-0425, $2 \theta=13.99$ ) , $\mathrm{Co}\left(\mathrm{NO}_{3}\right)_{2} \cdot 2 \mathrm{H}_{2} \mathrm{O}$ (JCPDS: $18-0424,2 \theta=13.6$ o). 


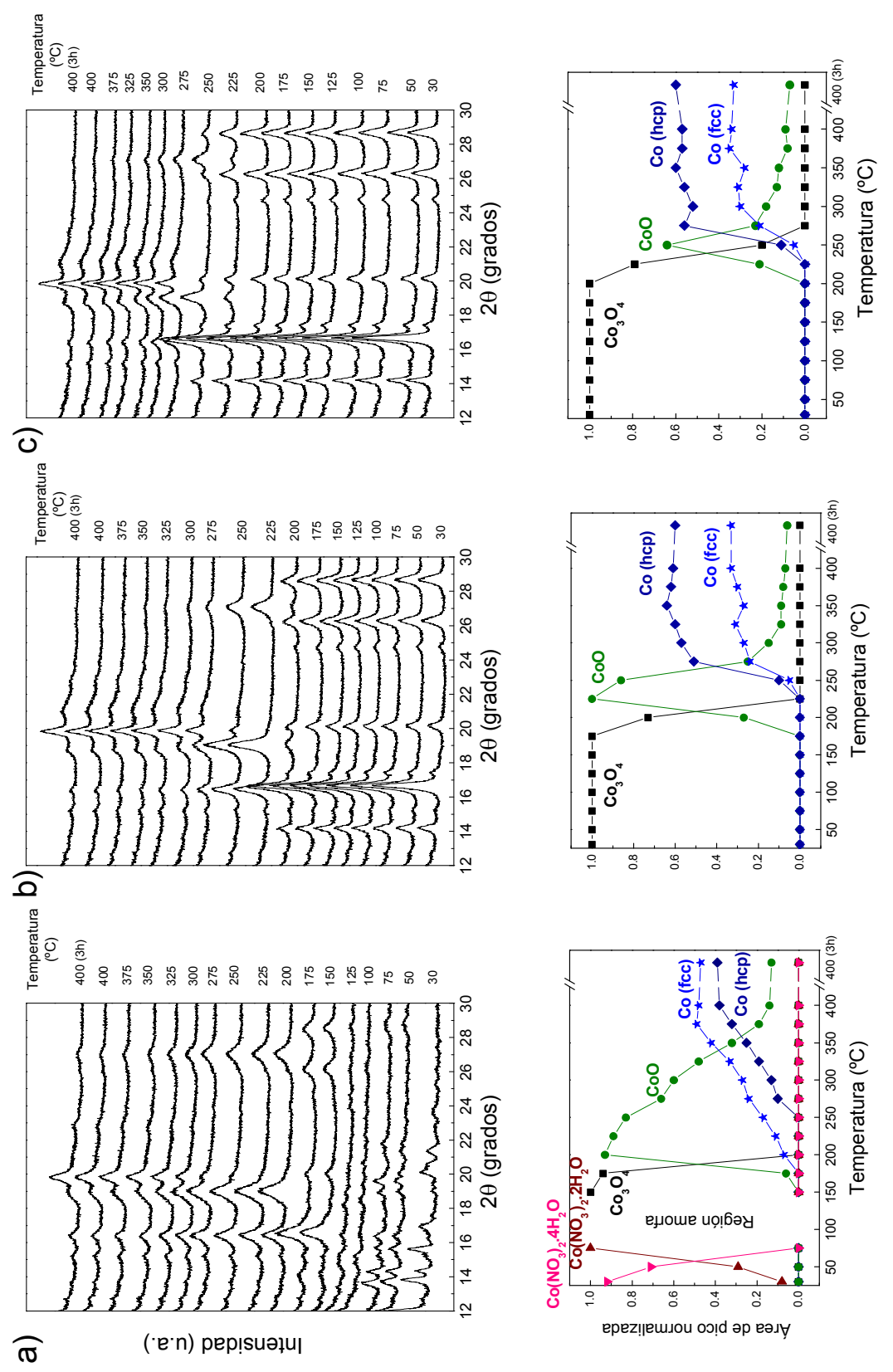

Figura 4.9: Difractogramas de rayos $x$ y evolución del área normalizada para las difracciones más intensas de las especies cristalinas durante la reducción in situ de los catalizadores a) $\left.\mathrm{Co} / \mathrm{SiO}_{2} \_r d, b\right) \mathrm{Co} / \mathrm{SiO}_{2} 300 \mathrm{y}$ c) $\mathrm{Co} / \mathrm{SiO}_{2}$ 550. 
Como se observa, la muestra no calcinada $\left(\mathrm{Co} / \mathrm{SiO}_{2}\right.$ rd) presenta, tras la impregnación y el tratamiento de secado, $\mathrm{Co}(\mathrm{NO})_{3} \cdot 4 \mathrm{H}_{2} \mathrm{O}$, que se deshidrata de manera progresiva hasta $\mathrm{Co}(\mathrm{NO})_{3} \cdot 2 \mathrm{H}_{2} \mathrm{O}$ en el rango de temperaturas de $30-75 \circ \mathrm{C}$. Subsecuentemente, los nitratos metálicos descomponen en especies amorfas en el rango de temperaturas de 75$125^{\circ} \mathrm{C}$ en el que no se detectan líneas de difracción definidas, y posteriormente tiene lugar la cristalización de la espinela $\mathrm{Co}_{3} \mathrm{O}_{4}$, que es la única fase cristalina presente a $150^{\circ} \mathrm{C}$. El rango de temperaturas de existencia de $\mathrm{CO}_{3} \mathrm{O}_{4}$ es muy estrecho, de modo que a 200 으 esta fase se ha reducido completamente a $\mathrm{CoO}$. A su vez, $\mathrm{CoO}$ se reduce progresivamente a $\mathrm{CO}^{0}(f c c+h c p)$ a lo largo de un amplio rango de temperaturas (200-400ㄷ). Estos resultados evidencian que el protocolo de reducción directa en $\mathrm{H}_{2}$ transcurre a través de los óxidos metálicos $\mathrm{Co}_{3} \mathrm{O}_{4}$ y $\mathrm{CoO}$ como ocurre en el caso de que la reducción se aplique a una muestra previamente calcinada en aire. Las señales de difracción de $C^{\circ}-f c c$ se detectan a partir de 200 드, mientras que la detección de las difracciones asociadas con $\mathrm{Co}^{0}-h c p$ se retrasa hasta $275^{\circ} \mathrm{C}$. Este hecho, no obstante, no es indicativo de un cambio de fase puesto que ambos polimorfos de $\mathrm{Co}^{\circ}$ se desarrollan simultáneamente en el rango de temperaturas de 275-400ㄷ. Más probablemente, las difracciones propias de $\mathrm{Co}^{0}-h c p$ no se detectan en el intervalo $200-275{ }^{\circ} \mathrm{C}$ debido a su naturaleza poco intensa y sensiblemente más ancha que las asociadas con la fase cúbica.

Por otro lado, los resultados de XRD durante la reducción in situ de los catalizadores previamente calcinados en aire $\left(\mathrm{Co} / \mathrm{SiO}_{2} 300\right.$ y $\left.\mathrm{Co} / \mathrm{SiO}_{2} \_50\right)$ concuerda, de manera cualitativa, con los diferentes comportamientos discutidos previamente en base a los resultados de $\mathrm{H}_{2}$-TPR. Así pues, la etapa de reducción $\mathrm{Co}_{3} \mathrm{O}_{4} \rightarrow \mathrm{CoO}$ se activa a una menor temperatura (200ㄷ) en el caso de $\mathrm{Co} / \mathrm{SiO}_{2} 300$, de modo que $\mathrm{CoO}$ es la única fase cristalina a 225 으, 
mientras que la reducción final a $\mathrm{Co}^{0}(h c p+f c c)$ se activa a $250^{\circ} \mathrm{C}$ y procede hasta una temperatura de $350-400$ ○. Por el contrario, en el caso de $\mathrm{Co} / \mathrm{SiO}_{2} 550$, la aparición de $\mathrm{CoO}$ se retrasa hasta 225 ㄷ $\mathrm{y}$, de manera interesante, $\mathrm{CoO}$ no es la única fase cristalina a ninguna temperatura puesto que la reducción final hasta $\mathrm{Co}^{0}(h c p+f c c)$ comienza, de hecho, cuando tanto $\mathrm{CO}_{3} \mathrm{O}_{4}$ como $\mathrm{CoO}$ están aún presentes en el catalizador (250ㄷ). Este comportamiento para la muestra calcinada en aire a elevadas temperaturas coincide con la detección de una única señal de reducción en el rango de temperaturas de $200-450^{\circ} \mathrm{C}$ en su perfil de $\mathrm{H}_{2}$-TPR y apunta a un desbalance en las cinéticas de las dos etapas de reducción de $\mathrm{Co}_{3} \mathrm{O}_{4}$, de modo que la reducción $\mathrm{CoO} \rightarrow \mathrm{Co}^{0}$ se activa cuando aún no se ha completado la etapa previa $\mathrm{CO}_{3} \mathrm{O}_{4} \rightarrow \mathrm{CoO}$.

En lo que respecta a los catalizadores reducidos (tras 3 horas a $400^{\circ} \mathrm{C}$ ), en la Fig. 4.10 se percibe un grado de reducción superior (menor contribución relativa de $\mathrm{CoO}$ ) para los catalizadores calcinados en aire que para la muestra activada por reducción directa, en completo acuerdo con el $\mathrm{GR}$ determinado mediante experimentos de $\mathrm{H}_{2}$-TPR (Tabla 4.2). Estos grados de reducción, no obstante, son elevados en todos los casos (82-93\%), lo que asegura que la contribución de especies metálicas oxidadas en el catalizador reducido es despreciable. 


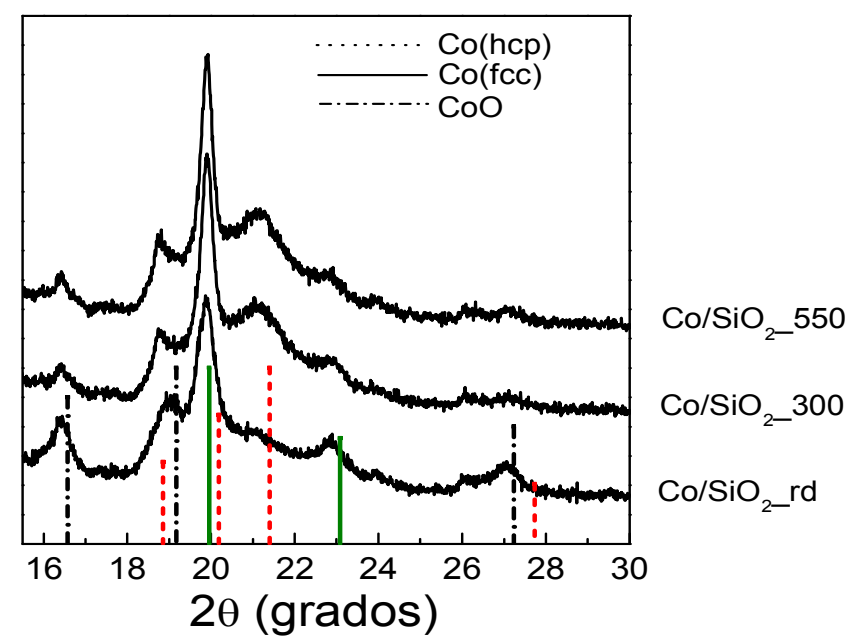

Figura 4.10: Difractogramas de rayos $X$ para catalizadores $\mathrm{Co} / \mathrm{SiO}_{2}$ seleccionados tras el tratamiento de reducción $\left(400^{\circ} \mathrm{C}, 3\right.$ horas) in situ en la celda de XRD. La figura incluye como referencia las difracciones para Co ${ }^{\circ}$-hcp (JCPDS:05-0727), Co ${ }^{0}-f c c$ (JCPDS:15-0806) y COO (JCPDS:09-0402).

Adicionalmente, cabe comentar que en todos los casos, los dos polimorfos de $\mathrm{Co}^{0}(f c c$ y $h c p)$ se desarrollan simultáneamente, no existiendo una temperatura de transición $h c p \rightarrow f c c$ como es conocido en el caso del metal en su forma másica, de acuerdo con los resultados previos de Saib y col. [41]. Así, ambas fases están presentes en todos los catalizadores reducidos. Este hecho se percibe con claridad en la Fig. 4.10 donde se representan los perfiles de XRD para los catalizadores reducidos ( $3 \mathrm{~h}, 400^{\circ} \mathrm{C}$ ) junto con las líneas de difracción para CoO (JCPDS:09-0402), Co Co-hcp (JCPDS:05-0727) y Co $^{0}-f c c$ (JCPDS:15-0806). A su vez, se evidencia una contribución relativa similar de las fases $h c p$ y $f c c$ en los dos catalizadores que se someten a calcinación en aire durante su síntesis, mientras que $\mathrm{Co} / \mathrm{SiO}_{2}$ rd presenta un mayor carácter $f c c$ (Figs. 4.9-a y 4.10). Este resultado parece en contradicción con los resultados publicados por Enache y col. [7], quienes encontraron una mayor contribución de $\mathrm{Co}^{0}$ hexagonal en catalizadores $\mathrm{Co} / \mathrm{ZrO}_{2}$ y $\mathrm{Co} / \mathrm{Al}_{2} \mathrm{O}_{3}$ activados mediante reducción directa, en 
comparación con las correspondientes muestras calcinadas previamente en aire. Por el contrario, la mayor contribución de la fase $f c c$ en el catalizador activado por reducción directa concurre con el mayor carácter cúbico encontrado por Saib y col. [41] para las NPs de Co de menor tamaño en catalizadores $\mathrm{Co} / \mathrm{SiO}_{2}$, puesto que $\mathrm{Co} / \mathrm{SiO}_{2}$ rd presenta el menor de los valores de $d\left(\mathrm{Co}^{0}\right)$ de toda la serie de catalizadores $\mathrm{Co} / \mathrm{SiO}_{2}$ (Tabla 4.2).

Finalmente, cabe resaltar que en todos los casos las difracciones asociadas con $\mathrm{CO}^{0}-h c p$ son significativamente más anchas que aquellas debidas a la fase $f c c$ (Fig. 4.10), evidenciando que la fase hexagonal presenta dominios cristalinos de menor tamaño. No obstante, esto no significa directamente que existan NPs de $\mathrm{Co}^{0}-h c p$ de menor tamaño coexistiendo con NPs mayores de $\mathrm{Co}^{0}-f c c$. Por el contrario, se ha propuesto recientemente la existencia de NPs de $\mathrm{Co}^{0}-f c c$ que presentan dominios intracristalinos $h c p$, de pequeño tamaño, debido a la existencia de dislocaciones en el cristal. La formación de estas dislocaciones en NPs de $\mathrm{Co}^{0}$ está favorecida por una barrera energética relativamente baja $\left(E_{a}=14 \mathrm{~kJ} / \mathrm{mol}\right.$ por átomo de Co) [41] para el desplazamiento relativo de los planos cristalinos.

4.3.3.3. Interpretación de las propiedades físico-químicas y de reducción de los catalizadores $\mathrm{Co} / \mathrm{SiO}_{2}$ en función de su historia térmica.

Los resultados obtenidos mediante la caracterización de las NPs de $\mathrm{CO}_{3} \mathrm{O}_{4}$ en los catalizadores calcinados a diferentes $\mathrm{T}_{\mathrm{c}}$ (propiedades tanto bulk como superficiales), así como los diferentes comportamientos observados durante la reducción de los catalizadores $\mathrm{Co} / \mathrm{SiO}_{2}$, pueden racionalizarse de manera conjunta.

El proceso de reducción de los óxidos metálicos comienza con la activación del $\mathrm{H}_{2}$ en la superficie de los cristales de óxido [42]. En este 
proceso de activación disociativa del $\mathrm{H}_{2}$, la composición superficial y la presencia de vacantes de oxígeno juegan un papel determinante, como se ha demostrado para el caso del $\mathrm{NiO}$ mediante una combinación de espectroscopias Auger, EXAFS y cálculos teóricos [43]. Por lo tanto, a la vista de la influencia que $\mathrm{T}_{\mathrm{c}}$ tiene en la proporción $\mathrm{Co}^{2+} / \mathrm{Co}^{3+}$ en la superficie de las NPs soportadas de $\mathrm{CO}_{3} \mathrm{O}_{4}$, como se demostró en el presente trabajo mediante XPS, se entiende que los fenómenos de reducción se activen a diferentes temperaturas para catalizadores que han sido activados previamente a temperaturas de calcinación distintas (Fig. 4.8). En este caso, las NPs de $\mathrm{CO}_{3} \mathrm{O}_{4}$ calcinadas a las temperaturas más elevadas se comportan de manera similar a $\mathrm{CoO}$, debido a su enriquecimiento superficial en $\mathrm{Co}^{2+}, \mathrm{y}$ la activación de la reducción se retrasa respecto de la de las nanopartículas de óxido cuya composición superficial presenta mayor proporción de $\mathrm{Co}^{3+}$. Tras la activación del proceso reductivo (siendo la etapa limitante la disociación de $\mathrm{H}_{2}$ [43]) la superficie del óxido, donde tiene lugar la reducción, se empobrece en oxígeno, y este gradiente establece una migración de oxígeno desde el núcleo de la NP de $\mathrm{CO}_{3} \mathrm{O}_{4}$ hacia su superficie. Esta migración tiene lugar a través de las posiciones de red e intersticiales de la estructura de la espinela, por lo que el grado de desorden catiónico y las ocupaciones relativas de las diferentes posiciones, que son una función de la historia térmica anterior como se demostró en la sección 4.3.2.1, determinarán la cinética de este proceso. Por lo tanto, la temperatura a la que se activan y la velocidad a la que ocurren los procesos de reducción que dan lugar a las fases activas de $\mathrm{Co}^{0}$ se ven influidos por la historia térmica anterior de las fases de $\mathrm{CO}_{3} \mathrm{O}_{4}$.

El balance entre las cinéticas de los fenómenos de activación superficial y de difusión intracristalina determinan las propiedades de las fases finales. En este sentido, se conoce que para el proceso inverso (re- 
oxidación de NPs de $\mathrm{Co}^{\circ}$ ) en caso de producirse un desbalance entre las velocidades de migración de Co desde el núcleo hacia la superficie y de los iones oxígeno desde la superficie hacia el núcleo del cristal pueden llegar a generarse oquedades en las partículas de $\mathrm{CoO}$ resultantes, a través del denominado efecto Kirkendall [44]. Para el caso del proceso de reducción, un efecto similar podría dar lugar a diferencias en la cristalinidad, la morfología o la topología superficial de las fases de $\mathrm{Co}^{0}$ resultantes en función de las propiedades bulk y superficiales de las fases de óxido originales. De hecho, Potoczna-Petru y Kepinski [45] han establecido una interrelación entre las fases de óxido originales y la fases de $\mathrm{Co}^{0}$ generadas durante la reducción de $\mathrm{Co}_{3} \mathrm{O}_{4}$ másico, concluyendo que la nucleación y crecimiento de $\mathrm{CoO}$ a partir de $\mathrm{Co}_{3} \mathrm{O}_{4}$ y de $\mathrm{Co}^{0}$ desde $\mathrm{CoO}$ tiene lugar de manera epitaxial.

Nuestros resultados de $\mathrm{H}_{2}$-XRD muestran que la microestructura de las NPs resultantes de $\mathrm{Co}^{0}$ no se ve afectada en gran medida por $\mathrm{T}_{\mathrm{c}}$, ni siquiera por el hecho de haber calcinado o no el catalizador en aire previamente (sección 4.3.3.2). No obstante, otras diferencias en las fases de $\mathrm{Co}^{0}$ como la morfología o la topología superficial no se observarían mediante técnicas de difracción, pero podrían tener consecuencias en catálisis.

En las siguientes dos secciones se estudia la actividad catalítica de los catalizadores $\mathrm{Co} / \mathrm{SiO}_{2}$ activados mediante diferentes protocolos con el fin de comprobar la validez de las tendencias establecidas en la Fig. 4.1 en base a una recopilación de resultados bibliográficos. Seguidamente, se emplea COFTIR con el objeto de estudiar la superficie de las NPs de $\mathrm{Co}^{0}$ y establecer relaciones entre la naturaleza de los centros metálicos superficiales y la actividad catalítica intrínseca (TOF). 
4.3.4. Actividad catalítica.

Los catalizadores $\mathrm{Co} / \mathrm{SiO}_{2}$ se han ensayado en la SFT a niveles de conversión quasi-diferenciales $\left(\mathrm{X}_{\mathrm{CO}}=5-10 \%\right)$, para evitar efectos derivados del papel autocatalítico que las elevadas presiones parciales de $\mathrm{H}_{2} \mathrm{O}$ ejercen en la SFT catalizada por $\mathrm{Co} / \mathrm{SiO}_{2}$ [46]. La Tabla 4.4 recoge la actividad catalítica para todos los catalizadores $\mathrm{Co} / \mathrm{SiO}_{2}$ expresada como CTY y TOF.

Tabla 4.4: Actividad catalítica de los catalizadores $\mathrm{Co} / \mathrm{SiO}_{2}$. Condiciones de reacción: $T=220 \stackrel{\circ}{\circ}, P=2.0 \mathrm{MPa}, \mathrm{H}_{2} / \mathrm{CO}=2, X_{\mathrm{CO}}=5-10 \%, \mathrm{H}_{2} / \mathrm{CO}=2$.

\begin{tabular}{|c|c|c|c|c|c|c|}
\hline \multirow[b]{2}{*}{ Catalizador } & \multicolumn{3}{|c|}{ Actividad catalítica } & \multicolumn{3}{|c|}{ Selectividad (\%C) } \\
\hline & $\begin{array}{c}\text { TOF }_{0}{ }^{a} \\
\left(10^{-3} \mathrm{~s}^{-1}\right)\end{array}$ & $\begin{array}{c}\text { TOF }_{e}{ }^{b} \\
\left(10^{-3} \mathrm{~s}^{-1}\right)\end{array}$ & $\begin{array}{c}\mathrm{CTY}_{\mathrm{e}}^{\mathrm{c}} \\
\left(10^{-3} \mathrm{~mol} \mathrm{CO} / \mathrm{g}_{\mathrm{cat}} \cdot \mathrm{h}\right)\end{array}$ & $\mathrm{CO}_{2}$ & $\mathrm{CH}_{4}$ & $\mathrm{C}_{5+}$ \\
\hline $\mathrm{Co} / \mathrm{SiO}_{2} \_r d$ & 48.2 & 35.9 & 135 & 0.3 & 19.7 & 66.8 \\
\hline $\mathrm{Co} / \mathrm{SiO}_{2}{ }_{3} 300$ & 37.9 & 24.7 & 69 & 0.8 & 13.5 & 72.3 \\
\hline $\mathrm{Co} / \mathrm{SiO}_{2}{ }_{4} 425$ & 20.8 & 13.7 & 34 & 1.1 & 11.1 & 74.6 \\
\hline $\mathrm{Co} / \mathrm{SiO}_{2} \_550$ & 18.0 & 11.6 & 24 & 2.5 & 10.8 & 75.4 \\
\hline $\mathrm{Co} / \mathrm{SiO}_{2}-d c$ & 38.3 & 26.4 & 71 & 0.7 & 11.9 & 67.1 \\
\hline
\end{tabular}

${ }^{a}$ Frecuencia de turnover inicial (extrapolada a $t_{r}=0$ ). Basada en la cuantificación de átomos metálicos superficiales mediante quimisorción de $\mathrm{H}_{2}$.

${ }^{b}$ Frecuencia de turnover en el estado pseudo-estacionario. Basada en la cuantificación de átomos metálicos superficiales mediante quimisorción de $\mathrm{H}_{2}$.

${ }^{c}$ Rendimiento temporal por masa de Co en el estado pseudo-estacionario. Valor medio para $t_{r}=8-16 \mathrm{~h}$.

Como se observa, el valor de TOF $_{\mathrm{e}}$ para el catalizador activado por reducción directa $\left(35.9 \cdot 10^{-3} \mathrm{~s}^{-1}\right)$ es entre 1.4 y 3 veces superior que para los catalizadores previamente calcinados en aire. En línea con este resultado, Enache y col. [7] encontraron un incremento de 1.5 a 2.2 veces en TOF para catalizadores $\mathrm{Co} / \mathrm{ZrO}_{2}$ activados por reducción directa respecto de los correspondientes sometidos a calcinación. En el caso de los catalizadores $\mathrm{Co} / \mathrm{SiO}_{2}$ calcinados, el valor de TOF disminuye progresivamente desde $24.7 \cdot 10^{-3}$ hasta $11.6 \cdot 10^{-3} \mathrm{~s}^{-1}$ cuando se incrementa $\mathrm{T}_{\mathrm{c}}$ desde 300 hasta $550 \circ \mathrm{C}$. A su vez, $\mathrm{Co} / \mathrm{SiO}_{2} d c$ muestra un valor de $\mathrm{TOF}_{\mathrm{e}}$ muy similar al de $\mathrm{Co} / \mathrm{SiO}_{2} 300$, lo que remarca la especificidad de la temperatura de calcinación aplicada a las fases de Co $\left(T_{c}\right)$ a la hora de determinar la actividad 
intrínseca final y descarta, a su vez, la contribución de un efecto paralelo relacionado con alguna modificación del soporte catalítico debida a los tratamientos térmicos a elevada temperatura.

Como es de esperar a la vista de los tamaños de nanopartícula $>16$ $\mathrm{nm}$, la variación del TOF no está relacionada con un efecto del tamaño de NP puesto que, de hecho, el valor de TOF y $d\left(\mathrm{CO}^{\circ}\right)$ siguen un comportamiento contrario al esperado en el caso de la sensibilidad a la estructura discutida en el capítulo 3 de esta memoria.

En este punto cabe a su vez descartar una influencia de fenómenos de aglomeración metálica durante la catálisis sobre las tendencias discutidas. A priori, los diferentes grados de agrupamiento (clustering) metálico observados por TEM en las muestras con diferente historia térmica podrían traducirse en diferentes velocidades de sinterizado metálico en las condiciones de SFT. No obstante, puesto que los valores de TOF $_{0}$ (extrapolados a tiempo de reacción cero) siguen una tendencia idéntica a la comentada para $\mathrm{TOF}_{\mathrm{e}}$, se descarta esta explicación, y por tanto, los diferentes valores de TOF obtenidos se deben a diferencias reales en la actividad intrínseca (por centro metálico superficial).

Como se observa en la Tabla 4.4, la combinación de la influencia de $T_{c}$ (300-550ㄷ) tanto sobre el valor de TOF como sobre la dispersión metálica resulta en variaciones de hasta el $190 \%$ en el rendimiento temporal por masa de $\mathrm{Co}\left(\mathrm{CTY}_{\mathrm{e}}\right)$. Adicionalmente, cuando se considera el tratamiento de activación mediante reducción directa, que da lugar a la máxima dispersión metálica y el máximo valor de TOF, resulta en un incremento de hasta un $460 \%$ en CTY con respecto a la muestra calcinada en aire a 550 ㅇ․

En cuanto a la selectividad de la SFT, las condiciones de reacción empleadas (niveles de conversión quasi-diferenciales), si bien son las 
adecuadas para obtener información acerca de la actividad intrínseca de los catalizadores, no permiten establecer comparaciones realistas en términos de selectividad, puesto que el patrón de selectividades se verá seriamente afectado al trabajar en condiciones de operación más realistas ( $\left.X_{C O}>40 \%\right)$. No obstante se pueden comentar algunas tendencias observadas en los datos de selectividad recogidos en la Tabla 4.4. De manera general, se observa que la actividad relativa hacia la WGSR así como la selectividad a hidrocarburos de elevado peso molecular se incrementa cuando los catalizadores se calcinan en aire con respecto a cuando se activan por reducción directa. A su vez, un incremento en $\mathrm{T}_{\mathrm{c}}$ da lugar a mayores selectividades a productos $\mathrm{C}_{5+}$. No obstante, cabe recordar que esta tendencia puede estar relacionada simplemente con el hecho de que la selectividad depende de $d\left(\mathrm{Co}^{0}\right)$ incluso para tamaños de NP para los que el TOF no depende de $d\left(\mathrm{Co}^{\circ}\right)$, como se concluyó en el capítulo 3 de esta memoria. Por su parte, algunos autores [47] han asociado recientemente un incremento en la selectividad a hidrocarburos de cadena larga con el grado de agrupamiento metálico en los catalizadores, una explicación que también es coherente con los resultados del presente capítulo. Los materiales catalíticos y los experimentos de los capítulos 3 y 4 de este trabajo se han diseñado para estudiar el efecto del tamaño de NP y la historia térmica sobre la actividad catalítica intrínseca de los catalizadores de Co. Por su parte, los efectos del tamaño de NP y/o el grado de agrupamiento metálico sobre la selectividad de la SFT deben de ser estudiados con más detalle en el futuro, de manera preferible, en condiciones de operación realistas $\left(X_{C O}>40 \%\right)$. En estas condiciones de reacción, no obstante, otros parámetros relacionados con el transporte de materia intra-pellet tienen una influencia determinante en la selectividad, tal y como se describirá en detalle en el próximo capítulo 5. 
A modo de conclusión de esta sección, se puede inferir de los resultados catalíticos que la historia térmica (el empleo o no de calcinación en aire y la temperatura de este tratamiento) influye no sólo en el número de centros $\mathrm{Co}^{0}$ superficiales en el catalizador reducido, como se consideraba en trabajos previos, sino también en la actividad intrínseca de dichos centros activos.

La siguiente sección emplea la espectroscopia CO-FTIR para entender la influencia de la historia térmica sobre la topología superficial de las NPs de $\mathrm{Co}^{\circ}$, como posible factor responsable de estas diferencias en TOF.

\subsubsection{Influencia de la historia térmica en la topología superficial de las NPs de $\mathrm{CO}^{\circ}$ estudiada mediante CO-FTIR.}

La influencia de la historia térmica previa sobre la topología superficial de las NPs de $\mathrm{Co}^{0}$ tras el tratamiento de reducción de los catalizadores $\mathrm{Co} / \mathrm{SiO}_{2}$ se ha estudiado mediante CO-FTIR. Las Figs. 4.11 y 4.12 muestran los espectros de CO-FTIR en la región de carbonilos metálicos para dosis de $\mathrm{CO}$ crecientes (5-250 mbar) sobre los catalizadores $\mathrm{Co} / \mathrm{SiO}_{2}$ rd y $\mathrm{Co} / \mathrm{SiO}_{2} 550$, respectivamente, reducidos in situ en la celda de FTIR mediante el mismo tratamiento de reducción empleado antes de la catálisis. Estos dos catalizadores se han seleccionado para este estudio puesto que presentan, respectivamente, la máxima y la mínima actividad catalítica por centro metálico superficial (TOF), como se comentó en la sección 4.3.4. 


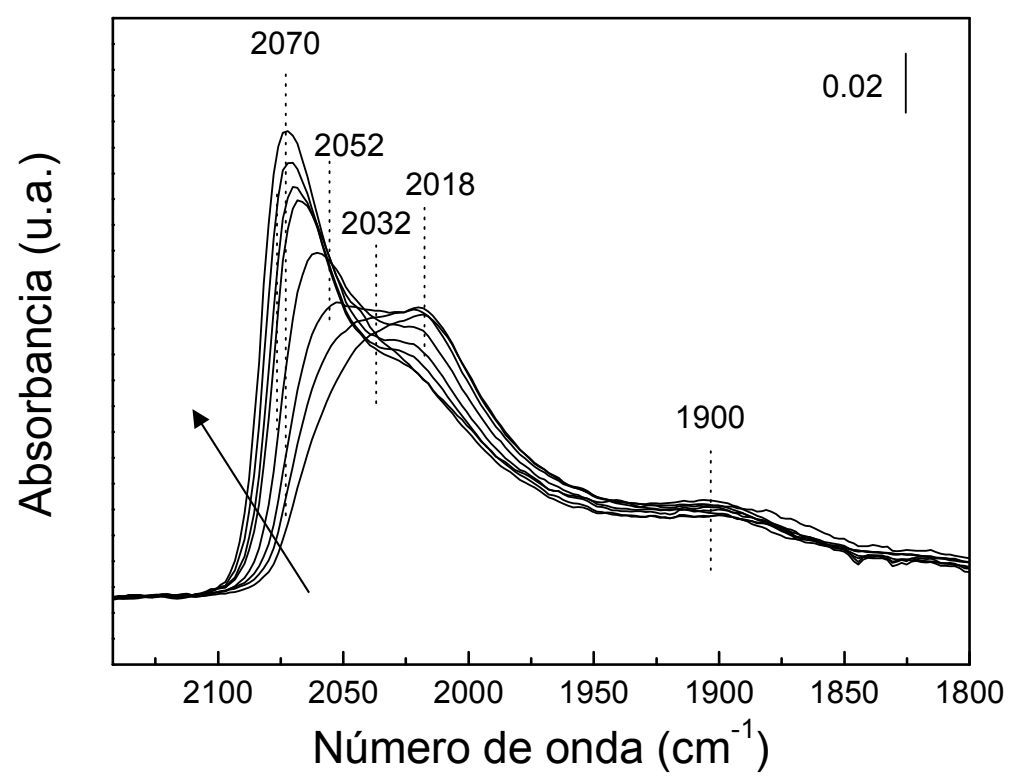

Figura 4.11: Espectros de CO-FTIR a temperatura ambiente tras la dosificación de 5250 mbar de $\mathrm{CO}$ sobre el catalizador $\mathrm{Co} / \mathrm{SiO}_{2}$ _rd reducido in situ en la celda de FTIR $\left(400^{\circ} \mathrm{C}, 2 \mathrm{~h}\right)$ y evacuado a la temperatura de reducción. La flecha indica el sentido de dosis crecientes de $\mathrm{CO}$.

Como se observa, en ambos casos se registran bandas asociadas con $\mathrm{CO}$ adsorbido sobre los centros de $\mathrm{Co}^{0}$ en configuración lineal (2000-2080 $\mathrm{cm}^{-1}$ ) y en configuración puenteada (aprox. $1900 \mathrm{~cm}^{-1}$ ). En ambos casos, especialmente a elevadas dosis de $\mathrm{CO}$, la banda de carbonilos metálicos más intensa es aquella registrada alrededor de $2050 \mathrm{~cm}^{-1}$, la cual se desplaza progresivamente hacia frecuencias superiores (hasta $2080 \mathrm{~cm}^{-1}$ ) a medida que se incrementa la dosis de $\mathrm{CO}$ en la celda, debido a las interacciones dipolo-dipolo entre las moléculas de $\mathrm{CO}$ adsorbidas cuando se incrementa el recubrimiento superficial. Esta banda se asignó en el capítulo 3 a la adsorción de CO en configuración lineal sobre átomos metálicos en terrazas de $\mathrm{Co}^{0}-f c c$. 


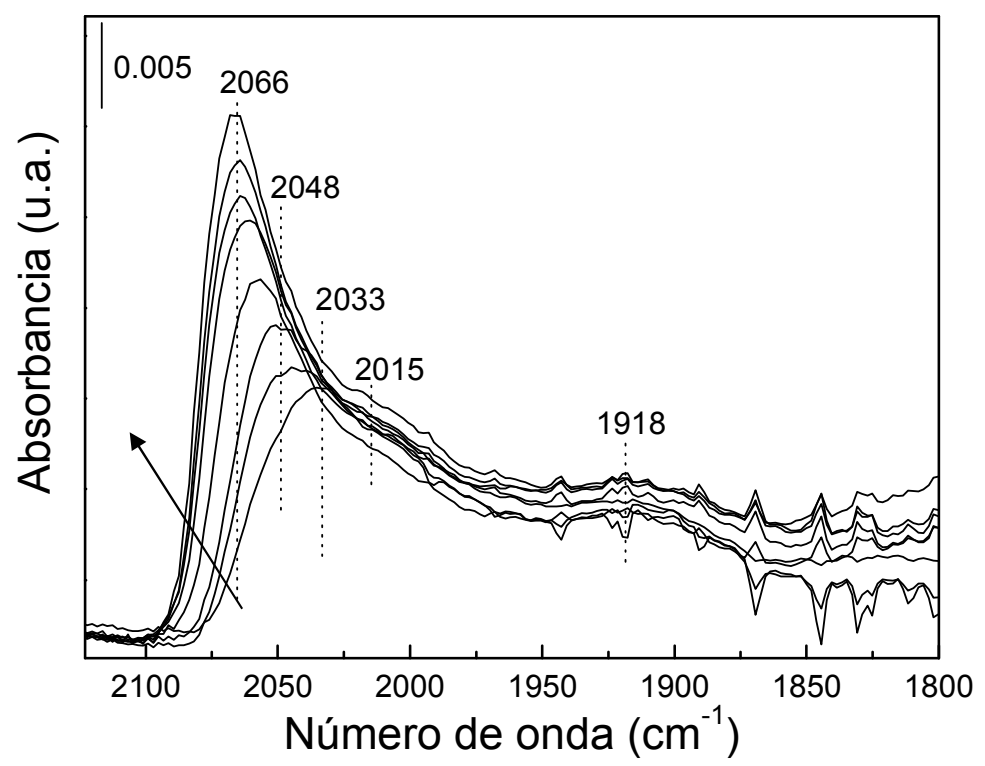

Figura 4.12: Espectros de CO-FTIR a temperatura ambiente tras la dosificación de 5250 mbar de CO sobre el catalizador $\mathrm{Co} / \mathrm{SiO}_{2} \_550$ reducido in situ en la celda de FTIR $\left(400^{\circ} \mathrm{C}, 2 \mathrm{~h}\right)$ y evacuado a la temperatura de reducción. La flecha indica el sentido de dosis crecientes de $\mathrm{CO}$.

No obstante estas similitudes, se percibe en las Figs. 4.11 y 4.12 una diferencia importante entre ambos catalizadores. Así, para las dosis iniciales de CO (recubrimiento de CO limitado adecuado para obtener información más precisa acerca de la topología metálica superficial) el catalizador $\mathrm{Co} / \mathrm{SiO}_{2}$ rd presenta una absorción prominente en la región de carbonilos lineales de baja frecuencia de vibración (2000-2020 $\left.\mathrm{cm}^{-1}\right)$, mientras que para el catalizador $\mathrm{Co} / \mathrm{SiO}_{2} 550$ la absorción relativa en esta región es significativamente menos importante, siendo la banda a $2030-2070 \mathrm{~cm}^{-1}$ la principal a todas las dosis de CO para este catalizador. Estas diferencias se perciben de manera más clara en los espectros de CO-FTIR a baja dosis de CO (5 mbar) comparados para ambos catalizadores en la Fig. 4.13. 


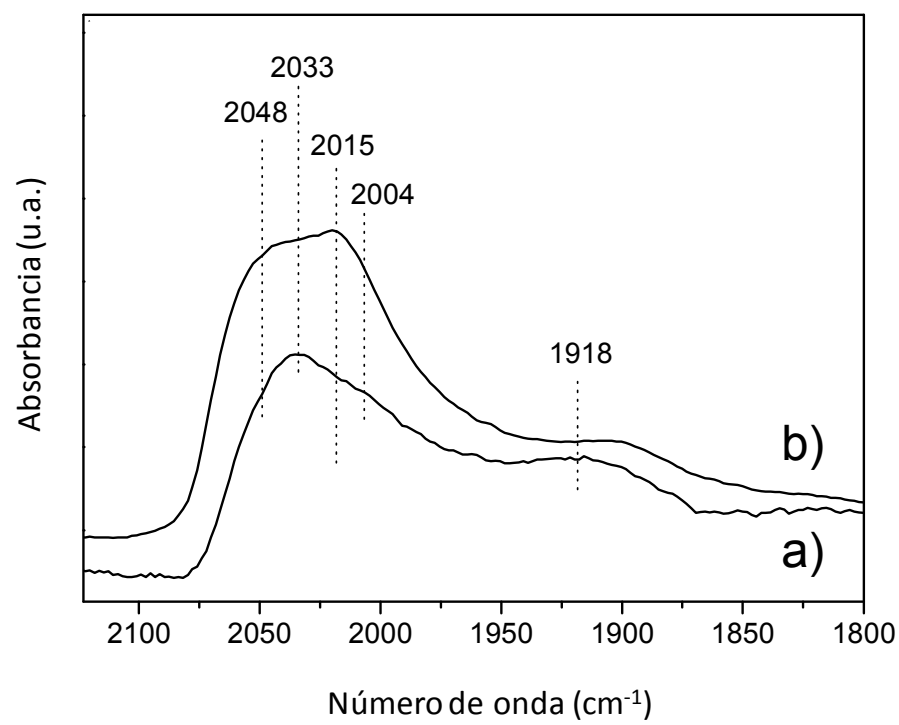

Figura 4.13: Espectros de CO-FTIR a temperatura ambiente tras la dosificación de 5 mbar de $\mathrm{CO}$ sobre los catalizadores a) $\mathrm{Co} / \mathrm{SiO}_{2} 550$ y b) $\mathrm{Co} / \mathrm{SiO}_{2}$ rd reducidos in situ en la celda de FTIR $\left(400^{\circ} \mathrm{C}, 2 \mathrm{~h}\right.$ ) y evacuados a la temperatura de reducción.

Los centros metálicos asociados con las bandas de carbonilos a bajas frecuencias $\left(2000-2020 \mathrm{~cm}^{-1}\right)$ son aquellos en posiciones de defectos en la superficie del cristal [48]. Por lo tanto, los resultados de CO-FTIR indican que la muestra que presenta un mayor valor de TOF es también aquella que presenta una mayor proporción de este tipo de defectos superficiales, de mayor densidad electrónica y, por ende, con una menor barrera energética para la disociación de CO [49]. De hecho la elevada actividad de este tipo de centros metálicos para la disociación de CO se percibe en la Fig. 4.11. Allí se observa cómo a medida que se incrementa la dosis de $\mathrm{CO}$, la intensidad de la banda de carbonilos a aprox. $2018 \mathrm{~cm}^{-1}$ disminuye en lugar de incrementarse como ocurre para el resto de señales, evidenciando que este tipo de centros disocian las moléculas de $\mathrm{CO}$ quimisorbidas incluso a temperatura ambiente.

Cabe recordar en este punto, que de acuerdo a los resultados de $\mathrm{H}_{2}$ XRD, el catalizador $\mathrm{Co} / \mathrm{SiO}_{2}$ r $r$ presenta un mayor carácter cúbico $(f c c)$ en el 
estado reducido. Este hecho contrasta con el predominio de las bandas de carbonilos metálicos de baja frecuencia $\left(2000-2020 \mathrm{~cm}^{-1}\right)$ en comparación con la banda asociada a la adsorción de CO sobre átomos en terrazas de $\mathrm{Co}^{\circ}$ $f c c$ a aprox. $2050 \mathrm{~cm}^{-1}$ (espectro b en Fig. 4.13). Así pues, los resultados del presente capítulo destacan la importancia de la topología superficial de las NPs de $\mathrm{CO}^{0}$ en términos de su actividad intrínseca (TOF), independientemente de la microestructura detectada por técnicas másicas como XRD.

En conclusión, los resultados de CO-FTIR muestran que la historia térmica de los catalizadores $\mathrm{Co} / \mathrm{SiO}_{2}$ determina la topología superficial (naturaleza de los centros metálicos en superficie) de las NPs de $\mathrm{Co}^{\circ}$, incluso tras un tratamiento de reducción en $\mathrm{H}_{2}$ idéntico. La influencia de la historia térmica previa en la cinética de los procesos que tienen lugar durante el tratamiento de reducción da lugar a diferentes grados de desorden metálico superficial que determina la densidad de centros $\mathrm{Co}^{0}$ superficiales de diferente naturaleza y con distintas actividades relativas para la disociación de CO. Puesto que son varios los estudios que han postulado la disociación de CO como la etapa limitante del proceso cinético global $[49,50]$, se entienden las implicaciones que la historia térmica tiene en la velocidad de reacción para la SFT.

Estudios posteriores, deberían, no obstante, ahondar en el conocimiento de la influencia que la topología superficial de las NPs de $\mathrm{Co}^{0}$ ejerce sobre los fenómenos de reconstrucción metálica superficial que tienen lugar durante la catálisis, como se estudió en el capítulo 3 en función de $d\left(\mathrm{Co}^{0}\right)$. 


\subsection{Conclusiones.}

La conclusión general del presente capítulo es que es posible racionalizar cómo se propaga la influencia de los protocolos empleados en las primeras etapas de activación de los catalizadores $\mathrm{Co} / \mathrm{SiO}_{2}$ hasta determinar la actividad intrínseca final, aún cuando median tratamientos homogéneos como la reducción in situ del catalizador.

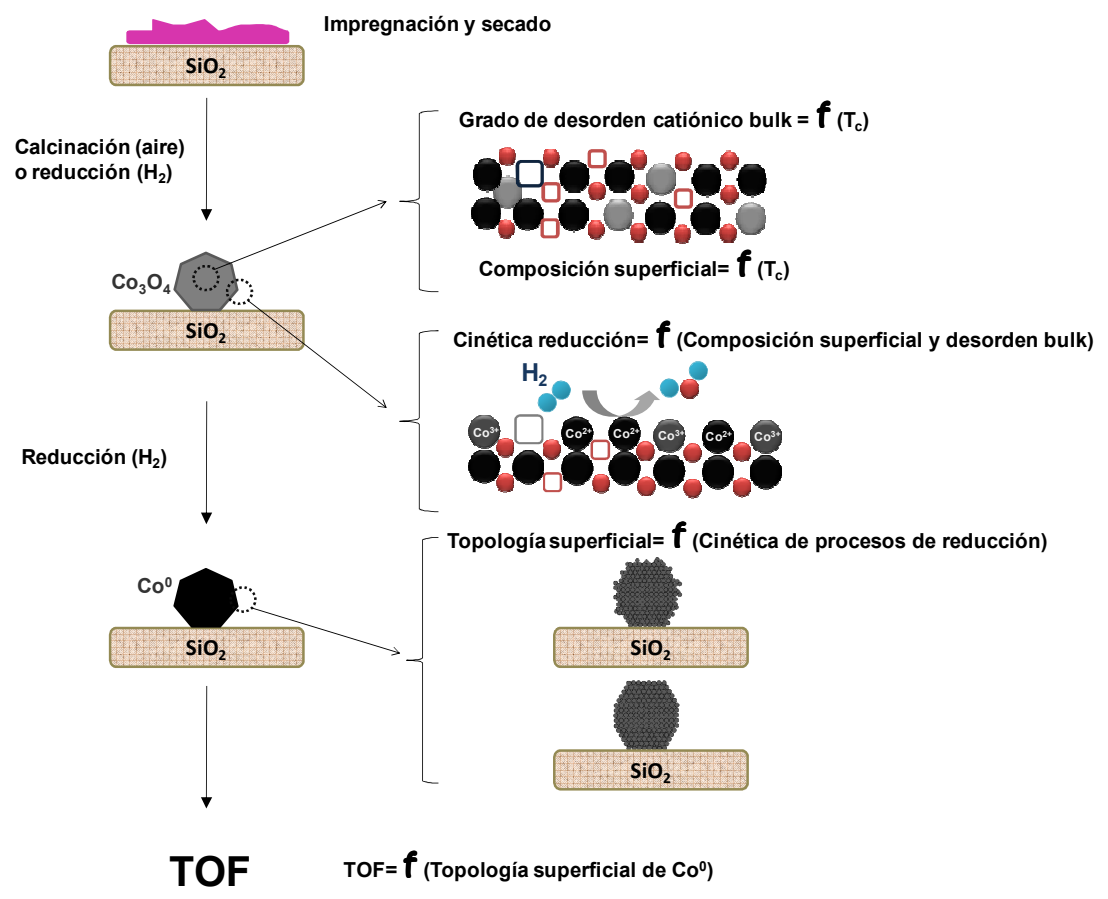

Figura 4.14: Resumen gráfico de la propagación de los efectos de la historia térmica, desde los primeros tratamientos, hasta el evento catalítico (TOF).

En base a los resultados expuestos, la química estructural de los catalizadores cuando aún se encuentran en forma de óxidos nanoparticulados juega un papel clave en esta propagación de información a través de toda la historia térmica de los catalizadores, como se esquematiza en la Fig. 4.14. Probablemente, este constituye el primer ejemplo de estudio sistemático de este tipo de fenómenos en un sistema catalítico constituido 
por nanopartículas metálicas, y podría ser extensible a otros sistemas en los que la topología superficial de las nanopartículas de $\mathrm{M}^{0}$ tenga influencia sobre su comportamiento catalítico.

Así pues, las principales conclusiones que se extraen de la investigación presentada en este capítulo se enumeran a continuación:

1. La temperatura de calcinación empleada durante la activación de catalizadores $\mathrm{Co} / \mathrm{SiO}_{2}$ para la SFT determina la distribución de los cationes de $\mathrm{Co}^{2+}$ y $\mathrm{Co}^{3+}$ en la estructura de la espinela $\mathrm{Co}_{3} \mathrm{O}_{4}$ resultante (grado de desorden catiónico) así como la composición química en la superficie de los cristales, incrementándose la relación $\mathrm{Co}^{2+} / \mathrm{Co}^{3+}$ superficial al incrementarse la temperatura del tratamiento de activación en aire.

2. La composición superficial de los cristales de $\mathrm{Co}_{3} \mathrm{O}_{4}$ en los catalizadores calcinados, que es función de la temperatura de calcinación empleada, en lugar del tamaño de cristal, determina en gran medida la cinética de los fenómenos de reducción hasta las fases activas de $\mathrm{CO}^{0}$.

3. El empleo de calcinación durante la activación de los catalizadores da lugar a menores dispersiones y mayores grados de agrupamiento (clustering) metálico que cuando se emplea un protocolo de activación basado en la descomposición-reducción directa en atmósfera de $\mathrm{H}_{2}$. A su vez, un incremento de la temperatura de calcinación resulta en un descenso de dispersión metálica y un aumento del grado de agrupamiento, que reduce la distancia media entre NPs metálicas.

4. A pesar de las diferentes cinéticas de los procesos de reducción, los catalizadores $20 \% \mathrm{Co} / \mathrm{SiO}_{2}$ sometidos a un mismo tratamiento de 
reducción en $\mathrm{H}_{2}$ presentan microestructuras similares, con presencia de dominios de $\mathrm{Co}^{0}-f c c$ y dominios de $\mathrm{Co}^{0}$-hcp de mucho menor tamaño, probablemente de naturaleza intra-cristalina y derivados de dislocaciones de planos cristalinos.

5. Las diferentes cinéticas de reducción, derivadas de las diferencias en la historia térmica anterior, resultan en cambios en la topología superficial de las nanopartículas de $\mathrm{Co}^{0}$ en el catalizador en su forma activa. El empleo de tratamientos de calcinación a elevada temperatura resulta finalmente en superficies de $\mathrm{Co}^{0}$ más cristalinas (mayor densidad de centros en terrazas), con menor concentración de defectos y menos activas intrínsecamente para la disociación de CO.

6. La historia térmica determina variaciones en TOF de hasta el 300\%, mientras que la combinación de su efecto sobre el TOF y la dispersión metálica resulta en diferencias en términos de rendimiento temporal por masa de Co de hasta un $460 \%$.

7. La química del estado sólido de las nanopartículas de $\mathrm{Co}_{3} \mathrm{O}_{4}$ y su influencia en la cinética de los fenómenos de reducción, para dar lugar a fases activas de $\mathrm{Co}^{\circ}$ con centros superficiales de diferente naturaleza, es probablemente la vía a través de la cual las etapas de activación más tempranas son capaces de determinar la actividad catalítica intrínseca final.

8. De las conclusiones anteriores se desprende que, en contra de lo asumido por científicos e industriales hasta el momento, para unas condiciones de operación determinadas, la actividad catalítica de un catalizador de Co para la SFT no queda definitivamente determinada por los parámetros de dispersión metálica y reducibilidad, sino que se requiere conocer la historia completa de su activación pues ésta influye 
de manera no despreciable en la actividad catalítica por centro metálico superficial (TOF). 


\section{Referencias.}

\footnotetext{
${ }^{1}$ V.A. de la Peña O'Shea, J.M. Campos-Martín, J.L.G. Fierro, Catal. Commun. 5 (2004) 635.

${ }^{2}$ A. Moen, D.G. Nicholson, M. Rønning, H. Emerich, J. Mater. Chem. 8 (1998) 2533.

3 S.L. Soled, E. Iglesia, R.A. Fiato, J.E. Baumgartner, H.Vroman, S.Miseo, Top. Catal. 26 (2003) 101.

${ }^{4}$ X. Dai, C. Yu, J. Nat. Gas Chem. 17 (2008) 288.

5 J.M. Jablonski, J. Okal, D. Potoczna-Petru, L. Krajczyk, J. Catal. 220 (2003) 146.

${ }^{6}$ Ø. Borg, E.A. Blekkan, S. Eri, D. Akporiaye, B. Vigerust, E. Rytter, A. Holmen, Top. Catal. 45 (2007) 39.

${ }^{7}$ D.I. Enache, B. Rebours, M. Roy-Auberger, R. Revel, J. Catal. 205 (2002) 346.

8 J.R.A. Sietsma, J.D. Meeldijk, J.P. den Breejen, M. Versluijs-Helder, A.J. van Dillen, P.E. de Jongh, K.P. de Jong, Angew. Chem. 119 (2007) 4631.

${ }^{9}$ E. Iglesia, Appl. Catal. A 161 (1997) 59.

${ }^{10}$ J.-S. Girardon, E. Quinet, A. Griboval-Constant, P.A. Chernavskii, L. Gengembre, A.Y.

Khodakov, J. Catal. 248 (2007) 143.

11 D.J. Kim, B.C. Dunn, P. Cole, G. Turpin, R.D. Ernst, R.J. Pugmire, M. Kang, J.M. Kim, E.M. Eyring, Chem. Commun. (2005) 1562.

12 A. Martínez, G. Prieto, J. Catal. 245 (2007) 470.

13 W. Chu, P.A. Chernavskii, L. Gengembre, G.A. Pankina, P. Fongarland, A.Y. Khodakov, J. Catal. 252 (2007) 215.

${ }^{14}$ R.B. Anderson, en Catalysis, P.H. Emmet Ed., Reinhold, New York (1959) vol IV.

15 B.G. Johnson, C.H. Bartholomew, D.W. Goodman, J. Catal. 128 (1991) 231.

${ }^{16}$ H.P. Withers, K.F. Eliezer, J.W. Mitchell, Ind. Eng. Chem. Res. 29 (1990) 1807.

${ }^{17}$ Ø. Borg, S. Eri, E.A. Blekkan, S. Storsæter, H. Wigum, E. Rytter, A. Holmen, J. Catal. 248 (2007) 89.

${ }^{18}$ A. Martínez, G. Prieto, J. Rollán, J. Catal. 263 (2009) 292.

${ }^{19}$ E. Iglesia, S.L. Soled, R.A. Fiato, G.H. Via, J. Catal. 143 (1993) 345.

${ }^{20}$ G. Prieto, A. Martínez, R. Murciano, M.A. Arribas, Appl. Catal. A 367 (2009) 146.

${ }^{21}$ G.L. Bezemer, J.H. Bitter, H.P.C.E. Kuipers, H. Oosterbeek, J.E. Holewijn, X. Xu, F. Kapteijn, A. J. van Dillen, K.P. de Jong, J. Am. Chem. Soc. 128 (2006) 3956.

${ }^{22}$ A. Barbier, A. Tuel, I. Arcon, A. Kodre, G.A. Martin, J. Catal. 200 (2001) 106.

${ }^{23}$ Iglesia, Appl. Catal. A 161 (1997) 59.

${ }^{24}$ A.Y. Khodakov, A. Griboval-Constant, R. Bechara, V.L. Zholobenko, J. Catal. 206 (2002) 230 .

${ }^{25}$ D.J. Kim, B.C. Drunn, P. Cole, G. Turpin, R.D. Ernst, R.J. Pugmire, M. Kang, J.M. Kim, E.M. Eyring, Chem. Commun. (2005) 1462.
} 
${ }^{26}$ G. Prieto, A. Martínez, P. Concepción, R. Moreno-Tost, J. Catal. 266 (2009) 129.

27 A. Martínez, G. Prieto, Proceedings of the EuropaCat-VII, Turku, Finland (2007).

${ }^{28}$ C. Oliva, L. Forni, L. Formaro, Appl. Spectrosc. 50 (1996) 1395.

${ }^{29}$ M. Casas-Cabanas, G. Binotto, D. Larcher, A. Lecup, V. Giordani, J.-M. Tarascon, Chem. Mater. 21 (2009) 1939.

30 A.K. Arora, M. Rajalakshmi, T.R. Ravindran, V. Sivasubramanian, J. Raman Spectrosc. 38 (2007) 604, y referencias incluidas.

${ }^{31}$ V.G. Hadjiev, M.N. Iliev, I.V. Vergilov, J. Phys C: Solid State Phys. 21 (1988) L199.

32 G.V.M. Jacintho, A.G. Brolo, P. Corio, P.A.Z. Suarez, J.C. Rubim, J. Phys. Chem. C 113

(2000) 7684 .

${ }^{33}$ C.V. Ramana, M. Massot, C.M. Julien, Surf. Interface Anal. 37 (2005) 412.

${ }^{34}$ I. Levin, S.A. Prosandeev, J.E. Maslar, Appl. Phys. Lett. 86 (2005) 011919.

${ }^{35}$ C.J. Howard, B.J. Kennedy, P.M. Woodward, Acta Crystallogr. Sect. B: Struct. Sci. B59 (2003) 463 .

${ }^{36}$ M. Douin, L. Guerlou-Demourgues, M. Ménétrier, E. Bekaert, L. Goubault, P. Bernard, C. Delmas, Chem. Mater. 20 (2008) 6880.

37 A. Restovic, E. Ríos, S. Barbato, J. Ortiz, J.L. Gautier, J. Electroanal. Chem. 522 (2002) 141.

${ }^{38}$ G. Jacobs, T. Das, Y.Q. Yang, J.L. Li, G. Tacoillet, B.H. Davis, Appl. Catal. A 233 (2002) 263.

39 B. Jongsomjit, J. Panpranot, J.G. Goodwin Jr., J. Catal. 204 (2001) 98.

${ }^{40}$ Y. Ji, Z. Zhao, A. Duan, G. Jiang, J. Liu, J. Phys. Chem. C 113 (2009) 7183.

${ }^{41}$ A.M. Saib, A. Borgna, J. van de Loosdrecht, P.J. van Berge, J.W. Geus, J.W.

Niemantsverdriet, J. Catal. 239 (2006) 326.

42 R.P. Furstenau, G. McDougall, M.A. Langell, Surf. Sci. 150 (1985) 55.

${ }^{43}$ J.A. Rodríguez, J.C. Hanson, A.I. Frenkel, J.Y. Kim, M. Prez, J. Am. Chem. Soc. 124 (2002) 346.

${ }^{44}$ P.A. Chernavskii, G.V. Pankina, V.I. Zaikovskii, N.V. Peskov, P. Afanasiev, J. Phys. Chem. C 112 (2008) 9573 .

45 D. Potoczna-Petru, L. Kepinski, Catal. Lett. 73 (2001) 41.

${ }^{46}$ S. Krishnamoorthy, M.Tu, M.P. Ojeda, D. Pinna, E. Iglesia, J. Catal. 211 (2002) 422.

${ }^{47}$ Ø. Borg, S. Eri, E.A. Blekkan, S. Storsæter, H. Wigum, E. Rytter, A. Holmen, J. Catal. 248 (2007) 89.

${ }^{48}$ G. Blyholder, L.D. Neff, J. Phys. Chem. 73 (1969) 3494.

${ }^{49}$ Q. Ge, M. Neurock, J. Phys. Chem. B 110 (2006) 15368.

${ }^{50}$ I.M. Ciobica, G.J. Kramer, Q. Ge, M. Neurock, R.A.van Santen, J. Catal. 212 (2002) 136. 


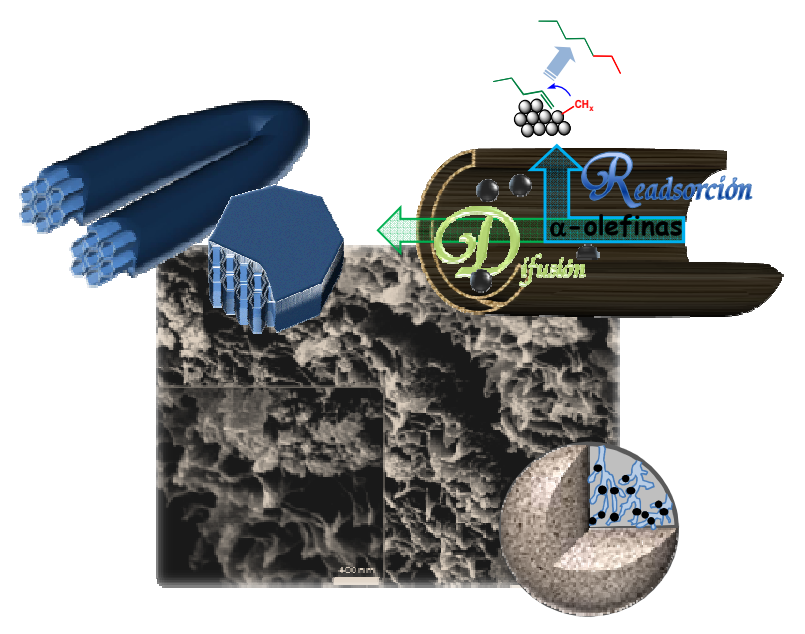

\section{SOPORTES CATALÍTICOS DE TEXTURA OPTIMIZADA PARA LA SÍNTESIS DE FISCHER-TROPSCH}


Como se comentó en la introducción general a esta memoria, la estructura porosa de los soportes catalíticos empleados en los catalizadores de Co para la SFT puede tener una influencia determinante en la actividad y selectividad de la síntesis, debido a la relevancia cinética de los fenómenos de transferencia de masa intra-pellet en las condiciones de trabajo estacionarias. Adicionalmente, la porosidad del soporte será un parámetro clave a la hora de determinar la dispersión metálica de las fases soportadas cuando los catalizadores se preparan mediante técnicas convencionales de fácil escalado industrial como la impregnación.

El presente capítulo acomete el diseño de estructuras porosas de $\mathrm{Al}_{2} \mathrm{O}_{3}$ y $\mathrm{SiO}_{2}$ y su empleo como soportes para catalizadores de Co para la SFT. El principal objetivo de este estudio es identificar los requerimientos de la estructura porosa del soporte que permitan optimizar el comportamiento catalítico de los catalizadores metálicos.

El capítulo se divide en dos partes:

En la primera de estas partes (5-A) se estudia la influencia combinada de la dispersión metálica (de acuerdo a los comportamientos descritos en el capítulo 3) y la estructura porosa del soporte en el comportamiento catalítico de catalizadores $\mathrm{RuCo} / \mathrm{Al}_{2} \mathrm{O}_{3}$ en condiciones de operación industrialmente relevantes.

Por otro lado, la segunda parte del capítulo (5-B) estudia la influencia del diámetro y, por primera vez, la longitud de poro de soportes mesoestructurados basados en $\mathrm{SiO}_{2}$ (SBA-15) en la dispersión metálica y las propiedades catalíticas de catalizadores RuCo/SBA-15. 


\section{5-A}

Catalizadores $\mathrm{RuCo} / \mathrm{Al}_{2} \mathrm{O}_{3}$ : Influencia combinada de dispersión metálica y diámetro de poro. 


\subsection{Introducción.}

\subsubsection{Dispersión y porosidad en la SFT.}

Como se comentó brevemente en el capítulo de Introducción General, un catalizador de la síntesis de Fischer-Tropsch, en condiciones de reacción realistas, es decir, elevada conversión y selectividad a hidrocarburos de cadena larga (ceras), presenta su estructura porosa llena de hidrocarburos pesados. Esto introduce restricciones difusionales intra-partícula tanto para los reactivos, especialmente $\mathrm{CO}$, como para los productos de la síntesis, que deben atravesar la densa capa de líquidos que rellena la estructura porosa de las partículas de catalizador en su difusión entre los centros activos y la fase gaseosa externa o viceversa. En configuraciones de reactor de lecho fijo se requieren pellets cuyo diámetro típicamente excede los $0.8 \mathrm{~mm}$, de modo que la actividad y selectividad de la síntesis están controladas por la etapa difusional intra-partícula para el CO hacia los centros activos [1]. La influencia relativa de los fenómenos de transferencia de materia intrapartícula sobre la selectividad de la reacción depende de un solo parámetro estructural $(\chi)$ que es función de la densidad volumétrica de centros activos, el diámetro de poro (DP) del catalizador y el diámetro de pellet (sección 1.3.7.2).

Puesto que el tamaño de pellet viene dictado por consideraciones operacionales, tan sólo la dispersión metálica y el diámetro de poro podrían considerarse grados de libertad a la hora de afrontar el diseño de nuevos catalizadores con propiedades de actividad y selectividad mejoradas para operaciones de la SFT en configuración de lecho fijo, es decir, bajo control cinético por la etapa de difusión de CO intra-partícula. 


\subsubsection{Soportes porosos convencionales: acoplamiento porosidad- dispersión.}

Para los sólidos inorgánicos de morfologías convencionales, como por ejemplo partículas pseudo-esféricas con porosidad intra-partícula, el área específica y el diámetro de poro son dos parámetros inversamente interrelacionados, de modo que incrementar el área superficial específica implica, normalmente, reducir el diámetro de poro medio. En este caso, las ventajas de utilizar soportes catalíticos de elevada área superficial, que den lugar a dispersiones metálicas mejoradas, pueden verse parcialmente mermadas por el hecho de reducir el diámetro de poro, lo que acentúa los problemas difusionales para el $\mathrm{CO}$ en los catalizadores de SFT.

\subsubsection{Nuevos materiales de morfología nanofibrosa y estructura porosa bimodal jerarquizada.}

Los catalizadores "eggshell", en los que se reduce la distancia de difusión para el $\mathrm{CO}$, introducen una penalización importante en términos de dispersión metálica (y por tanto en la actividad catalítica) y, sobre todo, de volumen de lecho catalítico para una determinada productividad, debido a la importante fracción de volumen de soporte catalítico que no contiene fase activa (sección 1.3.7.2). Una alternativa interesante pasaría por desacoplar los parámetros de área superficial y diámetro de poro (DP) en soportes catalíticos de textura no convencional, de forma que sean compatibles elevadas dispersiones metálicas y acceso difusional facilitado para el CO.

En este respecto, se han dirigido recientemente grandes esfuerzos científicos a la preparación de estructuras inorgánicas de morfología unidimensional (1D) a un nivel nanoscópico (nanocables, nanobarras, nanofibras, nanotubos, etc.) empleando rutas sintéticas basadas en plantillas (templates) sólidas [2,3] o "blandas", como surfactantes [4,5,6]. En muchos casos la nueva morfología 1D ha revelado propiedades catalíticas originales 
respecto de los correspondientes materiales nanométricos convencionales $[7,8,9]$. La morfología 1D a nivel nanoscópico es capaz de dar lugar a nuevos materiales que combinan elevadas áreas superficiales con estructuras porosas muy abiertas (porosidad inter-partícula principalmente) e incluso macroporosidad. En este sentido Blin y col. [10] han descrito la síntesis hidrotermal de varios materiales inorgánicos en presencia de grandes cantidades de surfactante, de modo que parte de éste confina el crecimiento de las nanopartículas del sólido sintetizado, normalmente induciendo morfologías primarias 1D, mientras que el exceso de surfactante se agrupa en macromicelas, resultando en una estructura secundaria macroporosa para el sólido sintetizado (Fig. 5.1). Debido a su amplio rango de aplicaciones como adsorbente y soporte catalítico, se ha estudiado extensamente la preparación de nanofibras de $\mathrm{\gamma}-\mathrm{Al}_{2} \mathrm{O}_{3}$ mediante rutas sintéticas en presencia de surfactantes, bien confinando un proceso sol-gel en el interior de medios micelares [4] o mediante tratamientos hidrotermales de hidróxidos $\mathrm{Al}(\mathrm{OH})_{\mathrm{x}}$ nanométricos en presencia de un gran exceso de surfactante (ruta denominada inducción de morfología de nanofibra por surfactantes o surfactant-induced fiber formation) [6]. 


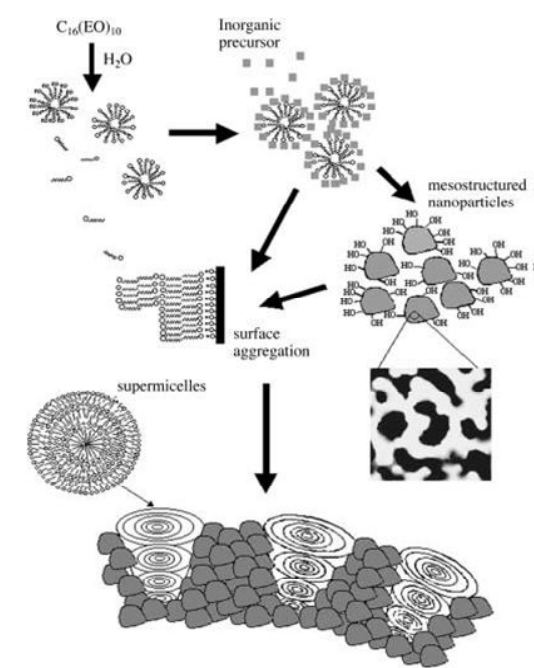

Figura 5.1: Esquema de la organización de surfactantes para dar lugar a materiales con partículas primarias de dimensiones nanométricas y estructuras secundarias macroporosas [10].

La alúmina $\left(\mathrm{Al}_{2} \mathrm{O}_{3}\right)$ es un óxido frecuentemente empleado como soporte para catalizadores de Fischer-Tropsch, debido a sus propiedades mecánicas, que le hacen especialmente resistente a la atricción, y a que presenta un nivel de interacción metal-soporte intermedio, que previene la aglomeración metálica (sintering), que es más probable en soportes menos "interaccionantes" con el Co como la $\mathrm{SiO}_{2}$, mientras evita la formación de especies poco reducibles, que tiene lugar con mayor facilidad en soportes que interaccionan fuertemente con las fases metálicas como es el caso de $\mathrm{TiO}_{2}$.

\subsection{Planteamiento.}

Esta parte de la investigación persigue estudiar el efecto relativo de la dispersión metálica y la porosidad (diámetro de poro) en la actividad y selectividad catalíticas de catalizadores $\mathrm{RuCo} / \mathrm{Al}_{2} \mathrm{O}_{3}$ para la SFT, en condiciones representativas de la operación industrial. Para ello se prepararon catalizadores basados en $\mathrm{Co}$, y promovidos por $\mathrm{Ru}$, soportados 
sobre $\mathrm{\gamma}-\mathrm{Al}_{2} \mathrm{O}_{3}$ de morfología primaria nanofibrosa y estructura porosa bimodal (macro-mesoporosa) a dos niveles de carga metálica (0.5\%Ru$20 \%$ Co y $1 \% R u-30 \%$ Co). El comportamiento catalítico de estos catalizadores con porosidad bimodal se comparó con el de otros catalizadores de referencia soportados sobre varias $\mathrm{Y}-\mathrm{Al}_{2} \mathrm{O}_{3}$ ultrapuras comerciales (Sasol Materials) con diferente diámetro de poro en el rango de 6-32 $\mathrm{nm}$. Se espera que el empleo de los nuevos materiales, de porosidad bimodal y elevada área superficial, como soportes catalíticos, permita ponderar el efecto que la dispersión metálica y los fenómenos difusionales tienen sobre el rendimiento y la selectividad de la SFT en condiciones de interés industrial.

Por simplicidad, las series de catalizadores se denominan en adelante $20 \mathrm{Co} / \mathrm{Al}_{2} \mathrm{O}_{3}$ y $30 \mathrm{Co} / \mathrm{Al}_{2} \mathrm{O}_{3}$, mientras que los catalizadores individuales contienen la denominación propia del soporte empleado, como se describió en la sección 2.1.3.4.

\subsection{Resultados y discusión.}

\subsubsection{Caracterización de los soportes.}

\subsubsection{Propiedades texturales.}

El soporte de morfología nanofibrosa $\left(\mathrm{Al}_{2} \mathrm{O}_{3} \_n f\right)$ y los soportes comerciales se prepararon y/o acondicionaron como se indicó en los apartados 2.1.2.3 y 2.1.2.4 de la Sección Experimental.

La Fig. 5.2 muestra las isotermas de adsorción-desorción de $\mathrm{N}_{2}$ para todos los soportes basados en $\mathrm{V}^{-} \mathrm{Al}_{2} \mathrm{O}_{3}$. Se observa que las isotermas muestran la histéresis característica de la condensación capilar en mesoporos (2-50 nm). Las isotermas para los sólidos $\mathrm{Al}_{2} \mathrm{O}_{3} \_1, \mathrm{Al}_{2} \mathrm{O}_{3} 2 \mathrm{y}$ $\mathrm{Al}_{2} \mathrm{O}_{3} 3$ tienden a un plateau al superarse cierta presión relativa, indicando que estos soportes son, principalmente, mesoporosos. El valor de $\mathrm{P} / \mathrm{P}_{0}$ para 
el que tiene lugar el llenado de los poros se incrementa de 0.87 para $\mathrm{Al}_{2} \mathrm{O}_{3}{ }_{-} 1$ hasta 0.97 para $\mathrm{Al}_{2} \mathrm{O}_{3}{ }_{3} 3$ como consecuencia de un incremento en el DP en el mismo orden. Sin embargo, se observa un comportamiento ligeramente diferente para $\mathrm{Al}_{2} \mathrm{O}_{3} 4$ y $\mathrm{Al}_{2} \mathrm{O}_{3}$ nf a elevadas presiones relativas $\left(\mathrm{P} / \mathrm{P}_{0}>0.9\right)$. Para estos dos sólidos no se alcanza un plateau y las ramas de adsorción y desorción crecen continuamente hasta la presión de saturación $\left(P / P_{0}=1\right)$.

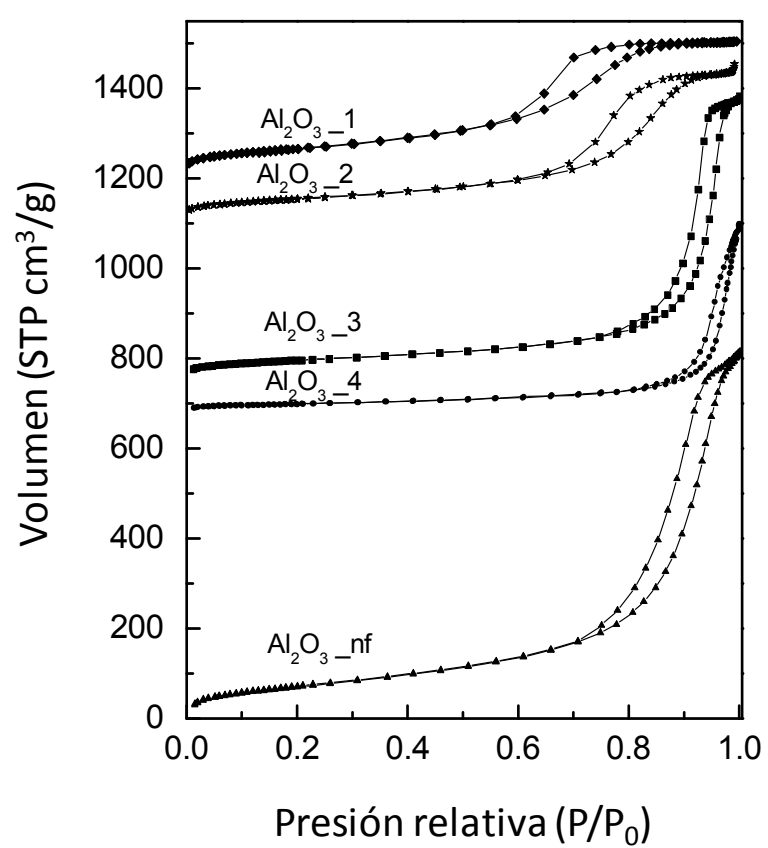

Figura 5.2: Isotermas de adsorción-desorción de $\mathrm{N}_{2}$ para los soportes comerciales $\mathrm{Al}_{2} \mathrm{O}_{3}$ _ 1-4 y el soporte nanofibroso $\mathrm{Al}_{2} \mathrm{O}_{3}$ _nf. Las isotermas para $\mathrm{Al}_{2} \mathrm{O}_{3}{ }_{-}{ }_{1-4}$ se han desplazado verticalmente $1200,1100,750$ y $650 \mathrm{~cm}^{3} / \mathrm{g}$, respectivamente.

Los lazos (loops) de histéresis para $\mathrm{Al}_{2} \mathrm{O}_{3}$ 1-3 pueden clasificarse como de tipo H2 de acuerdo a la clasificación de la IUPAC [11] y sugieren la presencia de mesoporos más o menos cilíndricos con una distribución de diámetros bastante estrecha. Por el contrario, los loops de histéresis para $\mathrm{Al}_{2} \mathrm{O}_{3}{ }_{4}$ y $\mathrm{Al}_{2} \mathrm{O}_{3}$ nf presentan características intermedias entre las categorías $\mathrm{H} 3$ y $\mathrm{H} 4$ [11], que son típicas de poros de tipo rendija asociados con porosidad inter-partícula en sólidos con morfología de partícula primaria de 
tipo "plancha" o "fibra". Esto sugiere que estos soportes pueden presentar poros inter-partícula de mayor tamaño con diámetros que no pueden ser medidos adecuadamente por adsorción de $\mathrm{N}_{2}$.

La Fig. 5.3 muestra las distribuciones de diámetro de poro obtenidas por adsorción de $\mathrm{N}_{2}$, donde se aprecia el carácter unimodal de las distribuciones, en el rango de DP de 6.0-32.4 nm. La Tabla 5.1 recoge las propiedades texturales para todos los soportes catalíticos. De acuerdo a los resultados de adsorción de $\mathrm{N}_{2}$, el DP de los soportes comerciales varía en el rango 6.0-32.4 nm mientras que la alúmina nanofibrosa $\mathrm{Al}_{2} \mathrm{O}_{3} \_\mathrm{nf}$ presenta un DP intermedio de $16.1 \mathrm{~nm}$. Además, la superficie específica disminuye de 254 a $70 \mathrm{~m}^{2} / \mathrm{g}$ cuando se incrementa DP de 6.0 a $32.4 \mathrm{~nm}$ para los soportes comerciales, evidenciando la interrelación inversa que presentan estos dos parámetros. La muestra nanofibrosa no sigue esta tendencia y presenta el mayor valor de área superficial $\left(321 \mathrm{~m}^{2} / \mathrm{g}\right)$. A su vez, el VP es también el mayor para esta muestra $\left(1.29 \mathrm{~cm}^{3} / \mathrm{g}\right)$.

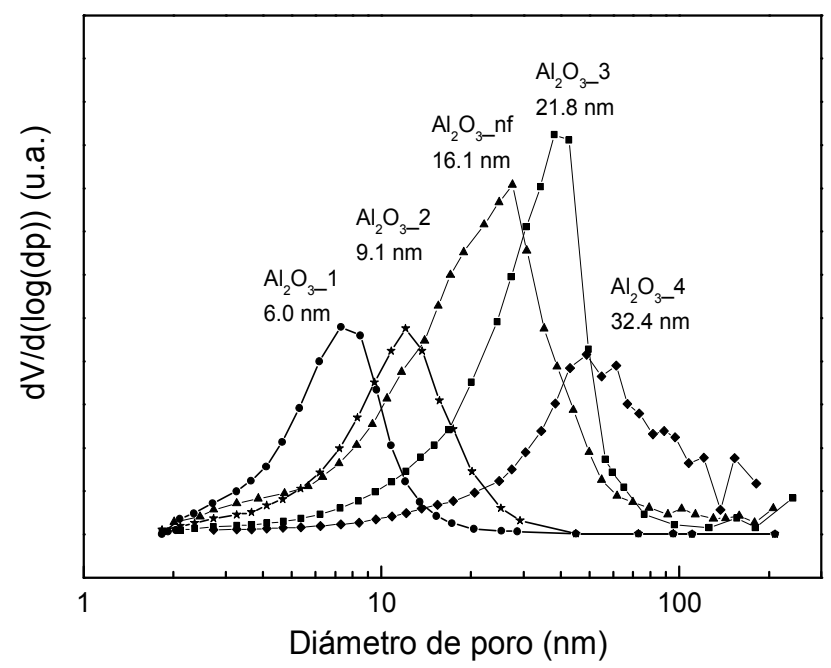

Figura 5.3: Distribuciones de diámetro de poro obtenidas por adsorción de $\mathrm{N}_{2}$ para los soportes comerciales $\mathrm{Al}_{2} \mathrm{O}_{3}{ }_{-} 1-4$ y la muestra de morfología nanofibrosa $\mathrm{Al}_{2} \mathrm{O}_{3}$ nf. 
Por otro lado, se estudió la presencia de macroporos en los soportes mediante porosimetría de $\mathrm{Hg}$. Como se muestra en la Tabla 5.1, el volumen de macroporos $\left(50-10^{3} \mathrm{~nm}\right)$ en $\mathrm{Al}_{2} \mathrm{O}_{3} \_$y $\mathrm{Al}_{2} \mathrm{O}_{3}{ }_{3}$ (0.04 y $0.09 \mathrm{~cm}^{3} / \mathrm{g}$, respectivamente) representa menos del $10 \%$ del volumen de poro total determinado por adsorción de $N_{2}$, sugiriendo una contribución de macroporos despreciable. La contribución relativa de macroporos se espera aún menor para la muestra de poro más estrecho $\left(\mathrm{Al}_{2} \mathrm{O}_{3} 1\right)$. Estos resultados están de acuerdo con los obtenidos por otros autores para materiales similares adquiridos del mismo proveedor (Sasol Materials) [12]. Por otro lado, el $\mathrm{VP}_{\text {macro }}$ determinado por porosimetría de $\mathrm{Hg}$ para $\mathrm{Al}_{2} \mathrm{O}_{3}{ }_{-} 4$ es de 0.11 $\mathrm{cm}^{3} / \mathrm{g}$, si bien parte de este volumen (poros entre 50 y $200 \mathrm{~nm}$ ) ya fue contabilizado en el volumen de poro total obtenido por adsorción de $\mathrm{N}_{2}$ (ver Fig. 5.3). En este punto conviene mencionar que el volumen de mesoporo $(\mathrm{DP}<50 \mathrm{~nm})$ determinado por ambas técnicas coincide razonablemente (datos no mostrados).

Tabla 5.1: Propiedades texturales de los soportes de $\mathrm{Y}-\mathrm{Al}_{2} \mathrm{O}_{3}$.

\begin{tabular}{|c|c|c|c|c|c|}
\hline \multirow[b]{2}{*}{ Soporte } & \multirow[b]{2}{*}{ Procedencia } & \multicolumn{3}{|c|}{ Adsorción $\mathrm{N}_{2}$} & \multirow{2}{*}{$\begin{array}{c}\text { Intrusión } \mathrm{Hg} \\
\mathrm{VP}_{\text {macro }} \mathrm{c} \\
\left(\mathrm{cm}^{3} / \mathrm{g}\right)\end{array}$} \\
\hline & & $\begin{array}{c}\text { Área B.E.T. } \\
\left(\mathrm{m}^{2} / \mathrm{g}\right)\end{array}$ & $\begin{array}{l}\mathrm{DP}^{\mathrm{a}} \\
(\mathrm{nm})\end{array}$ & $\begin{array}{c}V P^{b} \\
\left(\mathrm{~cm}^{3} / \mathrm{g}\right)\end{array}$ & \\
\hline $\mathrm{Al}_{2} \mathrm{O}_{3}{ }_{1}$ & (Sasol) & 254 & 6.0 & 0.48 & --- \\
\hline $\mathrm{Al}_{2} \mathrm{O}_{3} 2$ & (Sasol) & 192 & 9.1 & 0.55 & 0.04 \\
\hline $\mathrm{Al}_{2} \mathrm{O}_{3-} 3$ & (Sasol) & 157 & 21.8 & 0.98 & 0.09 \\
\hline $\mathrm{Al}_{2} \mathrm{O}_{3} 4$ & (Sasol) & 70 & 32.4 & 0.65 & 0.11 \\
\hline $\mathrm{Al}_{2} \mathrm{O}_{3} \mathrm{nf}$ & Síntesis & 321 & 16.1 & 1.29 & 0.26 \\
\hline
\end{tabular}

${ }^{a}$ Diámetro de poro.

${ }^{b}$ Volumen de poro total.

'Volumen de macroporos en el rango $50-10^{3} \mathrm{~nm}$.

De acuerdo a los resultados de porosimetría de $\mathrm{Hg}$, la muestra nanofibrosa $\mathrm{Al}_{2} \mathrm{O}_{3}$ nf presenta el mayor $\mathrm{VP}_{\text {macro }}\left(0.26 \mathrm{~cm}^{3} / \mathrm{g}\right) \mathrm{y}$, por lo tanto, la mayor contribución relativa de macroporosidad, considerando que no se detectaron macroporos para este sólido en el rango de DP analizado por 
adsorción de $\mathrm{N}_{2}$. Así pues, $\mathrm{Al}_{2} \mathrm{O}_{3}$ nf puede describirse por una porosidad bimodal conteniendo mesoporos de diámetro medio $16.1 \mathrm{~nm}$ y macroporos de diámetro medio $240 \mathrm{~nm}$, como se desprende de los resultados de adsorción de $\mathrm{N}_{2}$ y porosimetría de $\mathrm{Hg}$, respectivamente. Debido a este carácter bimodal, no se considera adecuado describir el material $\mathrm{Al}_{2} \mathrm{O}_{3} \mathrm{nf}$ mediante el DP determinado por adsorción de $\mathrm{N}_{2}(16.1 \mathrm{~nm})$, puesto que la presencia de los macroporos detectados por porosimetría de $\mathrm{Hg}$ puede tener consecuencias importantes en la cinética de los procesos difusionales intrapartícula en condiciones de SFT. Tampoco es riguroso combinar ambas técnicas de caracterización para dar lugar a un DP medio, como representativo de la porosidad del material. Por lo tanto, con el fin de evitar incongruencias al comparar las propiedades catalíticas del material nanofibroso con los catalizadores basados en soportes comerciales, en lo que sigue, se considerará $\mathrm{Al}_{2} \mathrm{O}_{3}$ nf como el soporte de mayor diámetro de poro ( $>40 \mathrm{~nm}$ ), sin asignársele un valor determinado, para tener en cuenta la importante contribución de macroporos. Para el resto de soportes comerciales se considerarán los valores de DP determinados por adsorción de $\mathrm{N}_{2}$, si bien la muestra de poro más ancho $\left(\mathrm{Al}_{2} \mathrm{O}_{3}{ }_{-} 4\right)$ presenta cierta macroporosidad.

\subsubsection{Propiedades estructurales.}

Mediante XRD se determinó que la única fase cristalina presente en

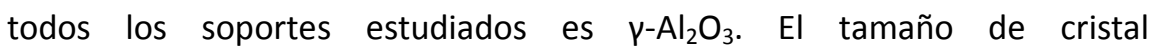
correspondiente decrece de 8.5 hasta $3.9 \mathrm{~nm}$ cuando disminuye el DP para los soportes comerciales en el orden $\mathrm{Al}_{2} \mathrm{O}_{3}{ }_{-}$a 1 . Por otro lado, la muestra nanofibrosa presenta el menor tamaño de cristal (3.5 nm), lo que puede deberse al hecho de que su síntesis tiene lugar en el confinamiento de dominios nanométricos delimitados por moléculas de surfactante. 


\subsubsection{Propiedades morfológicas.}

La morfología de los soportes basados en $\mathrm{Y}^{-\mathrm{Al}_{2} \mathrm{O}_{3}}$ se estudió por TEM y SEM.

La Fig. 5.4 muestra micrografías de TEM representativas para las cuatro $\mathrm{\gamma}-\mathrm{Al}_{2} \mathrm{O}_{3}$ comerciales y la muestra nanofibrosa. Como se observa, las muestras de poro estrecho $\left(\mathrm{Al}_{2} \mathrm{O}_{3}{ }_{-}\right.$y 2$)$ consisten en cristales nanométricos de morfología tipo "gusano" densamente ensamblados en una red porosa tridimensional. El tamaño de las partículas primarias se incrementa de 2-3 $\mathrm{x}$ 7-15 nm en $\mathrm{Al}_{2} \mathrm{O}_{3} 1$ ( $\mathrm{DP}=6.0 \mathrm{~nm}$ ) hasta $3-5 \times 10-25 \mathrm{~nm}$ en $\mathrm{Al}_{2} \mathrm{O}_{3}{ }_{-} 2$ (DP=9.1 $\mathrm{nm})$. Este tamaño se incrementa aún más hasta 7-12 x 25-40 nm para las partículas primarias con forma de nanobarras existentes en $\mathrm{Al}_{2} \mathrm{O}_{3}{ }_{3}$, cuyo DP es de $21.8 \mathrm{~nm}$. Por otro lado, la muestra comercial de mayor diámetro de poro $\left(\mathrm{Al}_{2} \mathrm{O}_{3} 4\right)$ consiste en partículas en forma de paralelepípedo, que presentan huecos internos o intra-partícula (Fig. 5.4-d) y que se ensamblan en una red bastante abierta, lo que concuerda con la presencia de macroporos en este sólido. Finalmente, las imágenes de TEM para $\mathrm{Al}_{2} \mathrm{O}_{3} \mathrm{nf}$ (Figs. 5.4-e y f) indican la presencia de nanofibras muy largas (2-3 x 20-50 $\mathrm{nm}$ ) mostrando, con diferencia, la mayor relación de aspecto de entre todos los sólidos estudiados. Las nanofibras se encuentran empaquetadas con baja densidad permitiendo la presencia de grandes huecos inter-partícula, lo que está en línea con la contribución relativamente elevada de macroporosidad para esta muestra.

En ninguno de los casos se encontraron regiones conteniendo nanopartículas de forma o tamaño marcadamente diferentes, al examinar distintas regiones a lo largo del porta-muestras. 
a)

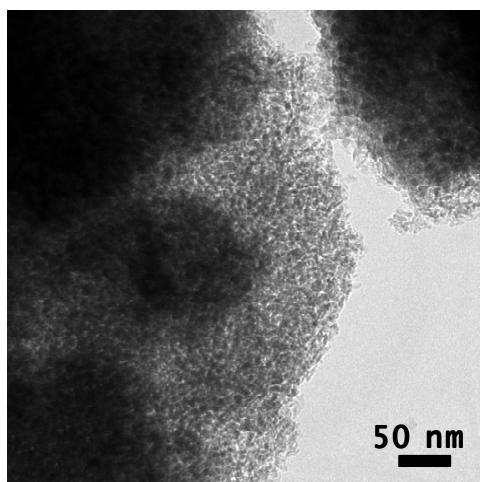

c)

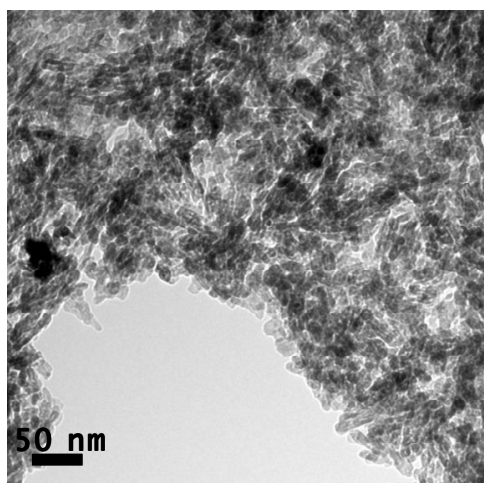

e)

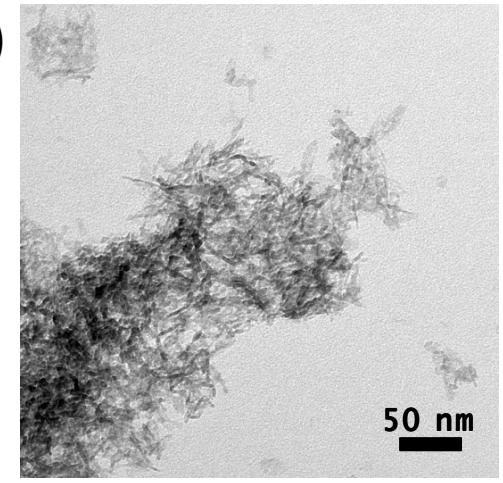

b)

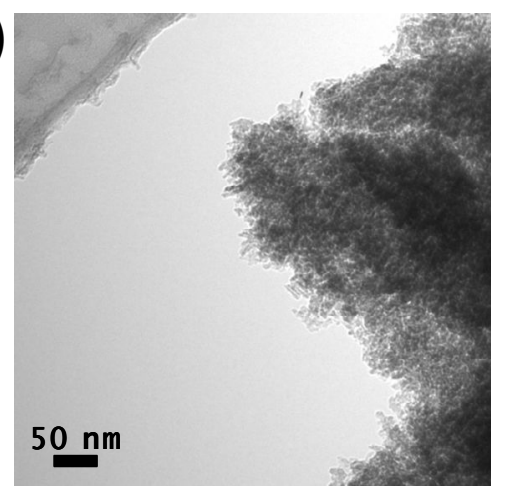

d)

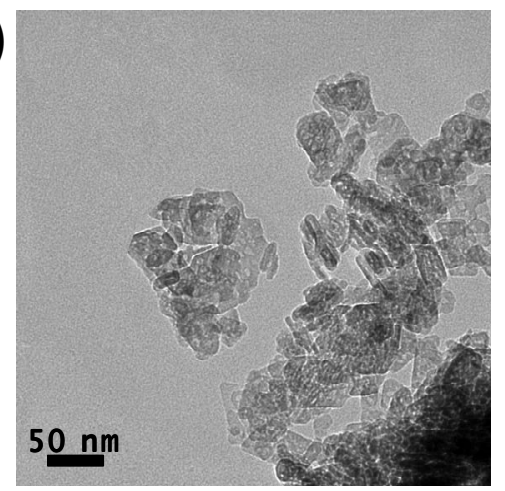

f)

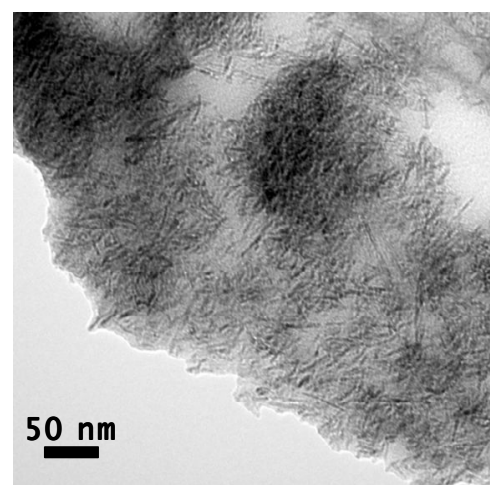

Figura 5.4: Micrografías de TEM representativas de los soportes $\mathrm{Al}_{2} \mathrm{O}_{3}{ }_{-} 1$ (a), $\mathrm{Al}_{2} \mathrm{O}_{3}$ _2 (b), $\mathrm{Al}_{2} \mathrm{O}_{3}{ }_{-} 3$ (c), $\mathrm{Al}_{2} \mathrm{O}_{3}{ }_{4} 4$ (d) y $\mathrm{Al}_{2} \mathrm{O}_{3}$ nf $(e$ y f).

La textura de la muestra nanofibrosa se estudió, a su vez, por SEM. La Fig. 5.5 muestra una micrografía representativa de la superficie de las partículas micrométricas $(45-65 \mu \mathrm{m})$ de $\mathrm{Al}_{2} \mathrm{O}_{3}$ nf. La imagen revela la presencia de macroporos de tamaño en el rango de $80-500 \mathrm{~nm}$, de acuerdo 
con los resultados de porosimetría de $\mathrm{Hg}$. Esta red de macroporos presenta un aspecto desordenado debido a la morfología corrugada de las paredes de los macroporos, como muestra el detalle de mayor magnificación incluido en la Fig. 5.5.

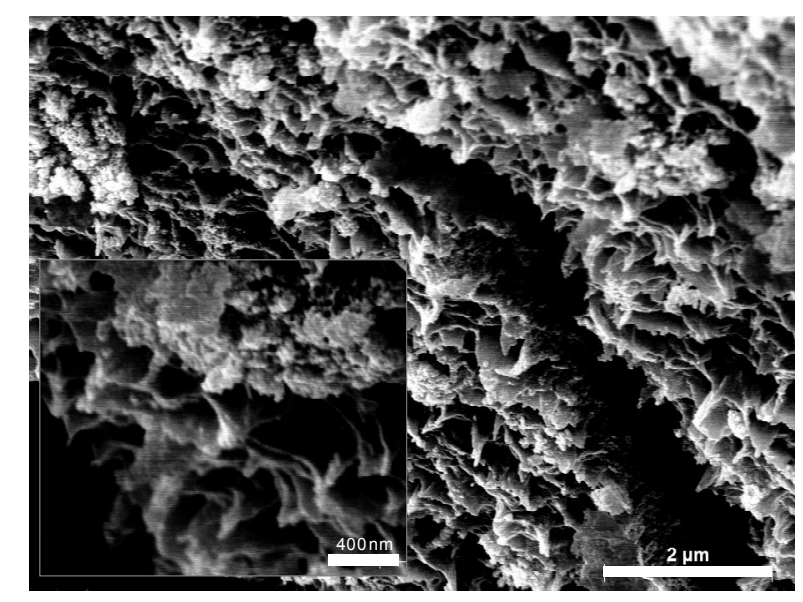

Figura 5.5: Micrografía de SEM de la superficie de las partículas de $\mathrm{Al}_{2} \mathrm{O}_{3} \_n f$. El detalle muestra una imagen a mayor magnificación de la boca de los macroporos presentes en esta muestra.

Así pues, de acuerdo a los resultados de microscopía, $\mathrm{Al}_{2} \mathrm{O}_{3}$ nf puede concebirse como un sólido con estructura porosa jerarquizada y bimodal en la que las paredes de los macroporos $(80-500 \mathrm{~nm})$ están construidas por un empaquetamiento desordenado de partículas primarias nanocristalinas de morfología fibrosa. Esta porosidad bimodal es consistente con la encontrada para otros sólidos inorgánicos sintetizados en presencia de grandes excesos de surfactante organizado en supermicelas $[10,13]$, como se mencionó en la introducción a este capítulo.

\subsubsection{Caracterización de los catalizadores $\mathrm{RuCO} / \mathrm{Al}_{2} \mathrm{O}_{3}$.}

\subsubsection{Composición química.}

Como se recoge en la Tabla 5.2, antes de la calcinación, los catalizadores $\mathrm{RuCo} / \mathrm{Al}_{2} \mathrm{O}_{3}$ presentan contenidos de nitrógeno de 5.1-5.3\% 
para la serie $20 \mathrm{Co} / \mathrm{Al}_{2} \mathrm{O}_{3}$ y de $6.6-6.9 \%$ para la serie $30 \mathrm{Co} / \mathrm{Al}_{2} \mathrm{O}_{3}$, asociados con el precursor de Co (nitrato). Tras la calcinación, el contenido en nitrógeno cae por debajo de $0.4 \%$ lo que indica la descomposición prácticamente completa del precursor durante la calcinación.

Tabla 5.2: Composición química de los catalizadores $\mathrm{RuCO} / \mathrm{Al}_{2} \mathrm{O}_{3}$.

\begin{tabular}{|c|c|c|c|c|c|c|}
\hline \multirow[t]{2}{*}{ Catalizador } & \multirow{2}{*}{$\begin{array}{c}\text { Co } \\
(\%(p))\end{array}$} & \multicolumn{3}{|c|}{$\begin{array}{c}\mathrm{Ru} \\
(\%(p))\end{array}$} & \multicolumn{2}{|c|}{$\begin{array}{c}\mathrm{N} \\
(\%(p))\end{array}$} \\
\hline & & $\mathrm{Seco}^{\mathrm{a}}$ & Calcinado & Usado $^{b}$ & Seco & Calcinado \\
\hline $20 \mathrm{Co} / \mathrm{Al}_{2} \mathrm{O}_{3}{ }_{1}$ & 20.7 & 0.58 & 0.28 & 0.24 & 5.1 & 0.3 \\
\hline $20 \mathrm{Co} / \mathrm{Al}_{2} \mathrm{O}_{3}{ }_{2} 2$ & 22.1 & 0.52 & 0.27 & 0.25 & 5.3 & 0.4 \\
\hline $20 \mathrm{Co} / \mathrm{Al}_{2} \mathrm{O}_{3}{ }_{3} 3$ & 22.3 & 0.50 & 0.28 & 0.27 & & \\
\hline $20 \mathrm{Co} / \mathrm{Al}_{2} \mathrm{O}_{3}{ }_{4}$ & 21.7 & & 0.21 & & & \\
\hline $20 \mathrm{Co} / \mathrm{Al}_{2} \mathrm{O}_{3} \mathrm{nf}$ & 21.8 & & 0.33 & & & \\
\hline $30 \mathrm{Co} / \mathrm{Al}_{2} \mathrm{O}_{3}{ }_{1}$ & 32.5 & 0.90 & 0.51 & 0.47 & 6.6 & 0.4 \\
\hline $30 \mathrm{Co} / \mathrm{Al}_{2} \mathrm{O}_{3 \_} 2$ & 33.5 & 0.92 & 0.57 & 0.45 & 6.9 & 0.3 \\
\hline $30 \mathrm{Co} / \mathrm{Al}_{2} \mathrm{O}_{3}{ }_{3} 3$ & 32.0 & & 0.48 & & & \\
\hline $30 \mathrm{Co} / \mathrm{Al}_{2} \mathrm{O}_{3}{ }_{4} 4$ & 32.4 & & 0.63 & & & \\
\hline $30 \mathrm{Co} / \mathrm{Al}_{2} \mathrm{O}_{3} \_\mathrm{nf}$ & 32.8 & & 0.54 & & & \\
\hline
\end{tabular}

La Tabla 5.2 recoge, a su vez, los contenidos metálicos en Co y Ru determinados por ICP-OES para los catalizadores calcinados. En el caso del $\mathrm{Ru}$, el contenido metálico se determinó también en muestras seleccionadas antes de la calcinación (catalizador seco) y después del ensayo catalítico (catalizador usado). Se observa que los contenidos experimentales de Co superan ligeramente el valor nominal $(20 \%$ o $30 \%)$ con desviaciones máximas del 11-12 \%. Por el contrario, para el caso del Ru, si bien los contenidos determinados en los precursores no calcinados concuerdan razonablemente con el valor nominal $\left(0.5 \%\right.$ y $1.0 \%$ para las series $20 \mathrm{Co} / \mathrm{Al}_{2} \mathrm{O}_{3}$ y $30 \mathrm{Co} / \mathrm{Al}_{2} \mathrm{O}_{3}$, respectivamente), se produce una caída drástica del $40-50 \%$ en el contenido de Ru tras la calcinación. Este fenómeno ha sido observado por otros autores en catalizadores de Ru o Co-Ru y atribuido a la formación 
de (sub)-óxidos de Ru volátiles en atmósferas de aire u oxígeno a T>200 ㄷ C $[14,15]$. Además, se observa un descenso adicional en el contenido de Ru tras el ensayo catalítico, lo que podría estar relacionado con la formación de carbonilos de Ru volátiles, en las condiciones de reacción [16]. Finalmente, no se observa pérdida alguna de Co durante la calcinación o el ensayo catalítico, al nivel de confianza de la técnica $( \pm 1 \%)$.

\subsubsection{Propiedades texturales.}

Las propiedades texturales de los catalizadores RuCo/ $/ \mathrm{Al}_{2} \mathrm{O}_{3}$ determinadas por adsorción de $\mathrm{N}_{2}$ se recogen en la tabla 5.3.

Tabla 5.3: Propiedades texturales de los catalizadores $\mathrm{RuCO} / \mathrm{Al}_{2} \mathrm{O}_{3}$.

\begin{tabular}{|c|c|c|c|}
\hline \multirow[b]{2}{*}{ Catalizador } & \multicolumn{3}{|c|}{ Adsorción $\mathrm{N}_{2}$} \\
\hline & $\begin{array}{l}\text { Área } \\
\text { B.E.T. } \\
\left(\mathrm{m}^{2} / \mathrm{g}\right)\end{array}$ & $\begin{array}{c}\text { VP } \\
\left(\mathrm{cm}^{3} / \mathrm{g}\right)\end{array}$ & $\begin{array}{c}\mathrm{DP} \\
(\mathrm{nm})\end{array}$ \\
\hline $20 \mathrm{Co} / \mathrm{Al}_{2} \mathrm{O}_{3}{ }_{1} 1$ & 196 & 0.35 & 5.9 \\
\hline $20 \mathrm{Co} / \mathrm{Al}_{2} \mathrm{O}_{3}{ }_{2} 2$ & 181 & 0.36 & 7.1 \\
\hline $20 \mathrm{Co} / \mathrm{Al}_{2} \mathrm{O}_{3}{ }_{3} 3$ & 127 & 0.58 & 15.1 \\
\hline $20 \mathrm{Co} / \mathrm{Al}_{2} \mathrm{O}_{3}{ }_{4}$ & 68 & 0.40 & 21.8 \\
\hline $20 \mathrm{Co} / \mathrm{Al}_{2} \mathrm{O}_{3} \_\mathrm{nf}$ & 231 & 0.76 & 13.3 \\
\hline $30 \mathrm{Co} / \mathrm{Al}_{2} \mathrm{O}_{3 \_} 1$ & 164 & 0.30 & 5.7 \\
\hline $30 \mathrm{Co} / \mathrm{Al}_{2} \mathrm{O}_{3}{ }_{2} 2$ & 149 & 0.31 & 7.9 \\
\hline $30 \mathrm{Co} / \mathrm{Al}_{2} \mathrm{O}_{3}{ }_{3} 3$ & 111 & 0.49 & 16.3 \\
\hline $30 \mathrm{Co} / \mathrm{Al}_{2} \mathrm{O}_{3}{ }_{4} 4$ & 66 & 0.36 & 21.1 \\
\hline $30 \mathrm{Co} / \mathrm{Al}_{2} \mathrm{O}_{3} \_\mathrm{nf}$ & 202 & 0.59 & 13.0 \\
\hline
\end{tabular}

Como cabe esperar, la incorporación de las fases metálicas de Co y Ru disminuye el área superficial específica de los materiales con respecto a los soportes originales (Tabla 5.1), siendo más pronunciado este descenso para la serie con mayor carga metálica (3-28\% para $20 \mathrm{Co} / \mathrm{Al}_{2} \mathrm{O}_{3}$, frente a $6-37 \%$ para $30 \mathrm{Co} / \mathrm{Al}_{2} \mathrm{O}_{3}$ ). A su vez, el descenso relativo del área superficial es mayor para los soportes comerciales con menor diámetro de poro $\left(\mathrm{Al}_{2} \mathrm{O}_{3}{ }_{-}\right.$y $\mathrm{Al}_{2} \mathrm{O}_{3}$ 2) sugiriendo que los fenómenos de bloqueo de poros son más 
probables al disminuir DP. En este punto, conviene mencionar que el descenso en el área B.E.T. para los catalizadores soportados sobre $\mathrm{Al}_{2} \mathrm{O}_{3} 4$ es incluso menor (3-6\%) que el esperado debido a la simple dilución másica por la presencia de $\mathrm{CO}_{3} \mathrm{O}_{4}$, que disminuye toda propiedad específica (por masa de catalizador), incluso sin considerar bloqueo de poros, (27\% y $41 \%$ para los catalizadores con $20 \%$ y $30 \%$ Co, respectivamente). No obstante, para un soporte con baja área superficial como $\mathrm{Al}_{2} \mathrm{O}_{3}{ }_{4}\left(70 \mathrm{~m}^{2} / \mathrm{g}\right)$, la contribución al área específica del material por parte de las nanopartículas de $\mathrm{Co}_{3} \mathrm{O}_{4}$, consideradas esféricas, con un tamaño medio de $44 \mathrm{~nm}$ (que es el valor de $d\left(\mathrm{CO}_{3} \mathrm{O}_{4}\right)$ x para $\left.20 \mathrm{Co} / \mathrm{Al}_{2} \mathrm{O}_{3} 44\right)$, es de un $31 \%$ de la superficie del soporte $\left(70 \mathrm{~m}^{2} / \mathrm{g}\right)$. De este modo, la superficie aportada por las fases metálicas no es despreciable y el efecto de dilución es menos relevante. Por su parte, los catalizadores basados en el soporte nanofibroso $\left(\mathrm{Al}_{2} \mathrm{O}_{3} \mathrm{nf}\right)$ presentan los mayores valores de área superficial para cualquiera de las dos series de catalizadores.

En lo relativo al DP, la incorporación de las fases metálicas provoca un ligero desplazamiento de las distribuciones de DP hacia menores valores, respecto de las correspondientes distribuciones para los soportes (Fig. 5.3), manteniendo, no obstante, el orden de DP que rige para los soportes (Tabla 5.1).

Finalmente, el $\mathrm{VP}_{\text {macro }}$ determinado por porosimetría de intrusión de $\mathrm{Hg}$ para los catalizadores calcinados basados en $\mathrm{Al}_{2} \mathrm{O}_{3}$ nf permanece en valores similares $\left(0.21 \mathrm{~cm}^{3} / \mathrm{g}\right)$ a los del soporte original (Tabla 5.1), una vez corregido por el efecto diluyente debido a la presencia del metal.

\subsubsection{Dispersión metálica.}

La espinela $\mathrm{CO}_{3} \mathrm{O}_{4}$ es la única fase metálica detectada en los catalizadores $\mathrm{RuCo} / \mathrm{Al}_{2} \mathrm{O}_{3}$ calcinados, no siendo visible por esta técnica 
ninguna fase cristalina asociada con Ru. La Tabla 5.4 recoge los tamaños de cristal para el óxido $\left(d\left(\mathrm{CO}_{3} \mathrm{O}_{4}\right) \mathrm{x}\right)$ y los correspondientes para el metal en forma reducida $\left(d\left(\mathrm{CO}^{\circ}\right) \mathrm{x}\right)$ derivados del análisis por XRD.

Tabla 5.4: Dispersión metálica y reducibilidad de los catalizadores $\mathrm{RuCO} / \mathrm{Al}_{2} \mathrm{O}_{3}$.

\begin{tabular}{|c|c|c|c|c|c|}
\hline \multirow{3}{*}{ Catalizador } & \multicolumn{4}{|c|}{ Dispersión metálica } & \multirow{3}{*}{$\begin{array}{l}G^{a} \\
(\%)\end{array}$} \\
\hline & \multicolumn{2}{|c|}{$\mathrm{XRD}$} & \multicolumn{2}{|c|}{ Quimis. $\mathrm{H}_{2}$} & \\
\hline & $\begin{array}{c}d\left(\mathrm{Co}_{3} \mathrm{O}_{4}\right)_{\mathrm{x}} \\
(\mathrm{nm})\end{array}$ & $\begin{array}{c}d\left(\mathrm{Co}^{0}\right)_{x} \\
(\mathrm{~nm})\end{array}$ & $\begin{array}{c}\mathrm{H}_{2, \mathrm{ads}} \\
(\mu \mathrm{mol} / \mathrm{g})\end{array}$ & $\begin{array}{c}d\left(\mathrm{Co}^{0}\right)_{\mathrm{H}} \\
(\mathrm{nm})\end{array}$ & \\
\hline $20 \mathrm{Co} / \mathrm{Al}_{2} \mathrm{O}_{3}{ }_{1} 1$ & 16.4 & 12.3 & 122 & 10.9 & 79 \\
\hline $20 \mathrm{Co} / \mathrm{Al}_{2} \mathrm{O}_{3}{ }_{2} 2$ & 17.3 & 13.0 & 144 & 11.5 & 92 \\
\hline $20 \mathrm{Co} / \mathrm{Al}_{2} \mathrm{O}_{3}{ }_{3}$ & 25.2 & 18.9 & 108 & 16.5 & 98 \\
\hline $20 \mathrm{Co} / \mathrm{Al}_{2} \mathrm{O}_{3}{ }_{4}$ & 44.7 & 33.5 & 70 & 25.2 & 99 \\
\hline $20 \mathrm{Co} / \mathrm{Al}_{2} \mathrm{O}_{3} \_\mathrm{nf}$ & 14.7 & 11.0 & 164 & 10.2 & 93 \\
\hline $30 \mathrm{Co} / \mathrm{Al}_{2} \mathrm{O}_{3}{ }_{-} 1$ & 23.5 & 17.6 & -- & -- & 86 \\
\hline $30 \mathrm{Co} / \mathrm{Al}_{2} \mathrm{O}_{3}{ }_{2} 2$ & 26.8 & 20.1 & -- & -- & 95 \\
\hline $30 \mathrm{Co} / \mathrm{Al}_{2} \mathrm{O}_{3}{ }_{3} 3$ & 31.7 & 23.8 & -- & -- & 98 \\
\hline $30 \mathrm{Co} / \mathrm{Al}_{2} \mathrm{O}_{3}{ }_{-} 4$ & 47.9 & 35.9 & -- & -- & 100 \\
\hline $30 \mathrm{Co} / \mathrm{Al}_{2} \mathrm{O}_{3} \_\mathrm{nf}$ & 16.8 & 12.6 & -- & -- & 95 \\
\hline
\end{tabular}

Como se observa, los valores de $d\left(\mathrm{CO}_{3} \mathrm{O}_{4}\right)_{x}$ exceden los valores de DP estimados por adsorción de $\mathrm{N}_{2}$ para los soportes catalíticos (Tabla 5.1). Este fenómeno ha sido descrito anteriormente para catalizadores de Co soportados en $\mathrm{SiO}_{2}$ y $\mathrm{Al}_{2} \mathrm{O}_{3}[12,17]$. De acuerdo con estos resultados previos, esta observación no excluye la localización de las nanopartículas metálicas en el interior de los poros del catalizador. En este sentido, se ha propuesto que las fases metálicas adquieren cierta morfología alargada, en lugar de la esférica ideal, lo que podría explicar la aparente contradicción entre $d\left(\mathrm{CO}_{3} \mathrm{O}_{4}\right)$ y DP [17]. Adicionalmente, estudios recientes basados en Tomografía Electrónica, que permiten una reconstrucción tridimensional de la estructura del soporte y las nanopartículas de Co en catalizadores de SFT, han llevado a la conclusión de que los modelos empleados para analizar los 
datos de adsorción de $\mathrm{N}_{2}$ simplifican demasiado las redes porosas reales, lo que podría explicar la incongruencia entre los datos de DP y tamaño de nanopartícula metálica [18]. No obstante, si bien este tipo de argumentos apuntan a que la mayor parte de las nanopartículas de $\mathrm{Co}_{3} \mathrm{O}_{4}$ podrían localizarse en el interior de la estructura porosa de los soportes, no puede descartarse la presencia de una cierta fracción de las mismas en la superficie externa de las partículas de soporte.

Como se muestra en la Tabla 5.4, para cada soporte catalítico, $d\left(\mathrm{CO}_{3} \mathrm{O}_{4}\right) \times$ se incrementa al incrementarse la carga metálica de los catalizadores. Las Figs. 5.6-a y 5.6-b recogen el impacto de las propiedades texturales del soporte en el tamaño de partícula $d\left(\mathrm{CO}_{3} \mathrm{O}_{4}\right)_{x}$ para los catalizadores $\mathrm{RuCo} / \mathrm{Al}_{2} \mathrm{O}_{3}$ calcinados. Como se observa en la Fig. 5.6-a, independientemente del nivel de carga metálica, $d\left(\mathrm{Co}_{3} \mathrm{O}_{4}\right)_{\mathrm{x}}$ crece continuamente cuando se incrementa el DP del soporte para los catalizadores basados en $\mathrm{y}^{-} \mathrm{Al}_{2} \mathrm{O}_{3}$ de origen comercial, de acuerdo con resultados previos $[12,17]$. Sin embargo, esta correlación no puede hacerse extensiva a los catalizadores basados en la muestra nanofibrosa, que muestran los menores valores de $d\left(\mathrm{CO}_{3} \mathrm{O}_{4}\right)_{x}$. La ausencia de correlación para los catalizadores soportados sobre $\mathrm{Al}_{2} \mathrm{O}_{3}$ nf se mantiene incluso si se emplea el DP de $16.1 \mathrm{~nm}$ determinado por adsorción de $\mathrm{N}_{2}$, obviándose la contribución de macroporos para este soporte. Por el contrario, cuando $d\left(\mathrm{CO}_{3} \mathrm{O}_{4}\right) \times$ se representa frente al área superficial del soporte (Fig. 5.6-b), se encuentra una correlación satisfactoria, que incluye los catalizadores nanofibrosos, en la que la dispersión metálica aumenta $\left(d\left(\mathrm{CO}_{3} \mathrm{O}_{4}\right)_{\mathrm{x}}\right.$ disminuye) al incrementarse el área B.E.T. del soporte catalítico. 


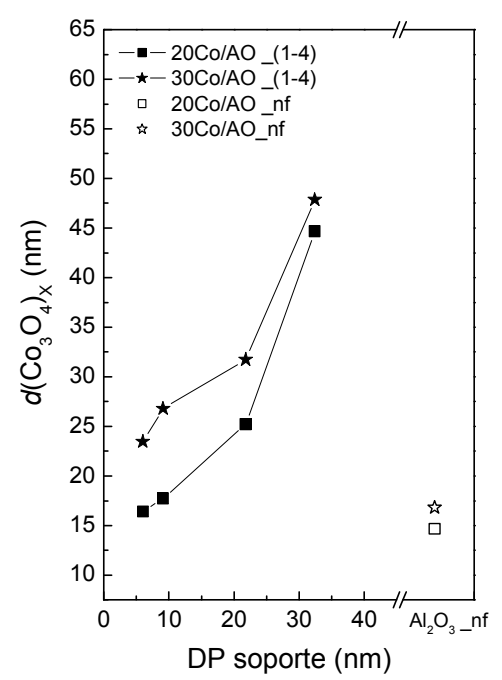

(a)

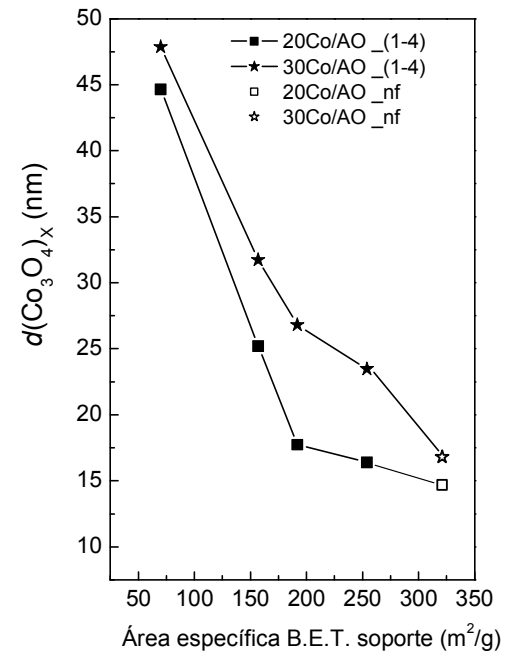

(b)

Figura 5.6: Variación del diámetro de nanopartícula de óxido de Co con el diámetro de poro (a) y el área superficial del soporte (b) para los catalizadores $\mathrm{RuCo} / \mathrm{Al}_{2} \mathrm{O}_{3}$ soportados sobre $\mathrm{\gamma}-\mathrm{Al}_{2} \mathrm{O}_{3}$ de origen comercial (símbolos cerrados) y nanofibrosa macro-mesoporosa (símbolos abiertos). En las figuras, $A O=\mathrm{Al}_{2} \mathrm{O}_{3}$.

Otros autores encontraron una correlación entre el DP del soporte y el tamaño de nanopartícula metálica $[12,17,19,20]$; sin embargo, en algunos casos, no se apreció una relación obvia del diámetro medio de nanopartícula con el área superficial del soporte [12]. Esto podría deberse al rango de valores de área superficial más limitado que se estudia en esos trabajos, utilizando soportes de origen comercial, de modo que la inclusión de la muestra nanofibrosa, con un área superficial significativamente incrementada respecto de las muestras comerciales, permite concluir en este trabajo que el área superficial del soporte, más que su DP, determinan la dispersión metálica final en los catalizadores $\mathrm{RuCo} / \mathrm{Al}_{2} \mathrm{O}_{3}$.

Los datos de quimisorción de $\mathrm{H}_{2}$ para la serie de catalizadores $20 \mathrm{Co} / \mathrm{Al}_{2} \mathrm{O}_{3}$ se recogen también en la Tabla 5.4. Se observa que los tamaños de nanopartícula $\left(d\left(\mathrm{CO}^{0}\right)_{\mathrm{H}}\right)$ están razonablemente de acuerdo con los derivados del análisis por XRD sobre los catalizadores calcinados $\left(d\left(\mathrm{Co}^{\circ}\right) \mathrm{x}\right)$, 
siendo ligeramente menores los diámetros de partícula obtenidos por quimisorción de $\mathrm{H}_{2}$, particularmente para las muestras menos dispersas $20 \mathrm{Co} / \mathrm{Al}_{2} \mathrm{O}_{3} 3$ y $20 \mathrm{Co} / \mathrm{Al}_{2} \mathrm{O}_{3}{ }_{4}$ para las que $d\left(\mathrm{Co}^{0}\right)_{\mathrm{H}}$ es aprox. un $25 \%$ menor que $d\left(\mathrm{Co}^{0}\right)_{x}$. Para el resto de catalizadores se encuentran incluso menores desviaciones relativas $(<12 \%)$. La buena concordancia entre los resultados de XRD y de quimisorción de $\mathrm{H}_{2}$ son indicativos de la ausencia de aglomeración masiva del metal durante el tratamiento de reducción en $\mathrm{H}_{2}$.

Por último, se estudió la localización y el tamaño de las nanopartículas metálicas mediante TEM en los catalizadores reducidos y pasivados. En el caso de los catalizadores de elevada dispersión metálica, como aquellos basados en el soporte nanofibroso, se requirió la adquisición de las micrografías ligeramente fuera de foco para la fase de soporte, con el fin de resaltar el contraste debido únicamente a las fases metálicas. La Fig. 5.7 muestra una imagen de TEM representativa del catalizador $20 \mathrm{Co} / \mathrm{Al}_{2} \mathrm{O}_{3}$ nf. Se observan nanopartículas de Co (indicadas con flechas) de diámetros, corregidos por la corteza de pasivado, en el rango de 8-10 nm coexistiendo con nanopartículas de mayor tamaño (10-15 nm), lo que es consistente con los resultados de XRD y quimisorción de $\mathrm{H}_{2}$ (Tabla 5.4). El detalle mostrado contiene una imagen de HRTEM en la que se observan nanopartículas de tamaño 6-9 nm mostrando orientaciones cristalográficas perpendiculares al plano cristalino $\left(\begin{array}{lll}1 & 1 & 1\end{array}\right)$ de la fase $\mathrm{Co}^{0}(f c c)$, identificados por un espaciado interplanar de $2.05 \AA$ A. Adicionalmente, para las partículas menores de $7 \mathrm{~nm}$ se observan los patrones de espaciado interplanar típicos del plano cristalino $\left(\begin{array}{lll}2 & 0 & 0\end{array}\right)$ de la fase $\mathrm{CoO}$, lo que indica re-oxidación completa de las nanopartículas de menor tamaño en las condiciones de pasivado empleadas. 


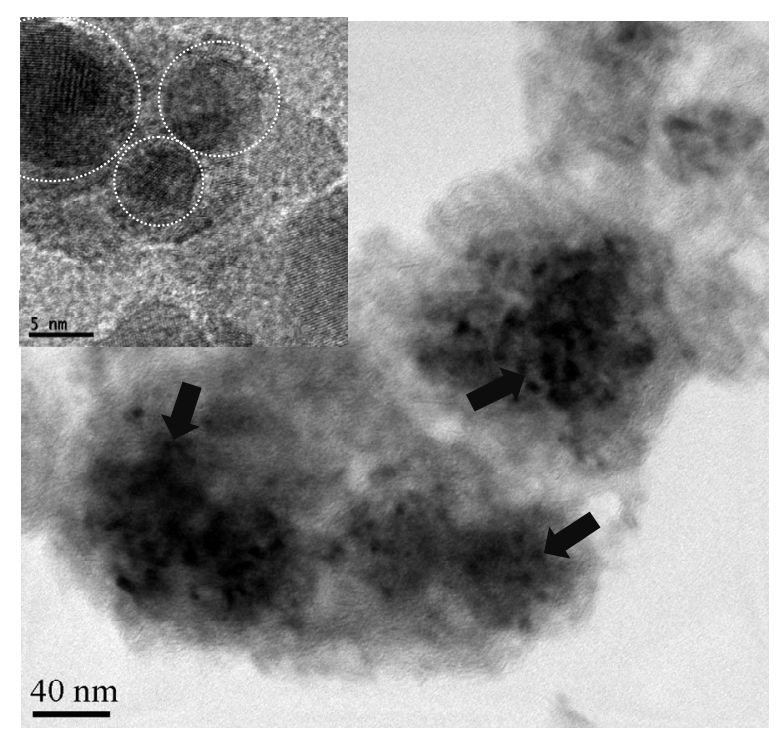

Figura 5.7: Imagen de TEM de media magnificación para el catalizador $20 \mathrm{Co} / \mathrm{Al}_{2} \mathrm{O}_{3}$ _nf reducido y pasivado. Como detalle se incluye una imagen de HRTEM mostrando nanopartículas de $\mathrm{Co}$, de las cuales, las de menor tamaño aparecen re-oxidadas a $\mathrm{CoO}$.

Adicionalmente, se realizaron medidas de EDX en regiones previamente examinadas en el modo imagen con el fin de confirmar la identificación de las fases metálicas y conocer con más detalle su posición

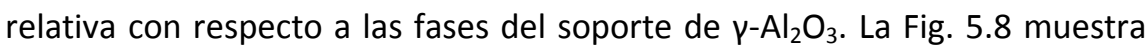
una imagen de TEM de media resolución para el catalizador de baja superficie específica $20 \mathrm{Co} / \mathrm{Al}_{2} \mathrm{O}_{3} 4$, junto con los perfiles de composición obtenidos por EDX para C (debido al film de la rejilla de TEM), Al, Co y O. Se puede observar que la asignación de los puntos de mayor contraste (en el modo imagen) a las especies metálicas está de acuerdo con los resultados de EDX. En este caso las nanopartículas presentan tamaños en el rango 21-37 $\mathrm{nm}$, también de acuerdo con los resultados de XRD y quimisorción de $\mathrm{H}_{2}$. Además, a la vista de la Fig. 5.8, las nanopartículas metálicas se encuentran, prácticamente en su totalidad, en el interior de la estructura porosa del soporte formada por las partículas primarias de $\mathrm{y}-\mathrm{Al}_{2} \mathrm{O}_{3} 4$. De este modo, se confirma la presencia de las fases metálicas en el interior de los poros del 
soporte, incluso en los catalizadores de baja área superficial, para los que la relación entre área superficial porosa y área externa es menor.
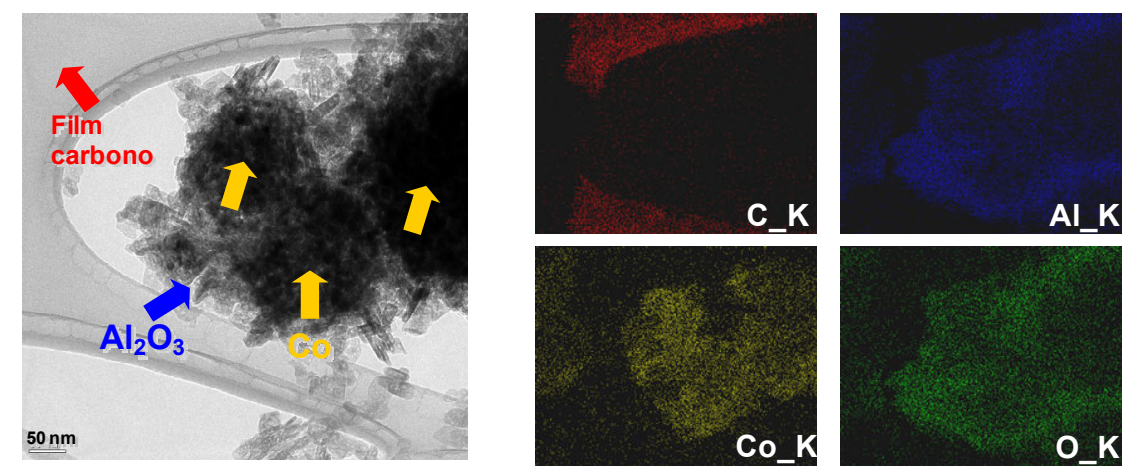

Figura 5.8: Imagen de TEM de media resolución para el catalizador $20 \mathrm{Co} / \mathrm{Al}_{2} \mathrm{O}_{3}{ }_{4} 4$ reducido y pasivado y perfiles de concentración obtenidos por EDX para $C, A l$, Co y $O$ en la misma región.

\subsubsection{Reducibilidad.}

La Fig. 5.9 muestra los perfiles de $\mathrm{H}_{2}$-TPR para las dos series de catalizadores $20 \mathrm{Co} / \mathrm{Al}_{2} \mathrm{O}_{3}$ y $30 \mathrm{Co} / \mathrm{Al}_{2} \mathrm{O}_{3}$. Para facilitar su análisis, las muestras se han ordenado verticalmente de acuerdo a $d\left(\mathrm{Co}^{0}\right)_{x}$, cuyos valores se incluyen también en la figura. Como es típico de la fase $\mathrm{Co}_{3} \mathrm{O}_{4}$ soportada, todos los catalizadores muestran dos señales de consumo de $\mathrm{H}_{2}$ principales, con máximos alrededor de $230^{\circ} \mathrm{C}$ (señal I a $\mathrm{T}_{1, \max }$ ) y en el rango $350-400^{\circ} \mathrm{C}$ (señal II a $\mathrm{T}_{2, \max }$ ) que corresponden con la reducción de $\mathrm{Co}_{3} \mathrm{O}_{4} \rightarrow \mathrm{CoO}$ y la reducción subsecuente de $\mathrm{CoO} \rightarrow \mathrm{Co}^{\circ}$, respectivamente. La relación de área (proporcional al consumo de $\mathrm{H}_{2}$ ) entre la segunda y la primera de estas señales es (1.7-3) sistemáticamente menor que el correspondiente a la relación estequiométrica ideal de 3 , lo que puede ser debido a una contribución extra en la señal I debida a la reducción de especies de Ru o la descomposición de la pequeña parte del precursor $\mathrm{Co}\left(\mathrm{NO}_{3}\right)_{2}$ que permanece en las muestras calcinadas, según se evidenció por la presencia de $\mathrm{N}$ en las mismas (Tabla 5.2). La ausencia de procesos de reducción a temperaturas superiores a $550 \circ \mathrm{C}$ descarta la presencia de especies de aluminato de Co, de 
baja reducibilidad, lo que puede atribuirse a la presencia de $\mathrm{Ru}$ como promotor de reducibilidad para las fases de Co.

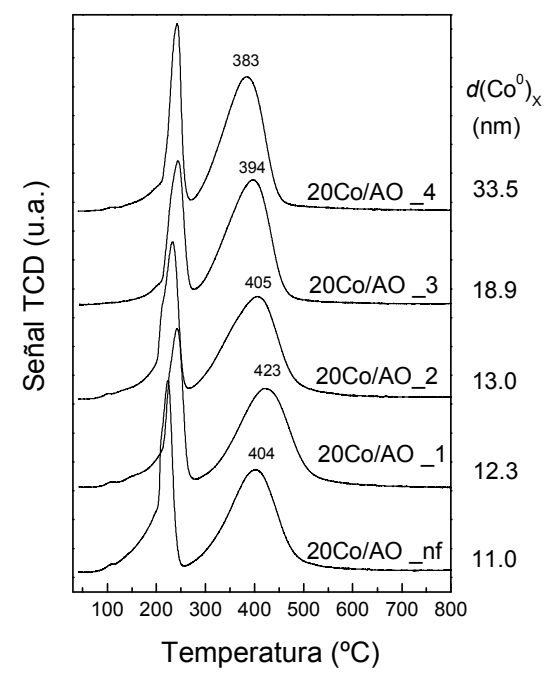

(a)

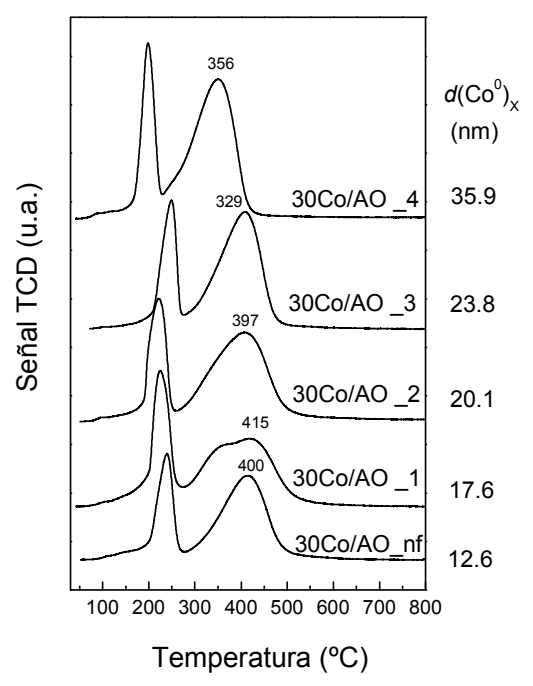

(b)

Figura 5.9: Perfiles de $\mathrm{H}_{2}$-TPR para los catalizadores $20 \mathrm{Co} / \mathrm{Al}_{2} \mathrm{O}_{3}$ (a) y $30 \mathrm{Co} / \mathrm{Al}_{2} \mathrm{O}_{3}$ (b).

Como se observa en los perfiles de las Figs. 5.9-a y b, la temperatura $T_{1, \max }$ varía ligeramente y de manera poco sistemática con el tamaño de nanopartícula, mientras que $T_{2, \max }$ muestra un comportamiento sistemático para todos los catalizadores basados en $\mathrm{y}^{-} \mathrm{Al}_{2} \mathrm{O}_{3}$ comerciales, de modo que $\mathrm{T}_{2, \max }$ disminuye cuando se incrementa $d\left(\mathrm{Co}^{0}\right)_{\mathrm{x}}$. Este comportamiento concurre con resultados previos [21] y suele relacionarse con un incremento en la interacción-metal soporte que dificulta la reducción $\mathrm{CoO} \rightarrow \mathrm{Co}^{\circ}$ en las nanopartículas de menor tamaño. Este hecho también explica que, para el mismo soporte catalítico, las muestras con mayor carga metálica (serie $30 \mathrm{Co} / \mathrm{Al}_{2} \mathrm{O}_{3}$ ) presentan menores valores para $\mathrm{T}_{2, \max }$ que los correspondientes catalizadores con menor contenido metálico, debido a la menor dispersión metálica de las primeras. Sin embargo, además del efecto del diámetro de nanopartícula metálica (interacción metal-soporte), se ha propuesto la 
influencia del tiempo de residencia del $\mathrm{H}_{2} \mathrm{O}$ formada durante la reducción en los poros del catalizador sobre la activación de los procesos reductivos en catalizadores metálicos $[22,23]$. De manera interesante, los catalizadores basados en el soporte de $\mathrm{\gamma}-\mathrm{Al}_{2} \mathrm{O}_{3}$ nanofibrosa se desvían de la tendencia mencionada entre $d\left(\mathrm{CO}^{0}\right)$ y y $T_{2, \max }$ y muestran valores de $T_{2, \max }$ inferiores (15$19{ }^{\circ} \mathrm{C}$, dependiendo de la carga metálica) respecto de catalizadores equivalentes soportados en la $\mathrm{\gamma}-\mathrm{Al}_{2} \mathrm{O}_{3}$ comercial de poro más estrecho $\left(\mathrm{Al}_{2} \mathrm{O}_{3}{ }_{3}\right)$ aún cuando los catalizadores nanofibrosos muestran menor $d\left(\mathrm{CO}^{0}\right) \mathrm{x}$. Este comportamiento anómalo puede explicarse en base a la estructura porosa bimodal del soporte nanofibroso, que contiene una contribución importante de macroporos, lo que facilita la evacuación del $\mathrm{H}_{2} \mathrm{O}$ formada durante la reducción, mejorando la cinética del proceso de reducción $\mathrm{CoO} \rightarrow \mathrm{Co}^{\circ}$.

Los grados de reducción (GR) tras el tratamiento de 10 horas a $400 \circ \mathrm{C}$ en flujo de $\mathrm{H}_{2}$ al que se someten los catalizadores antes del ensayo catalítico se incluyen en la Tabla 5.4. Como se observa, en todos los casos se alcanzan grados de reducción muy elevados (>80\%) y, por lo tanto, se espera una fracción muy baja de especies metálicas no reducidas en los catalizadores durante los ensayos catalíticos. A su vez, se observa un paralelismo entre el GR alcanzado y el valor de $T_{2, \max }$ en el perfil de TPR para todas las muestras, siendo los catalizadores preparados sobre el soporte comercial de poro estrecho, que aúnan una elevada dispersión metálica con una menor capacidad para evacuar por difusión el $\mathrm{H}_{2} \mathrm{O}$ formada, los que muestran los menores valores de GR (79-86\%, dependiendo de la carga metálica). Así pues, el grado de reducción de los catalizadores metálicos es consecuencia de un efecto combinado de dispersión metálica y porosidad. La porosidad bimodal del soporte $\mathrm{Al}_{2} \mathrm{O}_{3}$-nf permite obtener los catalizadores más dispersos, manteniendo grados de reducción superiores a los catalizadores 
de mayor dispersión obtenidos sobre los soportes comerciales de poro estrecho.

A modo de resumen parcial, de todos los resultados de caracterización presentados para los catalizadores $\mathrm{RuCo} / \mathrm{Al}_{2} \mathrm{O}_{3}$ se desprende que la original textura del soporte macro-mesoporoso de morfología nanofibrosa da lugar a catalizadores que combinan el mayor DP con la mayor dispersión metálica, al contrario de lo que puede obtenerse utilizando los soportes comerciales de morfologías más convencionales. Esta propiedad particular de los catalizadores nanofibrosos, junto con la variación coherente de las características físico-químicas para los catalizadores de referencia basados en soportes comerciales, nos coloca en posición de poder estudiar los efectos relativos que la dispersión metálica y la estructura porosa tienen sobre el comportamiento catalítico de los catalizadores de Co en condiciones de SFT. Las propiedades catalíticas de estos materiales se examinan en detalle en la siguiente sección.

\subsubsection{Resultados catalíticos.}

La Fig. 5.10 muestra la evolución de la conversión catalítica con el tiempo de reacción para un experimento catalítico extendido, de 100 horas de duración total, llevado a cabo con el catalizador $30 \mathrm{Co} / \mathrm{Al}_{2} \mathrm{O}_{3}$ 3. A la vista de la monotonía de la representación, el experimento completo se puede dividir, conceptualmente, en tres etapas diferentes denominadas (1), (2) y (3) en la figura. En un experimento catalítico típico de los recogidos en esta memoria, la duración total del ensayo (16 horas) coincide con la duración de las etapas denominadas (1) y (2). El ensayo catalítico extendido ofrece información adicional en cuanto al comportamiento del catalizador para tiempos de operación mayores, más representativos de una operación a escala piloto, por ejemplo. 
Se observa que la conversión de CO decrece de manera más acusada (aprox. 2.2\%/h) durante las primeras 6-7 horas de reacción, para seguidamente modificar su tendencia bruscamente y estabilizarse en la etapa (2) en la que la pérdida de actividad es mucho menos pronunciada (aprox. 0.2-0.3\%/h). Esta pérdida de actividad se mantiene el resto del experimento (etapa (3)), hasta dar lugar a una pérdida de actividad global de aprox. el 32\% de la actividad inicial, después de $100 \mathrm{~h}$ de operación.

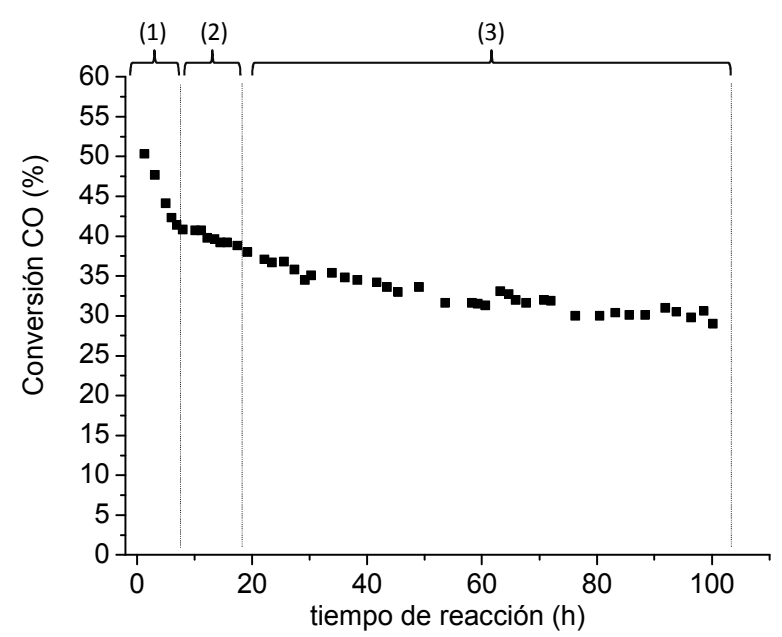

Figura 5.10: Evolución de la conversión de CO con el tiempo de reacción para un experimento catalítico extendido, de 100 horas de duración, para el catalizador $30 \mathrm{Co} / \mathrm{Al}_{2} \mathrm{O}_{3}{ }_{3}$.

Las diferencias en las pendientes de la representación para la etapa (1) y las etapas (2) y (3) evidencia que los procesos que provocan la pérdida de actividad han de ser diferentes. Por un lado, el descenso de conversión acusado que tiene lugar en la etapa (1), denominada en esta memoria estado transitorio, está relacionado con el llenado de los poros del catalizador con hidrocarburos líquidos, lo que introduce restricciones difusionales para el $\mathrm{CO}$ tan importantes como para producir un descenso de la actividad catalítica a pesar de que la reacción de Fischer-Tropsch presenta una dependencia cinética negativa con respecto a la fugacidad del CO [24]. 
Cuando se completa el llenado de los poros, se alcanza lo que se denomina en esta memoria el estado pseudo-estacionario, que es aquel en el que se evalúa la selectividad catalítica, puesto que es representativo de la mayoría del tiempo de operación del catalizador. La velocidad de disminución de la actividad catalítica que se observa para las etapas (2) y (3) concuerda con la observada en ensayos más prologados, a escala industrial [25], y está relacionada con la desactivación del catalizador.

Puesto que, a excepción de éste, los ensayos catalíticos recogidos en esta memoria duran 16 horas, éstos permiten analizar las etapas (a) (estado transitorio) y (b) (estado pseudo-estacionario), mientras que no contemplan la desactivación del catalizador, que es un fenómeno típicamente relacionado con operaciones de larga duración.

\subsubsection{Estado transitorio.}

Las Figs. 5.11, 5.12 y 5.13 muestran la evolución del CTY y la relación másica olefina/parafina (O/P) para los hidrocarburos en el rango $C_{5}-C_{7}$ con el tiempo de reacción, para los catalizadores $20 \mathrm{Co} / \mathrm{Al}_{2} \mathrm{O}_{3}{ }_{-} 1,20 \mathrm{Co} / \mathrm{Al}_{2} \mathrm{O}_{3} 4$ y $20 \mathrm{Co} / \mathrm{Al}_{2} \mathrm{O}_{3} \_\mathrm{nf}$, respectivamente. 


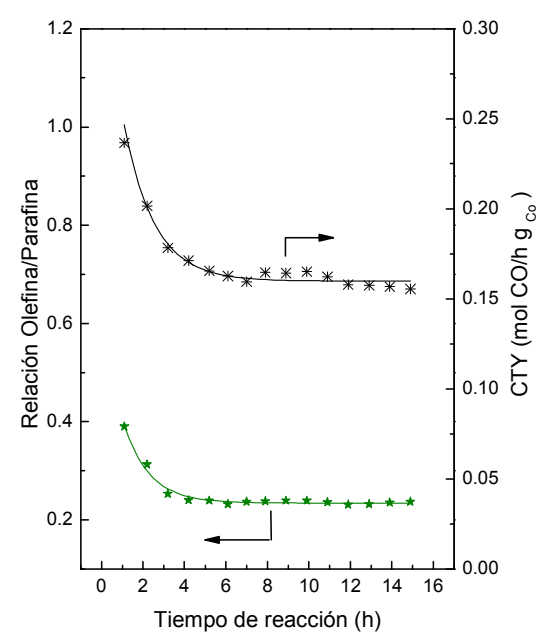

Figura 5.11: Evolución de la relación másica olefina/parafina (O/P) y el rendimiento temporal por masa de Co (CTY) con el tiempo de reacción para el catalizador $20 \mathrm{Co} / \mathrm{Al}_{2} \mathrm{O}_{3}{ }_{4}$.

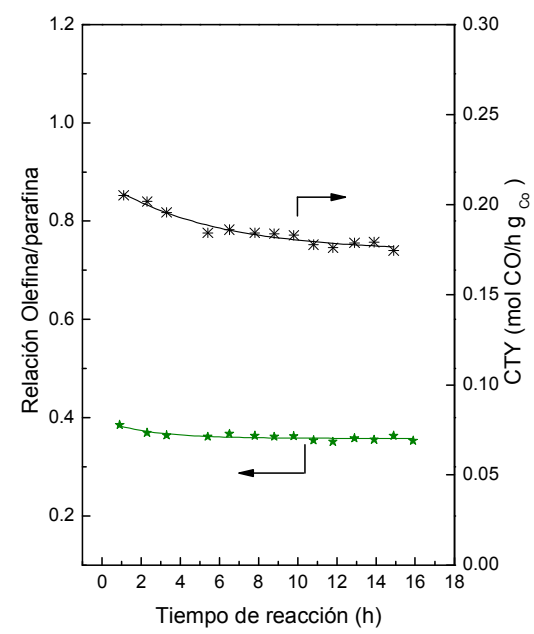

Figura 5.12: Evolución de la relación másica olefina/parafina $(O / P)$ y el rendimiento temporal por masa de Co (CTY) con el tiempo de reacción para el catalizador $20 \mathrm{Co} / \mathrm{Al}_{2} \mathrm{O}_{3}{ }_{-}$. 


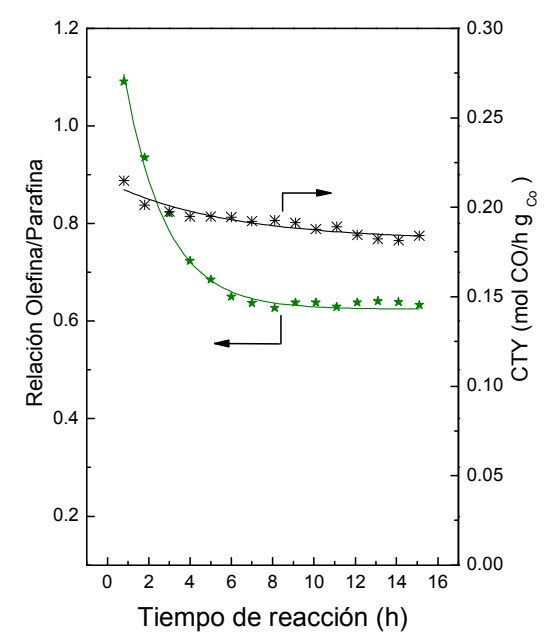

Figura 5.13: Evolución de la relación másica olefina/parafina $(O / P)$ y el rendimiento temporal por masa de Co (CTY) con el tiempo de reacción para el catalizador $20 \mathrm{Co} / \mathrm{Al}_{2} \mathrm{O}_{3} \_n f$.

Se observa un descenso inicial en la actividad mucho más acusado para el catalizador preparado sobre el soporte comercial de poro estrecho $\left(20 \mathrm{Co} / \mathrm{Al}_{2} \mathrm{O}_{3}{ }_{1}\right)$ que para el correspondiente catalizador soportado sobre $\psi$ $\mathrm{Al}_{2} \mathrm{O}_{3}$ comercial de poro ancho $\left(20 \mathrm{Co} / \mathrm{Al}_{2} \mathrm{O}_{3} 4\right)$. Es interesante, a su vez, que existe un cambio en la relación O/P que transcurre de manera paralela a la evolución de la actividad catalítica, de modo que ambas variaciones se atenúan al finalizar el estado transitorio del experimento (para $t>6 \mathrm{~h}$ ). Para los catalizadores $20 \mathrm{Co} / \mathrm{Al}_{2} \mathrm{O}_{3} 2$ y 3 , cuyo DP es intermedio, se observan comportamientos intermedios (no mostrados). El incremento del descenso relativo en CTY y relación O/P durante este periodo inicial, al pasar de $20 \mathrm{Co} / \mathrm{Al}_{2} \mathrm{O}_{3} 4$ a $20 \mathrm{Co} / \mathrm{Al}_{2} \mathrm{O}_{3}{ }_{-} 1$, refleja la importancia creciente de la resistencia difusional intra-partícula para el CO y las $\alpha$-olefinas producidas, a través de la capa de hidrocarburos líquidos que rellena progresivamente los poros del catalizador durante este periodo transitorio, cuando se disminuye el DP del soporte catalítico $[26,27]$. Por otro lado, el catalizador basado en $\gamma^{-}$ $\mathrm{Al}_{2} \mathrm{O}_{3}$ nanofibrosa muestra un descenso relativo del CTY limitado durante las primeras horas de reacción, comportándose, en este sentido, como un 
catalizador comercial de poro ancho. De manera contraria, se observa un descenso marcado de la relación O/P durante el estado transitorio para este catalizador, recordando el comportamiento del catalizador comercial de poro estrecho $\left(20 \mathrm{Co} / \mathrm{Al}_{2} \mathrm{O}_{3}\right.$ 1), si bien, mostrando valores absolutos de la relación O/P casi 4 veces superiores a los encontrados para $20 \mathrm{Co} / \mathrm{Al}_{2} \mathrm{O}_{3} \_1$ y aprox. el doble de los encontrados para $20 \mathrm{Co} / \mathrm{Al}_{2} \mathrm{O}_{3}{ }_{3} 4$. El descenso inicial de la relación O/P para este catalizador puede explicarse por la porosidad bimodal que presenta el soporte nanofibroso, de modo que se incrementa sensiblemente la re-adsorción de $\alpha$-olefinas debido a su mayor tiempo de difusión en los mesoporos de aprox. $16 \mathrm{~nm}$, cuando éstos se llenan de hidrocarburos líquidos.

A modo de conclusión parcial, puede decirse que la porosidad del soporte determina en gran medida la evolución de la actividad y la selectividad durante las primeras horas del ensayo catalítico, correspondientes al denominado estado transitorio.

\subsubsection{Estado pseudo-estacionario.}

Puesto que un catalizador trabajará en el estado pseudo-estacionario la mayor parte de su vida útil, es de vital importancia determinar las implicaciones que la dispersión metálica y la textura porosa del catalizador puedan tener en la actividad y la selectividad de la SFT durante esta etapa. Como se mencionó en el apartado anterior, el valor relativo de la relación O/P a partir de las 6 horas de experimento, es decir, durante el estado pseudo-estacionario, está directamente relacionada con las restricciones difusionales para las $\alpha$-olefinas formadas como productos primarios, en su transporte intra-partícula hacia la fase gas externa, lo que determina la probabilidad para su re-adsorción. La influencia que tiene la estructura porosa del soporte en este proceso se percibe claramente en la Fig. 5.14 en 
la que se representa la relación $\mathrm{O} / \mathrm{P}$ en estado pseudo-estacionario para productos de reacción de diferente longitud de cadena $\left(\mathrm{C}_{5}-\mathrm{C}_{9}\right)$ frente al DP del soporte catalítico, para los catalizadores pertenecientes a la serie $20 \mathrm{Co} / \mathrm{Al}_{2} \mathrm{O}_{3}$.

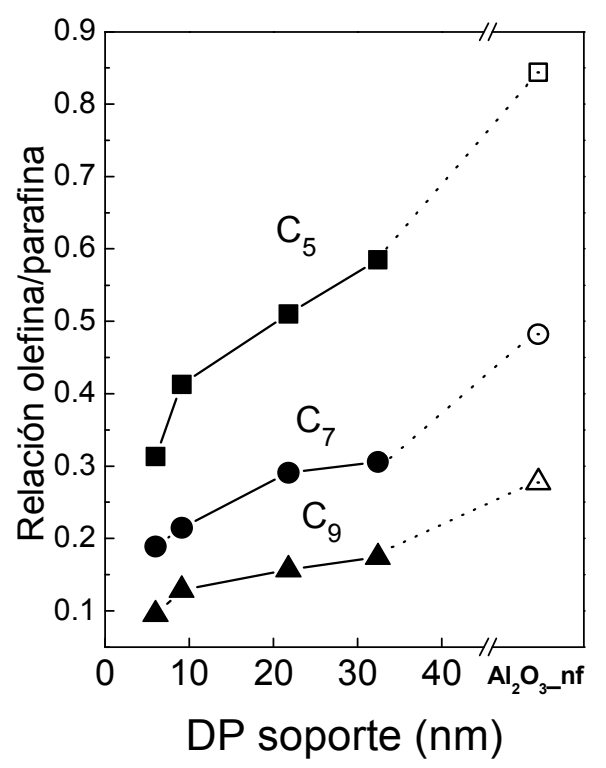

Figura 5.14: Relación másica olefina/parafina $(O / P)$ en el estado pseudo-estacionario para los productos con longitud de cadena $C_{5}, C_{7}$ y $C_{9}$ en función del diámetro de poro del soporte para los catalizadores $20 \mathrm{Co} / \mathrm{Al}_{2} \mathrm{O}_{3}$ preparados sobre soportes comerciales (símbolos llenos) y nanofibroso (símbolos abiertos).

Para todos los catalizadores, la relación O/P decrece cuando se incrementa la longitud de cadena del hidrocarburo, de $C_{5}$ a $C_{9}$, debido a un incremento en el tiempo de residencia intra-partícula para los productos de mayor peso molecular (y menor coeficiente de difusión), lo que incrementa la probabilidad de sufrir re-adsorción y posteriores etapas cinéticas de inserción en cadena e hidrogenación (para desorberse en forma de parafina) sobre los centros activos metálicos [26]. Además, para una longitud de cadena determinada, la relación $\mathrm{O} / \mathrm{P}$ crece a medida que se incrementa el DP del soporte, evidenciando una mayor velocidad de transporte intra- 
partícula para las $\alpha$-olefinas a través de poros de mayor diámetro. Para las $\gamma$ $\mathrm{Al}_{2} \mathrm{O}_{3}$ comerciales este efecto es más marcado en el rango de DP entre $6.0 \mathrm{y}$ $9.1 \mathrm{~nm}$ que para mayores tamaños de poro. Por otro lado, el catalizador preparado sobre el soporte de estructura porosa macro-mesoporosa, muestra un valor de la relación O/P significativamente mayor que todos los catalizadores preparados sobre soportes comerciales. Este hecho manifiesta claramente la importante contribución de los macroporos en la evacuación por difusión de los productos de reacción hacia afuera de los pellets del catalizador, lo que reduce la probabilidad de re-adsorción para las $\alpha$ olefinas. Estos resultados, refuerzan la asignación del mayor valor de DP al soporte $\mathrm{Al}_{2} \mathrm{O}_{3}$ nf, realizada en la sección 5.3.1 en base a los resultados de porosimetría de Hg y SEM.

Además de los fenómenos difusionales asociados con la porosidad del catalizador, la posible influencia del diámetro de nanopartícula metálica en la actividad y selectividad de la SFT catalizada por Co es una de las materias que despierta mayor interés científico en la actualidad. El capítulo 3 de esta memoria ha demostrado que el tamaño de nanopartícula metálica determina en gran medida la actividad intrínseca y la selectividad de la síntesis. No obstante, en condiciones en las que los fenómenos difusionales son cinéticamente relevantes, la importancia relativa de la dispersión metálica y la porosidad a la hora de determinar la actividad y selectividad del proceso catalítico son desconocidas. Esto es así en gran parte porque dispersión y porosidad suelen ser parámetros interrelacionados en los catalizadores con morfologías convencionales, debido al acoplamiento entre superficie específica y DP (ver Fig. 5.6-a). En este estudio, la singular morfología del soporte catalítico nanofibroso permite aunar la mayor dispersión metálica y la menor barrera difusional intra-partícula de la serie de catalizadores estudiados. Además, la elevada reducibilidad que presentan 
todos los catalizadores, descarta efectos significativos en catálisis por parte de fases de Co no reducidas. Todas estas características hacen del conjunto de catalizadores preparados un sistema ideal para elucidar la importancia relativa de la dispersión metálica y la transferencia de materia intra-pellet en la actividad y selectividad de la SFT en condiciones realistas de operación.

La Fig. 5.15 representa la selectividad a $\mathrm{CH}_{4}$ inicial (extrapolada a $\mathrm{t}_{\mathrm{r}}=0$ ) y en estado pseudo-estacionario en función del diámetro de nanopartícula metálica para la serie de catalizadores $20 \mathrm{Co} / \mathrm{Al}_{2} \mathrm{O}_{3}$. La selectividad inicial a $\mathrm{CH}_{4}$, en ausencia de restricciones difusionales (poros vacíos de líquidos) permanece prácticamente constante en $8.3-8.5 \%$ para $d\left(\mathrm{Co}^{\circ}\right)_{x}$ en el rango 13.0-33.5 nm, mientras que los dos catalizadores más dispersos, es decir, $20 \mathrm{Co} / \mathrm{Al}_{2} \mathrm{O}_{3} \mathrm{I}_{3}$ y $20 \mathrm{Co} / \mathrm{Al}_{2} \mathrm{O}_{3}$ nf, muestran selectividades iniciales a $\mathrm{CH}_{4}$ ligeramente superiores (9.1-9.2\%). Este resultado puede explicarse por el hecho de que las nanopartículas de Co cuyo tamaño es menor de unos 10 $\mathrm{nm}$ presentan, de manera intrínseca, una mayor selectividad a $\mathrm{CH}_{4}$, como se desprende de los resultados del capítulo 3 de esta memoria. Estos catalizadores más dispersos $\left(d\left(\mathrm{Co}^{0}\right)_{\mathrm{H}}=10.2-10.9 \mathrm{~nm}\right)$ presentarán una contribución importante de nanopartículas menores de $10 \mathrm{~nm}$. De hecho, la presencia de tales nanopartículas con $d\left(\mathrm{CO}^{0}\right)_{T}<10 \mathrm{~nm}$ se evidenció por medio de HRTEM en el catalizador nanofibroso (Fig. 5.7). 


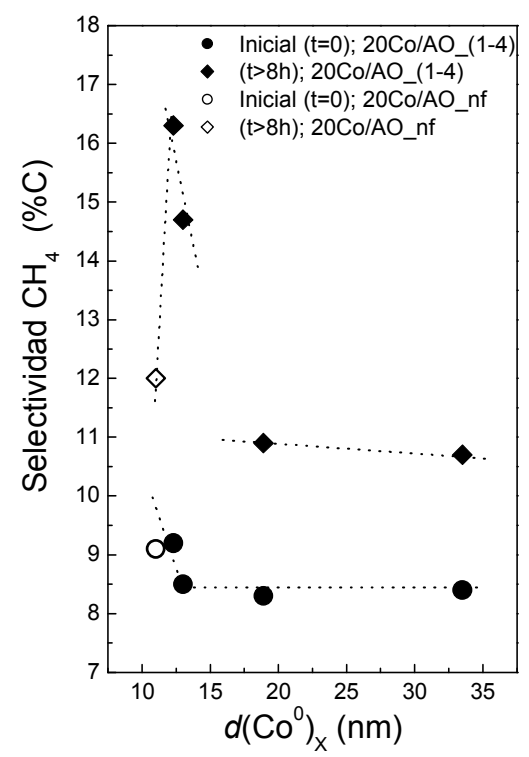

(a)

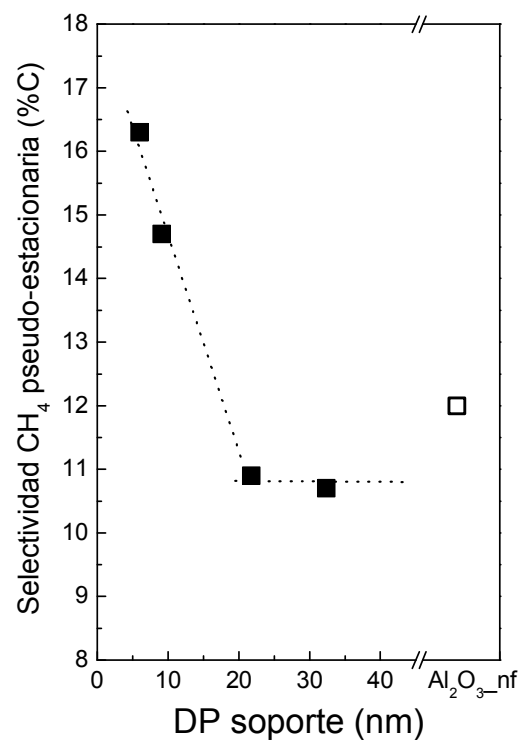

(b)

Figura 5.15: (a) Evolución de la selectividad a $\mathrm{CH}_{4}$ inicial y pseudo-estacionaria con el tamaño de nanopartícula de Co; y (b) evolución de la selectividad a $\mathrm{CH}_{4}$ pseudoestacionaria con el diámetro de poro del soporte para los catalizadores $20 \mathrm{Co} / \mathrm{Al}_{2} \mathrm{O}_{3}$ En las figuras, $\mathrm{AO}=\mathrm{Al}_{2} \mathrm{O}_{3}$.

Como se muestra también en la Fig. 5.15, la selectividad a $\mathrm{CH}_{4}$ en estado pseudo-estacionario presenta valores sistemáticamente mayores y experimenta cambios de magnitud más drásticos con $d\left(\mathrm{Co}^{\circ}\right)_{\mathrm{x}}$ (en el rango $<20 \mathrm{~nm}$ ) que la selectividad inicial a $t_{r}=0$. Además, no existe una correlación aparente entre esta selectividad pseudo-estacionaria y $d\left(\mathrm{Co}^{0}\right)_{x}$ cuando se incluye en la comparación el catalizador nanofibroso, como muestran las líneas discontinuas incluídas en la Fig. 5.15-a a modo de referencia visual. Por el contrario, si la selectividad pseudo-estacionaria a $\mathrm{CH}_{4}$ se representa frente al DP del soporte catalítico (Fig. 5.15-b) se percibe una tendencia más sistemática. Para los soportes comerciales, la selectividad a $\mathrm{CH}_{4}$ decrece desde 16.3 hasta $10.9 \%$ cuando se incrementa el DP del soporte desde 6.0 hasta $21.8 \mathrm{~nm}$ y permanece prácticamente invariante para poros de mayor tamaño $(32.4 \mathrm{~nm})$. La muestra nanofibrosa sigue aproximadamente esta 
correlación selectividad-DP, si bien presenta un valor de selectividad a $\mathrm{CH}_{4}$ pseudo-estacionaria ligeramente superior a las alúminas comerciales de poro ancho. Este efecto parece relacionado con la mayor selectividad a $\mathrm{CH}_{4}$ que muestran intrínsecamente las nanopartículas de menor tamaño $(<10$ $\mathrm{nm}$ ) presentes en esta muestra, algo que ya es evidente para los momentos iniciales de reacción (Fig. 5.15-a). Estos resultados, junto con las conclusiones presentadas en trabajos previos [27] en los que se describe que la selectividad a $\mathrm{CH}_{4}$ permanece invariante desde el comienzo del experimento catalítico en ausencia de restricciones difusionales intrapartícula para el $\mathrm{CO}$, evidencian el papel preponderante de los fenómenos de transferencia de materia intra-pellet a la hora de determinar la selectividad para la SFT en las condiciones de operación pseudoestacionarias. La tendencia mostrada por la selectividad a $\mathrm{CH}_{4}$ en condiciones estacionarias se puede racionalizar en base al incremento local de la relación $\mathrm{H}_{2} / \mathrm{CO}$ en las cercanías de los centros activos como consecuencia de las restricciones difusionales para el $\mathrm{CO}$, las cuales adquieren mayor magnitud para los catalizadores con menor DP.

La Tabla 5.5 recoge los CTY iniciales y pseudo-estacionarios así como los valores de TOF iniciales obtenidos para las dos series de catalizadores $\mathrm{RuCo} / \mathrm{Al}_{2} \mathrm{O}_{3}$. 
Tabla 5.5: Actividad catalítica de los catalizadores $\mathrm{RuCO} / \mathrm{Al}_{2} \mathrm{O}_{3}$. Condiciones de reacción: $T=220^{\circ} \mathrm{C}, P=2.0 \mathrm{MPa}, \mathrm{GHSV}=7.2 \mathrm{~L} \mathrm{~g}^{-1} \mathrm{~h}^{-1}$.

\begin{tabular}{|c|c|c|c|c|}
\hline \multirow{2}{*}{ Catalizador } & \multicolumn{3}{|c|}{$\begin{array}{l}\text { CTY } \\
\left.\text { ( CO/g } g_{\text {Co }} h\right)\end{array}$} & \multirow{2}{*}{$\begin{array}{c}\text { TOF }_{0}{ }^{d} \\
\left(10^{-2} \mathrm{~s}^{-1}\right)\end{array}$} \\
\hline & $\mathrm{CTY}_{0}{ }^{\mathrm{a}}$ & $\mathrm{CTY}_{\mathrm{e}}{ }^{\mathrm{b}}$ & $\begin{array}{c}\Delta C T Y^{\mathrm{C}} \\
(\%)\end{array}$ & \\
\hline $20 \mathrm{Co} / \mathrm{Al}_{2} \mathrm{O}_{3}{ }_{3} 1$ & 0.271 & 0.153 & 43.5 & $6.2(6.2)$ \\
\hline $20 \mathrm{Co} / \mathrm{Al}_{2} \mathrm{O}_{3}{ }_{2} 2$ & 0.285 & 0.202 & 30.0 & $6.6(5.9)$ \\
\hline $20 \mathrm{Co} / \mathrm{Al}_{2} \mathrm{O}_{3}{ }^{3} 3$ & 0.260 & 0.205 & 21.2 & $8.2(7.2)$ \\
\hline $20 \mathrm{Co} / \mathrm{Al}_{2} \mathrm{O}_{3}{ }_{3} 4$ & 0.223 & 0.185 & 17.0 & $11.8(9.3)$ \\
\hline $20 \mathrm{Co} / \mathrm{Al}_{2} \mathrm{O}_{3} \_\mathrm{nf}$ & 0.225 & 0.183 & 18.7 & $4.2(4.5)$ \\
\hline $30 \mathrm{Co} / \mathrm{Al}_{2} \mathrm{O}_{3}{ }_{1} 1$ & 0.215 & 0.128 & 40.5 & 7.1 \\
\hline $30 \mathrm{Co} / \mathrm{Al}_{2} \mathrm{O}_{3}{ }_{3} 2$ & 0.204 & 0.132 & 35.3 & 7.2 \\
\hline $30 \mathrm{Co} / \mathrm{Al}_{2} \mathrm{O}_{3}{ }_{3} 3$ & 0.202 & 0.150 & 25.7 & 8.1 \\
\hline $30 \mathrm{Co} / \mathrm{Al}_{2} \mathrm{O}_{3}{ }_{3} 4$ & 0.151 & 0.125 & 17.2 & 8.9 \\
\hline $30 \mathrm{Co} / \mathrm{Al}_{2} \mathrm{O}_{3} \_\mathrm{nf}$ & 0.224 & 0.177 & 21.0 & 5.0 \\
\hline \multicolumn{5}{|c|}{ 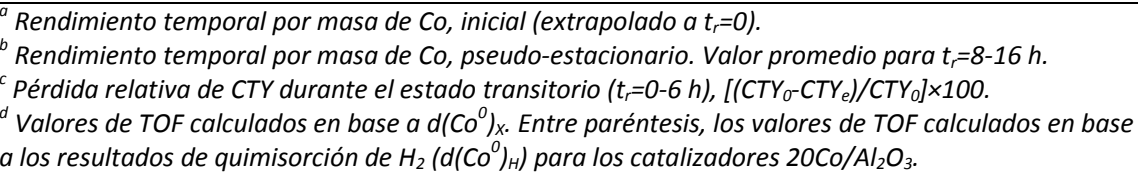 } \\
\hline
\end{tabular}

EI CTY inicial (en ausencia de relevancia cinética para fenómenos de transferencia de materia) para los catalizadores preparados sobre soportes comerciales decrece, de forma general, cuando se incrementa el DP del soporte en el orden $\mathrm{Al}_{2} \mathrm{O}_{3}{ }_{3} 1<\ldots<\mathrm{Al}_{2} \mathrm{O}_{3}{ }_{-} 4$. La muestra $20 \mathrm{Co} / \mathrm{Al}_{2} \mathrm{O}_{3} \_1$ muestra un valor de $\mathrm{CTY}_{0}$ ligeramente menor que $20 \mathrm{Co} / \mathrm{Al}_{2} \mathrm{O}_{3} 2$ a pesar de su mayor dispersión metálica (Tabla 5.4), lo cual puede atribuirse al menor grado de reducción alcanzado para el primero ( $79 \%$ frente $92 \%$, ver Tabla 5.4 ) y a su mayor proporción relativa de nanopartículas de Co de tamaño $<10 \mathrm{~nm}$ (cuyo TOF ha de ser menor, de acuerdo a los resultados del capítulo 3). La dependencia del TOF ${ }_{0}$ con el diámetro de nanopartícula sirve también para explicar el valor de $\mathrm{CTY}_{0}$ relativamente bajo que presenta el catalizador nanofibroso $20 \mathrm{Co} / \mathrm{Al}_{2} \mathrm{O}_{3}$ nf, el cual también presenta una fracción importante de nanopartículas $<10 \mathrm{~nm}$ (ver Fig. 5.7). Sin embargo, para la 
serie de catalizadores de mayor carga metálica, la muestra nanofibrosa $30 \mathrm{Co} / \mathrm{Al}_{2} \mathrm{O}_{3}$ nf es la que presenta el mayor valor de $\mathrm{CTY}_{0}$, gracias a su mayor dispersión metálica y al desplazamiento progresivo de la población de nanopartículas hacia tamaños superiores a $10 \mathrm{~nm}$ cuando se incrementa la carga metálica.

El efecto del tamaño de nanopartícula sobre la actividad intrínseca queda claro en la Fig. 5.16 en la que se representa el valor de TOF inicial frente al diámetro de nanopartícula.

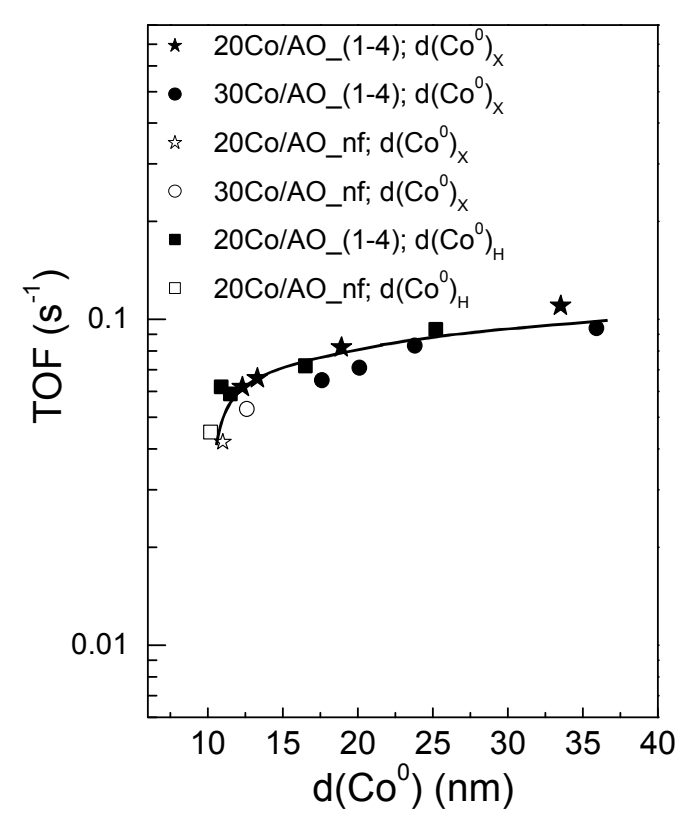

Figura 5.16: Evolución del TOF inicial con el diámetro de nanopartícula de Co (basado en XRD o quimisorción de $\mathrm{H}_{2}$ ) para los catalizadores $20 \mathrm{Co} / \mathrm{Al}_{2} \mathrm{O}_{3}$ y $30 \mathrm{Co} / \mathrm{Al}_{2} \mathrm{O}_{3}$ soportados sobre $\mathrm{r}-\mathrm{Al}_{2} \mathrm{O}_{3}$ comerciales (símbolos llenos) y nanofibrosa (símbolos vacíos).

Como se observa, el valor de $\mathrm{TOF}_{0}$ se incrementa, para ambas series de catalizadores, cuando $d\left(\mathrm{Co}^{\circ}\right)$ se incrementa en el rango de tamaños de nanopartícula $<15 \mathrm{~nm}$, donde la población de nanopartículas con $d\left(\mathrm{Co}^{\circ}\right)<10$ $\mathrm{nm}$ ha de ser mayor, especialmente para los catalizadores preparados sobre $\mathrm{v}-\mathrm{Al}_{2} \mathrm{O}_{3}$ nanofibrosa. Para mayores valores de $d\left(\mathrm{CO}^{\circ}\right)$ los cambios en el TOF se 
hacen mucho menos pronunciados, tendiéndose a alcanzar un plateau para tamaños de nanopartícula $>20 \mathrm{~nm}$, en concordancia con los resultados del capítulo 3. Merece la pena mencionar en este punto que las tendencias observadas para el TOF inicial son las mismas si éste se calcula en base a los a tamaños de partícula obtenidos por XRD o por quimisorción de $\mathrm{H}_{2}$, como se observa en la propia Fig. 5.16 para la serie de catalizadores $20 \mathrm{Co} / \mathrm{Al}_{2} \mathrm{O}_{3}$.

Por otro lado, como se muestra en la Fig. 5.17 para la serie $20 \mathrm{Co} / \mathrm{Al}_{2} \mathrm{O}_{3}$, la pérdida relativa de CTY durante el estado transitorio se incrementa continuamente desde $17 \%$ hasta $43 \%$ cuando se disminuye el DP del soporte para las muestras preparadas sobre $\mathrm{y}-\mathrm{Al}_{2} \mathrm{O}_{3}$ de origen comercial. Los catalizadores basados en el soporte nanofibroso macro-mesoporoso se comportan como soportes de poro ancho, como es de esperar de sus propiedades texturales. Esta tendencia puede relacionarse con el incremento en la cinética de transporte de CO intra-pellet cuando se incrementa DP, como se mencionó con anterioridad. Gracias a un valor de $\mathrm{CTY}_{0}$ elevado y a la limitada pérdida de actividad durante el periodo transitorio, la muestra nanofibrosa $30 \mathrm{Co} / \mathrm{Al}_{2} \mathrm{O}_{3}$ nf ofrece la mayor actividad en estado pseudo-estacionario, con un $\mathrm{CTY}_{\mathrm{e}}$ de $0.177 \mathrm{~mol} \mathrm{CO} / \mathrm{g}_{\mathrm{Co}} \cdot \mathrm{h}$, aproximadamente un $20 \%$ superior al de la muestra comercial más activa dentro de la serie $\left(30 \mathrm{Co} / \mathrm{Al}_{2} \mathrm{O}_{3} 3\right)$. 


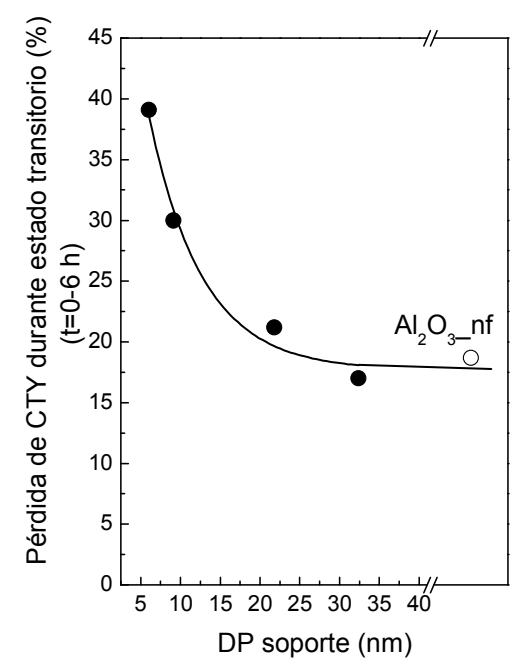

Figura 5.17: Evolución de la pérdida relativa de actividad ( $\triangle C T Y$ ) durante el estado transitorio $\left(t_{r}=0-6 h\right)$ con el diámetro de poro del soporte catalítico para los catalizadores 20Co/Al $\mathrm{O}_{3}$ soportados sobre $\mathrm{\gamma}-\mathrm{Al}_{2} \mathrm{O}_{3}$ comerciales (símbolos llenos) y nanofibrosa (símbolo vacío).

Por su parte, la Tabla 5.6 recoge las selectividades a las diferentes fracciones de hidrocarburos en estado pseudo-estacionario, a un nivel de conversión de $\mathrm{CO}$ de $40 \%$, obtenidas con los catalizadores $\mathrm{RuCo} / \mathrm{Al}_{2} \mathrm{O}_{3}$.

Tabla 5.6: Selectividad de la síntesis de Fischer-Tropsch para los catalizadores $\mathrm{RuCO} / \mathrm{Al}_{2} \mathrm{O}_{3}$. Condiciones de reacción: $T=220^{\circ} \mathrm{C}, P=2.0 \mathrm{MPa}, X_{\mathrm{CO}}=40 \pm 2 \%, \mathrm{H}_{2} / \mathrm{CO}=2$.

\begin{tabular}{|c|c|c|c|c|c|c|}
\hline \multirow[b]{2}{*}{ Catalizador } & \multicolumn{5}{|c|}{ Distribución de hidrocarburos $(\% \mathrm{C})$} & \multirow{2}{*}{ P.Diesel $^{a}$} \\
\hline & $\mathrm{C}_{1}$ & $\mathrm{C}_{2}-\mathrm{C}_{4}$ & $\mathrm{C}_{5}-\mathrm{C}_{12}$ & $\mathrm{C}_{13+}$ & $\begin{array}{l}\text { Relación } \\
C_{23+} / C_{13+}\end{array}$ & \\
\hline $20 \mathrm{Co} / \mathrm{Al}_{2} \mathrm{O}_{3}{ }_{1} 1$ & 16.3 & 12.1 & 40.8 & 30.8 & 0.22 & 76 \\
\hline $20 \mathrm{Co} / \mathrm{Al}_{2} \mathrm{O}_{3 \_} 2$ & 14.7 & 12.8 & 40.9 & 31.5 & 0.28 & 101 \\
\hline $20 \mathrm{Co} / \mathrm{Al}_{2} \mathrm{O}_{3}{ }_{3}$ & 10.9 & 9.9 & 39.0 & 40.2 & 0.34 & 121 \\
\hline $20 \mathrm{Co} / \mathrm{Al}_{2} \mathrm{O}_{3}{ }_{4}$ & 10.7 & 8.7 & 33.3 & 47.3 & 0.38 & 118 \\
\hline $20 \mathrm{Co} / \mathrm{Al}_{2} \mathrm{O}_{3} \_\mathrm{nf}$ & 12.0 & 12.5 & 40.0 & 35.5 & 0.29 & 101 \\
\hline $30 \mathrm{Co} / \mathrm{Al}_{2} \mathrm{O}_{3 \_} 1$ & 15.6 & 15.3 & 50.8 & 18.3 & 0.15 & 65 \\
\hline $30 \mathrm{Co} / \mathrm{Al}_{2} \mathrm{O}_{3 \_} 2$ & 14.7 & 16.2 & 43.7 & 25.4 & 0.16 & 94 \\
\hline $30 \mathrm{Co} / \mathrm{Al}_{2} \mathrm{O}_{3} 3$ & 12.8 & 10.6 & 38.9 & 37.7 & 0.32 & 123 \\
\hline $30 \mathrm{Co} / \mathrm{Al}_{2} \mathrm{O}_{3}{ }_{4}$ & 11.1 & 9.0 & 34.3 & 45.6 & 0.37 & 116 \\
\hline $30 \mathrm{Co} / \mathrm{Al}_{2} \mathrm{O}_{3}$ nf & 13.8 & 13.2 & 38.8 & 34.2 & 0.29 & 141 \\
\hline
\end{tabular}


Se observa que la selectividad a la fracción de hidrocarburos de cadena larga $\mathrm{C}_{13+}$, que incluye tanto la fracción más interesante en el rango de diesel $\left(C_{13}-C_{22}\right)$ como las ceras $\left(C_{23+}\right)$, se incrementa al incrementarse el DP

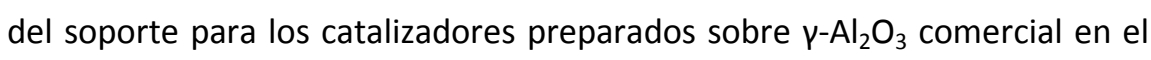
orden $\mathrm{Al}_{2} \mathrm{O}_{3}{ }_{1}$ a 4 , independientemente del nivel de carga metálica (20\% o $30 \%(\mathrm{C})$. Para los catalizadores empleados en el presente estudio, el parámetro estructural definido por Iglesia y col. $(\chi)$ toma valores en el rango de $113 \cdot 10^{16}-1350 \cdot 10^{16} \mathrm{~m}^{-1}$ en el que la selectividad de la SFT está controlada por el acceso difusional de Co hacia los centros activos [26]. Así pues, el incremento de la selectivividad a $\mathrm{C}_{13+}$ con el DP del soporte es una consecuencia de la mejora en la cinética de acceso difusional de $\mathrm{CO}$ a través de los poros rellenos de hidrocarburos líquidos y el consiguiente impacto positivo de la fugacidad de $\mathrm{CO}$, en las cercanías de los centros activos, sobre las etapas cinéticas de crecimiento de cadena [1].

Por otro lado, los catalizadores soportados sobre $\mathrm{\gamma}-\mathrm{Al}_{2} \mathrm{O}_{3}$ nanofibrosa muestran una selectividad a $\mathrm{C}_{13+}$ inferior a la de los catalizadores soportados

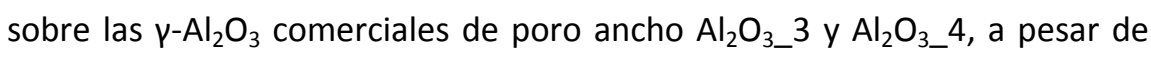
que las muestras nanofibrosas también permiten un acceso difusional facilitado de $\mathrm{CO}$, como se desprende de su valor de $\triangle \mathrm{CTY}$ durante el estado transitorio (ver Fig. 5.17). Esto es una evidencia de que otros factores a parte de los fenómenos de transferencia de CO intra-pellet tienen una influencia en la selectividad de la síntesis en estado pseudo-estacionario. En este sentido, los resultados presentados en el capítulo 3 indican que la selectividad a los productos más pesados se incrementa con el tamaño de nanopartícula de $\mathrm{Co}^{\circ}$. De forma similar, se han publicado recientemente algunas patentes en las que se reivindica una elevada selectividad a hidrocarburos de cadena larga para catalizadores de Co soportados sobre $\mathrm{Al}_{2} \mathrm{O}_{3}$ total o parcialmente cristalizada en forma de $\alpha-\mathrm{Al}_{2} \mathrm{O}_{3}$, que poseen un 
área superficial baja $\left(15-70 \mathrm{~m}^{2} / \mathrm{g}\right)$ y, por lo tanto, dan lugar a catalizadores de baja dispersión metálica, con respecto a catalizadores similares más dispersos soportados sobre $\mathrm{Al}_{2} \mathrm{O}_{3}$ de mayor superficie específica [28]. De este modo, la mayor selectividad a $\mathrm{C}_{13+}$ que muestran los catalizadores basados en $\mathrm{y}-\mathrm{Al}_{2} \mathrm{O}_{3}$ comercial de poro ancho y baja superficie específica en este estudio, puede relacionarse con una contribución debida a la mayor selectividad intrínseca hacia productos de cadena larga para las partículas de Co de mayor tamaño presentes en los mismos.

Por tanto, de los resultados anteriores puede concluirse que son dos los factores que determinan la selectividad de la SFT en estado estacionario para los catalizadores $\mathrm{RuCo} / \mathrm{Al}_{2} \mathrm{O}_{3}$ estudiados: por un lado, la relación $\mathrm{H}_{2} / \mathrm{CO}$ real en las cercanías de los centros activos que viene determinada por la velocidad de transferencia de CO intra-pellet y es una función del DP del soporte catalítico empleado; y por otro lado, el tamaño medio de nanopartícula de Co (dispersión metálica) que es función, principalmente, del área específica del soporte catalítico (Fig. 5.6-b).

En este punto conviene mencionar que la selectividad a $\mathrm{C}_{13+}$ ligeramente inferior que se observa sistemáticamente para los catalizadores de mayor carga metálica $\left(30 \mathrm{Co} / \mathrm{Al}_{2} \mathrm{O}_{3}\right)$ con respecto a la serie de menor contenido metálico $\left(20 \mathrm{Co} / \mathrm{Al}_{2} \mathrm{O}_{3}\right)$ parece debida a la mayor (aprox. un 30\%) velocidad espacial (GHSV) requerida para alcanzar el nivel de conversión del $40 \%$ en el caso de los primeros (más activos por masa de catalizador). Una mayor GHSV produce un descenso en el tiempo medio de residencia de las $\alpha$-olefinas en el lecho catalítico, disminuyendo la probabilidad de su readsorción e incorporación en cadenas en crecimiento. Para cada una de las series por separado, la variación en GHSV para alcanzar un mismo nivel de conversión del $40 \%$ debido a las diferencias en actividad, es mucho menor (3.5-6\%). Esto descarta cualquier efecto importante de la velocidad espacial 
en las tendencias de selectividad que se establecen de forma independiente para cada serie de catalizadores.

Por último, la relación de selectividades $\mathrm{C}_{23+} / \mathrm{C}_{13+}$, recogida en la Tabla 5.6, indica que las nanopartículas de Co de mayor tamaño, predominantes en los catalizadores soportados sobre $\mathrm{Al}_{2} \mathrm{O}_{3} 3$ y $\mathrm{Al}_{2} \mathrm{O}_{3}{ }_{-}$, promueven la formación de ceras $\left(\mathrm{C}_{23+}\right)$ con respecto a los catalizadores basados en soportes comerciales de poro más estrecho o en $\mathrm{\gamma}-\mathrm{Al}_{2} \mathrm{O}_{3}$ nanofibrosa. De manera interesante, los catalizadores nanofibrosos macro-mesoporosos se muestran más selectivos a la fracción de hidrocarburos en el rango del diesel $\left(\mathrm{C}_{13}-\mathrm{C}_{22}\right)$, dentro de la fracción de productos pesados $\left(\mathrm{C}_{13+}\right)$. Esto revela que la formación de productos en el rango del diesel se favorece cuando las etapas cinéticas de crecimiento de cadena se ven incentivadas tan sólo por los fenómenos de difusión intra-pellet de CO (evitando un enriquecimiento en $\mathrm{H}_{2}$ cerca de los centros activos) con soportes de porosidad muy abierta y elevada área superficial como los basados en $\mathrm{\gamma}-\mathrm{Al}_{2} \mathrm{O}_{3}$ nanofibrosa macromesoporosa, con respecto a cuando este efecto viene acompañado por una menor dispersión metálica como es el caso de los soportes comerciales de poro ancho y baja superficie específica $\left(\mathrm{Al}_{2} \mathrm{O}_{3} 3\right.$ y $\left.\mathrm{Al}_{2} \mathrm{O}_{3} 4\right)$. Como resultado de su mayor CTY inicial, su limitada pérdida de actividad durante el estado transitorio y su buena selectividad a $\mathrm{C}_{13}-\mathrm{C}_{22}$, el catalizador nanofibroso $30 \mathrm{Co} / \mathrm{Al}_{2} \mathrm{O}_{3}$ nf da lugar a la mayor productividad de hidrocarburos en el rango de diesel $\left(141 \mathrm{~mol} / \mathrm{g}_{\mathrm{cat}} \cdot \mathrm{h}\right)$, como se recoge en la última columna de la Tabla 5.6.

\subsubsection{Conclusiones.}

Las principales conclusiones que se extraen de esta primera parte de la investigación recogida en este capítulo son:

1. La síntesis de $\mathrm{y}-\mathrm{Al}_{2} \mathrm{O}_{3}$ en un medio hidrotermal, y en presencia de un 
surfactante no iónico, permite obtener un soporte catalítico que presenta simultáneamente un área superficial y un diámetro de poro superiores de los soportes de $\mathrm{y}^{-} \mathrm{Al}_{2} \mathrm{O}_{3}$ comerciales, gracias a una morfología primaria nanofibrosa y una porosidad bimodal con importante contribución de macroporos. Estas singulares propiedades texturales desacoplan, para este soporte, los parámetros de área superficial y diámetro de poro, interrelacionados inseparablemente para soportes comerciales de textura más convencional.

2. El área superficial específica del soporte es un parámetro más determinante que el diámetro de poro a la hora de determinar la dispersión metálica en los catalizadores RuCo/ $\mathrm{\gamma}-\mathrm{Al}_{2} \mathrm{O}_{3}$.

3. La actividad y selectividad catalíticas iniciales de los catalizadores RuCo/ $\mathrm{\gamma}-\mathrm{Al}_{2} \mathrm{O}_{3}$ vienen dictadas principalmente por la dispersión metálica, de acuerdo a la sensibilidad a la estructura no clásica encontrada en el capítulo 3.

4. Por el contrario, en condiciones pseudo-estacionarias y niveles de conversión industrialmente relevantes (40\%), la estructura porosa del soporte catalítico es el parámetro determinante de la actividad y la selectividad catalítica, reflejando la relevancia cinética de los fenómenos de transporte de materia intra-pellet para reactivos (CO) y productos ( $\alpha$-olefinas).

5. La elevada superficie específica y la estructura porosa abierta del soporte nanofibroso macro-mesoporoso resultan en una mayor dispersión metálica y una cinética mejorada para el transporte de materia intra-pellet, respectivamente, en relación a los catalizadores preparados sobre soportes comerciales. 
6. Los beneficios de emplear el soporte de $\mathrm{y}-\mathrm{Al}_{2} \mathrm{O}_{3}$ nanofibroso macromesoporoso se manifiestan para cargas metálicas elevadas (30\%Co), típicas de los catalizadores empleados a escala comercial, resultando en una actividad catalítica incrementada en un $20-42 \%$ respecto a los catalizadores sintetizados sobre $\mathrm{y}-\mathrm{Al}_{2} \mathrm{O}_{3}$ de origen comercial.

7. La selectividad a los productos de cadena larga (destilados medios y ceras) viene dictada por una combinación de los fenómenos de difusión intra-pellet para el CO y el tamaño de nanopartícula metálica. Mientras que la producción de ceras se favorece en el caso de catalizadores comerciales de poro ancho y baja dispersión metálica, la combinación de un acceso difusional facilitado para el CO y nanopartículas metálicas de menor tamaño en los catalizadores macro-mesoporosos resulta en una selectividad incrementada a la fracción diesel $\left(C_{13}-C_{22}\right)$, en detrimento de las ceras. 


\section{5-B}

Catalizadores mesoestructurados RuCo/SBA-15: Influencia de la longitud de poro. 


\subsection{Introducción.}

Desde el impacto científico que causó la síntesis de los materiales M41S por parte de los investigadores de Mobil en los primeros años 90 [29,30], las sílices mesoporosas ordenadas (SMO) han atraído un interés científico extraordinario en campos tan variados como separación, catálisis, transporte y dosificación controlada de fármacos, entre otros [31,32,33]. Sus propiedades estructurales más destacadas son su elevada área superficial específica, y su DP extremadamente uniforme, el cual puede variarse con precisión en un rango amplio de diámetros (típicamente entre 2 y $15 \mathrm{~nm}$ ). Estas propiedades exclusivas les han conferido un papel prominente en el campo de la catálisis a lo largo de las últimas dos décadas [32]. Varias funcionalidades catalíticas se han incorporado con éxito en las paredes de carácter amorfo de las SMO mediante una gran variedad de procedimientos aunque, probablemente, la aplicación catalítica más estudiada haya sido su empleo como soportes catalíticos para dispersar nanopartículas de metales u óxidos metálicos en el interior de sus mesoporos.

La elevada área superficial específica de estos materiales mesoestructurados permite lograr mayores dispersiones que cuando se emplean soportes más convencionales, no ordenados, de menor superficie específica. A su vez, el diámetro de poro homogéneo y ajustable que ofrecen las SMO puede, bajo condiciones de síntesis controladas, impartir esa uniformidad a las partículas catalíticas alojadas en su interior. Esto ha resultado en numerosos estudios científicos en los que se examina la influencia del DP en el tamaño, estructura y propiedades catalíticas de las nanopartículas soportadas $[34,35,36,37]$.

No obstante, a pesar de sus exclusivas y prometedoras propiedades texturales, los catalizadores heterogéneos basados en SMO han estado, 
generalmente, restringidos al mundo académico, por ejemplo, para estudiar de forma controlada ciertos aspectos catalíticos como los efectos del DP del soporte y/o el tamaño de nanopartícula metálica, y rara vez han sido propuestos para superar este rol de "sistemas modelo" y considerados para potenciales aplicaciones comerciales, como alternativa real a otros soportes convencionales no estructurados a nivel mesoscópico. Aunque pueda parecer contradictorio, uno de los principales inconvenientes asociados con la aplicación catalítica de las SMO es, precisamente, su orden estructural. Así, las SMO más ampliamente empleadas (MCM-41 y SBA-15 [38,39]) están constituidas, comúnmente, por partículas de gran tamaño conteniendo mesoporos unidimensionales (1D) estrictamente paralelos, densamente empaquetados y poco o nada interconectados entre sí, dando lugar a grandes distancias de difusión que típicamente son indeseadas en catálisis, donde se prefieren estructuras principalmente "vacías" y altamente desordenadas con el objetivo de evitar restricciones difusionales [40]. Esto es especialmente remarcable en el caso de la SMO tipo SBA-15, que es la preferida para numerosas aplicaciones catalíticas debido a su DP ancho (5-12 nm) y su aceptable estabilidad (hidro)termal [39], para la cual los mesoporos muestran, de manera común, un aspecto altamente curvado en una escala mesoscópica, dando lugar a morfologías secundarias complicadas y haciendo que, en muchos casos, la longitud de los poros doble el tamaño de partícula primaria [41]. Recientemente, se han dirigido numerosos esfuerzos de investigación a controlar, no sólo el diámetro de mesoporo (persiguiendo la síntesis de mesoestructuras con poros ultra-anchos (>10 nm) [42]), sino también a avanzar en el control morfológico y de la longitud de los poros de las SMO. En este sentido, se ha publicado la síntesis de SBA-15 cuyas partículas tienen forma de fibras [43], esferas [44], nanobarras [45], o láminas de reducido espesor [46]. A pesar de la vasta literatura dedicada 
recientemente al control morfológico de las SMO, no se ha considerado el impacto de estos avances en la preparación y las propiedades catalíticas de catalizadores heterogéneos basados en nanopartículas metálicas soportadas en estos materiales.

Las SMO han sido estudiadas como soportes catalíticos para catalizadores de SFT basados en Co durante la última década persiguiendo, principalmente, dispersiones metálicas mejoradas como una estrategia razonable para incrementar los rendimientos (CTY) [47]. Sin embargo, para los sistemas Co/MCM-41 se evidenció una limitada reducibilidad del metal y un incremento en la metanación como resultado de la elevada dispersión metálica de los catalizadores, agravándose estos inconvenientes por el hecho de que esta mesoestructura no presenta suficiente estabilidad hidrotermal en las condiciones de reacción [48]. Por otro lado, los materiales SBA-15 presentan diámetros de poro mayores que las sílices MCM-41 así como un grosor de pared superior, lo que les confiere una mayor estabilidad (hidro)térmica. Así, el empleo de SBA-15 como soporte catalítico permitió preparar catalizadores más reducibles, a expensas de una menor dispersión metálica $[48,49]$. No obstante, a pesar de que el empleo del soporte ordenado SBA-15 en lugar de sílices mesoporosas no estructuradas resultó en dispersiones metálicas ligeramente superiores, no siempre se alcanzó homogeneidad en el tamaño de nanopartícula metálica a pesar de la uniformidad de la estructura porosa del soporte. Adicionalmente, un severo bloqueo de los mesoporos 1D de SBA-15 reduce la accesibilidad a las nanopartículas catalíticas situadas en el interior de los poros bloqueados, en comparación con otros soportes estructuralmente desordenados, que disponen de redes porosas más interconectadas [49]. Generalmente, al contrario de lo esperado, el empleo de SMO como soportes para catalizadores de Fischer-Tropsch ha evidenciado tan sólo mejoras modestas 
y algunos inconvenientes importantes, en comparación con soportes no ordenados más convencionales. No obstante, algunos de estos inconvenientes pueden superarse, especialmente a la vista de recientes resultados que demuestran que la estructura porosa uniforme de las SMO (en concreto SBA-15) puede impartir homogeneidad sobre las nanopartículas de óxidos metálicos soportadas, incluso para elevados niveles de carga, siempre que se controle de forma exhaustiva los procedimientos de incorporación y activación térmica de los catalizadores [50].

Por otro lado, los descubrimientos más recientes en lo que respecta a la SFT catalizada por Co, pueden retornar la atención sobre las SMO como soportes catalíticos. Así, como se ha publicado recientemente, y se mostró en el capítulo 3 de esta memoria, la SFT muestra una sensibilidad a la estructura no clásica que maximiza el CTY para nanopartículas metálicas de alrededor de 8-10 nm [51,52]. Así pues, parece deseable preparar nuevos catalizadores con distribuciones de tamaño de nanopartícula estrechas y centradas en torno a estos valores óptimos, con el objetivo de utilizar de forma óptima el metal. A pesar de que se pueden aplicar metodologías de síntesis más o menos complejas para controlar el tamaño de nanopartícula de forma homogénea (el empleo de microemulsiones inversas presentado en el capítulo 3 es un ejemplo [53]), desde un punto de vista práctico, la impregnación es el método de preparación más deseado. Alcanzar tamaños de nanopartícula de Co uniformes mediante impregnación (y la activación térmica consiguiente) requeriría de una elevada uniformidad para la estructura porosa del soporte catalítico.

\subsection{Planteamiento.}

La combinación del orden estructural y la distribución de DP estrecha de mesoestructuras SBA-15 de poro ancho (alrededor de $10 \mathrm{~nm}$ ) con 
protocolos de activación térmica cuidadosamente controlados parece una estrategia racional para preparar catalizadores con un diámetro de nanopartícula entorno al valor óptimo $(8-10 \mathrm{~nm})$. A su vez, puesto que los fenómenos de transferencia de masa a través de los poros rellenos de hidrocarburos líquidos son muy influyentes en las condiciones de operación [54,55], como se evidenció en la primera parte de este capítulo, la SFT también puede beneficiarse de los tiempos de difusión acortados en los soportes mesoestructurados de morfologías no convencionales.

Este estudio traslada al campo de la catálisis los recientes avances en términos de control morfológico para la mesoestructura silícea SBA-15, con el objeto de investigar la influencia de la longitud de poro (LP) en la preparación de catalizadores 1\%Ru-20Co/SBA-15 y sus propiedades catalíticas en la SFT en condiciones industrialmente relevantes. Para ello, como se recoge en el apartado 2.1.2.5 de la Sección Experimental, se han sintetizado una serie de tres soportes SBA-15 de poro ancho (11 nm) que poseen poros unidimensionales de diferente longitud (hasta un orden de magnitud de diferencia). Empleando esos soportes se han preparado una serie de catalizadores RuCo/SBA-15 mediante impregnación y activación térmica (calcinación) controladas, como se recoge en la sección 2.1.3.5. Con el objetivo de percibir la influencia relativa del DP, que ha sido el parámetro considerado de manera más común en trabajos previos, y la LP, que es la contribución más original del presente estudio, se ha sintetizado con fines comparativos un soporte SBA-15 de morfología convencional y menor diámetro de poro $(7 \mathrm{~nm})$. Las siguientes secciones analizan la influencia ponderada de DP y LP sobre las propiedades físico-químicas y catalíticas de los catalizadores RuCo/SBA-15. 


\subsection{Resultados y discusión.}

\subsubsection{Caracterización de los soportes SBA-15.}

\subsubsection{Propiedades texturales.}

Como se muestra en la Fig. 5.18, las isotermas de adsorción-desorción de $\mathrm{N}_{2}$ para los cuatro soportes SBA-15 sintetizados son de tipo IV, mostrando un lazo de histéresis de categoría H1, de acuerdo a la clasificación de la IUPAC [56]. Ambas características son típicas de la mesoestructura SBA-15. Los bruscos eventos de condensación intra-poro que muestran las isotermas son indicativos de una elevada uniformidad en el diámetro de poro. La Fig. 5.19 por su parte, muestra las correspondientes distribuciones de diámetro de poro (DP), las cuales son estrechas, unimodales y centradas en aprox. 11 nm para 11SBA_x y en aprox. $7 \mathrm{~nm}$ para 7SBA_L, de acuerdo con lo pretendido en cada una de las preparaciones.

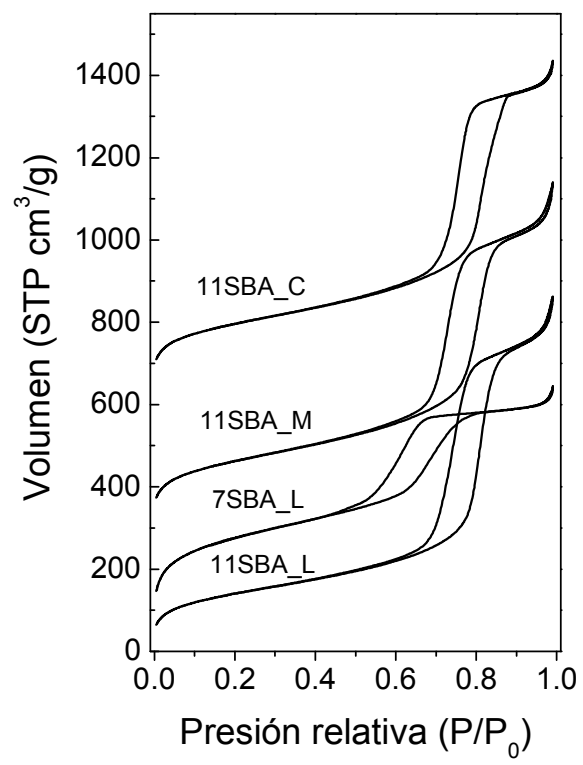

Figura 5.18: Isotermas de adsorción-desorción de $N_{2}$ para los soportes mesoestructurados SBA-15. 


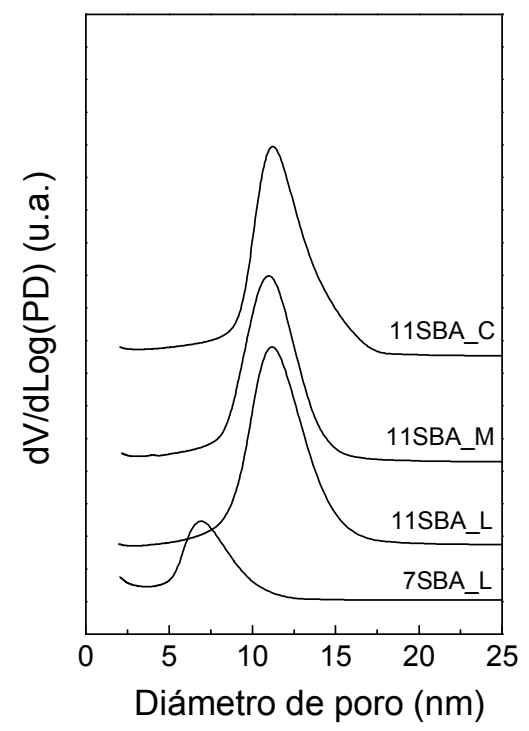

Figura 5.19: Distribuciones de diámetro de poro para los soportes mesoestructurados SBA-15.

Por otra parte, la Tabla 5.7 recoge las principales propiedades texturales de los soportes mesoestructurados.

Tabla 5.7: Propiedades texturales de los soportes mesoestructurados SBA-15.

\begin{tabular}{ccccccc}
\hline Muestra & \multirow{2}{*}{$\begin{array}{c}\text { A B.E.T. } \\
\left(\mathrm{m}^{2} / \mathrm{g}\right)\end{array}$} & $\begin{array}{c}\mathrm{A}_{\text {mesop }}{ }^{\mathrm{a}} \\
\left(\mathrm{m}^{2} / \mathrm{g}\right)\end{array}$ & $\begin{array}{c}\mathrm{VP}_{\text {meso }}{ }^{\mathrm{b}} \\
\left(\mathrm{cm}^{3} / \mathrm{g}\right)\end{array}$ & $\begin{array}{c}\mathrm{VP}_{\text {micro }}{ }^{\mathrm{c}} \\
\left(\mathrm{cm}^{3} / \mathrm{g}\right)\end{array}$ & $\begin{array}{c}\mathrm{DP}^{\mathrm{d}} \\
(\mathrm{nm})\end{array}$ & $\begin{array}{c}\mathrm{LP}^{\mathrm{e}} \\
(\mu \mathrm{m})\end{array}$ \\
\hline 11SBA_L & 504 & 430 & 1.30 & 0.037 & 11.1 & 5.70 \\
11SBA_M & 630 & 467 & 1.26 & 0.072 & 10.9 & 1.15 \\
11SBA_C & 665 & 458 & 1.22 & 0.094 & 11.2 & 0.33 \\
7SBA_L & 957 & 573 & 0.80 & 0.199 & 7.0 & 6.90 \\
\hline
\end{tabular}

${ }^{a}$ Área de mesoporo, calculada sustrayendo el área de microporo (determinada mediante la herramienta del t-plot) al área B.E.T. total.

${ }^{b}$ Volumen de mesoporo.

${ }^{c}$ Volumen de microporo.

${ }^{d}$ Diámetro medio de mesoporo, basado en el máximo de la distribución de diámetro de poro obtenida según el modelo B.J.H. (Fig. 5.19).

${ }^{e}$ Longitud media de poro estimada midiendo 50 partículas, mediante TEM, en la dirección de los poros.

Como se muestra, los soportes de poro ancho (11SBA_x) presentan una superficie específica en el rango de $504-665 \mathrm{~m}^{2} / \mathrm{g}$. Las ligeras diferencias en superficie específica entre estos sólidos son principalmente debidas a 
diferencias en microporosidad, presente en las paredes de los mesoporos de SBA-15, más que en el área de mesoporo, la cual toma valores menos dispersos en el rango de $430-467 \mathrm{~m}^{2} / g$ para estos tres sólidos. El VPeso toma valores entre $1.22-1.30 \mathrm{~cm}^{3} / \mathrm{g}$ para estos soportes de poro ancho. En lo relativo a la microporosidad, 11SBA_L presenta un $\mathrm{VP}_{\text {micro }}\left(0.037 \mathrm{~cm}^{3} / \mathrm{g}\right)$ sensiblemente inferior a 11SBA_M y 11SBA_C $\left(V P_{\text {micro }}=0.072\right.$ y $0.094 \mathrm{~cm}^{3} / \mathrm{g}$, respectivamente). Este hecho se debe a la mayor temperatura empleada durante la síntesis hidrotermal del primero $\left(120^{\circ} \mathrm{C}\right)$, que se conoce que promueve el colapso parcial de los microporos existentes en las paredes silíceas de los mesoporos [57]. Esta mayor temperatura de síntesis es necesaria para obtener un material de poro ancho en ausencia de sustancias orgánicas [58], al contrario de los casos de 11SBA_M y 11SBA_C para los cuales se introducen alcanos en el gel de síntesis, que juegan el papel de agentes de hinchado de las micelas tubulares estabilizadas por el surfactante. Por otro lado, el soporte de poro estrecho 7SBA_L muestra una superficie específica sustancialmente mayor $\left(957 \mathrm{~m}^{2} / \mathrm{g}\right)$. No obstante, su área de mesoporo $\left(573 \mathrm{~m}^{2} / \mathrm{g}\right.$ ) es tan solo un $27 \%$ mayor que la de los soportes 11SBA_x lo que resulta de su menor diámetro de mesoporo, mientras que el resto del exceso de superficie específica de 7SBA_L es debido a su mayor microporosidad $\left(\mathrm{VP}_{\text {micro }}=0.199 \mathrm{~cm}^{3} / \mathrm{g}\right)$, como resultado de la menor temperatura empleada en su síntesis $\left(80^{\circ} \mathrm{C}\right)$ [58]. Finalmente, como también se recoge en la Tabla 5.7, el diámetro de poro medio es de $11 \pm 0.2 \mathrm{~nm}$ y 7.0 para los materiales 11 SBA_x y 7SBA_L, respectivamente.

\subsubsection{Morfología y direccionalidad de los poros.}

La morfología de las partículas primarias, así como la direccionalidad de los poros, para los soportes SBA-15 se estudiaron empleando técnicas de microscopía electrónica. La Fig. 5.20 muestra imágenes de SEM y TEM representativas de los soportes mesoestructurados en su forma calcinada. 
Se pueden observar diferencias significativas en la morfología de partícula primaria. Así, 11SBA_C consiste en láminas nanométricas de forma hexagonal, espacialmente desordenadas [59]. Las imágenes de TEM para esta muestra (Fig. 5.20-e) revelan una orientación inusual de los mesoporos, que son paralelos al eje corto (aprox. 300-400 nm) de las partículas hexagonales [46]. 
a)

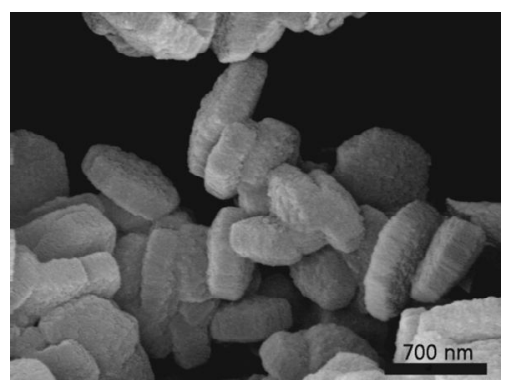

b)

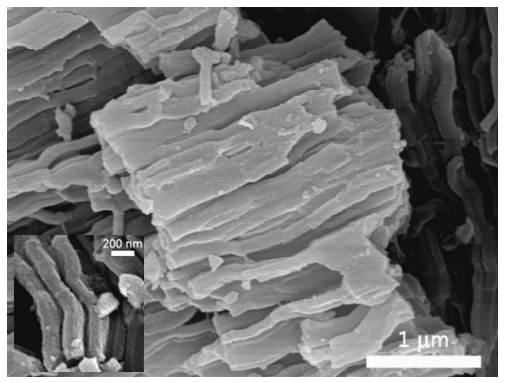

c)

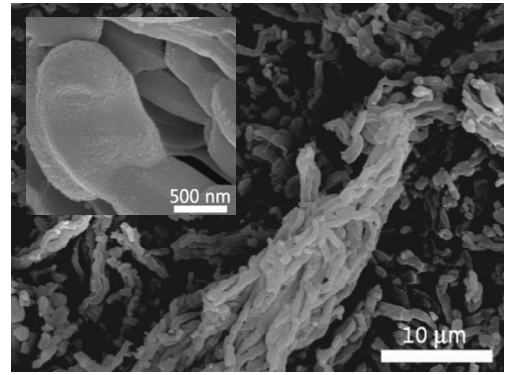

d)

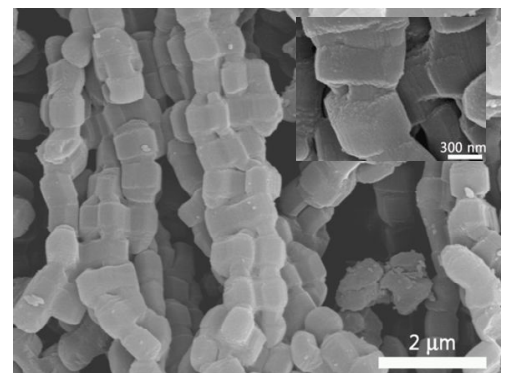

e)

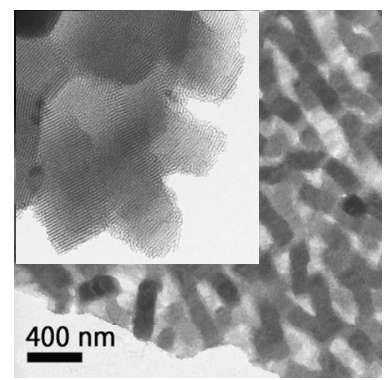

f)

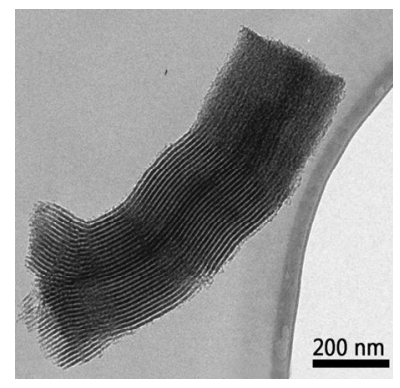

g)

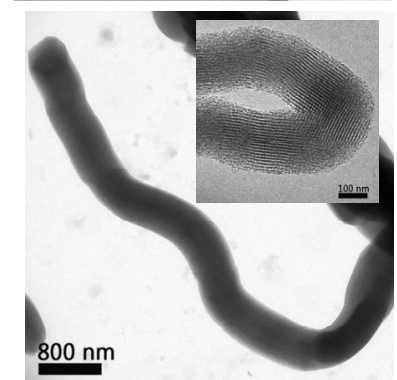

h)

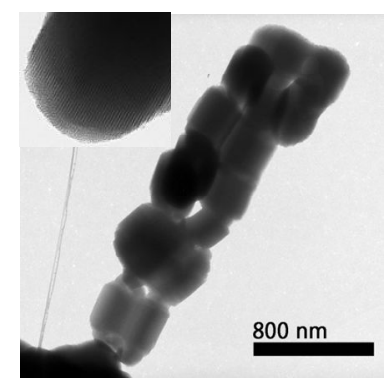

Figura 5.20: Micrografías de SEM (a-d) y TEM (e-h) representativas de los soportes mesoestructurados $(a, e) 11 S B A \_C,(b, f) 11 S B A \_M,(c, g) 11 S B A \_L y(d, h) 7 S B A \_L$.

En el caso de 11SBA_M, se observan partículas en forma de barras alineadas en grupos, cuya longitud es de aprox. 800-1500 nm (Fig. 5.20-b). Estas barras nanométricas son generalmente rectas, aunque pueden encontrarse algunas partículas que muestran un limitado grado de curvatura 
(detalle en Fig. 5.20-b). La inspección mediante TEM (Fig. 5.20-f) evidencia que, en este caso, los mesoporos ordenados son paralelos al eje $z$ (longitudinal) de la partícula.

Una morfología marcadamente diferente se observa para las partículas primarias de 11SBA_L. Estas partículas muestran una forma de cuerdas y un aspecto altamente curvado, apareciendo frecuentemente agrupadas en agregados de tipo "trenza". La imagen de SEM de mayor resolución incluida como detalle en Fig. 5.20-c revela que en algunos extremos de las partículas primarias pueden observarse curvas empaquetadas densamente lo que significa que, en determinados casos, el extremo de la partícula no corresponde con una región de boca de poro. Esto se confirma adicionalmente mediante TEM (detalle en Fig. 5.20-g) que muestra cómo los mesoporos ordenados, paralelos al eje $z$ de la partícula, forman estructuras curvas en forma de " $U$ ". Janssen y colaboradores [41] mostraron que este comportamiento refleja la morfología más común de las partículas de SBA-15 convencional, lo que determina que en estos casos la longitud real de los poros sea prácticamente el doble que la longitud de las partículas primarias del sólido.

Por último, el material 7SBA_L está compuesto de partículas en forma de cuerda de gran longitud $(5-15 \mu \mathrm{m})$ que consisten en monolitos individuales, más cortos (300-500 nm), ensamblados (Fig. 5.20-d). La inspección por TEM revela que estos monolitos se encuentran unidos cabeza-cola por porciones de sílice de menor grosor, determinando la continuidad de los mesoporos, los cuales son paralelos al eje $z$ de las partículas (Fig. 5.20-h).

La determinación cuantitativa de la longitud de poro de un material poroso no es trivial. A pesar de que se han desarrollado metodologías 
híbridas basadas en adsorción de $\mathrm{N}_{2}$ e intrusión de $\mathrm{Hg}$ [60], su empleo no está muy extendido en la literatura y no existe consenso en la interpretación de los resultados. En un intento de considerar de una manera más cuantitativa las diferencias en la relación de aspecto observadas por SEM y TEM para las partículas de los diferentes soportes, se han determinado las distribuciones de longitud de poro basadas en la medida de 50 partículas en la dirección de los poros, mediante TEM de media magnificación, para cada uno de sólidos. En el caso de partículas curvadas se segmentó la partícula en regiones rectas para realizar la medida tal y como se muestra esquemáticamente en la Fig. 5.21, y en el caso de los extremos de partícula curvados en forma de $\mathrm{U}$, se han considerado como semi-circunferencias para tener en cuenta su contribución a la longitud de poro. No se han encontrado diferencias significativas en el número de poros por partícula (dimensión transversal de las partículas) de modo que la medida de partículas individuales representa adecuadamente la distribución de longitud de poro (LP). Las distribuciones de LP obtenidas de este modo se muestran en la Fig. 5.22, mientras que la longitud de poro media estimada para cada sólido se recoge en la Tabla 5.7.

a)

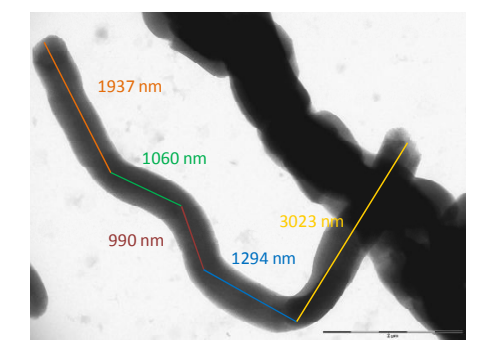

b)

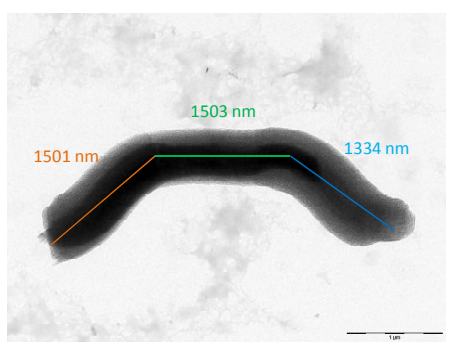

Figura 5.21: Representación esquemática del procedimiento de segmentación empleado para estimar la longitud de poro en partículas de SBA-15 curvas, para partículas primarias de 11SBA_L de (a) $8.30 \mu \mathrm{m}$ y (b) $4.34 \mu \mathrm{m}$ de longitud total. 
a)

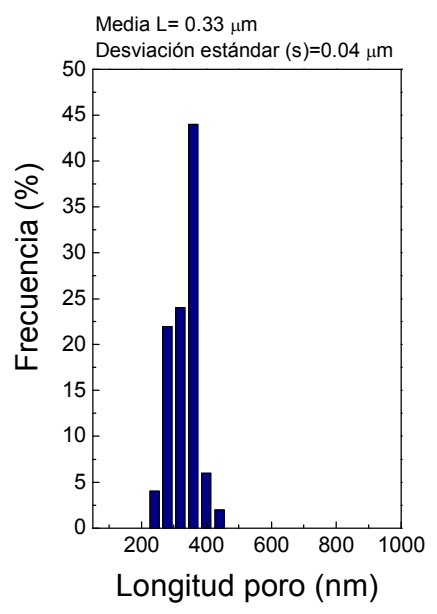

c)

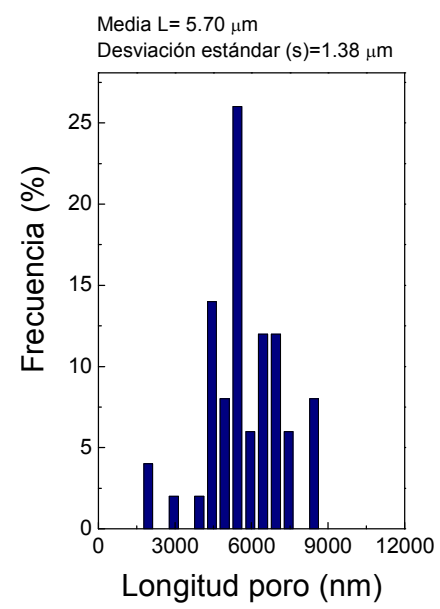

b)

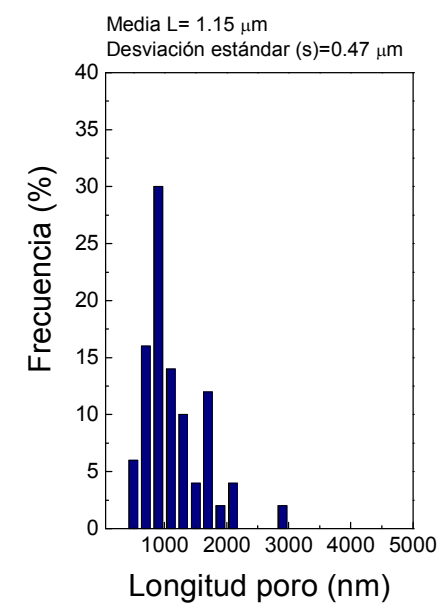

d)

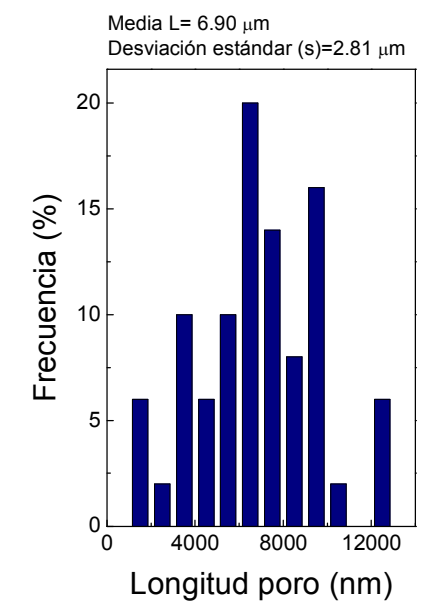

Figura 5.22: Distribuciones de longitud de mesoporo basadas en la medida de 50 partículas de SBA-15 en la dirección de los poros mediante TEM, trabajando a media magnificación.

Por su parte, la Tabla 5.8 recoge los resultados del análisis de las distribuciones de longitud de poro incluidas en la Fig. 5.22 mediante la herramienta estadística de la $t$ de Student. La aplicación de la herramienta de la $t$ de Student es especialmente útil cuando no es posible analizar un tamaño de muestra lo suficientemente grande como para que la aproximación de la media poblacional por la media de la muestra analizada sea correcta. En este caso, al contrario de lo que ocurre cuando se estudia 
por TEM el tamaño de nanopartículas metálicas, evaluar la longitud de las partículas primarias en un número superior a 50 partículas es metodológicamente demasiado complicado, por lo que estimar los intervalos de confianza para la media poblacional a partir de las distribuciones obtenidas para 50 medidas permitirá conocer la fiabilidad estadística de los valores medios de LP que se incluyen en la Tabla 5.7.

Esta metodología permite estimar los intervalos de confianza alrededor de la media de la muestra analizada (LP) en los que se encuentra la media verdadera de toda la población $\left(L P_{p o b}\right)$, a un nivel de confianza determinado. En este caso concreto la muestra es una porción de la población "longitud de poro" con un tamaño de muestra de 50 elementos. La ecuación 5.1 delimita el intervalo de confianza entorno a LP donde se encuentra $L P_{p o b}$ a un determinado nivel de confianza:

$$
L P_{p o b}=L P \pm I C=L P \pm t \cdot(s / \sqrt{N}) \quad \text { (Ec. 5.1) }
$$

donde $L P_{\text {pob }}$ y LP son la media poblacional y muestra respectivamente, s es la desviación típica para la muestra analizada, $\mathrm{N}$ el tamaño de la muestra (50) y t el valor del parámetro de $t$ de Student para un tamaño muestral de $\mathrm{N}$ y un nivel de confianza determinado. 
Tabla 5.8: Intervalos de confianza (90\%) para la longitud de poro media, estimados mediante el análisis basado en el formalismo de t-Student de la muestra resultante de medir 50 partículas de soporte.

\begin{tabular}{llccc}
\hline Muestra & $\begin{array}{c}\mathrm{LP}^{\mathrm{a}} \\
(\mu \mathrm{m})\end{array}$ & $\begin{array}{c}\mathrm{s}^{\mathrm{b}} \\
(\mu \mathrm{m})\end{array}$ & $\begin{array}{c}t_{\text {Student }}{ }^{\mathrm{c}} \\
(90 \%, \mathrm{~N}=50)\end{array}$ & $\mathrm{IC}(\mathrm{L})_{90 \%}(\mu \mathrm{m})$ \\
\hline 11SBA_L & 5.70 & 1.38 & & \pm 0.33 \\
11SBA_M & 1.15 & 0.47 & 1.676 & \pm 0.11 \\
11SBA_C & 0.33 & 0.04 & & \pm 0.01 \\
7SBA_L & 6.90 & 2.81 & \pm 0.67 \\
\hline${ }^{a}$ Longitud media de poro. Valor medio para la "muestra" de 50 partículas analizada. \\
${ }^{b}$ Desviación típica para la "muestra" de 50 partículas analizada. \\
"Valor del parámetro t de Student para un tamaño de "muestra" de 50 elementos y un nivel de \\
confianza del 90\%. \\
dintervalo de confianza de la media poblacional con respecto a la media de la "muestra" (LP) \\
para un nivel de confianza del 90\%.
\end{tabular}

De acuerdo a los resultados recogidos en la Tabla 5.8, los intervalos para la media poblacional alrededor de la media de la muestra (LP) al 90\% de confianza son, en todos los casos, de amplitud inferior a $\pm 10 \%$ del valor de la media muestral LP, lo que asegura la significancia estadística de las diferencias entre las longitudes de poro medias evaluadas a partir de 50 medidas, que son muy superiores a ese $\pm 10 \%$.

Así pues, se observa un incremento de unas 20 veces en la longitud de poro (de 0.33 a $5.7 \mu \mathrm{m}$ ) entre 11SBA_C y 11SBA_L, los cuales poseen el mismo diámetro de poro (Tabla 5.7). Adicionalmente, el soporte de poro estrecho 7SBA_L muestra la mayor longitud media de poro $(6.9 \mu \mathrm{m})$ y, por lo tanto, supone una buena referencia para estudiar, de manera independiente, el efecto del diámetro y la longitud de poro en las propiedades físico-químicas y catalíticas de los catalizadores RuCo/SBA-15.

\subsubsection{Caracterización de los catalizadores RuCo/SBA-15.}

\subsubsection{Composición química.}

Como se recoge en la Tabla 5.9, los catalizadores RuCo/SBA-15 calcinados presentan contenidos en Co de acuerdo con el valor nominal de 
$20 \%(p)$, con desviaciones relativas máximas del $8 \%$.

Por el contrario, los contenidos en $\mathrm{Ru}$ determinados experimentalmente están en el rango 0.2-0.4 \%(p), y son un 64-78\% inferiores a los determinados por ICP-OES en las correspondientes muestras antes del tratamiento de calcinación, los cuales sí están de acuerdo con el contenido nominal de $1 \%(p)$. Estos resultados evidencian una pérdida de metal significativa durante el tratamiento de calcinación en forma de (sub)óxidos $\mathrm{RuO}_{\mathrm{x}}$ volátiles $[61,62]$.

Tabla 5.9: Composición química y propiedades texturales de los catalizadores RuCo/SBA-15 calcinados.

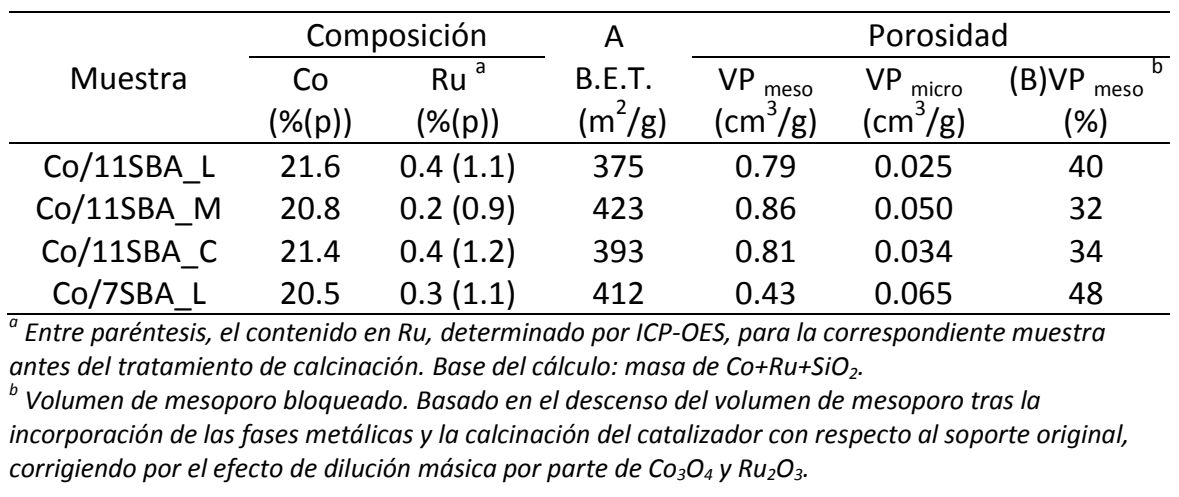

\subsubsection{Propiedades texturales.}

En cuanto a las características texturales, como se muestra en la Fig. 5.23, todos los catalizadores RuCo/SBA-15 muestran isotermas de adsorcióndesorción de $\mathrm{N}_{2}$ no reversibles, de tipo IV. Los catalizadores metálicos presentan una adsorción total de $\mathrm{N}_{2}$ significativamente inferior a la de los correspondientes soportes silíceos originales (Fig. 5.18). De manera adicional, la rama de desorción para Co/7SBA_L muestra un cierre en dos etapas, que tienen lugar a presiones relativas $\left(P / P_{0}\right)$ de 0.55 y 0.45 , respectivamente. Este vaciado secuencial de los poros no se observa en la 
isoterma de ninguno de los soportes originales.

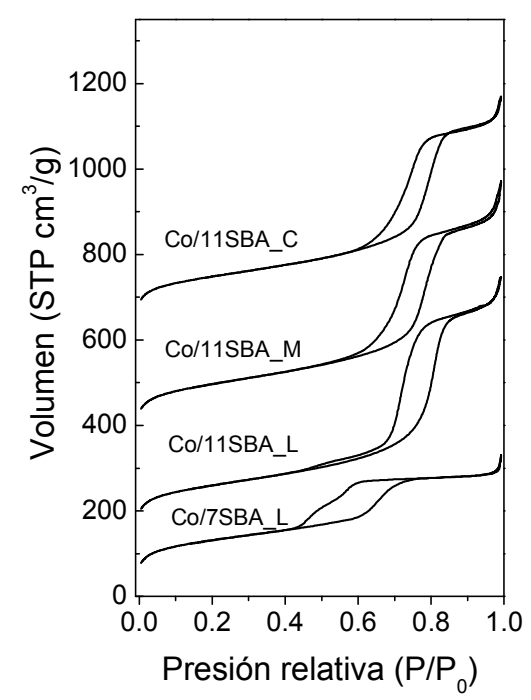

Figura 5.23: Isotermas de adsorción-desorción de $\mathrm{N}_{2}$ para los catalizadores RuCo/SBA-15 calcinados. Las isotermas se han desplazado verticalmente 150, 370 y $630 \mathrm{~cm}^{3} / \mathrm{g}$ para Co/11SBA_L,CO/11SBA_M y Co/11SBA_S, respectivamente.

La aparición de una etapa de desorción forzada a $P / P_{0} \approx 0.45$ se ha relacionado previamente con el bloqueo de los mesoporos de SBA-15 $[63,64]$. Este efecto se ha adscrito a un fenómeno de cavitación, debido a la presencia de aperturas de tipo "bote de tinta" (microporos) a través de los cuales se vacían los mesoporos bloqueados durante la desorción de $\mathrm{N}_{2}$, como se muestra de manera esquemática en la Fig. 5.24 [64]. 


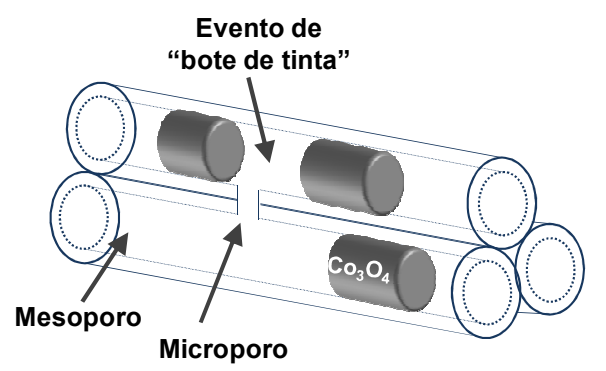

Figura 5.24: Representación esquemática de la formación de eventos de "bote de tinta" cuando se bloquean los mesoporos de SBA-15 por especies metálicas y la desorción tiene lugar a través de microporos que conectan los mesoporos. Adaptada de [64].

Así pues, se puede inferir un bloqueo significativo de los mesoporos de 7SBA_L debido a la presencia de las nanopartículas de óxidos metálicos en el catalizador calcinado. Una inspección detallada de la rama de desorción de Co/11SBA_L muestra que tiene lugar un efecto similar para este catalizador, aunque en este caso, la proporción de mesoporos que se vacían en la etapa de baja presión relativa $\left(P / P_{0} \approx 0.45\right)$ es casi despreciable, lo que puede estar relacionado con el mayor DP del soporte 11SBA_L o su menor microporosidad (Tabla 5.7), dificultándose la formación de eventos de tipo "bote de tinta" cuando las nanopartículas metálicas se desarrollan en el interior de los mesoporos. Para los catalizadores restantes, Co/11SBA_M y Co/11SBA_C, por el contrario, no se observa cavitación durante la desorción, lo que puede estar relacionado con un menor grado de bloqueo de poros.

La Tabla 5.9 recoge las propiedades texturales de los catalizadores RuCo/SBA-15. Como se observa, tanto el área B.E.T. (375-423 m²/g) como el $\mathrm{VP}_{\text {meso }}\left(0.43-0.86 \mathrm{~cm}^{3} / \mathrm{g}\right)$ y el $V P_{\text {micro }}\left(0.025-0.065 \mathrm{~cm}^{3} / \mathrm{g}\right)$ decrecen con respecto a las magnitudes para el soporte original. Este descenso es mayor que el relacionado con una simple contribución de la masa aportada por las fases metálicas introducidas, que disminuye todas las propiedades específicas (por unidad de masa). Así, pues, se evidencian fenómenos de bloqueo de poro, como ya se ha discutido en base a las isotermas de 
adsorción-desorción de $\mathrm{N}_{2}$. El porcentaje de volumen de mesoporo completamente bloqueado ( $\left.(\mathrm{B}) \mathrm{VP}_{\text {meso }}\right)$ se ha estimado a partir de la pérdida de $\mathrm{VP}_{\text {meso }}$ en los catalizadores metálicos, con respecto a los correspondientes soportes, corrigiendo por la contribución debida al efecto de dilución de masa asociado con a la presencia de las fases metálicas (considerando propiedades por masa de $\mathrm{SiO}_{2}$ ).

Como se muestra en la Tabla 5.9, el soporte de poro estrecho 7SBA_L es aquel en el que tiene lugar un mayor bloqueo de mesoporos (48\%) al incorporar las fases metálicas, mientras que en la serie de soportes de poro ancho 11SBA_x las mesoestructuras de poros más cortos (11SBA_M y 11SBA_C) muestran un menor grado de bloqueo de mesoporo (32-34\%) que el correspondiente soporte de poros largos 11SBA_L (40\%). Este resultado está de acuerdo con lo que se podría esperar a priori, ya que el grado de bloqueo debería ser mayor para aquellos poros de mayor longitud, para los cuales el volumen de poro contenido entre dos extremos del mismo poro es mayor.

\subsubsection{Dispersión metálica.}

La dispersión metálica en los catalizadores RuCo/SBA-15 es estudió empleando DRX, TEM y quimisorción de $\mathrm{H}_{2}$.

La espinela mixta $\mathrm{CO}_{3} \mathrm{O}_{4}$ es la única fase metálica cristalina detectada por XRD en los catalizadores calcinados. Como se recoge en la Tabla 5.10, el tamaño de cristal $d\left(\mathrm{CO}_{3} \mathrm{O}_{4}\right)_{x}$ disminuye de 13.8 a $11.4 \mathrm{~nm}$ cuando se acortan progresivamente los poros del soporte para la serie de poro ancho 11SBA_x. Por otro lado, el catalizador preparado sobre la mesoestructura de poro estrecho (Co/7SBA_L) muestra un $d\left(\mathrm{Co}_{3} \mathrm{O}_{4}\right) \times$ de $12.1 \mathrm{~nm}$. En todos los casos, el valor de $d\left(\mathrm{CO}_{3} \mathrm{O}_{4}\right)_{x}$ excede el DP del correspondiente soporte lo que no excluye la presencia de las fases metálicas en el interior de los poros, tal y 
como se ha descrito con anterioridad $[65,66]$ y como también se encontró para los catalizadores $\mathrm{RuCo} / \mathrm{Al}_{2} \mathrm{O}_{3}$ estudiados en la sección 5.3.2.3. De estos resultados se desprende que una reducción del DP de 11 (en 11SBA_L) a 7 $\mathrm{nm}$ (en 7SBA_L) para las sílices mesoestructuradas de morfología convencional (poros largos) da lugar tan sólo a una mejora limitada en la dispersión metálica del correspondiente catalizador metálico. De acuerdo con esta conclusión, otros autores han encontrado una correlación entre el DP y el tamaño de nanopartícula de Co en catalizadores Co/SBA-15 [35,65], mientras que en muchos casos, las diferencias encontradas en el tamaño de nanopartícula de Co en el rango de diámetro de poro de 7-11 nm han sido limitadas [35].

De manera interesante, de nuestro estudio se puede concluir que la dispersión metálica se ve más afectada por la longitud del poro que por su diámetro, encontrándose el menor valor de $d\left(\mathrm{CO}_{3} \mathrm{O}_{4}\right)_{x}=11.4 \mathrm{~nm}$ para el catalizador preparado sobre el soporte de poros anchos y cortos (Co/11SBA_C).

Tabla 5.10: Dispersión metálica y grado de reducción (400드, 10h) para los catalizadores RuCo/SBA-15.

\begin{tabular}{|c|c|c|c|c|c|c|}
\hline \multirow{3}{*}{ Muestra } & \multicolumn{5}{|c|}{ Dispersión metálica } & \multirow{3}{*}{$\begin{array}{l}\mathrm{GR}^{\mathrm{C}} \\
(\%)\end{array}$} \\
\hline & \multicolumn{2}{|c|}{ XRD } & \multicolumn{3}{|c|}{ Quimisorción $\mathrm{H}_{2}$} & \\
\hline & $\begin{array}{c}d\left(\mathrm{Co}_{3} \mathrm{O}_{4}\right)_{x} \\
(\mathrm{~nm})^{\mathrm{a}}\end{array}$ & $\begin{array}{c}\mathrm{d}\left(\mathrm{Co}^{0}\right)_{\mathrm{x}} \\
(\mathrm{nm})\end{array}$ & $\begin{array}{c}\mathrm{H}_{2} \text { ads } \\
(\mu \mathrm{mol} / \mathrm{g})\end{array}$ & $\begin{array}{l}D^{b} \\
(\%)\end{array}$ & $\begin{array}{c}d\left(\mathrm{Co}^{0}\right)_{\mathrm{H}} \\
(\mathrm{nm})\end{array}$ & \\
\hline Co/11SBA_L & 13.8 & 10.4 & 96.0 & 5.6 & 17.8 & $\sim 100$ \\
\hline Co/11SBA_M & 12.5 & 9.4 & 144.4 & 8.8 & 11.3 & 95 \\
\hline Co/11SBA_C & 11.4 & 8.6 & 149.3 & 9.8 & 10.2 & 87 \\
\hline Co/7SBA_L & 12.1 & 9.1 & 100.4 & 7.0 & 14.2 & 85 \\
\hline $\begin{array}{l}\text { El error típico }(s /(N \\
\text { del } 2 \% \text {. } \\
\text { Dispersión metálice } \\
\text { Estimado mediante }\end{array}$ & lestimado & e $3 \mathrm{me}$ & endiente & & $\mathrm{raCo} / 1$ & \\
\hline
\end{tabular}

La microscopía TEM se ha empleado para estudiar el tamaño y la 
localización de las nanopartículas de $\mathrm{CO}_{3} \mathrm{O}_{4}$ en muestras calcinadas seleccionadas. Las Figs. 5.25-a y b muestran micrografías de media magnificación representativas para Co/11SBA_L y Co/11SBA_C, respectivamente.
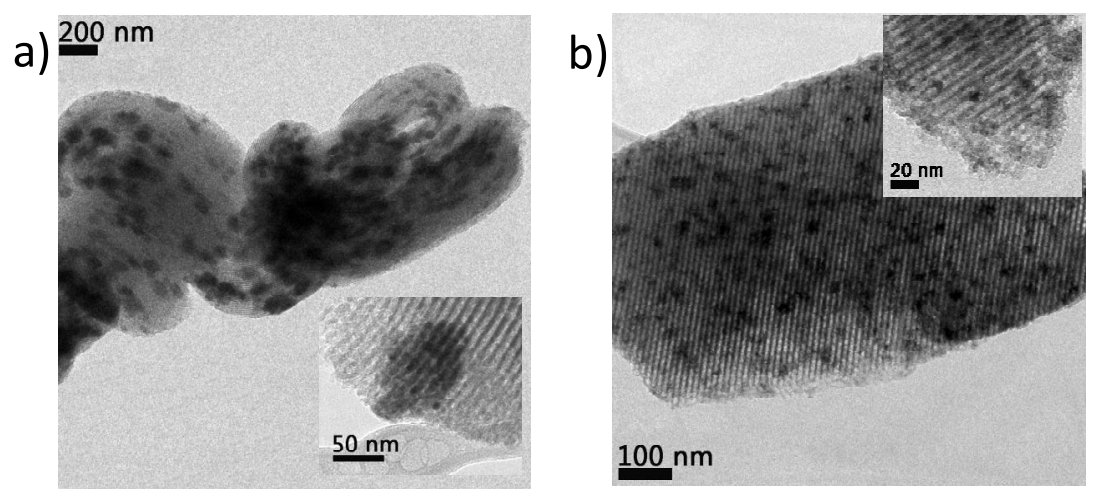

Figura 5.25: Micrografías de TEM representativas de los catalizadores (a) Co/11SBA_L y (b) Co/11SBA_C calcinados. Los detalles muestran imágenes de mayor resolución para las nanopartículas de $\mathrm{CO}_{3} \mathrm{O}_{4}$ en el interior de los mesoporos.

Se observa la presencia de agregados metálicos en el interior de los mesoporos de las partículas de SBA-15 altamente curvadas en Co/11SBA_L. Como se muestra en el detalle de la Fig. 5.25-a, estos agregados consisten en agrupaciones de nanocristales de $\mathrm{CO}_{3} \mathrm{O}_{4}$ con forma de nano-barras (nanorods) presentes en el interior de mesoporos individuales. Morfologías alargadas similares a éstas se evidenciaron recientemente, por medio de Tomografía Electrónica (TE), en muestras de catalizadores Ni/SBA-15 calcinadas en aire [50]. Estos nanorods poseen dimensiones similares al diámetro de poro (11 nm) a lo largo de su eje más corto, sugiriendo el bloqueo de poro, en línea con los resultados de adsorción de $\mathrm{N}_{2}$ (Tabla 5.9). Sin embargo, en su dirección longitudinal, las dimensiones típicamente exceden los 20-30 nm, lo que puede estar relacionado con el hecho de que los valores de $d\left(\mathrm{CO}_{3} \mathrm{O}_{4}\right)_{x}$ excedan sistemáticamente el valor de DP. A su vez, una importante proporción de los mesoporos se encuentran completamente 
vacíos, de acuerdo con observaciones recientes para este tipo de materiales soportados en sílices mesoestructuradas [67], mientras que no se encontró ninguna contribución apreciable de nanopartículas fuera de los mesoporos del soporte, incluso trabajando en el microscopio a varios ángulos de inclinación de muestra.

De manera diferente, la Fig. 5.25-b muestra la presencia de nanopartículas menos alargadas (pseudo-esféricas) de $\mathrm{Co}_{3} \mathrm{O}_{4}$, cuyo tamaño está comprendido en el rango 8-15 nm, en el interior de los mesoporos del soporte 11SBA_C. Tampoco en este caso se evidenció la presencia de nanopartículas de Co sobre la superficie externa del soporte.

Así pues, los resultados de TEM concuerdan con los obtenidos por XRD, mostrando que se obtiene una mayor dispersión metálica para el catalizador de poros cortos Co/11SBA_C que para el correspondiente catalizador de poros largos Co/11SBA_L, a pesar de que los soportes catalíticos empleados presentan exactamente el mismo diámetro de poro (Tabla 5.7).

Finalmente, el estudio de los catalizadores reducidos mediante quimisorción de $\mathrm{H}_{2}$ resulta en tamaños medios de nanopartícula de $\mathrm{Co}^{0}$ $\left(d\left(\mathrm{Co}^{0}\right)_{H}\right)$ en el rango de 10.2-17.8 nm, como se recoge en la Tabla 5.10.

A pesar de que la caracterización por TEM evidenció que la técnica de XRD subestima, en cierto modo, el tamaño de las partículas de $\mathrm{Co}_{3} \mathrm{O}_{4}$, una comparación directa de los valores de $d\left(\mathrm{Co}^{0}\right)_{x}$ y los diámetros de nanopartícula de $\mathrm{Co}^{0}$ obtenidos por quimisorción de $\mathrm{H}_{2}\left(d\left(\mathrm{Co}^{0}\right)_{H}\right)$ puede ofrecer una idea de los cambios de dispersión metálica durante el tratamiento de reducción. Puesto que los valores de $d\left(\mathrm{Co}^{0}\right)_{H}$ son un $18-71 \%$ mayores que los correspondientes $d\left(\mathrm{Co}^{0}\right)_{x}$, se sugiere la existencia de sinterizado metálico durante el tratamiento de reducción. Es destacable, a 
su vez, que el incremento porcentual en el diámetro de nanopartícula tras la reducción, con respecto al valor predicho por XRD (que no considera aglomeración), es significativamente mayor para aquellos catalizadores preparados sobre soportes de poro largo (56\% para Co/7SBA_L y 71\% para Co/11SBA_L) que para los correspondientes catalizadores de poro más corto (20\% para Co/11SBA_M y 18\% para Co/11SBA_C). Así pues, el empleo de soportes de poro corto es más efectivo a la hora de preservar la dispersión metálica inicial de las muestras calcinadas durante el tratamiento de reducción en $\mathrm{H}_{2}$. La combinación de las diferentes dispersiones metálicas ya encontradas en las muestras calcinadas, junto con las diferencias en la magnitud relativa de la aglomeración metálica durante el tratamiento de reducción, da lugar a diferencias de hasta un $75 \%$ en la dispersión metálica para los catalizadores reducidos soportados sobre mesoestructuras de idéntico diámetro de poro $(11 \mathrm{~nm})$ pero longitudes de poro significativamente diferentes (Tabla 5.7).

En resumen, los resultados de caracterización muestran un efecto preponderante de la longitud de poro sobre la dispersión metálica de los catalizadores RuCo/SBA-15. De este modo, acortar los poros del soporte mesoestructurado es más beneficioso para obtener una mayor dispersión metálica que reducir el diámetro del mismo, que es la estrategia que ha sido más ampliamente empleada para controlar la dispersión metálica en catalizadores soportados en SMO [34,35,65].

A lo largo de las dos secciones siguientes, se estudiarán los procesos de calcinación y reducción de los catalizadores RuCo/SBA-15 con el objetivo de entender el origen de las diferencias en dispersión metálica en función de la morfología del soporte mesoestructurado. 


\subsubsection{Tratamiento de calcinación en aire.}

Recientemente, se ha estudiado de manera sistemática el efecto de los tratamientos de calcinación sobre la dispersión metálica de catalizadores preparados empleando nitratos como precursores de las fases metálicas $[50,68,69,70]$. A la vista de estos trabajos, se ha concluido que algunas especies gaseosas, que se generan durante la activación térmica, pueden tener un impacto importante sobre la dispersión metálica final en el catalizador calcinado $[68,69,70]$. En concreto, un elevado tiempo de residencia de gases derivados de la descomposición de los nitratos precursores, como $\mathrm{O}_{2}$ y óxidos de nitrógeno, tiene como resultado pobres dispersiones metálicas, incluso cuando los catalizadores se preparan sobre SMO de elevada superficie específica [50]. Así, limitar el tiempo de residencia de estos gases oxidantes en el lecho del catalizador durante los tratamientos de activación ayuda a aprovechar las propiedades texturales del soporte a la hora de preparar catalizadores muy dispersos, con la totalidad de las especies metálicas localizadas en el interior de los mesoporos [50].

Con el objetivo de estudiar las causas que provocan la dependencia de la dispersión metálica con la longitud de poro en los catalizadores RuCo/SBA15 sintetizados en este estudio, se monitorizó, mediante TPO-MS, el tratamiento de calcinación en flujo de aire para muestras seleccionadas que poseen poros con el mismo diámetro (11 $\mathrm{nm})$ pero longitudes marcadamente diferentes. La Fig. 5.26 muestra los perfiles de TPO-MS para los fragmentos de $\mathrm{m} / \mathrm{z}=30\left(\mathrm{NO}^{+}\right), 44\left(\mathrm{~N}_{2} \mathrm{O}^{+}\right)$y $46\left(\mathrm{NO}_{2}{ }^{+}\right)$, correspondientes a los gases $\mathrm{NO}_{2}$ y $\mathrm{N}_{2} \mathrm{O}$, para los catalizadores Co/11SBA_L y Co/11SBA_C. En ambos casos se detectan $\mathrm{NO}_{2}$ (fragmentos $\mathrm{NO}_{2}^{+}$y $\mathrm{NO}^{+}$) y $\mathrm{N}_{2} \mathrm{O}$ en el rango de temperaturas $80-250^{\circ} \mathrm{C}$. No obstante, se pueden observar algunas diferencias significativas en la forma, y en ciertos casos, en la intensidad 
relativa de los perfiles para ambas muestras. Así, la detección de óxidos de nitrógeno en los gases que dejan la muestra comienza alrededor de $95 \circ \mathrm{C}$ para ambos catalizadores. Sin embargo, el perfil de TPO-MS para Co/11SBA_L es más ancho y ambas especies $\left(\mathrm{NO}_{2}\right.$ y $\left.\mathrm{N}_{2} \mathrm{O}\right)$ se detectan hasta una temperatura de $240 \circ \mathrm{C}$, mientras que los gases están virtualmente libres de óxidos de nitrógeno a partir de 200ㄷ en el caso de Co/11SBA_C. El hecho de que los gases derivados de la descomposición del nitrato de Co estén en contacto con las especies metálicas a temperaturas más elevadas en el caso de Co/11SBA_L puede ser la razón para la menor dispersión metálica (mayor $\left.d\left(\mathrm{CO}_{3} \mathrm{O}_{4}\right)_{\mathrm{x}}\right)$ observada para este catalizador.

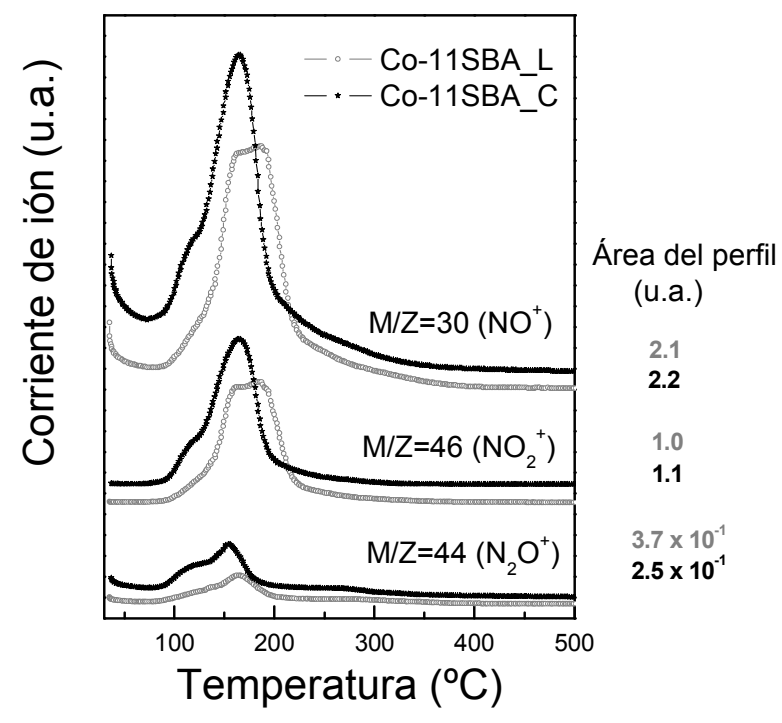

Figura 5.26: Perfiles de TPO-MS obtenidos durante la calcinación de los catalizadores Co/11SBA_L y Co/11SBA_C.

Considerando difusión de tipo Knudsen, que es el mecanismo de difusión gaseosa más probable en el interior de los mesoporos unidimensionales de las SMO [71,72], la aplicación del criterio de Gorte [73,74] indica que las etapas de difusión contribuirán de forma no 
despreciable a los perfiles de TPO-MS para DP $\leq 9 \mathrm{~nm}$. Así pues, probablemente, durante la descomposición térmica de los precursores metálicos que resulta en eventos de bloqueo de poro, el diámetro de poro efectivo para el escape de los gases derivados de dicha descomposición es inferior a este valor. En estas condiciones, las velocidades de difusión y/o readsorción contribuyen al perfil de TPO-MS. Se infiere, de este modo, que la emisión retrasada de los gases derivados de los nitratos durante la activación de Co/11SBA_L, en comparación con Co/11SBA_C, resulta de un mayor tiempo de residencia de estas especies gaseosas en los mesoporos largos del primero.

Además, a pesar de que no se observan diferencias significativas en el área del perfil de detección de los fragmentos $\mathrm{NO}^{+}$y $\mathrm{NO}_{2}^{+}$para ambas muestras, el área bajo el perfil para el fragmento $\mathrm{N}_{2} \mathrm{O}^{+}$es un $34 \%$ menor en el caso de Co/11SBA_L, como una evidencia adicional de que algunas reacciones secundarias para $\mathrm{N}_{2} \mathrm{O}$ (probablemente actuando como oxidante) ocurren en una mayor extensión durante la calcinación de Co/11SBA_L como consecuencia del mayor tiempo de residencia de los gases generados dentro de los mesoporos de mayor longitud. De acuerdo a la dependencia cuadrática del tiempo de difusión unidimensional con la longitud de difusión (ecuación de Einstein-Smoluchowski $[75,76]$ ), un incremento de 20 veces en la longitud de poro, como el que tiene lugar entre 11SBA_L y 11SBA_C, tiene como consecuencia un incremento del tiempo de residencia en el poro unidimensional de 400 veces. Estas diferencias en el tiempo de residencia de las especies gaseosas oxidantes $\mathrm{NO}_{\mathrm{x}}$ en los mesoporos 1D, favoreciendo el sinterizado de los cristales de óxido de Co en forma de agregados con morfología de nanorods (Fig. 5.25-a), sirve para explicar la dependencia de la dispersión metálica con la longitud del poro en los catalizadores RuCo/SBA15 calcinados. 


\subsubsection{Tratamiento de reducción en hidrógeno.}

Los perfiles de $\mathrm{H}_{2}$-TPR para los catalizadores RuCo/SBA-15 se muestran en la Fig. 5.27. En todos los casos se registra un consumo de $\mathrm{H}_{2}$ de poca cuantía relativa en el rango de temperaturas de $80-120^{\circ} \mathrm{C}$, que se relaciona con la reducción de óxidos de Ru. Adicionalmente, se observan dos señales principales de reducción a temperaturas de 173-231ํC (señal I a una temperatura $T_{1, \text { máx }}$ ) y $306-368^{\circ} \mathrm{C}$ (señal II a $T_{2, \text { máx }}$ ), que corresponden a la reducción de $\mathrm{Co}_{3} \mathrm{O}_{4}$ en dos etapas: $\mathrm{Co}_{3} \mathrm{O}_{4} \rightarrow \mathrm{CoO}$ (señal I) y $\mathrm{CoO} \rightarrow \mathrm{Co}^{0}$ (señal II) [77]. Por último, se observa un consumo de $\mathrm{H}_{2}$ a elevada temperatura $\left(732^{\circ} \mathrm{C}\right)$, que es típico de especies de silicato de Co, exclusivamente en el catalizador Co/7SBA_L.

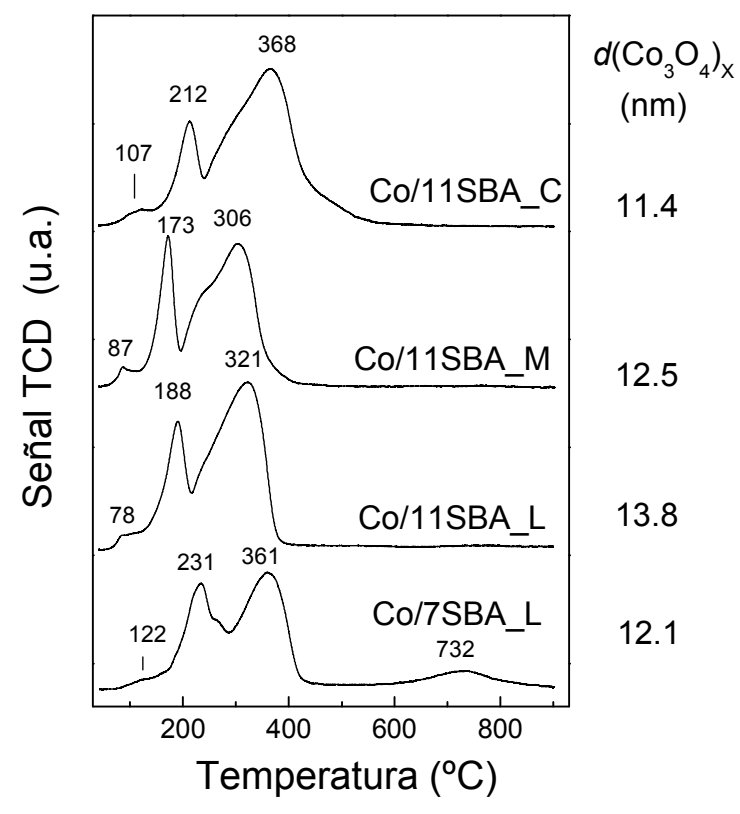

Figura 5.27: Perfiles de $\mathrm{H}_{2}$-TPR para los catalizadores $\mathrm{RuCO} / \mathrm{SBA}-15$ calcinados. En la figura se incluye el diámetro de partícula de $\mathrm{CO}_{3} \mathrm{O}_{4}$ obtenido mediante XRD.

Como se observa en la Fig. 5.27, existen variaciones de hasta $60^{\circ} \mathrm{C}$ tanto en $T_{1, \text { máx }}$ como en $T_{2 \text {,máx }}$ entre las diferentes muestras. En el capítulo 3 se mostró que la temperatura a la que se activan estas dos etapas de 
reducción dependen del tamaño de partícula de $\mathrm{Co}_{3} \mathrm{O}_{4}[52,78]$. En el presente caso, sin embargo, no se encuentra una correlación entre las temperaturas de reducción y $d\left(\mathrm{CO}_{3} \mathrm{O}_{4}\right)$, cuyos valores se han incluido en la Fig. 5.27, de modo que $T_{1 \text {,máx }}$ y $T_{2 \text {,máx }}$ toman los valores mínimos para $\mathrm{Co} / 11 \mathrm{SBA}$ M, que presenta un valor de $d\left(\mathrm{CO}_{3} \mathrm{O}_{4}\right)_{\mathrm{x}}=12.5 \mathrm{~nm}$ intermedio. En este sentido, en la sección 5.3.2.4 y en estudios previos se sugirió que el tiempo de residencia del agua formada en los procesos de reducción en el interior de los poros del catalizador puede tener una influencia no despreciable sobre la cinética de reducción. Así, un mayor tiempo de residencia intra-poro resulta en una cinética de reducción más lenta, e incluso puede promover la formación de silicatos de Co por reacción de las fases metálicas con el soporte $[36,49,79]$. De este modo, el hecho de que $T_{1, \text { máx }}$ y $T_{2 \text {,máx }}$ pasen por un mínimo cuando el tamaño de nanopartícula se incrementa de 11.4 a $13.8 \mathrm{~nm}$ en el orden Co/11SBA_C < Co/11SBA_M < Co/11SBA_L para la serie de catalizadores de poro ancho se puede explicar por la combinación de las influencias tanto del tamaño de nanopartícula de $\mathrm{Co}_{3} \mathrm{O}_{4}$ como de la evacuación del agua por difusión sobre la cinética de reducción. De hecho, la consideración de un tiempo de difusión para el agua progresivamente más corto cuando se reduce la longitud de los poros del soporte en el orden Co/11SBA_L > Co/11SBA_M > Co/11SBA_C permite racionalizar los comportamientos observados en los perfiles de $\mathrm{H}_{2}$-TPR. EI mismo argumento explicaría la formación de silicatos de Co (proceso de reducción a $732^{\circ} \mathrm{C}$ ) en el catalizador Co/7SBA_L, de poro más estrecho.

Asimismo, y en línea con esta explicación, el mayor grado de sinterizado metálico que se observa durante el tratamiento de reducción de las muestras de poro largo, como se comentó en la sección 5.6.2.3, puede tener su origen en un mayor tiempo de residencia del agua formada en el interior de la estructura porosa del catalizador, lo que promueve los 
fenómenos de movilidad y aglomeración de las especies metálicas.

Finalmente, resta comentar que todos los catalizadores alcanzan grados de reducción (GR) muy elevados (85-100\%) tras el tratamiento de reducción a 400 ㅇ C en flujo de $\mathrm{H}_{2}$ (Tabla 5.10), encontrándose los menores valores (85-87\%) para los catalizadores Co/11SBA_C y Co/7SBA_L debido a la mayor $\mathrm{T}_{2 \text {, máx }}$ de su perfil de $\mathrm{H}_{2}$-TPR $\left(361-368^{\circ} \mathrm{C}\right) \mathrm{y}$, adicionalmente, a la presencia de especies de silicato de Co en el último.

\subsubsection{Resultados catalíticos.}

Las propiedades catalíticas de los catalizadores RuCo/SBA-15 se recogen en la Tabla 5.11. Como se observa, los CTY iniciales (CTY, extrapolados a tiempo de reacción cero) toman valores en el rango $245 \cdot 10^{-3}$. $408 \cdot 10^{-3} \mathrm{~mol} \mathrm{CO} / \mathrm{g}_{\mathrm{co}} \cdot \mathrm{h}$. No obstante, la actividad inicial normalizada por centro metálico superficial $\left(\mathrm{TOF}_{0}\right)$ permanece prácticamente constante en el rango de $6.9 \cdot 10^{-2}-7.9 \cdot 10^{-2} \mathrm{~s}^{-1}$, con una desviación estándar de tan sólo el $7 \%$. La igualdad en $\mathrm{TOF}_{0}$ indica que los valores de $\mathrm{CTY}_{0}$ vienen determinados, fundamentalmente, por la dispersión metálica y el grado de reducción de los catalizadores (Tabla 5.10).

Tabla 5.11: Actividad catalítica para los catalizadores RuCo/SBA-15. Condiciones de reacción: $T=220{ }^{\circ} \mathrm{C}, \mathrm{P}=2.0 \mathrm{MPa}, \mathrm{H}_{2} / \mathrm{CO}=2$.

\begin{tabular}{|c|c|c|c|c|}
\hline \multirow[b]{2}{*}{ Catalizador } & \multicolumn{4}{|c|}{ Actividad catalítica } \\
\hline & $\begin{array}{c}\mathrm{CTY}_{0}{ }^{\mathrm{a}} \\
\left(10^{-3} \mathrm{~mol} \mathrm{CO} / \mathrm{g}_{\mathrm{Co}} \cdot \mathrm{h}\right)\end{array}$ & $\begin{array}{c}\mathrm{CTY}_{\mathrm{e}}^{\mathrm{b}} \\
\left(10^{-3} \mathrm{~mol} \mathrm{CO} / \mathrm{g}_{\mathrm{Co}} \cdot \mathrm{h}\right)\end{array}$ & $\begin{array}{c}\Delta \mathrm{CTY}^{\mathrm{C}} \\
(\%)\end{array}$ & $\begin{array}{c}\mathrm{TOF}_{0}{ }^{\mathrm{d}} \\
\left(10^{-2} \mathrm{~s}^{-1}\right)\end{array}$ \\
\hline Co/11SBA_L & 245 & 154 & 37 & 7.4 \\
\hline Co/11SBA_M & 408 & 285 & 30 & 7.9 \\
\hline Co/11SBA_C & 367 & 269 & 26 & 7.0 \\
\hline Co/7SBA_L & 254 & 149 & 42 & 6.9 \\
\hline \multicolumn{5}{|c|}{$\begin{array}{l}{ }^{a} \text { Rendimiento temporal por masa de Co al inicio del experimento, extrapolado a tiempo de reacción } \\
\text { cero. } \\
{ }^{b} \text { Rendimiento temporal por masa de Co en el estado pseudo-estacionario. Valor medio para el } \\
\text { segundo día de reacción }\left(t_{r}=8-16 \mathrm{~h}\right) \text {. } \\
{ }^{c} \text { Pérdida porcentual de } C T Y \text { durante el estado transitorio, }\left[\left(C T Y_{0}-C T Y_{e}\right) / C T Y_{0}\right] \times 100 \text {. } \\
{ }^{d} \text { Frecuencia de turnover inicial, extrapolada a tiempo de reacción cero. Basada en la cuantificación } \\
\text { de átomos metálicos superficiales mediante quimisorción de } \mathrm{H}_{2} \text {. }\end{array}$} \\
\hline
\end{tabular}


En todos los casos, tiene lugar un descenso en el CTY durante las primeras 5-6 horas de reacción. Después de este estado transitorio, la actividad alcanza un comportamiento pseudo-estacionario ( $t=6-16 \mathrm{~h}$ ) en el que tienen lugar variaciones mucho menores en la actividad, como ya se ha visto para otros experimentos catalíticos recogidos en esta memoria. Como se muestra en la Tabla 5.11, la pérdida de CTY es de entre un $26 \%$ y un $42 \%$ del valor inicial y está relacionada con la textura y la morfología del soporte catalítico, no existiendo una correlación evidente con la dispersión metálica. Así pues, el catalizador de poro más estrecho Co/7SBA_L muestra la mayor pérdida de actividad (42\%) durante el estado transitorio, mientras que esta pérdida decrece del $37 \%$ al $26 \%$ cuando se reduce la longitud de poro del soporte en el orden 11SBA_L > 11SBA_M > 11SBA_C para la serie de catalizadores de poro ancho. Estas pérdidas de actividad experimentadas durante las primeras horas de reacción se han adscrito al llenado progresivo de los poros del catalizador con hidrocarburos líquidos, dando lugar a un descenso en la velocidad de difusión del CO desde la fase gas externa a los centros activos metálicos $[54,55]$ y la textura del soporte tiene una influencia muy marcada sobre la magnitud de estas restricciones difusionales, como se evidenció en la primera parte de este capítulo [66]. En el presente estudio, el incremento en DP en 11SBA_x con respecto a 7SBA_L, así como la reducción del camino de difusión intra-poro mediante la reducción progresiva de la LP en el orden 11SBA_L > 11SBA_M > 11SBA_C, facilitan el acceso difusional de CO a los centros activos, resultando en menores pérdidas de actividad durante el estado transitorio de la reacción.

En el estado pseudo-estacionario, los valores de $\mathrm{CTY}_{\mathrm{e}}$ oscilan en el rango de $149 \cdot 10^{-3}-285 \cdot 10^{-3} \mathrm{~mol} \mathrm{CO} / \mathrm{g}_{\mathrm{Co}} \cdot \mathrm{h}$. Conviene destacar que, para los catalizadores de poro ancho y corto (Co/11SBA_C y Co/11SBA_M), su elevada actividad inicial, junto con los menores valores de $\triangle C T Y$, dan como 
resultado valores de $\mathrm{CTY}_{\mathrm{e}}$ en el rango de $269 \cdot 10^{-3}-285 \cdot 10^{-3} \mathrm{~mol} \mathrm{CO} / \mathrm{g}_{\mathrm{Co}} \cdot \mathrm{h}$, que son entre un $31 \%$ y un $86 \%$ mayores que los correspondientes para los catalizadores $\mathrm{RuCo} / \mathrm{Al}_{2} \mathrm{O}_{3}$ preparados sobre $\mathrm{y}^{-} \mathrm{Al}_{2} \mathrm{O}_{3}$ comercial, recogidos en la sección 5.3.3.2, bajo condiciones de operación similares. De hecho, estos valores de CTY se encuentran entre los más elevados descritos para catalizadores de FT basados en Co, de acuerdo a la Fig. 5.28 en la que se recogen valores de CTY descritos en varios trabajos científicos, alguno de los cuales emplean soportes mesoestructurados o protocolos de activación optimizados (calcinación en flujo de $\mathrm{NO} / \mathrm{He}$, por ejemplo) para lograr dispersiones metálicas elevadas y tamaños de nanopartícula homogéneos. Este mayor "aprovechamiento" catalítico del metal se alcanza gracias a una estrecha distribución de nanopartículas de $\mathrm{Co}^{0}$ centrada alrededor del valor óptimo de aprox. $10 \mathrm{~nm}$, determinado en el capítulo 3 de esta memoria, que se obtiene cuando se emplean mesoestructuras silíceas SBA-15 de poro ancho $(11 \mathrm{~nm})$ y poros relativamente cortos $(\leq 1.2 \mu \mathrm{m})$ como soportes catalíticos. 


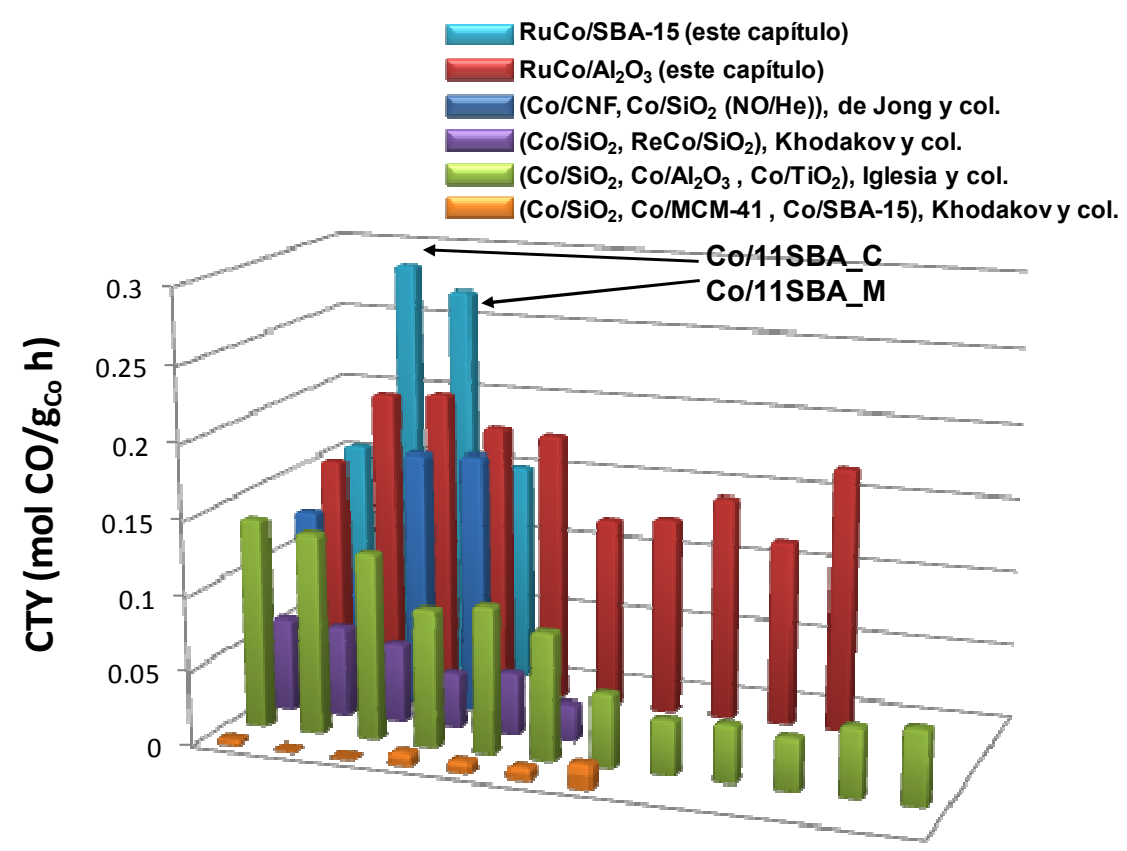

Figura 5.28: Comparación de los valores de CTY obtenidos con los catalizadores RuCo/SBA-15 con una colección de valores de CTY para diferentes catalizadores basados en Co, extraídos de esta memoria y de otros trabajos científicos (ver leyenda).

En el estado pseudo-estacionario, las selectividades a las diferentes fracciones de hidrocarburos, a un 55\% de conversión de CO, se incluyen en la Tabla 5.12.

Tabla 5.12: Selectividad catalítica y productividad para los catalizadores RuCo/SBA15. Condiciones de reacción: $T=220{ }^{\circ} \mathrm{C}, P=2.0 \mathrm{MPa}, X_{\mathrm{CO}}=55 \pm 2 \%, \mathrm{H}_{2} / \mathrm{CO}=2$.

\begin{tabular}{|c|c|c|c|c|c|}
\hline \multirow{2}{*}{ Catalizador } & \multicolumn{4}{|c|}{ Selectividad Hidrocarburos (\%C) } & \multirow{2}{*}{ P. Diesel ${ }^{2}$} \\
\hline & $\mathrm{CH}_{4}$ & $\mathrm{C}_{2}-\mathrm{C}_{4}$ & $\mathrm{C}_{5+}$ & $\mathrm{C}_{13}-\mathrm{C}_{22}$ & \\
\hline Co/11SBA_L & 12.8 & 11.2 & 76.0 & 26.8 & 83 \\
\hline Co/11SBA_M & 10.1 & 9.2 & 80.8 & 33.0 & 188 \\
\hline Co/11SBA_C & 9.5 & 8.6 & 81.9 & 32.3 & 174 \\
\hline Co/7SBA_L & 13.5 & 14.0 & 72.5 & 24.6 & 73 \\
\hline
\end{tabular}

a Productividad para la fracción de hidrocarburos en el rango del diesel $\left(C_{13}-C_{22}\right)$ en $10^{-4} \mathrm{~mol} /\left(g_{\text {cat }} \cdot h\right)$. 
El empleo de catalizadores de poro ancho Co/11SBA_ $x$ da lugar a selectividades a la fracción de hidrocarburos líquidos $\left(C_{5+}\right)$ un 5-13\% superiores respecto al catalizador con diámetro de poro más estrecho. A su vez, en la serie Co/11SBA_x una disminución progresiva de la longitud de poro en el sentido Co/11SBA_L>...>Co/11SBA_C da lugar a un incremento en la selectividad a $\mathrm{C}_{5+}$ desde el 76.0 hasta el $81.9 \%$. Los catalizadores de poro corto (Co/11SBA_M y Co/11SBA_C) son, a su vez, los más selectivos a la fracción en el rango del diesel $\left(\mathrm{C}_{13}-\mathrm{C}_{22}\right)$. La combinación de unas superiores actividad y selectividad catalíticas para estos catalizadores de poro corto resulta en las máximas productividades a la fracción de hidrocarburos en el rango del diesel ((174-188) $\left.10^{-4} \mathrm{molC} / \mathrm{g}_{\mathrm{cat}} \cdot \mathrm{h}\right)$. Estas productividades son un $45-150 \%$ superiores a las obtenidas con los catalizadores $20 \mathrm{Co} / \mathrm{Al}_{2} \mathrm{O}_{3}$ estudiados en la primera parte de este capítulo. Por tanto, el empleo de mesoestructuras de poro ancho y morfología no-convencional (poros cortos) como soportes catalíticos da lugar a nuevos catalizadores más activos y selectivos a destilados medios.

\subsubsection{Conclusiones.}

Las principales conclusiones que se extraen de esta segunda parte del capítulo son:

1. El empleo de mesoestructuras tipo SBA-15 con morfologías no convencionales, presentando poros cortos $(\leq 1.2 \mu \mathrm{m})$ para preparar catalizadores de Co para la SFT $(1 \% \mathrm{Ru}, 20 \% \mathrm{Co})$ da lugar a mayores dispersiones metálicas que en el caso de utilizar SBA-15 de morfología convencional, con poros muy largos $(>5 \mu \mathrm{m})$ y curvos.

2. El empleo de soportes mesoestructurados con poros cortos $(\leq 1.2 \mu \mathrm{m})$, en lugar de mesoestructuras de morfología convencional con poros largos y curvados, reduce los tiempos de residencia para los gases 
oxidantes derivados de los nitratos y el $\mathrm{H}_{2} \mathrm{O}$, generados durante la calcinación y la reducción de los catalizadores, respectivamente, lo que resulta en dispersiones metálicas mejoradas en los catalizadores finales.

3. La mayor dispersión metálica de los catalizadores RuCo/SBA-15 soportados sobre mesoestructuras no convencionales, de poros cortos, resulta en diámetros de nanopartícula cercanos al valor óptimo de aprox. $10 \mathrm{~nm}$ y, por ende, en actividades catalíticas muy elevadas (>250 $\left.\cdot 10^{-3} \mathrm{~mol} \mathrm{CO} / \mathrm{g}_{\mathrm{co}} \cdot \mathrm{h}\right)$, que se encuentran entre las más altas descritas para catalizadores de Co en las condiciones de reacción empleadas.

4. En estado pseudo-estacionario y a niveles de conversión de relevancia industrial (55\%), los soportes de poros cortos dan lugar, a su vez, a selectividades mejoradas a la fracción de productos de interés (destilados medios) en comparación con los catalizadores preparados sobre SBA-15 convencional, los cuales presentan mayores selectividades a las fracciones de productos ligeros.

5. La longitud de los mesoporos del soporte mesoestructurado SBA-15 (0.3-5.7 $\mu \mathrm{m}$ ) es más influyente en la dispersión metálica y la actividad catalítica que el diámetro de poro (7-11 nm), lo que sugiere que la longitud del poro es un parámetro clave en la optimización de catalizadores de Co mesoestructurados para la SFT. 


\section{Referencias.}

${ }^{1}$ C.S. Kellner, A.T. Bell, J. Catal. 70 (1981) 418.

${ }^{2}$ Y. Wu, G. Cheng, K. Katsov, S.W. Sides, J. Wang, J. Tang, G.H. Fredrickson, M. Moscovits, G.D. Stucky, Nature Mat. 3 (2004) 816.

${ }^{3}$ X. Chen, M. Knez, A. Berger, K. Nielsch, U. Gösele, M. Steinhart, Angew. Chem. Int. Ed. 46 (2007) 6829 .

${ }^{4}$ H.C. Lee, H.J. Kim, S.H. Chung, K.H. Lee, H.C. Lee, J.S. Lee, J. Am. Chem. Soc. 125 (2003) 2882.

${ }^{5}$ H.C. Lee, H.J. Kim, C.H. Rhee, K.H. Lee, J.S. Lee, S.H. Chung, Micropor. Mesop. Mat. 79 (2005) 61 .

${ }^{6}$ H.Y. Zhu, J.D. Riches, J.C. Barry, Chem. Mater. 14 (2002) 2086.

${ }^{7}$ Y. Lan, X. Gao, H. Zhu, Z. Zheng, T. Yan, F. Wu, S.P. Ringer, D. Song, Adv. Funct. Mater. 15 (2005) 1310.

${ }^{8}$ K. Zhou, X. Wang, X. Sun, Q. Peng, Y. Li, J. Catal. 229 (2005) 206.

${ }^{9}$ G. Glaspell, H.M.A. Hassan, A. Elzatahry, L. Fuoco, N.R.E. Radwan, M.S. El-Shall, J. Phys. Chem. B 43 (2006) 21387.

10 J-L Blin, A. Léonard, Z-Y Yuan, L. Gigot, A. Vantomme, A.K. Cheetham, B-L Su, Angew. Chem. Int. Ed. 42 (2003) 2872.

${ }^{11}$ K.S.W. Sing, D.H. Everett, R.A.W. Haul, L. Moscou, R.A. Pierotti, J. Rouquérol, T. Siemieniewska, Pure \& Appl. Chem. 57-4 (1985) 603.

${ }^{12}$ ø. Borg, S. Eri, E.A. Blekkan, S. Storsæter, H. Wigum, E. Rytter, A. Holmen, J. Catal. 248 (2007) 89.

${ }^{13}$ T-Z Ren, Z-Y Yuan, B-L Su, Langmuir 20 (2004) 1531.

${ }^{14}$ J.G. Goodwin, D.O. Goa, S. Erdal, F.H. Rogan, Appl. Catal. 24 (1986) 199.

${ }^{15}$ S. Uchiyama, B.C. Gates, J. Catal. 110 (1988) 388.

${ }^{16}$ H. Abrevaya, M. J. Cohn, W. M. Targos, H. J. Robota, Catal. Lett. 7 (1990) 183.

${ }^{17}$ A.Y. Khodakov, A. Griboval-Constant, R. Bechara, V.L. Zholobenko, J. Catal. 206 (2002) 230 .

${ }^{18}$ S. Storsæter, ø. Borg, E. A. Blekkan, A. Holmen, J. Catal. 231 (2005) 405.

${ }^{19}$ H. Xiong, Y. Zhang, S. Wang, J. Li, Catal. Commun. 6 (2005) 512.

${ }^{20}$ A.M. Saib, M. Caeys, E. van Steen, Catal. Today 71 (2002) 395.

${ }^{21}$ A.Y. Khodakov, A. Griboval, R. Bechara, F. Villain, J. Phys. Chem. B 105 (2001) 9805.

${ }^{22}$ J. Panpranot, J. G. Goodwin Jr., A. Sayari, Catal. Today 77 (2002) 269.

${ }^{23}$ P. Concepción, C. López, A. Martínez, V.F. Puntes, J. Catal. 228 (2004) 321.

24 A.T. Bell, Catal. Rev. Sci. Eng., 23 (1981) 203. 
${ }^{25}$ J. van Loosdrecht, B. Balzhinimaev, J.-A. Dalmon, J. W. Niematnsverdriet, S.V. Tsybulya, A.M. Saib, P.J. van Berge, J.L. Visagie, Catal. Today 123 (2007) 293.

${ }^{26}$ E. Iglesia, S.C. Reyes, R.J. Madon, J. Catal. 129 (1991) 238.

${ }^{27}$ R.J. Madon, E. Iglesia, J. Catal. 149 (1994) 428.

${ }^{28}$ S. Eri, J. Kinnari, D. Schanke, A-M. Hilmen, patente US0077737 (2004).

${ }^{29}$ J.S. Beck, C.T.-W. Chu, I.D. Johnson, C.T. Kresge, M.E. Leonowicz, W.J. Roth, J.C. Vartuli, patente WO 9111390 (1991).

${ }^{30}$ C.T. Kresge, M.E. Leonowicz, W.J. Roth, J.C. Vartuli, J.S. Beck, Nature 359 (1992) 710.

${ }^{31}$ D.T. On, D. Desplantier-Giscard, C. Danumah, S. Kaliaguine, Appl. Catal. A 253 (2003) 545.

32 A. Taguchi, F. Schüth, Microp. Mesop. Mater. 77 (2005) 1.

${ }^{33}$ P. Van der Voort, C. Vercaemst, D. Schaubroeck, F. Verpoort, Phys. Chem. Chem. Phys. 10 (2008) 347.

${ }^{34}$ A.Y. Khodakov, A. Griboval-Constant, R. Bechara, F. Villain, J. Phys. Chem. B 105 (2001) 9805.

${ }^{35}$ H. Xiong, Y. Zhang, K. Liew, J. Li, Appl. Catal. A 295 (2008) 68.

${ }^{36}$ J. Panpranot, J.G. Goodwin Jr., A. Sayari, J. Catal. 211 (2002) 530.

${ }^{37}$ M.T. Bore, H.N. Pham, E.E. Switzer, T.L. Ward, A. Fukuoka, A.K. Datye, J. Phys. Chem B 109 (2005) 2873.

${ }^{38}$ D. Zhao, J. Feng, Q.S. Huo, N. Melosh, G.H. Fredrickson, B.F. Chmelka, G.D. Stucky, Science 279 (1998) 548.

${ }^{39}$ D. Zhao, Q. Huo, J. Feng, B.F. Chmelka, G.D. Stucky, J. Am. Chem. Soc. 120 (1998) 6024.

${ }^{40}$ D.R. Rolison, Science 14 (2003) 1698.

${ }^{41}$ A.H. Janssen, P. Van der Voort, A.J. Koster, K.P. de Jong, Chem. Commun. (2002) 1632.

${ }^{42}$ Y. Wang, Y. Shi, D. Zhao, Chem. Commun. (2007) 897.

43 J. Wang, J. Zhang, B.Y. Asoo, G.D. Stucky, J. Am. Chem. Soc. 125 (2003) 13966.

${ }^{44}$ C. Boissiere, A. Larbot, A. Van der Lee, P.J. Kooyman, E. Prouzet, Chem. Mater. 12 (2000) 2902.

${ }^{45}$ X. Ji, K.T. Lee, M. Monjauze, L.F. Nazar, Chem. Commun. (2008) 4288.

${ }^{46}$ H. Zhang, J. Sun, D. Ma, X. Bao, A. Klein-Hoffmann, G. Weinberg, D. Su, R. Schlögl, J. Am. Chem. Soc. 126 (2008) 7440.

47 A. Martínez, G. Prieto, Top. Catal. 52 (2009) 75.

48 A.Y. Khodakov, V.L. Zholobenko, R. Bechara, D. Durand, Microp. Mesop. Mater. 79 (2005) 29.

${ }^{49}$ A. Martínez, C. López, F. Márquez, I. Díaz, J. Catal. 220 (2003) 486.

${ }^{50}$ J.R.A. Sietsma, J.D. Meeldijk, J.P. den Breejen, M. Versluijs-Helder, A.J. van Dillen, P.E. de Jongh, K.P. de Jong, Angew. Chem. 119 (2007) 4631. 
${ }^{51}$ G.L. Bezemer, J.H. Bitter, H.P.C.E. Kuipers, H. Oosterbeek, J.E. Holewijn, X. Xu, F. Kapteijn, A.J. van Dillen, K.P. de Jong, J. Am. Chem. Soc. 128 (2006) 3956.

${ }^{52}$ G. Prieto, A. Martínez, P. Concepción, R. Moreno-Tost, J. Catal. 266 (2009) 129.

${ }^{53}$ A. Martínez, G. Prieto, J. Catal. 245 (2007) 470.

${ }^{54}$ E. Iglesia, S.C. Reyes, R.J. Madon, J. Catal. 129 (1991) 238.

55 R.J. Madon, E. Iglesia, J. Catal. 149 (1994) 428.

${ }^{56}$ K.S.W. Sing, D.H. Everett, R.A.W. Haul, L. Moscou, R.A. Pierotti, J. Rouquérol, T. Siemieniewska, Pure. Appl. Chem. 57 (1985) 603.

${ }^{57}$ A. Galarneau, H. Cambon, F. Di Renzo, R. Ryoo, M. Choi, F. Fajula, New J. Chem. 27 (2003) 73.

${ }^{58}$ P.F. Fulvio, S. Pikus, M. Jaroniec, J. Mater. Chem. 15 (2005) 5049.

${ }^{59}$ H. Zhang, J. Sun, D. Ma, G. Weinberg, D.S. Su, X. Bao, J. Phys. Chem. B 110 (2006) 25908.

${ }^{60}$ S.P. Rigby, M.J. Watt-Smith, R.S. Fletcher, J. Catal. 227 (2004) 68.

${ }^{61}$ W. Zou, R.D. González, Catal. Today 15 (1992) 443.

${ }^{62}$ T. López, L. Herrera, R. Gómez, W. Zou, K. Robinson, R.D. González, J. Catal. 136 (1992) 621.

${ }^{63}$ P. Van der Voort, P.I. Ravikovitch, K.P. de Jong, A.V. Neimark, A.H. Janssen, M.

Benjelloun, E. van Bavel, P. Cool, B.M. Weckhuysen, E.F. Vansant, Chem. Commun. (2002) 1010.

${ }^{64}$ J.R.A. Sietsma, H. Friedrich, A. Broersma, M. Versluijs-Helder, A. Jos van Dillen, P. E. de Jongh, K.P. de Jong, J. Catal. 260 (2008) 227.

${ }^{65}$ A.Y. Khodakov, A. Griboval-Constant, R. Bechara, V.L. Zholobenko, J. Catal. 206 (2002) 230.

${ }^{66}$ A. Martínez, G. Prieto, J. Rollán, J. Catal. 263 (2009) 292.

${ }^{67}$ H. Friedrich, J.R.A. Sietsma, P.E. de Jongh, A.J. Verkleij, K.P. de Jong, J. Am. Chem. Soc. 129 (2007) 10249.

${ }^{68}$ J. van de Loosdrecht, S. Barradas, E.A. Caricato, N.G. Ngwenya, P.S. Nkwanyana, M.A.S. Rawat, B.H. Sigwebela, P.J. van Berge, J.L. Visagie, Top. Catal. 26 (2003) 121.

${ }^{69}$ J.R.A. Sietsma, H. Friedrich, A. Broersma, M. Versluijs-Helder, A.J. van Dillen, P.E. de Jongh, K.P. de Jong, J. Catal. 260 (2008) 227.

${ }^{70}$ J.R.A. Sietsma, J.D. Meeldijk, M. Versluijs-Helder, A. Broersma, A.J. van Dillen, P.E. de Jongh, K.P. de Jong, Chem. Mater. 20 (2008) 2921.

${ }^{71}$ V-T. Hoang, Q. Huang, M. Eic, T-O. Do, S. Laliaguine, Langmuir 21 (2005) 2051.

72 D.M. Ruthven, W.J. DeSito, S. Higgins, Chem. Eng. Sci. 64 (2009) 3201.

${ }^{73}$ J.S. Rieck, A.T. Bell, J. Catal. 85 (1984) 143.

${ }^{74}$ R.A. Demmin, R.J. Gorte, J. Catal. 90 (1984) 32.

${ }^{75}$ M. von Smoluchowski, Annalen der Physik 4(21) (1906) 756. 
${ }^{76}$ A. Eisntein, Investigations on the theory of the brownian movement, Ed. R. Fürth, Dover Public. New York (1976).

${ }^{77}$ P. Arnoldy, J.A. Moulijn, J. Catal. 93 (1985) 38.

${ }^{78}$ A.Y. Khodakov, J. Lynch, D. Bazin, B. Rebours, N. Zanier, B. Moison, P. Chaumette, J. Catal. 168 (1997) 16.

${ }^{79}$ D.G. Castner, P.R. Watson, I.Y. Chan, J. Phys. Chem. 94 (1990) 819. 


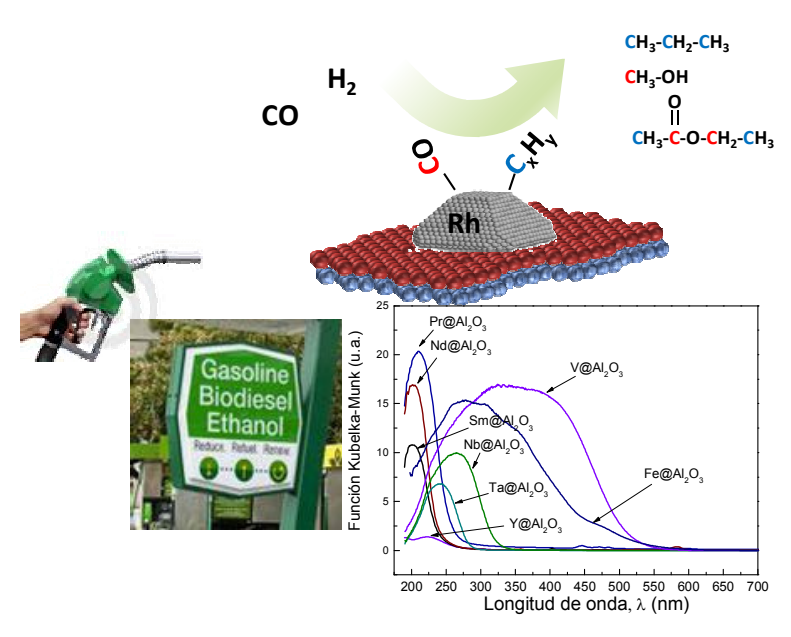

\section{APROXIMACIÓN AL EFECTO PROMOTOR EN CATALIZADORES DE Rh PARA LA SÍNTESIS SELECTIVA DE COMPUESTOS OXIGENADOS}




\subsection{Introducción.}

Como se comentó en la Introducción General, los catalizadores basados en Rh para la síntesis selectiva de compuestos oxigenados (SSO) son una alternativa que presenta importantes ventajas respecto a otros sistemas catalíticos, como una baja actividad relativa para la reacción WGSR, una elevada selectividad a compuestos oxigenados $C_{2+}$ de carácter lineal, sin necesidad de la presencia de azufre en los gases reactivos, así como la exclusiva propiedad de dirigir la SSO alternativamente hacia alcoholes o hacia otros oxigenados de gran interés comercial como ácidos carboxílicos o sus correspondientes ésteres, en función de la composición del catalizador y las condiciones de operación. Por otro lado, los inconvenientes que históricamente han alejado a los catalizadores de Rh de una potencial aplicación comercial, de entre los que destacan la baja disponibilidad y el elevado coste del metal, pueden solventarse con las mejoras tecnológicas más recientes en materia de gestión y recuperación de metales catalíticos, como también se comentó en la Introducción General.

La función de los óxidos metálicos promotores $\left(\mathrm{FeO}_{x}, \mathrm{VO}_{x}, \mathrm{LaO}_{x}, \mathrm{TaO}_{x}\right.$ $\mathrm{MnO}_{\mathrm{x}}$, etc) es indispensable para incrementar la actividad y la selectividad de los catalizadores de Rh, así como para dirigir la síntesis hacia uno u otro producto oxigenado mayoritario. A pesar de numerosos estudios durante las últimas décadas, aún hoy en día no se conoce cuál es el promotor o combinación de promotores óptima, en qué proporción con respecto a las fases de Rh y cuál debe ser su localización relativa respecto de las NPs de Rh para dirigir la síntesis hacia uno u otro oxigenado y minimizar la producción de hidrocarburos. Se han descrito elevadas selectividades a oxigenados para catalizadores basados en nanopartículas de Rh soportadas sobre óxidos metálicos de propiedades ácido-base y redox tan dispares como $\mathrm{V}_{2} \mathrm{O}_{5}, \mathrm{ZrO}_{2}$, $\mathrm{La}_{2} \mathrm{O}_{3}, \mathrm{ThO}_{2}$ o $\operatorname{Pr}_{6} \mathrm{O}_{11}[1,2,3]$. De hecho, un análisis de los trabajos publicados 
en este campo durante el último año evidencia la variedad de composiciones estudiadas por diferentes grupos de investigación $\left(\mathrm{LaO}_{x}-\mathrm{VO}_{x}-\mathrm{Rh} / \mathrm{SiO}_{2}, \mathrm{FeO}_{x^{-}}\right.$ $\mathrm{Rh} / \mathrm{TiO}_{2}, \mathrm{MnO}_{x}-\mathrm{FeO}_{\mathrm{x}}-\mathrm{LiO}-\mathrm{Rh} / \mathrm{SiO}_{2}$, etc), sin que exista, aparentemente, una explicación general acerca de qué requerimientos físico-químicos han de satisfacer los promotores adecuados o qué centros activos es necesario crear mediante la combinación adecuada de las fases metálicas de Rh y las fases oxídicas del promotor $\left(\mathrm{MO}_{\mathrm{x}}\right)$. La ausencia de modelos generales para este sistema catalítico ha contribuido ciertamente a la diversidad de composiciones estudiadas y también al interés científico sobre este tipo de catalizadores, que ha hecho que las limitaciones que han impedido su consideración como una alternativa desde el punto de vista comercial no hayan disminuido el número de estudios científicos publicados a lo largo de los últimos 20 años, como se recoge en la Fig. 6.1.

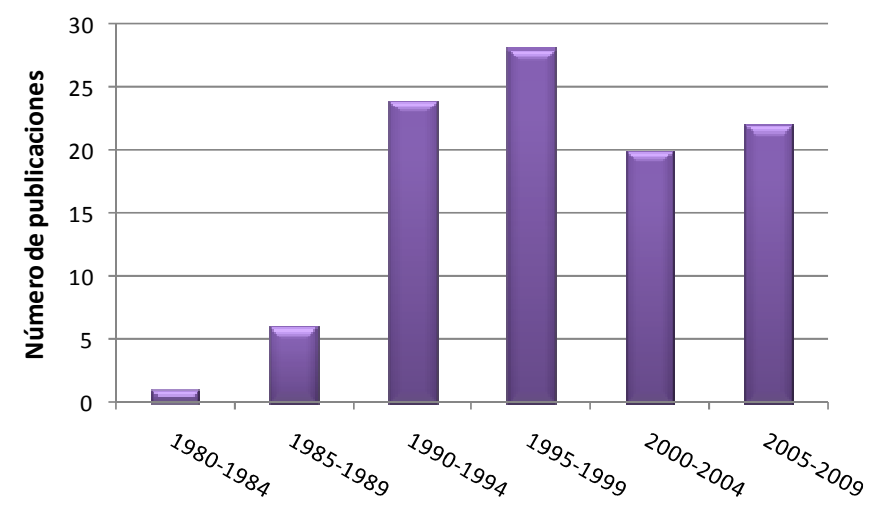

Figura 6.1: Evolución del número de publicaciones relacionadas con la SSO mediante catalizadores basados en Rodio a lo largo de los últimos 30 años. Fuente: web of knowledge (claves de búsqueda: Rhodium + oxygenates como topic) a fecha de octubre de 2009.

Queda claro, por lo tanto, que sería interesante acometer un estudio sistemático que esclarezca los requerimientos para el "efecto promotor" en estos catalizadores a la hora de maximizar la selectividad a compuestos oxigenados y minimizar la producción de hidrocarburos, así como para dirigir 
la síntesis hacia varios tipos de compuestos oxigenados. Somorjai y col. [4] llevaron a cabo un estudio exhaustivo empleando "catalizadores modelo inversos" consistentes en monocristales de Rh parcialmente recubiertos con parches de los óxidos metálicos promotores $\left(\mathrm{MO}_{\mathrm{x}}\right)$. No obstante, este estudio empleaba catalizadores demasiado diferentes de los sistemas reales, en los que la fase dispersa en forma de NPs es el Rh, y tan sólo se consideraba la actividad catalítica en la hidrogenación de $\mathrm{CO}$, es decir, no se llevaba a cabo un análisis de las implicaciones de la naturaleza del promotor en términos de selectividad.

\subsection{Planteamiento.}

En el presente capítulo se aborda un estudio sistemático del papel del promotor en catalizadores de $\mathrm{Rh}$ empleando óxidos promotores de características electrónicas muy diversas. A diferencia de estudios previos con monocristales metálicos, los catalizadores modelo a sintetizar constarán de una fase de Rh dispersa en forma de NPs sobre un soporte poroso. Adicionalmente, se han de controlar dos variables que se han descrito como influyentes en las propiedades catalíticas de los catalizadores de Rh para la SSO:

1. La dispersión metálica: el empleo de diferentes óxidos metálicos como soporte-promotor en estudios previos da lugar, generalmente, a dispersiones metálicas muy diferentes entre los distintos catalizadores, en función de las propiedades texturales del soporte. Así el área superficial de éste puede variar desde $<10 \mathrm{~m}^{2} / \mathrm{g}$ para soportes basados en $\mathrm{ZrO}_{2}, \mathrm{Pr}_{6} \mathrm{O}_{11} \circ \mathrm{V}_{2} \mathrm{O}_{5}$ hasta $>200 \mathrm{~m}^{2} / \mathrm{g}$ para catalizadores soportados sobre $\mathrm{SiO}_{2}, \mathrm{Al}_{2} \mathrm{O}_{3}$ o hidrotalcitas. Diferencias en el tamaño medio de NP de Rh pueden introducir una 
interferencia indeseada en estos estudios. De hecho se ha descrito la influencia del tamaño de NP de Rh en la actividad y selectividad de la SSO [5].

2. La localización relativa Rh-promotor y la extensión de la superficie de contacto entre ambas fases: los catalizadores modelo han de permitir controlar la disposición relativa de las fases de promotor $\left(\mathrm{MO}_{\mathrm{x}}\right)$ y $\mathrm{Rh}$ en el catalizador, siendo indispensable maximizar la superficie de contacto entre ambas fases, de modo que se maximice la densidad de centros catalíticos en la frontera $\mathrm{MO}_{\mathrm{x}}-\mathrm{Rh}$, donde se ha descrito que se desarrollan los centros selectivos hacia la formación de compuestos oxigenados [6].

Con el objetivo de satisfacer todas estas características en los catalizadores modelo, se propone el empleo de un sistema catalítico formado por un soporte poroso de elevada área superficial cuya superficie se encuentra recubierta, idealmente de manera completa, por una "monocapa" del óxido promotor $\left(\mathrm{MO}_{\mathrm{x}}\right)$, sobre el que finalmente se dispersa la fase de Rh en forma de nanopartículas. De este modo, todos los catalizadores poseen propiedades texturales similares, dictadas por las características del soporte poroso común, a la vez que se maximiza la superficie de contacto $\mathrm{MO}_{\mathrm{x}}-\mathrm{Rh}$. El soporte poroso ha de presentar determinadas características indispensables para lograr dispersar óxidos metálicos sobre su superficie de modo que se alcance un recubrimiento completo y homogéneo (idealmente una monocapa de óxido bidimensional). Tanto $\gamma-\mathrm{Al}_{2} \mathrm{O}_{3}$ como $\mathrm{SiO}_{2}$ son los soportes preferidos debido a su elevada porosidad y área superficial. Se conoce que para varios óxidos de metales de transición de interés como promotores del $\mathrm{Rh}\left(\mathrm{VO}_{\mathrm{x}}, \mathrm{NbO}_{\mathrm{x}}, \mathrm{TaO}_{\mathrm{x}}, \mathrm{TiO}_{\mathrm{x}}, \mathrm{FeO}_{\mathrm{x}}\right)$ $[4,5]$, es posible la preparación de una monocapa (recubrimientos 
superficiales de 4.5-7 átomos $/ \mathrm{nm}^{2}$ ) sobre $\gamma-\mathrm{Al}_{2} \mathrm{O}_{3}$ mientras que esto no es posible sobre $\mathrm{SiO}_{2}$, donde especies de óxido tridimensional se desarrollan a recubrimientos $<3$ átomos $/ \mathrm{nm}^{2}$. Por lo tanto, se empleará $\gamma-\mathrm{Al}_{2} \mathrm{O}_{3}$ de elevada área superficial como soporte de los catalizadores modelo $\mathrm{Rh} / \mathrm{M} @ \mathrm{Al}_{2} \mathrm{O}_{3}$.

La Fig. 6.2 recoge representaciones esquemáticas tanto para el procedimiento de preparación como para la disposición final de los constituyentes en los catalizadores modelo Rh/ $/ \mathrm{M} \mathrm{Al}_{2} \mathrm{O}_{3}$.

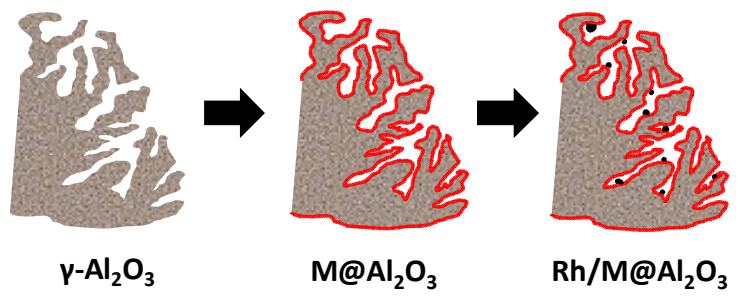

(a)

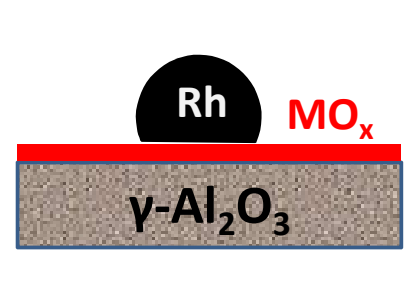

(b)

Figura 6.2: (a) Esquema de la síntesis por pasos de los catalizadores modelo $\mathrm{Rh} / \mathrm{M} @ \mathrm{Al}_{2} \mathrm{O}_{3}$ que involucra, en primer lugar, el recubrimiento de la superficie de la $\mathrm{Al}_{2} \mathrm{O}_{3}$ porosa con una "monocapa" del óxido promotor $\left(\mathrm{MO}_{x}\right)$ y, por último, la incorporación de la fase dispersa de $\mathrm{R}$; (b) representación de la ubicación relativa de las tres fases en los catalizadores $\mathrm{Rh} / \mathrm{M} @ \mathrm{Al}_{2} \mathrm{O}_{3}$.

La preparación de una monocapa de óxidos de metales de transición sobre soportes inorgánicos, como $\gamma-\mathrm{Al}_{2} \mathrm{O}_{3}$, ha sido extensamente estudiada. Generalmente se requiere del empleo de precursores orgánicos (alcóxidos o acetilacetonatos) y rutas sintéticas en condiciones anhidras para permitir una interacción coherente de estos precursores metálicos con los grupos hidroxilo superficiales del soporte y evitar la hidrólisis del precursor metálico lejos de la superficie del soporte [7]. Por el contrario, en el caso de los óxidos de lantánidos, de carácter más básico, se ha descrito que el empleo de precursores orgánicos no permite alcanzar recubrimientos de monocapa, siendo en este caso los nitratos, en 
disolución acuosa, los precursores idóneos para la preparación de monocapas $[8,9]$.

De acuerdo con una revisión exhaustiva de la literatura científica, el recubrimiento máximo en forma de óxido bidimensional (o recubrimiento de monocapa) para diferentes óxidos de metales de transición y de lantánidos sobre la superficie de $\mathrm{\gamma}-\mathrm{Al}_{2} \mathrm{O}_{3}$ se alcanza para valores de recubrimiento superficial ( $\delta$ ) entorno a 4.5-5 átomos $/ \mathrm{nm}^{2}$, como se recoge en la Tabla 6.1 para algunos ejemplos. Por su parte, el especial empaquetamiento de los átomos de oxígeno en los polioxovanadatos superficiales permite recubrimientos de hasta 7 átomos $\mathrm{V} / \mathrm{nm}^{2}$ antes del desarrollo de cristales $3 \mathrm{D}$ de $\mathrm{V}_{2} \mathrm{O}_{5}$ [10]. Para el caso de los lantánidos, no obstante, algunos autores reclaman recubrimientos sobre la superficie de $\mathrm{Y}-\mathrm{Al}_{2} \mathrm{O}_{3}$ de hasta 8-10 átomos $/ \mathrm{nm}^{2}$ antes del desarrollo de cristales de óxido 3D [11,12]. Sin embargo, se ha comprobado experimentalmente a lo largo del presente trabajo de tesis doctoral para algunos casos seleccionados ( $\operatorname{Pr}($ III) y Sm(III)) que, en las condiciones de preparación empleadas, recubrimientos superiores a 4.5-5 átomos $/ \mathrm{nm}^{2}$ dan lugar a cristales de óxidos de $\mathrm{M}(\mathrm{Pr}, \mathrm{Sm})$

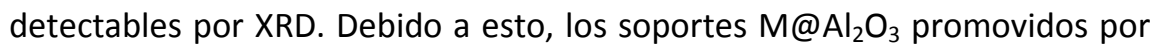
óxidos de lantánidos se han sintetizado con un recubrimiento nominal de 4.5 átomos $/ \mathrm{nm}^{2}$ (sección 2.1.2.6). 
Tabla 6.1: Recubrimientos de saturación de monocapa descritos en la literatura científica para óxidos de metales de transición y de lantánidos soportados sobre $\gamma$ $\mathrm{Al}_{2} \mathrm{O}_{3}$.

\begin{tabular}{|c|c|c|}
\hline Ref. & Sistema & $\begin{array}{c}\delta_{\text {monocapa }}{ }^{\mathrm{a}} \\
\text { (átomos } \mathrm{M} / \mathrm{nm}^{2} \text { ) }\end{array}$ \\
\hline [10] & $\mathrm{VO}_{\mathrm{x}} / \mathrm{Al}_{2} \mathrm{O}_{3}$ & 7.0 \\
\hline [10] & $\mathrm{NbO}_{x} / \mathrm{Al}_{2} \mathrm{O}_{3}$ & 5.0 \\
\hline [10] & $\mathrm{TaO}_{x} / \mathrm{Al}_{2} \mathrm{O}_{3}$ & 5.0 \\
\hline [13] & $\mathrm{FeO}_{x} / \mathrm{Al}_{2} \mathrm{O}_{3}$ & 4.7 \\
\hline [14] & $\mathrm{ZrO}_{\mathrm{x}} / \mathrm{Al}_{2} \mathrm{O}_{3}$ & 4.5 \\
\hline [15] & $\mathrm{WO}_{x} / \mathrm{Al}_{2} \mathrm{O}_{3}$ & 4.5 \\
\hline [16] & $\mathrm{LaO}_{x} / \mathrm{Al}_{2} \mathrm{O}_{3}$ & $4.5-5$ \\
\hline [17] & $\mathrm{YbO}_{\mathrm{x}} / \mathrm{Al}_{2} \mathrm{O}_{3}$ & 4.5-5 \\
\hline
\end{tabular}

Por lo tanto, para llevar a cabo el presente estudio se han preparado una serie de soportes promovidos por una monocapa de óxidos metálicos seleccionados de acuerdo a resultados previos que sugieren un efecto promotor sobre los catalizadores de Rh, que incrementa la selectividad de la SSO hacia compuestos oxigenados. Para garantizar una visión representativa del espacio de estudio, se han empleado óxidos promotores que presentan diferentes propiedades electrónicas en un amplio rango. Estos promotores (M) comprenden, por un lado, varios metales de transición de los grupos 8 (Fe(III)) [13], 5 (V(V), Nb(V), Ta(V)) [18,19,20], 4 (Ti(IV)) y 3 (Y(III)) del sistema periódico. Adicionalmente, puesto que se han descrito incrementos en la selectividad a compuestos oxigenados para catalizadores conteniendo óxidos de tierras raras tales como Ce [21], La [22], Sm [23,] o $\operatorname{Pr}[2]$ en el papel de soporte catalítico o promotor, la serie de promotores estudiada en este trabajo comprende a su vez varios lantánidos ( $\operatorname{Pr}(\mathrm{III}), \mathrm{Nd}(\mathrm{III}), \mathrm{Sm}(\mathrm{III}))$. En este punto cabe mencionar que el uso de $\mathrm{Ce}(\mathrm{IV})$ no es conveniente en el presente estudio puesto que no es posible obtener recubrimientos de monocapa de $\mathrm{CeO}_{\mathrm{x}}$ sobre $\mathrm{Al}_{2} \mathrm{O}_{3}$, tal y como se ha descrito en la literatura [24], probablemente debido a su capacidad para oxidarse $(\mathrm{Ce}(\mathrm{III}) \rightarrow \mathrm{Ce}(\mathrm{IV}))$ a 
temperaturas inferiores a las empleadas en la calcinación de los materiales $\mathrm{M} @ \mathrm{Al}_{2} \mathrm{O}_{3}$, que promueve la nucleación de cristales de $\mathrm{CeO}_{2}$ para recubrimientos superficiales $<3$ átomos $\mathrm{Ce} / \mathrm{nm}^{2}$.

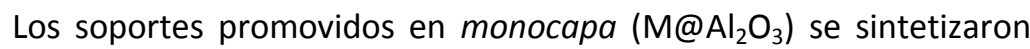
con los recubrimientos superficiales nominales recogidos en la Tabla 2.2

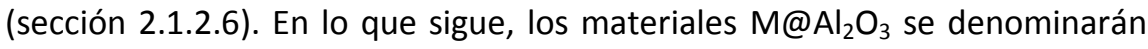
"soportes promovidos" para diferenciarlos de la $\mathrm{y}-\mathrm{Al}_{2} \mathrm{O}_{3}$ original, a pesar de que quizás el término no sea completamente adecuado puesto que las especies $\mathrm{MO}_{\mathrm{x}}$ en realidad promueven a las fases de $\mathrm{Rh}$ en los catalizadores

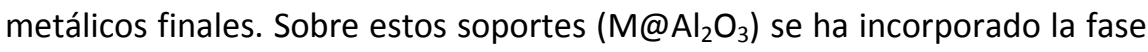
activa de Rh 2.5\%(p) (sección 2.1.3.6). A lo largo de este capítulo se estudian las propiedades físico-químicas y catalíticas de esta serie de catalizadores modelo, intentando identificar patrones generales en el mecanismo de promoción de los catalizadores de Rh para la SSO.

\subsection{Resultados y discusión.}

\subsubsection{Caracterización de los soportes catalíticos.}

\subsubsection{Composición química y propiedades texturales.}

La Tabla 6.2 recoge los contenidos de los promotores $M$ en la serie de

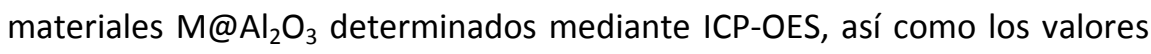
correspondientes de recubrimiento superficial. Para los soportes promovidos por óxidos de lantánidos e itrio, la disgregación química en una mezcla de $\mathrm{HCl} / \mathrm{HNO}_{3} / \mathrm{HF}$ da lugar a la formación de complejos fluorados de los lantánidos que no permiten su determinación por ICP-OES, mientras que el empleo de agua regia no disuelve la fracción de $\mathrm{Al}_{2} \mathrm{O}_{3}$ del sólido. En estos casos se ha empleado la fluorescencia de rayos $X$, empleando muestras patrón preparadas por mezcla física de los correspondientes óxidos, para determinar el contenido real en $\mathrm{M}$ en muestras seleccionadas. Como se 
observa, los recubrimientos superficiales derivados del análisis de los sólidos $\mathrm{M} @ \mathrm{Al}_{2} \mathrm{O}_{3}$ están de acuerdo con los valores nominales, con deviaciones máximas del $15 \%$.

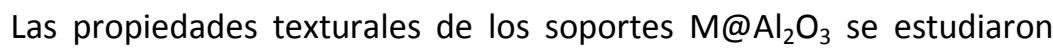
mediante adsorción de $\mathrm{N}_{2}$. La Tabla 6.2 recoge el área superficial específica, el volumen de poro y el diámetro de poro medio determinados para la serie de soportes promovidos $\mathrm{M} @ \mathrm{Al}_{2} \mathrm{O}_{3}$, así como para el soporte de $\mathrm{\gamma}-\mathrm{Al}_{2} \mathrm{O}_{3}$ empleado para sintetizarlos. De acuerdo a estos resultados, el soporte de $\gamma$ $\mathrm{Al}_{2} \mathrm{O}_{3}$ presenta un área superficial de $205 \mathrm{~m}^{2} / \mathrm{g}$, un VP de $0.51 \mathrm{~cm}^{3} / \mathrm{g}$ y un DP de $8.9 \mathrm{~nm}$. Tanto el área superficial como el VP y el DP disminuyen un 10$24 \%, 11-33 \%$ y $4.5-21 \%$, respectivamente, con la incorporación de las fases

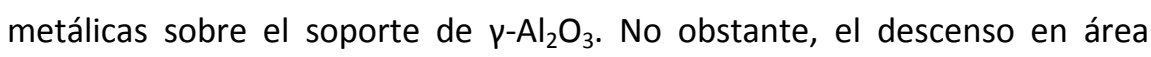
superficial y VP se debe principalmente a un efecto de dilución másica por parte de las especies $\mathrm{MO}_{\mathrm{x}}$. De hecho, cuando el VP de los materiales

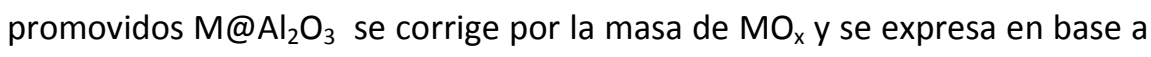
la masa de $\mathrm{\gamma}-\mathrm{Al}_{2} \mathrm{O}_{3}$, se observa que la disminución es $<9.7 \%$ respecto del VP del soporte original de $\mathrm{\gamma}-\mathrm{Al}_{2} \mathrm{O}_{3}$. Esto descarta que ocurran fenómenos de bloqueo de poros por parte de las especies metálicas, al menos en una extensión importante, sugiriendo que éstas se encuentran muy dispersas sobre la superficie de la alúmina en forma de óxidos bidimensionales. En este sentido, el descenso del DP debido a la incorporación de los promotores metálicos estaría relacionado con la contribución del espesor de la monocapa de $\mathrm{MO}_{\mathrm{x}}$ que recubre las paredes de los poros de $\mathrm{y}-\mathrm{Al}_{2} \mathrm{O}_{3}$. Teniendo en cuenta que DP disminuye entre 0.6 y $1.9 \mathrm{~nm}$, el espesor de las especies bidimensionales $\mathrm{MO}_{\mathrm{x}}$ se estimaría en 0.3-0.9 nm, asumiendo a una geometría de poro cilíndrica. 
Tabla 6.2: Composición química (ICP-OES) y propiedades texturales (adsorción de $\mathrm{N}_{2}$ ) de los soportes catalíticos $\mathrm{M@Al} \mathrm{O}_{3}$.

\begin{tabular}{|c|c|c|c|c|c|c|}
\hline \multirow[b]{2}{*}{ Muestra } & \multicolumn{2}{|c|}{ Composición química } & \multicolumn{4}{|c|}{ Propiedades texturales } \\
\hline & $\begin{array}{c}M \\
(\%(p))\end{array}$ & $\begin{array}{c}\delta^{\mathrm{a}} \\
\left(\mathrm{a} t / \mathrm{nm}^{2}\right)\end{array}$ & $\begin{array}{c}\text { A B.E.T. } \\
\left(\mathrm{m}^{2} / \mathrm{g}\right)\end{array}$ & $\begin{array}{c}V P^{b} \\
\left(\mathrm{~cm}^{3} / \mathrm{g}\right)\end{array}$ & $\begin{array}{l}\mathrm{DP}^{\mathrm{C}} \\
(\mathrm{nm})\end{array}$ & $\begin{array}{c}\text { VP } \\
\left(\mathrm{cm}^{3} / \mathrm{g} \mathrm{Al}_{2} \mathrm{O}_{3}\right)\end{array}$ \\
\hline $\mathrm{Al}_{2} \mathrm{O}_{3}$ & --- & --- & 205 & 0.51 & 8.9 & 0.52 \\
\hline $\mathrm{Fe} @ \mathrm{Al}_{2} \mathrm{O}_{3}$ & 7.9 & 4.7 & 169 & 0.43 & 8.5 & 0.48 \\
\hline $\mathrm{Ti} @ \mathrm{Al}_{2} \mathrm{O}_{3}$ & 6.80 & 4.7 & 193 & 0.44 & 7.5 & 0.47 \\
\hline $\mathrm{V} @ \mathrm{Al}_{2} \mathrm{O}_{3}$ & 10.3 & 6.9 & 179 & 0.38 & 7.3 & 0.47 \\
\hline $\mathrm{Nb} @ \mathrm{Al}_{2} \mathrm{O}_{3}$ & 15.1 & 5.9 & 185 & 0.38 & 7.2 & 0.49 \\
\hline $\mathrm{Ta} @ \mathrm{Al}_{2} \mathrm{O}_{3}$ & 23.5 & 5.2 & 176 & 0.34 & 7.0 & 0.48 \\
\hline $\mathrm{Y} @ \mathrm{Al}_{2} \mathrm{O}_{3}$ & $12.1^{\mathrm{e}}$ & $4.6^{\mathrm{e}}$ & 174 & 0.44 & 7.9 & 0.48 \\
\hline $\mathrm{Pr} @ \mathrm{Al}_{2} \mathrm{O}_{3}$ & $17.0^{e}$ & $4.4^{\mathrm{e}}$ & 165 & 0.45 & 7.9 & 0.52 \\
\hline $\mathrm{Nd} @ \mathrm{Al}_{2} \mathrm{O}_{3}$ & n.d. ${ }^{f}$ & n.d. & 159 & 0.42 & 7.8 & 0.51 \\
\hline $\mathrm{Sm} @ \mathrm{Al}_{2} \mathrm{O}_{3}$ & n.d. & n.d. & 155 & 0.39 & 7.9 & 0.49 \\
\hline
\end{tabular}

${ }^{a}$ Recubrimiento superficial.

${ }^{b}$ Volumen de poro.

' Diámetro medio de poro, determinado a partir de la isoterma de adsorción (modelo B.J.H.).

${ }^{d}$ VP corregido por la dilución debida a la masa de $\mathrm{MO}_{\mathrm{x}}$ en el soporte promovido.

${ }^{e}$ Análisis mediante fluorescencia de rayos $X$.

${ }^{f}$ n.d.: No determinado.

\subsubsection{Difracción de rayos $X$.}

La Fig. 6.3 muestra los difractogramas de rayos $\mathrm{X}$ para la serie de

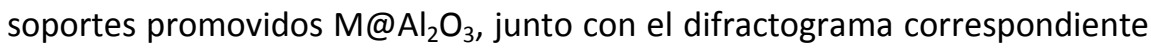
al soporte de $\mathrm{y}^{-} \mathrm{Al}_{2} \mathrm{O}_{3}$. Como se observa, tras la incorporación de los promotores no se desarrollan nuevas señales de difracción diferentes de aquellas asociadas con la fase de $\mathrm{\gamma}-\mathrm{Al}_{2} \mathrm{O}_{3}$. En todo caso, las señales de difracción correspondientes a la alúmina disminuyen en intensidad debido al efecto diluyente de las fases de $\mathrm{MO}_{\mathrm{x}}$, de manera especial para los elementos más pesados (Ta y lantánidos), para los que el recubrimiento de monocapa requiere de cargas metálicas $>20 \%(p)$ en $M$. 


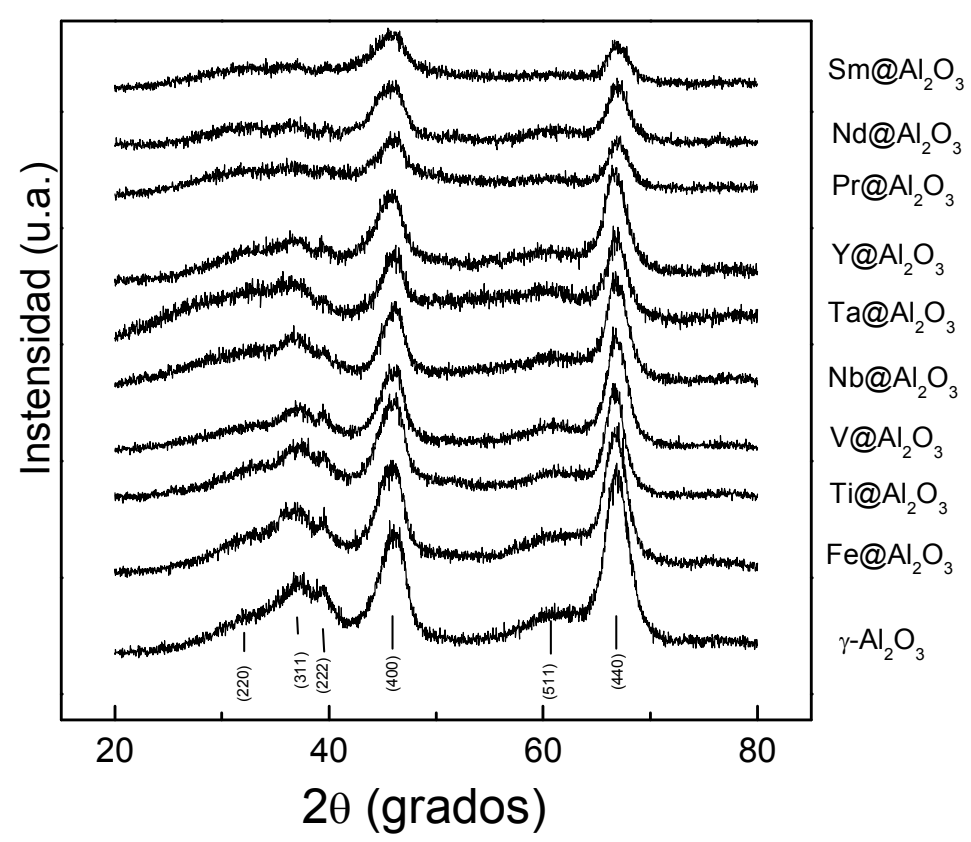

Figura 6.3: Difractogramas de rayos $X$ para los soportes promovidos en "monocapa" $\mathrm{M} @ \mathrm{Al}_{2} \mathrm{O}_{3}$, así como para el soporte de $\mathrm{\gamma}-\mathrm{Al}_{2} \mathrm{O}_{3}$ empleado para su síntesis.

El hecho de que no se detectan difracciones debidas a las fases metálicas indica que éstas presentan un carácter amorfo o bien están presentes en forma de nanocristales de dimensiones muy reducidas, que no pueden ser detectadas mediante la técnica de difracción de rayos $X$ (típicamente $<2 \mathrm{~nm}$ ). Esto constituye una evidencia experimental coherente con la obtención de recubrimientos de la superficie de la alúmina con óxidos bidimensionales de los metales introducidos como promotores $\left(\mathrm{MO}_{\mathrm{x}}\right)$. De hecho, para algunos promotores (M), se ha requerido la preparación de

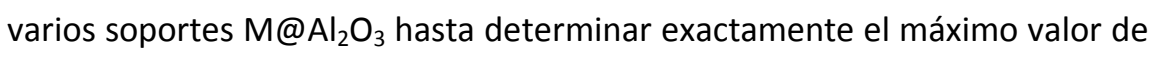
recubrimiento $(\delta)$ para el que no se detectan cristales tridimensionales de $\mathrm{MO}_{\mathrm{x}}$ mediante XRD. Recubrimientos tan sólo 0.3-0.5 átomos $/ \mathrm{nm}^{2}$ superiores a los óptimos resultaron en la detección de señales de XRD para los óxidos metálicos (espectros no mostrados). 
6.3.1.3. Propiedades electrónicas: poder electro donante-aceptor de los óxidos bidimensionales $\mathrm{MO}_{\mathrm{x}}$.

Como se mencionó en la Introducción General, los mecanismos de promoción catalítica implican, generalmente, intercambios de densidad electrónica entre las fases de promotor y las fases activas a las que "promueven", de modo que se modifican las propiedades adsorptivas de las últimas o bien se crean nuevos centros activos que involucran tanto a átomos de fase activa como de promotor. Por lo tanto, en el presente estudio, parece razonable que una caracterización adecuada de las propiedades electrónicas de las fases de promotor $\left(\mathrm{MO}_{\mathrm{x}}\right)$ es indispensable para entender los mecanismos de promoción catalítica sobre las fases de Rh.

Los científicos han reconocido, desde hace tiempo, la necesidad de generar escalas universales para las propiedades electrónicas (capacidad electro donante-aceptora) de los óxidos metálicos. Las teorías más modernas en lo concerniente a la física del estado sólido y la reactividad de superficies proponen agrupar conceptos originalmente considerados de manera independiente como poder oxidante, acidez, poder reductor y basicidad, y considerarlos como diferentes escalones de una única realidad determinada por la distribución de la densidad electrónica en los materiales catalíticos [25]. En este sentido se han desarrollado un gran número de parámetros descriptores para las propiedades electrónicas de los óxidos metálicos, cuya universalidad se ha probado estableciendo correlaciones para extensas series de materiales [26]. Algunos de los parámetros más destacados son:

- Electronegatividad del catión en un óxido $\left(\mathrm{S}_{\mathrm{M}}\right)$, siendo quizás la escala de Sanderson la más empleada [27]. 
- Polarizabilidad electrónica del catión $\left(\alpha_{M}\right)$ y del anión óxido $\left(\alpha o^{2}\right)$, definida como la susceptibilidad de las densidades electrónicas de ambos iones para polarizarse en presencia de un campo eléctrico externo (debido a otros iones vecinos en la estructura).

- Parámetro iónico-covalente (ICP), definido por Portier y col. [28] en base a las electronegatividades de Sanderson y los radios iónicos de las especies enlazadas en la estructura del óxido. Este parámetro describe adecuadamente el carácter iónico-covalente del enlace M-O en los óxidos.

- Espaciado de banda (band energy gap o Eg), definido como la diferencia energética entre las bandas de valencia $y$ conducción, de acuerdo a la descripción de la estructura electrónica del óxido mediante la teoría de bandas.

- Basicidad óptica $(\Lambda)$, definida como el poder electro-donante de los iones $\mathrm{O}^{2-}$ de la red del óxido en un material vítreo (amorfo). Este concepto, fue desarrollado originalmente por Duffy [29] como un descriptor que permite predecir de manera sencilla el comportamiento óptico de un material cuando se introduce en su estructura un determinando ión metálico como dopante.

Todos estos parámetros descriptores están relacionados con un único concepto: la distribución de la densidad electrónica entre iones $\mathrm{M}^{\mathrm{x+}}$ y $\mathrm{O}^{2-}$, lo que determina el poder electro donante-aceptor del óxido. De hecho, varios autores han encontrado correlaciones entre los diferentes descriptores para una gran variedad de óxidos metálicos. Originalmente, Duffy encontró una correlación lineal entre $\Lambda$ y el índice de refracción (IR) [29]. Por su parte, 
Lebouteiller y Courtine [30] encontraron una dependencia lineal de $\Lambda$ con ICP, para óxidos con el mismo tipo de coordinación para los iones metálicos, mientras que Dimitrov y Sakka [31] encontraron una correlación de tipo potencial entre el espaciado de banda (Eg) e IR, así como entre Eg y $\alpha o^{2}$ para una extensa serie de óxidos de metales de transición y metaloides. Por su parte, Zhao y col. [32] extendieron recientemente el concepto a los óxidos de lantánidos mostrando correlaciones lineales entre $\Lambda$ y $\alpha_{0^{2}}$, así como entre Eg y $\alpha_{0^{2}}$. La basicidad óptica $(\Lambda)$ es, quizás, el parámetro que más atención ha recibido, lo que ha resultado en su incorporación desde el campo de la óptica a la catálisis, en un intento de establecer correlaciones generales de las propiedades electrónicas de los óxidos con su actividad catalítica en reacciones de oxidación catalizadas por óxidos de metales de transición [33].

Sin embargo, todos estos parámetros son conceptos másicos (bulk), mientras que en catálisis son relevantes las propiedades electrónicas de la superficie, las cuales pueden variar significativamente respecto de las del

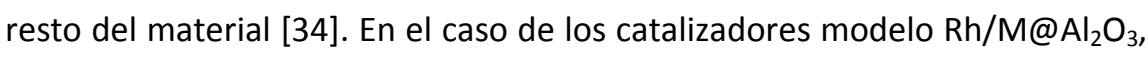
las propiedades de la monocapa de $\mathrm{MO}_{\mathrm{x}}$ no coincidirán con las del correspondiente óxido másico, por lo que no se emplearán valores tabulados de los descriptores antes mencionados para los correspondientes óxidos másicos para representar las propiedades electrónicas de los promotores dispersos en forma de óxidos bidimensionales.

Para óxidos semiconductores como los empleados en el papel de promotores del Rh, la evaluación de Eg se puede llevar a cabo de manera sencilla mediante DR UV-vis, puesto que Eg coincide con la energía en el borde de absorción (EBA), es decir, la energía mínima del fotón incidente para promover una transición electrónica HOMO(valencia) $\rightarrow$ LUMO(conducción) [35]. La Fig. 6.4 muestra los espectros de DR UV-vis para 


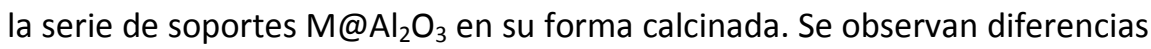
en el valor de $\lambda$ para la absorción incipiente, que se traducen en diferentes valores de EBA (calculados asumiendo transiciones electrónicas directaspermitidas, de acuerdo a lo descrito en la sección 2.2.11) en el rango de 2.55-5.68 eV, como se recoge en la Tabla 6.3. Este amplio rango de valores de EBA es indicativo de que la serie de promotores $\mathrm{MO}_{\mathrm{x}}$ seleccionados para este estudio es representativa de una gran variedad de propiedades electrónicas (carácter electro donante-aceptor o acidez-basicidad según el concepto de Lewis). A su vez, en todos los casos, el valor de Eg determinado para los óxidos $\mathrm{MO}_{\mathrm{x}}$ dispersos en los soportes promovidos $\mathrm{M@Al}_{2} \mathrm{O}_{3}$ es ligeramente superior al correspondiente para los óxidos másicos, de acuerdo con resultados teóricos y experimentales previos [35,36], debido a diferencias en el índice de coordinación y el empaquetamiento de las subunidades $\mathrm{MO}_{\mathrm{x}}$ con respecto a la estructura del correspondiente óxido másico, que contribuyen a ensanchar el espaciado de banda.

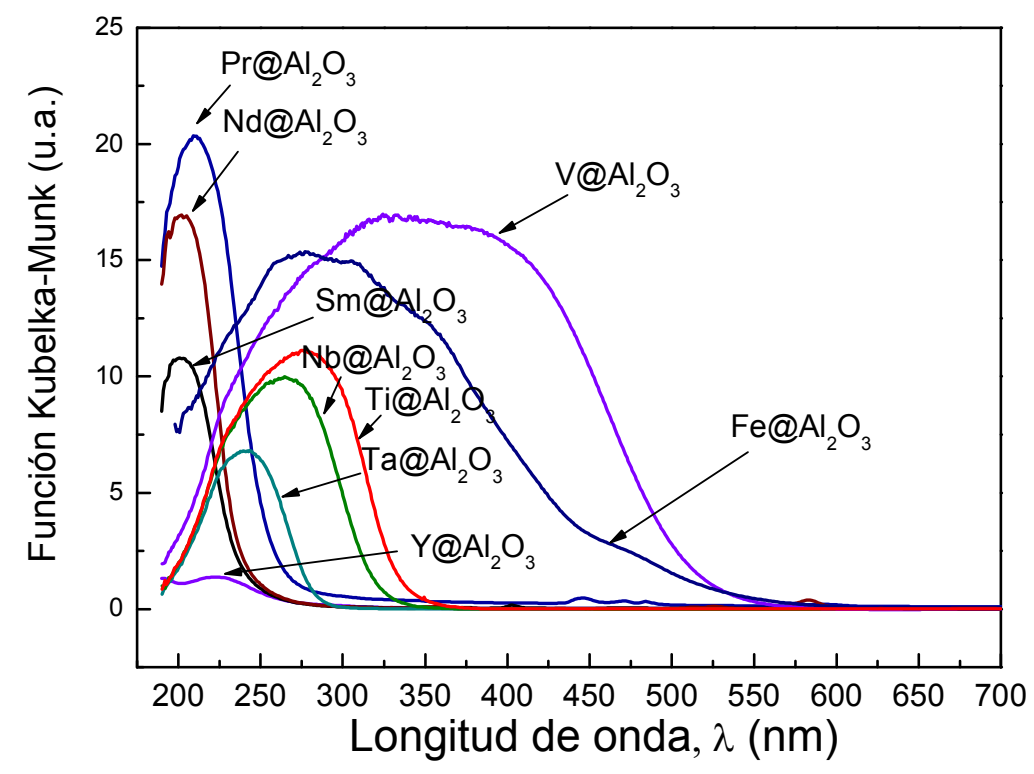

Figura 6.4: Espectros de DR UV-vis de los soportes catalíticos $\mathrm{M@Al} \mathrm{O}_{3}$. 
Tabla 6.3: Parámetros descriptores de las propiedades electrónicas (carácter electro

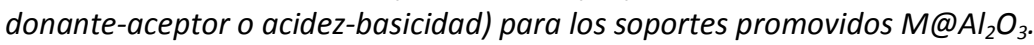

\begin{tabular}{ccc}
\hline Muestra (M) & $\begin{array}{c}\mathrm{EBA}^{\mathrm{a}} \\
(\mathrm{eV})\end{array}$ & $\begin{array}{c}\mathrm{E}(\mathrm{IMCT})^{\mathrm{b}} \\
\text { alizarina } \\
(\mathrm{eV})\end{array}$ \\
\hline $\mathrm{Fe} @ \mathrm{Al}_{2} \mathrm{O}_{3}$ & 2.56 & $\left(2.54^{\mathrm{C}}\right) 2.29^{\mathrm{d}}$ \\
$\mathrm{V} @ \mathrm{Al}_{2} \mathrm{O}_{3}$ & 2.55 & $\left(2.64^{\mathrm{C}}\right) 2.52^{\mathrm{d}}$ \\
$\mathrm{Nb} @ \mathrm{Al}_{2} \mathrm{O}_{3}$ & 4.03 & 2.59 \\
$\mathrm{Ta} @ \mathrm{Al}_{2} \mathrm{O}_{3}$ & 4.53 & 2.52 \\
$\mathrm{Ti} @ \mathrm{Al}_{2} \mathrm{O}_{3}$ & 3.70 & 2.51 \\
$\mathrm{Y} @ \mathrm{Al}_{2} \mathrm{O}_{3}$ & 4.77 & 2.46 \\
$\mathrm{Pr} @ \mathrm{Al}_{2} \mathrm{O}_{3}$ & 5.04 & 2.42 \\
$\mathrm{Nd} @ \mathrm{Al}_{2} \mathrm{O}_{3}$ & 5.38 & 2.41 \\
$\mathrm{Sm} @ \mathrm{Al}_{2} \mathrm{O}_{3}$ & 5.68 & 2.38 \\
\hline el borde de absorción UV-vis (EBA) o ancho de banda (band gap) de los \\
s dispuestos en monocapa en el estado calcinado. \\
ara la transición electrónica intramolecular (Intramolecular Charge-Transfer o \\
de el grupo catecol hasta el sistema de anillos de la molécula de alizarina adsorbida \\
perficie de los soportes promovidos $M @ A l_{2} \mathrm{O}_{3}$. Error estándar <0.5\%. \\
ado para el soporte en su forma calcinada. \\
ado para el soporte reducido, es decir, en las condiciones en que el promotor se
\end{tabular}

De manera adicional, con el objeto de comprobar que la tendencia establecida por el parámetro EBA (o Eg) es representativa de las propiedades electrónicas de los promotores en la superficie, donde tendrá lugar su interacción con las NPs de Rh y, por lo tanto, se localizará su papel como promotor catalítico, se ha empleado la técnica de DR UV-vis acoplada a la adsorción superficial de alizarina, como molécula sonda, para determinar de manera cuantitativa la capacidad electro donante-aceptora de las monocapas de $\mathrm{MO}_{\mathrm{x}}$. Esta técnica, que ha sido desarrollada muy recientemente por Yoon y col. [37], está basada en la propiedad de que la transición electrónica intramolecular (IMCT) desde el grupo catecol hasta el sistema de anillos aromáticos de la molécula de alizarina es la transición electrónica de menor energía incluso cuando la molécula está adsorbida sobre un sólido [38]. La energía de esta transición E(IMCT) constituye una sonda extremadamente sensible que permite establecer escalas universales 
y cuantitativas de carácter electro donante-aceptor (o acidez Lewis) para óxidos metálicos, incluidos los óxidos de lantánidos [37].

La Fig. 6.5 recoge los espectros UV-vis tras la adsorción de alizarina

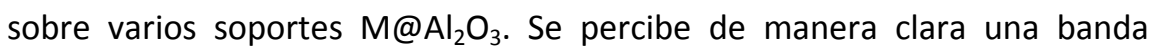
ligeramente asimétrica en el rango de energías de 2-3 eV, asignada a la IMCT para la molécula de alizarina adsorbida. Por razones que se explicarán más adelante en este capítulo, para los soportes $\mathrm{V} @ \mathrm{Al}_{2} \mathrm{O}_{3}$ y $\mathrm{Fe} @ \mathrm{Al}_{2} \mathrm{O}_{3}$ se ha llevado a cabo la caracterización tanto en su forma oxidada (tras la calcinación del soporte) como tras un tratamiento de reducción ex situ en $\mathrm{H}_{2}$ a temperaturas de 500 y $650 \stackrel{\circ}{\circ}$, respectivamente. En estos casos, la presencia de cationes reducidos en las especies $\mathrm{MO}_{\mathrm{x}}$ introduce absorciones adicionales en la región visible del espectro relacionadas con transiciones electrónicas intra-atómicas $d$-d. En estos casos la determinación de la posición de la banda de IMCT para la alizarina adsorbida se ha llevado a cabo por sustracción de los espectros para el soporte reducido antes y después de la adsorción de la molécula sonda, con el objetivo de eliminar la contribución de las adsorciones correspondientes a las especies $\mathrm{MO}_{\mathrm{x}}$, como se muestra esquemáticamente en la Fig. 6.5-b para el caso de $\mathrm{V} @ \mathrm{Al}_{2} \mathrm{O}_{3}$. 


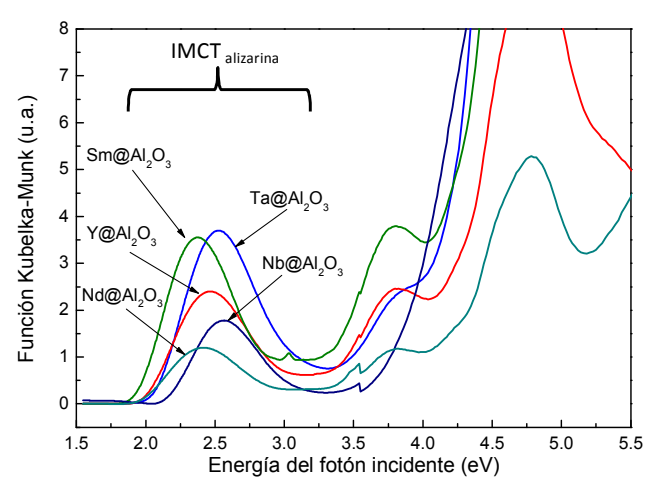

(a)

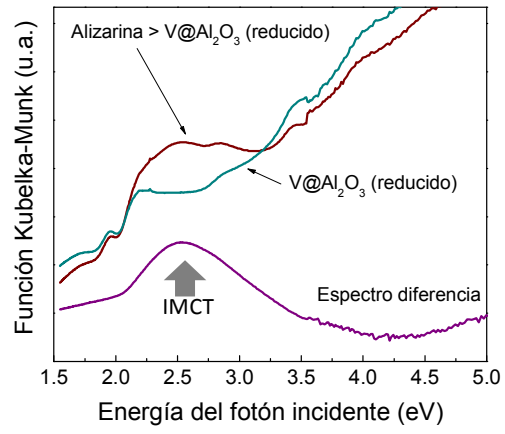

(b)

Figura 6.5: Espectros de DR UV-vis de los soportes catalíticos $\mathrm{M@Al}_{2} \mathrm{O}_{3}$ tras la adsorción de alizarina. En (a) se muestran los soportes que carecen de bandas de transiciones $d$ - $d$ en el visible; en (b) se muestra la determinación de la banda de IMCT para la alizarina adsorbida (espectro diferencia) sobre el soporte $\mathrm{V} @ \mathrm{Al}_{2} \mathrm{O}_{3}$ reducido, como representativo de los soportes que poseen bandas de transiciones $d$ - $d$ en la región del espectro visible con $\mathrm{E}<3 \mathrm{eV}$.

Por su parte, la Tabla 6.3 recoge los valores de E(IMCT) determinados a partir de los espectros mostrados en la Fig. 6.5. Como se observa, E(IMCT) disminuye, de manera general, a medida que se incrementa el valor de $\mathrm{Eg}$, es decir, en el orden en el que aumenta el carácter básico (electrodonante) del óxido promotor.

Por lo tanto, como conclusión de la presente sección se puede indicar que la serie de promotores estudiados comprende desde óxidos de marcado carácter ácido (electro-aceptor) como $\mathrm{VO}_{\mathrm{x}}, \mathrm{NbO}_{\mathrm{x}} \circ \mathrm{TaO}_{\mathrm{x}}$, hasta óxidos de marcado carácter básico (electro-donante) como los lantánidos $\left(\mathrm{PrO}_{x}, \mathrm{NdO}_{x}\right.$ y $\mathrm{SmO}_{x}$ ), pasando por óxidos de características intermedias como $\mathrm{YO}_{\mathrm{x}}$ y $\mathrm{TiO}_{\mathrm{x}}$, de acuerdo a su situación en el sistema periódico. 


\subsubsection{Caracterización de los catalizadores modelo $\mathrm{Rh} / \mathrm{M} @ \mathrm{Al}_{2} \mathrm{O}_{3}$.}

\subsubsection{Contenido metálico (Rh).}

El contenido metálico en los catalizadores $\mathrm{Rh} / \mathrm{M} @ \mathrm{Al}_{2} \mathrm{O}_{3}$, determinado experimentalmente mediante ICP-OES, toma valores en el rango 2.5-2.7 $\%(p)$, lo que supone desviaciones $<8 \%$ respecto del valor nominal de $2.5 \%(p)$.

\subsubsection{Dispersión metálica.}

La dispersión metálica en catalizadores $\mathrm{Rh} / \mathrm{M} @ \mathrm{Al}_{2} \mathrm{O}_{3}$ seleccionados se estudió por medio de quimisorción de $\mathrm{CO}$ a la temperatura de $35^{\circ} \mathrm{C}$. En este caso se ha empleado $\mathrm{CO}$ como adsorbato, en lugar de $\mathrm{H}_{2}$, con el objetivo de minimizar la contribución de las fases promotoras $\mathrm{MO}_{\mathrm{x}}$ a la adsorción total. En este sentido, en los experimentos de CO-FTIR, que se discutirán más adelante en este capítulo, no se detectan señales de IR debidas a la adsorción de $\mathrm{CO}$ sobre las fases $\mathrm{MO}_{\mathrm{x}}$ a temperatura ambiente, lo que sugiere la especificidad de las fases de $\mathrm{Rh}^{0}$ para el fenómeno de quimisorción de CO a $35 \circ \mathrm{C}$.

La Tabla 6.4 recoge los resultados de dispersión metálica y tamaño de $\mathrm{NP}$ de $\mathrm{Rh}^{0}$ estimados a partir de los experimentos de quimisorción de CO. Como se comentará en secciones posteriores, se ha determinado por espectroscopia CO-FTIR que el modo de adsorción de la molécula de CO sobre las NPs de $\mathrm{Rh}^{0}$ predominante a temperatura ambiente corresponde con la formación de di-carbonilos $\left(\mathrm{CO} / \mathrm{Rh}_{(\mathrm{s})}=2\right)$, siendo significativamente menos importantes las señales de FTIR asociadas a los modos de adsorción de tipo lineal $\left(\mathrm{CO} / \mathrm{Rh}_{(\mathrm{s})}=1\right)$ y puenteado $\left(\mathrm{CO} / \mathrm{Rh}_{(\mathrm{s})}=0.5\right)$. Por lo tanto, la relación estequiométrica real de quimisorción será un valor cercano a 2 . Se observa en la Tabla 6.4 que el tamaño de NP estimado para los catalizadores analizados por quimisorción de $\mathrm{CO}$ asumiendo $\mathrm{CO} / \mathrm{Rh}_{(\mathrm{s})}=2$ es de $1.7 \pm 0.2 \mathrm{~nm}$, mientras que la suposición de una relación $\mathrm{CO} / \mathrm{Rh}_{(\mathrm{s})}=1$ resultaría en valores 
de dispersión metálica incongruentes (>100\%), confirmando la formación mayoritaria de especies di-carbonilo. La preponderancia del modo de adsorción en forma de di-carbonilos es típico de NPs de Rh de tamaño muy reducido $[39,40,41]$. No obstante, se discutirá en la sección 6.3.4.2 la validez de la caracterización de la dispersión metálica en catalizadores de Rh altamente dispersos mediante quimisorción de $\mathrm{CO}$, en base a los fenómenos que tienen lugar en la estructura de las NPs de metal cuando quimisorben $\mathrm{CO}$, de acuerdo a los resultados de CO-FTIR obtenidos en este trabajo.

Tabla 6.4: Dispersión metálica en catalizadores $\mathrm{Rh} / \mathrm{M} @ \mathrm{Al}_{2} \mathrm{O}_{3}$ seleccionados.

\begin{tabular}{|c|c|c|c|c|}
\hline \multirow[b]{2}{*}{ Catalizador } & \multicolumn{3}{|c|}{ Quimisorción CO } & \multirow{2}{*}{$\begin{array}{c}\text { TEM } \\
d\left(\mathrm{Rh}^{0}\right)_{T} \\
(\mathrm{~nm})\end{array}$} \\
\hline & $\begin{array}{c}\mathrm{CO}_{\text {ads, irrev }}{ }^{\mathrm{a}} \\
(\mu \mathrm{mol} / \mathrm{g})\end{array}$ & $\begin{array}{l}D^{b} \\
(\%)\end{array}$ & $\begin{array}{c}d\left(\mathrm{Rh}^{0}\right)_{\mathrm{CO}} \\
(\mathrm{nm})\end{array}$ & \\
\hline $\mathrm{Rh} / \mathrm{Ta} @ \mathrm{Al}_{2} \mathrm{O}_{3}$ & 286 & $57(113)^{c}$ & 1.9 & $1-2$ \\
\hline $\mathrm{Rh} / \mathrm{Y} @ \mathrm{Al}_{2} \mathrm{O}_{3}$ & 349 & 66 (133) & 1.7 & n.d. ${ }^{c}$ \\
\hline $\mathrm{Rh} / \mathrm{Sm} @ \mathrm{Al}_{2} \mathrm{O}_{3}$ & 321 & $64(127)$ & 1.7 & $0.5-2$ \\
\hline $\mathrm{Rh} / \mathrm{Li}-\mathrm{Ta} @ \mathrm{Al}_{2} \mathrm{O}_{3}$ & 382 & $73(146)$ & 1.5 & n.d. \\
\hline \multicolumn{5}{|c|}{$\begin{array}{l}{ }^{a} \text { Cantidad de CO adsorbido de manera irreversible (obtenido por extrapolación de la } \\
\left.\text { isoterma diferencia, antes y tras evacuación a } 35^{\circ} \mathrm{C} \text {, a } P_{c o} \rightarrow 0\right) \text {. } \\
{ }^{b} \text { Dispersión metálica. Valores determinados asumiendo una estequiometria } \mathrm{CO} / R h_{(s)}=2(\mathrm{mod} \\
\text { de adsorción di-carbonilo). Entre paréntesis se muestran los valores incongruentes obtenidos } \\
\text { asumiendo adsorción lineal, es decir } C O / R h_{(s)}=1 \text {. } \\
{ }^{c} \text { n.d.: No determinado. }\end{array}$} \\
\hline
\end{tabular}
catalizadores $\mathrm{Rh} / \mathrm{Ta} @ \mathrm{Al}_{2} \mathrm{O}_{3}$ y $\mathrm{Rh} / \mathrm{Sm} @ \mathrm{Al}_{2} \mathrm{O}_{3}$ previamente reducidos en $\mathrm{H}_{2}$ (300C, 6h) empleando TEM. La presencia de una fase de soporte cristalina $\left(\mathrm{\gamma}-\mathrm{Al}_{2} \mathrm{O}_{3}\right)$ y de una monocapa de óxido de elementos de elevado peso atómico son dos factores que incrementan el contraste óptico del soporte

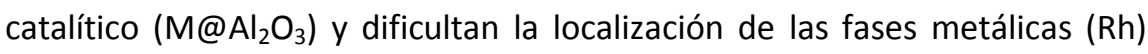
incluso empleando técnicas de HRTEM, especialmente si la fase metálica se encuentra muy dispersa como en el presente caso. 


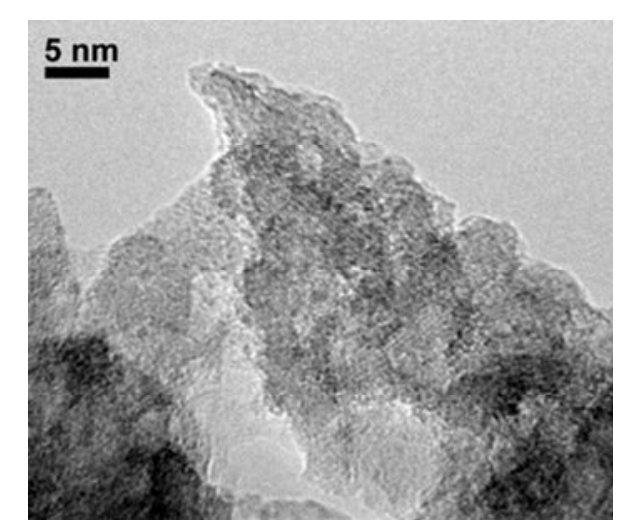

(a)

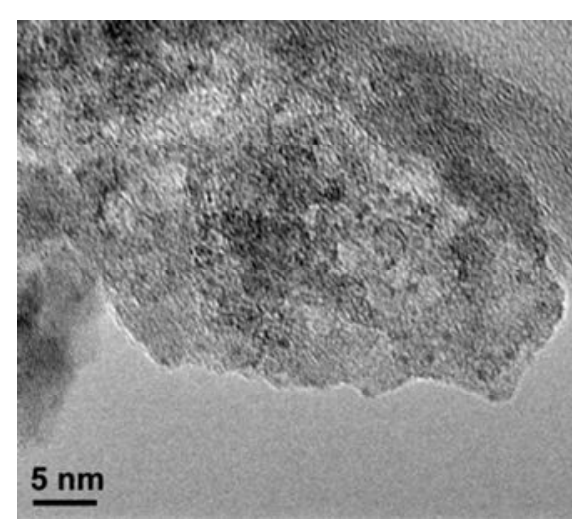

(b)

Figura 6.6: Micrografías de TEM de los catalizadores $\mathrm{Rh} / \mathrm{Sm} @ \mathrm{Al}_{2} \mathrm{O}_{3}$ (a) y $\mathrm{Rh} / \mathrm{Ta} @ \mathrm{Al}_{2} \mathrm{O}_{3}(\mathrm{~b})$ reducidos.

No obstante, en las micrografías representativas mostradas en la Fig. 6.6 se percibe la presencia de nanopartículas metálicas de tamaño muy reducido $(0.5-2 \mathrm{~nm})$ en ambos catalizadores. Este resultado concuerda de manera adecuada con los obtenidos mediante quimisorción de $\mathrm{CO}$ y confirma la elevada dispersión metálica alcanzada en los catalizadores modelo de Rh, independientemente de las características electrónicas de las fases de promotor $\left(\mathrm{MO}_{\mathrm{x}}\right)$.

\subsubsection{Reducibilidad de las fases $M O_{x}$ y $R h$.}

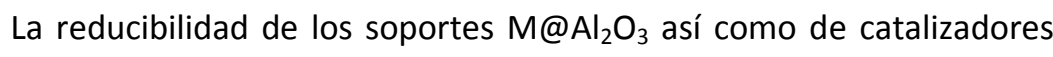
$\mathrm{Rh} / \mathrm{M} @ \mathrm{Al}_{2} \mathrm{O}_{3}$ seleccionados se estudió por medio de $\mathrm{H}_{2}-\mathrm{TPR}$. Antes de llevar a cabo los experimentos de $\mathrm{H}_{2}$-TPR se determinó la temperatura de descarbonatación requerida, en atmósfera de aire, para los soportes y catalizadores que contienen óxidos de lantánidos e itrio, cuyo carácter básico promueve la formación de carbonatos superficiales durante su exposición al $\mathrm{CO}_{2}$ ambiental. Para ello se realizaron experimentos de TPOMS y TG que indican que las especies de carbonato superficiales se descomponen completamente a temperaturas de 500-600ㄷ․ La emisión de 
gases como $\mathrm{CO}_{2}$ debidos a la descomposición de carbonatos superficiales durante los experimentos de $\mathrm{H}_{2}$-TPR podría generar señales en el detector TCD no relacionadas con fenómenos de reducción. Por esto, con el objetivo de retirar las especies carbonato antes de los experimentos de $\mathrm{H}_{2}$-TPR las muestras se trataron in situ en flujo de aire sintético a $600 \circ \mathrm{C}$ durante 1 hora antes de enfriar a $30 \circ \mathrm{C}$ en flujo de aire y comenzar, seguidamente, el experimento de $\mathrm{H}_{2}$-TPR para la muestra descarbonatada.

La Fig. 6.7 muestra los correspondientes perfiles de reducción a temperatura programada. Como se observa en la Fig. 6.7-a, los soportes promovidos por lantánidos ( $\mathrm{Sm}, \mathrm{Nd}, \mathrm{Pr}), \mathrm{Y}, \mathrm{Ti}, \mathrm{Ta}$ y $\mathrm{Nb}$ no presentan eventos de reducción en el rango de temperaturas estudiado (30-900ㄷ). Sin embargo, el soporte $\mathrm{Fe} @ \mathrm{Al}_{2} \mathrm{O}_{3}$ presenta varias señales de reducción anchas en el rango de temperaturas de $250-700 \circ \mathrm{C}$, mientras que $\mathrm{V} @ \mathrm{Al}_{2} \mathrm{O}_{3}$ presenta una única señal de reducción a 468 ㄷ․

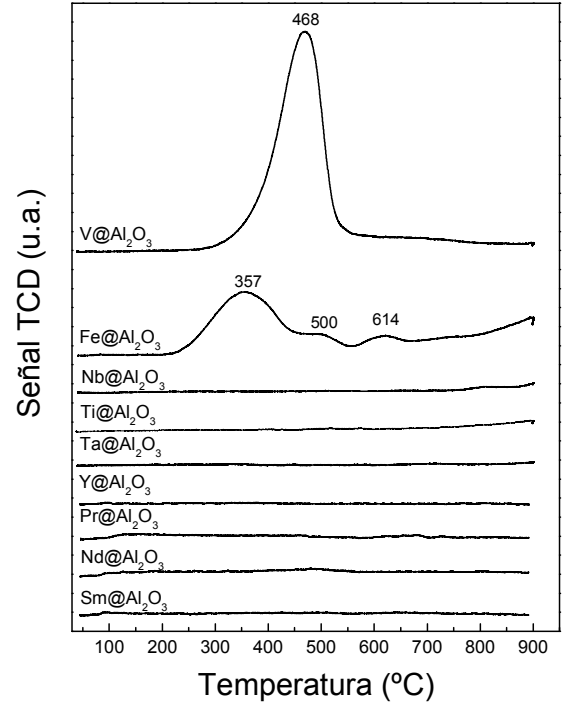

(a)

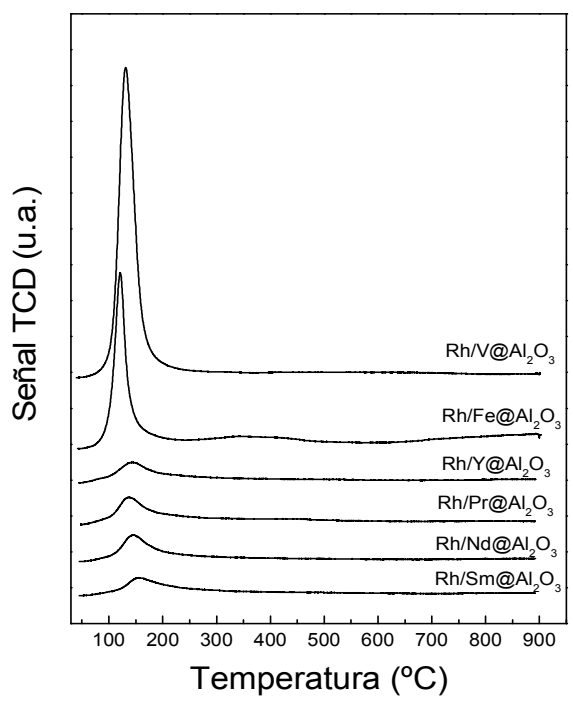

(b)

Figura 6.7: Perfiles de $\mathrm{H}_{2}$-TPR para los soportes catalíticos $\mathrm{MOAl}_{2} \mathrm{O}_{3}$ (a) y catalizadores $\mathrm{Rh} / \mathrm{M} @ \mathrm{Al}_{2} \mathrm{O}_{3}$ seleccionados (b). 
Por su parte, todos los catalizadores metálicos $\mathrm{Rh} / \mathrm{M} @ \mathrm{Al}_{2} \mathrm{O}_{3}$ analizados presentan una única señal de reducción en el rango de 110170 ㄷ C, relacionada con la reducción de las especies de $\mathrm{Rh}$ hasta $\mathrm{Rh}^{0}$ [42]. Cabe destacar, por otro lado, que las señales de reducción de las especies de $\mathrm{FeO}_{\mathrm{x}}$ y $\mathrm{VO}_{\mathrm{x}}$ en el rango de $250-700$ 으 ya no se detectan, lo que sugiere que estas etapas de reducción para los óxidos promotores ocurren a temperaturas muy inferiores en presencia de las fases de Rh y, por lo tanto, contribuyen a la señal detectada a $<150$ 으 en ambos casos. De hecho, esta señal de reducción es significativamente más intensa para estos dos catalizadores en comparación con el resto de muestras cuyas fases de $\mathrm{MO}_{\mathrm{x}}$ no se reducen. Por lo tanto, se infiere que la reducción de las fases de Rh promueve la disociación de $\mathrm{H}_{2}$ sobre las especies $\mathrm{Rh}^{0}$ y su envío mediante fenómenos de migración superficial (spill-over) hacia las fases $\mathrm{MO}_{\mathrm{x}}$ vecinas, promoviendo su reducción a temperaturas muy inferiores a aquellas a las que tiene lugar en ausencia de Rh.

Los resultados del análisis cuantitativo de los perfiles de $\mathrm{H}_{2}$-TPR se recogen en la Tabla 6.5. En todos los casos, el consumo teórico debido a las especies de Rh se estimó considerando los contenidos de Rh determinados por ICP-OES y asumiendo $\mathrm{RhCl}_{3}$ como única especie de $\mathrm{Rh}$ en los catalizadores calcinados, de acuerdo a los resultados de XPS que se presentarán en la sección 6.3.4.1. Por lo tanto, la estequiometría de reducción responderá a la ecuación 6.1:

$$
\mathrm{RhCl}_{3}+3 / 2 \mathrm{H}_{2} \rightarrow \mathrm{Rh}^{0}+3 \mathrm{HCl} \quad \text { (Ec. 6.1) }
$$

La cuantificación de los consumos de $\mathrm{H}_{2}$ experimentales se llevó a cabo en base al calibrado realizado en el equipo empleando CuO como patrón (sección 2.2.7.1). Como se observa en la Tabla 6.5, la combinación del consumo de $\mathrm{H}_{2}$ teórico asociado con las especies de Rh (ecuación 6.1) con el 
consumo de $\mathrm{H}_{2}$ asociado con las especies de promotor $\left(\mathrm{MO}_{\mathrm{x}}\right)$, determinadas

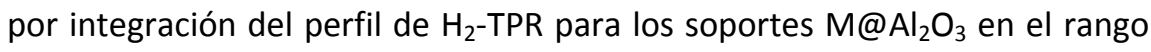
de temperaturas estudiado, da lugar a estimaciones "teóricas" del consumo total de $\mathrm{H}_{2}$ para la reducción de los catalizadores metálicos Rh/M@ $@ \mathrm{Al}_{2} \mathrm{O}_{3}$. Estos valores están de acuerdo con los determinados experimentalmente por integración de la única señal detectada en los perfiles de los catalizadores metálicos, presentando desviaciones relativas $<15.2 \%$. Esto confirma que, para los óxidos reducibles $\left(\mathrm{FeO}_{x}\right.$ y $\left.\mathrm{VO}_{\mathrm{x}}\right)$, la reducción de las especies de promotor tiene lugar junto con la reducción de las especies de $\mathrm{Rh}$ a temperaturas $<150^{\circ} \mathrm{C}$ y en la misma extensión en la que ocurre a mayores temperaturas en ausencia de Rh. Para el resto de catalizadores se puede descartar que tenga lugar una reducción, al menos significativa, de las especies $\mathrm{MO}_{\mathrm{x}}$ incluso en presencia de $\mathrm{Rh}$.

Tabla 6.5: Interpretación cuantitativa de los perfiles de $\mathrm{H}_{2}$-TPR para soportes $\mathrm{M} @ \mathrm{Al}_{2} \mathrm{O}_{3}$ y catalizadores metálicos $\mathrm{R} h / \mathrm{M} @ \mathrm{Al}_{2} \mathrm{O}_{3}$ seleccionados.

\begin{tabular}{|c|c|c|c|c|c|}
\hline $\begin{array}{l}\text { Promotor } \\
\text { (M) }\end{array}$ & $\begin{array}{c}\mathrm{H}_{2, \text { cons }} \\
\text { (Rh) } \\
\text { teórico a } \\
\text { (mmol/g) }\end{array}$ & $\begin{array}{c}\mathrm{H}_{2} \text {, cons }(\mathrm{M}) \\
\text { experimental }^{\mathrm{b}} \\
(\mathrm{mmol} / \mathrm{g})\end{array}$ & $\begin{array}{c}\mathrm{H}_{2} \text {, cons } \\
(\mathrm{Rh}+\mathrm{M}) \\
\text { teórico }{ }^{\mathrm{c}} \\
\text { (mmol/g) }\end{array}$ & $\begin{array}{c}\mathrm{H}_{2, \text { cons }} \\
(\mathrm{Rh}+\mathrm{M}) \\
\text { experimental }^{\mathrm{d}} \\
(\mathrm{mmol} / \mathrm{g})\end{array}$ & $\begin{array}{c}\text { Desviación } \\
\text { relativa teórico- }^{\text {experimental }} \\
\text { (\%) }\end{array}$ \\
\hline $\mathrm{V}$ & 0.37 & 1.58 & 1.94 & 1.88 & 3.2 \\
\hline $\mathrm{Fe}$ & 0.36 & 0.65 & 1.01 & 0.94 & 7.4 \\
\hline$Y$ & 0.38 & 0.0 & 0.38 & 0.42 & 9.5 \\
\hline $\mathrm{Pr}$ & 0.39 & 0.0 & 0.39 & 0.46 & 15.2 \\
\hline $\mathrm{Nd}$ & 0.39 & 0.0 & 0.39 & 0.43 & 9.3 \\
\hline $\mathrm{Sm}$ & 0.39 & 0.0 & 0.39 & 0.42 & 7.1 \\
\hline
\end{tabular}

${ }^{a}$ Considerando la reducción de $\mathrm{RhCl}_{3}$ de acuerdo a la estequiometría $\mathrm{RhCl} 3+3 / 2 \mathrm{H}_{2} \rightarrow \mathrm{Rh}+3 \mathrm{HCl}$ y el contenido en $\mathrm{Rh}$ determinado por ICP-OES.

${ }^{b}$ Determinado mediante integración del perfil de $\mathrm{H}_{2}$-TPR para el soporte promovido $\mathrm{M} @ \mathrm{Al}_{2} \mathrm{O}_{3}$.

' Suma de los consumos de $\mathrm{H}_{2}$ teórico para las fases de $\mathrm{Rh}$ y experimental para las fases de promotor.

${ }^{d}$ Determinado mediante integración del perfil de $\mathrm{H}_{2}$-TPR para el catalizador metálico $\mathrm{Rh} / \mathrm{M} @ \mathrm{Al}_{2} \mathrm{O}_{3}$.

${ }^{e}$ Error relativo calculado a partir de los consumos de $\mathrm{H}_{2}$ teóricos y experimentales para los catalizadores metálicos $\mathrm{Rh} / \mathrm{M} @ \mathrm{Al}_{2} \mathrm{O}_{3}$ como [(Teórico-Experimental)/Experimental]·100 (\%).

Por lo tanto, la serie de promotores estudiados comprende desde óxidos de carácter reducible como $\mathrm{FeO}_{\mathrm{x}} \circ \mathrm{VO}_{\mathrm{x}}$, que se encontrarán parcialmente reducidos tras el tratamiento de reducción previo a la catálisis, hasta óxidos que no se reducen apreciablemente en las condiciones del 
pretratamiento, incluso en presencia de las fases de $\mathrm{Rh}$, como $\mathrm{NbO}_{\mathrm{x}}, \mathrm{TaO}_{\mathrm{x}}$, $\mathrm{YO}_{x}$ y los óxidos de lantánidos $\left(\mathrm{PrO}_{x}, \mathrm{NdO}_{x}\right.$ y $\left.\mathrm{SmO}_{x}\right)$.

\subsubsection{Comportamiento catalítico.}

La Tabla 6.6 resume los resultados catalíticos obtenidos con la serie de catalizadores modelo Rh/M@ $@ \mathrm{Al}_{2} \mathrm{O}_{3}$.

Como se observa, la actividad catalítica por masa de Rh (RTY) es máxima para el catalizador Rh/Fe@ $\mathrm{Al}_{2} \mathrm{O}_{3}$, mientras que los catalizadores promovidos por metales de transición de los grupos 4 y 5 del sistema períódico presentan actividades catalíticas aprox. 2-2.5 veces inferiores. Finalmente, los catalizadores promovidos por $Y$ y lantánidos son los menos activos, presentando valores de RTY hasta 10 veces inferiores al obtenido con Rh/Fe@ $\mathrm{Al}_{2} \mathrm{O}_{3}$.

Tabla 6.6: Resultados catalíticos para los catalizadores $R h / M @ A l_{2} \mathrm{O}_{3}$. Condiciones de reacción: $T=280^{\circ} \mathrm{C}$. $P=5.0 \mathrm{MPa}, \mathrm{H}_{2} / \mathrm{CO}=1, X_{C O}=15 \pm 3 \%$.

\begin{tabular}{|c|c|c|c|c|c|c|c|}
\hline \multirow{3}{*}{ Catalizador } & \multirow{3}{*}{$\mathrm{RTY}^{\mathrm{a}}$} & \multicolumn{6}{|c|}{ Selectividad (\%C) } \\
\hline & & \multirow{2}{*}{$\begin{array}{l}H C^{b} \\
(\%)\end{array}$} & \multirow{2}{*}{$\begin{array}{l}\mathrm{CO}_{2} \\
(\%)\end{array}$} & \multirow{2}{*}{$\begin{array}{c}\text { Oxigen. }{ }^{c} \\
(\%)\end{array}$} & \multicolumn{2}{|c|}{ Fracción oxigenados } & \multirow{2}{*}{$\frac{\mathrm{ROH}}{\left[\mathrm{C}_{2+} / \mathrm{C}_{1}\right]^{\mathrm{f}}}$} \\
\hline & & & & & $\begin{array}{l}\mathrm{ROH}^{\mathrm{d}} \\
(\%)\end{array}$ & $\begin{array}{c}{[\mathrm{AcOOH}+\mathrm{AcOOR}]^{\mathrm{e}}} \\
(\%)\end{array}$ & \\
\hline $\mathrm{Rh} / \mathrm{Fe} @ \mathrm{Al}_{2} \mathrm{O}_{3}$ & 4.28 & 51.4 & 7.5 & 41.1 & 86.2 & 8.6 & 3.2 \\
\hline $\mathrm{Rh} / \mathrm{V} @ \mathrm{Al}_{2} \mathrm{O}_{3}$ & 1.93 & 70.1 & 7.0 & 23.0 & 54.5 & 38.4 & 5.2 \\
\hline $\mathrm{Rh} / \mathrm{Nb} @ \mathrm{Al}_{2} \mathrm{O}_{3}$ & 1.69 & 78.7 & 9.3 & 12.0 & 41.4 & 50.4 & 1.5 \\
\hline $\mathrm{Rh} / \mathrm{Ta} @ \mathrm{Al}_{2} \mathrm{O}_{3}$ & 2.10 & 75.5 & 4.1 & 20.4 & 46.0 & 51.5 & 2.8 \\
\hline $\mathrm{Rh} / \mathrm{Ti} @ \mathrm{Al}_{2} \mathrm{O}_{3}$ & 1.65 & 70.3 & 3.2 & 26.5 & 41.2 & 54.0 & 2.5 \\
\hline $\mathrm{Rh} / \mathrm{Y} @ \mathrm{Al}_{2} \mathrm{O}_{3}$ & 0.64 & 58.7 & 5.1 & 36.2 & 70.5 & 26.2 & 3.0 \\
\hline $\mathrm{Rh} / \mathrm{Pr} @ \mathrm{Al}_{2} \mathrm{O}_{3}$ & 0.53 & 44.1 & 4.7 & 51.2 & 72.4 & 22.2 & 2.1 \\
\hline $\mathrm{Rh} / \mathrm{Nd} @ \mathrm{Al}_{2} \mathrm{O}_{3}$ & 0.44 & 42.6 & 8.9 & 48.5 & 78.5 & 17.0 & 1.7 \\
\hline $\mathrm{Rh} / \mathrm{Sm} @ \mathrm{Al}_{2} \mathrm{O}_{3}$ & 0.40 & 30.6 & 10.0 & 59.4 & 83.4 & 12.2 & 0.7 \\
\hline $\mathrm{Rh} / \mathrm{Li}-\mathrm{Ta} @ \mathrm{Al}_{2} \mathrm{O}_{3}$ & 2.20 & 64.0 & 4.1 & 31.9 & 34.8 & 59.9 & 2.0 \\
\hline $\begin{array}{l}{ }^{a} \text { Rendimiento tem } \\
\left(t_{r}>6 h\right) \text {. } \\
{ }_{b}^{b} \text { Hidrocarburos. } \\
{ }^{c} \text { Compuestos oxig } \\
{ }^{d} \mathrm{ROH}: \text { Alcoholes. } \\
{ }^{e} \text { AcOOH+AcOOR: }\end{array}$ & $\begin{array}{l}\text { l por m } \\
\text { los. }\end{array}$ & sa de $R$ & $\left(10^{-1}\right.$ & $\left.\mathrm{olCO} / g_{R h} \cdot h\right)$ & Eondicion & es de estado pseudo-e & onario \\
\hline
\end{tabular}


Además de estas diferencias en términos de actividad catalítica, se perciben también variaciones importantes en el patrón de selectividades. Así, los catalizadores promovidos por Fe y lantánidos ( $\mathrm{Pr}, \mathrm{Nd}, \mathrm{Sm}$ ) presentan los mayores valores de selectividad a compuestos oxigenados (41.1-59.4\%), siendo los alcoholes los compuestos oxigenados mayoritarios ( $>70 \%$ en la fracción de oxigenados). Por el contrario, en el caso los catalizadores promovidos por metales de transición de los grupos $5(\mathrm{~V}, \mathrm{Nb}, \mathrm{Ta})$ y 4 (Ti) la selectividad a compuestos oxigenados no supera el $26.5 \%$, siendo mayoritaria la formación de hidrocarburos $\left(\mathrm{S}_{\mathrm{HC}}>70 \%\right)$. Asimismo, en el caso de estos catalizadores los compuestos carboxílicos (ácido acético y los correspondientes ésteres metílico y etílico) son más abundantes en la fracción de oxigenados, siendo los compuestos oxigenados mayoritarios, a expensas de los alcoholes, para los catalizadores promovidos por $\mathrm{Ti}, \mathrm{Nb}$ y $\mathrm{Ta}$ (>50\% en la fracción de oxigenados).

Estos resultados catalíticos sugieren diferencias importantes en la naturaleza y proporción de centros activos en la serie de catalizadores, lo que condiciona la importancia relativa de diferentes rutas catalíticas hacia los distintos productos de reacción. La Fig. 6.8 describe esquemáticamente los diferentes caminos de reacción que se han propuesto para la SSO empleando catalizadores de $\mathrm{Rh}$ y que resultan en la formación de hidrocarburos $(\mathrm{HC})$ y compuestos oxigenados de diferentes longitudes de cadena [43]. La formación de hidrocarburos procede mediante la activación disociativa de CO seguida de eventos de hidrogenación y, opcionalmente, crecimiento de cadena para dar lugar a especies $\mathrm{C}_{\mathrm{x}} \mathrm{H}_{\mathrm{y}}$. Estas especies intermedias no oxigenadas pueden hidrogenarse $\mathrm{y}$ desorberse como hidrocarburos, pero también pueden participar en las rutas catalíticas que resultan en la formación de compuestos oxigenados superiores $\left(C_{2+}\right)$, a través de la inserción en la cadena en crecimiento de una molécula de CO 
activada de manera no disociativa. Finalmente, la formación de oxigenados $\mathrm{C}_{1}$ no requiere de la disociación de $\mathrm{CO}$ sino de la hidrogenación directa de la molécula activada no disociativamente.

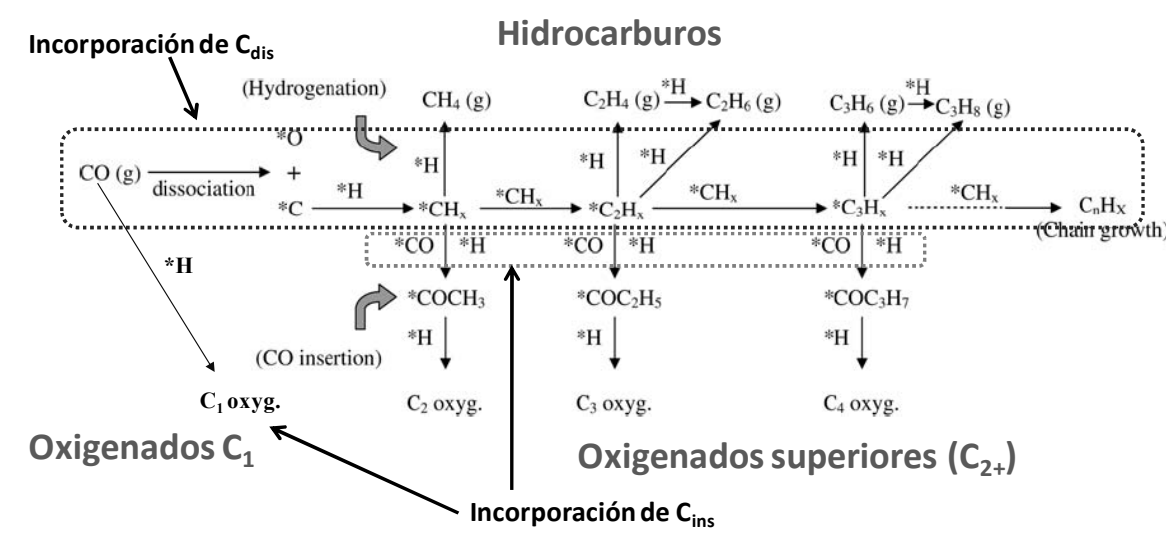

Figura 6.8: Esquema resumen de los eventos de reacción elementales involucrados en la SSO catalizada por Rh. Adaptado de [43] .

La Fig. 6.8 no considera un aspecto adicional, que complica significativamente el esquema de caminos de reacción, como la formación de diferentes tipos de compuestos oxigenados superiores (alcoholes, aldehídos, ácidos carboxílicos, ésteres carboxílicos, etc). Han existido discrepancias acerca de si la formación de cada tipo de compuestos oxigenados involucra modos diferentes de inserción de la molécula de $\mathrm{CO}$ e intermedios distintos $\mathrm{o}$, por el contrario, existen especies intermedias que pueden resultar en uno u otro tipo de producto en función de la etapa cinética que preceda a su desorción. En este sentido, por ejemplo, Underwood y Bell [44] propusieron que especies acilo (RCHO) son intermedios para la formación de aldehídos y que los alcoholes se forman por hidrogenación posterior de estos aldehídos. Por el contrario, Bao y col. postularon intermedios de diferente naturaleza (acilo y acetato) para la formación de etanol y acetaldehído, respectivamente, en el sistema $\mathrm{LiO}_{\mathrm{x}^{-}}$ $\mathrm{MnO}_{x}-\mathrm{ZrO}_{x}-\mathrm{Rh} / \mathrm{SiO}_{2}$ [45]. No obstante, independientemente del grupo 
funcional, la presencia de una función oxigenada en un producto de reacción involucra la activación no disociativa de una molécula de CO.

La gran variabilidad de productos de reacción, con diferentes longitudes de cadena y con posibilidad de contener o no diferentes funciones oxigenadas complica significativamente las discusiones acerca de los efectos promotores en este sistema catalítico. Todos los autores que han publicado trabajos científicos acerca de los catalizadores de Rh para la SSO, se limitan a considerar las selectividades relativas a oxigenados o a una determinada familia de compuestos (alcoholes, principalmente) o un producto determinado (metanol, etanol, acetaldehído, ácido acético) en sus discusiones, obviando que simplemente las diferencias en la longitud de cadena hidrocarbonada ya están relacionadas con diferencias en las probabilidades de disociación/inserción de $\mathrm{CO}$. Bien es cierto que la gran mayoría de los trabajos anteriores estudian sistemas catalíticos más homogéneos y que, por lo tanto, no presentan una variabilidad de selectividades $\tan$ amplia como la observada en el presente trabajo empleando promotores con propiedades electrónicas en un amplio rango.

Por lo tanto, considerando el esquema representado en la Fig. 6.8, y con el objeto de estudiar de una manera lo más rigurosa posible la influencia de la naturaleza del promotor $\left(\mathrm{MO}_{\mathrm{x}}\right)$ en el patrón de selectividades de la SSO, se definirá un parámetro descriptor (factor de selectividad) que pondera la existencia de dos tipos de átomos de carbono en los productos de la síntesis. Un primer tipo de átomos de carbono, denominado $C_{\text {dis, }}$ procede de especies intermedias no oxigenadas $\left(\mathrm{C}_{x} \mathrm{H}_{y}, \mathrm{x} \geq 1\right)$ cuya formación involucra la disociación de la molécula de $\mathrm{CO}$, a través de un mecanismo de tipo Fischer-Tropsch. Un segundo tipo de átomos de carbono, denominado $\mathrm{C}_{\text {ins, }}$ procede de la hidrogenación directa o la inserción en cadenas $\mathrm{C}_{\mathrm{x}} \mathrm{H}_{\mathrm{y}}$ de moléculas de $\mathrm{CO}$ activadas no disociativamente, de modo que los átomos $\mathrm{C}_{\text {ins }}$ 
se encuentran enlazados a un átomo de oxígeno en los productos de reacción. Los átomos $C_{\text {dis }}$ son los únicos presentes en las moléculas de hidrocarburos (olefinas y parafinas) mientras que aparecen en combinación con átomos $C_{\text {ins }}$ en compuestos oxigenados superiores $\left(C_{2+}\right)$ excepto el dimetil-éter. Por su parte, las moléculas de metanol, formaldehido, ácido fórmico y dimetil-éter sólo contienen átomos de tipo $C_{\text {ins. }}$ En términos de contabilización de $\mathrm{C}_{\text {ins }}$ Y $\mathrm{C}_{\text {dis, }}$ las moléculas de éteres se consideran como dos moléculas de los correspondientes alcoholes, de modo que no se considera su formación como productos de reacción primarios, sino que derivan de eventos de deshidratación. La Fig. 6.9 esquematiza estos conceptos mostrando los diferentes átomos de carbono considerados en las moléculas de propano, metanol y acetato de etilo, como ejemplos.

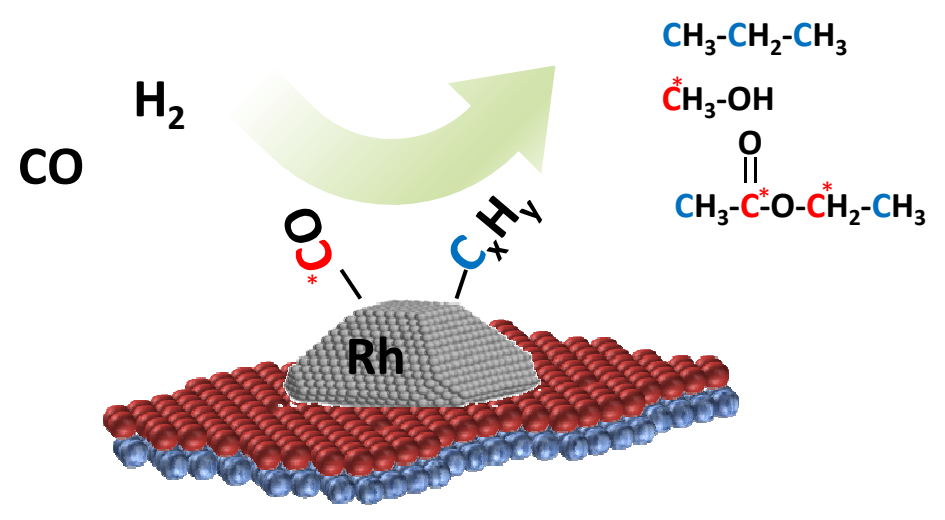

Figura 6.9: Representación esquemática de los tipos de átomos de carbono considerados en los productos de reacción en función de si se requiere un mecanismo de activación disociativa (azul) o no disociativa (rojo + asterisco) para la molécula de $\mathrm{CO}$.

El cociente entre el número de átomos de carbono $C_{\text {dis }} / C_{\text {ins }}$ en los productos de reacción, denominado a partir de ahora factor de selectividad $(\phi)$ es, por tanto, una medida de la capacidad para insertar moléculas de CO no disociadas en los productos de reacción (dando lugar a oxigenados) en relación a la capacidad para activar la molécula de $\mathrm{CO}$ de manera disociativa 
(directamente relacionada con la producción de metano como principal hidrocarburo, y también con el crecimiento de cadena).

La Fig. 6.10 representa la evolución del factor de selectividad $(\phi)$ con las propiedades electrónicas del óxido promotor $\left(\mathrm{MO}_{\mathrm{x}}\right)$, empleando el valor de $E(I M C T)$ como parámetro descriptor de las mismas. Como se observa en la representación, existe una correlación entre $\phi$ y $E(I M C T)$ para todos los catalizadores a excepción del catalizador promovido por Fe. De acuerdo a esta correlación, $\phi$ disminuye de manera potencial en el rango de 0.94-0.08 con el valor de $E(I M C T)$ entre 2.38 y $2.59 \mathrm{eV}$. Puesto que el parámetro E(IMCT) para la alizarina adsorbida es una medida de las propiedades electrónicas de las especies promotoras $\left(\mathrm{MO}_{\mathrm{x}}\right)$, los resultados indican que los óxidos promotores de carácter electro-donante (base de Lewis) promueven la inserción no-disociativa de CO en los productos de la SSO, incrementando la selectividad a productos oxigenados, a expensas de los hidrocarburos. Por el contrario, la formación de hidrocarburos y productos $C_{2+}$ se ve favorecida con el empleo de un óxido promotor de características electro- aceptoras (ácido de Lewis). 


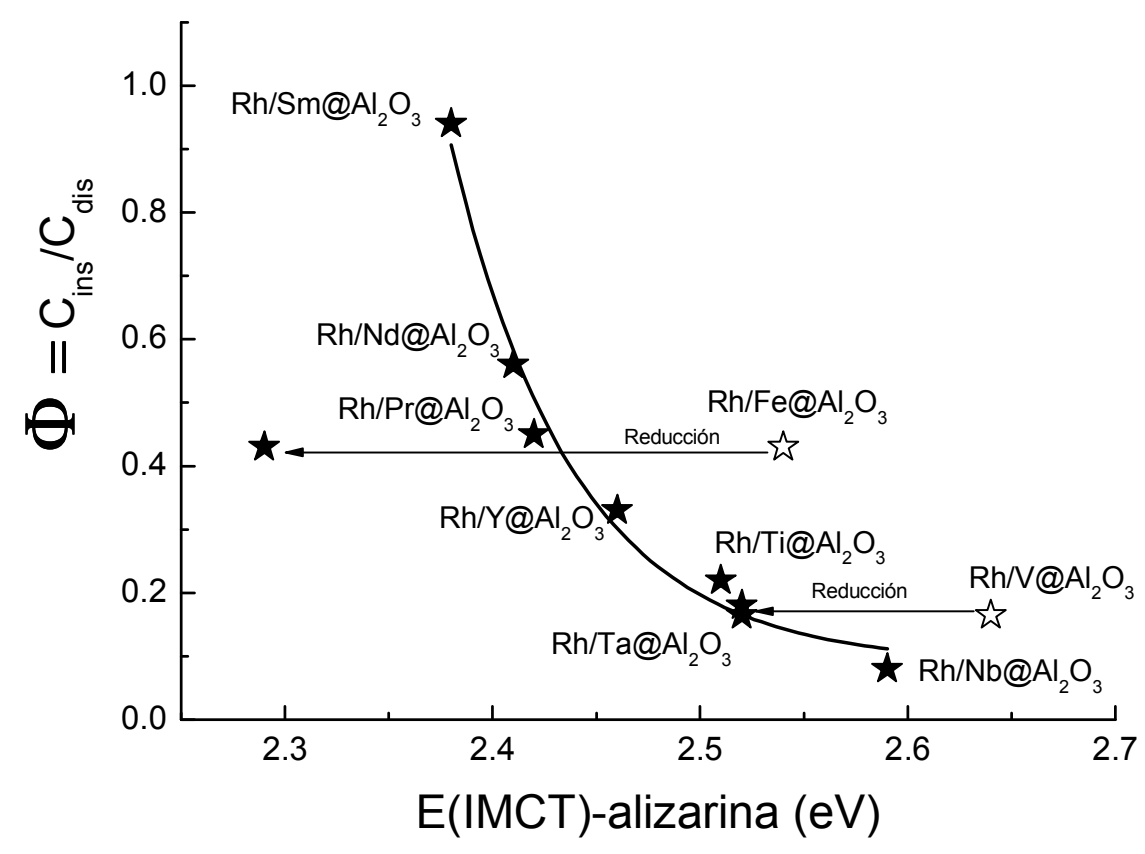

Figura 6.10: Evolución del "parámetro de selectividad" $\phi$ para los catalizadores $\mathrm{Rh} / \mathrm{M} @ \mathrm{Al}_{2} \mathrm{O}_{3}$ (condiciones de reacción: $\mathrm{T}=280^{\circ} \mathrm{C} . \mathrm{P}=5.0 \mathrm{MPa}, \mathrm{H}_{2} / \mathrm{CO}=1, X_{\mathrm{CO}}=15 \pm 3 \%$ ) con la $E(I M C T)$ para la molécula de alizarina adsorbida sobre el óxido promotor $M O_{x}$ dispuesto en monocapa (escala universal de acidez Lewis o carácter electro donanteaceptor [37]).

Asimismo, en la Fig. 6.10 se han incluido dos puntos para cada uno de los dos catalizadores promovidos por especies $\mathrm{MO}_{\mathrm{x}}$ cuya co-reducción con las fases de Rh se evidenció mediante $\mathrm{H}_{2}$-TPR (sección 6.3.2.3), esto es, $\mathrm{Rh} / \mathrm{Fe} @ \mathrm{Al}_{2} \mathrm{O}_{3}$ y $\mathrm{Rh} / \mathrm{V} @ \mathrm{Al}_{2} \mathrm{O}_{3}$. Estos dos puntos corresponden con la evaluación de $E(I M C T)$ para el soporte promovido en su forma calcinada (puntos vacíos) o tras el correspondiente tratamiento de reducción en flujo de $\mathrm{H}_{2}$ a 500 y $650^{\circ} \mathrm{C}$ para $\mathrm{VO}_{x}$ y $\mathrm{FeO}_{x}$, respectivamente (puntos rellenos). Estas temperaturas de reducción se escogieron de forma que el tratamiento reduce las fases de óxido promotor en la misma extensión en la que éstas se reducen durante la reducción de los catalizadores $\mathrm{Rh} / \mathrm{M} @ \mathrm{Al}_{2} \mathrm{O}_{3}$ previa a la catálisis (ver Fig. 6.7 y Tabla 6.5). En este caso, los procesos de reducción incrementan la densidad electrónica en los clusters bidimensionales de $\mathrm{MO}_{\mathrm{x}}$ 
lo que incrementa el carácter electro-donante (básico) de estas especies con la consiguiente disminución del parámetro E(IMCT).

Como se observa, en el caso del catalizador promovido por $\mathrm{V}$, la caracterización de las propiedades electrónicas de las fases promotoras en el estado en que éstas se encuentran durante el experimento catalítico es esencial para que este catalizador se incorpore a la correlación representada en la Fig. 6.10. Esto no es necesario para aquellos catalizadores cuyas fases $\mathrm{MO}_{\mathrm{x}}$ no se reducen durante el tratamiento en $\mathrm{H}_{2}$ previo a la catálisis (los 8 restantes en la correlación), para los que, por tanto, la caracterización de las propiedades de las fases $\mathrm{MO}_{\mathrm{x}}$ en su forma oxidada describe correctamente sus propiedades catalíticas.

Finalmente, se observa que el catalizador promovido con una monocapa de $\mathrm{FeO}_{x}$ no sigue la correlación mencionada ni utilizando el parámetro $\mathrm{E}(\mathrm{IMCT})$ para las fases $\mathrm{FeO}_{x}$ calcinadas ni para las fases $\mathrm{FeO}_{x}$ reducidas. Este comportamiento sugiere que los mecanismos de promoción del Fe son distintos al del resto de promotores estudiados. Es probable que la elevada actividad catalítica ofrecida por este catalizador (Tabla 6.6) esté relacionada con este hecho. A priori, la principal característica distintiva del Fe es que es un metal con capacidad propia para activar las moléculas de CO e $\mathrm{H}_{2}$ en las condiciones de reacción y puede, por tanto, activar determinados eventos cinéticos que aceleran el proceso global de SSO. De hecho, el Fe es uno de los metales más empleados para la SFT, presentando una elevada selectividad hacia olefinas de cadena corta. Estas características exclusivas seguramente contribuyen al especial comportamiento catalítico de $\mathrm{Rh} / \mathrm{Fe} @ \mathrm{Al}_{2} \mathrm{O}_{3}$. Por lo tanto, el enfoque general empleado en el presente estudio no será aplicable en el caso del empleo de $\mathrm{FeO}_{x}$ como promotores catalíticos del Rh, y probablemente, este caso en concreto requiera de estudios posteriores con enfoques diferentes. 
Cabe mencionar en este punto que un factor adicional, como la deshidratación intramolecular de alcoholes para dar lugar a olefinas, podría contribuir de manera no despreciable al valor del parámetro $\phi$. La ocurrencia de esta reacción secundaria en una extensión importante, catalizada por centros ácidos, resultaría en una subestimación del valor de $\phi$ real, puesto que productos primarios que contienen $C_{\text {ins }}$ se convierten en productos secundarios que sólo contienen $\mathrm{C}_{\text {dis }}$ y $\mathrm{H}_{2} \mathrm{O}$. Puesto que se conoce que los óxidos de metales del grupo $5(\mathrm{~V}, \mathrm{Nb}, \mathrm{Ta})$ dispuestos en monocapa sobre $\mathrm{Al}_{2} \mathrm{O}_{3}$ pueden poseer centros ácidos Brønsted y Lewis, es necesario comprobar si la deshidratación de alcoholes contribuye a la tendencia representada en la Fig. 6.10.

En este sentido, existen algunas evidencias experimentales que indican que la reacción secundaria de deshidratación intramolecular de alcoholes no contribuye de manera importante a la correlación mostrada.

Por un lado, los catalizadores promovidos por óxidos de carácter ácido $\left(\mathrm{VO}_{\mathrm{x}}, \mathrm{NbO}_{\mathrm{x}}, \mathrm{TaO}_{\mathrm{x}}\right)$ son aquellos que presentan una mayor selectividad a hidrocarburos $\mathrm{C}_{2+}$, lo que podría, en un principio, estar relacionado con reacciones de deshidratación de oxigenados $C_{2}$ como etanol, que apenas se detecta en los productos. Sin embargo, un análisis de la fracción de hidrocarburos (parafinas $+\alpha$-olefinas) obtenida con estos catalizadores evidencia que la distribución de hidrocarburos puede describirse de manera satisfactoria por una distribución tipo ASF (típica de los procesos de FischerTropsch), como se muestra en la Fig. 6.11. Asimismo, la adición de Li en el catalizador Rh/Li-Ta@ $\mathrm{Al}_{2} \mathrm{O}_{3}$, si bien reduce ligeramente la selectividad a hidrocarburos, no modifica sustancialmente la forma de la distribución. Por el contrario, si existiese una contribución importante de olefinas provenientes de la deshidratación de oxigenados $C_{2}$ (que son los oxigenados predominantes en la mayoría de los catalizadores basados en Rh) se 
esperaría una desviación respecto de la distribución ASF debido, por ejemplo, a un exceso de producción de etileno. Por lo tanto, se puede concluir que la formación de los hidrocarburos tiene lugar, de manera más probable, a través de un mecanismo tipo SFT sobre los centros metálicos y no existe una contribución importante por parte de reacciones secundarias que obedezcan a otro mecanismo.

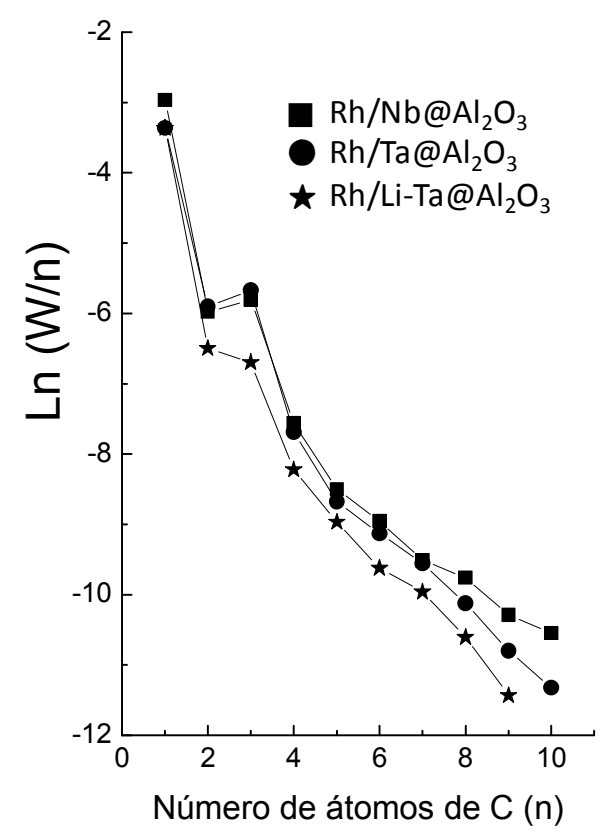

Figura 6.11: Diagrama de ASF para los hidrocarburos (parafinas $+\alpha$-olefinas) en los

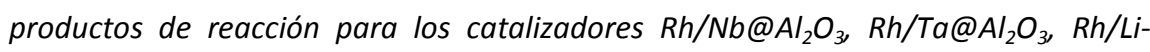
$\mathrm{Ta} @ \mathrm{Al}_{2} \mathrm{O}_{3}$ (condiciones de reacción: $T=280^{\circ} \mathrm{C}$. $P=5.0 \mathrm{MPa}, X_{C O}=15 \pm 3 \%$ ).

Asimismo, la contribución de éteres en la fracción de oxigenados es, de hecho, mayor para los catalizadores promovidos por óxidos de carácter básico (hasta $26.1 \%$ para $\mathrm{Rh} / \mathrm{Sm} @ \mathrm{Al}_{2} \mathrm{O}_{3}$ ) que para aquellos promovidos por óxidos ácidos (6.3\% para $\mathrm{Rh} / \mathrm{Nb} @ \mathrm{Al}_{2} \mathrm{O}_{3}$ ) reflejando que la ausencia de alcoholes entre los productos de reacción para éstos últimos no se debe a reacciones secundarias de deshidratación sino a que no se forman sobre los centros activos para la SSO. 
Por otro lado, como ya se comentó, se ha estudiado el efecto de la introducción de un metal alcalino para neutralizar la acidez superficial del soporte Ta@ $\mathrm{Al}_{2} \mathrm{O}_{3}$. Se conoce que una monocapa de óxidos de $\mathrm{V}, \mathrm{Nb}$ ó Ta sobre $\mathrm{Al}_{2} \mathrm{O}_{3}$ contiene una densidad superficial de aprox. 0.7-0.8 centros ácidos (Brønsted + Lewis) por $\mathrm{nm}^{2}$ [46]. Para la neutralización de la acidez en los catalizadores de síntesis de oxigenados se han empleado metales alcalinos, siendo los preferidos Li, Na y K [47]. El empleo de Li está muy extendido para una gran variedad de sistemas catalíticos de SSO, entre ellos, los catalizadores basados en Rh $[48,49]$. Varios autores $[50,51]$ han descrito que los metales alcalinos introducidos en catalizadores de Rh ( $\mathrm{u}$ otros metales nobles y seminobles) soportados sobre soportes de carácter ácido se localizan predominantemente sobre la superficie del soporte, neutralizando los centros ácidos, y no interaccionan significativamente con las fases de Rh. En base a estas premisas, se sintetizó el catalizador Rh/Li-

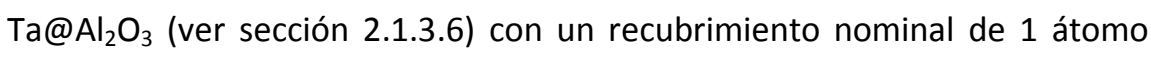
$\mathrm{Li} / \mathrm{nm}^{2}$, es decir, un $20-30 \%$ en exceso frente a la densidad esperada de centros ácidos totales. Los resultados catalíticos para este catalizador se recogen también en la Tabla 6.6. Se observa que la presencia de Li apenas modifica la actividad catalítica específica con respecto al catalizador $\mathrm{Rh} / \mathrm{Ta} @ \mathrm{Al}_{2} \mathrm{O}_{3}$, de acuerdo con la hipótesis de una interacción limitada Li-Rh. Por otro lado, la adición de Li incrementa la selectividad a oxigenados, en detrimento de los hidrocarburos, tan sólo de manera modesta, ofreciendo selectividades a oxigenados aún inferiores al catalizador $\mathrm{Rh} / \mathrm{Y} @ \mathrm{Al}_{2} \mathrm{O}_{3}$. Por otro lado, en la fracción de alcoholes, la relación $C_{2+} / C_{1}$ disminuye de 2.8 para $\mathrm{Rh} / \mathrm{Ta} @ \mathrm{Al}_{2} \mathrm{O}_{3}$ hasta 2.0 para $\mathrm{Rh} / \mathrm{Li}-\mathrm{Ta} @ \mathrm{Al}_{2} \mathrm{O}_{3}$, sugiriendo que la deshidratación de alcoholes, que es más probable para los alcoholes $C_{2+}$ que para el metanol, no contribuye de manera significativa a los resultados catalíticos obtenidos para el catalizador $\mathrm{Rh} / \mathrm{Ta} @ \mathrm{Al}_{2} \mathrm{O}_{3}$, representativo de los catalizadores promovidos por óxidos de carácter ácido (electro-aceptor). De 
hecho, la introducción de Li como agente neutralizante de la acidez superficial incrementa el valor de $\phi$ tan sólo hasta 0.29 , lo que apenas modificaría la tendencia representada en la Fig. 6.10.

En línea con estas observaciones, Ichikawa [52], trabajando a presiones de reacción reducidas, condiciones que favorecen la metanación, encontró que catalizadores de Rh soportados sobre óxidos de carácter ácido como $\mathrm{SiO}_{2}, \mathrm{Al}_{2} \mathrm{O}_{3}, \mathrm{SnO}_{2}, \mathrm{~V}_{2} \mathrm{O}_{5}$ y $\mathrm{WO}_{3}$ dan lugar a la formación de metano como producto predominante, el cual no puede provenir de la deshidratación de productos primarios oxigenados. De manera interesante, el propio autor encontró que el empleo de soportes denominados "anfóteros" como $\mathrm{TiO}_{2}, \mathrm{ZrO}_{2}$ y $\mathrm{La}_{2} \mathrm{O}_{3}$ maximiza la formación de oxigenados $\mathrm{C}_{2+}$, mientras que los soportes denominados "fuertemente básicos" (MgO, $\mathrm{CaO}, \mathrm{BeO})$ dan lugar fundamentalmente a metanol, lo que supone un antecedente a las tendencias descritas de manera cuantitativa en el presente trabajo.

Finalmente, ha de considerarse que el balance $C_{\text {dis }} / C_{\text {ins }}$ no sólo está relacionado con la selectividad relativa hacia hidrocarburos y compuestos oxigenados, sino también con los eventos de crecimiento de cadena, lo que influye en la longitud de cadena tanto de los hidrocarburos como de los compuestos oxigenados.

En este sentido, los alcoholes superiores $\left(C_{2+}\right)$ de naturaleza lineal constituyen un conjunto de productos de reacción cuyo valor añadido es superior al del metanol, para cuya síntesis se dispone de procesos alternativos operados a escala industrial. Como se observa en la Tabla 6.6, los catalizadores promovidos por óxidos de lantánidos son aquellos que presentan una mayor selectividad a compuestos oxigenados, y especialmente a alcoholes. La Fig. 6.12 representa la relación $C_{2+} / C_{1}$ en la 
fracción de alcoholes en función del valor de $E(I M C T)$ para la serie de catalizadores promovidos por $\mathrm{YO}_{x}, \mathrm{PrO}_{x}, \mathrm{NdO}_{x}$ y $\mathrm{SmO}_{x}$. Se percibe claramente que existe una correlación lineal entre ambos parámetros para esta serie de catalizadores, de modo que la proporción de alcoholes superiores as mayor cuanto mayor es el valor de $\mathrm{E}(\mathrm{IMCT})$. En un extremo de esta tendencia, para el catalizador $\mathrm{Rh} / \mathrm{Sm} @ \mathrm{Al}_{2} \mathrm{O}_{3}$, que presenta la mayor selectividad a oxigenados (Tabla 6.6), el metanol constituye la gran mayoría de la fracción de alcoholes. Es decir, el carácter electro-donante del óxido promotor, que incrementa el valor de $\phi$ (Fig. 6.9), disminuye a su vez la longitud de cadena media de los productos oxigenados de interés, como los alcoholes.

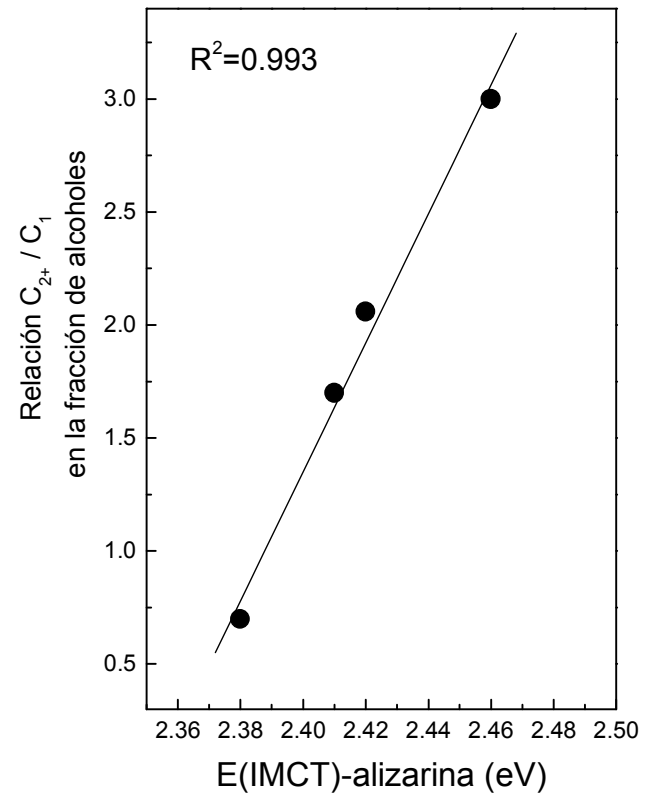

Figura 6.12: Evolución de la relación de alcoholes superiores $\left(C_{2+}\right)$ a metanol en la fracción de oxigenados con $E(I M C T)$ para los catalizadores $R h / M @ \mathrm{Al}_{2} \mathrm{O}_{3}$ promovidos por óxidos de lantánidos e itrio.

Esta evolución de la longitud de cadena de los productos oxigenados en función de las propiedades electrónicas del promotor resulta en variaciones importantes en la contribución de los alcoholes superiores en la 
fracción de alcoholes, que pasa de suponer el 75\% para $\mathrm{Rh} / \mathrm{Y}_{\mathrm{A}} \mathrm{Al}_{2} \mathrm{O}_{3}$ a tan sólo el $33 \%$ en el caso de $\mathrm{Rh} / \mathrm{Sm} @ \mathrm{Al}_{2} \mathrm{O}_{3}$. Asimismo, esto supone una indicación adicional de que las reacciones de deshidratación de alcoholes no contribuyen de manera significativa a las tendencias discutidas, al menos en las condiciones de reacción empleadas. De hecho, considerando que el metanol es el alcohol más difícil de deshidratar, se esperaría un incremento en la contribución de productos $\mathrm{C}_{2+}$ en la fracción de alcoholes cuando se incrementa la basicidad del promotor (disminuye $\mathrm{E}(\mathrm{IMCT}$ ) en la Fig. 6.12), contrariamente a lo observado experimentalmente. Por lo tanto, la evolución de $\mathrm{C}_{\text {ins }} / \mathrm{C}_{\text {dis, }}$ la naturaleza de los oxigenados mayoritarios (alcoholes vs. ácidos carboxílicos y carboxilatos) y la longitud de cadena de los productos oxigenados parecen estar relacionados principalmente con el fenómeno de promoción por parte de las fases $\mathrm{MO}_{\mathrm{x}}$ con diferentes propiedades electrónicas.

Así pues, estos resultados apuntan a que un incremento en el carácter electro-donante de las fases promotoras $\mathrm{MO}_{\mathrm{x}}$ induce determinadas propiedades en las partículas de $\mathrm{Rh}$, o bien genera determinados centros activos en la interfase $\mathrm{Rh}-\mathrm{MO}_{\mathrm{x}}$ que promueven la formación de productos oxigenados frente a los hidrocarburos. En un principio, esta tendencia parece contradecir la creencia generalizada de que centros metálicos electrodeficientes $\mathrm{Rh}^{\delta+}[45,53]$ (que se favorecerían en NPs de Rh con menor densidad electrónica, en contacto con fases promotoras $\mathrm{MO}_{\mathrm{x}}$ electroaceptoras) juegan un papel relevante en el mecanismo de inserción no disociativa de CO que da lugar a la formación de productos oxigenados. La batería de catalizadores $\mathrm{Rh} / \mathrm{M} @ \mathrm{Al}_{2} \mathrm{O}_{3}$ con diversas propiedades electrónicas (o ácido-base) en un amplio rango, suponen un sistema idóneo para acometer estudios que arrojen luz sobre este tipo de disyuntivas. Las siguientes secciones persiguen realizar una extensa caracterización de las 
fases de Rh con el objetivo de conocer la influencia que la naturaleza de los promotores $\mathrm{MO}_{\mathrm{x}}$ ejerce sobre las propiedades electrónicas y catalíticas de las NPs de Rh.

\subsubsection{Propiedades electrónicas de las NPs de Rh en los catalizadores activados.}

6.3.4.1. Estado de oxidación y propiedades electrónicas de los componentes: XPS.

Una serie de catalizadores $\mathrm{Rh} / \mathrm{M} @ \mathrm{Al}_{2} \mathrm{O}_{3}$ seleccionados se han estudiado mediante XPS con el objetivo de obtener información acerca del estado de oxidación de los promotores (M) y el Rh, así como de la carga electrónica parcial en las especies de Rh. En determinados casos, el estudio se ha llevado a cabo para el catalizador tanto en su forma calcinada como en su estado reducido, tras la activación en $\mathrm{H}_{2}$ de acuerdo al tratamiento que se lleva a cabo antes de la catálisis ( 300 ㅇ, 6 horas, flujo de $\mathrm{H}_{2}$ ).

La Fig. 6.13 muestra los espectros de XPS en la región de la línea Rh3d para los catalizadores Rh/ $\mathrm{V} @ \mathrm{Al}_{2} \mathrm{O}_{3}, \mathrm{Rh} / \mathrm{Ta} @ \mathrm{Al}_{2} \mathrm{O}_{3}, \mathrm{Rh} / \mathrm{Y} @ \mathrm{Al}_{2} \mathrm{O}_{3}$ y $\mathrm{Rh} / \mathrm{Sm} @ \mathrm{Al}_{2} \mathrm{O}_{3}$ reducidos, mientras que la Tabla 6.7 recoge los resultados obtenidos del estudio completo mediante XPS.

En cuanto a las fases promotoras, como se recoge en la Tabla 6.7, los catalizadores promovidos por $\mathrm{Ta}(\mathrm{V}), \mathrm{Y}(\mathrm{III})$ y $\mathrm{Sm}$ (III) contienen exclusivamente $\mathrm{Ta}^{5+}, \mathrm{Y}^{3+}$ y Sm${ }^{3+}$, evidenciando que los metales promotores no se reducen durante el tratamiento de activación en $\mathrm{H}_{2}$. Por su parte, el catalizador promovido por $\mathrm{V}(\mathrm{V})$ contiene exclusivamente $\mathrm{V}^{5+}$ en su estado oxidado, mientras que el promotor se reduce completamente hasta $\mathrm{V}^{3+}$ tras el tratamiento de reducción. Estos resultados se encuentran de acuerdo con los perfiles de $\mathrm{H}_{2}$-TPR (Fig. 6.7) y evidencian que la descripción del comportamiento catalítico de los catalizadores Rh/M@ $\mathrm{Al}_{2} \mathrm{O}_{3}$ mediante 
parámetros físico-químicos determinados en su estado oxidado sólo es adecuado para los promotores que no se co-reducen con las fases de Rh (todos excepto $\mathrm{V}(\mathrm{V})$ y $\mathrm{Fe}(\mathrm{III})$ ).

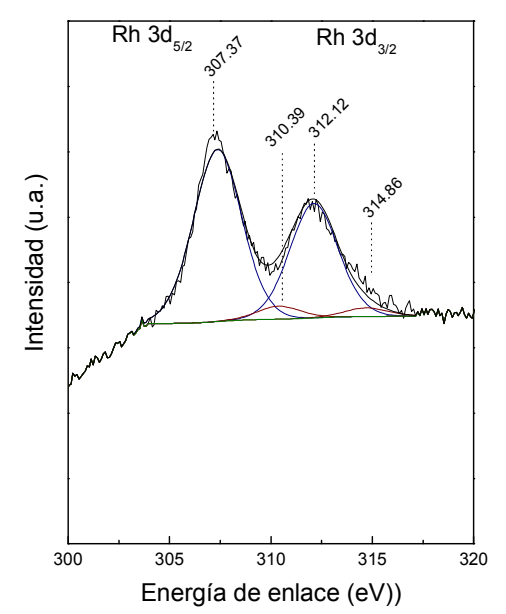

(a)

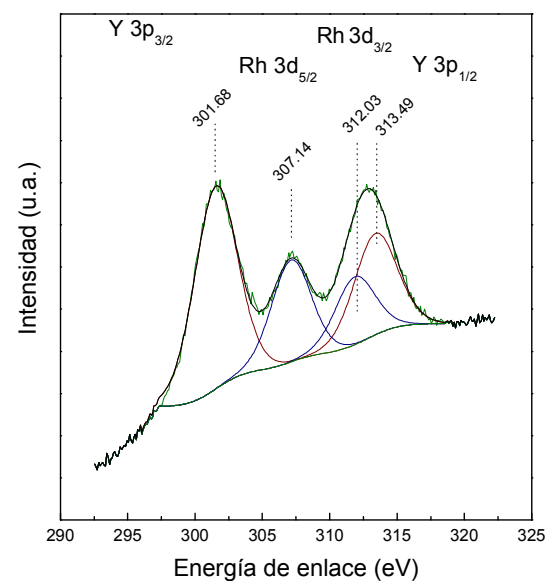

(c)

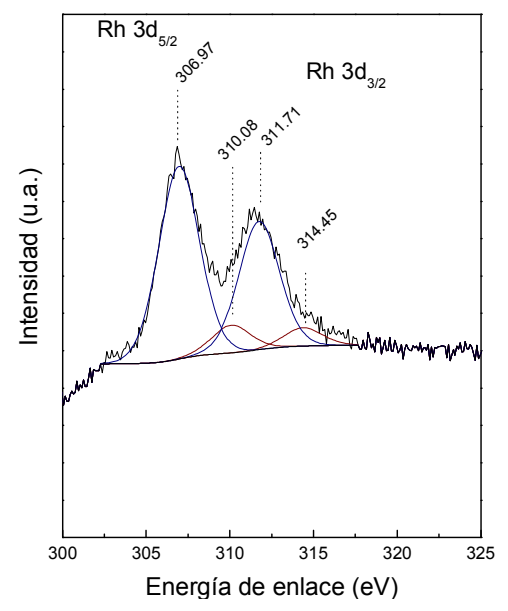

(b)

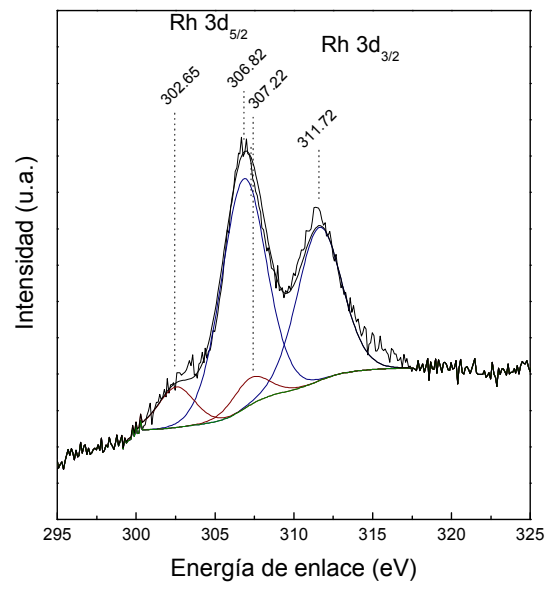

(d)

Figura 6.13: Espectros de XPS en la región de la señal Rh3d para los catalizadores (a) $R h / V @ A I_{2} O_{3}$, (b) Rh/Ta@Al $\mathrm{O}_{3}$, (c) $R h / Y @ A l_{2} \mathrm{O}_{3}$ y (d) Rh/Sm@Al $\mathrm{O}_{3}$ reducidos in situ en $\mathrm{H}_{2}$ a $300^{\circ} \mathrm{C}$.

Por su parte, las especies de $\mathrm{RhCl}_{3}\left(\mathrm{E} . \mathrm{E}_{\text {.Rh3d }}\left(\mathrm{RhCl}_{3}\right)=310.2 \mathrm{eV}\right.$ [54]) son las únicas detectadas en los catalizadores analizados en su forma calcinada, 
de modo que no se observan contribuciones debidas a especies de óxido (E.E.rh3d $\left.\left(\mathrm{Rh}_{2} \mathrm{O}_{3}\right)=308.2 \mathrm{eV}\right)$, lo que apunta a que el tratamiento de calcinación en aire $\left(400^{\circ} \mathrm{C}\right)$ no descompone el precursor de Rh. Por otro lado, en la Fig. 6.13 se observa que para todos los catalizadores reducidos predominan las especies de $\mathrm{Rh}^{0}$ (E.E.Rh3d $\approx 306.8-307.3 \mathrm{eV}$ ). No obstante, aunque muy minoritarias $(<12 \%)$, algunas contribuciones adicionales se pueden discernir en determinadas muestras. Así, los catalizadores promovidos por $\mathrm{V}$ y Ta presentan especies de $\mathrm{RhCl}_{3}$ no descompuestas tras el tratamiento de reducción (E.E.Rh3d $\approx 310.0-310.4 \mathrm{eV}$ ). La especificidad de este hecho para los soportes promovidos por óxidos de características ácidas indica que el precursor clorado de Rh se estabiliza sobre los promotores de carácter electro-aceptor. El átomo metálico en $\mathrm{RhCl}_{3}$ es un ácido de Lewis que, probablemente, interacciona de manera más intensa con los soportes promovidos por óxidos de carácter básico, lo que parece promover la descomposición del precursor metálico clorado. Finalmente, en el caso de $\mathrm{Rh} / \mathrm{Sm} @ \mathrm{Al}_{2} \mathrm{O}_{3}$ se percibe una componente adicional en la que el Rh presenta un valor de E.E.Rh3d de $302.54 \mathrm{eV}$, lo que podría corresponder con la formación de una aleación Rh-Sm en la frontera de contacto entre las fases de Rh y el promotor. De hecho, se conoce la estabilidad de las aleaciones que el Rh puede formar con algunos lantánidos, especialmente de carácter marcadamente básico, como La o Sm [55], siendo $\Delta \mathrm{H}_{\mathrm{f}}^{0}$ para las aleaciones $\mathrm{Sm}_{5} \mathrm{Rh}_{4}$ y $\mathrm{SmRh}_{2}$ de -66.5 y $-65.5 \mathrm{~kJ} / \mathrm{mol}$, respectivamente [56]. No obstante, en el presente caso, a la vista del espectro presentado en la Fig. 6.13-d, la proporción de Rh formando parte de esta aleación sería, en todo caso, muy minoritaria lo que hace suponer que su contribución a los resultados catalíticos no es importante. 
Tabla 6.7: Energías de enlace, estados de oxidación de promotores y Rh, parámetro Auger (de acuerdo a Wagner y col. [57]) y parámetro de carga de estado inicial derivados del análisis por XPS de catalizadores $\mathrm{Rh} / \mathrm{M} @ \mathrm{Al}_{2} \mathrm{O}_{3}$ seleccionados en su estado calcinado y reducido.

\begin{tabular}{|c|c|c|c|c|c|}
\hline \multirow{2}{*}{ Catalizador } & \multirow{2}{*}{ Estado } & \multirow{2}{*}{$\begin{array}{c}\mathrm{M} \\
(\mathrm{V}, \mathrm{Ta}, \mathrm{Y}, \mathrm{Sm})^{\mathrm{a}} \\
\text { E.E. (eV) }\end{array}$} & \multirow{2}{*}{$\frac{\operatorname{Rh} 3 d_{5 / 2}^{b}}{\text { E.E. }(e V)}$} & \multirow{2}{*}{$\begin{array}{c}\text { Rh } \\
\text { M5VV } \\
\Delta(\alpha)^{\mathrm{c}} \\
(\mathrm{eV})\end{array}$} & \multirow[t]{2}{*}{$\begin{array}{l}\Delta(\varepsilon)^{\mathrm{d}} \\
(\mathrm{eV})\end{array}$} \\
\hline & & & & & \\
\hline $\mathrm{Rh} / \mathrm{V} @ \mathrm{Al}_{2} \mathrm{O}_{3}$ & Calcinado & $517.62\left(\mathrm{~V}^{5+}\right)$ & $310.12\left(\mathrm{RhCl}_{3}\right)$ & --- & --- \\
\hline $\mathrm{Rh} / \mathrm{V} @ \mathrm{Al}_{2} \mathrm{O}_{3}$ & Reducido & $515.93\left(\mathrm{~V}^{3+}\right)$ & $\begin{array}{c}307.37\left(\mathrm{Rh}^{\circ}\right) \\
310.39\left(\mathrm{RhCl}_{3}\right)\end{array}$ & 1.46 & 0.56 \\
\hline $\mathrm{Rh} / \mathrm{Ta} @ \mathrm{Al}_{2} \mathrm{O}_{3}$ & Reducido & $230.11\left(\mathrm{Ta}^{5+}\right)$ & $\begin{array}{c}306.97\left(\mathrm{Rh}^{0}\right) \\
310.08\left(\mathrm{RhCl}_{3}\right)\end{array}$ & 1.44 & 0.95 \\
\hline $\mathrm{Rh} / \mathrm{Y} @ \mathrm{Al}_{2} \mathrm{O}_{3}$ & Calcinado & $158.22\left(\mathrm{Y}^{3+}\right)$ & $309.46\left(\mathrm{RhCl}_{3}\right)$ & --- & --- \\
\hline $\mathrm{Rh} / \mathrm{Y} @ \mathrm{Al}_{2} \mathrm{O}_{3}$ & Reducido & $158.28\left(\mathrm{Y}^{3+}\right)$ & $307.14\left(\mathrm{Rh}^{0}\right)$ & 1.87 & 1.00 \\
\hline $\mathrm{Rh} / \mathrm{Sm} @ \mathrm{Al}_{2} \mathrm{O}_{3}$ & Reducido & $1081.29\left(\mathrm{Sm}^{3+}\right)$ & $\begin{array}{c}306.82\left(\mathrm{Rh}^{0}\right) \\
(s h) 302.65\end{array}$ & 4.10 & 2.43 \\
\hline
\end{tabular}

\footnotetext{
${ }^{a}$ Energía de enlace para la línea $2 p$ del $V$ y la línea $3 d$ para el resto de los metales promotores ( $\left.M\right)$.

${ }^{b}$ Energía de enlace para la línea $3 d$ del $R h$.

${ }^{c}$ Variación del parámetro Auger $(\alpha)$ respecto de $R h^{0}$ monocristalino como referencia. Parámetro Auger definido de acuerdo a Wagner y col. [57], $\alpha=(E . E .)_{X P S}+(E . C .)_{X A E S}$. Referencia para monocristal de $R h^{0}$ (E.E. $=307.20 \mathrm{eV}$, E.C.=608.5 eV). E.C.: Energía cinética para los electrones Auger de la línea M5VV del Rh.

${ }^{d}$ Variación del parámetro de carga de estado inicial respecto de $R h^{0}$ monocristalino como referencia. $\Delta(\varepsilon)=\Delta(E . E)+.\Delta(\operatorname{Rex})$, donde $\Delta(\operatorname{Rex})=1 / 2 \cdot \Delta(\alpha)$ es el parámetro de relajación de los estados finales.
}

De manera adicional, el conjunto de catalizadores $\mathrm{Rh} / \mathrm{M} @ \mathrm{Al}_{2} \mathrm{O}_{3}$ supone un sistema idóneo para estudiar cómo influyen las propiedades electrónicas de los promotores $\left(\mathrm{MO}_{\mathrm{x}}\right)$ en la densidad electrónica de las NPs de $\mathrm{Rh}^{0}$. Como se observa en la Tabla 6.7, todos los catalizadores presentan variaciones del parámetro de carga de los estados iniciales $(\Delta(\varepsilon))$ positivos, lo que indica que en todos los casos las especies de Rh presentan una mayor densidad electrónica con respecto a la referencia de un monocristal de $\mathrm{Rh}^{0}$, debido a su dispersión en forma de nanopartículas de tamaños en el rango sub-nanométrico. A su vez, de acuerdo a los valores relativos de $\Delta(\varepsilon)$, los catalizadores se pueden clasificar en términos de densidad de carga electrónica sobre las NPs de $\mathrm{Rh}^{0}$ en el orden siguiente: $\mathrm{Rh} / \mathrm{Sm} @ \mathrm{Al}_{2} \mathrm{O}_{3}>$ $\mathrm{Rh} / \mathrm{Y} @ \mathrm{Al}_{2} \mathrm{O}_{3} \approx \mathrm{Rh} / \mathrm{Ta} @ \mathrm{Al}_{2} \mathrm{O}_{3}>\mathrm{Rh} / \mathrm{V} @ \mathrm{Al}_{2} \mathrm{O}_{3}$. De manera interesante, esta tendencia está completamente de acuerdo con la secuencia de poder electro donante-aceptor establecido previamente para los promotores dispuestos 
en monocapa sobre la $\mathrm{Al}_{2} \mathrm{O}_{3}$ en base al ancho de banda y la energía de IMCT para la molécula de alizarina adsorbida.

Por lo tanto, del estudio de XPS sobre los catalizadores reducidos se concluye que la densidad de carga electrónica en las NPs de $\mathrm{Rh}^{0}$ en los catalizadores, tras el tratamiento de reducción previo a la catálisis, sigue el orden dictado por los fenómenos de transferencia de carga desde el soporte, en función del poder electro donante-aceptor de las especies promotoras $\mathrm{MO}_{\mathrm{x}}$.

\subsubsection{Interacción de las NPs de Rh con CO: CO-FTIR.}

La espectroscopia CO-FTIR es una técnica particularmente útil para estudiar la carga parcial en los átomos superficiales de las nanopartículas metálicas. En el presente trabajo, se ha llevado a cabo el estudio de dos catalizadores en su estado reducido, representativos de los comportamientos extremos en la tendencia comentada en la sección anterior (6.3.4.1), mediante CO-FTIR a la temperatura de -175으. Las Figs. 6.14 y 6.15 muestran los espectros correspondientes a los catalizadores $\mathrm{Rh} / \mathrm{Ta} @ \mathrm{Al}_{2} \mathrm{O}_{3}$ y $\mathrm{Rh} / \mathrm{Sm} @ \mathrm{Al}_{2} \mathrm{O}_{3}$, respectivamente, reducidos in situ en flujo de $\mathrm{H}_{2}$. 


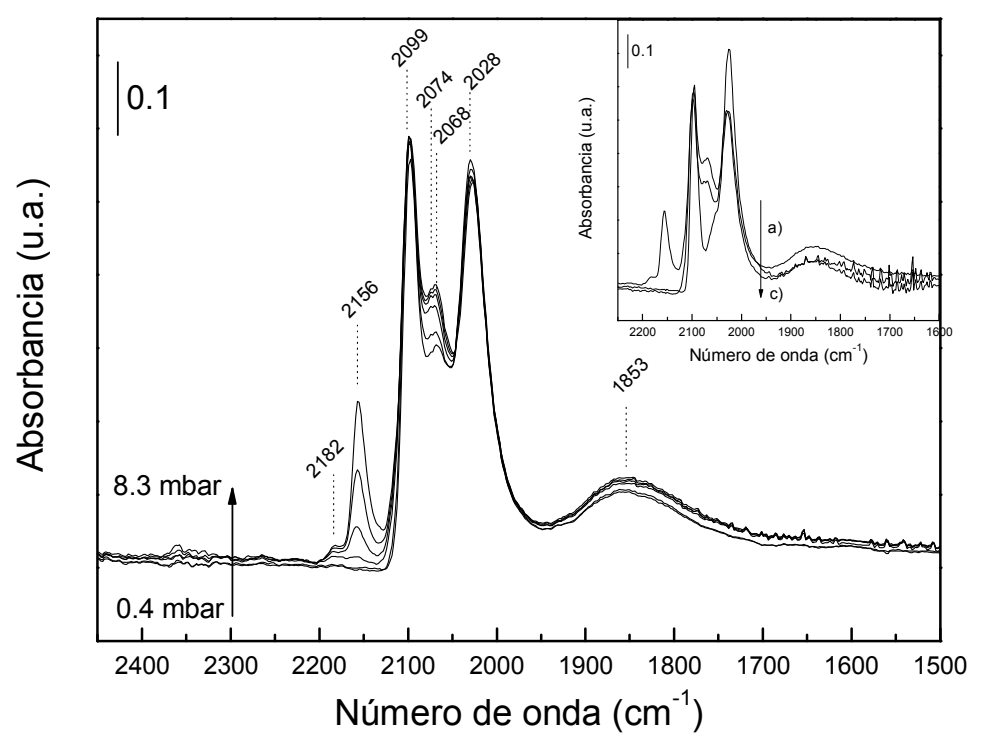

Figura 6.14: Espectros de CO-FTIR a -175으 tras dosis de 0.4-8.3 mbar de CO en la celda, sobre el catalizador $\mathrm{Rh} / \mathrm{Ta} @ \mathrm{Al}_{2} \mathrm{O}_{3}$ previamente reducido in situ a $300{ }^{\circ} \mathrm{C}$ en flujo de $\mathrm{H}_{2}$ y evacuado a $350^{\circ} \mathrm{C}$ tras la reducción. El detalle de la figura muestra el espectro tras dosis de 8.3 mbar (a) y dos espectros tras evacuación (10 ${ }^{-4}$ mbar) durante $1 \mathrm{~h}(\mathrm{~b})$ y $12 \mathrm{~h}$ (c).

En ambos casos, se observan bandas en la región de 2150 a $2180 \mathrm{~cm}^{-1}$ asociadas con $\mathrm{CO}$ adsorbido sobre los átomos metálicos y los grupos hidroxilo superficiales correspondientes con las especies $\mathrm{MO}_{\mathrm{x}} \mathrm{y} / \mathrm{o}$ regiones de $\mathrm{Al}_{2} \mathrm{O}_{3}$ que no se encuentren recubiertas por los óxidos bidimensionales. 


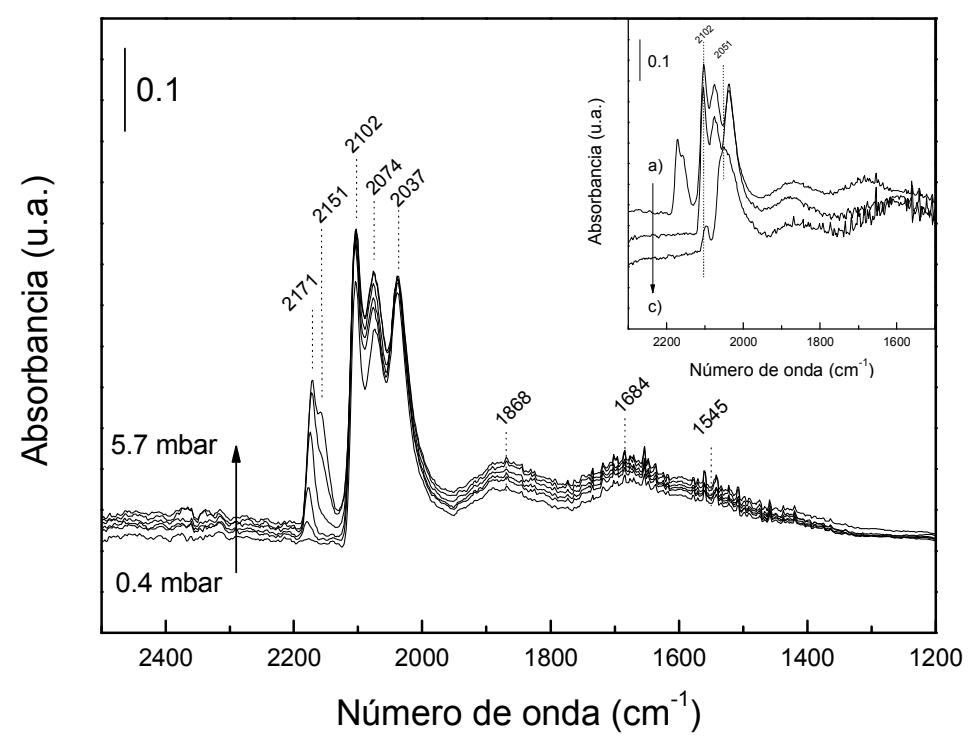

Figura 6.15: Espectros de CO-FTIR a -175으 tras dosis de 0.4-8.3 mbar de CO en la celda, sobre el catalizador Rh/Sm@ $\mathrm{Al}_{2} \mathrm{O}_{3}$ previamente reducido in situ a $300{ }^{\circ} \mathrm{C}$ en flujo de $\mathrm{H}_{2}$ y evacuado a $350^{\circ} \mathrm{C}$ tras la reducción. El detalle de la figura muestra el espectro tras dosis de 8.3 mbar (a) y dos espectros tras evacuación (10 $0^{-5}$ mbar) durante $1 \mathrm{~h}$ (b) y $12 \mathrm{~h}$ (c).

Por su parte, en la región de carbonilos metálicos $\left(\mathrm{Rh}(\mathrm{CO})_{x}\right)$, se perciben bandas intensas a aprox. 2100 y $2030 \mathrm{~cm}^{-1}$ asociadas con la vibraciones de tensión simétrica y asimétrica de especies di-carbonilo geminales $\left(\mathrm{Rh}(\mathrm{CO})_{2}\right)$, bandas en el rango de $2060-2080 \mathrm{~cm}^{-1}$ asociadas a la adsorción de $\mathrm{CO}$ en configuración lineal $\left(\mathrm{Rh}^{0}(\mathrm{CO})-\mathrm{L}\right)$ y una banda de carácter más ancho a aprox. $1860 \mathrm{~cm}^{-1}$ asociada con la adsorción de CO en configuración puenteada $\left(\mathrm{Rh}_{2}^{0}(\mathrm{CO})-\mathrm{P}\right)$. De manera adicional, en el espectro correspondiente a Rh/Sm@ $@ \mathrm{Al}_{2} \mathrm{O}_{3}$ se observa una banda débil a $1684 \mathrm{~cm}^{-1}$ que varios autores han asociado con el modo de adsorción "inclinado" o tilted en la interfase $\mathrm{Rh} / \mathrm{MO}_{x}$ [58] y una banda muy débil a $1545 \mathrm{~cm}^{-1}$ que podría estar relacionada con la formación de carbonatos en la superficie de $\mathrm{SmO}_{x}$ debido a su carácter marcadamente básico. Cabe comentar en este punto que la estructura generalmente asumida para la adsorción de $\mathrm{CO}$ en 
configuración inclinada (tilted) consiste en la adsorción del extremo $\mathrm{C}$ de la molécula de CO sobre un centro metálico y la estabilización del extremo $\mathrm{O}$ por coordinación sobre un centro metálico $\mathrm{M}$ de carácter electro-aceptor. No obstante, los resultados presentados en esta sección muestran que este tipo de especies se detectan en el catalizador $\mathrm{Rh} / \mathrm{Sm} @ \mathrm{Al}_{2} \mathrm{O}_{3}$ mientras que no se perciben en el catalizador Rh/Ta @ $\mathrm{Al}_{2} \mathrm{O}_{3}$, a pesar de que los átomos de $\mathrm{Ta}(\mathrm{V})$ presentan un carácter marcadamente más electro-aceptor que los de Sm(III). Este hecho, arroja dudas razonables acerca de los requerimientos reales necesarios para la estabilización de este modo de adsorción de la molécula de $\mathrm{CO}$ en las interfases $\mathrm{Rh}-\mathrm{MO}_{\mathrm{x}}$.

La elevada intensidad relativa de las bandas asociadas a di-carbonilos de $\mathrm{Rh}$ indica, de manera inequívoca, que las NPs de $\mathrm{Rh}^{0}$ sufren una ruptura oxidativa en presencia de $\mathrm{CO}$, que resulta en la formación de terrazas (rafts) constituidas por una monocapa de átomos de $\mathrm{Rh}(\mathrm{I})$ sobre la superficie del soporte $[59,60]$. Este tipo de ruptura oxidativa se ha descrito a mayores temperaturas para NPs de Rh de varios tamaños. Sin embargo, el hecho de que ocurra a una temperatura tan baja como $-175 \circ \mathrm{C}$ es exclusivo para NPs de Rh de tamaños inferiores a 1-2 nm [61]. Este es el caso de los catalizadores preparados sobre el soporte de $\mathrm{Al}_{2} \mathrm{O}_{3}$ de alta área superficial recubierto por una monocapa de $\mathrm{MO}_{\mathrm{x}}$, como quedó patente en el análisis mediante TEM (Fig. 6.6). Por el contrario, a la vista de la mayoría de los trabajos previos en este campo, la preparación de NPs de Rh de tamaños tan reducidos $(<2 \mathrm{~nm})$ soportadas sobre los correspondientes óxidos $\mathrm{MO}_{\mathrm{x}}$ másicos, de baja área superficial, sólo es posible empleando cargas metálicas muy reducidas (típicamente $<1 \%(p)$ ) y/o precursores metálicos de tipo carbonilo $\left(\mathrm{Rh}(\mathrm{CO})_{\mathrm{x}}\right)$.

El carácter invasivo del CO sobre las NPs de Rh en estos catalizadores, incluso a temperaturas tan bajas como -175 으, evidentemente imposibilita 
el empleo de resultados de quimisorción de $\mathrm{CO}$ a temperatura ambiente para estimar el tamaño de NP original (antes de la ruptura oxidativa). A pesar de este hecho, son varios los autores que, de manera poco rigurosa, han basado las discusiones en la dispersión metálica obtenida de este modo [62,63]. En realidad, los resultados de quimisorción de CO a temperatura ambiente ofrecen una caracterización de las terrazas o rafts de $\mathrm{Rh}(\mathrm{I})$ obtenidas por reestructuración oxidativa de las NPs originales, sobre las que se forman las especies di-carbonilo resultando en una estequiometría de quimisorción $\mathrm{CO} / \mathrm{Rh}_{(\mathrm{s})}>1$. En este sentido, de nuestros resultados de quimisorción de CO (Tabla 6.4) tan sólo se puede derivar el diámetro estimado de estos rafts bidimensionales de Rh, que de acuerdo a Yates y col. [60] varía entre 3 y $5 \mathrm{~nm}$, para relaciones $\mathrm{CO} / \mathrm{Rh}_{\text {(tot) }}$ entre 1.2 y 1.5 , como las obtenidas en el caso de los catalizadores Rh/M@ $@ \mathrm{Al}_{2} \mathrm{O}_{3}$ analizados.

Existe controversia acerca del mecanismo por el que tiene lugar la ruptura oxidativa de las NPs de Rh en presencia de CO [59]. Por un lado, se ha propuesto que la disociación de CO sobre los átomos de Rh puede aportar adátomos de $\mathrm{O}$ que promuevan la disrupción oxidativa de las NPs [59]. A pesar de ser improbable la disociación de CO a temperaturas tan bajas como $-175^{\circ} \mathrm{C}$, se ha propuesto que este fenómeno podría ocurrir para NPs de dimensiones subnanométricas [64], como las obtenidas en los catalizadores $\mathrm{Rh} / \mathrm{M} @ \mathrm{Al}_{2} \mathrm{O}_{3}$. Por otro lado, se ha propuesto la participación de grupos hidroxilo del soporte en el mecanismo de ruptura oxidativa $[65,66,67]$. En este sentido, se observa que la intensidad relativa de las bandas de di-carbonilos es más importante en el caso del catalizador promovido por $\mathrm{TaO}_{x}$ que para el promovido por $\mathrm{SmO}_{x}$. Esto parece sugerir que la ruptura oxidativa tiene lugar en mayor extensión para las NPs soportadas sobre $\mathrm{Ta}_{\mathrm{A}} \mathrm{Al}_{2} \mathrm{O}_{3}$. Adicionalmente, los experimentos de evacuación (espectros incluidos en los detalles de las Figs. 6.14 y 6.15) 
muestran una mayor estabilidad para las especies di-carbonilo en el caso de $\mathrm{Rh} / \mathrm{Ta} @ \mathrm{Al}_{2} \mathrm{O}_{3}$, para el que las señales de $\mathrm{Rh}(\mathrm{CO})_{2}$ no se modifican considerablemente mediante la evacuación prolongada, que en el caso de $\mathrm{Rh} / \mathrm{Sm} @ \mathrm{Al}_{2} \mathrm{O}_{3}$, para el que el mismo tratamiento de evacuación desorbe, prácticamente de manera completa, las especies di-carbonilo dejando tan sólo CO adsorbido de forma lineal (banda desplazada a $2051 \mathrm{~cm}^{-1}$ ) y puenteado (aprox. $1870 \mathrm{~cm}^{-1}$ ). Esta dependencia de la estabilidad de los dicarbonilos con la naturaleza de las especies promotoras podría ser una indicación de que los grupos $\mathrm{OH}$ del soporte (en este caso las especies $\mathrm{MO}_{\mathrm{x}}$ ) intervienen en el mecanismo de ruptura oxidativa, aunque la disociación de CO sobre centros metálicos en posiciones de defectos en NPs de Rh de dimensiones tan reducidas, no puede descartarse como promotor de la ruptura oxidativa.

No obstante, independientemente del mecanismo real, la ruptura oxidativa impide caracterizar mediante CO-FTIR las NPs "originales" presentes en los catalizadores tras el tratamiento de reducción, que se estudiaron mediante XPS-XAES en la sección anterior. Esto también explica porqué no existe correspondencia entre la posición de las bandas de CO adsorbido de forma lineal sobre los átomos de $\mathrm{Rh}^{0}$ en regiones de las NPs que no han sido reconvertidas en terrazas $2 \mathrm{D}$ monoatómicas, con la carga electrónica parcial en las NPs determinada por XPS-XAES. En este sentido, se esperaría una menor frecuencia de vibración para los carbonilos $\mathrm{Rh}^{\circ}(\mathrm{CO})$ - $\mathrm{L}$ en el caso de las partículas más electronegativas (en $\mathrm{Rh} / \mathrm{Sm} @ \mathrm{Al}_{2} \mathrm{O}_{3}$ de acuerdo a la sección 6.3.4.1) mientras que a la vista de los espectros mostrados en las Figs. 6.14 y 6.15 , experimentalmente se observa lo contrario. Probablemente los centros $\mathrm{Rh}^{0}$ que quimisorben $\mathrm{CO}$ en configuración lineal se ven influidos por las regiones vecinas que hayan sufrido reestructuración oxidativa. De hecho, la influencia que los rafts 2D, 
formados por ruptura oxidativa, ejercen sobre los centros $\mathrm{Rh}^{0}$ no reconstruidos, que quimisorben CO de manera lineal y puenteada, se percibe a la vista del desplazamiento de la banda $\mathrm{Rh}^{0}$ (CO)-L desde $2074 \mathrm{~cm}^{-1}$ hasta $2051 \mathrm{~cm}^{-1}$ cuando se retiran los di-carbonilos por evacuación en la muestra Rh/Sm@Al $\mathrm{O}_{3}$.

Por lo tanto, de los resultados presentados en esta sección puede concluirse que el contacto de las NPs de Rh con CO y el carácter marcadamente invasivo del adsorbato sobre el metal, incluso a $-175^{\circ} \mathrm{C}$, altera sustancialmente la morfología superficial y el carácter electrónico de las NPs de Rh originales, que se estableció en la sección 6.3.4.1 en base a los resultados de XPS-XAES.

\subsubsection{Estudio mediante CO-FTIR en condiciones de reacción.}

La diversidad de patrones de selectividad obtenidos con la serie de catalizadores $\mathrm{Rh} / \mathrm{M} @ \mathrm{Al}_{2} \mathrm{O}_{3}$ convierte a este conjunto de materiales en un sistema idóneo para obtener información acerca de los mecanismos de reacción y las especies intermedias involucradas en la formación de los diferentes tipos de productos de reacción. Una de las técnicas de caracterización más adecuadas para llevar a cabo este tipo de estudios durante la reacción catalítica (operando) es precisamente la espectroscopia CO-FTIR, como se mostró en el capítulo 3 para el caso de los catalizadores de Co para la SFT. Así pues, a lo largo de esta última sección se discuten los resultados obtenidos mediante CO-FTIR aplicada sobre catalizadores $\mathrm{Rh} / \mathrm{M} @ \mathrm{Al}_{2} \mathrm{O}_{3}$ seleccionados, en condiciones de reacción y a presión atmosférica.

Los catalizadores seleccionados para este estudio son: Rh/Sm@ $@ \mathrm{Al}_{2} \mathrm{O}_{3}$ que es el catalizador menos activo y cuyo principal producto de reacción es metanol, Rh/Pr@ $\mathrm{Al}_{2} \mathrm{O}_{3}$ que presenta una actividad catalítica ligeramente 
superior así como una mayor selectividad a alcoholes lineales superiores $\left(\mathrm{C}_{2+}\right)$, especialmente etanol, $\mathrm{y}$, por último $\mathrm{Rh} / \mathrm{Li}-\mathrm{Ta} @ \mathrm{Al}_{2} \mathrm{O}_{3}$, que es el catalizador más activo de los tres, más selectivo a hidrocarburos superiores $\left(\mathrm{C}_{2+}\right)$ y apenas produce alcoholes, siendo el ácido acético y los acetatos los compuestos oxigenados mayoritarios entre los productos oxigenados.

Las Figs. 6.16, 6.18 y 6.19 muestran los espectros de CO-FTIR obtenidos con los catalizadores $\mathrm{Rh} / \mathrm{Sm} @ \mathrm{Al}_{2} \mathrm{O}_{3}, \mathrm{Rh} / \mathrm{Pr} @ \mathrm{Al}_{2} \mathrm{O}_{3}$ y $\mathrm{Rh} / \mathrm{Li}-$ Ta@Al $\mathrm{O}_{3}$, respectivamente, tras un tratamiento de reducción en flujo de $\mathrm{H}_{2}$ en la celda de FTIR $\left(300^{\circ} \mathrm{C}, 2 \mathrm{~h}\right.$ ) y la posterior exposición a un flujo de gas de síntesis $\left(\mathrm{H}_{2} / \mathrm{CO}=1\right)$, a presión atmosférica, temperaturas crecientes y durante diferentes tiempos de reacción a la temperatura final de reacción (280드).

En primer lugar cabe mencionar que las especies carbonato que se detectan en los catalizadores promovidos por óxidos de carácter básico, como $\mathrm{PrO}_{x}$ y $\mathrm{SmO}_{x}$, en su estado calcinado (bandas de IR a 1510 y $1398 \mathrm{~cm}^{-1}$ ), que son consecuencia de la captación de $\mathrm{CO}_{2}$ por exposición a la atmósfera, se descomponen durante el tratamiento de reducción a 300 ㄷ que se lleva a cabo en la celda de IR antes de los experimentos de CO-FTIR.

En todos los casos, tras la admisión de gas de síntesis en la celda a temperatura ambiente (TA), se observan cuatro bandas principales en la región de carbonilos metálicos, cuyas asignaciones ya se han discutido en la sección 6.3.4.2: el doblete a aprox. $2090-2100 \mathrm{~cm}^{-1}$ y $2020-2030 \mathrm{~cm}^{-1}$ se adscribe a la formación de di-carbonilos $\mathrm{Rh}(\mathrm{I})(\mathrm{CO})_{2}$ generados como resultado de la ruptura oxidativa de las NPs de $\mathrm{Rh}^{0}$, mientras que las bandas a $2050-2070 \mathrm{~cm}^{-1}$ y $1850-1860 \mathrm{~cm}^{-1}$ son debidas a especies $\mathrm{Rh}^{0}(\mathrm{CO})-\mathrm{L}$ y $\mathrm{Rh}^{0}{ }_{2}(\mathrm{CO})-\mathrm{P}$, respectivamente, en regiones metálicas que no se han reestructurado en presencia de CO para dar lugar a terrazas (rafts) bidimensionales. Para el caso del catalizador Rh/Sm@ $\mathrm{Al}_{2} \mathrm{O}_{3}$, en flujo de gas 
de síntesis a temperatura ambiente (TA), no se percibe la señal a $1684 \mathrm{~cm}^{-1}$ que se discernía con claridad en el estudio con CO puro a la temperatura de 175ํ y que se asignó a un modo de adsorción de tipo inclinado (tilted) en la interfase de las NPs de Rh y las especies promotoras.

Un incremento de temperatura en el rango de $50-200^{\circ} \mathrm{C}$ se traduce en un comportamiento cualitativamente similar en todos los catalizadores en la región de carbonilos metálicos. En todos los casos, cuando la temperatura alcanza aprox. $100^{\circ} \mathrm{C}$, las señales de di-carbonilos se hacen más prominentes a expensas de la señal asociada con la adsorción de CO en configuración lineal, evidenciando que este aumento de temperatura resulta en un incremento en la extensión de la ruptura oxidativa. Asimismo, se percibe la influencia que tiene este fenómeno de ruptura oxidativa sobre los centros metálicos que permanecen en estado reducido $\left(\mathrm{Rh}^{0}\right)$, y que por lo tanto no han sufrido la reestructuración oxidativa. En este sentido, en la Fig. 6.16, por ejemplo, se observa un desplazamiento de la señal de carbonilos puenteados desde 1849 a $1825 \mathrm{~cm}^{-1}$ cuando se incrementa la temperatura entre TA y $100^{\circ} C$, es decir, en el rango de temperaturas en el que la extensión del fenómeno de ruptura oxidativa se incrementa a la vista de la transición del triplete al doblete en la región de $2000-2100 \mathrm{~cm}^{-1}$. Este comportamiento podría estar relacionado con la proximidad entre los átomos de Rh que sufren reestructuración oxidativa a terrazas $2 \mathrm{D}$ de $\operatorname{Rh}(\mathrm{I})$ y aquellos que permanecen en regiones no reestructuradas. 


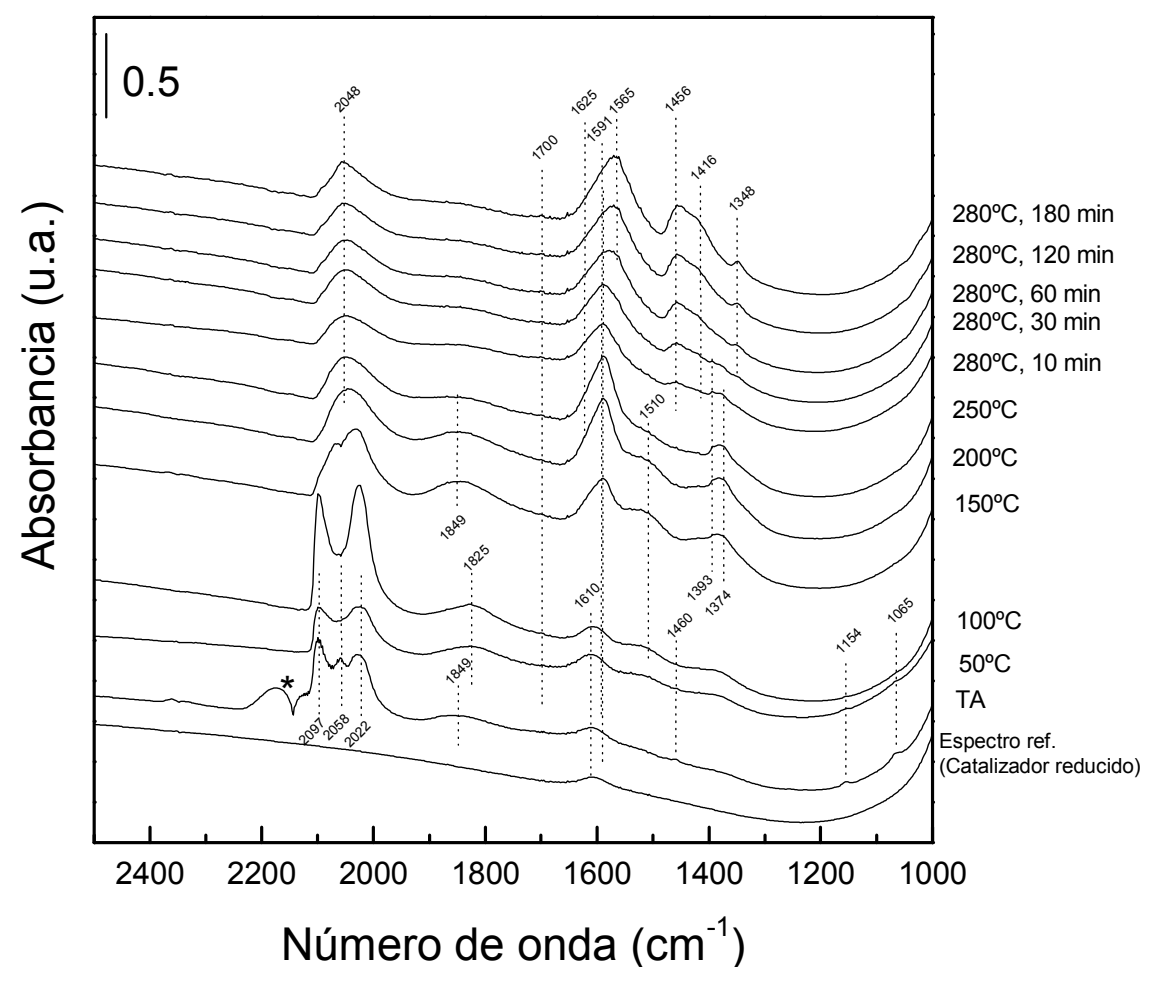

Figura 6.16: Espectros de CO-FTIR para el catalizador Rh/Sm@ $@ \mathrm{Al}_{2} \mathrm{O}_{3}$ expuesto a un flujo de gas de síntesis a temperaturas crecientes y varios tiempos de reacción a la temperatura final de reacción $\left(280^{\circ} \mathrm{C}\right)$. (*:bandas asociadas con $\mathrm{CO}$ en la fase gaseosa).

No obstante, en todos los casos, un incremento ulterior de la temperatura hasta $200{ }^{\circ} \mathrm{C}$ hace desaparecer las señales asociadas con la adsorción geminal (di-carbonilos) sobre los centros metálicos oxidados en las terrazas 2D, mientras que restaura la señal de adsorción de CO en configuración lineal sobre centros $\mathrm{Rh}^{0}$. A 200 ㄷ $\tan$ sólo se perciben los carbonilos lineales $\left(2035-2048 \mathrm{~cm}^{-1}\right)$ y puenteados $\left(1845-1855 \mathrm{~cm}^{-1}\right)$ en todos los catalizadores, no volviendo a percibirse las señales asociadas con los di-carbonilos a temperaturas más elevadas. Otros autores percibieron un comportamiento similar en catalizadores de Rh tras la exposición a gas de síntesis o $\mathrm{CO}$ a temperaturas $>150^{\circ} \mathrm{C}$ [59]. Este comportamiento se ha 
relacionado con un fenómeno de aglomeración reductiva que revierte la ruptura oxidativa que tiene lugar a menores temperaturas y devuelve el metal a un estado de NPs de $\mathrm{Rh}^{0}[59,68]$, a priori, diferente del estado original de las NPs en el catalizador reducido, antes de la exposición a CO o gas de síntesis. Como se observa en los espectros representados en las Figs. $6.16,6.18$ y 6.19, las señales de carbonilos metálicos (lineales y puenteados) no sufren cambios ulteriores a temperaturas más elevadas, ni por exposición a tiempos prolongados a las condiciones de reacción, lo que sugiere que una vez que el metal sufre la aglomeración reductiva, éste se encuentra en su forma catalíticamente activa y no sufre transformaciones adicionales importantes en las condiciones de catálisis.

Una vez comentadas las características comunes a todos los catalizadores, se pasará a discutir las peculiaridades individuales, relacionadas con las diferentes propiedades catalíticas.

En primer lugar, en el caso del catalizador Rh/Sm@ $@ \mathrm{Al}_{2} \mathrm{O}_{3}$ (Fig. 6.16), incluso en los espectros registrados en el rango de temperaturas de TA a 100 C , se perciben señales de IR a 1065 y $1154 \mathrm{~cm}^{-1}$, junto con una banda adicional más débil a $1460 \mathrm{~cm}^{-1}$ que pueden asignarse a especies de tipo metoxi ( $\left.\mathrm{CH}_{3} \mathrm{O}-\right)$ adsorbidas [69]. No obstante, el hecho de que estas señales se registren a temperaturas tan bajas, cuando incluso las especies de Rh aún no han sufrido aglomeración reductiva, y, por lo tanto, no se encuentran en su estado catalítico final, sugiere que estas especies no presentan relevancia desde el punto de vista del mecanismo de reacción. A temperaturas superiores $200-250^{\circ} \mathrm{C}$, cuando la región de carbonilos metálicos sugiere que las fases de Rh han alcanzado su estado final, en el espectro se perciben señales intensas a 1591 y $1374 \mathrm{~cm}^{-1}$, que se asignan a las vibraciones $v_{a}$ (OCO) y $v_{s}(\mathrm{OCO})$ en especies formiato (HCOO-) [70]. A estas temperaturas también se registran señales a $1625 \mathrm{~cm}^{-1}(\mathrm{sh})$, asociada a las vibraciones de 
deformación del $\mathrm{H}_{2} \mathrm{O}$ adsorbida y a 1510 y $1393 \mathrm{~cm}^{-1}$ asociadas con la formación de especies carbonato $\left(\mathrm{CO}_{3}{ }^{2-}\right)$ en la superficie de las especies $\mathrm{SmO}_{\mathrm{x}}$, de acuerdo a los espectros registrados para el catalizador no descarbonatado, antes de la reducción (no mostrado). No obstante, estos carbonatos superficiales parecen inestables a temperaturas superiores, ya que no se perciben con claridad las mencionadas bandas a la temperatura final de reacción. La detección de las especies formiato en el rango de temperaturas de reacción incipiente, es decir, justo cuando la región de carbonilos metálicos evidencia que las fases metálicas acaban de convertirse a su estado activo definitivo, sugiere que pueden ser especies relevantes para el mecanismo de reacción. En este sentido, este catalizador es especialmente selectivo a metanol (ver Tabla 6.6) y las especies de tipo formiato se han propuesto previamente como intermedios en la síntesis de metanol $[71,72,73]$. A temperaturas más elevadas (>250으) comienzan a percibirse bandas adicionales a 1565, 1456 y $1348 \mathrm{~cm}^{-1}$ para cuya asignación a las vibraciones $v_{a}(\mathrm{OCO}), v_{s}(\mathrm{OCO})$ y $\delta_{s}\left(\mathrm{CH}_{3}\right)$, respectivamente, en especies acetato $\left(\mathrm{H}_{3} \mathrm{CHCOO}-\right)$ adsorbidas existe consenso en la literatura $[44,74]$. La intensidad de estas bandas se incrementa lentamente con el tiempo de reacción, lo que sugiere que las especies acetato se acumulan en el catalizador durante la exposición prolongada a las condiciones de reacción.

Finalmente, un análisis de la región de carbonilos metálicos evidencia la presencia de una banda ancha centrada a $2048 \mathrm{~cm}^{-1}$ asociada con carbonilos lineales, mientras que la banda asociada con adsorción en configuración puenteada es muy débil para las NPs de Rh en este catalizador tras la aglomeración reductiva sufrida a 150-200ㄷ.

Asimismo, con el objetivo de conocer la estabilidad relativa de las especies detectadas por FTIR, tras 3 horas en condiciones de reacción 
$\left(280^{\circ} \mathrm{C}\right)$, la celda de IR se evacuó de manera progresiva y los espectros registrados durante este proceso de evacuación se recogen en la Fig. 6.17.

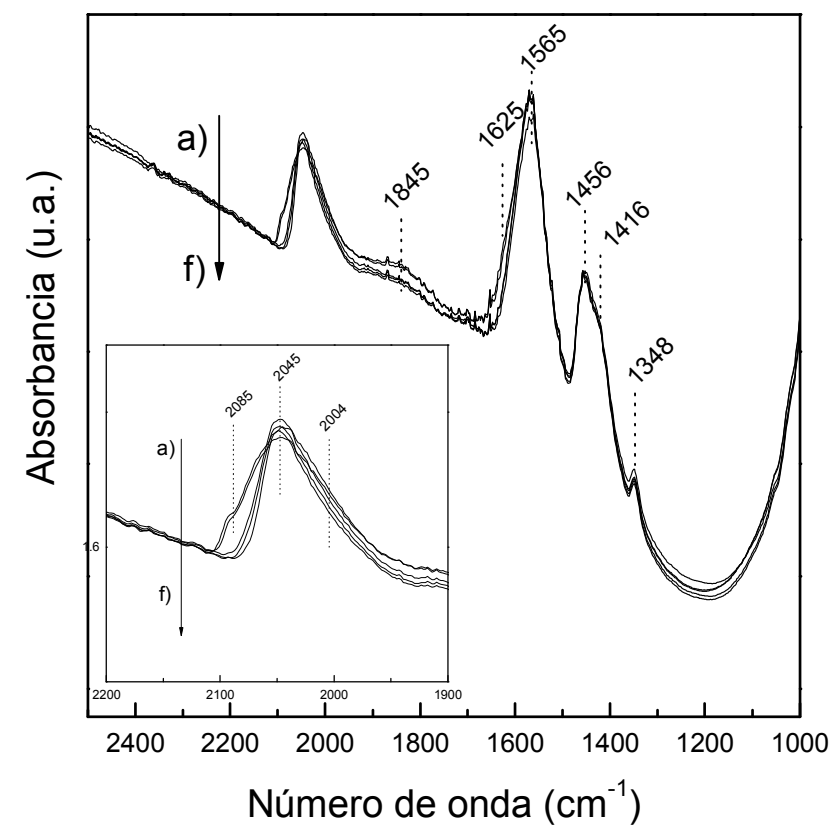

Figura 6.17: Espectros de CO-FTIR registrados durante la evacuación diferencial $(a \rightarrow f)$ del catalizador Rh/Sm@Al ${ }_{2} \mathrm{O}_{3}$ tras 3 horas en condiciones de SSO en la celda de FTIR. El detalle incluido en la figura muestra una ampliación de la región de carbonilos lineales de $R h$.

Como se observa en la Fig. 6.17, las señales relacionadas con las especies acetato no se ven afectadas por la evacuación, lo que sugiere que se encuentran fuertemente adsorbidas, probablemente sobre la superficie del soporte (especies $\mathrm{SmO}_{\mathrm{x}}$ ). Este comportamiento, sumado al hecho de su acumulación en el espectro con el tiempo de reacción, sugiere que su papel es de simples espectadores y no son especies relevantes en el mecanismo de la SSO. Este resultado está en desacuerdo con varios autores que han propuesto que los acetatos son intermedios de reacción $[45,75,76]$. Por el contrario, en línea con el presente trabajo, algunos investigadores han 
asignado previamente un papel de espectadores a las especies acetato durante la SSO [44].

Asimismo, cabe destacar que las únicas señales que sufren una evacuación perceptible se encuentran en la región de carbonilos metálicos. Así, en la Fig. 6.17 se percibe cómo se reduce la intensidad de la señal de carbonilos puenteados (banda a $1845 \mathrm{~cm}^{-1}$ ) durante la evacuación. Por su parte, en la región de carbonilos lineales tan sólo una componente a elevada frecuencia $\left(2085 \mathrm{~cm}^{-1}\right)$ es sensible al tratamiento de evacuación. Este hecho evidencia que el resto de centros $\mathrm{Rh}^{0}$ en los que el CO se adsorbe de forma lineal (2045 y $2004 \mathrm{~cm}^{-1}$ ) quimisorben fuertemente las moléculas de CO, lo que sugiere que no participan en la reacción en las condiciones de SSO. Por el contrario, los centros $\mathrm{Rh}^{0}$ identificados por una frecuencia de vibración más elevada (2085 cm $\mathrm{cm}^{-1}$ ), y que por tanto se corresponden con centros de baja capacidad de retrodonación electrónica hacia la molécula de CO, presentan una mayor probabilidad de permanecer activos durante la catálisis debido a que la quimisorción de CO sobre los mismos es reversible.

Por otro lado, el catalizador Rh/Pr@ $\mathrm{Al}_{2} \mathrm{O}_{3}$ (Fig. 6.18) presenta un comportamiento cualitativamente muy similar al discutido para $\mathrm{Rh} / \mathrm{Sm} @ \mathrm{Al}_{2} \mathrm{O}_{3}$. Este catalizador, como el anterior, presenta una elevada selectividad a compuestos oxigenados, a expensas de los hidrocarburos, aunque es más selectivo a alcoholes superiores en la fracción de oxigenados.

Como se observa en la Fig. 6.18, en este caso no se observan las bandas debidas a especies metoxi $\left(\mathrm{CH}_{3} \mathrm{O}-\right)$ a bajas temperaturas, lo que sugiere que el catalizador promovido por Sm presenta alguna característica físico-química que le hace especialmente selectivo a la activación no disociativa de $\mathrm{CO}$ para dar lugar a oxigenados $C_{1}$. 


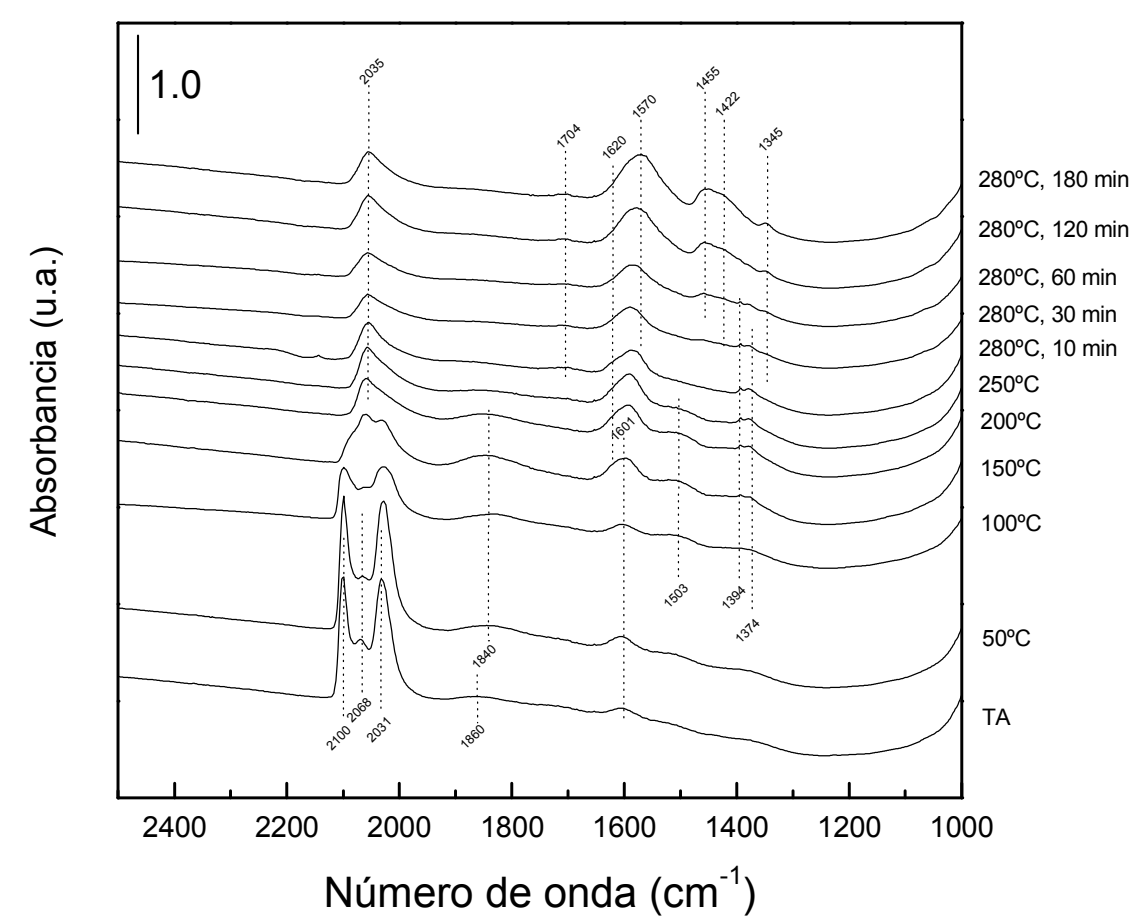

Figura 6.18: Espectros de CO-FTIR para el catalizador Rh/Pr@Al ${ }_{2} \mathrm{O}_{3}$ expuesto a un flujo de gas de síntesis a temperaturas crecientes y varios tiempos de reacción a la temperatura final de reacción $\left(280^{\circ} \mathrm{C}\right)$.

Sin embargo, al igual que para $\mathrm{Rh} / \mathrm{Sm} @ \mathrm{Al}_{2} \mathrm{O}_{3}$, las especies formiato y carbonato son las que predominan en el rango de temperaturas de reacción incipiente. Asimismo, las especies acetato se acumulan sobre la superficie del catalizador a temperaturas más elevadas y tiempos de exposición más prolongados. No obstante, los espectros correspondientes al catalizador $\mathrm{Rh} / \mathrm{Pr} @ \mathrm{Al}_{2} \mathrm{O}_{3}$ presentan una diferencia con los correspondientes para el catalizador promovido con Sm que, aunque sutil, puede tener relevancia en el mecanismo de la síntesis de alcoholes. En este caso, desde la temperatura de reacción incipiente (250드), se percibe en el espectro una banda débil y de carácter ancho a $1704 \mathrm{~cm}^{-1}$. En esta región del espectro se registran las vibraciones $v(C=0)$ de los grupos carbonilo en aldehídos y cetonas. En este sentido, Sachtler y col. [76] describieron la absorción a $1720 \mathrm{~cm}^{-1}$ para la 
molécula de acetaldehído adsorbida sobre $\mathrm{Rh}-\mathrm{Mn} / \mathrm{SiO}_{2}$. Por su parte, Hindermann y col. [69] asignaron bandas a aprox. $1670 \mathrm{~cm}^{-1}$ a especies formilo $(\mathrm{CHO})$ adsorbidas sobre catalizadores $\mathrm{Rh} / \mathrm{CeO}_{2}$ y $\mathrm{Rh} / \mathrm{Pr}_{6} \mathrm{O}_{11}$ durante la descomposición de metanol. Por lo tanto, esta señal de IR parece relacionada con la presencia de especies acilo con enlaces $\mathrm{C}=\mathrm{O}$. Su presencia en los espectros CO-FTIR operando para el catalizador Rh/Pr@ $\mathrm{Al}_{2} \mathrm{O}_{3}$ y su ausencia en el caso del catalizador $\mathrm{Rh} / \mathrm{Sm} @ \mathrm{Al}_{2} \mathrm{O}_{3}$ apuntan a que este tipo de especies podrían ser precursores de los alcoholes superiores, teniendo en cuenta que los aldehídos son productos de reacción muy minoritarios para todos los catalizadores $\mathrm{Rh} / \mathrm{M} @ \mathrm{Al}_{2} \mathrm{O}_{3}$. La aparición de este tipo de especies a bajas temperaturas, en la región de reacción incipiente, así como la débil intensidad de la señal en IR, que indica que no se acumulan en la superficie del catalizador, sugieren su participación en el mecanismo de reacción, aunque su identificación como verdaderos intermedios requeriría de estudios adicionales.

En cuanto a la región de carbonilos metálicos durante la SSO, al igual que para el catalizador promovido por $\mathrm{Sm}$, apenas se perciben especies de $\mathrm{CO}$ adsorbidas sobre $\mathrm{Rh}^{0}$ en configuración puenteada (aprox. $1850 \mathrm{~cm}^{-1}$ ), mientras que la banda de carbonilos lineales, con máximo a $2035 \mathrm{~cm}^{-1}$, es la predominante.

La principal diferencia espectral en esta región con respecto al catalizador Rh/Sm@ $\mathrm{Al}_{2} \mathrm{O}_{3}$ es la ausencia de una componente importante en la banda de carbonilos metálicos lineales a elevadas frecuencias $\left(>2070 \mathrm{~cm}^{-}\right.$ ${ }^{1}$ ). De hecho, en los correspondientes espectros de evacuación (no mostrados) no se detecta esta componente como en el caso del catalizador promovido por $\mathrm{SmO}_{x}$ (Fig. 6.17). Por lo tanto, tiene sentido hipotetizar que este tipo de centros de $\mathrm{Rh}^{0}$, que poseen una menor capacidad de retrodonación electrónica hacia la molécula de $\mathrm{CO}, \mathrm{y}$, por ende, una menor 
capacidad para su disociación, pueden estar relacionados con la superior selectividad a metanol que presenta el catalizador $\mathrm{Rh} / \mathrm{Sm} @ \mathrm{Al}_{2} \mathrm{O}_{3}$. Este estudio no aclara porqué existe una mayor densidad de este tipo de centros metálicos en el catalizador promovido por el óxido de mayor carácter básico (en el orden dictado por E(IMCT)). La explicación a esta observación podría estar relacionada con cambios en las morfologías de las NPs de $\mathrm{Rh}^{0}$ en función de las propiedades electrónicas de las fases $\mathrm{MO}_{\mathrm{x}}$ sobre las que está soportadas.

Por último, se estudia el comportamiento del catalizador $\mathrm{Rh} / \mathrm{Li}-$ $\mathrm{Ta} @ \mathrm{Al}_{2} \mathrm{O}_{3}$. En este caso, se encuentran diferencias más significativas en los espectros de CO-FTIR resueltos en temperatura y tiempo de reacción, relacionados con las diferencias existentes en el comportamiento catalítico de esta muestra con respecto a los catalizadores promovidos por óxidos de lantánidos.

Como se observa en la Fig. 6.19, en este caso no se detectan señales de IR para especies de tipo formiato ( $\mathrm{HCOO}-$ ) y carbonatos $\left(\mathrm{CO}_{3}{ }^{2-}\right)$ en el rango de temperaturas de catálisis incipiente. En el caso de los carbonatos, su ausencia está relacionada con el carácter electro-aceptor de $\mathrm{TaO}_{\mathrm{x}}$ que reduce significativamente la captación de $\mathrm{CO}_{2}$. Asimismo, la presencia de formiatos parece ser una característica exclusiva de los catalizadores selectivos a la formación de alcoholes. 


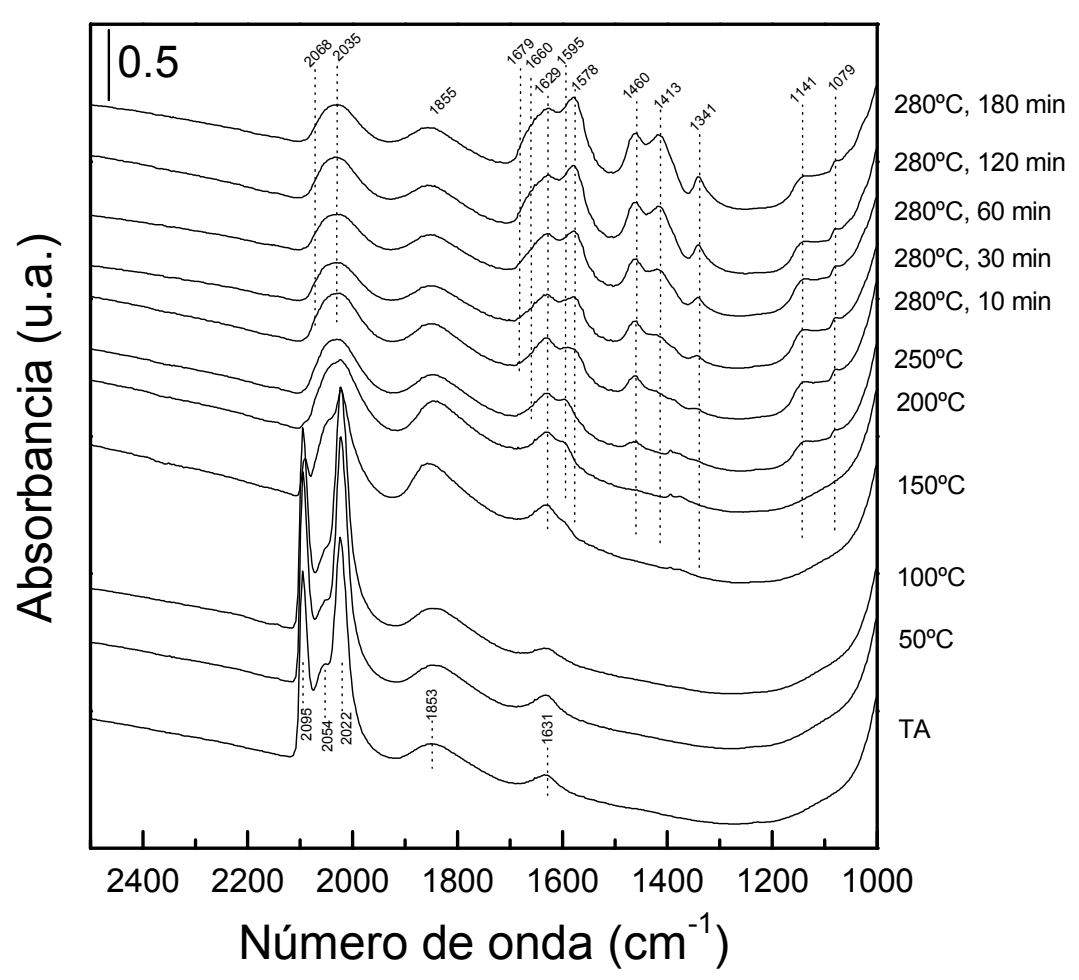

Figura 6.19: Espectros de CO-FTIR para el catalizador Rh/Li-Ta@AI $\mathrm{O}_{3}$ expuesto a un flujo de gas de síntesis a temperaturas crecientes y varios tiempos de reacción a la temperatura final de reacción $\left(280^{\circ} \mathrm{C}\right)$.

Por su parte, en el rango de temperaturas en el que las especies de $\mathrm{Rh}^{0}$ alcanzan su estado final tras la aglomeración reductiva, en la región del espectro de $1000-1700 \mathrm{~cm}^{-1}$ se detectan señales asociadas con la presencia de $\mathrm{H}_{2} \mathrm{O}\left(1629 \mathrm{~cm}^{-1}\right)$, especies acetato $\left(1578,1460\right.$ y $\left.1341 \mathrm{~cm}^{-1}\right)$ y cadenas hidrocarbonadas $\mathrm{C}_{\mathrm{x}} \mathrm{H}_{\mathrm{y}}\left(1595(\mathrm{v}(\mathrm{C}-\mathrm{C}))\right.$ y $1413 \mathrm{~cm}^{-1}\left(\delta\left(\mathrm{CH}_{2}\right)\right)$ derivadas de la disociación de $\mathrm{CO}$ y eventos de crecimiento de cadena. Asimismo, se perciben bandas a 1679 y $1660 \mathrm{~cm}^{-1}$, en la región de vibraciones $v(C O)$ de enlaces $\mathrm{C}=\mathrm{O}$ especies acilo, así como a 1079 y $1141 \mathrm{~cm}^{-1}$, en la región de vibraciones $\mathrm{v}(\mathrm{CO})$ de enlaces $\mathrm{C}-\mathrm{O}$ en especies alcóxido. Probablemente, algunas de las señales $v(C=O)$ y $v(C-O)$ se encuentren en mutua correspondencia y sean debidas a especies de tipo éster (RHCOOR') en la 
superficie del catalizador, en línea con la importancia de los acetatos de etilo y metilo en los productos de reacción obtenidos con este catalizador.

Por lo tanto, los espectros sugieren que el catalizador Rh/Li-Ta@ $\mathrm{Al}_{2} \mathrm{O}_{3}$ presenta una mayor capacidad para oxidar las especies acilo ( $\mathrm{RC}=\mathrm{O}-$ ), probablemente estabilizadas en la interfase $\mathrm{Rh}-\mathrm{TaO}_{\mathrm{x}}$, mediante la inserción de un átomo de oxígeno adicional para formar especies carboxilato, detectadas por CO-FTIR desde el rango de temperaturas de reacción incipiente. El oxígeno adicional empleado para oxidar estos grupos puede provenir de la disociación de $\mathrm{CO}$ sobre los centros de $\mathrm{Rh}^{0}$ vecinos, y la acidez Lewis de los centros $\mathrm{Ta}(\mathrm{V})$ puede promover los eventos de oxidación. En este sentido, los fenómenos de intercambio de adátomos de oxígeno entre las especies promotoras $\left(\mathrm{MO}_{\mathrm{x}}\right)$ y los intermedios de reacción de tipo carboxilato de la SSO, en la interfase $\mathrm{Rh}-\mathrm{MO}_{\mathrm{x}}$, se ha propuesto para explicar el intercambio isotópico de oxígeno observado durante la catálisis [77]. Asimismo, se conocen la estabilización de adátomos de $\mathrm{O}$, derivados de la disociación de $\mathrm{CO}$, se favorece sobre centros de carácter ácido de Lewis como $\mathrm{V}(\mathrm{V})$ [78], y la capacidad de estos ácidos de Lewis para promover reacciones de oxidación [79]. Estas características suponen la principal diferencia con respecto a los catalizadores promovidos por lantánidos, en los que no se detectan este tipo de vibraciones en el rango de temperaturas de reacción incipiente, posiblemente, porque en esos casos no está favorecida la oxidación de las especies acilo en la interfase $\mathrm{Rh}-\mathrm{MO}_{\mathrm{x}}$.

A su vez, se perciben diferencias significativas e interesantes para este catalizador, en relación a los dos anteriores, en la región de carbonilos metálicos. En este caso, en condiciones de reacción, la señal v(CO) para las moléculas de CO adsorbidas en configuración puenteada $\left(1855 \mathrm{~cm}^{-1}\right)$ es significativamente más intensa que para los catalizadores promovidos por lantánidos. Esta diferencia espectral podría ser la clave para la mayor 
actividad catalítica y el menor valor de $\phi$ que presenta el catalizador $\mathrm{Rh} / \mathrm{Li}-$ $\mathrm{Ta}_{\mathrm{Al}} \mathrm{O}_{3}$. Es decir, probablemente, la adsorción de $\mathrm{CO}$ en configuración puenteda esté relacionada con una mayor actividad para los eventos de disociación de CO.

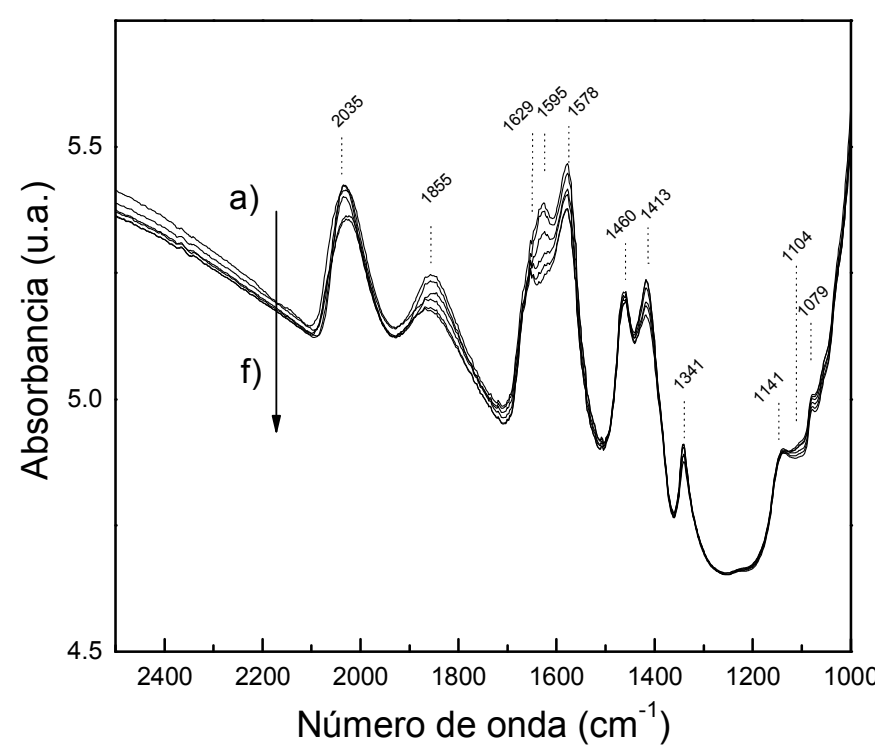

Figura 6.20: Espectros de CO-FTIR registrados durante la evacuación diferencial $(a \rightarrow f)$ del catalizador Rh/Li-Ta@Al $\mathrm{O}_{3}$ tras 3 horas en condiciones de SSO en la celda de FTIR.

De hecho, de manera interesante, en los espectros de evacuación progresiva (Fig. 6.20) se observa que en este caso, tanto los carbonilos lineales como los puenteados son sensibles al tratamiento de evacuación, sugiriendo una adsorción de $\mathrm{CO}$ sobre los centros de $\mathrm{Rh}^{0}$ más débil que para el caso de los catalizadores Rh/Sm@ $\mathrm{Al}_{2} \mathrm{O}_{3}$ y Rh/Pr@ $\mathrm{Al}_{2} \mathrm{O}_{3}$. Por lo tanto, los resultados catalíticos y espectroscópicos sugieren la participación de las moléculas de $\mathrm{CO}$ adsorbidas en configuración puenteada en el mecanismo de SSO, al contrario que para los catalizadores promovidos por lantánidos, para los que apenas se detecta $\mathrm{CO}$ adsorbido sobre $\mathrm{Rh}^{0}$ en esta configuración. Así pues, se está en condiciones de adscribir de manera 
tentativa la activación disociativa de CO con la adsorción sobre $\mathrm{Rh}^{0}$ en configuración puenteada. Una revisión de la literatura evidencia que algunos autores han propuesto con anterioridad que la adsorción puenteada de CO sobre Rh podría favorecer su disociación $[80,81]$. A su vez, gracias a la sistemática del presente estudio, se puede establecer una relación entre este modo de adsorción y la presencia de óxidos promotores de carácter electro-aceptor. Las características electrónicas de las fases promotoras podrían, por tanto, tener una influencia sobre el tamaño o la morfología de las NPs de $\mathrm{Rh}^{0}$, tras la aglomeración reductiva, que modifica el balance entre los modos de adsorción de CO (lineal/puenteado) y, por lo tanto, las propiedades catalíticas. Estudios recientes han mostrado que la naturaleza del soporte puede influir de manera determinante no sólo sobre el tamaño, sino también en la morfología de las NPs metálicas soportadas, en varios sistemas catalíticos [82].

Finalmente, cabe reseñar, asimismo, que en la región de 1000-1600 $\mathrm{cm}^{-1}$ de los espectros de evacuación recogidos en la Fig. 6.20, las bandas asociadas con las cadenas hidrocarbonadas $\mathrm{C}_{\mathrm{x}} \mathrm{H}_{\mathrm{y}}\left(1595,1413\right.$ y $1104 \mathrm{~cm}^{-1}$ $(\delta(C-C-C))$ son las únicas que experimentan un descenso en intensidad durante la evacuación, lo que sugiere que estos intermedios se encuentran más débilmente adsorbidos que las especies que poseen funciones oxigenadas en su estructura. Probablemente, éstas últimas, debido a su carácter polar, se encuentren interaccionando más fuertemente con las especies del promotor, lo que también puede estar relacionado con una menor probabilidad de desorción hidrogenante en forma de productos de reacción (oxigenados).

En el caso de las especies acetato, su acumulación progresiva con el tiempo de reacción y su resistencia a la evacuación sugieren, de nuevo, un papel de espectadores. Por lo tanto, el presente estudio sugiere, a su vez, 
que las especies acetato son espectadores independientemente de la naturaleza físico-química del catalizador y del patrón de selectividades de la SSO. Esta inespecificidad apunta a que este tipo de especies se encuentran adsorbidas sobre las fases $\mathrm{MO}_{\mathrm{x}}$ lejos de las NPs de Rh, donde es más probable que tengan lugar los eventos cinéticos de hidrogenación que permiten desorber los productos de reacción.

\subsection{Conclusiones.}

El presente capítulo demuestra que es posible describir el comportamiento catalítico de catalizadores de Rh para una reacción tan compleja como la SSO, donde son posibles una gran variedad de productos de reacción con diferentes longitudes de cadena y con o sin funciones oxigenadas, definiendo adecuadamente parámetros que describen de manera sencilla tanto el patrón de selectividades de la SSO como las propiedades electrónicas de los óxidos empleados como promotores de las fases de Rh. Tras los trabajos previos en el campo de las reacciones de oxidación de hidrocarburos que han permitido describir y predecir tanto la actividad como la selectividad catalíticas mediante la combinación de parámetros descriptores para las moléculas de reactivos (potencial de ionización) y los óxidos catalíticos (basicidad óptica) [33], la presente investigación supone un nuevo ejemplo de elucidación generalista de las relaciones propiedades-catálisis, que permite predecir el comportamiento catalítico de los materiales $\mathrm{Rh} / \mathrm{M} @ \mathrm{Al}_{2} \mathrm{O}_{3}$ en función de parámetros descriptores de fácil evaluación (como E(IMCT)). En oposición a los sistemas catalíticos mencionados en reacciones de oxidación, en el presente caso, la cooperación entre una fase activa $(\mathrm{Rh})$ y las fases promotoras $\left(\mathrm{MO}_{\mathrm{x}}\right)$ confiere más relevancia a esta descripción generalista, empleando descriptores físicoquímicos sencillos. Este tipo de correlaciones entre descriptores físicoquímicos, cuya evaluación es metodológicamente simple y rápida, y las 
propiedades catalíticas de sistemas catalíticos, de mayor o menor complejidad, es de especial interés en el marco de las metodologías de investigación que se aplican hoy en día en el campo de la catálisis heterogénea. En este sentido, cada día toman más importancia las técnicas de investigación de alta capacidad (High Throughput) que generan un gran flujo de datos catalíticos, los cuales requieren ser analizados en base a parámetros de caracterización físico-química disponibles en un corto plazo de tiempo y a un coste limitado.

Asimismo, los resultados recogidos en este capítulo suponen una información muy valiosa que ayuda a comprender los mecanismos a través de los que tiene lugar el singular "efecto promotor" en los catalizadores de Rh para la SSO. Estos conocimientos seguramente servirán para dirigir las investigaciones futuras, encaminadas a optimizar estos sistemas catalíticos, y que podrían derivar en la competitividad industrial de los catalizadores de Rh para la SSO.

De manera más detallada, las principales conclusiones que se extraen de los resultados presentados en este capítulo son:

1. El empleo de $\mathrm{Y}_{-}-\mathrm{Al}_{2} \mathrm{O}_{3}$ de elevada área, cuya superficie se encuentra recubierta por óxidos metálicos bidimensionales, como soporte catalítico para catalizadores de Rh para la SSO resulta en nanopartículas de $\mathrm{Rh}$ de tamaño subnanométrico $(<2 \mathrm{~nm})$ a niveles de carga metálica de $2.5 \%(p)$.

2. La identidad del óxido promotor $\left(\mathrm{MO}_{\mathrm{x}}\right)$ determina las propiedades electrónicas (poder electro donante-aceptor o carácter ácido-base según el concepto de Lewis) de estas fases promotoras, si bien los parámetros físico-químicos para el correspondiente óxido másico no 
son adecuados para describir las propiedades de las especies $\mathrm{MO}_{\mathrm{x}}$ soportadas sobre $\mathrm{\gamma}-\mathrm{Al}_{2} \mathrm{O}_{3}$.

3. La proporción de átomos de C que provienen de la activación disociativa o de la inserción no disociativa de las moléculas de CO en los productos de reacción está directamente relacionada con el poder electro donante-aceptor del óxido promotor $\left(\mathrm{MO}_{\mathrm{x}}\right)$, donde $\mathrm{M}=\mathrm{V}, \mathrm{Nb}$, $\mathrm{Ta}, \mathrm{Ti}, \mathrm{Y}, \mathrm{Pr}, \mathrm{Nd}$ o Sm, no pudiendo aplicarse esta correlación cuando se emplea $\mathrm{FeO}_{x}$ como promotor.

4. Por tanto, las características electrónicas de las fases de promotor dictan tanto la selectividad a compuestos oxigenados como la longitud de cadena media de los productos de reacción.

5. La densidad electrónica sobre las nanopartículas de $\mathrm{Rh}$ en los catalizadores $\mathrm{Rh} / \mathrm{M} @ \mathrm{Al}_{2} \mathrm{O}_{3}$ reducidos está directamente relacionada con las propiedades electrónicas de las fases promotoras $\mathrm{MO}_{\mathrm{x}}$, siendo tanto mayor cuanto mayor sea el poder electro-donante del óxido promotor.

6. La interacción de las nanopartículas de Rh con CO (o gas de síntesis) provoca severos cambios morfológicos y electrónicos en éstas a temperaturas en el rango de -175 a 100 ํㅡ, a través de un proceso de ruptura oxidativa. A temperaturas superiores el CO promueve una aglomeración reductiva que revierte el metal a un estado nanoparticulado, a priori, diferente del original antes del contacto con CO. Estos procesos tienen lugar de manera común en todos los catalizadores, independientemente de las propiedades de los promotores $\mathrm{MO}_{\mathrm{x}}$, aunque la naturaleza de éstos introduce peculiaridades en cada caso. 
7. Las propiedades electrónicas de las fases promotoras determinan los modos preferenciales de adsorción de CO sobre las nanopartículas de Rh desarrolladas tras el fenómeno de aglomeración reductiva, lo que podría estar relacionado con diferentes morfologías de nanopartícula en función de la naturaleza de las fases promotoras $\mathrm{MO}_{x}$.

8. Los estudios de CO-FTIR operando sugieren una relación directa entre los centros metálicos de adsorción de CO con baja capacidad de retrodonación (elevadas frecuencias en IR) y la formación de metanol por hidrogenación directa de CO no disociado. Por otro lado, la adsorción de CO sobre Rh en configuración puenteada favorece la disociación de $\mathrm{CO}$ y, por lo tanto, la formación de hidrocarburos y especies $\mathrm{C}_{2+}$ en general.

9. Los estudios de CO-FTIR operando sugieren la participación de especies acilo ( $\mathrm{RC}=\mathrm{O}-$ ) y formiato (HCOO-) en el mecanismo de formación de alcoholes. Asimismo, la capacidad para catalizar la oxidación de las especies acilo parece ser la característica que promueve la formación de compuestos oxigenados carboxílicos en catalizadores promovidos por óxidos de carácter electro-aceptor. Finalmente, se puede concluir que especies espectadoras de tipo acetato $\left(\mathrm{H}_{3} \mathrm{CHCOO}-\right)$ recubren la superficie del soporte catalítico durante la catálisis. 


\section{Referencias.}

${ }^{1}$ P. Gronchi, E. Tempesti, C. Mazzocchia, Appl. Catal. A 120 (1994) 115.
${ }^{2}$ D. Yu-Hua, C. De-An, T. Khi-Rui, Appl. Catal. 35 (1987) 77.
${ }^{3}$ M. Ichikawa, K. Shikakura, M. Kawai, Heterogeneous catalysis related to energy problems, Proceedings of Symposium, Dalian (China) 1982.

4 A. Boffa, C. Lin, A.T. Bell, G.A. Somorjai, J. Catal. 149 (1994) 149.

${ }^{5}$ M. Ojeda, S. Rojas, M. Boutonnet, F. J. Pérez-Alonso, F. J. García-García, J.L.G. Fierro, Appl. Catal. 274 (2004) 33.

${ }^{6}$ R. Burch, M. J. Hayes, J. Catal. 165 (1997) 249.

${ }^{7}$ W. Yan, S.M. Mahurin, S.H. Overbury, S. Dai, Top. Catal. 39 (2006) 199.

${ }^{8}$ J. Sauer, F. Mallow, B. Spliethoff, F. Schüth, Chem. Mater. 14 (2002) 217.

${ }^{9}$ M. J. Capitán, M. A. Centeno, P. Malet, I. Carrizosa, J. A. Odriozola, A. Márquez, J. F. Sanz, J. Phys. Chem. 99 (1995) 4655.

${ }^{10}$ I.E. Wachs, Y. Chen, J.-M. Jehng, L.E. Briand, T. Tanaka, Catal. Today 78 (2003) 13.

${ }^{11}$ M. Scheithauer, H. Knözinger, M.A. Vannice, J. Catal. 178 (1998) 701.

12 M.J. Capitán, M.A. Centeno, P. Malet, I. Carrizosa, J.A. Odriozola, A. Márquez, J. Fernández-Sanz, J. Phys. Chem. 99 (1995) 4655.

${ }^{13}$ R. Burch, M.J. Hayes, J. Catal. 165 (1997) 249.

${ }^{14}$ Damyanova, P. Grange, B. Delmon, J. Catal. 168 (1997) 421.

${ }^{15}$ F.J. Gil-Llambías, N. Escalona, C. Pfaff, C. Scott, J. Goldwasser, React. Kinet. Catal. Lett. 66 (1999) 225.

${ }^{16}$ M. Bettman, R.E. Chase, K. Otto, W.H. Weber, J. Catal. 117 (1989) 447.

17 T. Yamamoto, T. Tanaka, T. Matsuyama, T. Funabiki, S. Yoshida, J. Phys. Chem. B 105 (2001) 1908.

18 T. Beutel, V. Siborov, B. Tesche, H. Knözinger, J. Catal. 167 (1997) 379.

19 T. Beutel, O.S. Alekseev, Y.A. Ryndin, V.A. Likholobov, H. Knözinger, J. Catal. 169 (1997) 132.

${ }^{20}$ S.I. Ito, T. Fujimori, K. Nagashima, K. Yuzaki, K. Kuhimori, Catal. Today 57 (2000) 247.

${ }^{21}$ A. Kiennemann, R. Breault, J-P. Hindermann, J. Chem. Soc. Faraday Trans. 83 (1987) 2119.

${ }^{22}$ R.P. Underwood, A.T. Bell, J. Catal. 109 (1988) 61.

${ }^{23}$ H. Y. Luo, W. Zhang, H. W. Zhou, S. Y. Huang, P. Z. Lin, Y. J. Ding, L. W. Lin, Appl. Catal. A 214 (2001) 161.

${ }^{24}$ T. Yamamoto, T. Tanaka, T. Matsuyama, T. Funabiki, S. Yoshida, J. Phys. Chem. B 105 (2001) 1908.

${ }^{25}$ C. Noguera, Physique et chimie des surfaces d'oxydes, Eyrolles, Paris (1995).

${ }^{26}$ Metal oxides: chemistry and applications, J.L.G. Fierro Ed. Taylor \& Francis (2006).

${ }^{27}$ R.T. Sanderson J. Am. Chem. Soc. 105 (1983) 2259. 
${ }^{28}$ J. Portier, G. Campet, J. Etourneau, M.C.R. Shastry, B. Tanguy, J. Compounds Alloys 209 (1994) 59.

29 J.A. Duffy, Geochem. Cosmoche. Acta. 57 (1993) 3961.

${ }^{30}$ A. Lebouteiller, P. Courtine, J. Solid State Chem. 137 (1998) 94.

${ }^{31}$ V. Dimitrov, S. Sakka, J. Appl. Phys. 79 (1996) 1736.

32 X. Zhao, X. Wang, H. Lin, Z. Wang, Physica B 392 (2007) 132.

${ }^{33}$ E. Bordes-Richard, P. Courtine, en Metal oxides: chemistry and applications, J.L.G. Fierro Ed. Taylor \& Francis (2006).

${ }^{34}$ V. Simic-Milosevic, N. Nilius, H.P. Rust, H.-J. Freund, Phys. Rev. B 77 (2008) 125112.

${ }^{35}$ D.C. Barton, M. Stein, R.D. Wilson, S.L. Soled, E. Iglesia, J. Phys. Chem. B 103 (1999) 630.

${ }^{36}$ D. Masure, P. Chaquin, C. Louis, M. Che, M. Fournier, J. Catal. 119 (1989) 415.

${ }^{37}$ N.C. Jeong, J.S. lee, E.L. Tae, Y.J. Lee, K.B. Yoon, Angew. Chem. Int. Ed. 47 (2008) 10128.

${ }^{38}$ W.R. Duncan, O.V. Prezhdo, J. Phys. Chem. B 109 (2005) 365.

39 M. Primet, J. Chem. Soc., Faraday Trans. I 74 (1978) 2570.

40 J.F. Goellner, B.C. Gates, G.N. Vayssilov, N. Rösch, J. Am. Chem. Soc. 122 (2000) 8056.

${ }^{41}$ E. Ivanova, M. Mihaylov, F. Thibault-Starzyk, M. Daturi, K. Hadjiivanov, J. Catal. 236 (2005) 168.

42 E. Ruckenstein, H. Y. Wang, J. Catal. 190 (2000) 32.

${ }^{43}$ S.C. Chuang, Y.H. Tian, J.G. Goodwin, Jr. and I. Wender, J. Catal. 96 (1985) 396.

${ }^{44}$ R.P. Underwood, A.T. Bell, J. Catal. 111 (1988) 325.

45 Y. Wang, H. Luo, D. Liang, X. Bao, J. Catal. 196 (2000) 46.

${ }^{46}$ I.E. Wachs, Y. Chen, J.-M. Jehng, L.E. Briand, T. Tanaka, Catal. Today 78 (2003) 13.

${ }^{47}$ N. Tien-Thao, M.H. Zahedi-Niaki, H. Alamdari, S. Kaliaguine, J. Catal. 245 (2007) 348.

${ }^{48}$ H.Y. Luo, P.Z. Lin, S.B. Xie, H.W. Zhou, C.H. Xu, S.Y. Huang, L.W. Lin, D.B. Liang, P.L. Yin, Q. Xin. J. Mol. Catal. A 122 (1997) 115.

49 H.Yin, Y. Ding, H. Luo, H. Zhu, D. He, J. Xiong, L, Lin, Appl. Catal. A 243 (2003) 155.

${ }^{50}$ T. Mori, A. Miyamoto, N.Takahashi, H.Niizuma, T. Hattori, Y. Murakami, J. Catal. 102 (1986) 199.

${ }^{51}$ P. Panagiotopoulou, D.I. Kondarides, J. Catal. 260 (2008) 141.

52 M. Ichikawa, J. Chem. Soc. Chem. Commun. (1978) 566.

${ }^{53}$ P.R. Watson, G.A. Somorjai, J. Catal. 74 (1982) 282.

${ }^{54}$ Y. He, G. Chen, S. Kawi, S. Wong, J. Porous Mater. 16 (2009) 721.

${ }^{55}$ J. Zhu, Y. Ma, S. Zhuang, Surf. Sci. 603 (2009) 1802.

${ }^{56}$ Q. Guo, O.J. Kleppa, Metall. Mater. Trans. B 29B (1998) 815.

${ }^{57}$ C. D. Wagner, A. Joshi, J. Electron. Spectrosc. 47 (1988) 283.

${ }^{58}$ W.M.H. Sachtler, M. Ichikawa, J. Phys. Chem. 90 (1986) 4752. 
${ }^{59}$ H. F. J. van 't Blik, J. B. A. D. van Zon, T. Huizinga, J. C. Vis, D. C. Koningsberger, R. Prim, J. Am. Chem. Soc. 107 (1985) 3139.

${ }^{60}$ D.J.C. Yates, L.L. Murrell, E.B. Prestidge, J. Catal. 57 (1979) 41.

${ }^{61}$ M. Primet, J. Chem. Soc. Far. Trans. 174 (1978) 2570.

62 J. Gao, X. Mo, A.C-Y. Chien, W. Torres, J.G. Goodwin Jr., J. Catal. 262 (2009) 119.

${ }^{63}$ Z.Fan, W. Chen, X.Pan, X. Bao, Catal. Today 147 (2009) 86.

${ }^{64}$ J. Raskó, J. Bontovics, Catal. Lett. 58 (1999) 27.

${ }^{65}$ F. Solymosi, M. Pásztor, J. Phys. Chem. 89 (1983) 4783 y J. Catal. 104 (1987) 312.

${ }^{66}$ F. Solymosi, H. Knözinger, J. Chem. Soc. Faraday Trans. 86 (1990) 389.

${ }^{67}$ M.I. Zaki, B. Tesche, L. Kraus, H. Knözinger, Surf. Interf. Anal. 12 (1988) 239.

${ }^{68}$ E. Finocchio, G.Busca, P. Forzatti, G. Groppi, A. Beretta, Langmuir 23 (2007) 10419.

${ }^{69}$ D. Demri, L. Chateau, J.P. Hindermann, A. Kiennemann, M.M. Bettahar, J. Mol. Catal. A 104 (1996) 237.

${ }^{70}$ V. Lochař, Appl. Catal. A 309 (2006) 33.

71 J.S. Szanyi and W. Goodman. Catal. Lett. 10 (1991) 383.

${ }^{72}$ P.B. Rasmussen, M. Kazuta and I. Chorkendorff. Surf. Sci. 318 (1994) 267.

73 J. Yoshihara and C.T. Campbell. J. Catal. 161 (1996) 776.

${ }^{74}$ T. Fukushima, H. Arakawa, M. Ichikawa, J. Chem. Soc. Chem. Commun. (1985) 729.

75 G. van der Lee, V. Ponec, J. Catal. 99 (1986) 511.

${ }^{76}$ H. Treviño, T. Hyeon, W.M.H. Sachtler, J. Catal. 170 (1997) 236.

${ }^{77}$ M. Ichikawa, P.E. Hoffmann, A. Fukuoka, J. Chem. Soc. Chem. Commun. (1989) 1395.

${ }^{78}$ M. Bowker, Y. Li, Catal. Lett. 10 (1991) 249.

79 A. Corma, H. García, Chem. Rev. 102 (2002) 3837.

${ }^{80}$ T. Koerts, W.J.J. Welters, R.A. van Santen, J. Catal. 134 (1992) 1.

${ }^{81}$ K. Fujimoto, M. Kameyama, T. Kung, J. Catal. 61 (1980) 7.

${ }^{82}$ A.Y. Stakheev, L.M. Kustov, Appl. Catal. A 188 (1999) 3. 


\section{CONCLUSIONES}

\section{GENERALES}


A lo largo de los capítulos dedicados a la discusión de los resultados de esta tesis doctoral se han ido enumerando las conclusiones extraídas de los mismos de manera detallada.

De forma más general, se enumeran a continuación las conclusiones más importantes de la presente tesis doctoral:

- La síntesis de Fischer-Tropsch catalizada por Co presenta una sensibilidad a la estructura no clásica, de acuerdo a la cual, el valor de TOF disminuye para nanopartículas de $\mathrm{Co}^{0}$ de tamaño inferior a aprox. $10 \mathrm{~nm}$. Los resultados catalíticos, espectroscópicos y microscópicos apuntan a que esta sensibilidad a la estructura está relacionada con cambios morfológicos que sufren las nanopartículas metálicas en las condiciones de reacción, y que resultan en la formación de centros $\mathrm{Co}^{\delta+}$ menos activos en la interfase metalsoporte, de manera especial para nanopartículas de pequeño tamaño $(<10 \mathrm{~nm})$.

- La historia térmica de los catalizadores $\mathrm{Co} / \mathrm{SiO}_{2}$ influye no sólo en la dispersión metálica y la reducibilidad de las fases de Co, sino que también es determinante para la topología superficial de las nanopartículas de $\mathrm{Co}^{\circ}$ en el catalizador final, lo que resulta en variaciones importantes del valor de TOF. Las propiedades másicas (bulk) y superficiales del óxido $\mathrm{Co}_{3} \mathrm{O}_{4}$ son sensibles a las condiciones empleadas en los primeros tratamientos de activación, de modo que la química de este óxido transmite esta información a lo largo de toda la historia térmica de los catalizadores hasta el evento catalítico.

- En el estado pseudo-estacionario, tanto la dispersión metálica como la estructura porosa del soporte catalítico contribuyen de manera no despreciable a la actividad y la selectividad de los 
catalizadores de Co en la síntesis de Fischer-Tropsch. La combinación de elevadas dispersiones, con un tamaño de nanopartícula óptimo entorno a $10 \mathrm{~nm}$, y porosidades muy abiertas da lugar a los catalizadores más activos y selectivos a la fracción de destilados medios. El empleo de soportes basados en $\mathrm{Y}-\mathrm{Al}_{2} \mathrm{O}_{3}$ de morfología primaria nanofibrosa y estructura macro-mesoporosa, así como sílices mesoporosas ordenadas SBA-15 de morfología no convencional, presentando poros anchos y cortos, resultan en catalizadores con propiedades catalíticas superiores a los soportes convencionales.

Como conclusión general de los capítulos dedicados a la síntesis de Fischer-Tropsch se puede comentar que las nuevas generaciones de catalizadores de Co avanzados deberán aunar una dispersión metálica homogénea, con un tamaño de nanopartícula óptimo de aprox. $10 \mathrm{~nm}$, y una estructura porosa muy abierta, con una red primaria de mesoporos anchos (10-20 nm) y cortos $(<1 \mu \mathrm{m})$, preferiblemente asociada con una red secundaria de macroporos. A su vez, con el objetivo de maximizar la actividad catalítica intrínseca, la activación de los catalizadores preferiblemente no debe comprender tratamientos en atmósfera de aire a elevadas temperaturas, en ningún momento a lo largo de su historia térmica completa. Los catalizadores basados en sílices mesoporosas ordenadas de poro ancho y morfología de partícula no convencional, con longitud de poro ultra corta, son un buen ejemplo de catalizadores avanzados, de acuerdo a los requerimientos evidenciados en la presente tesis doctoral.

- Por último, el papel de los promotores en los catalizadores nanoparticulados de Rh para la conversión selectiva de gas de síntesis en compuestos oxigenados puede describirse, de manera general, empleando descriptores simples para el patrón de selectividades obtenido y las propiedades electrónicas (ácido-base) de las fases de 
promotor. Estas propiedades electrónicas de los promotores influyen tanto en la forma de adsorción de $\mathrm{CO}$ sobre las fases de $\mathrm{Rh}^{0}$ como en la adsorción de las especies oxigenadas, posiblemente sobre las fases promotoras cerca de las nanopartículas de $\mathrm{Rh}^{0}$.

Probablemente, los resultados presentados en esta tesis acerca de los catalizadores de Rh para la síntesis selectiva de oxigenados ayuden a conciliar varios resultados publicados en las últimas décadas y condicionen el enfoque empleado en la optimización de este sistema catalítico en el futuro. 
ANEXOS 


\section{ANEXO I: ÍNDICE DE FIGURAS}

\begin{tabular}{|c|c|}
\hline Pag. & Pie de Figura \\
\hline 6 & $\begin{array}{l}\text { Figura 1.1: Evolución de la demanda mundial estimada de combustibles gaseosos y } \\
\text { líquidos, por tipo, durante el presente siglo. Fuente: International Energy Agency } \\
\text { (www.IEA.org). }\end{array}$ \\
\hline 11 & $\begin{array}{l}\text { Figura 1.2: Variación del coste de transporte con la distancia de transporte para } \mathrm{H}_{2} \\
\text { gas natural (GN), gas natural licuado (GNL) y varios productos de conversión de gas de } \\
\text { síntesis (metanol, etanol e hidrocarburos derivados de la síntesis de Fischer-Tropsch) } \\
\text { para su transporte desde las regiones de producción mediante conducciones (conduc.) } \\
\text { y mediante tanques en buques petroleros (tanq.). Adaptada de [28]. }\end{array}$ \\
\hline 23 & $\begin{array}{l}\text { Figura 1.3: Distribuciones de productos de la sintesis de Fischer-Tropsch real (línea } \\
\text { continua) y predicha por el modelo de ASF (línea punteada). }\end{array}$ \\
\hline 24 & $\begin{array}{l}\text { Figura 1.4: Composición de la mezcla de hidrocarburos obtenidos en la SFT en función } \\
\text { del parámetro } \alpha \text {. }\end{array}$ \\
\hline 24 & $\begin{array}{l}\text { Figura 1.5: Grupos de metales de transición agrupados según su capacidad de disociar } \\
\mathrm{CO}, \mathrm{H}_{2}, \mathrm{o} \mathrm{CO} \text { e } \mathrm{H}_{2} \text {. }\end{array}$ \\
\hline 32 & $\begin{array}{l}\text { Figura 1.6: (a) Representación esquemática del diagrama de flujo para el proceso } \\
S P D^{\circledR} \text { (Sasol Phase Distillate); (b) vista nocturna de la planta Oryx-GTL }{ }^{\circledR} \text { operada por } \\
\text { Sasol-QP en Ras Laffan (Qatar) en la que se identifican las operaciones básicas } \\
\text { esquematizadas en (a). }\end{array}$ \\
\hline 35 & $\begin{array}{l}\text { Figura 1.7: Representación esquemática de los diferentes niveles de observación para } \\
\text { el estudio de un catalizador de Fischer-Tropsch. }\end{array}$ \\
\hline 39 & $\begin{array}{l}\text { Figura 1.8: Representación esquemática de los fenómenos de difusión intra-partícula } \\
\text { que se establecen en un catalizador de Fischer-Tropsch en condiciones de operación. } \\
\text { Adaptada de [84]. }\end{array}$ \\
\hline 40 & $\begin{array}{l}\text { Figura 1.9: Selectividad a la fracción de hidrocarburos } C_{5+} \text { en función del parámetro } \\
\text { estructural } \chi \text {. Adaptada de [85]. }\end{array}$ \\
\hline 42 & $\begin{array}{l}\text { Figura 1.10: (a) Imagen de microscopía óptica de la sección de un catalizador } \mathrm{Co}_{\mathrm{SiO}} \\
\text { con distribución de fase soportada tipo "eggshell"; (b) Esquema representativo de la } \\
\text { síntesis de un soporte de } \mathrm{SiO}_{2} \text { macro-mesoporoso por introducción de un sol } \\
\text { nanoparticulado en los macroporos de un sustrato macroporoso, adaptado de [87]. }\end{array}$ \\
\hline 44 & $\begin{array}{l}\text { Figura 1.11: Dependencia de la actividad intrínseca (TOF) con el tamaño de } \\
\text { nanopartícula para diferentes tipos de sensibilidad a la estructura. Adaptada de [91]. }\end{array}$ \\
\hline 45 & $\begin{array}{l}\text { Figura 1.12: (a) Representación tridimensional de una superficie metálica real } \\
\text { obtenida mediante STM [93]; y (b) esquema de una superficie metálica conteniendo } \\
\text { varios tipos de centros metálicos derivados de su no-idealidad, [94]. }\end{array}$ \\
\hline 47 & $\begin{array}{l}\text { Figura 1.13: Regímenes de estabilidad para diferentes estructuras metálicas en } \\
\text { función del tamaño de partícula. }\end{array}$ \\
\hline 50 & $\begin{array}{l}\text { Figura 1.14: Imagen de STM (Scanneling Tunneling Microscopy) de la superficie } \\
\text { metálica de un "foil" de } \mathrm{CO}^{\circ}(0001) \text { antes (a) y después de su exposición a condiciones } \\
\text { de hidrogenación de } \mathrm{CO}\left(\mathrm{H}_{2} / \mathrm{CO}=2, T=250^{\circ} \mathrm{C}, P=0.4 \mathrm{MPa}\right) \text { durante } 1 \text { hora [110]. }\end{array}$ \\
\hline 55 & $\begin{array}{l}\text { Figura 1.15: Evolución del precio del Rh durante los últimos } 3 \text { años. Fuente: } \\
\text { www.infomine.com (Agosto 2009). }\end{array}$ \\
\hline 105 & $\begin{array}{l}\text { Figura 2.1: Representación esquemática de los fenómenos de donación electrónica CO- } \\
\text { metal y retro-donación metal-CO para una molécula de CO adsorbida sobre un sitio } \\
\text { metálico. La figura incluye, a su vez, el diagrama de orbitales moleculares para la }\end{array}$ \\
\hline
\end{tabular}


107 molécula de CO.

Figura 2.2: Representación esquemática de diferentes modos de adsorción de CO sobre centros metálicos que dan lugar a señales de FTIR a diferentes frecuencias: (a) adsorción lineal sobre un centro metálico en terraza, (b) adsorción lineal sobre un

107 centro metálico de baja coordinación (defecto superficial), (c) adsorción de CO en geometría puenteada (bridged) sobre centros metálicos en terraza, (d) adsorción tipo "inclinado" (tilted) sobre un centro metálico en la vecindad de un átomo electronegativo que coordina al extremo oxígeno de la molécula de CO.

110 Figura 2.3: Esquema simplificado del sistema de reacción empleado para los experimentos catalíticos, [29].

118 Figura 2.4: Cromatograma representativo de un análisis de los productos en línea en el canal del detector TCD.

119 Figura 2.5: Cromatograma representativo de un análisis de los productos en línea en el canal del detector FID.

120 Figura 2.6: Cromatograma representativo de un análisis de los productos recogidos en trampa 1.

120 Figura 2.7: Cromatograma representativo de un análisis de los productos en recogidos en trampa 2 .

Figura 2.8: Representación esquemática de la formación de un perfil de concentración

124 alrededor de las partículas de catalizador cuando la etapa de transferencia de materia extra-partícula presenta relevancia cinética.

Figura 2.9: Diagrama de Arrhenius para el TOF obtenido en los experimentos

125 catalíticos realizados con el catalizador $30 \mathrm{Co} / \mathrm{SiO}_{2}(\mathrm{mf})$ en el rango de temperaturas de $220-260^{\circ} \mathrm{C}$.

Figura 2.10: Diagrama de Arrhenius para las velocidades de formación de $\mathrm{CH}_{4}$ y etanol

126 para los experimentos catalíticos realizados con el catalizador $2.5 \mathrm{Rh} / \mathrm{La}_{0} \mathrm{Al}_{2} \mathrm{O}_{3}$ en el rango de temperaturas de $280-320^{\circ} \mathrm{C}$.

141 Figura 3.1: Representación esquemática de la preparación de nanopartículas metálicas empleando una microemulsión inversa.

\begin{tabular}{|c|c|}
\hline 144 & Figura 3.2: Esquema de la estructura de la zeolita deslaminada ITQ-2, [29]. \\
\hline 147 & $\begin{array}{l}\text { Figura 3.3: Micrografías SEM del precursor laminar con estructura MWW (a) y la } \\
\text { zeolita deslaminada ITQ-2(a) obtenida por deslaminación del mismo (b). }\end{array}$ \\
\hline 148 & $\begin{array}{l}\text { Figura 3.4: Micrografías TEM representativas de dos regiones de estudio para la } \\
\text { muestra SITQ-2(a). }\end{array}$ \\
\hline 150 & $\begin{array}{l}\text { Figura 3.5: Espectros de }{ }^{29} \text { Si-NMR para la zeolita deslaminada ITQ-2 en sus formas } \\
\text { calcinada y sililada. El detalle muestra un ejemplo de la deconvolución de picos en la } \\
\text { región -90 a -120 ppm del espectro para el material calcinado. }\end{array}$ \\
\hline 152 & $\begin{array}{l}\text { Figura 3.6: Espectros de FTIR para la zeolita deslaminada ITQ-2 en sus formas } \\
\text { calcinada y sililada. }\end{array}$ \\
\hline 154 & $\begin{array}{l}\text { Figura 3.7: Micrografía de TEM y distribución de tamaño de las nanopartículas } \\
\text { sintetizadas en la microemulsión inversa y empleadas para preparar los catalizadores } \\
\text { me_10Co/ITQ y me_10Co/SITQ. }\end{array}$ \\
\hline 156 & $\begin{array}{l}\text { Figura 3.8: Perfiles de TG (incluyendo derivada dM/dT) y DTA (parte superior), así } \\
\text { como los correspondientes perfiles de TPO-MS para fragmentos con } m / z=18,30,44 \text { y } \\
46 \text { (parte inferior) durante la calcinación en aire del catalizador me_Co/SITQ. }\end{array}$ \\
\hline 159 & Figura 3.9: Difractogramas de XRD para los catalizadores $10 \% \mathrm{Co} / \mathrm{ITQ}-2$ calcinados.' \\
\hline 160 & $\begin{array}{l}\text { Figura 3.10: Micrografías de TEM representativas para los catalizadores } \\
\text { me_10Co/SITQ (a y b) e im_10Co/SITQ (c) reducidos y pasivados así como los }\end{array}$ \\
\hline
\end{tabular}


correspondientes histogramas de tamaño de nanopartícula (d).

163 Figura 3.11: Perfiles de $\mathrm{H}_{2}$-TPR para los catalizadores $10 \% \mathrm{CO} / \mathrm{ITQ}-2$.

Figura 3.12: Detalle del difractograma de rayos $X$ mostrando la difracción del plano (3

1 1) para $\mathrm{Co}_{3} \mathrm{O}_{4}$ en los catalizadores 10Co/ITQ(5) (b), 10Co/ITQ(4) (c), 10Co/ITQ(2) (d),

$17010 \mathrm{Co} / \mathrm{ITQ}(1)$ (e) y $30 \mathrm{Co} / \mathrm{SiO}_{2}(\mathrm{mf})(\mathrm{f})$ calcinados. El difractograma para el soporte ITQ2(a) se muestra también como referencia (a).

173 fe tamaño de nanopartícula para los catalizadores 10Co/ITQ(4) (a), Co/ITQ(2) (b), 10Co/ITQ(1) (c) y 30CoSiO $2(\mathrm{mf})(\mathrm{d})$ reducidos y pasivados.

Figura 3.14: Micrografía de alta resolución (HR-TEM) para el catalizador 10Co/ITQ(4)

175 reducido y pasivado y perfil de espaciado cristalino, que evidencia la re-oxidación completa a $\mathrm{COO}$.

177 Figura 3.15: Perfiles de $\mathrm{H}_{2}$-TPR para los catalizadores $10 \mathrm{Co} / \mathrm{ITQ}(1-7)$ y $30 \mathrm{Co} / \mathrm{SiO}_{2}(\mathrm{mf})$.

178 Figura 3.16: Evolución de la temperatura para los procesos de reducción de los catalizadores 10Co/ITQ(1 a 7) en función del tamaño de nanopartícula.

180 Figura 3.17: Espectros de DR UV-vis para catalizadores 10\%Co/ITQ-2 calcinados seleccionados.

Figura 3.18: Dependencia de la actividad (TOF) (a) y la selectividad catalítica (b) con el

186 diámetro de nanopartícula de $\mathrm{CO}^{\circ}$. Condiciones de reacción: $T=220^{\circ} \mathrm{C}, P=2.0 \mathrm{MPa}$, $\mathrm{H}_{2} / \mathrm{CO}=2, X_{\mathrm{CO}}=10 \pm 2 \%$.

Figura 3.19: Espectros de FTIR tras la exposición de los catalizadores 10Co/ITQ(1) (a),

$18910 \mathrm{Co} / \mathrm{ITQ}(4)$ (b) y 10Co/SiO $(\mathrm{mf})$ (c) previamente reducidos a 5 mbar de $\mathrm{CO}$, a temperatura ambiente.

Figura 3.20: Evolución de la proporción de átomos superficiales en posiciones de baja

191 coordinación (vértices+aristas) con el tamaño de nanopartícula para nanopartículas de $\mathrm{Co}^{0}$ de geometría cuboctaédrica ideal [61].

Figura 3.21: Evolución del espectro de FTIR con la dosis de CO ( $P_{C O}=5-250$ mbar) a temperatura ambiente para el catalizador 10Co/ITQ(1) previamente reducido. EI

193 detalle de la figura muestra el espectro en la región de carbonilos metálicos a baja dosis de CO (5 mbar) para la muestra recién reducida (a) y la muestra re-evacuada tras alcanzar una primera dosis de 250 mbar de CO (b).

Figura 3.22: Evolución del espectro de FTIR con la dosis de CO ( $P_{C O}=5-250$ mbar) a temperatura ambiente para el catalizador 10Co/ITQ(4) previamente reducido. El

194 detalle de la figura muestra el espectro en la región de carbonilos metálicos a baja dosis de CO (5 mbar) para la muestra recién reducida (a) y la muestra re-evacuada tras alcanzar una primera dosis de 250 mbar de CO (b).

Figura 3.23: Evolución del espectro de FTIR con la dosis de $C O\left(P_{C O}=5-250 \mathrm{mbar}\right)$, a temperatura ambiente, para el catalizador $10 \mathrm{Co} / \mathrm{SiO}_{2}(\mathrm{mf})$ previamente reducido. El

195 detalle de la figura muestra el espectro en la región de carbonilos metálicos a baja dosis de CO (5 mbar) para la muestra recién reducida (a) y la muestra re-evacuada tras alcanzar una primera dosis de 250 mbar de CO (b).

Figura 3.24: Evolución del espectro de FTIR con la temperatura para el catalizador 10Co/ITQ(1) reducido y expuesto a una corriente de gas de síntesis $\left(\mathrm{H}_{2} / \mathrm{CO}=2\right)$ a 25oC

198 (a), $160^{\circ} \mathrm{C}(\mathrm{b}), 200^{\circ} \mathrm{C}$ (c); y evolución del espectro de FTIR con el tiempo de reacción después de 120 (d), 210 (e) y 240 (f) minutos en condiciones de síntesis de FischerTropsch.

Figura 3.25: Espectros de FTIR después de 4 horas en condiciones de síntesis de

202 Fischer-Tropsch $\left(T=220^{\circ} \mathrm{C}, P_{\text {atm }}\right)$ para los catalizadores 10Co/ITQ(1) (a), $10 \mathrm{Co} / \mathrm{SiO}_{2}(\mathrm{mf})(\mathrm{b})$, y 10Co/ITQ(4) (c); y espectros de FTIR tras 4 horas de reacción y 
posterior evacuación de la celda a 25ㅇ C para 10Co/ITQ(1) (d), 10Co/ITQ(4) (e) y $10 \mathrm{Co} / \mathrm{SiO}_{2}(\mathrm{mf})(\mathrm{f})$.

Figura 3.26: Micrografías de TEM para el catalizador 10Co/ITQ(2) después de 12 horas en condiciones de reacción en la síntesis de Fischer-Tropsch a elevada presión

$205\left(T=220^{\circ} \mathrm{C}, P=2.0 \mathrm{MPa}, X_{C O}=10 \%\right)$. Las flechas en las figuras indican la presencia de nanopartículas de Co aplanadas, observadas en perfil en los bordes de las láminas del soporte.

morfológicos que sufren las nanopartículas de $\mathrm{Co}^{\circ}$ en condiciones de reacción de acuerdo a los resultados de CO-FTIR y TEM para las nanopartículas cuyo tamaño es $>10 \mathrm{~nm}$ (TOF máximo) ó <10 nm (TOF disminuido).

Figura 4.1: Evolución de la actividad catalítica por centro superficial (TOF $\left(220^{\circ} \mathrm{C}\right)$ ) con el tamaño de nanopartícula de Co ${ }^{\circ}$ para catalizadores activados por reducción directa o calcinación a baja temperatura $\left(<350^{\circ} \mathrm{C}\right.$ ) (símbolos llenos y línea continua), activados por calcinación a temperaturas elevadas $\left(>450^{\circ} \mathrm{C}\right.$ ) (símbolos abiertos y línea quebrada) y bimetálicos promovidos por Ru o Re (símbolos semi-llenos y línea punteada) extraídos de la literatura (ver Tabla 4.1 para más detalles).

225 Figura 4.2: Micrografías de TEM representativas y los correspondientes histogramas de tamaño de nanopartícula metálica para los catalizadores a) $\mathrm{Co} / \mathrm{SiO}_{2} \mathrm{rd}$, b) $\mathrm{Co} / \mathrm{SiO}_{2}$ _ 425 y c) $\mathrm{Co} / \mathrm{SiO}_{2} \_550$ reducidos y pasivados.

226 Figura 4.3: Micrografía de HRTEM para el catalizador $\mathrm{Co} / \mathrm{SiO}_{2} \_$rd reducido y pasivado.

228 Figura 4.4: Estructura cristalina de la espinela de $\mathrm{Co}^{2+}$ y $\mathrm{Co}^{3+}$, adaptada de [29].

Figura 4.5: (a) Espectro Raman para los catalziadores calcinados a) $\mathrm{Co} / \mathrm{SiO}_{2} \_550, b$ )

$\mathrm{Co} / \mathrm{SiO}_{2}$ _425, c) Co/SiO${ }_{2} 300$ y d) $\mathrm{Co} / \mathrm{SiO}_{2}$ _dc en el rango de desplazamiento Raman

$230 \quad 600-750 \mathrm{~cm}^{-1}$ (modo de vibración fundamental $A_{1 g}$ ) ; y (b) evolución de la posición y la anchura de banda de la señal $A_{1 g}$ con la temperatura de calcinación de los catalizadores.

Figura 4.6: Espectro Raman para los catalizadores calcinados a) $\mathrm{Co} / \mathrm{SiO}_{2} \quad 550$, b)

$231 \mathrm{Co} / \mathrm{SiO}_{2} \_425$, c) $\mathrm{Co} / \mathrm{SiO}_{2}{ }_{3} 300$ y d) $\mathrm{Co} / \mathrm{SiO}_{2}$ _dc en el rango de desplazamiento Raman $450-580 \mathrm{~cm}^{-1}$ (modos de vibración fundamentales $E_{g y} F_{2 g}(1)$ ).

Figura 4.7: Espectros de XPS (CO2p) para los compuestos patrón (a) $\mathrm{Co}\left(\mathrm{CH}_{3} \mathrm{CO}_{2}\right)_{2} \cdot 4 \mathrm{H}_{2} \mathrm{O}$, (b) $\mathrm{Co}\left(\mathrm{C}_{5} \mathrm{H}_{7} \mathrm{O}_{2}\right)_{3}$ y los catalizadores calcinados (c) $\mathrm{Co} / \mathrm{SiO}_{2}{ }_{3} 300$ y (d) $\mathrm{Co} / \mathrm{SiO}_{2}$ 550. El espectro incluido en (e) muestra una comparativa de la línea XAES Co(LMM) para los cuatro sólidos.

Figura 4.8: Perfiles de $\mathrm{H}_{2}$-TPR para los catalizadores a) $\mathrm{Co} / \mathrm{SiO}_{2} \_300$, b) $\mathrm{Co} / \mathrm{SiO}_{2} 425 \mathrm{y}$

237 c) $\mathrm{Co} / \mathrm{SiO}_{2}$ 550. La figura incluye dos anexos, A-I: perfil de $\mathrm{H}_{2}$-TPR para el catalizador $\mathrm{Co} / \mathrm{SiO}_{2}$ dc , y A-Il: perfiles de reducción para las muestras de baja dispersión $10 \mathrm{Co} / \mathrm{SiO}_{2}$ (mf) calcinadas a a) $300^{\circ} \mathrm{C}$, b) $425^{\circ} \mathrm{C}$ y c) $550^{\circ} \mathrm{C}$.

Figura 4.9: Difractogramas de rayos $X$ y evolución del área normalizada para las

239 difracciones más intensas de las especies cristalinas durante la reducción in situ de los catalizadores a) $\mathrm{Co} / \mathrm{SiO}_{2} \_r d$, b) $\mathrm{Co} / \mathrm{SiO}_{2} \_300$ y c) $\mathrm{Co} / \mathrm{SiO}_{2} \_550$.

Figura 4.10: Difractogramas de rayos $X$ para catalizadores $\mathrm{Co} / \mathrm{SiO}_{2}$ seleccionados tras

242 el tratamiento de reducción $\left(400^{\circ} \mathrm{C}, 3\right.$ horas) in situ en la celda de XRD. La figura incluye como referencia las difracciones para $\mathrm{Co}^{\circ}$-hcp (JCPDS:05-0727), $C 0^{\circ}$-fcc (JCPDS:15-0806) y COO (JCPDS:09-0402) .

Figura 4.11: Espectros de CO-FTIR a temperatura ambiente tras la dosificación de 5-

250250 mbar de $\mathrm{CO}$ sobre el catalizador $\mathrm{Co} / \mathrm{SiO}_{2}$ r rd reducido in situ en la celda de FTIR $\left(400^{\circ} \mathrm{C}, 2 \mathrm{~h}\right)$ y evacuado a la temperatura de reducción. La flecha indica el sentido de dosis crecientes de $\mathrm{CO}$. 
Figura 4.12: Espectros de CO-FTIR a temperatura ambiente tras la dosificación de 5-

251250 mbar de CO sobre el catalizador $\mathrm{Co} / \mathrm{SiO}_{2} \_550$ reducido in situ en la celda de FTIR $\left(400^{\circ} \mathrm{C}, 2 \mathrm{~h}\right)$ y evacuado a la temperatura de reducción. La flecha indica el sentido de dosis crecientes de $\mathrm{CO}$.

Figura 4.13: Espectros de CO-FTIR a temperatura ambiente tras la dosificación de 5

252 mbar de $\mathrm{CO}$ sobre los catalizadores a) $\mathrm{Co} / \mathrm{SiO}_{2} 550$ y b) $\mathrm{Co} / \mathrm{SiO}_{2}$ rd reducidos in situ en la celda de FTIR $\left(400^{\circ} \mathrm{C}, 2 \mathrm{~h}\right)$ y evacuados a la temperatura de reducción.

254 Figura 4.14: Resumen gráfico de la propagación de los efectos de la historia térmica, desde los primeros tratamientos, hasta el evento catalítico (TOF).

Figura 5.1: Esquema de la organización de surfactantes para dar lugar a materiales

267 con partículas primarias de dimensiones nanométricas y estructuras secundarias macroporosas [10].

Figura 5.2: Isotermas de adsorción-desorción de $\mathrm{N}_{2}$ para los soportes comerciales

$269 \mathrm{Al}_{2} \mathrm{O}_{3}{ }_{1} 1-4$ y el soporte nanofibroso $\mathrm{Al}_{2} \mathrm{O}_{3}$ nf. Las isotermas para $\mathrm{Al}_{2} \mathrm{O}_{3}{ }_{1} 1-4$ se han desplazado verticalmente 1200, 1100, 750 y $650 \mathrm{~cm}^{3} / \mathrm{g}$, respectivamente.

270 Figura 5.3: Distribuciones de diámetro de poro obtenidas por adsorción de $\mathrm{N}_{2}$ para los soportes comerciales $\mathrm{Al}_{2} \mathrm{O}_{3}$ 1-4 y la muestra de morfología nanofibrosa $\mathrm{Al}_{2} \mathrm{O}_{3} \_n f$.

274 Figura 5.4: Micrografías de TEM representativas de los soportes $\mathrm{Al}_{2} \mathrm{O}_{3}{ }_{1} 1(a), \mathrm{Al}_{2} \mathrm{O}_{3}{ }_{2} 2$ (b), $\mathrm{Al}_{2} \mathrm{O}_{3} 3$ (c), $\mathrm{Al}_{2} \mathrm{O}_{3} 4$ (d) y $\mathrm{Al}_{2} \mathrm{O}_{3}$ nf (e y f).

Figura 5.5: Micrografía de SEM de la superficie de las partículas de $\mathrm{Al}_{2} \mathrm{O}_{3}$ nf. El detalle

275 muestra una imagen a mayor magnificación de la boca de los macroporos presentes en esta muestra.

Figura 5.6: Variación del diámetro de nanopartícula de óxido de Co con el diámetro de

281 poro (a) y el área superficial del soporte (b) para los catalizadores $\mathrm{RuCO}_{\mathrm{Al}} \mathrm{I}_{2} \mathrm{O}_{3}$ soportados sobre $\mathrm{\gamma}-\mathrm{Al}_{2} \mathrm{O}_{3}$ de origen comercial (símbolos cerrados) y nanofibrosa macro-mesoporosa (símbolos abiertos).

Figura 5.7: Imagen de TEM de media magnificación para el catalizador $20 \mathrm{Co} / \mathrm{Al}_{2} \mathrm{O}_{3} \_n f$

283 reducido y pasivado. Como detalle se incluye una imagen de HRTEM mostrando nanopartículas de Co, de las cuales, las de menor tamaño aparecen re-oxidadas a CoO.

Figura 5.8: Imagen de TEM de media resolución para el catalizador $20 \mathrm{Co} / \mathrm{Al}_{2} \mathrm{O}_{3}{ }_{4} 4$

284 reducido y pasivado y perfiles de concentración obtenidos por EDX para $C, A l, C o$ y $O$ en la misma región.

285 Figura 5.9: Perfiles de $\mathrm{H}_{2}$-TPR para los catalizadores $20 \mathrm{Co} / \mathrm{Al}_{2} \mathrm{O}_{3}$ (a) y $30 \mathrm{Co} / \mathrm{Al}_{2} \mathrm{O}_{3}(\mathrm{~b})$.

Figura 5.10: Evolución de la conversión de CO con el tiempo de reacción para un

288 experimento catalítico extendido, de 100 horas de duración, para el catalizador $30 \mathrm{Co} / \mathrm{Al}_{2} \mathrm{O}_{3}{ }_{3} 3$.

Figura 5.11: Evolución de la relación másica olefina/parafina $(O / P)$ y el rendimiento

290 temporal por masa de Co (CTY) con el tiempo de reacción para el catalizador $20 \mathrm{Co} / \mathrm{Al}_{2} \mathrm{O}_{3} 4$.

Figura 5.12: Evolución de la relación másica olefina/parafina $(O / P)$ y el rendimiento

290 temporal por masa de Co (CTY) con el tiempo de reacción para el catalizador $20 \mathrm{Co} / \mathrm{Al}_{2} \mathrm{O}_{3}{ }_{2}$.

Figura 5.13: Evolución de la relación másica olefina/parafina $(O / P)$ y el rendimiento

291 temporal por masa de Co (CTY) con el tiempo de reacción para el catalizador $20 \mathrm{Co} / \mathrm{Al}_{2} \mathrm{O}_{3}$ nf.

Figura 5.14: Relación másica olefina/parafina $(O / P)$ en el estado pseudo-estacionario

293 para los productos con longitud de cadena $C_{5}, C_{7}$ y $C_{9}$ en función del diámetro de poro del soporte para los catalizadores $20 \mathrm{Co} / \mathrm{Al}_{2} \mathrm{O}_{3}$ preparados sobre soportes comerciales 
(símbolos llenos) y nanofibroso (símbolos abiertos).

Figura 5.15: (a) Evolución de la selectividad a $\mathrm{CH}_{4}$ inicial y pseudo-estacionaria con el

296 tamaño de nanopartícula de Co; y (b) evolución de la selectividad a $\mathrm{CH}_{4}$ pseudoestacionaria con el diámetro de poro del soporte para los catalizadores $20 \mathrm{Co} / \mathrm{Al}_{2} \mathrm{O}_{3}$.

Figura 5.16: Evolución del TOF inicial con el diámetro de nanopartícula de Co (basado en $X R D$ o quimisorción de $\mathrm{H}_{2}$ ) para los catalizadores $20 \mathrm{Co} / \mathrm{Al}_{2} \mathrm{O}_{3}$ y $30 \mathrm{Co} / \mathrm{Al}_{2} \mathrm{O}_{3}$ soportados sobre $\mathrm{Y}-\mathrm{Al}_{2} \mathrm{O}_{3}$ comerciales (símbolos llenos) y nanofibrosa (símbolos vacíos).

Figura 5.17: Evolución de la pérdida relativa de actividad $(\triangle C T Y)$ durante el estado transitorio de los experimentos catalíticos $\left(t_{r}=0-6 \mathrm{~h}\right)$ con el diámetro de poro del soporte catalítico para los catalizadores $20 \mathrm{Co} / \mathrm{Al}_{2} \mathrm{O}_{3}$ soportados sobre $\mathrm{v}-\mathrm{Al}_{2} \mathrm{O}_{3}$ comerciales (símbolos llenos) y nanofibrosa (símbolo vacío).

313 Figura 5.18: Isotermas de adsorción-desorción de $\mathrm{N}_{2}$ para los soportes mesoestructurados SBA-15.

314 Figura 5.19: Distribuciones de diámetro de poro para los soportes mesoestructurados SBA-15.

317 Figura 5.20: Micrografías de SEM (a-d) y TEM (e-h) representativas de los soportes mesoestructurados $(a, e)$ 11SBA_C, $(b, f)$ 11SBA_M, $(c, g)$ 11SBA_L y $(d, h)$ 7SBA_L.

Figura 5.21: Representación esquemática del procedimiento de segmentación

319 empleado para estimar la longitud de poro en partículas de SBA-15 curvas, para partículas primarias de 11SBA_L de (a) $8.30 \mu \mathrm{m}$ y (b) $4.34 \mu \mathrm{m}$ de longitud total.

Figura 5.22: Distribuciones de longitud de mesoporo basadas en la medida de 50

320 partículas de SBA-15 en la dirección de los poros mediante TEM, trabajando a media magnificación.

Figura 5.23: Isotermas de adsorción-desorción de $N_{2}$ para los catalizadores RuCo/SBA-

32415 calcinados. Las isotermas se han desplazado verticalmente 150,370 y $630 \mathrm{~cm}^{3} / \mathrm{g}$ para Co/11SBA_L, Co/11SBA_M y Co/11SBA_S, respectivamente.

Figura 5.24: Representación esquemática de la formación de eventos de "bote de tinta" cuando se bloquean los mesoporos de SBA-15 por especies metálicas y la desorción tiene lugar a través de microporos que conectan los mesoporos. Adaptada de [64].

Figura 5.25: Micrografías de TEM representativas de los catalizadores (a) Co/11SBA_L

328 y (b) Co/11SBA_C calcinados. Los detalles muestran imágenes de mayor resolución para las nanopartículas de $\mathrm{Co}_{3} \mathrm{O}_{4}$ en el interior de los mesoporos.

332 Figura 5.26: Perfiles de TPO-MS obtenidos durante la calcinación de los catalizadores Co/11SBA_L y CO/SBA_C.

334 Figura 5.27: Perfiles de $\mathrm{H}_{2}$-TPR para los catalizadores RuCo/SBA-15 calcinados. En la figura se incluye el diámetro de partícula de $\mathrm{CO}_{3} \mathrm{O}_{4}$ obtenido mediante XRD.

Figura 5.28: Comparación de los valores de CTY obtenidos con los catalizadores

339 RuCo/SBA-15 con una colección de valores de CTY para diferentes catalizadores basados en Co, extraídos de esta memoria y de otros trabajos científicos (ver leyenda).

Figura 6.1: Evolución del número de publicaciones relacionadas con la SSO mediante

349 catalizadores basados en Rodio a lo largo de los últimos 30 años. Fuente: web of knowledge (claves de búsqueda: Rhodium + oxygenates como topic) a fecha de octubre de 2009.

Figura 6.2: (a) Esquema de la síntesis por pasos de los catalizadores modelo

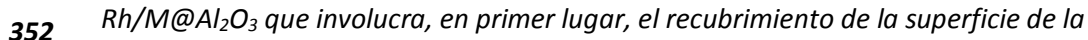
$\mathrm{Al}_{2} \mathrm{O}_{3}$ porosa con una "monocapa" del óxido promotor $\left(\mathrm{MO}_{x}\right)$ y, por último, la incorporación de la fase dispersa de $R h$; (b) representación de la ubicación relativa de 
las tres fases en los catalizadores $\mathrm{Rh} / \mathrm{M} @ \mathrm{Al}_{2} \mathrm{O}_{3}$.

\begin{tabular}{|c|c|}
\hline 358 & $\begin{array}{l}\text { Figura 6.3: Difractogramas de rayos } X \text { para los soportes promovidos en "monocapa" } \\
M @ \mathrm{Al}_{2} \mathrm{O}_{3} \text {, así como para el soporte de } \mathrm{\gamma}-\mathrm{Al}_{2} \mathrm{O}_{3} \text { empleado para su síntesis. }\end{array}$ \\
\hline 362 & Figura 6.4: Espectros de DR UV-vis de los soportes catalíticos $\mathrm{M} @ \mathrm{Al}_{2} \mathrm{O}_{3}$. \\
\hline 365 & 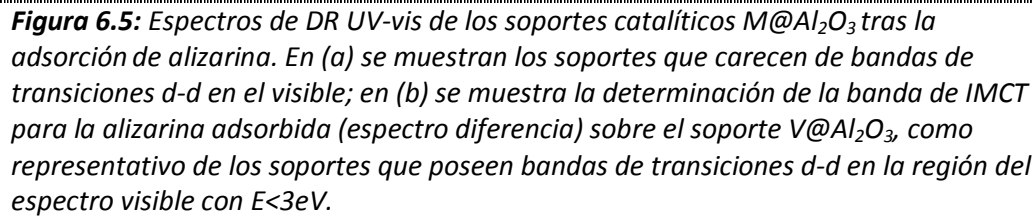 \\
\hline
\end{tabular}

368 Figura 6.6: Micrografías de TEM de los catalizadores $\mathrm{Rh} / \mathrm{Sm} @ \mathrm{Al}_{2} \mathrm{O}_{3}$ (a) y $\mathrm{Rh} / \mathrm{Ta} @ \mathrm{Al}_{2} \mathrm{O}_{3}$ (b) reducidos.

369 Figura 6.7: Perfiles de $\mathrm{H}_{2}$-TPR para los soportes catalíticos $\mathrm{M@Al}_{2} \mathrm{O}_{3}(a)$ y catalizadores $\mathrm{Rh} / \mathrm{M@Al} \mathrm{O}_{3}$ seleccionados (b).

374 Figura 6.8: Esquema resumen de los eventos de reacción elementales involucrados en la SSO catalizada por Rh. Adaptado de [43] .

Figura 6.9: Representación esquemática de los tipos de átomos de carbono

376 considerados en los productos de reacción en función de si se requiere un mecanismo de activación disociativa (azul) o no disociativa (rojo + asterisco) para la molécula de CO.

Figura 6.10: Evolución del "parámetro de selectividad" $\phi$ para los catalizadores $\mathrm{Rh} / \mathrm{M} @ \mathrm{Al}_{2} \mathrm{O}_{3}$ (condiciones de reacción: $\mathrm{T}=280^{\circ} \mathrm{C}$. $P=5.0 \mathrm{MPa}, X_{\mathrm{CO}}=15 \pm 3 \%$ ) con la

$378 E(I M C T)$ para la molécula de alizarina adsorbida sobre el óxido promotor $M O_{x}$ dispuesto en monocapa (escala universal de acidez Lewis o carácter electro donantaceptor [37]).

Figura 6.11: Diagrama de ASF para los hidrocarburos (parafinas $+\alpha$-olefinas) en los

381 productos de reacción para los catalizadores $\mathrm{Rh} / \mathrm{Nb} @ \mathrm{Al}_{2} \mathrm{O}_{3}, \mathrm{Rh} / \mathrm{Ta} @ \mathrm{Al}_{2} \mathrm{O}_{3}, \mathrm{Rh} / \mathrm{Li}$ $\mathrm{Ta} @ \mathrm{Al}_{2} \mathrm{O}_{3}$ (condiciones de reacción: $\mathrm{T}=280^{\circ} \mathrm{C}$. $\mathrm{P}=5.0 \mathrm{MPa}, X_{\mathrm{CO}}=15 \pm 3 \%$ ).

Figura 6.12: Evolución de la relación de alcoholes superiores $\left(C_{2+}\right)$ a metanol en la

384 fracción de oxigenados con $\mathrm{E}(\mathrm{IMCT})$ para los catalizadores $\mathrm{Rh} / \mathrm{M} @ \mathrm{Al}_{2} \mathrm{O}_{3}$ promovidos por óxidos de lantánidos e itrio.

Figura 6.13: Espectros de XPS en la región de la señal Rh3d para los catalizadores (a)

$387 \mathrm{Rh} / \mathrm{V} @ \mathrm{Al}_{2} \mathrm{O}_{3}$, (b) $\mathrm{Rh} / \mathrm{Ta} @ \mathrm{Al}_{2} \mathrm{O}_{3}$, (c) $\mathrm{Rh} / \mathrm{Y} @ \mathrm{Al}_{2} \mathrm{O}_{3} \mathrm{y}$ (d) $\mathrm{Rh} / \mathrm{Sm} @ \mathrm{Al}_{2} \mathrm{O}_{3}$ reducidos in situ en $\mathrm{H}_{2}$ a $300^{\circ} \mathrm{C}$.

Figura 6.14: Espectros de CO-FTIR a-175oC tras dosis de 0.4-8.3 mbar de CO en la celda, sobre el catalizador $\mathrm{Rh} / \mathrm{Ta} @ \mathrm{Al}_{2} \mathrm{O}_{3}$ previamente reducido in situ a 300 ㅇ en flujo

391 de $\mathrm{H}_{2}$ y evacuado a $350^{\circ} \mathrm{C}$ tras la reducción. El detalle de la figura muestra el espectro tras dosis de 8.3 mbar (a) y dos espectros tras evacuación $\left(10^{-4} \mathrm{mbar}\right)$ durante $1 \mathrm{~h}(\mathrm{~b})$ y $12 h(c)$.

Figura 6.15: Espectros de CO-FTIR a -175C tras dosis de 0.4-8.3 mbar de CO en la celda, sobre el catalizador $\mathrm{Rh} / \mathrm{Sm} @ \mathrm{Al}_{2} \mathrm{O}_{3}$ previamente reducido in situ a $300^{\circ} \mathrm{C}$ en flujo

392 de $\mathrm{H}_{2}$ y evacuado a $350^{\circ} \mathrm{C}$ tras la reducción. El detalle de la figura muestra el espectro tras dosis de $8.3 \mathrm{mbar}(\mathrm{a})$ y dos espectros tras evacuación $\left(10^{-5} \mathrm{mbar}\right)$ durante $1 \mathrm{~h}(\mathrm{~b})$ y $12 \mathrm{~h}(\mathrm{c})$.

Figura 6.16: Espectros de CO-FTIR para el catalizador $\mathrm{Rh} / \mathrm{Sm} @ \mathrm{Al}_{2} \mathrm{O}_{3}$ expuesto a un

399 flujo de gas de síntesis a temperaturas crecientes y varios tiempos de reacción a la temperatura final de reacción (280ㄷ). ( *: bandas asociadas con $\mathrm{CO}$ en la fase gaseosa).

402 Figura 6.17: Espectros de CO-FTIR registrados durante la evacuación diferencial $(a \rightarrow f)$ 
del catalizador $\mathrm{Rh} / \mathrm{Sm}_{\mathrm{AAl}} \mathrm{O}_{3}$ tras 3 horas en condiciones de $\mathrm{SSO}$ en la celda de FTIR. El detalle incluido en la figura muestra una ampliación de la región de carbonilos lineales de $R h$.

404

Figura 6.18: Espectros de CO-FTIR para el catalizador Rh/Pr@Al $\mathrm{O}_{3}$ expuesto a un flujo de gas de síntesis a temperaturas crecientes y varios tiempos de reacción a la temperatura final de reacción $\left(280^{\circ} \mathrm{C}\right)$.

Figura 6.19: Espectros de CO-FTIR para el catalizador $\mathrm{Rh} / \mathrm{Li}-\mathrm{Ta} @ \mathrm{Al}_{2} \mathrm{O}_{3}$ expuesto a un

407 flujo de gas de síntesis a temperaturas crecientes y varios tiempos de reacción a la temperatura final de reacción $\left(280^{\circ} \mathrm{C}\right)$.

409 Figura 6.20: Espectros de CO-FTIR registrados durante la evacuación diferencial $(a \rightarrow f)$ del catalizador $\mathrm{Rh} / \mathrm{Li}-\mathrm{Ta} @ \mathrm{Al}_{2} \mathrm{O}_{3}$ tras 3 horas en condiciones de SSO en la celda de FTIR. 


\section{ANEXO II: ÍNDICE DE TABLAS}

\begin{tabular}{|c|c|}
\hline Pag. & Encabezado de Tabla \\
\hline 31 & $\begin{array}{l}\text { Tabla 1.1: Operador, localización, tecnología, producción y antigüedad de las plantas } \\
\text { comerciales de sintesis de Fischer-Tropsch operativas e instaladas. }\end{array}$ \\
\hline 54 & $\begin{array}{l}\text { Tabla 1.2: Procesos, catalizadores y nivel de escala de desarrollo para la síntesis de } \\
\text { alcoholes superiores por vía termoquímica [115]. }\end{array}$ \\
\hline 70 & Tabla 2.1: Denominación de los soportes basados en $\mathrm{\gamma}-\mathrm{Al}_{2} \mathrm{O}_{3}$ de origen comercial. \\
\hline 75 & $\begin{array}{l}\text { Tabla 2.2: Denominación, naturaleza del promotor, recubrimiento superficial, } \\
\text { precursor y disolvente empleados en la síntesis de los soportes cataliticos basados en } \\
\mathrm{Al}_{2} \mathrm{O}_{3} \text { recubiertos por óxidos bidimensionales en "monocapa". }\end{array}$ \\
\hline 81 & $\begin{array}{l}\text { Tabla 2.3: Denominación y programa térmico de calcinación para los catalizadores } \\
20 \% \mathrm{Co} / \mathrm{SiO}_{2} \text { estudiados en el capítulo } 4 .\end{array}$ \\
\hline 116 & $\begin{array}{l}\text { Tabla 2.4: Características del programa empleado en el CG para la separación de los } \\
\text { productos de reacción }\end{array}$ \\
\hline 146 & $\begin{array}{l}\text { Tabla 3.1: Propiedades texturales de los soportes catalíticos basados en zeolita } \\
\text { deslaminada ITQ-2 calcinada y sililada. }\end{array}$ \\
\hline 149 & $\begin{array}{l}\text { Tabla 3.2: Contenido en carbono determinado por análisis elemental para la zeolita } \\
\text { deslaminada ITQ-2 calcinada y sililada. }\end{array}$ \\
\hline 153 & $\begin{array}{l}\text { Tabla 3.3: Nomenclatura, método de síntesis y soporte catalítico empleado para los } \\
\text { catalizadores } 10 \% \text { Co/ITQ- } 2 \text {. }\end{array}$ \\
\hline 158 & Tabla 3.4: Contenido en cobalto de los catalizadores $10 \% \mathrm{Co} / \mathrm{ITQ}-2$. \\
\hline 159 & Tabla 3.5: Dispersión metálica de los catalizadores 10\%Co/ITQ-2. \\
\hline 166 & $\begin{array}{l}\text { Tabla 3.6: Detalle de los parámetros de las microemulsiones inversas empleadas para } \\
\text { sintetizar los catalizadores modelo } 10 \% \mathrm{Co} / \mathrm{ITQ}-2 \text {. }\end{array}$ \\
\hline 166 & $\begin{array}{l}\text { Tabla 3.7: Propiedades texturales y contenido en carbono para los soportes catalíticos } \\
\text { basados en zeolita deslaminada ITQ-2(b) en sus formas calcinada y sililada, y } \mathrm{SiO}_{2} \\
\text { porosa comercial. }\end{array}$ \\
\hline 168 & $\begin{array}{l}\text { Tabla 3.8: Carga metálica y contenido en carbono de los catalizadores } 10 \% \mathrm{Co} / \mathrm{ITQ}-2 \text { y } \\
30 \% \mathrm{Co} / \mathrm{SiO}_{2} \text { calcinados. }\end{array}$ \\
\hline 171 & Tabla 3.9: Dispersión metálica de los catalizadores $10 \% \mathrm{Co} / \mathrm{ITQ}-2$ y $30 \% \mathrm{Co} / \mathrm{SiO}_{2}$. \\
\hline 185 & $\begin{array}{l}\text { Tabla 3.10: Resultados catalíticos para catalizadores modelo } 10 \% \mathrm{Co} / \mathrm{ITQ}-2 \\
\text { seleccionados y } 30 \% \mathrm{Co} / \mathrm{SiO}_{2}(\mathrm{mf}) \text {. Condiciones de reacción: } T=220^{\circ} \mathrm{C}, P=2.0 \mathrm{MPa} \text {, } \\
\mathrm{H}_{2} / \mathrm{CO}=2, X_{\mathrm{CO}}=10 \pm 2 \% \text {. }\end{array}$ \\
\hline 220 & $\begin{array}{l}\text { Tabla 4.1: Simbología, tipo de catalizadores y condiciones de reacción empleadas en } \\
\text { los trabajos científicos recogidos en la recopilación de datos catalíticos representada } \\
\text { en la Fig. 4.1. }\end{array}$ \\
\hline 223 & $\begin{array}{l}\text { Tabla 4.2: Contenido metálico, dispersión metálica y grado de reducción (400ㄷ, } 10 \mathrm{~h}) \\
\text { para los catalizadores RuCo/SBA-15. }\end{array}$ \\
\hline 234 & $\begin{array}{l}\text { Tabla 4.3: Interpretación cuantitativa de los resultados de XPS para catalizadores } \\
\mathrm{Co} / \mathrm{SiO}_{2} \text { seleccionados en su estado calcinado. }\end{array}$ \\
\hline 246 & $\begin{array}{l}\text { Tabla 4.4: Actividad catalitica de los catalizadores } \mathrm{Co}_{\mathrm{SiO}} \text {. Condiciones de reacción: } \\
T=220 \circ \mathrm{C}, \mathrm{P}=2.0 \mathrm{MPa}, \mathrm{H}_{2} / \mathrm{CO}=2, X_{\mathrm{CO}}=5-10 \%, \mathrm{H}_{2} / \mathrm{CO}=2 \text {. }\end{array}$ \\
\hline 271 & Tabla 5.1: Propiedades texturales de los soportes de $\mathrm{\gamma}-\mathrm{Al}_{2} \mathrm{O}_{3}$. \\
\hline
\end{tabular}




\begin{tabular}{|c|c|}
\hline 276 & Tabla 5.2: Composición química de los catalizadores $\mathrm{RuCo} \mathrm{Al}_{2} \mathrm{O}_{3}$. \\
\hline 277 & Tabla 5.3: Propiedades texturales de los catalizadores $\mathrm{RuCO}_{\mathrm{Al}} \mathrm{O}_{3}$. \\
\hline 279 & Tabla 5.4: Dispersión metálica y reducibilidad de los catalizadores $\mathrm{RuCo} \mathrm{Al}_{2} \mathrm{O}_{3}$. \\
\hline 298 & $\begin{array}{l}\text { Tabla 5.5: Actividad catalítica de los catalizadores } \mathrm{Co} / \mathrm{Al}_{2} \mathrm{O}_{3} \text {. Condiciones de reacción: } \\
T=220^{\circ} \mathrm{C}, P=2.0 \mathrm{MPa}, \mathrm{GHSV}=7.2 \mathrm{~L} \mathrm{~g}^{-1} \mathrm{~h}^{-1} \text {. }\end{array}$ \\
\hline 301 & $\begin{array}{l}\text { Tabla 5.6: Selectividad de la síntesis de Fischer-Tropsch para los catalizadores } \\
\mathrm{Co} / \mathrm{Al}_{2} \mathrm{O}_{3} \text {. Condiciones de reacción: } \mathrm{T}=22 \mathrm{O}^{\circ} \mathrm{C}, \mathrm{P}=2.0 \mathrm{MPa}, \mathrm{X}_{\mathrm{CO}}=40 \pm 2 \%, \mathrm{H}_{2} / \mathrm{CO}=2 \text {. }\end{array}$ \\
\hline 314 & Tabla 5.7: Propiedades texturales de los soportes mesoestructurados SBA-15. \\
\hline 322 & $\begin{array}{l}\text { Tabla 5.8: Intervalos de confianza (90\%) para la longitud de poro media, estimados } \\
\text { mediante el análisis basado en el formalismo de t-Student de la muestra resultante de } \\
\text { medir } 50 \text { partículas de soporte. }\end{array}$ \\
\hline 323 & $\begin{array}{l}\text { Tabla 5.9: Composición química y propiedades texturales de los catalizadores } \\
\text { RuCo/SBA-15 calcinados. }\end{array}$ \\
\hline 327 & $\begin{array}{l}\text { Tabla 5.10: Dispersión metálica y grado de reducción (400C, 10h) para los } \\
\text { catalizadores RuCo/SBA-15. }\end{array}$ \\
\hline 336 & $\begin{array}{l}\text { Tabla 5.11: Actividad catalítica para los catalizadores RuCo/SBA-15. Condiciones de } \\
\text { reacción: } T=22{ }^{\circ} \mathrm{C}, \mathrm{P}=2.0 \mathrm{MPa}, \mathrm{H}_{2} / \mathrm{CO}=2 \text {. }\end{array}$ \\
\hline 339 & $\begin{array}{l}\text { Tabla 5.12: Selectividad catalítica y productividad para los catalizadores RuCo/SBA-15. } \\
\text { Condiciones de reacción: } T=220 \stackrel{\circ}{\circ} \mathrm{C}, P=2.0 \mathrm{MPa}, X_{\mathrm{CO}}=55 \pm 2 \%, \mathrm{H}_{2} / \mathrm{CO}=2 \text {. }\end{array}$ \\
\hline 354 & $\begin{array}{l}\text { Tabla 6.1: Recubrimientos de saturación de monocapa descritos en la literatura } \\
\text { científica para óxidos de metales de transición y de lantánidos soportados sobre } \gamma \text { - } \\
\mathrm{Al}_{2} \mathrm{O}_{3} \text {. }\end{array}$ \\
\hline 357 & $\begin{array}{l}\text { Tabla 6.2: Composición química (ICP-OES) y propiedades texturales (adsorción de } \mathrm{N}_{2} \text { ) } \\
\text { de los soportes catalíticos } \mathrm{M} @ \mathrm{Al}_{2} \mathrm{O}_{3} \text {. }\end{array}$ \\
\hline 363 & 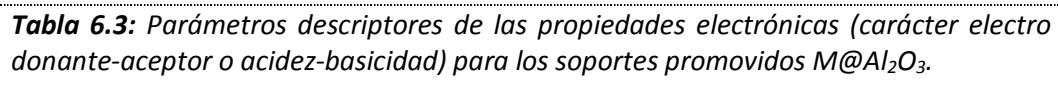 \\
\hline 367 & Tabla 6.4: Dispersión metálica en catalizadores $\mathrm{Rh} / \mathrm{M} @ \mathrm{Al}_{2} \mathrm{O}_{3}$ seleccionados. \\
\hline 371 & $\begin{array}{l}\text { Tabla 6.5: Interpretación cuantitativa de los perfiles de } \mathrm{H}_{2} \text {-TPR para soportes } \mathrm{M} @ \mathrm{Al}_{2} \mathrm{O}_{3} \\
\text { y catalizadores metálicos } \mathrm{Rh} / \mathrm{M} @ \mathrm{Al}_{2} \mathrm{O}_{3} \text { seleccionados. }\end{array}$ \\
\hline 372 & $\begin{array}{l}\text { Tabla 6.6: Resultados catalíticos para los catalizadores } \mathrm{Rh} / \mathrm{M} @ \mathrm{Al}_{2} \mathrm{O}_{3} \text {. Condiciones de } \\
\text { reacción: } T=280^{\circ} \mathrm{C} . P=5.0 \mathrm{MPa}, X_{\mathrm{CO}}=15 \pm 3 \%, \mathrm{H}_{2} / \mathrm{CO}=1 \text {. }\end{array}$ \\
\hline 389 & $\begin{array}{l}\text { Tabla 6.7: Energías de enlace, estados de oxidación de promotores y Rh, parámetro } \\
\text { Auger modificado y parámetro de carga de estado inicial derivados del análisis por XPS } \\
\text { de catalizadores } \mathrm{Rh} / \mathrm{M} @ \mathrm{Al}_{2} \mathrm{O}_{3} \text { seleccionados en su estado calcinado y reducido. }\end{array}$ \\
\hline
\end{tabular}




\section{ANEXO III: LISTA DE ACRÓNIMOS Y ABREVIATURAS}

\section{Abreviatura Significado}

\begin{tabular}{|c|c|}
\hline$(\mathrm{B}) \mathrm{VP}$ & Volumen de poro bloqueado \\
\hline $1 \mathrm{D}$ & Unidimensional \\
\hline $3 \mathrm{D}$ & Tridimensional \\
\hline A & Área \\
\hline $\mathrm{ASF}$ & Anderson-Shulz-Flory \\
\hline B.E.T. & Brunnauer-Emmet-Teller \\
\hline B.J.H. & Barret-Joyner-Halenda \\
\hline $\mathrm{BC}$ & Balance de carbono \\
\hline BTL & Biomass-to-liquids (biomasa a líquidos) \\
\hline C(B.E.T.) & Parámetro de interacción adsorbente-adsorbato del modelo B.E.T. \\
\hline CFBR & Continuous Fixed Bed Reactor (Reactor en continuo de lecho fijo) \\
\hline $\mathrm{CG}$ & Cromatógrafo de gases \\
\hline $\mathrm{CNF}$ & Carbon nanofibers (nanofibras de carbono) \\
\hline $\mathrm{CO}_{\mathrm{ads}, \text { irrev }}$ & CO adsorbido de manera irreversible \\
\hline CTABr & Bromuro de cetil-trimetil-amonio \\
\hline CTL & Coal-to-liquids (carbón a líquidos) \\
\hline CTY & Cobalt-time-yield (Rendimiento temporal por masa de Co) \\
\hline $\mathrm{D}$ & Dispersión metálica \\
\hline d & Espaciado interplanar cristalino \\
\hline DP & Diámetro de poro \\
\hline DR UV-vis & $\begin{array}{l}\text { Diffuse Reflectance Ultraviolet-visible spectroscopy } \\
\text { (espectroscopia ultravioleta-visible de reflectancia difusa) }\end{array}$ \\
\hline EA & Elemental analysis (análisis elemental) \\
\hline $\mathrm{E}_{\mathrm{a}}$ & Energía de activación \\
\hline EBA & Energía en el borde de absorción UV-vis \\
\hline EDX & $\begin{array}{l}\text { Energy Dispersive X-ray spectroscopy (espectroscopia de } \\
\text { dispersión de rayos X) }\end{array}$ \\
\hline Eg & Band Energy gap (ancho de banda) \\
\hline $\mathrm{E}(\mathrm{IMCT})$ & $\begin{array}{l}\text { Energy of Intramolecular Charge Transfer (Energía de transición } \\
\text { de carga intramolecular para alizarina adsorbida) }\end{array}$ \\
\hline ER & Exceso de reductor \\
\hline E.E. & Energía de enlace (XPS) \\
\hline f & Factor de respuesta cromatográfico \\
\hline $\mathrm{F}(\mathrm{R})$ & Función de Kubelka-Munk \\
\hline$f c c$ & face cubic centred (cúbica centrada en las caras) \\
\hline
\end{tabular}




\begin{tabular}{|c|c|}
\hline FTIR & $\begin{array}{l}\text { Fourier-Transform Infrared spectroscopy (Espectroscopia } \\
\text { infrarrojo de transformada de Fourier), CO-: con adsorción de CO } \\
\text { como molécula sonda }\end{array}$ \\
\hline FWHM & Full with at half maximum (anchura de pico a la mitad de altura) \\
\hline GHSV & Gas Hourly Space Velocity (Velocidad espacial de gas) \\
\hline GN & Gas natural \\
\hline GNL & Gas natural licuado \\
\hline GR & Grado de reducción \\
\hline GS & Grado de sililación \\
\hline GTL & Gas-to-liquids (Gas a líquidos) \\
\hline h' & '"'nonstante de Plank \\
\hline $\mathrm{H}_{2, \text { ads }}$ & $\mathrm{H}_{2}$ adsorbido total \\
\hline $\mathrm{H}_{2, \mathrm{cons}}$ & $\mathrm{H}_{2}$ consumido \\
\hline$h c p$ & hexagonal closed packed (hexagonal empaquetada) \\
\hline HMDS & 1,1,1,3,3,3,-hexametildisilazano \\
\hline HOMO & $\begin{array}{l}\text { Highest Ocuppied Molecular Orbital (Orbital molecular de mayor } \\
\text { energía ocupado) }\end{array}$ \\
\hline IC & Indice de cetano \\
\hline IC & Intervalo de confianza \\
\hline ICP & Ionic-covalent parameter (parámetro iónico-covalente) \\
\hline ICP-OES & $\begin{array}{l}\text { Inductively Coupled Plasma-Optical Emission Spectrometry } \\
\text { (Espectrometría de emisión óptica acoplada a plasma de } \\
\text { acoplamiento inductivo) }\end{array}$ \\
\hline IMCT & $\begin{array}{l}\text { Intramolecular Charge Transfer (transición de carga } \\
\text { intramolacular) }\end{array}$ \\
\hline IR & Indice de refracción \\
\hline JCPDS & $\begin{array}{l}\text { Joint Comitee on Powder Diffraction Standards (Comité } \\
\text { Internacional de patrones de difracción en polvo) }\end{array}$ \\
\hline LP & Longitud de poro \\
\hline LRS & $\begin{array}{l}\text { Laser Raman Spectroscopy (espectroscopia Raman con excitación } \\
\text { laser) }\end{array}$ \\
\hline LUMO & $\begin{array}{l}\text { Lowest Unocuppied Molecular Orbital (Orbital molecular de } \\
\text { menor energía desocupado) }\end{array}$ \\
\hline n & Número de átomos de carbono \\
\hline $\mathrm{N}_{\mathrm{A}}$ & Número de Avogadro \\
\hline NMR & $\begin{array}{l}\text { Nuclear Magnetic Resonance (Espectroscopia de resonancia } \\
\text { magnética nuclear) }\end{array}$ \\
\hline NP & Nanopartícula \\
\hline $\mathrm{O} / \mathrm{P}$ & Relación olefina/parafina \\
\hline $\mathrm{Oh}$ & Coordinación octahédrica \\
\hline OPEP & Organización de los Países Exportadores de Petróleo \\
\hline $\mathrm{P} 123$ & Surfactante Pluronic 123 \\
\hline
\end{tabular}




\begin{tabular}{|c|c|}
\hline PID & Control Proporcional-Integral-Diferencial \\
\hline PM & Peso molecular \\
\hline PM-RAIRS & $\begin{array}{l}\text { Polarization Modulation Reflection Absorption Infrared } \\
\text { Spectroscopy (Espectroscopia de reflexión-absorción con } \\
\text { polarización modulada) }\end{array}$ \\
\hline R & Radio de pellet \\
\hline $\mathrm{R}$ & "'melación agua/surfactante \\
\hline RTY & Rhodium-time-yield (Rendimiento temporal por masa de $\mathrm{Rh}$ ) \\
\hline S & "'selectividad" \\
\hline S & Desviación típica de una muestra \\
\hline SBCR & $\begin{array}{l}\text { Slurry Bubble Continuous Reactor (Reactor continuo de tanque } \\
\text { agitado por burbujas) }\end{array}$ \\
\hline SEM & $\begin{array}{l}\text { Scanning Electron Microscopy (Microscopía electrónica de } \\
\text { barrido) }\end{array}$ \\
\hline SFT & Síntesis de Fischer-Tropsch \\
\hline $\mathrm{sh}$ & Hombro (shoulder) \\
\hline $\mathrm{S}_{\mathrm{M}}$ & Electronegatividad de Sanderson del catión M \\
\hline SMDS & Shell Middle Distillate Synthesis \\
\hline SMO & Sílices mesoporosas ordenadas \\
\hline SPD & Sasol Phase Distillate \\
\hline SSO & Síntesis selectiva de oxigenados \\
\hline STM & $\begin{array}{l}\text { Scanning-Tunneling Microscopy (microscopía electrónica de } \\
\text { barrido de efecto túnel) }\end{array}$ \\
\hline$t$ & Parámetro t de Student \\
\hline TB-FBR & $\begin{array}{l}\text { Trickel-Bed Fixed-Bed Reactor (Reactor de lecho fijo con flujo } \\
\text { trifásico) }\end{array}$ \\
\hline $\mathrm{T}_{\mathrm{c}}$ & Temperatura de calcinación \\
\hline TCD & $\begin{array}{l}\text { Thermal Conductivity Detector (Detector de conductividad } \\
\text { térmica) }\end{array}$ \\
\hline $\mathrm{TE}$ & Tomografía electrónica \\
\hline TEM & $\begin{array}{l}\text { Transmission Electron Microscopy (Microscopía electrónica de } \\
\text { transmisión), (HR)-: High resolution (alta resolución) }\end{array}$ \\
\hline TEOS & Tetra-etil-ortosilicato \\
\hline TG-DTA & $\begin{array}{l}\text { Thermogravimetry and Differential Thermal Analysis (análisis } \\
\text { termogravimetríco y térmico diferencial) }\end{array}$ \\
\hline$T h$ & Coordinación Tetrahédrica \\
\hline THF & Tetrahidrofurano \\
\hline TOF & Turn-over frequency (frecuencia de renovación de sitio activo) \\
\hline TPAOH & Hidróxido de tetrapropil-amonio \\
\hline TPD & $\begin{array}{l}\text { Temperature-Programmed Decomposition or Desorption } \\
\text { (Descomposición o desorción a temperatura programada) }\end{array}$ \\
\hline TPO & $\begin{array}{l}\text { Temperature-Programmed Oxidation (Oxidación a temperatura } \\
\text { programada), -MS: (acoplada a espectrometría de masas) }\end{array}$ \\
\hline
\end{tabular}




\begin{tabular}{|c|c|}
\hline TPR & $\begin{array}{l}\text { Temperature-Programmed Reduction (Reducción a temperatura } \\
\text { programada), } \mathrm{H}_{2}-: \text { (empleando hidrógeno como reductor) }\end{array}$ \\
\hline$t_{r}$ & Tiempo de reacción \\
\hline $\mathrm{T}_{\mathrm{r}}$ & Temperatura de reducción \\
\hline VP & Volumen de poro \\
\hline $\mathrm{VP}_{\text {macro }}$ & 'Volumen de macroporo \\
\hline $\mathrm{VP}_{\text {meso }}$ & Volumen de mesoporo \\
\hline $\mathrm{VP}_{\text {micro }}$ & Volumen de microporo \\
\hline W & Caudal \\
\hline WGSR & Waster gas shift reaction (reacción de desplazamiento de agua) \\
\hline$x$ & Contenido metálico \\
\hline $\mathrm{X}_{\mathrm{CO}}$ & Conversión de CO \\
\hline XAES & $\begin{array}{l}X \text {-ray excited Auger Electron Spectroscopy (espectroscopia Auger } \\
\text { con excitación por rayos X) }\end{array}$ \\
\hline XPS & $\begin{array}{l}\text { X-ray Photoemission Spectroscopy (espectroscopia de fotoemisión } \\
\text { con excitación por rayos X) }\end{array}$ \\
\hline XRD & X-ray diffraction (difracción de rayos X) \\
\hline
\end{tabular}

\section{Alfabeto griego}

\begin{tabular}{ll}
$\alpha$ & Probabilidad de crecimiento de cadena \\
\hline$\alpha$ & Recubrimiento superficial de sililación \\
\hline$\alpha$ & Parámetro Auger \\
\hline$\alpha_{\mathrm{M}}$ & Polarizabilidad electrónica del catión M \\
\hline$\delta$ & Recubrimiento superficial \\
\hline$\Delta$ & Incremento de una magnitud \\
\hline$\delta$ & Desplazamiento químico \\
\hline$\Delta \mathrm{H}_{\mathrm{f}}$ & Incremento de entalpía estándar de formación \\
\hline$\varepsilon$ & Porosidad \\
\hline$\varepsilon$ & Parámetro de carga de estado inicial (XPS) \\
\hline$\theta$ & Angulo \\
\hline$\theta$ co & Densidad superficial de centros de Co metálico \\
\hline$\Lambda$ & Basicidad óptica \\
\hline$\lambda$ & Longitud de onda \\
\hline$v$ & Frecuencia de onda \\
\hline$\sigma$ & Desviación típica poblacional \\
\hline$\varphi$ & Parámetro de selectividad
\end{tabular}




\section{Subíndices}

Tamaño de nanopartícula: $d(\square)$ ?

\begin{tabular}{ll}
$X$ & Difracción de rayos $X$ \\
\hline$T$ & TEM \\
\hline$H$ & Quimisorción de $\mathrm{H}_{2}$ \\
\hline CO & Quimisorción de $\mathrm{CO}$
\end{tabular}

Medidas de actividad catalítica: $\mathrm{TOF}_{?}, \mathrm{CTY}_{\text {? }}, \mathrm{RTY}$ ?

\begin{tabular}{cc}
$0 \quad$ Inicial (extrapolada a TOS $\rightarrow 0$ ) \\
\hline e & Estado pseudo-estacionario
\end{tabular}

Átomos metálicos: $\mathrm{Co}_{(?)}, \mathrm{Rh}_{\text {(?) }}$

\begin{tabular}{ll}
$\mathrm{s}$ & Superficiales \\
\hline tot & Totales
\end{tabular}

\section{Acentos}

Caudal: W

\begin{tabular}{|c|c|}
\hline$\sim$ & Molar \\
\hline$\hat{\imath}$ & Másico \\
\hline$u$ & Volumétrico \\
\hline
\end{tabular}





\section{RESUMEN}

La presente tesis doctoral emplea herramientas de síntesis y caracterización de catalizadores metálicos nanoparticulados modelo, con el objetivo de elucidar la influencia de varias características estructurales y físico-químicas relevantes y sentar las bases para el diseño de nuevas generaciones de catalizadores avanzados para las rutas catalíticas de conversión de gas de síntesis.

Por un lado, el diseño y la síntesis de catalizadores de Co monodispersos, empleando coloides metálicos y soportes nanométricos, en combinación con espectroscopias in situ y operando, ha permitido relacionar la sensibilidad a la estructura no clásica de la síntesis de Fischer-Tropsch (SFT) con modificaciones morfológicas y electrónicas de las nanopartículas de Co durante la catálisis, en función del tamaño de nanopartícula.

Por otro lado, este trabajo esclarece la influencia de la historia térmica de los catalizadores de Co, desde los tratamientos más tempranos, en la topología metálica superficial del catalizador activado final y sus consecuencias en la actividad catalítica intrínseca.

Adicionalmente, en base al conocimiento adquirido, se ha optimizado la estructura porosa de los catalizadores de Co para la SFT mediante un diseño racional de los soportes catalíticos. De este modo, se ha demostrado que estructuras porosas bimodales macro-mesoporosas así como soportes mesoestructurados con poros uniformes y de longitud reducida dan lugar a catalizadores de actividad mejorada y elevada selectividad a destilados medios.

Finalmente, el empleo de soportes sintetizados mediante técnicas de deposición de óxidos capa-por-capa ha permitido sintetizar una serie de catalizadores de Rh promovidos y estudiar su comportamiento en la síntesis selectiva de compuestos oxigenados. Esta tesis presenta, por primera vez, una interpretación general para el papel de los promotores en este sistema, en base a un análisis de las propiedades electrónicas de las fases metálicas nanoparticuladas y estudios espectroscópicos in situ y operando. 


\begin{abstract}
The present doctoral thesis employs synthetic and characterization methods on nanoparticulate metallic model catalysts, aiming at elucidating the influence of several structural and physico-chemical features and establishing the basis for the design of new generations of advanced catalysts for the catalytic routes of synthesis gas conversion.

On one hand, the design and synthesis of monodisperse Co catalysts, using metal colloids in conjunction with nanosized supports, in combination with in situ and operando spectroscopic studies, has allowed to establish a relationship between the non classical structure sensitivity of the Cocatalysed Fischer-Tropsch synthesis (FTS) and the morphological and electronic changes evidenced for the Co nanoparticles under reaction conditions, as a function of the nanoparticle size.

On the other hand, this work has contributed to rationalize the influence of the thermal history of Co catalysts, from the very early treatments, on the metal surface topology in the final activated catalyst, and its consequences on the intrinsic (per surface metal site) catalytic activity.

Additionally, on the bases of the gained knowledge, the porous structure of Co-based FTS catalysts has been optimized by a rational design of the catalytic support. In this way, it has been found that both bimodal macro-mesoporous structures as well as mesostructures displaying uniform and short pores lead to catalysts which display enhanced catalytic activity and high selectivity toward middle distillates.

Finally, the employment of catalytic supports synthesized by layer-bylayer techniques has allowed to prepare a series of promoted Rh-based catalysts and to study their behavior in the selective synthesis of oxygenate compounds. The present thesis introduces, for the first time, a general interpretation of the role of promoters in this catalytic system, on the basis of a detailed analysis of the electronic properties of the metallic phases and in situ and operando spectroscopic studies.
\end{abstract}




\section{RESUM}

La present tesi empra eines de síntesi i caracterització de catalitzadors metàl-lics nanoparticulats model, amb l'objectiu d'elucidar la influència de diverses característiques estructurals i físico-químiques rellevants i asseure les bases per al disseny de noves generacions de catalitzadors avançats per a les rutes catalítiques de conversió de gas de síntesi.

D'una banda, el disseny i la síntesi de catalitzadors de Co monodispersos, emprant collloides metàl-lics i suports nanomètrics, en combinació amb espectroscòpies in situ i operando, ha permés relacionar la sensibilitat a l'estructura no clàssica de la síntesi de Fischer-Tropsch (SFT) amb modificacions morfològiques i electròniques de les nanopartícules de Co durant la catàlisi, en funció de la grandària de nanopartícula.

D'altra banda, aquest treball esclareix la influència de la història tèrmica dels catalitzadors de $\mathrm{Co}$, des dels tractaments més primerencs, en la topologia metàl-lica superficial del catalitzador activat final i les seues conseqüències en l'activitat catalítica intrínseca.

Addicionalment, sobre la base del coneixement adquirit, s'ha optimitzat l'estructura porosa dels catalitzadors de Co per a la SFT mitjançant un disseny racional dels suports catalítics. D'aquest manera, s'ha demostrat que estructures poroses bimodals macro-mesoporoses així com suports mesoestructurats amb porus uniformes i de longitud reduïda donen lloc a catalitzadors d'activitat millorada i elevada selectivitat a destil.lats mitjans.

Finalment, l'ocupació de suports sintetitzats mitjançant tècniques de deposició d'òxids capa-per-capa ha permès sintetitzar una sèrie de catalitzadors de Rh promoguts i estudiar el seu comportament en la síntesi selectiva de compostos oxigenats. Aquesta tesi presenta, per primera vegada, una interpretació general per al paper dels promotors en aquest sistema, sobre la base d'una anàlisi de les propietats electròniques de les fases metàl-liques nanoparticulades $\mathrm{i}$ estudis espectroscòpics in situ $\mathrm{i}$ operando. 